\title{
Cerámica Romana Altoimperial de fabricación regional del Chao Samartín (Grandas de Salime, Asturias) ${ }^{1}$
}

\author{
Autores ${ }^{2}$ : \\ Susana Hevia González \\ Rubén Montes López \\ Plan Arqueológico del Navia-Eo. Consejería de Cultura y Turismo del Principado de Asturias.
}

\begin{abstract}
Resumen
Las sucesivas campañas de investigación desarrolladas en el castro de Chao Samartín (Grandas de Salime, Asturias) y en otros asentamientos del entorno asociados al Plan Arqueológico del Navia-Eo, han permitido abordar el estudio del material cerámico recuperado. La excepcional claridad estratigráfica del yacimiento y su singular desarrollo histórico han proporcionado una ajustada panorámica acerca de la cerámica de época romana altoimperial. En su seno, las producciones regionales constituyen el conjunto más numeroso y el que mayores dificultades de sistematización presenta, dada la ausencia de tipificación. En este trabajo se expone un estado de la cuestión del conocimiento sobre estas producciones en el Chao Samartín, presentando los tipos definidos hasta la fecha y analizando su evolución, sobre la base de su contextualización estratigráfica.
\end{abstract}

PALABRAS CLAVE: Cerámica regional, época romana, castro, Asturias.

\begin{abstract}
The consecutive campaigs of investigation developed in the hill fort of Chao Samartín (Grandas de Salime, Asturias) and in other settlements associated with the archaeological plan of Navia-Eo, have allowed the study of recovered ceramic material. The exceptional stratigraphic clarity of the site and its singular historical evolution have provided a narrow view of the early roman empire pottery. In this respect the regional pottery productions constitute the most numerous collection and present the largest amount of difficulties of systematization, given the absence of classification. This work sets out how things are in relation to the knowledge about these pottery productions in Chao Samartín, presenting up to date defined types and analysing their evolution, based on their estratigraphic contextualization.
\end{abstract}

KEY WORDS: Regional pottery, roman period, hill fort, Asturias.

\section{INTRODUCCIÓN}

En el ámbito de la arqueología castreño-romana los restos cerámicos constituyen, con notable diferencia, el conjunto material más numeroso de cuantos se recuperan durante el proceso de exca-

1 Este trabajo se ha realizado en el marco del Proyecto Nacional I+D "Formación y disolución de civitates en el NW peninsular. Estructuras de poblamiento y territorio" (HAR-06018-CO3/HIST) dirigido por C. Fernández Ochoa (Universidad Autónoma de Madrid). vación y uno de los mejores indicadores del escenario económico, social y cultural de sus usuarios. Los estudios sobre cerámica romana se han centrado tradicionalmente de manera prioritaria en aquellas familias que como la terra sigillata, las

2 Los dibujos del material cerámico ha sido realizados por Cecilia Berlanga, Cristóbal Burckhalter, Pablo Navieras, José Mon y Beatriz Alonso. El montaje de las figuras y la revisión de los dibujos ha corrido a cargo de Cecilia Berlanga. 
ánforas, las lucernas o las paredes finas permiten una más fácil individualización y la obtención de conclusiones de índole económica, cronológica y cultural relevantes en la elaboración del discurso histórico general de los asentamientos.

$\mathrm{Al}$ margen de estas series cerámicas bien definidas y que cuentan con trayectorias de investigación específicas y dilatadas se sitúa el extenso y difuso conjunto de la denominada cerámica común romana. Este término, de notable imprecisión, ha dado lugar a no pocos intentos de definición y acotación semántica, a pesar de los cuales sigue aún manifestándose como un gran fondo de saco que, pese a su ambigüedad, es reconocido por los investigadores como un lugar común en el que se incluyen por exclusión todas aquellas manufacturas que no se integran en producciones tipificadas.

La relevancia cuantitativa de estas vajillas en los ajuares y su indudable significación como documento histórico carece de un refrendo bibliográfico equivalente. Esta circunstancia encuentra explicación en buena medida en la dificultad de identificación de formas e individualización de ejemplares a partir de una cantidad con frecuencia ingente de fragmentos cuyo procesamiento y estudio a corto plazo resulta inabarcable, máxime cuando las intervenciones arqueológicas en las que se recuperan a menudo se hallan condicionadas por una urgencia que obliga a priorizar el estudio de otros materiales que no requieren un proceso de reconstrucción tan arduo y proporcionan un rendimiento investigador inmediato mayor.

En las últimas décadas el creciente interés por el conocimiento de estas vajillas y los nuevos enfoques de la investigación han permitido la definición de producciones específicas para las que ha sido posible determinar centros de fabricación, áreas de distribución, series tipológicas y evolución cronológica, adquiriendo de este modo carta de naturaleza propia, más allá de su imprecisa valoración como cerámica común ${ }^{3}$.

3 Baste citar, ciñéndonos al ámbito geográfico y temporal que centra nuestra atención, notables monografías dedicadas al estudio de repertorios de la importancia de los recuperados en Lucus Augusti (Alcorta 2001) o Petavonium (Carretero, 2000). Determinadas reuniones científicas u obras de conjunto de carácter más general también han contribuido al
La parquedad de estudios y publicaciones sobre este material resulta especialmente acusada en el contexto del noroeste peninsular y más específicamente, en el ámbito asturiano, para el que las obras básicas de referencia remiten a las tesis de los profesores C. Fernández Ochoa (1982) y J.L. Maya (1988). No obstante, y aunque en menor medida a lo ocurrido en otros ámbitos peninsulares, en los últimos años se han incorporado nuevas aportaciones. Ciñéndose al ámbito castreño pueden citarse los inventarios más o menos extensos incluidos como apéndices en memorias de excavación, caso del castro de La Campa Torres (Maya y Cuesta, 2001) o El Castiellu de Llagú (Berrocal et alii, 2002). A estos hay que añadir algunas referencias generales en obras de síntesis y catálogos de exposiciones (Maya y Cuesta, 1993; Fernández Miranda y Fernández Ochoa, 1995) o artículos de aproximación a repertorios de yacimientos concretos, caso del castro de San Chuis (Manzano, 1990; Marín, 2007) o Arancedo (Marín, 2008).

La continuidad de las intervenciones arqueológicas que desde el año 1995 se desarrollan bajo el programa de investigación denominado Plan Arqueológico del Navia-Eo $\mathrm{E}^{4}$ han favorecido un notable incremento del conocimiento de la cerámica castreña de época romana en Asturias derivado de los hallazgos proporcionados fundamentalmente por el Chao Samartín (Grandas de Salime) y también por otros yacimientos incluidos en el proyecto, caso de Os Castros de Taramundi (Expósito, 2004; Rodríguez del Cueto, 2004; Villa et alii, 2007) o el Monte Castrelo de Pelóu (Grandas de Salime).

Centrándonos en las vajillas cerámicas objeto del presente trabajo, se ha abordado hasta la fecha el análisis global del repertorio obtenido en un sector específico del yacimiento: la construcción $\mathrm{C}-10$. Sus conclusiones se tradujeron en dos artículos de conjunto referidos, respectivamente, a la vajilla de mesa y despensa (Benéitez et alii, 1999) y a la de cocina y almacenamiento (Hevia et alii, 2001), posteriormente compendiadas en un artí-

avance de la investigación (Fernández Ochoa y García, 2005; Morillo, 2006; Bernal y Ribera, 2008).

4 Programa actualmente en curso patrocinado por la Consejería de Cultura y Turismo del Principado de Asturias bajo la dirección científica del arqueólogo Á. Villa Valdés. 
culo de síntesis al que se incorporaron elementos procedentes de otros sectores (Montes et alii, 2001). El estudio del material de esta edificación, completado con las aportaciones derivadas del análisis paralelo de la terra sigillata (Hevia et alii, 1999), permitió elaborar una completa tipología y una caracterización productiva sólida del ajuar tipo que se encontraba en uso en la segunda mitad del siglo II d.C., cuando tiene lugar el incidente sísmico que pone fin a la ocupación romana del poblado (Villa, 1998: 41). Además de este enfoque sectorial se ha afrontado el análisis transversal de familias funcionales concretas, como la vajilla para beber (Montes, 2005).

Así mismo, la identificación de depósitos estratigráficos circunscritos al siglo I d.C. durante las sucesivas campañas de excavación, ha permitido abordar la caracterización de los repertorios en uso durante esa centuria (Hevia, 2006). Esta circunstancia ha resultado particularmente provechosa pues ha permitido afrontar una de las principales complicaciones a que se enfrentan los estudios de cerámica romana: la amplia perduración de los patrones de ocupación y las frecuentes dificultades que se encuentran para aislar segmentos cronológicos cortos y bien definidos.

No pretende este ser un trabajo finalista que establezca una tipología de formas cerrada. Como se ha referido, la investigación se halla aún en curso y los fragmentos integrables en el universo de estudio que proporciona el yacimiento se cuentan por miles cada campaña de excavación. No obstante, sí puede presentarse como un estado de la cuestión argumentado sobre la base de la solidez de las conclusiones estratigráficas del yacimiento y el volumen material analizado hasta la fecha, que permiten individualizar y caracterizar las diferentes producciones y tipos cerámicos en vigor en el yacimiento en las dos fases que se han podido fijar.

\section{EL REPERTORIO MATERIAL: CARACTERIZACIÓN GENERAL Y METODOLOGÍA DE ESTUDIO}

Al igual que sucede en otros yacimientos de ámbito geocultural similar, también en el Chao Samartín y, aún a pesar de su singular relevancia en época altoimperial, el predominio de los hallazgos cerámicos correspondientes a producciones de fabricación local o regional resulta abrumador respecto a los registros que pueden adscribirse a los tipos romanos clásicos importados, tanto en términos de fragmentos absolutos como de representación porcentual de ejemplares.

Ya se ha hecho referencia a la escasa precisión de la denominación de cerámica común romana aplicada a estas vajillas debido, sobre todo, a que no introduce elementos de discriminación identificativos de las particularidades de unas fabricaciones regionales frente a otras ni de éstas frente al paradigma clásico. Los intentos de redefinición de estos conjuntos han sido varios, existiendo en la bibliografía actual un cierto consenso sobre la necesidad de abandonar las denominaciones generalistas en favor de fórmulas conceptuales más concretas. Resulta una aspiración compleja en tanto no se disponga de un elenco de estudios más amplio que permita definir centros de fabricación, áreas de difusión y resolver cuestiones como la convivencia en un mismo centro productor de imitaciones directas de formulaciones romanas, morfologías originales, adaptaciones de tipos tanto clásicos como provenientes de los sustratos locales o formas resultado de la fusión de tradiciones técnicas y estéticas diferenciadas.

En algunos casos muy próximos geográfica y culturalmente como Lugo se aplica el término de cerámica común romana para designar a aquella en la que ya se deja sentir la plena integración de los modelos clásicos en el mundo indígena, a partir del siglo II d.C., reservando los de cerámica de tradición indígena, común importada y local influenciada respectivamente para la que mantiene los rasgos prerromanos, para los productos foráneos y para las producciones locales que recrean modelos clásicos (Alcorta, 2001).

Esta denominación de cerámica de tradición indígena ha sido empleada en un sentido similar en otras ocasiones (Sánchez-Palencia y Fernández-Posse, 1985: 245; Maya, 1988: 154). En cualquier caso, aunque es innegable la influencia de ciertos aspectos de la tradición o tradiciones regionales en la cerámica de época altoimperial romana, expresados tanto mediante estrictas pervivencias formales, técnicas o decorativas como a través de fenómenos de singulares síntesis, no es válida para la generalidad del material, ya que en ciertos tipos el componente latino es preponderante. Quedaría pues este término reservado para una parte del todo, aquella en la que, en 
la simbiosis entre lo indígena y lo romano, destaca poderosamente el primer componente.

En algún otro caso se han planteado denominaciones como la de cerámica castreña, cerámica de tradición castreña (Arias, 1985: 15) o cerámica castreño-romana aplicada, al menos, a algunos de estos materiales. El empleo de estos términos implica la identificación del material con un determinado tipo de hábitat, quedando excluidos otros contextos como, por ejemplo, los yacimientos urbanos o las villae, que no ofrecen diferencias significativas respecto a lo registrado en los contextos castreños coetáneos. En este sentido, cabe además adelantar que buena parte de las producciones no importadas halladas en el Chao Samartín, han sido precisamente fabricadas en la ciudad de Lucus Augusti.

Otra corriente terminológica es la que combina el etnónimo regional con el carácter cronológico y el aporte cultural romano en el que se inscribe la cerámica. De esta forma se puede rastrear en la bibliografía el uso, entre otras, de denominaciones como cerámica galaico-romana (Alcorta, 2001: 54), astur-romana (Carretero, 2000: 574577) o galo-romana (Tuffreau-Libre, 1987: 203), que tratan de definir la particular síntesis que cristaliza en cada caso por la fusión de elementos de raíz regional con el influjo de la romanidad.

Las propuestas de esta última tendencia resultan más expresivas de la naturaleza de los materiales que pretenden definir, siendo la denominación de cerámica galaico-romana la que se ajustaría a los materiales que se analizan en este trabajo que quedarían, de este modo, precisados por la particularidad geocultural de su procedencia y por su contexto cronológico. Restaría, no obstante, resolver cual puede ser el alcance de la consideración de galaica para unas producciones que en algunos tipos se muestran extremadamente locales, algo que sólo la multiplicación de estudios sobre estas familias cerámicas permitirá precisar.

En tanto no se establezca un consenso entre los distintos autores y dado que este estudio se centra en exclusiva en los materiales de un yacimiento, hemos preferido caracterizar el conjunto como cerámica romana altoimperial de fabricación regional. De este modo se acota el conjunto en virtud de su adscripción cronológica y de su procedencia productiva, entendiendo por regional una fabricación que se inscribe, en virtud de sus características técnicas, en la órbita alfarera lucense ya tenga ésta un carácter local, comarcal o regional.

Otra cuestión no menos problemática que se plantea al abordar el análisis de estas vajillas es el de la designación de los tipos identificados, dado que las producciones regionales, por su propia naturaleza, carecen de una terminología consolidada, adoptando cada autor un sistema de clasificación propio. A este respecto, la denominación de los tipos cerámicos del ajuar doméstico romano que, como las producciones regionales, pueden inscribirse en el extenso y difuso ámbito de la cerámica común, ha generado una amplia bibliografía y un debate, aún sin cerrar. Los diversos especialistas parecen estar de acuerdo en la necesidad de consensuar posiciones, sin que hasta el momento esta pretensión se haya traducido en una unificación de criterios ni en la elaboración de un corpus terminológico de general aceptación. Las propuestas de designación van desde el empleo de códigos alfanuméricos que remiten al yacimiento de procedencia de las piezas o al autor de su estudio, a la búsqueda de definiciones morfológicas, pasando por ensayos, muy interesantes pero de difícil aplicación, de identificar las formas con los utensilios descritos por los autores clásicos. En otras ocasiones, es la tecnología de fabricación de las piezas o sus elementos compositivos los que se imponen como criterio de clasificación.

En el estado actual de conocimientos, tanto en el contexto lucense y galaico en general como en el Chao Samartín en particular, no parece aconsejable fijar una compleja y encorsetada nomenclatura que irremediablemente se verá sometida a cambios al compás del avance de las investigaciones. Necesariamente, además, si se fija como objetivo la identificación de producciones específicas y no la elaboración de una sistematización tipológica basada en la simple concomitancia formal, resulta imprescindible la concurrencia de los diversos autores, superando las fronteras que imponen los yacimientos concretos. Esto resulta particularmente urgente en nuestro ámbito de trabajo para el que ya se ha verificado como los talleres de Lucus Augusti abastecieron, más allá de los límites de la ciudad, un área que por el momento sólo podemos intuir.

Este estado de la cuestión nos ha inclinado a optar en el Chao Samartín por una denominación 
descriptiva de los tipos analizados, de modo que a partir del enunciado de las formas pueda reconocerse su adscripción funcional y su caracterización morfológica básica. Ocasionalmente, cuando los tipos cuentan con rasgos técnicos de marcada personalidad que permiten una identificación incontrovertible, se ha optado por designaciones basadas en ese rasgo específico (es el caso de las ollas ovoides micáceas o la vajilla engobada).

Los aspectos morfofuncionales empleados como criterio de agrupamiento preliminar en trabajos anteriores y que, aún con sus innegables limitaciones $^{5}$, consideramos irrenunciables en el camino a la obtención de valoraciones de índole social y cultural, adquieren en este contexto una relevancia menor en tanto que susceptibles de proporcionar conclusiones firmes al respecto. Éstas habrían de ser necesariamente sesgadas dado que el conjunto seleccionado procede de contextos estratigráficos diversos y aún en fase de estudio y que además se restringe a unas producciones cerámicas concretas, por lo que las consideraciones sobre distribuciones y significaciones funcionales se abordan, de manera individual, en el análisis de cada tipo concreto.

En la selección del universo de estudio ha resultado determinante la valoración de los contextos estratigráficos aportados por el yacimiento hasta la fecha, siendo los resultados de su confrontación el factor que ha conducido a su elección definitiva. La individualización de los fragmentos susceptibles de constituir una pieza o ejemplar cuantificable se ha realizado de acuerdo a los parámetros clásicos de borde, base o fragmento de pared diferenciada. Hemos prescindido de realizar una estimación cuantitativa de los fragmentos de cuerpo y base que tras esta fase no se han singularizado, dada su escasa representatividad y la sobrevaloración estadística de determinadas producciones y tipos a que podría conducir. La naturaleza de los contextos de procedencia introduce, como veremos, una distorsión en la

5 La ausencia de analíticas específicas y la polivalencia funcional de muchas formas dificulta notablemente la identificación de su uso. Además, el análisis de la significación de los diversos grupos funcionales adquiere su verdadero sentido cuando se estudian conjuntos completos, sin exclusión de tipos ni de vajillas no cerámicas, en contextos bien definidos estratigráficamente. identificación y evaluación de formas a favor de los ajuares del siglo II d.C. Así, en la primera centuria, son varios los tipos que se reconocen como tales en virtud de la identificación de un único ejemplar, sin que la parquedad de la muestra permita realizar valoraciones sobre su significación dentro del ajuar y su carácter o no de producción consolidada. La caracterización técnica de las piezas se ha realizado de manera macroscópica por observación directa bajo las mismas condiciones de luz natural. En la descripción de las pastas se ha optado por enunciar exclusivamente aquellas inclusiones reconocibles, describiendo el tamaño y la apariencia física de las restantes ${ }^{6}$, cuya naturaleza específica deberá ser concretada mediante analítica? .

Hemos evitado en lo posible la tentación de referir paralelos que de modo genérico presentan concordancias morfológicas con los tipos definidos pero que se insertan en tradiciones productivas completamente ajenas a las que se tratan de definir. En sentido contrario, se refieren en ocasiones afinidades que, aunque distantes en lo formal, evidencian una génesis común, sumamente expresiva del ámbito geocultural de fabricación de los recipientes.

\section{LA VAJILLA DEL SIGLO I D.C.}

\subsection{Contextos Estratigráficos}

La ocupación continuada del mismo espacio habitado que se constata en el Chao Samartín dificulta la percepción de los segmentos intermedios de una secuencia estratigráfica que se presenta ininterrumpida desde la fundación del poblado hasta el definitivo abandono del mismo en la segunda mitad del siglo II d.C. (Villa, 2005 a: 59). Esta circunstancia ha dificultado notablemente la individualización de depósitos inalterados anteriores a estas fechas finales, convirtiéndose los estratos en los que se recuperan materiales cerámicos fabricados en el siglo I d.C. en relictos de

6 Para la descripción granulométrica de los desgrasantes se ha empleado el criterio comúnmente adoptado que define como inclusiones muy finas/muy pequeñas las inferiores a $1 \mathrm{~mm}$, finas/medias entre 1 y $2 \mathrm{~mm}$, medias entre 3 y $5 \mathrm{~mm}$ y grandes/gruesas de $5 \mathrm{~mm}$ o más.

7 El análisis de pastas de la cerámica común del yacimiento se halla en proceso de ejecución. 
ocasional registro. Este tipo de estratos se localizan en unas zonas muy determinadas del yacimiento y se vinculan a contextos que remiten a tres tipos de localizaciones específicas bien diferentes, cada una de las cuales cuenta con unas peculiares circunstancias estratigráficas que conviene especificar como paso previo al estudio del repertorio de cerámica común regional que contienen.

\section{EL VERTEDERO DE LA DOMUS (Figuras 1 a 18)}

La primera de estas localizaciones y la más relevante en lo tocante al volumen del material recuperado y a su potencial informativo consiste en un vertedero relacionado con la domus de fisonomía clásica y fundación julio-claudia erigida en la zona septentrional del yacimiento (Figura 1). En concreto, nos referimos a una serie de depósitos de naturaleza heterogénea que componen un basurero ubicado en la esquina noroeste del complejo doméstico y al exterior de éste, en el espacio que queda entre la vetusta muralla de la Edad del Hierro y el cierre mural septentrional de este edificio. Estos vertidos contribuyen a la completa colmatación de la zanja de fundación de la referida estructura, que había dejado abierta una trinchera de trayectoria longitudinal de cierta profundidad. Los aportes sedimentarios no sólo rellenaron la cuenca de deposición que representaba esta

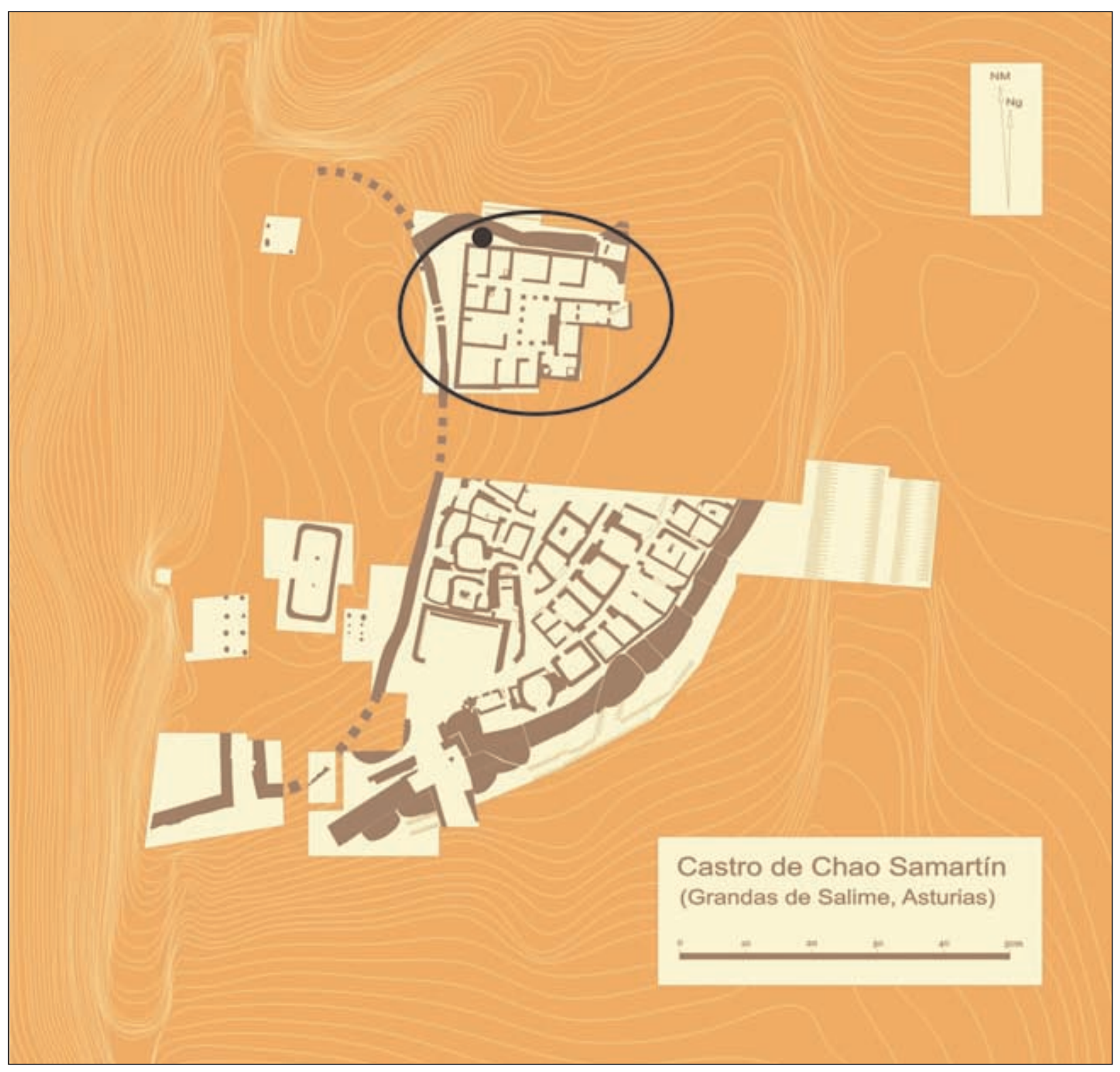

Figura 1. Croquis general del Chao Samartín. Ubicación de la domus altoimperial y del vertedero asociado. Dibujo: E. Martín y Á. Villa. 


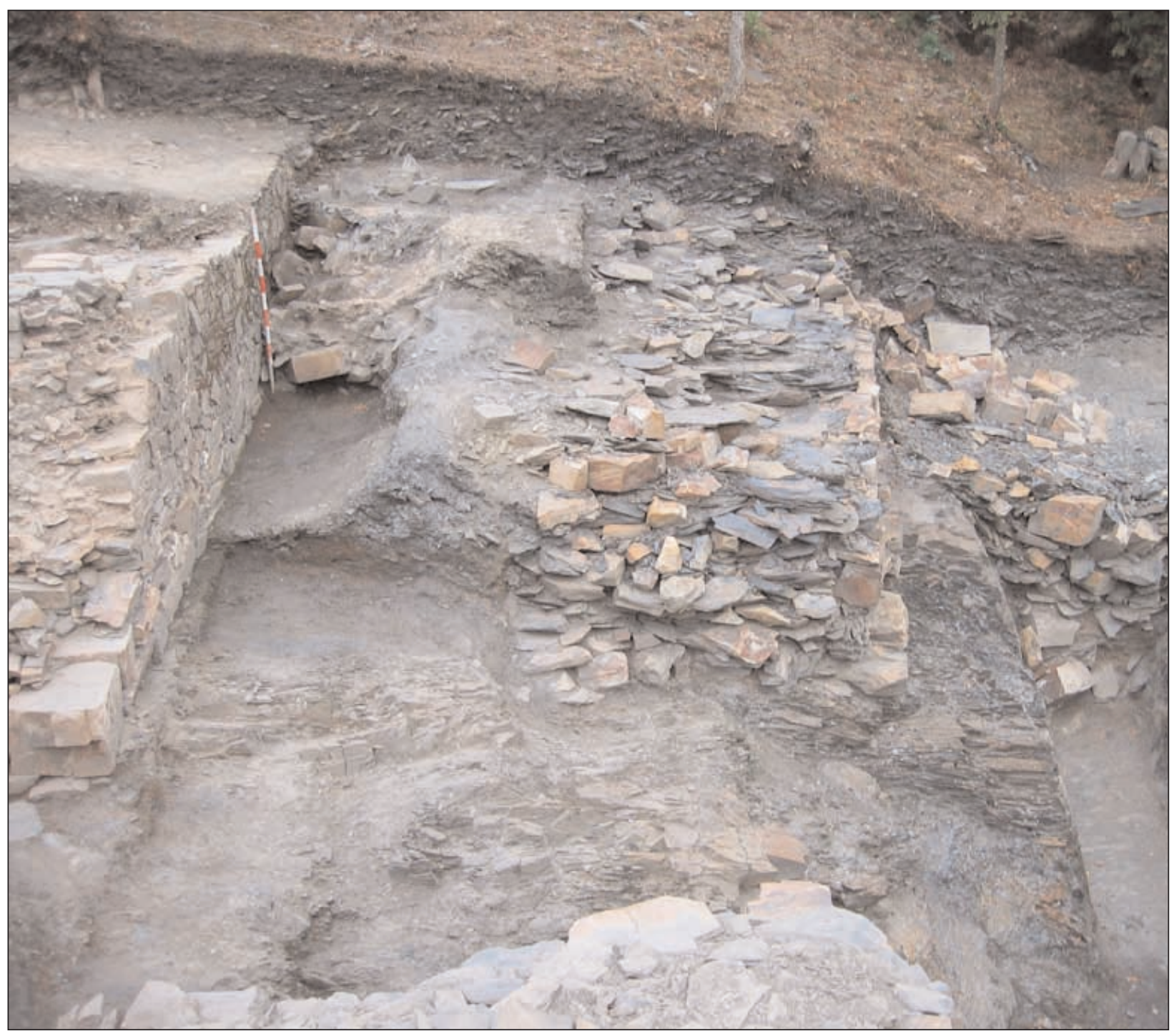

Figura 2. Zanja de cimentación del muro septentrional de la domus (izquierda) y Foso E (derecha). Autor: Á. Villa.

zanja de cimentación, sino que alcanzaron ámbitos situados más al norte, lo que explica satisfactoriamente el hecho de que se integren también en la estratigrafía que amortiza el pequeño foso (Figura 2) que recorre la zona por el flanco septentrional. En efecto, en los niveles basales que colmatan la trinchera defensiva, el material cerámico registrado resulta no sólo coherente en lo cronológico, sino que incluso se identifican fragmentos de las mismas piezas, conformando conjuntamente el elenco analizado (Hevia y Montes, 2009: 639-641).

Las alteraciones estratigráficas posteriores, al contrario de lo que acontece en zonas aledañas, no han dejado huella significativa en este área concreta de la domus, quedando los aludidos estratos, tras su deposición, sellados por aportes sedimentarios procedentes del abandono del complejo y, en el caso de los rellenos del foso, de la ruina definitiva de la muralla, sin que perturbaciones ulteriores como las generadas por la instalación de una necrópolis altomedieval (Figura 3) en el lugar (Villa et alii, 2008), por la acción de fenómenos erosivos o por la secular actividad agraria, incidiesen de una forma notable.

La aproximación cronológica a este vertedero y, por extensión, a la vigencia de la propia domus a la que se vincula y del último uso del aparato defensivo en la zona, goza de las ventajas que supone para un ajuste temporal fidedigno el registro en su seno de un nutrido elenco de importaciones cerámicas.

El conjunto más expresivo y cuantioso a este respecto lo constituye sin duda el de la 


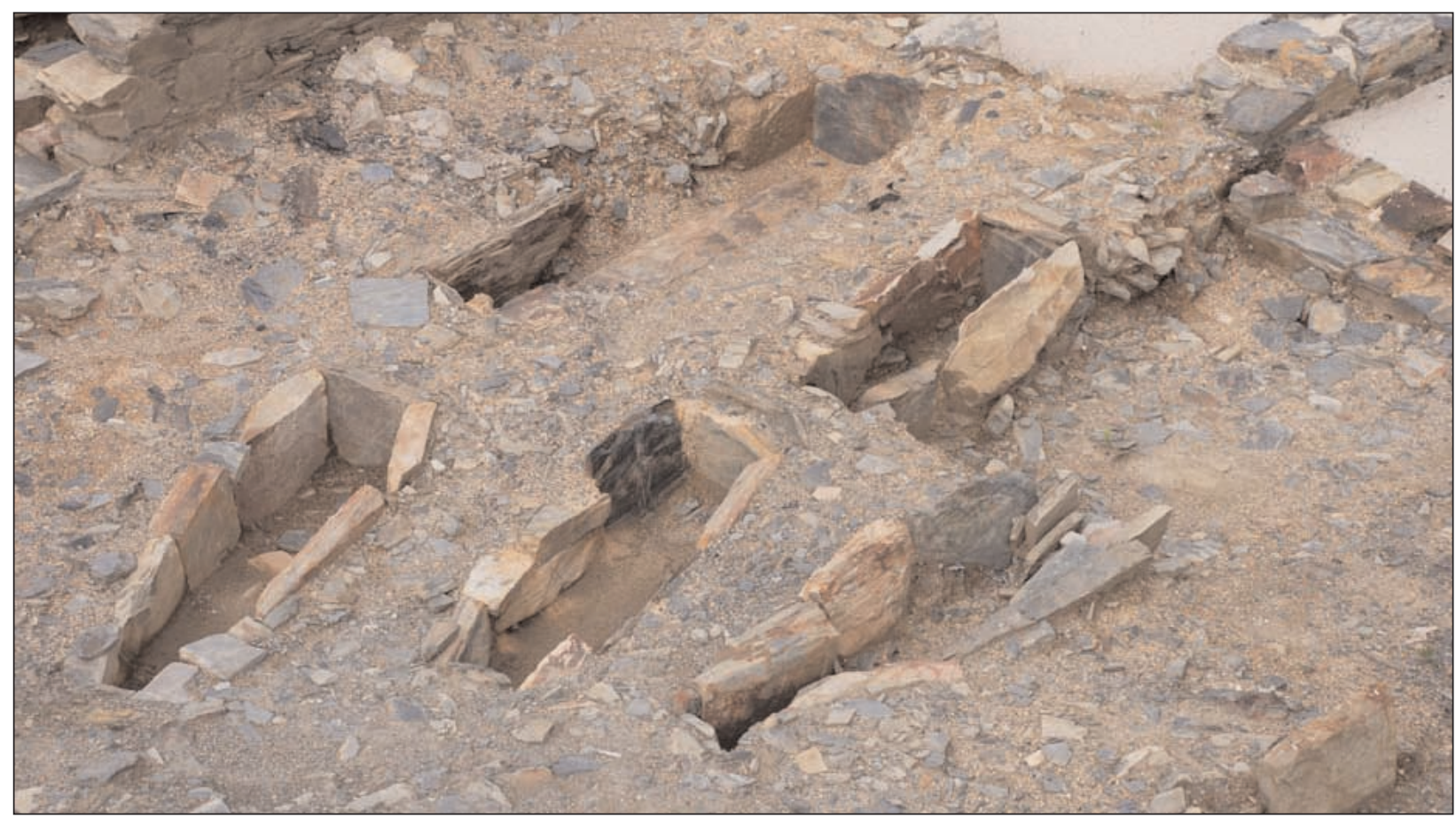

Figura 3. Grupo de tumbas perteneciente a la necrópolis altomedieval instalada sobre la ruina de la domus altoimperial. Foto: Á. Villa

terra sigillata ${ }^{8}$ (Menéndez y Sánchez, e.p.), caracterizado por la coexistencia de producciones sudgálicas fabricadas tanto en los alfares de Montans como en los de La Graufesenque y de piezas hispánicas manufacturadas a partir del último tercio del siglo I d.C. en el centro de Tritium Magallum (Villa et alii, 2006: Nota 12).

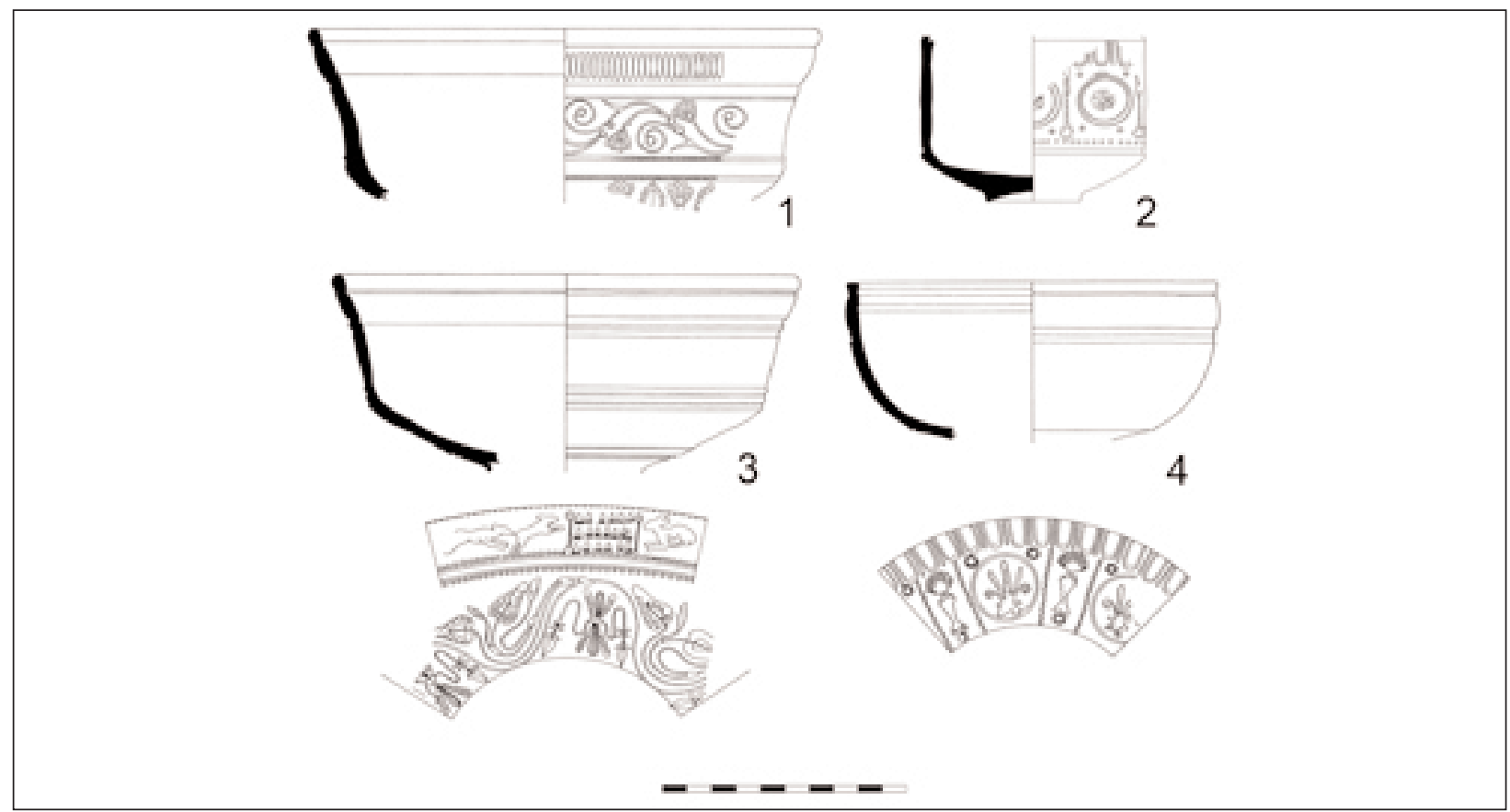

Figura 4. Terra sigillata gálica decorada del vertedero de la domus. 1: Drag. 29. 2: Knorr 78. 3: Drag. 29. 4: Drag. 37.

8 El repertorio de terra sigillata, tanto de la domus como del resto del yacimiento, está siendo estudiado por los arqueólogos A. Menéndez y E. Sánchez. Para una información más detallada de los resultados de la investigación, consúltese la bibliografía indicada. 
Entre las primeras (Figura 4), porcentualmente menos numerosas ${ }^{9}$, se identifican diversos cuencos Drag. 29 (Figura 4 y 4.1 y 3) (Villa et alii, 2005: Fig. 4. 8-9; Menéndez y Sánchez, 2009: 288-289), que proporcionan cronologías de fabricación que van desde el 10 d.C. (Costa, 2003: 114) hasta el 70-80 d.C. (Oswald y Pryce, 1920: 66), y los Drag. 37 a (Figura 4.4) (Villa et alii, 2005: Fig. 4.7), cuya producción parece iniciarse en datas más recientes, hacia el 60 d.C.

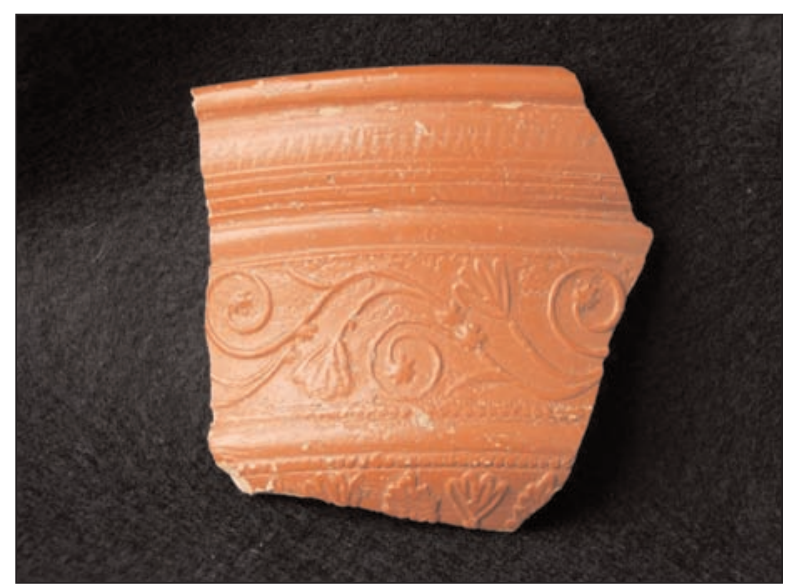

Figura 5. Fragmento de Drag. 29 gálica fabricada en La Graufesenque procedente del vertedero del vertedero de la domus. Foto: Á. Villa

(Oswald \& Price, 1920: 95). Se encuentran presentes igualmente piezas como un cubilete decorado de la forma Knorr 78 (Figura 6 y 4.2) fabricado en Montans a partir del 75 d.C. (Menéndez y Sánchez, 2009: 286-287).

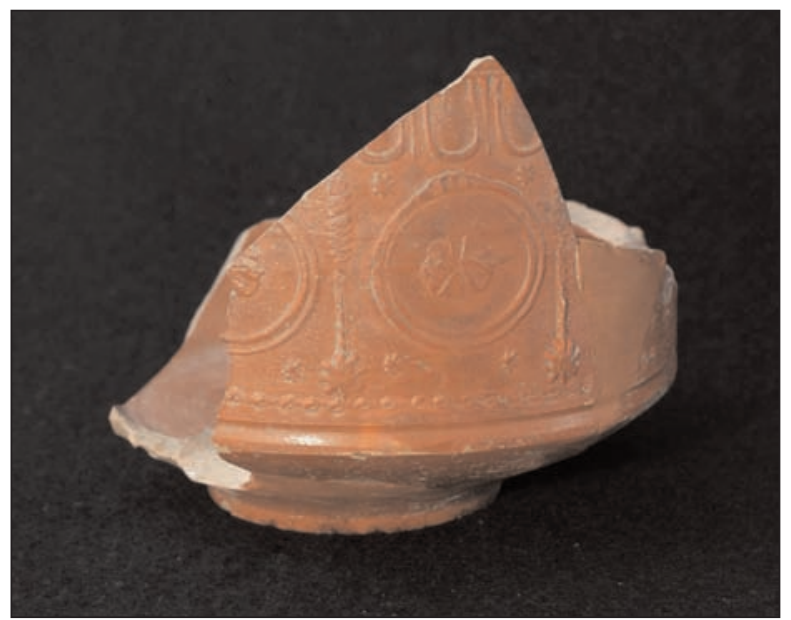

Figura 6. Terra sigillata gálica. Forma Knorr 78. Foto: J. Arrojo

\footnotetext{
${ }^{9}$ Una aproximación estadística al repertorio ha estimado en torno al $25 \%$ su representación (Menéndez, 2003).
}

Por lo que se refiere a las piezas lisas (Figura 7), se conocen platos Drag. 15/17 y 18, asimilados a época de Claudio (Sánchez y Menéndez, 2005:253) varios vasos Drag. 27 (Figura 7.1) de cronologías neronianas (Menéndez, 2003), un singular fragmento de tintero de la forma Hermet 18 (Figura 7.2) (Menéndez y Sánchez, 2009: 376-377) y diversos recipientes adscritos a las morfologías Drag. 36 (Figura 7.3), Ritt.12 (Figura 7.6), Curle 11 y Drag. 16 respectivamente (Figura 7.4) (Menéndez, 2003).

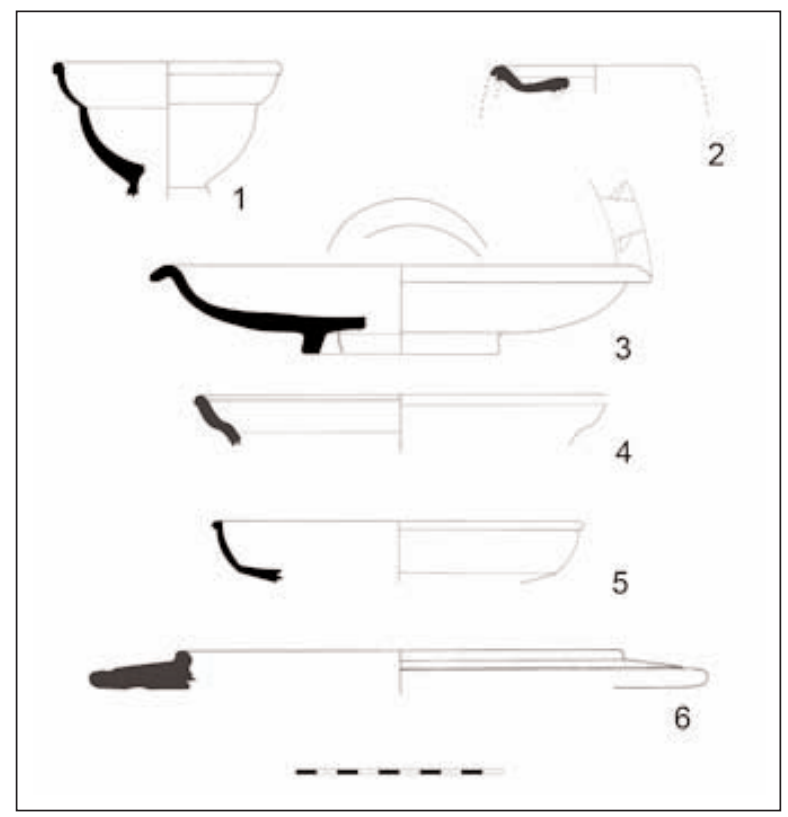

Figura 7. Terra sigillata gálica lisa del vertedero de la domus. 1: Drag. 27. 2: Ritt. 13. 3: Drag. 36. 4: Drag. 16. 5: Drag. 18. 6: Ritt.12.

Entre las formas hispánicas decoradas (Figura 11) se documentan varios cuencos Drag. 29 (Figura 8 y 11.5) (Menéndez y Sánchez, 2009: 330-331) (Figura 11.5) que comienzan a producirse mediada la centuria para prolongarse hasta

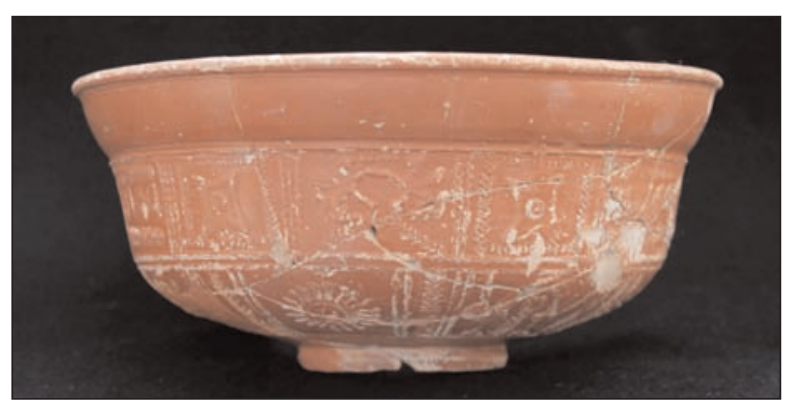

Figura 8. Terra Sigillata Hispánica. Forma Drag. 29. Foto: Á. Villa 
el 80-85 d.C. (Mezquiriz, 1961: 93; Romero, 1985: 91). Este tipo de cuencos se acompañan de algunos ejemplares de Drag. 29/37 (Figura 11.2) (Menéndez, 2003), fabricados a partir del 65 d. C. (Roca, 1976: 73) o el 70 d. C. (Mezquiriz, 1961: 105) y de Drag. 37 B (Figura 9 y 11.1) (Villa et alii, 2005: Fig.5.9; Menéndez y Sánchez, 2009: 332-333), datables en el último tercio de siglo.

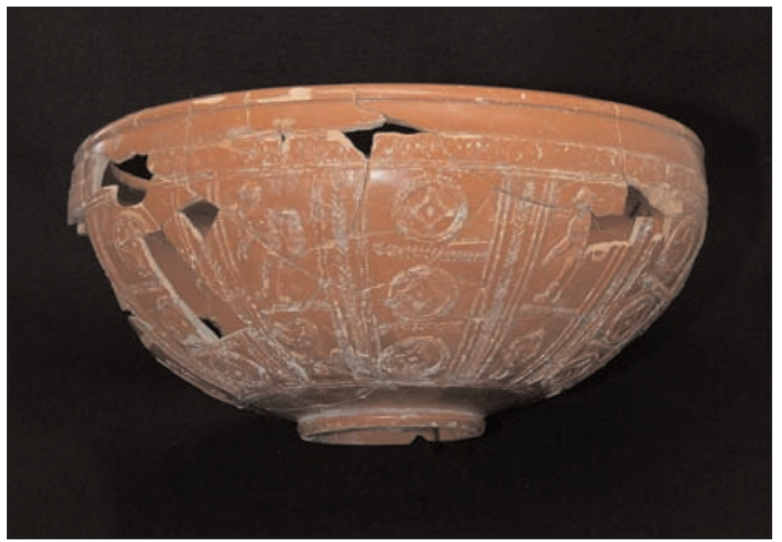

Figura 9. Terra Sigillata Hispánica. Forma Drag. 37b. Foto: J. Arrojo

Tan expresiva como la presencia de estas morfologías resulta la total ausencia de las Drag. 37 A, tan frecuentes en otros contextos del yacimiento y cuya producción se prolongará más allá que la de la variante B (Menéndez, 2003). El repertorio de piezas hispánicas decoradas se completa con un vaso de la forma Déchelette 67 (Figura 10 y 11.4) (Menéndez y Sánchez, 2009: 296-297) elaborado a partir de mediados del siglo I d. C. (Mezquiriz,

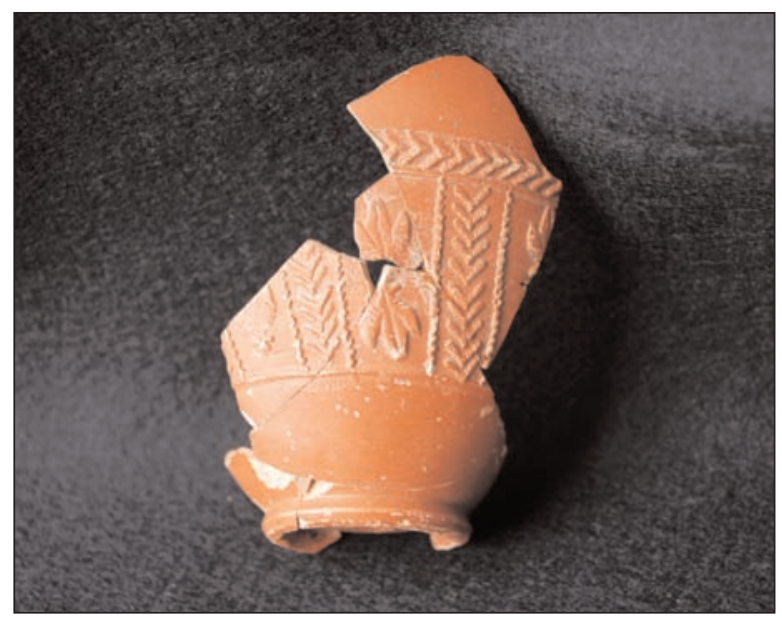

Figura 10. Terra Sigillata Hispánica. Forma Déchelette 67. Foto: Á. Villa

1961: 74), una cantimplora del tipo Hermet 13 (Villa et alii, 2005: Fig.5.10) de rasgos arcaicos (Mezquiriz, 1961: 70), cuya fabricación es remontada por ciertos autores a fechas entre el 65 y 70 d. C. (Romero, 1985: 115) y varios ejemplares de la forma Drag. 30 (Figura 11.3) (Menéndez, 2003).

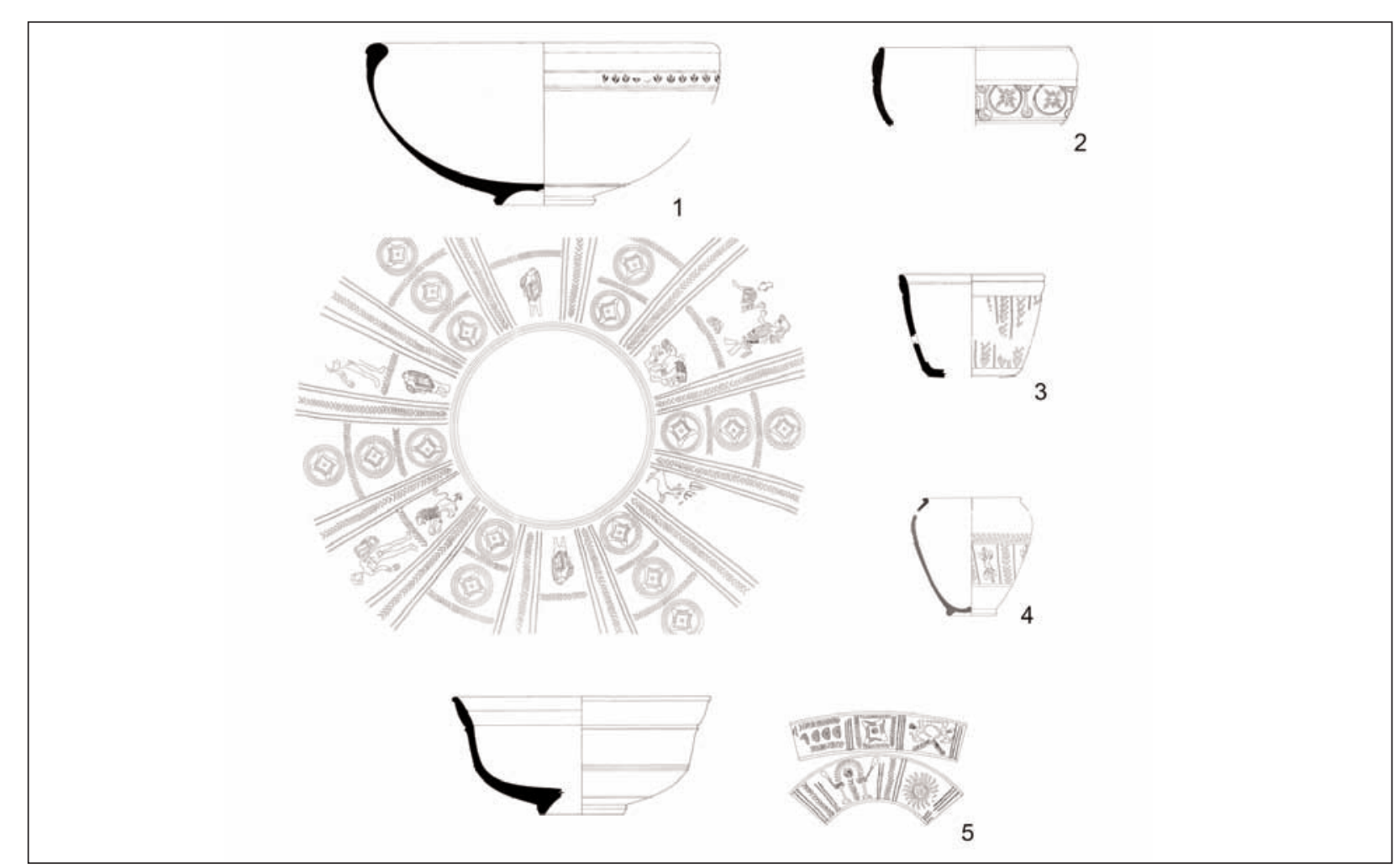

Figura 11. Terra sigillata hispánica decorada del vertedero de la domus.

1: Drag. 37b. 2: Drag.29/37. 3: Drag. 30. 4: Dech. 67. 5: Drag. 29. 


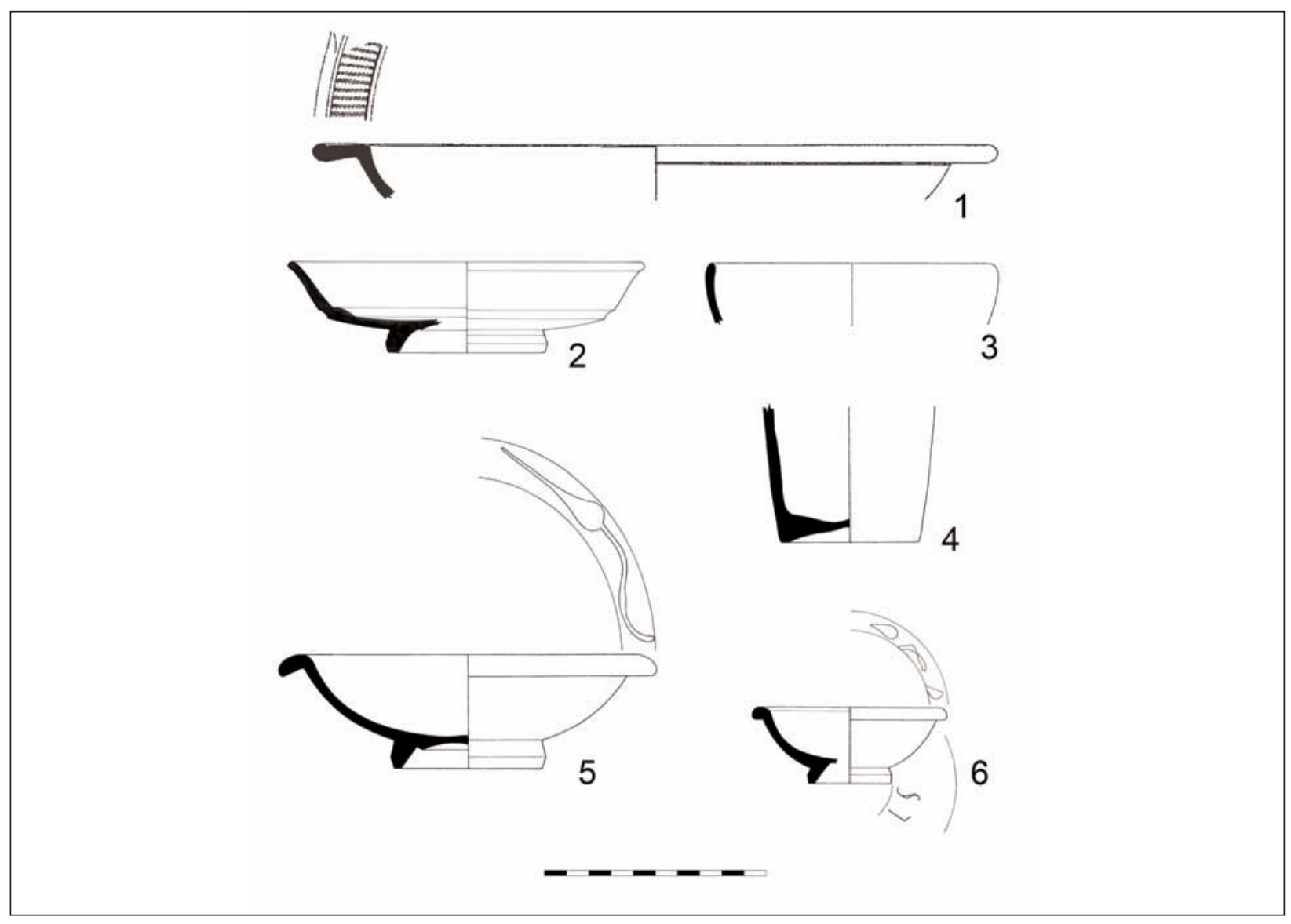

Figura 12. Terra sigillata hispánica lisa documentada en el vertedero de la domus. 1: Hisp. 4. 2: Drag. 15/17. 3: Ritt. 8. 4: Hisp. 55. 5: Drag. 36. 6: Drag. 35.

Entre las formas lisas (Figura 12) se registran platos de las formas Drag. 15/17 (Figura 12.3), Hisp.4 (Figura 12.1) y Drag. 36 (Figura 12.5), cuencos Ritt. 8 (Figura 12.3), vasos Drag. 27 y 35 (Figura 12.6) y una botella adscribible al tipo Hisp. 55 (Figura 12.4).

Determinados productos clásicos de cerámica común importada (Hevia, 2006; Hevia y Montes, 2009: 643-646, Fig.2) confirman los indicios cronológicos obtenidos a partir del análisis de la terra sigillata. Destacan entre éstos varios morteros itálicos del tipo Dramont D2 (Figura 16.4) (Joncheray, 1973), uno de los cuales (Figura 13) presenta sobre el borde un sello inscrito en cartela cuadrangular de lectura (STA)TTIAE.VOL(VTIA) / (PRIS)CVS.FE(CIT) (Sánchez, 2003; Hevia y Montes, 2009: 644; Fig.2.6). Esta marca cuenta con paralelos en diversos puntos del occidente del Imperio como el

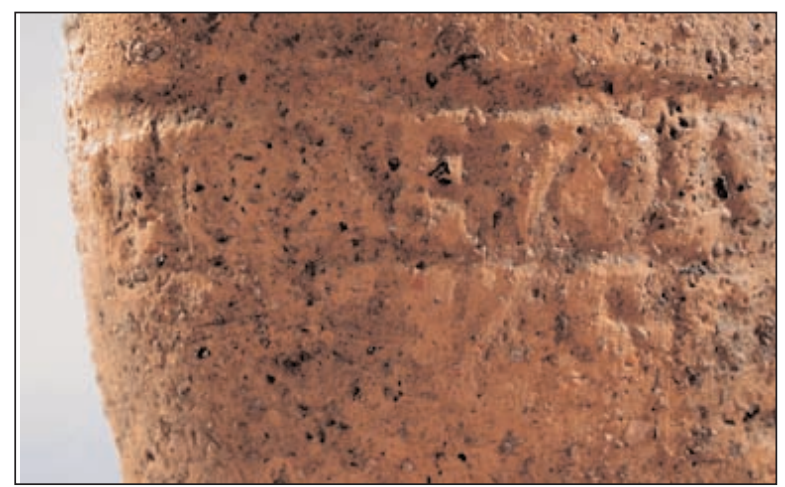

Figura 13. Detalle de sello sobre mortero itálico de la forma Cap Dramont D2. Foto: Á. Villa.

pecio castellonense de Ben Afeli (Fernández Izquierdo, 1980: 179-181, Fig.12) ${ }^{10}$, Saint Remy de Provence ${ }^{11}$ y Nimega ${ }^{12}$ (Hartley, 1973: 53). La relación que se ha planteado entre la inclinación del borde de este tipo de mortaria y su cronología (Hartley, 1973: 155; Sabrié, 1981: 89-90; Aguarod, 1991: 140-141) permite adscribir los
10 Lectura (STA)TIAE.VOL(VTIA)/(PR)ISCVS.F(ECIT).

11 Lectura ATTIAE.VOLV../...E.LVS.I..
12 Lectura ...E.VOLVT.../..VS.FI 
ejemplares registrados en este vertedero a la denominada Fase 3 (Aguarod, 1991: 141, Fig. VIII.3), en la que los bordes, de notable desarrollo y perfil curvo, se disponen en ángulo aproximadamente recto respecto a la línea marcada por la trayectoria del galbo. Hacen su aparición en este periodo, además, las características acanaladuras que se sitúan en la cara interna de la pieza, en el tránsito entre el borde y el cuerpo. La pertenencia a esta etapa permite situar las fechas de producción de las piezas registradas, dentro del marco general establecido para el tipo, hacia la segunda mitad del siglo I d.C., aproximadamente entre los últimos momentos de Claudio y los primeros antoninos (Aguarod, 1991: 141).

Aún resultando exiguo, el repertorio lychnológico recuperado en este basurero facilita igualmente la aquilatación temporal de los depósitos. Se han reconocido varios fragmentos pertenecientes a sendos ejemplares que se corresponden respectivamente a una pieza del grupo de las lucernas conocidas como derivadas de la forma Dressel 3 tipo Andújar (Figura 16.1) (Hevia, 2006; Hevia y Montes, 2009: 645; Fig.2.4) y a un ejemplar de disco del tipo Dressel 19 (Figura 14 y 16.2) (Hevia, 2006; Hevia y Montes, 2009: 644) de probable procedencia itálica (Morillo, 1999: 114).

La primera representa una producción hispana cuya elaboración está constatada en diversos talleres que desarrollan su actividad en el siglo I d.C., caso del propio Andújar (Sotomayor et alii, 1976), Corduba (Amaré, 1988/89; Bernal, 1993) y Emerita Augusta (Rodríguez Martín, 1996: 143-144), aunque no deben descartarse otros focos productores (Morillo y Rodríguez, 2008: 416). El lapso temporal concreto de su fabricación podría iniciarse en época tiberio-claudia (Sotomayor et alii, 1976: 135; Morillo, 1999: 100), para prolongarse, a lo sumo, durante época flavia (López Rodríguez, 1982: 382).

Por lo que respecta a la segunda de las lucernas documentada (Figura 14), de la forma Dressel 19 y con una decoración, habitual en el tipo (Morillo, 1999: 266) ${ }^{13}$, consistente en una hilera de ovas que ornamenta la orla, se manejan cronologías de fabricación de la segunda mitad del siglo I o principios del II d.C. (Ibidem: 113).

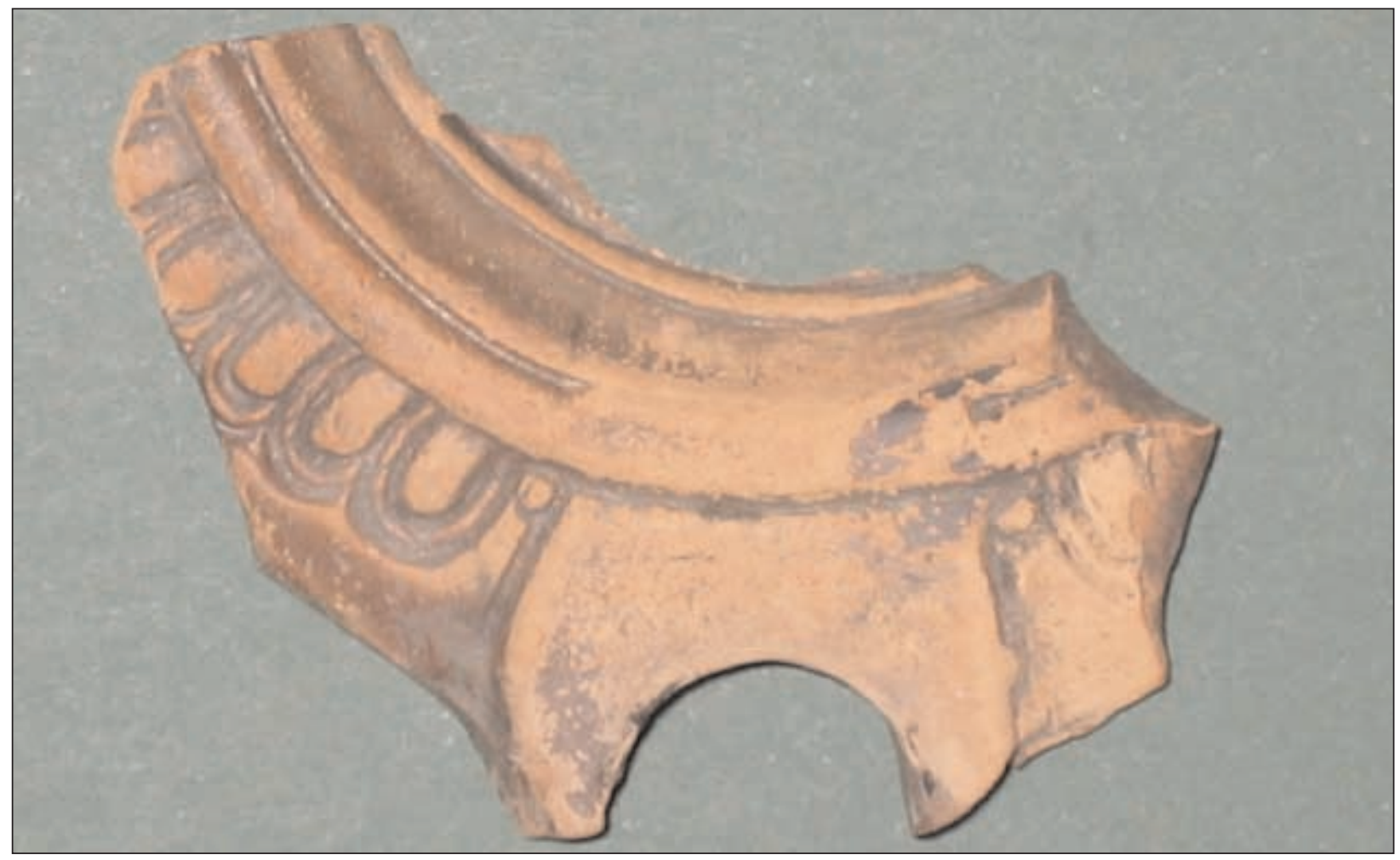

Figura 14. Lucerna de disco de la forma Dressel 19 con decoración de ovas en la orla. Foto: R. Montes

13 Véanse, por ejemplo, las piezas recopiladas por Á. Morillo peninsular como Astorga, Herrera de Pisuerga o León. (1999: 265) procedentes de diferentes yacimientos del Norte 
Los vasos de paredes finas registrados contribuyen de igual modo a dotar de contexto temporal a los depósitos. Cabe distinguir dos grupos de producciones bien diferenciados (Montes, 2005; Montes y Hevia: 2008: 764-765): el de las piezas emeritenses de pastas blanquecinas y el más numeroso de los vasos elaborados en el alfar zamorano de Melgar de Tera (Gimeno, 1990).

Lo escueto de la representación de piezas fabricadas en Mérida (Hevia y Montes, 2009: 643, Fig.2.1), reducida a un pequeño vaso de la forma Mayet VI (Mayet, 1975: 37-38, Pl. XI no 81-87) con decoración de depresiones (Figura 15 y 16.6) (Montes, 2009: 308-309) y a un alto cubilete fusiforme ornado con diversas bandas buriladas (Figura 16.3) (Montes, 2005), no impide la valoración de su importancia cualitativa, tanto como privilegiado indicador cronológico, ya que se apuntan fechas de vigencia de estos alfares entre el periodo tiberio-claudio y época flavia (Rodríguez Martín, 1996: 165), como como ejemplo de la difusión septentrional de este tipo de productos.

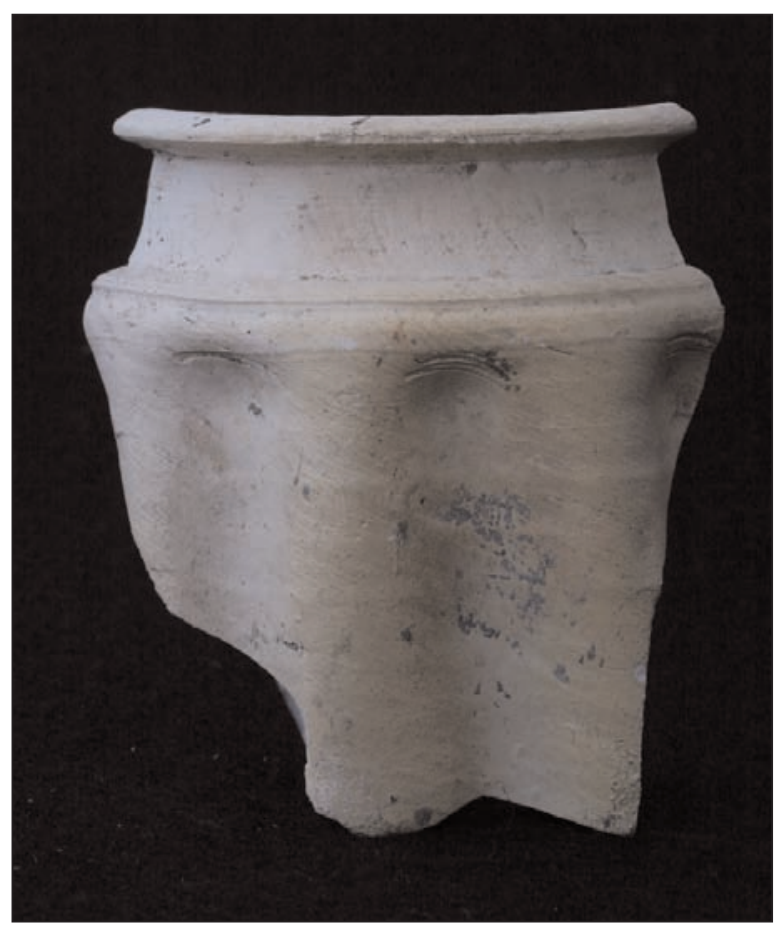

Figura 15. Vaso de paredes finas de la forma Mayet VI de procedencia emeritense hallado en el vertedero de la domus. Foto: J. Arrojo

${ }^{14}$ Se trataría, en cualquier caso, de una producción alboral de caracteres dubitativos con formas y decoraciones poco definidas y de distribución restringida, que poco tendría que ver con los estandarizados productos posteriores.

${ }^{15}$ En fechas recientes se ha identificado la fabricación de esta
Esta arribada a territorios norteños peninsulares, hasta hace bien poco ignorada (Mayet, 1975), se ha venido apuntando recientemente (Rodríguez Martín, 2006) para yacimientos del territorio astur como Rosinos de Vidriales (Carretero, 2000: 549), Asturica Augusta (Morillo et alii, 2005: 147) o León (Martín, 2006 y 2008: 128).

Las paredes finas melgarenses (Figura 16.5), aún sin llegar a poder ser consideradas abundantes, se hallan bien representadas en el repertorio estudiado (Montes, 2004 y 2005), hasta el punto de constituir el grupo de vasa potoria más numeroso. Las cronologías que se proponen para el inicio de la producción a gran escala en el alfar se suelen remontar a fechas en torno a los años 70-80 d.C. (Sánchez-Palencia y FernándezPosse, 1985: 280), sin menoscabo de la hipótesis planteada por S. Carretero (2000: 540-541) de una posible producción anterior, desde época claudio-neroniana, relacionada con el impulso que generaría la instalación de la Legio $X$ Gemina en los campamentos de Petavonium hasta su traslado en el año 63 d.C. (Carretero y Romero, 1996: 21) ${ }^{14}$.

Por último, debemos reseñar el registro de ciertos fragmentos anfóricos, alguno de los cuales podrían clasificarse como pertenecientes a una pieza del tipo Dressel 7-11 (Figura 16.8), originaria de las oficinas de las costas béticas ${ }^{15} \mathrm{y}$ destinada al comercio de salazones en general, según confirman los tituli picti documentados, que especifican un contenido de garum o muria (Carreras y Berni, 2003: 644). La datación de los ejemplares más arcaicos de este tipo podría retrotraerse a época tardo-republicana (Vegas, 1973: 131), aunque es en el periodo augusteo cuando comienzan a documentarse de modo masivo, sobre todo en los campamentos militares centroeuropeos (Sánchez Sánchez, 1992: 288). El final de su producción puede establecerse a finales del siglo I o inicios del II d.C., considerando algunos autores (Beltrán et alii, 1998: 76-77) que, de acuerdo al depósito de época claudia del Castro Pretorio de Roma, su etapa de máximo desarrollo habría de situarse en la primera mitad del siglo I d.C.

forma, a partir de los análisis de pastas, en el valle del Guadalquivir (Carreras, 2000). Se trataría, no obstante, de una producción que en términos geo-culturales remite igualmente a Baetica. 


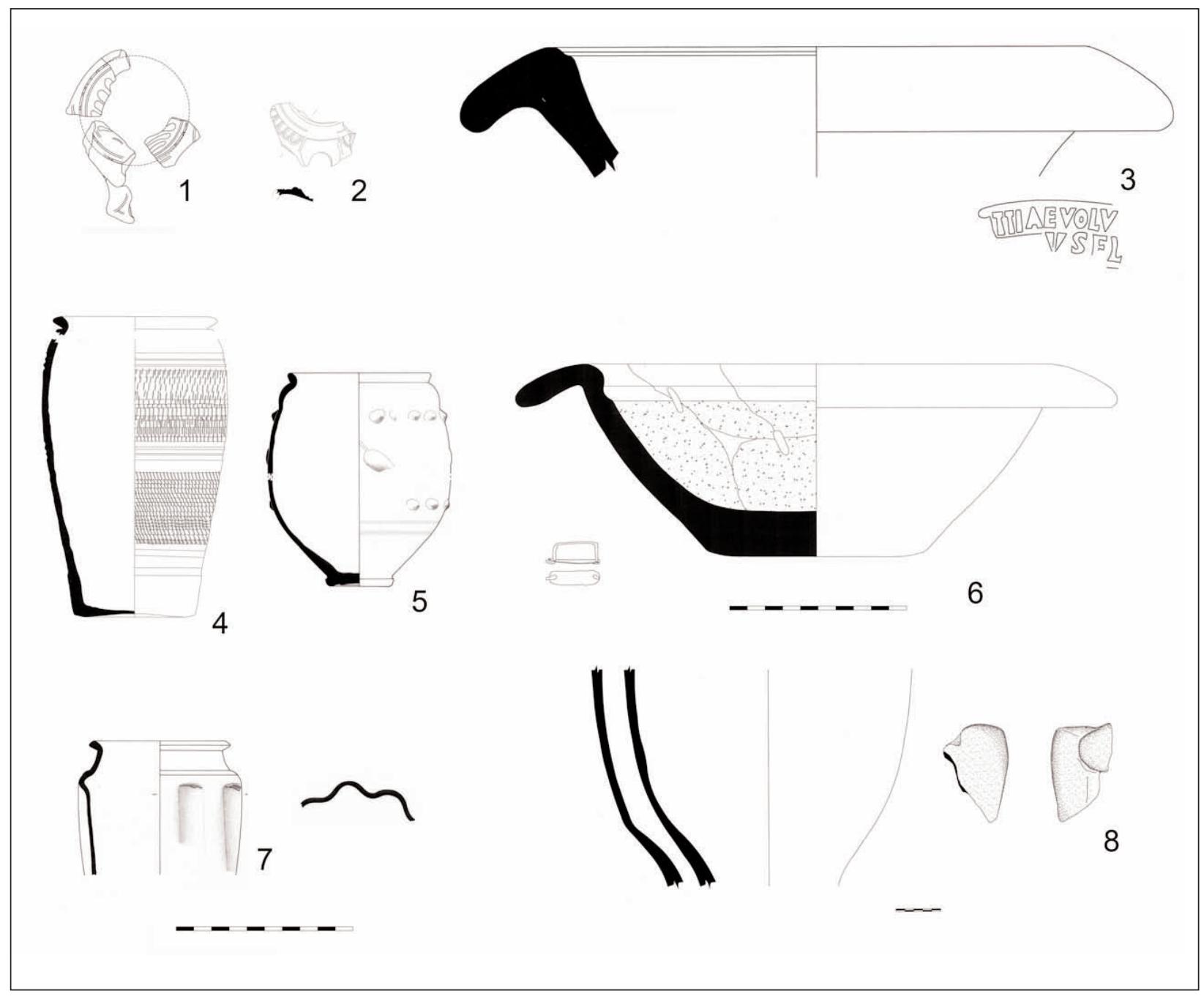

Figura 16. Cerámicas comunes de importación procedentes del vertedero de la domus.

1: Lucerna de volutas tipo Andújar. 2: Lucerna de disco tipo Dressel 19. 3: Mortero itálico forma Cap Dramont D2. 4: Cubilete fusiforme de procedencia emeritense. 5: Vaso paredes finas Melgar de Tera (forma II).

6: Mortero hispánico. 7: Mayet VI emeritense. 8: Ánfora Dressel 7-11.

Dejando a un lado los materiales cerámicos, otro producto de importación con potencial datante presente en este vertedero es el vidrio. La colección resulta exigua y desgraciadamente, no demasiado explícita en lo cronológico. Incluye varios fragmentos de los habituales cuencos de costillas de color verde azulado (Madariaga, 2009: 318-319) del tipo Isings 3 (1957) y otro más de un vaso troncocónico de gran calidad adscribible a la tipología Isings 21 (Ibidem) con decoración de facetas losángicas talladas componiendo un motivo de nido de abeja (Madariaga, 2005: 263; Fig. 6.3 y 2009: 322-323) (Figura 17). Las cronologías de fabricación que se proponen para los recipientes de costillas arrancan de época augustea para llegar al siglo II d.C. (Madariaga, 2009: 318), mientras que los vasos Isings 21 forman parte de los servicios de mesa lujosos a fines del siglo I d.C. y en la centuria posterior (Foy y Nenna, 2001: 183).

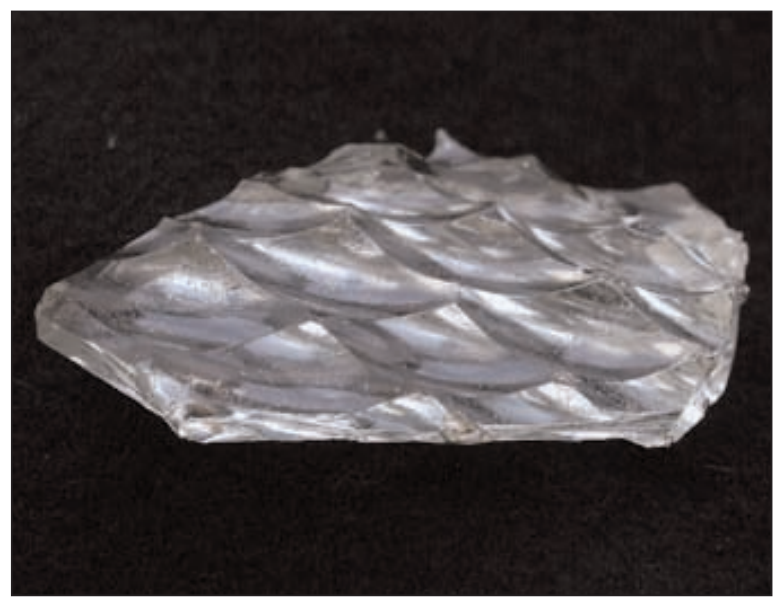

Figura 17. Fragmento de vaso de vidrio incoloro de la forma Isings 21. Foto: J. Arrojo 
Otro referente cronológico, si bien en este caso no integrado directamente en los depósitos analizados, lo constituyen las pinturas murales (Gago, 2009 b) que ornaron las paredes del interior de la domus (Gago, 2008: 811). Su cronología inicial, dejando a un lado puntuales retoques posteriores, nos lleva a época de Claudio (Gago, 2009 a: 214) (Figura 18).

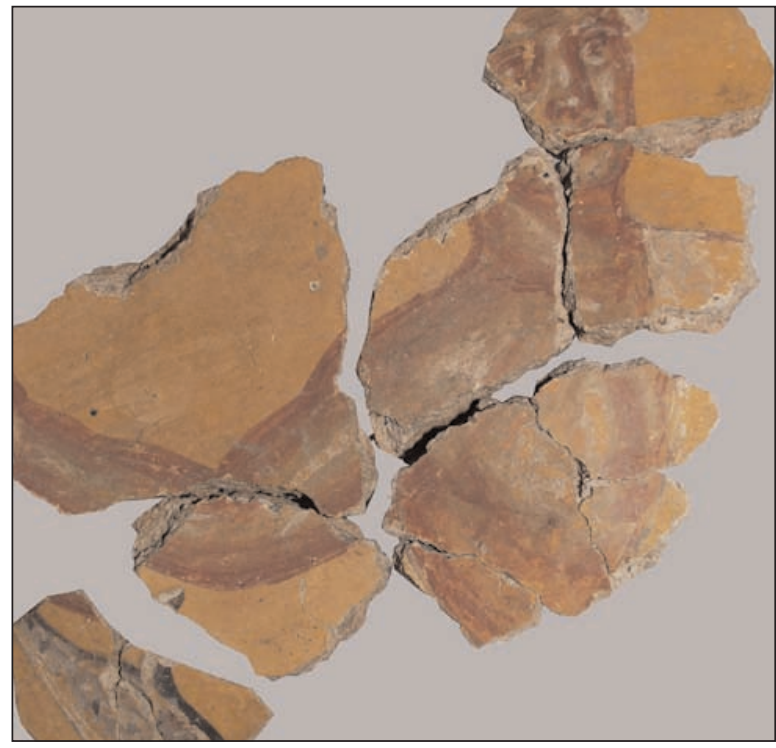

Figura 18. Decoración figurativa proveniente del repertorio pictórico de la domus. Foto: Á. Villa
En definitiva, todos los materiales con alguna capacidad datante apuntan cronologías de fabricación que no superan el cambio de siglo (Villa et alii, 2006). Por tanto, debemos suponer que el proceso de génesis estratigráfica del vertedero concluye en algún momento durante los años finales del siglo I d.C.

\section{LOS ESTRATOS RELICTOS (Figuras 19 a 24)}

El segundo tipo de localizaciones responde a determinados estratos relictos que tienen en común la circunstancia de haber quedado sellados por depósitos de fechas posteriores (Hevia y Montes, 2009: 641). Estos contextos, habitualmente parcos en lo referente al volumen de contenido material y bastante reducidos en extensión espacial, cuentan con manifestaciones diversas diseminadas por todo el yacimiento.

Uno de los mejores ejemplos de este tipo de estratos lo encontramos en el sector denominado R-V (Figura 19), consistente en un enfoscadero que se ubica entre la gran plaza enlosada localizada en el extremo meridional del poblado y el caserío adyacente sobreelevado al Norte de este espacio de uso comunal que se abre al acceso principal.

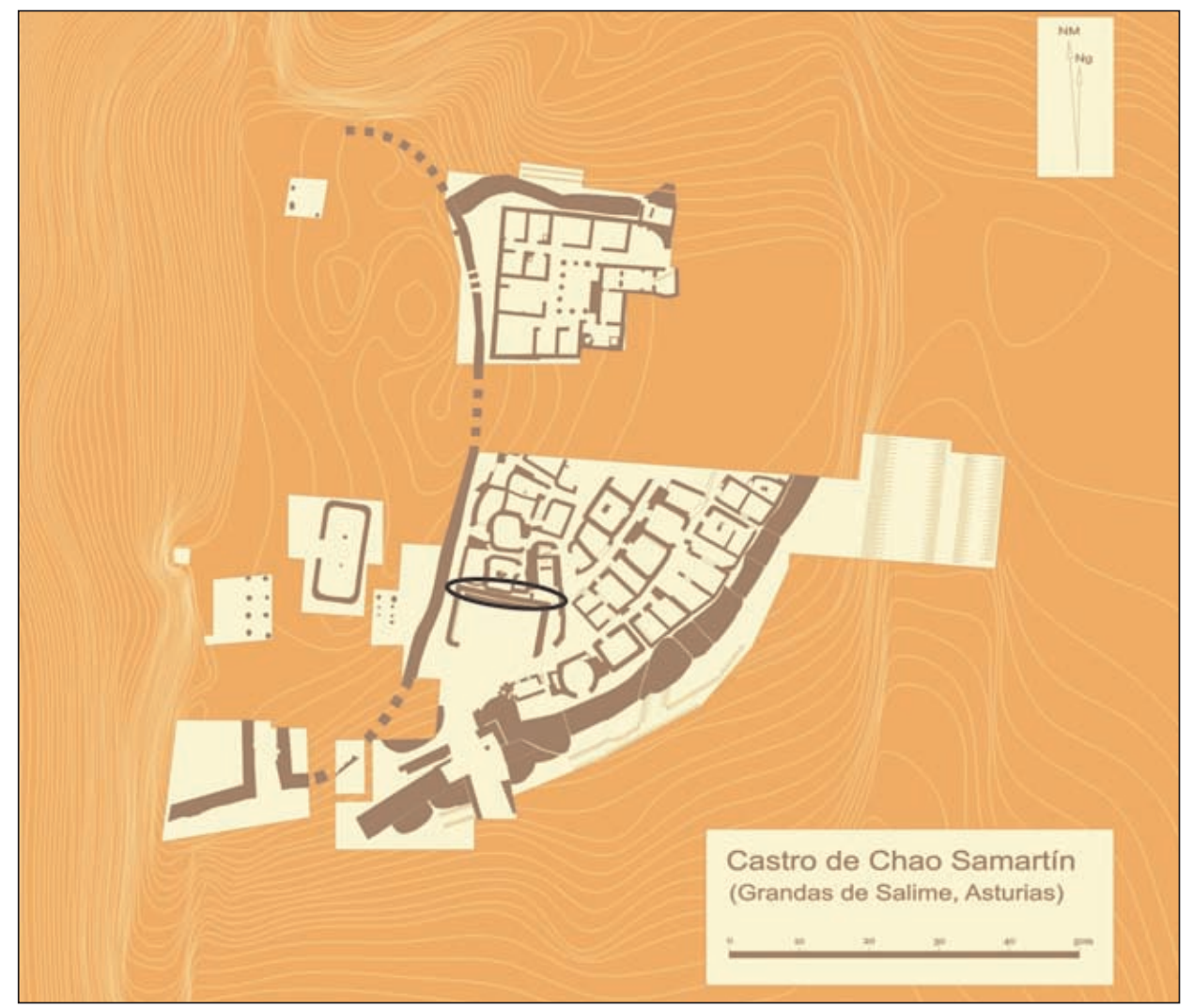

Figura 19. Chao Samartín. Croquis general de los sectores excavados. Situación del sector R-V. Según Á. Villa. Dibujo: E. Martín 
La secuencia estratigráfica contenida por los paramentos de estas estructuras denuncia el uso, continuado durante largo tiempo, del angosto pasillo a modo de basurero. Entre los diferentes aportes que configuran esta estratigrafía se individualizan, sobre los depósitos antiguos de la Edad del Hierro, y sellados por el estrato que corresponde al abandono final de fechas avanzadas del siglo II d.C., vertidos asimilables a datas indeterminadas del siglo I d.C. (Figura 20).

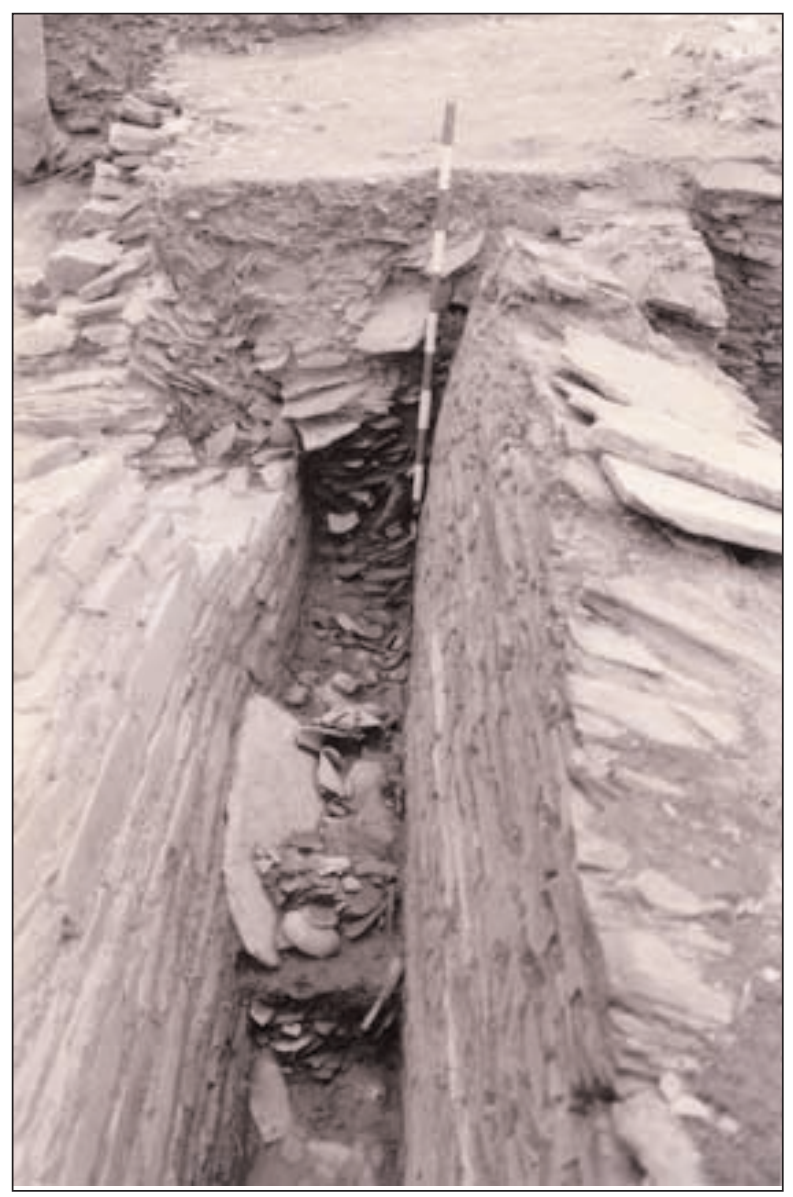

Figura 20. Sector R-V. Foto: Á. Villa Valdés

Por desgracia, los materiales con capacidad datante resultan bastante menos numerosos y expresivos en esta ocasión. Cabe no obstante, destacar el registro de sendos fragmentos de cerámica vidriada (Hevia y Montes, 2009: 645-
646; Fig. 2.5) verosímilmente relacionables con una pieza tipo skyphos de la forma II de López Mullor (1981: 206-208, Fig.v1.II). Las cronologías propuestas para estas manufacturas suelen remontarse, para el sector occidental del imperio, a comienzos del siglo I d.C., momento en el que se comienzan a elaborar las manufacturas itálicas (Maccabruni, 1987: 171) y en el que parece se centran las fechas de los escasos productos de este tipo documentados en el cuadrante noroeste de la península (Carretero, 2000: $450)^{16}$. El repertorio de importaciones se completa con un magro conjunto de piezas de terra sigillata, tanto de producción gálica como hispánica ${ }^{17}$.

La expresiva estratificación del gran foso exterior (Foso C), excavado en el flanco oriental del asentamiento, alberga de igual modo depósitos asimilables a este periodo (Figura 21). Este foso experimentó a lo largo del tiempo un complejo historial de colmataciones y reexcavaciones (Figura 22) que sucintamente se puede resumir en los siguientes términos (Villa et alii, 2006: 589591; Fig. 6 y 7):

- Excavación original que interviene los materiales pizarrosos del sustrato y cuya obra se remonta a la Edad del Hierro.

- Acumulación de los depósitos basales procedentes de la degradación del sustrato y de aportes estratigráficos diversos arrastrados. Su contenido material denuncia una cronología inequívocamente prerromana.

- Sedimentación previa a los posteriores fenómenos de reexcavación.

- Reexcavación de los sedimentos acumulados, configurando una nueva trinchera cuyas dimensiones, tanto en profundidad como en anchura, no alcanzan la magnitud de la obra primigenia. Su apertura coincide con la de la trinchera menor (Foso D) paralela al exterior, con la que compone conjuntamente una fossa duplex. La cronología estimada para esta inter-

\footnotetext{
${ }^{16}$ Sin ánimo de resultar exhaustivos, se dispone de noticias de un magnífico ejemplar de skyphos en León (Suárez, 1995: 281), de ciertos fragmentos procedentes del castro asturiano de la Campa Torres (Maya, 1988: 223, Fig.57.C) y de un fragmento documentado en el campamento militar de Petavonium (Carretero, 2000: 450, Fig. 271), a los que cabría agregar, fuera ya del mundo astur-galaico, las piezas
}

conocidas en Palencia (García y Bellido et alii, 1970: 14, fig.12), Herrera de Pisuerga (López Mullor, 1981: 204) y Conímbriga (Alarçao, 1976).

${ }^{17} \mathrm{El}$ repertorio permanece inédito. No obstante, un análisis evaluativo preliminar, realizado por A. Menéndez, a quién agradecemos la desinteresada colaboración, apunta cronologías acordes con la de los contextos que se tratan. 
Figura 21. Chao Samartín. Croquis general. Situación del Foso C. Dibujo: E. Martín y A. Villa

Figura 22. Imagen y croquis explicativo de la evolución de las defensas orientales. Fosos C y D.

Foto y croquis: Á. Villa
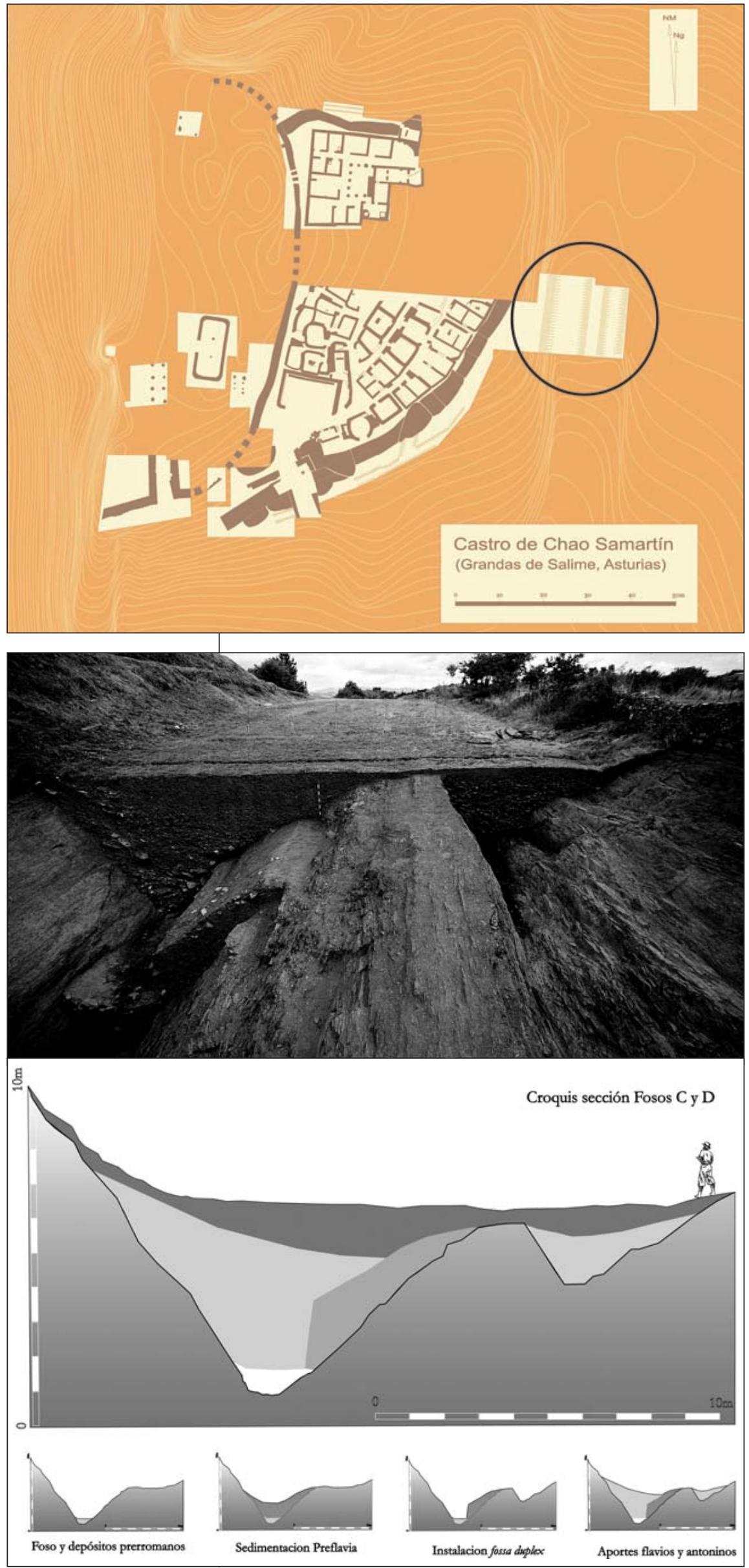
vención se sitúa, como veremos, en las primeras décadas de la segunda mitad del siglo I d.C.

- Colmatación paulatina de las nuevas trincheras altoimperiales a partir de época flavia, momento coincidente con la definitiva incuria de las defensas y con cambios en el carácter general del asentamiento, que pierde el sesgo militar que le había distinguido en los primeros momentos tras la conquista para convertirse en un centro de carácter eminentemente civil (Villa, 2005 a: 42).

Las cerámicas de importación asociadas a los estratos respetados por la reexcavación de la gran trinchera constituyen un testimonio de gran valor cronológico que permiten, no sólo la fijación temporal de los fenómenos de refortificación, sino también la contextualización de los materiales cerámicos de fabricación regional con los que comparten depósito.

La terra sigillata recuperada resulta muy expresiva en este sentido (Figura 23). La colección se compone de piezas sudgálicas entre las que destacan formas como los platos Ritt. 1 (Figura 23.4), Drag. 15/17 (Figura 23.3) y Drag.
18 (Figura 23.2) (Sánchez y Menéndez, 2005: 252; Lám.1. 1, 3 y 5; Villa et alii, 2005: 590, nota 13; Fig.4.1-3) o los cuencos del tipo Drag. 29 (Figura 23.1) (Villa et alii, 2005: 590, nota 13 y Fig. 5.6).

La producción de la Ritt.1 arranca en época temprana, augusteo-tiberiana (Oswald y Pryce, 1920: 181) o ligeramente posterior (Passelac y Vernhet, 1993: 577), para alcanzar el reinado de Claudio (Polak, 2000: 83). Por lo que se refiere a los platos Drag.15/17 y 18, ambos comienzan a elaborarse a principios del siglo I d.C., considerándose que el auge de las exportaciones de los segundos se produce en época de Claudio (Polak, 2000: 86 y 91). Las Drag. 29, por su parte, inician su producción hacia el 10 d.C. para mantenerse vigentes en todo el periodo julio-claudio y rarificarse a partir de época de Vespasiano (Passlac y Vernhet, 1993: 573). Resulta pues un conjunto coherente, verosímilmente datable en época julioclaudia.

Los materiales incluidos en los estratos que configuran los rellenos que fosilizan definitiva-

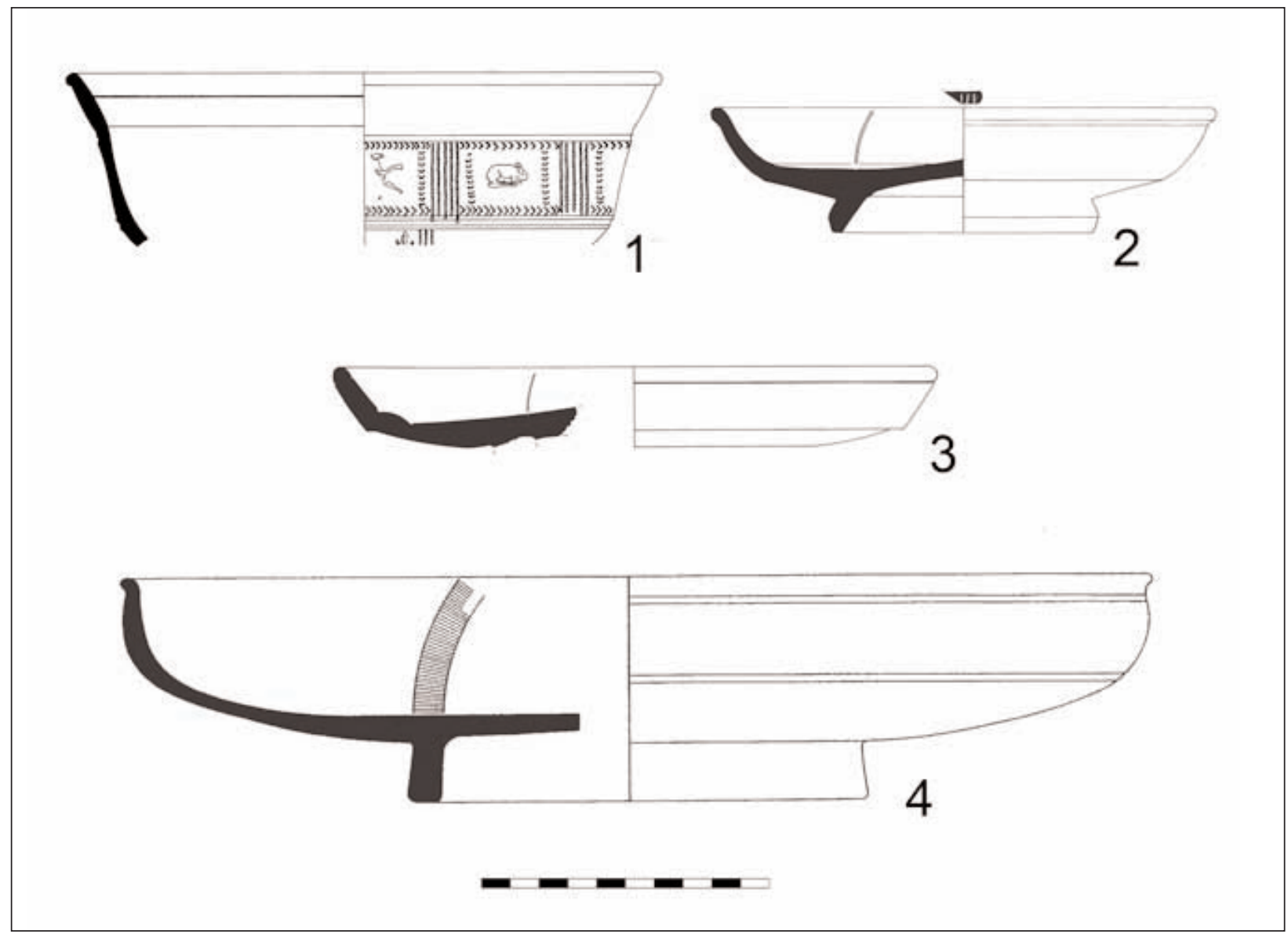

Figura 23. Terra Sigillata de la fase antigua del Foso C. 1: Drag. 29. 2: Drag. 18. 3: Drag. 15/17. 4: Ritt. 1. 
mente los fosos resultan igualmente elocuentes como indicadores cronológicos ante quem para su reexcavación y por ende, para los materiales que centran nuestro interés (Figura 24). El elenco de terra sigillata recuperado en este caso (Villa et alii, 591; nota 14) incluye producciones hispánicas cuya característica común estriba en su incorporación al registro habitual en la región a partir de época flavia (Urteaga, 2003: 195).

El repertorio cuenta con la presencia de diversos cuencos de las formas Drag. 29, 29/37 (Figura 24.3) y 37 (Figura 24.1), en sus dos variantes. Para los primeros se postulan cronologías para el inicio de su producción en torno al 50 d.C. (Mezquiriz, 1961) o el 55-60 d.C. (Romero, 1985: 91) que en el caso de las Drag. 29/37 (Villa et alii, 2005: 590; Fig.5.5) se adelantan hasta el 65 d.C. (Ibidem: 103). Algo más tardíos son los cuencos de la forma 37 (Ibidem: Fig. 5.5), cuya fabricación arranca hacia el 70 d.C. (Mezquiriz, 1961: 110).

Tampoco resultan desconocidos en los estratos asociados a este contexto los platos Drag. 15/17 y los vasos Drag. 24/25 (Figura 24.3) (Villa et alii, 2005: 590; Fig.4.5), ambas morfologías realizadas a partir del 50 d.C. (Mezquiriz, 1961: 55-58). Más expresivas se manifiestan formas con datas de fabricación más modernas, caso de las Drag. 35 (Figura 24.4) (Villa et alii, 2005: 590; Fig.5.3) y 36, con orígenes en época flavia (Mezquiriz, 1961: 63-64).

LOS NIVELES DE ABANDONO (Figuras 25 a 31)

Otro tipo de contextos al que se asocian los materiales cerámicos del siglo I d.C. se corresponde con estratos relacionados con el abandono final del poblado. Este tercer tipo de localizaciones específicas remite a los niveles de abandono de determinados ambientes domésticos cuya pérdida de función se estima coetánea del final general de la ocupación altoimperial del poblado, datada en algún momento de la segunda mitad del siglo II d.C.

A pesar de estas referencias temporales, el repertorio cerámico que contienen, en claro contraste con el de otros sectores contemporáneos de la misma naturaleza, combina elementos propios de ese tiempo con otros de inequívoca producción notablemente más antigua. Estos peculiares ajuares, formados mediante agregación artefactual (Villa et alii, 2006: 584), deben explicarse teniendo presente la clave histórica que supone el asentamiento de la domus en el solar del viejo castro en tiempos julio-claudios. Los moradores de este privilegiado espacio constructivo, miembros de la administración imperial, actuaron como foco demandante de materiales de singular calidad que, de no ser por esta circunstancia, raramente alcanzarían estas latitudes. La llegada de estas

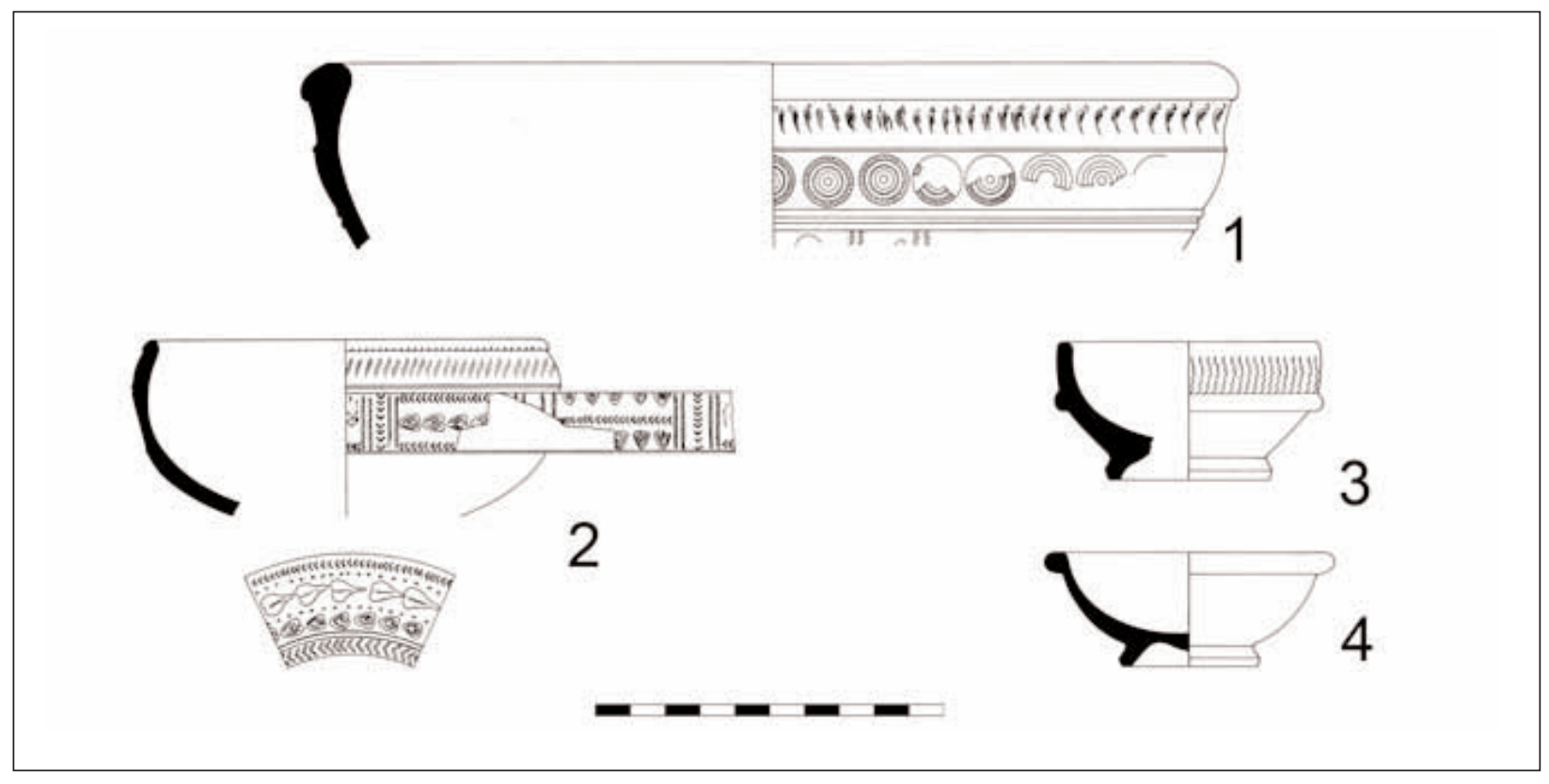

Figura 24. Terra sigillata de la fase moderna del Foso C. 1: Drag. 37 b. 2: Drag. 29/37. 3: Drag. 24/25. 4 Drag. 35. 
importaciones cesará en torno al cambio de siglo coincidiendo con el abandono del edificio y la consolidación de la regionalización de la producción cerámica. Estos acontecimientos convertirán a las viejas manufacturas en artefactos de prestigio (Figuras 25 y 26) codiciados por las pujantes

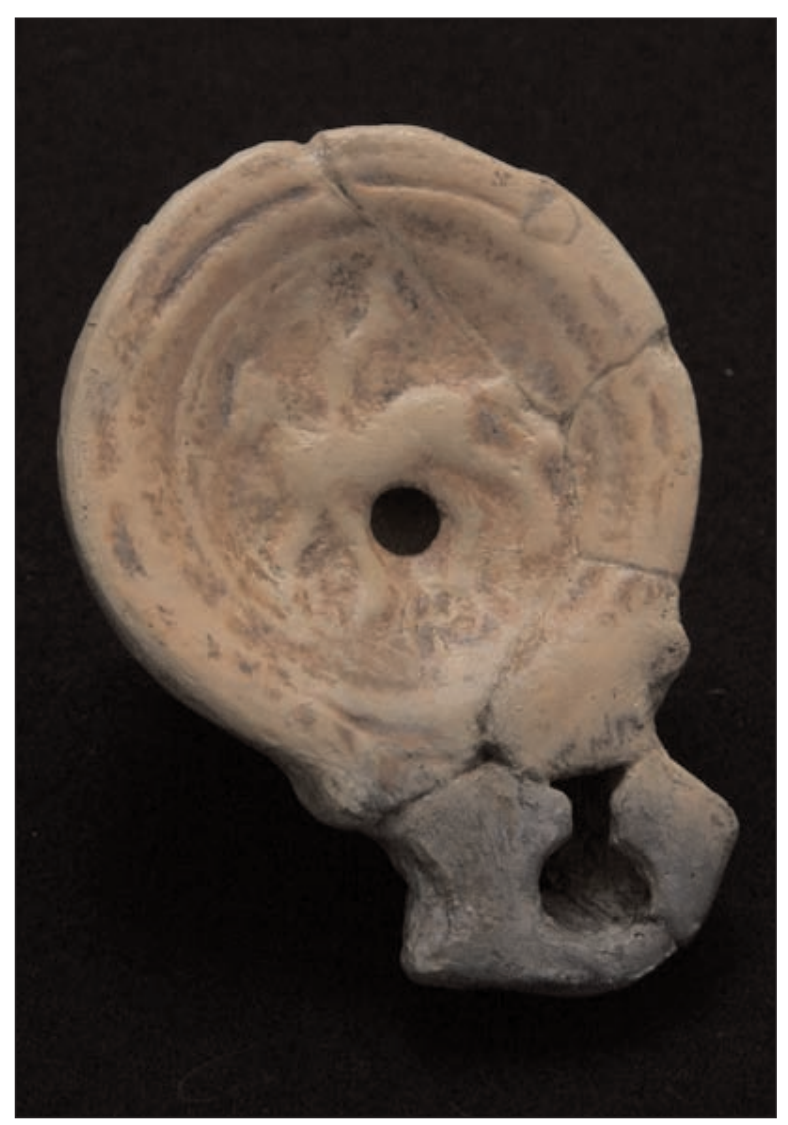

Figura 25. Lucerna de volutas de la forma Loeschcke IB con decoración mitológica. Foto: J. Arrojo

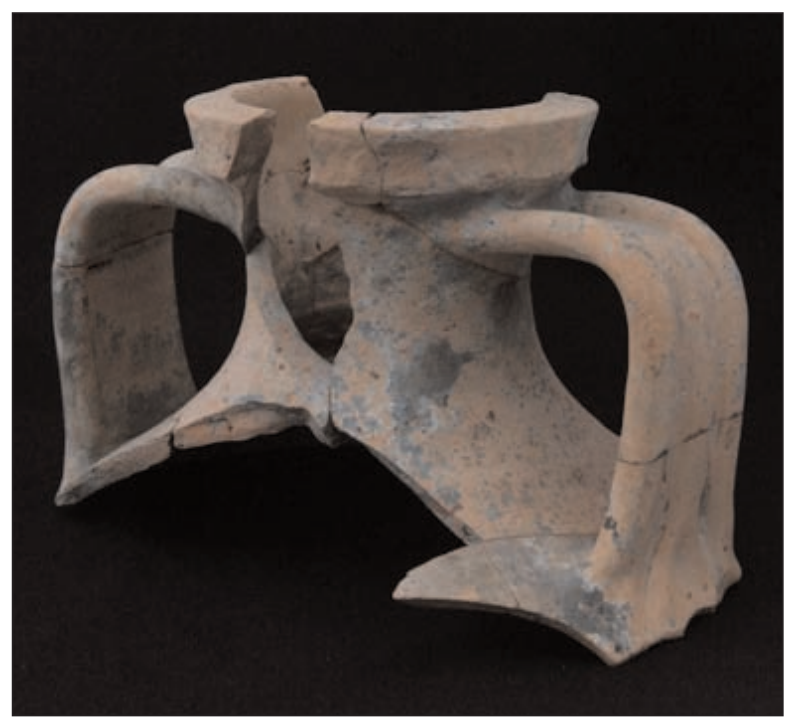

Figura 26. Ánfora Gauloise 2 de fabricación gala. Foto: J. Arrojo elites locales, depositarias en estos nuevos tiempos de una preeminencia social y económica que viene a sustituir el papel de la administración militar que la había ejercido en tiempos pretéritos (Villa, 2005 a: 98).

La constatación más evidente, aunque no única, de este fenómeno lo constituye el sector que integra a la construcción denominada C-12 y las estancias aledañas (Figura 27) algunas de ellas espacios antaño públicos incorporados al ámbito privado en el siglo II d.C. (Villa, 2002: 169) al compás de fenómenos subyacentes de estratificación social y disolución definitiva de la comunidad castreña.

El curioso ajuar cerámico de esta unidad de habitación (Figura 28), en uso en la segunda mitad del siglo II d.C., se compone de numerosas piezas con cronologías de fabricación mucho más antigua que la fecha del abandono, según se constata en el análisis de la terra sigillata (Figura 31), que ofrece muestras de fabricación julio-claudia junto a otras de fechas avanzadas, fruto de una prolongada acumulación mobiliar en un proceso de más de un siglo (Villa et alii, 2006: 584). Entre las producciones antiguas destacan, por resultar particularmente significativas, determinadas piezas. Una de ellas es un plato de la forma Drag. 15/17 (Figura 29 y 31.5) sellado por el alfarero Albinvs (Sánchez y Menéndez, 2005: Fig. 3 y Lám.1.2; Menéndez y Sánchez, 2009: 282-283), que desarrolló su actividad en La Graufesenque en algún momento del siglo I d.C. (Oswald, 1931: 10). De los talleres de Montans, por su parte, proceden otro plato del tipo Drag. 18 (Oswald, 1931: 257) que ostenta una marca del ceramista Quintvs (Sánchez y Menéndez, 2005: Fig.2 y Lám.1.4; Menéndez y Sánchez, 2009: 304-305) (Figura 30 y 31.3) y un cuenco Drag. 29 b (Menéndez y Benéitez, 2002: Fig.8.1; Sánchez y Menéndez, 2005: Lám.3.1) (Figura 31.8). Estas piezas fabricadas en el siglo I d.C. comparten contexto con otras inequívocamente datables en el siglo II d.C. como varios cuencos Drag. 37 con decoración del estilo de círculos (Menéndez y Sánchez, 2009: 328-329; Menéndez y Benéitez, 2002: Fig.11.6) (Figura 31.7). 


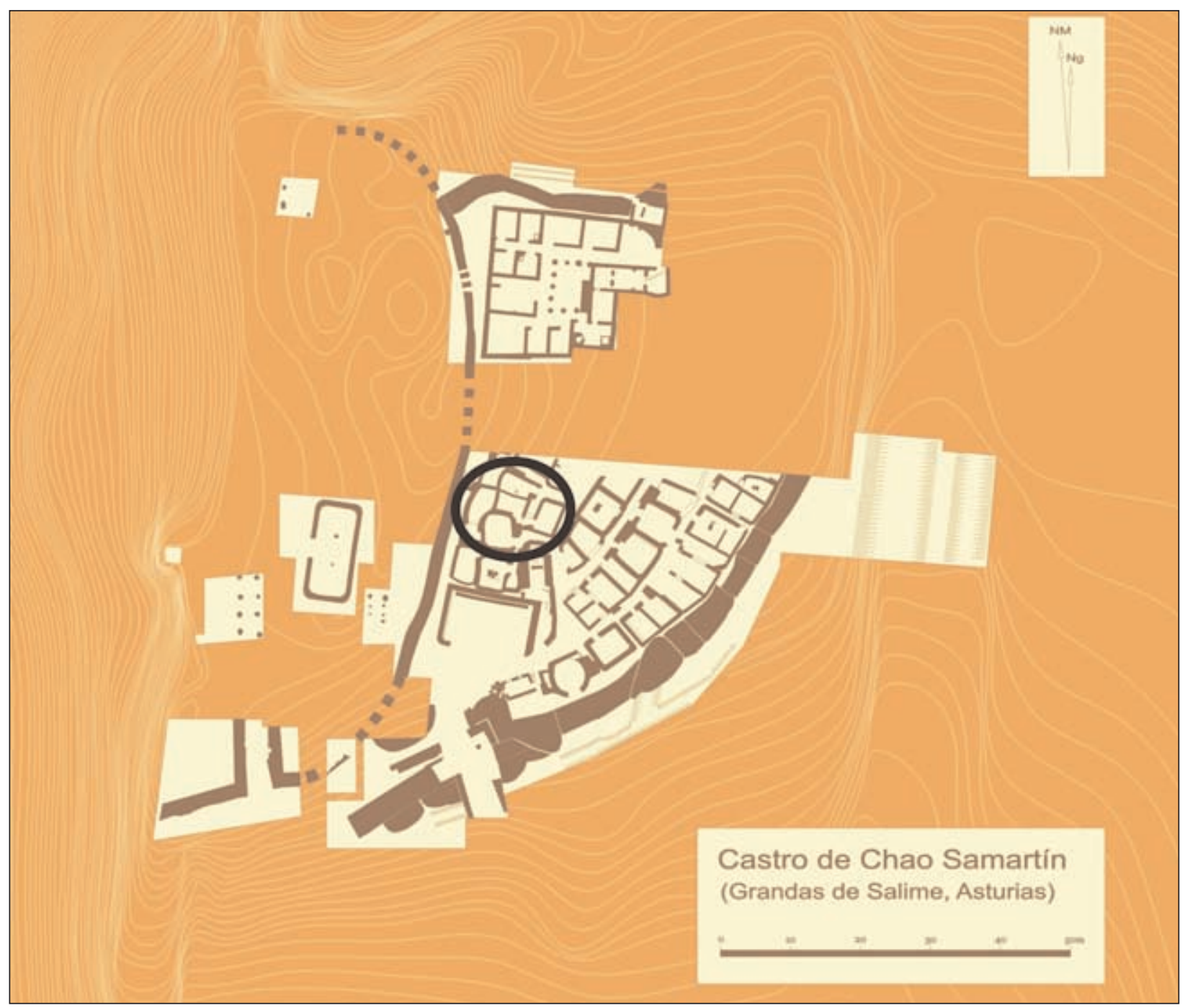

Figura 27. Chao Samartín. Croquis general. Situación del sector C-12. Dibujo: E. Martín y A. Villa.

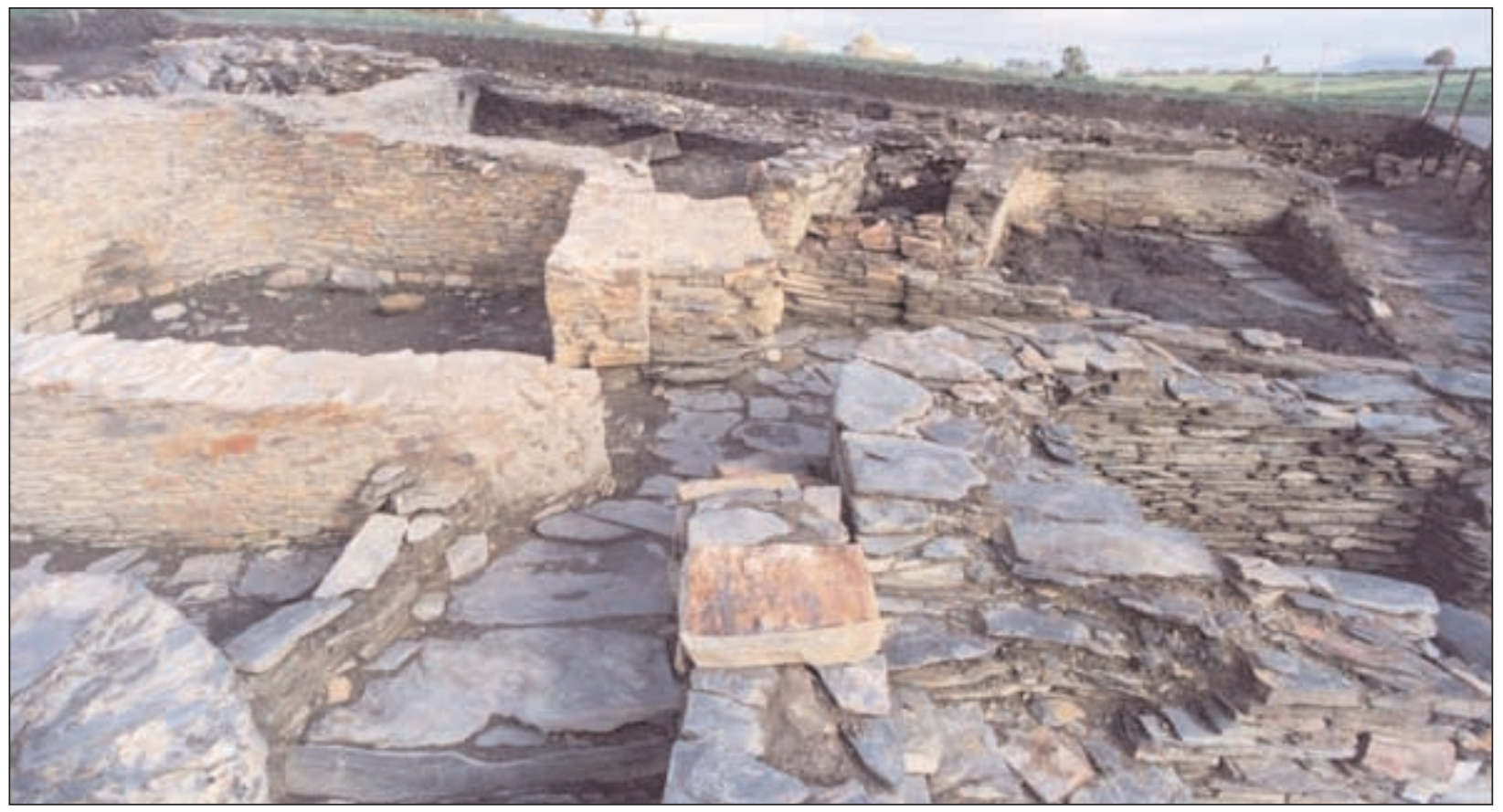

Figura 28. Barrio relacionado con la construcción C-12. Foto: Á. Villa 

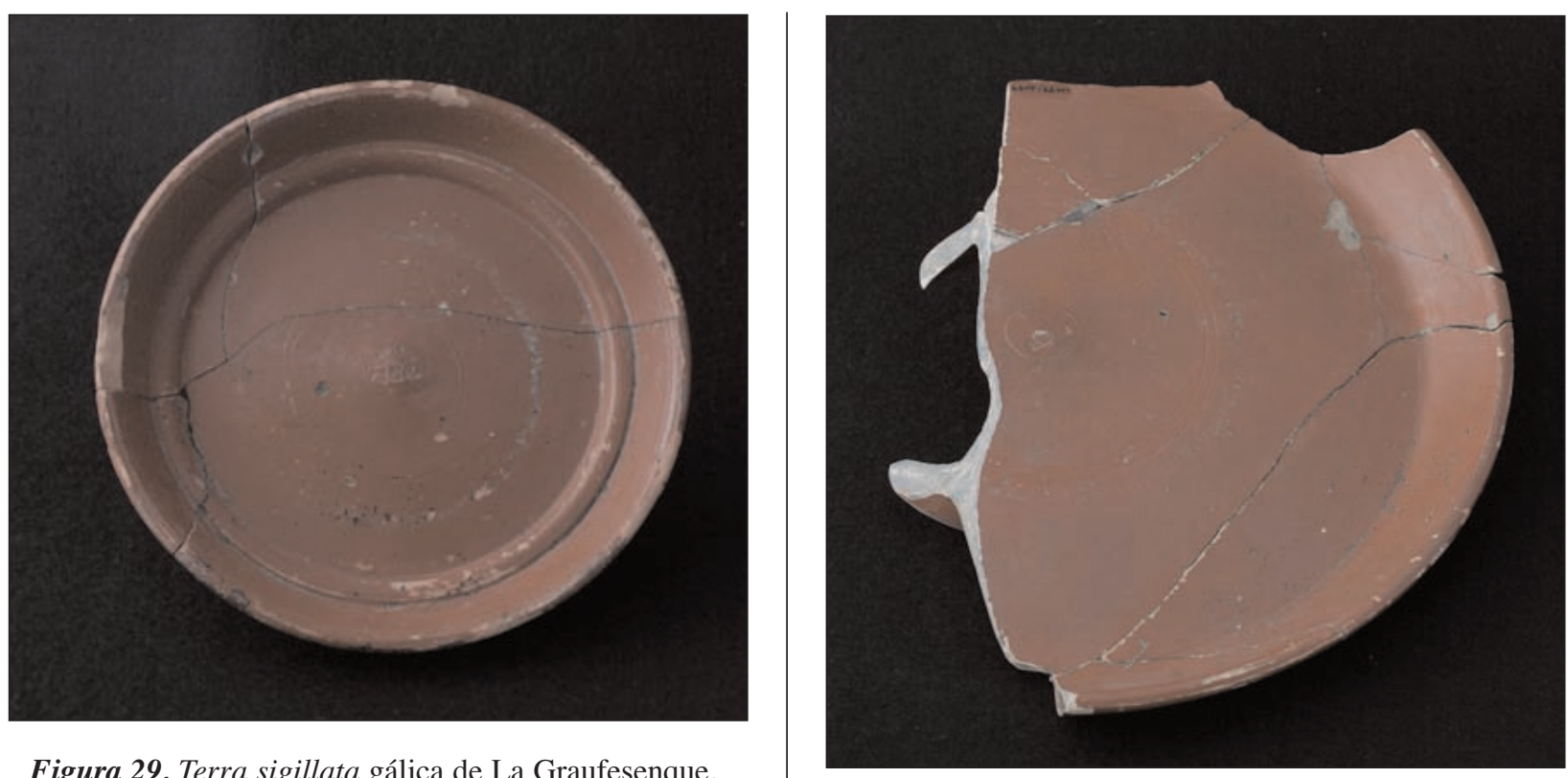

Figura 29. Terra sigillata gálica de La Graufesenque. Forma Drag. 15/17 sellada por el alfarero Albinus. Foto: J. Arrojo

Figura 30. Plato de terra sigillata de la forma Drag. 18 fabricada en los talleres de Montans. Foto: J. Arrojo
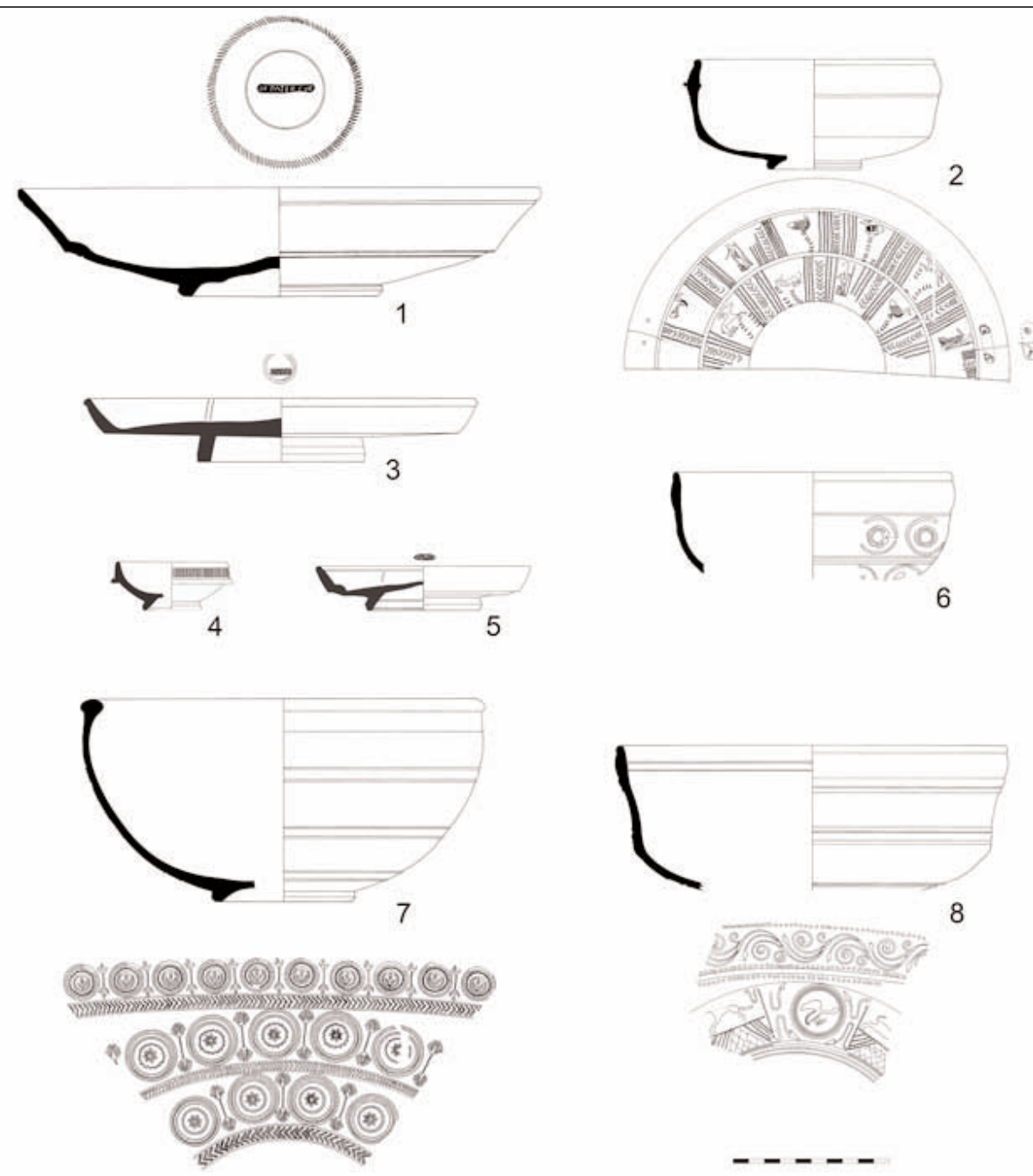

$---$

Figura 31. Terra sigillata de la construcción C-12. 1: Drag. 15/17. 2: Drag. 29/37. 3: Drag. 18. 4: Drag. 24/25. 5: Drag. 15/17. 6: Drag. 37. 7: Drag. 37 b. 8: Drag. 29 
A modo de recapitulación podemos señalar que los materiales cerámicos que componen el repertorio analizado en este capítulo proceden de tres tipos de contextos específicos: el vertedero de la domus, estratos relictos diversos y niveles de abandono en que se detectan singulares fenómenos acumulativos en la formación de los ajuares. Sin embargo, la estricta sincronía entre éstos resulta imposible de asegurar, aunque sí se puede afirmar una datación genérica de mediados o finales del siglo I d.C. Las datas individuales concretas no pueden ser tan precisas, intuyéndose no obstante un mayor arcaismo en los repertorios de los estratos relictos tipo $\mathrm{R}-\mathrm{V}$ o Foso $\mathrm{C}$, frente al vertedero de la domus. Este matiz arcaico no necesariamente ha de traducirse en una mayor antiguiedad, si tenemos en cuenta las especiales connotaciones del material vinculado a la domus. En efecto, a pesar de su especial nitidez cronoestratigráfica, no se debe soslayar una conveniente reflexión sobre las particulares características sociales del contexto de este vertedero. Los gustos y costumbres plenamente romanos del consumidor y su potencial como demandante privilegiado pudieran distorsionar el catálogo en el sentido de que éste no responda de forma estricta al repertorio-tipo habitual en la época. Cabe sospechar al respecto una sobrerepresentación de tipos importados, alguno de los cuales, dada su cronología particularmente antigua, pudiera responder al bagaje inicial que llega en el momento de la instalación de la domus en el yacimiento (Hevia, 2006).

\subsection{Caracterización general de las PRODUCCIONES REGIONALES DEL SIGLO I.D.C.}

La comentada naturaleza de los depósitos de procedencia de los materiales condiciona, como es lógico, el carácter del repertorio. A diferencia de los contextos habitacionales del momento final de la ocupación romana del poblado, que han proporcionado, según relataremos más adelante, la práctica totalidad del ajuar en uso, la condición de basureros de los contextos del siglo I d.C. hace que resulten mucho más escuetos, debiendo considerar meros desechos a los materiales en ellos documentados. Esta circunstancia se traduce, por un lado, en la visión sesgada que proporcionan del ajuar con que debieron contar sus usufructua- rios y por otro, en el alto grado de fragmentación de las piezas y la consiguiente dificultad de restitución de perfiles completos e identificación del número mínimo de individuos de cada forma, sobre todo en el caso de las que agrupan a recipientes de gran volumetría. El estado de conservación de los fragmentos es, en general y por las mismas razones expuestas, más deficiente, afectando las alteraciones de modo significativo a los tratamientos específicos de las piezas, cuyos acabados se encuentran con frecuencia muy deteriorados cuando no totalmente perdidos, circunstancia que introduce una dificultad añadida en la caracterización técnica de las vasijas.

Estos condicionantes justifican el hecho de que los tipos presentados cuenten en ocasiones con representaciones porcentuales en el elenco mínimas, hasta el punto de que de muchos de ellos dispongamos tan sólo de un único ejemplar. Esta circunstancia no debe ser soslayada, ya que puede introducir un factor de distorsión en la valoración de su trascendencia dentro del conjunto (Hevia, 2006).

A esta menor fiabilidad en la caracterización tipológica contribuye igualmente el propio carácter de la industria regional en estos momentos iniciales de su producción, que se presenta en muchas ocasiones dubitativo en la definición de unos tipos que, en cualquier caso, muestran una variabilidad interna bastante elevada y una aparente indefinición funcional (Montes y Hevia, 2009: 210). Nos encontramos, en definitiva, con una industria en pleno proceso de formación en la que se comienza a fraguar el singular proceso de síntesis entre los gustos y modos de hacer tradicionales y las innovaciones que incorpora el mundo clásico (Montes y Hevia, 2008: 769).

Las características técnicas generales de la vajilla de esta época se fundamentan en el uso de arcillas de naturaleza cuarzo-micácea o esquistosa de rasgos genuinamente regionales y por lo general, más toscas que las habituales en fechas más avanzadas. Por lo que se refiere a los acabados, las superficies externas son sometidas de modo casi invariable a bruñidos bastante groseros, a excepción de determinadas producciones singularmente finas. El cromatismo superficial habitual se encuentra dominado por los tonos oscuros, negruzcos, resultado de cocciones en atmósferas reductoras de gusto tradicional. 
Las morfologías dominantes enlazan de igual modo con el acervo prerromano, toda vez que se observa un neto predominio de las formas cerradas de perfiles acusadamente globulares, sólo puntualmente roto por la introducción en los ajuares de los primeros tipos abiertos, influidos por el repertorio clásico. Frente al grueso de los materiales, que se ajustan a estas características ligadas al componente tradicional, se revelan ciertas innovaciones radicales que establecen un severo contraste entre fórmulas tipológicas novedosas como las imitaciones de terra sigillata o las primeras manifestaciones de vajilla engobada, y el resto del ajuar (Montes y Hevia, 2009: 210).

\subsection{LOS TIPOS CERÁMICOS}

\section{TAzones monoasados (Figuras 32 y 33 )}

La denominación escogida para definir este tipo cerámico denuncia ya en su propia formulación el vínculo filogenético que se propone para estas piezas respecto a los recipientes homónimos de momentos más avanzados (Figuras 99 y 100). No obstante, debe tenerse en cuenta que ambas tipologías presentan notables diferencias de índole formal y técnica (Montes, 2005). Este modelo temprano consiste en un tipo de dimensiones reducidas ${ }^{18}$ caracterizado por un borde corto, exvasado y oblicuo, bien diferente del más desarrollado de los tazones posteriores. El cuerpo, con trayectoria de tendencia troncocónica levemente curvada en su parte superior, dibuja una carena muy baja que difiere sensiblemente también del perfil de los tazones carenados del siglo II d.C (Montes, 2009: 406-407 y 434-435). La presencia de una única asa en $\mathrm{C}$ instalada en la parte media del cuerpo completa los rasgos esenciales de su caracterización formal. La decoración bruñida, enmarcada en el típico friso delimitado por acanaladuras y ocupando la parte media-alta de la superficie externa del cuerpo, constituye igualmente un rasgo definitorio del tipo (Hevia y Montes, 2009: Fig.3.1) ${ }^{19}$.

\footnotetext{
${ }^{18}$ Los diámetros del borde rondan los $130 \mathrm{~mm}$.

${ }^{19}$ En Lugo predominan también las decoraciones bruñidas, ya sea de líneas verticales o componiendo las clásicas retículas
}

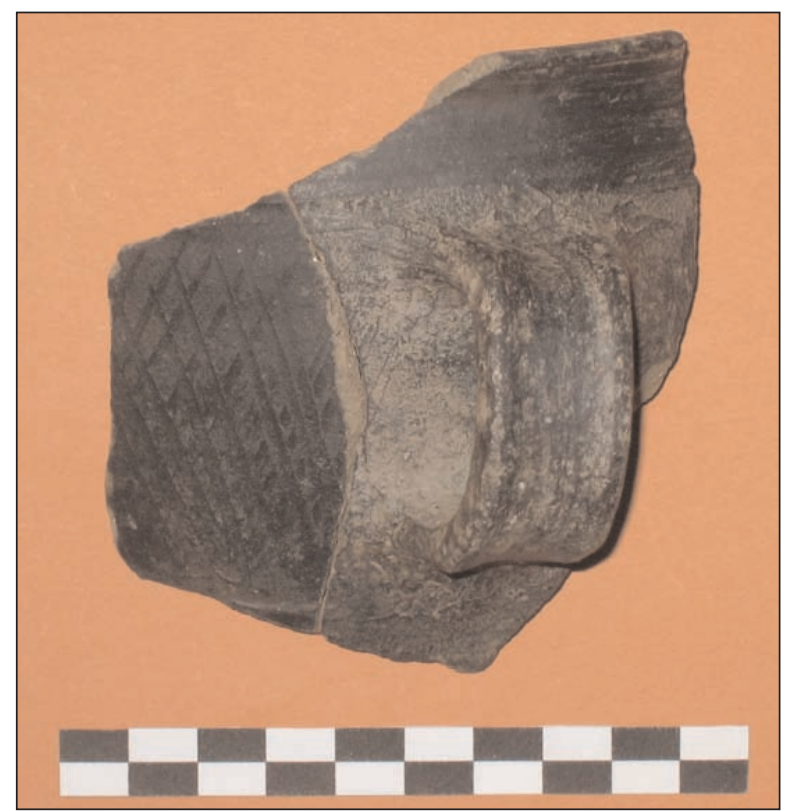

Figura 32. Tazón monoasado. Foto: R. Montes

La naturaleza de pastas y acabados entronca con las de los repertorios comarcales del momento, claramente diferenciadas de las que caracterizan a los tazones de la segunda centuria. Las arcillas utilizadas en la fabricación de estas piezas, aún manifestándose como indudablemente regionales, resultan más toscas que las típicas cuarzo-micáceas finas lucenses que de forma casi invariable dominarán más tarde. Algo similar acontece con los tratamientos superficiales que, en el caso de los ejemplares tardíos reiteran de modo constante los característicos bruñidos bien conseguidos, mientras que en los tempranos resultan más groseros. El cromatismo superficial habitual en estos últimos es oscuro, negruzco, mientras que entre los primeros dominan los tonos grisáceos.

Este modelo puede relacionarse con los denominados vasos carenados, decorados, monoasados, de breve borde triangular -tipo L16- de Lugo, datados en época preflavia y considerados, al igual que insinuamos para el Chao Samartín, el precedente de las formas V1 / V1 A o tazones monoasados típicos de la segunda centuria (Alcorta, 2001: 122-124, Fig. 54).

romboidales, con ocasionales temas impresos complementarios (Alcorta, 2001: 122, Fig.54). 


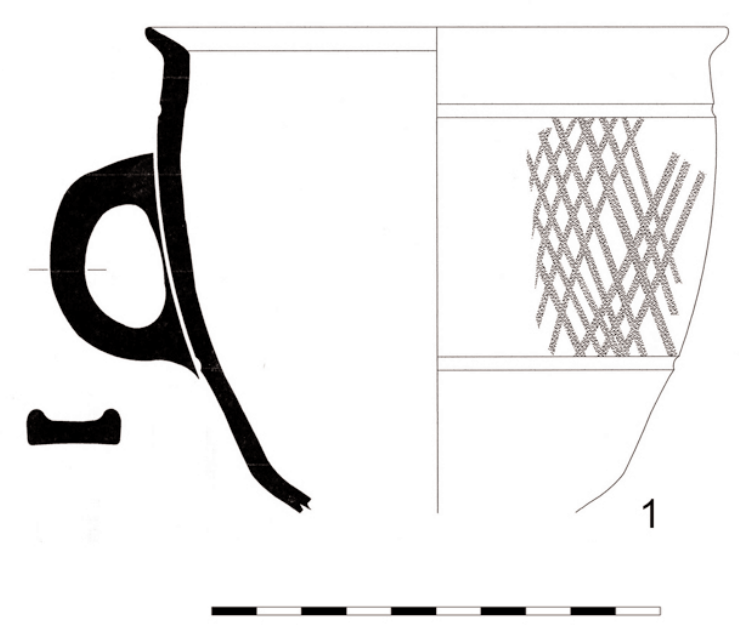

Figura 33. Tazón monoasado

\section{CATÁl OGo}

1. CH.02/1849. Sector N-1. Fragmento de borde, cuerpo y asa. Borde corto, exvasado, oblicuo y recto al interior con labio de perfil redondeado. Cuerpo de tendencia vertical en lo conservado surcado por sendas acanaladuras bastante anchas, una en el tercio superior y otra en la zona central. Decoración de retícula romboidal simple bruñida de trama estrecha que se desarrolla en el friso de unos $54 \mathrm{~mm}$ de ancho que delimitan las acanaladuras. Pasta de tonalidad grisácea con abundantes desgrasantes micáceos y cuarcíticos de pequeño y mediano tamaño. Superficies grises oscuras, con acabado toscamente bruñido en la externa y el borde. Dimensiones: diámetro borde: $132 \mathrm{~mm}$; diámetro máximo cuerpo: $127 \mathrm{~mm}$; altura conservada: $93 \mathrm{~mm}$; grosor medio sección pared: $5 \mathrm{~mm}$. Bibliografía: Montes, 2005; Hevia, 2006; Hevia y Montes, 2009: Fig.3.1.

\section{TAZAS CARENADAS MONOASADAS}

\section{(Figuras 34 y 35)}

Se trata de un tipo cuya caracterización morfológica recuerda vivamente perfiles y técnicas pre-

\footnotetext{
${ }^{20}$ Ver, por ejemplo, Coelho, 1986: Est. XLV.

${ }^{21}$ En algunos casos, la solución de la carena e incluso el desarrollo morfológico general de estas piezas, recuerda, salvando las notables diferencias técnicas, dimensionales e incluso
}

rromanas (Hevia, 2009: 358-359 y 366-367). Los bordes, indiferenciados, muestran un desarrollo curvo levemente abierto con labios de sección redondeada que se inscribe en la tradición protohistórica comarcal ${ }^{20}$. El galbo describe un contorno característico en el que se aprecian dos partes bien diferenciadas separadas mediante la interposición de una carena doble o triple ${ }^{21}$ : una zona superior de trayectoria aproximadamente vertical y curva que conforma un típico perfil acampanado y otra inferior globular que se asienta sobre una sencilla base plana o ligeramente cóncava, según los casos. Disponen de un asa en C de sección elipsoidal que partiendo bajo el borde descansa en la carena (Hevia y Montes, 2009: Fig. 3.10).

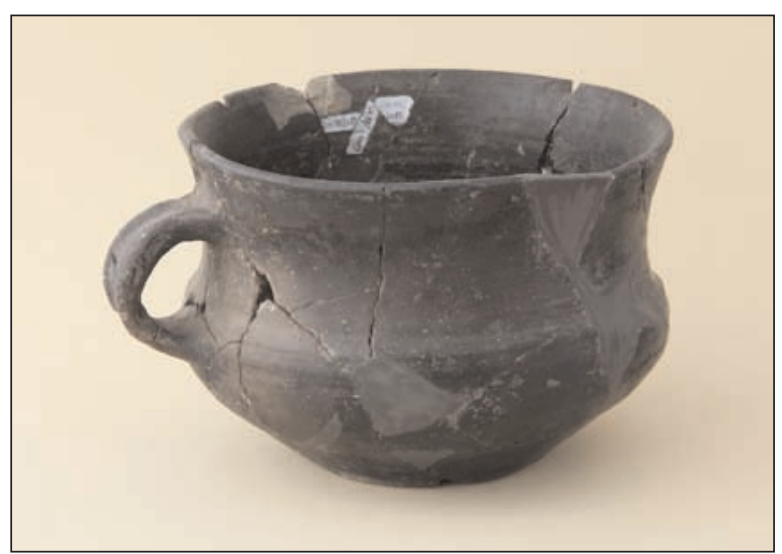

Figura 34. Taza carenada. Foto: R. Montes

genéticas, a las adoptadas en las jarritas facetadas, consideradas una importación del ámbito astur cismontano (Montes, 2005). 
El acabado, siempre consistente en un tosco bruñido en el que resultan perfectamente visibles las huellas del espatulado, y las cocciones reductoras dotan a estos recipientes de unas superficies pulidas y oscuras, normalmente negruzcas. Así pues, tanto forma como tratamiento convierten a estas tazas en ejemplos paradigmáticos de la inercia que mantiene en el siglo I d.C. la tradición alfarera local (Montes y Hevia, 2009: 210).

Ocasionalmente, sobre la carena y enmarcada en un friso no demasiado ancho, se desarrolla una banda decorada en la que se plasman motivos de líneas bruñidas del tipo habitual entre la cerámica regional.

Estas tazas se presentan como unos recipientes de dimensiones modestas, con bordes cuyo diámetro ronda los $150 \mathrm{~mm}$ y alturas en torno a los $110 \mathrm{~mm}$. Este tamaño reducido, unido a la concepción morfológica general, así como el escaso grosor de las paredes y los tratamientos superficiales, sugieren un destino funcional relacionado con el servicio de mesa.

\section{CATÁl OGO}

1. CH.98/1525. Sector R-V. Perfil completo. Borde curvo indiferenciado casi vertical con labio de sección redondeada. Carena media que estructura la pared en un sector superior de perfil exterior cóncavo y otro inferior de perfil globular. De este punto parte un asa en $\mathrm{C}$ de sección elipsoidal rehundida al exterior que alcanza las proximidades del borde. Base plana. El borde y la superficie externa presentan un tosco bruñido, mientras que en la cara interna resultan visibles las líneas de torno. Dimensiones: diámetro borde: $154 \mathrm{~mm}$; diámetro máximo cuerpo: $154 \mathrm{~mm}$; diámetro base: $72 \mathrm{~mm}$.; altura: $112 \mathrm{~mm}$.; grosor medio sección: 5 mm. Bibliografía: Hevia, 2009: Ficha 118, 366-367.

2. CH.98/0406. Sector R-V. Perfil completo. Borde curvo indiferenciado con labio de sección redondeada. Cuerpo bitroncocónico con triple carena baja bien marcada, la superior de las cuales viene remarcada al

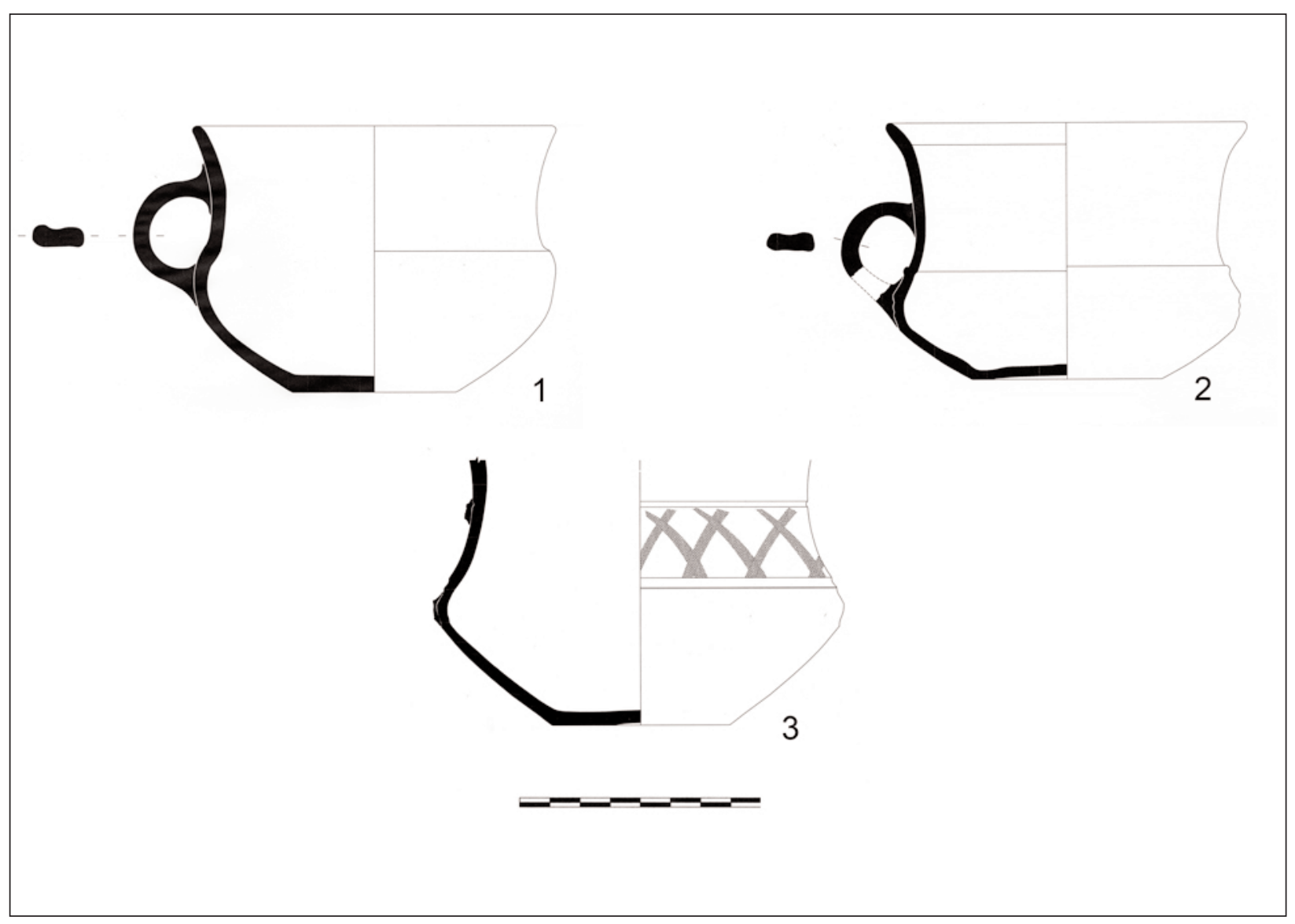

Figura 35. Tazas carenadas 
exterior por una moldura de sección redondeada. Asa en $\mathrm{C}$ de sección elipsoidal rehundida al exterior que parte de la carena para llegar a la parte superior del cuerpo. Base ligeramente cóncava al exterior. El borde y la superficie externa presentan un tosco bruñido. Dimensiones: diámetro borde: $150 \mathrm{~mm}$; diámetro máximo cuerpo: $144 \mathrm{~mm}$; diámetro base: $80 \mathrm{~mm}$; altura: 107 mm; grosor medio sección: $4 \mathrm{~mm}$. Bibliografía: Hevia, 2009: Ficha 114; 358359; Hevia y Montes, 2009: Fig. 3.10.

3. CH.98/3395. Sector R-VIII. Fragmento de cuerpo, base y asa. Cuerpo bitroncocónico con doble carena media-baja bien marcada recorrido al exterior por una acanaladura en el tramo superior y otras dos, la inferior muy ancha, sobre la zona de la carena. Asa en $\mathrm{C}$ de sección elipsoidal rehundida que parte de la carena y alcanza las proximidades del borde. Base ligeramente cóncava al exterior. Decoración entre las acanaladuras consistente en una retícula ancha de gruesas líneas bruñidas. Pasta de tonalidad grisácea con desgrasantes micáceos menudos y cuarcíticos pequeños y medianos. Superficies grises oscuras. Acabado bruñido al exterior, mientras que en el interior resultan visibles las estrías del torneado. Dimensiones: diámetro máximo cuerpo: $170 \mathrm{~mm}$; diámetro base: $74 \mathrm{~mm}$; altura: $111 \mathrm{~mm}$; grosor medio sección: $4.5 \mathrm{~mm}$. Bibliografía: Inédita.

\section{Taza Engobada (Figuras 36 y 37)}

La morfología presentada consiste en una tacita de perfil hemisférico con dimensiones muy reducidas que apenas alcanzan los $80 \mathrm{~mm}$ de apertura de boca y una altura en torno a los 60 $\mathrm{mm}$. El borde se muestra corto, exvasado y oblicuo rematado en un labio de sección redondeada. Un rasgo formal especialmente peculiar lo constituye el asa que, arrancando del borde, llega a la zona media del galbo. Se trata de una típica asa en C de sección subromboidal cuya parte superior se desarrolla en horizontal, componiendo una superficie plana y ensanchada.
En la mitad superior de la pared y acotada arriba por una acanaladura previa al borde y abajo por una doble acanaladura, se desarrolla una banda decorada que alberga una secuencia de gruesos trazos verticales incisos de ejecución muy regular. El tramo horizontal del asa exhibe también un programa ornamental consistente en una línea de pequenos círculos tangentes estampados que siguen su eje mayor, enmarcada por líneas incisas paralelas de trazado curvo. (Montes, 2005).

Las superficies muestran al exterior un cuidado acabado bruñido y tonalidades pardo grisáceas, mientras que la cara interna, el borde y la parte superior del asa se encuentran recubiertas de engobe rojo.

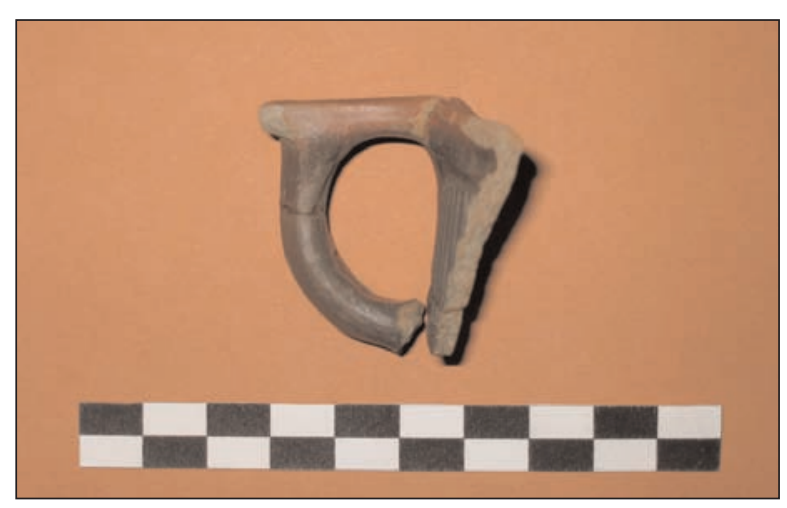

Figura 36. Taza engobada. Foto: R. Montes

La naturaleza de las pastas, así como el característico bruñido exterior y el engobe que recubre la superficie interna, relaciona el tipo con la serie de fabricaciones engobadas con decoración por lo general estampillada perfectamente definidas en el Chao Samartín (Benéitez et alii, 1999: 31-32, Fig. 6 y 7.1-3; Hevia, 2009: 360-361; Montes, 2209: 440-441) y su entorno próximo (Carrocera y Requejo, 1989; Alcorta, 2001: 117-121, Fig. 52.1 y 53.1), que se detallan entre las producciones del siglo II d.C (Figuras 122, 126 y 128). Si bien el tratamiento técnico y la incorporación de engobe parecen adelantar una síntesis que más adelante se verá confirmada, no así la formulación morfológica y los motivos decorativos, ya que las formas que adquirirán un cierto grado de estandarización remiten fundamentalmente a recipientes tipo olla (Benéitez et alii, 1999: 31-32, Fig. 6 y 7.1 y 2) ornamentados de forma preferente mediante arquerías tangentes de cuyas uniones penden elementos circulares o vegetales. 


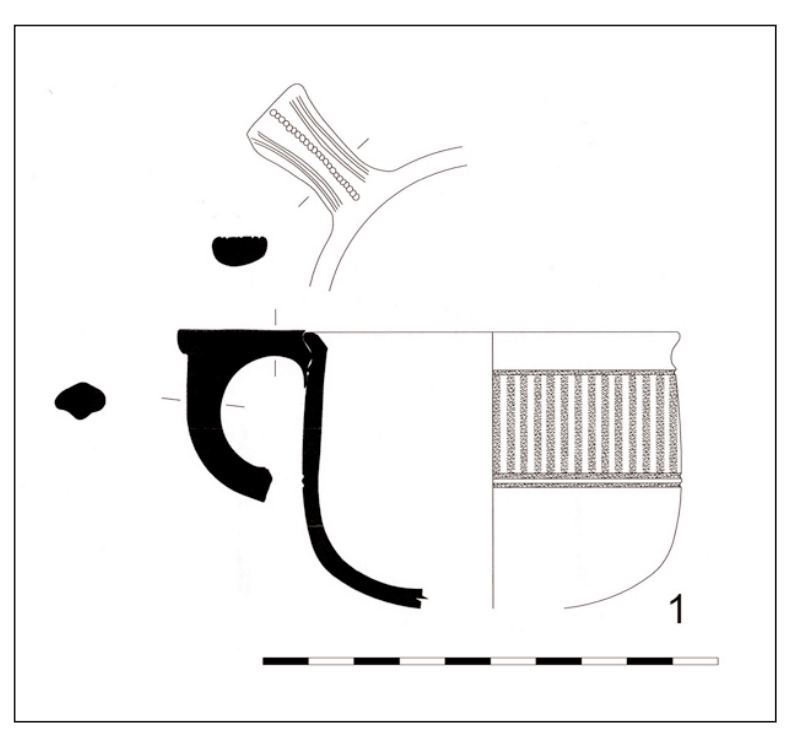

Figura 37. Taza engobada

\section{Catalogo}

1. CH.98/0449. Sector R-V. Fragmento de borde, cuerpo y asa. Borde corto, exvasado, oblicuo y curvo con labio de perfil redondeado separado al exterior del cuerpo por una moldura de sección redondeada. Cuerpo hemisférico recorrido en su extremo superior por una acanaladura y más abajo por otras dos. Asa de perfil en C de sección subromboidal que adquiere en su parte superior un mayor desarrollo en horizontal que sirve de soporte a una ornamentación de líneas incisas curvas que enmarcan una cadena formada por pequeños círculos secantes impresos. Las acanaladuras delimitan una banda decorada con líneas incisas verticales ejecutadas con gran esmero técnico. Pasta fina micácea de tonalidad gris anaranjada. En el borde, la superficie interna y la parte horizontal del asa se ha aplicado un engobe rojo de buena calidad, mientras que en la superficie externa se puede apreciar un acabado bruñido. Dimensiones: diámetro borde: $80 \mathrm{~mm}$; diámetro máximo cuerpo: $83 \mathrm{~mm}$; altura conservada: $60 \mathrm{~mm}$; grosor medio sección pared: $3.5 \mathrm{~mm}$. Bibliografía: Montes, 2005.

\section{Cuencos hemisféricos (Figuras 38 y 39)}

La forma (Hevia, 2006) se define como un recipiente de perfil simple con pared marcada- mente curva que describe un contorno hemisférico que remata en un borde indiferenciado ligeramente envasado con labio de sección redondeada. El grosor de la pared se adelgaza conforme se acerca hacia al contacto con la base, de trayectoria horizontal (Hevia y Montes, 2009: Fig. 3.3).

Las pastas ofrecen tonalidades grisáceas y en ellas resultan visibles abundantes inclusiones micáceas, cuarcíticas y esquistosas. Las superficies externas se encuentran toscamente bruñidas como constituye norma habitual en las producciones regionales del momento.

La apertura de la embocadura, que ronda los $150 \mathrm{~mm}$, la estructura formal y las dimensiones generales, apuntan un empleo en el servicio de mesa como receptor individual de sólidos y/o líquidos, sin menoscabo de un posible uso subsidiario en labores culinarias (Hevia, 2006).

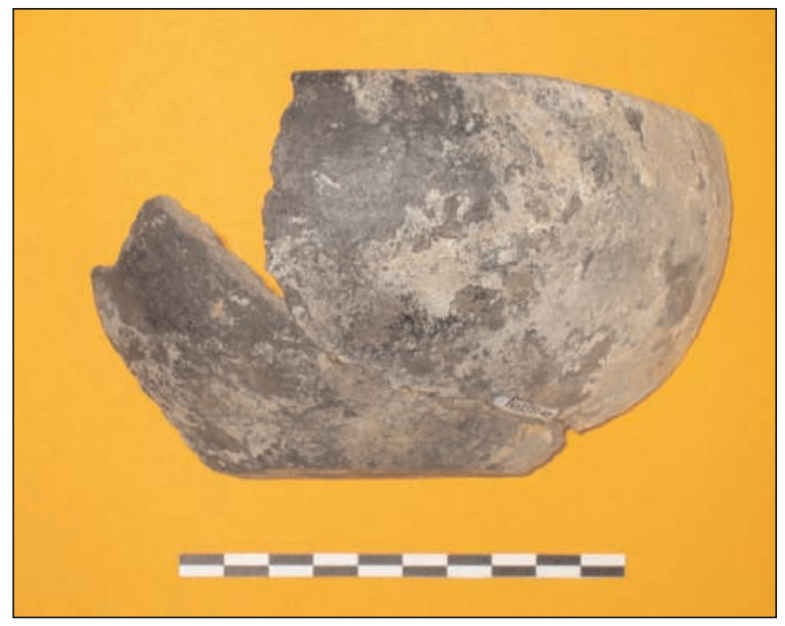

Figura 38. Cuenco hemisférico. Foto: R. Montes

La caracterización tecnológica no ofrece dudas acerca de la fabricación regional, aún cuando no se han podido encontrar sino escasos paralelos que remiten a vagas similitudes formales. La morfología es conocida en los repertorios de la Edad del Hierro previos a la romanización según atestigua la presencia en la Corona de Corporales, cuyas datas no superan los momentos finales del siglo I a.C., de tres ejemplares de dimensiones similares aunque de perfil más invasado (Sánchez-Palencia y Fernández-Posse, 1985: 101102 , fig. $42, \mathrm{n}^{\mathrm{o}} 66,81$ y 123 ). Estas piezas son interpretadas como platos o escudillas cuya escasa entidad numérica parece indicar una forma poco frecuente y escasamente exitosa, hecho que 
podría confirmar la documentación de un único fragmento del tipo en la primera fase de ocupación del cercano Castro de Corporales, fechada entre los años 40/50 y 65/75 d.C. (Ibidem: 207, fig. 95. 573). Una solución formal similar, limitada a un único ejemplar (Carretero, 2000: 554-595, fig. 308. 47), si bien de borde marcadamente reentrante, se documenta en Petavonium ${ }^{22}$, también en contextos de la segunda mitad del siglo I d.C. En Lucus Augusti, una proximidad mayor en los aspectos tecnológicos, pero más difusa en los formales, puede establecerse con los cuencos carenados de reborde envasado (Tipo L12) para los que se propone una cronología flavia o preflavia y que no se documentan en los contextos posteriores al siglo I d.C. (Alcorta, 2001: 111-112, fig. 49.3-5).

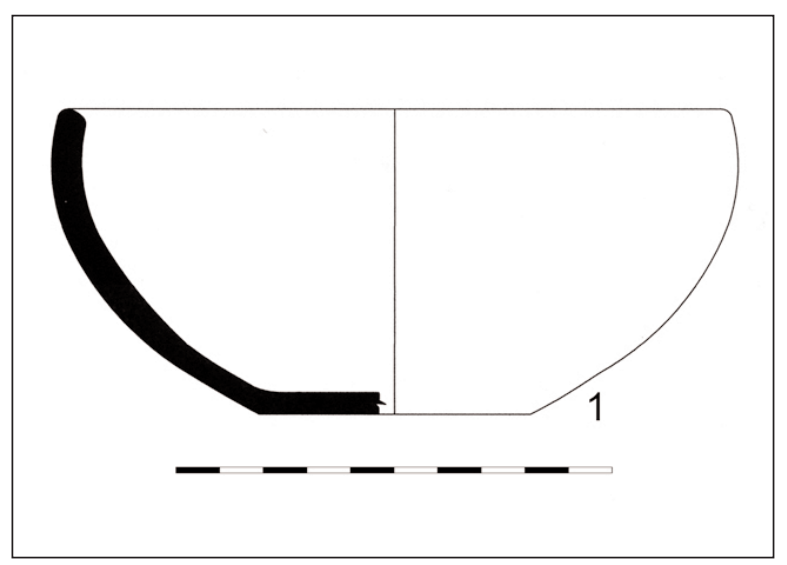

Figura 39. Cuenco hemisférico

\section{CATÁl OGO}

1. CH.02/2458. Sector N-1/ Foso E. Perfil completo. Borde indiferenciado con labio de perfil redondeado. Cuerpo hemisférico. Base plana. Pasta grisácea con desgrasantes micáceos pequeños y abundantes cuarzos y esquistos medios. Superficies grisáceas con tosco acabado bruñido. Dimensiones: diámetro borde: $155 \mathrm{~mm}$; diámetro máximo cuerpo: $158 \mathrm{~mm}$; diámetro base: $62 \mathrm{~mm}$; altura: $70 \mathrm{~mm}$; grosor sección: 4.5/8 mm. Bibliografía: Hevia, 2006; Hevia y Montes, 2009: Fig.3.3.

\section{Cuencos engobados (Figuras 40 y 41)}

Los cuencos engobados se convertirán en los ajuares del siglo II d.C en uno de los tipos cerámicos más genuinos de la industria regional, inserto en una familia de manufacturas cerámicas engobadas, entre las que destacan junto a los platos con engobe rojo interior, que cuajaron como producción de éxito durante largo tiempo en el convento lucense y gozaron de proyección incluso extrarregional.

El reconocimiento de un ejemplar de esta clase en los depósitos romanos tempranos del yacimiento, aún resultando un testimonio escueto, indica el arranque de su producción al menos a fines del siglo I d.C, aún cuando pueden reseñarse algunas peculiaridades significativas que apuntan hacia momentos tempranos de la producción, en los que el morfotipo no se encuentra plenamente fijado, y que podrían permitir intuir un cierto proceso evolutivo de la forma.

Así, los estandarizados cuencos del siglo II d.C. (Figura 116) presentarán dimensiones más reducidas, con diámetros de borde en torno a los $150 \mathrm{~mm}$, mientras que este ejemplar temprano alcanza los $250 \mathrm{~mm}$. En otro orden de cosas, las pastas se muestran menos depuradas, con presencia de las abundantes partículas de mica que caracterizan a toda la serie pero incorporando, en escasa proporción, desgrasantes de granulometría más grosera. El acabado superficial también difiere, con superficies más oscuras y un engobe más denso y de tonos granates que cubre al exterior una banda más ancha de la que será habitual más adelante (Hevia, 2006).

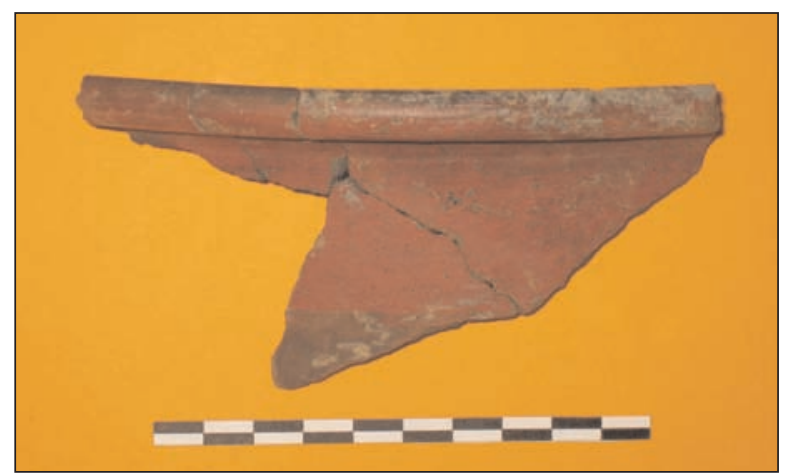

Figura 40. Cuenco engobado. Foto: R. Montes

\footnotetext{
${ }^{22}$ Tipo L IV denominado cuenco de cuerpo hemiesféri-
} tradición astur. 
Aunque no se dispone de un elenco suficiente para establecer una hipótesis evolutiva sólida, resulta innegable que estas características físicas se ajustan más a la tradición regional, gustosa de las cocciones reductoras y las superficies oscuras. Este tratamiento técnico se hallará totalmente ausente en los modelos posteriores y tampoco se documenta en los paralelos conocidos. La diferencia de volumen debe ponerse en relación con una especialización funcional y desvestirse de apreciaciones cronológicas, dado que algunos de los ejemplos de mayor tamaño remiten a piezas recuperadas en contextos para los que se proponen datas tardías ${ }^{23}$.

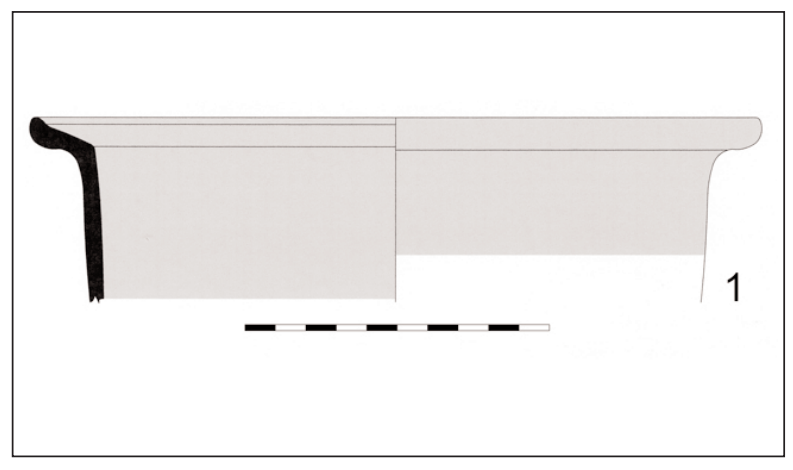

Figura 41. Cuenco engobado

\section{CATÁlogo}

1. CH.02/1587. Sector N-1. Fragmento de borde y cuerpo. Borde exvasado, oblicuo y de perfil ligeramente cóncavo al interior con labio engrosado de sección redondeada. Cuerpo vertical en lo conservado. Pasta de tonalidad grisácea con desgrasantes micáceos pequeños y muy pequeños y cuarcíticos pequeños y medianos. Superficie interna, borde y parte superior de la pared exterior (banda de unos 30 $\mathrm{mm}$ de anchura media) recubiertos con

23 Es el caso de los procedentes de Sasamón (Abásolo y García, 1993: 157 -159, Fig. 78.9) y Gijón (Fernández Ochoa, 1994: 66, Fig. 10, n 51).

24 Se recoge un ejemplar muy similar en forma documentado en un pozo de época de Domiciano en Lliria y encuadrado en el grupo de los catini tipo lanx (Escrivá, 1995: 176, Fig.7.6).

25 E. Serrano presenta entre los ejemplares de dimensiones más destacadas de los denominados "platos con baquetón" un engobe rojo oscuro. El resto de la superficie externa se encuentra finamente bruñida y presenta coloración parda. Concreciones de hollín en borde y parte superior de la cara interna. Dimensiones: diámetro borde: $250 \mathrm{~mm}$; diámetro máximo cuerpo: $227 \mathrm{~mm}$; altura conservada: $63 \mathrm{~mm}$; grosor sección: $6 \mathrm{~mm}$. Bibliografía: Hevia, 2006.

\section{Fuentes Carenadas Con baQuetón} (Figuras 42 y 43)

El tipo, no obstante su rareza en el repertorio, sintetiza de modo muy expresivo las características técnicas de esta etapa productiva temprana de la cerámica galaico-romana. Factura y acabado responden a los gustos tradicionales, fieles a las cocciones reductoras y los tratamientos espatulados.

A pesar de que en los aspectos técnicos se inscribe en la cerámica regional del momento, la forma remite a un modelo conocido con relativa profusión en la Hispania altoimperial y para el que disponemos de referentes formales bastante próximos, por ejemplo, en el País Valenciano ${ }^{24} \mathrm{O}$ en el alfar bético de La Cartuja. ${ }^{25}$ Se trata de una fuente de tamaño medio, con una apertura de boca en torno a los $360 \mathrm{~mm}$ y poco profunda, puesto que la altura apenas alcanza los $70 \mathrm{~mm}$. El borde se presenta engrosado y de sección trapezoidal y queda separado de la pared al exterior por una incisión. El cuerpo desarrolla un perfil carenado con inflexión alta claramente marcada en la que sitúa un baquetón de perfil redondeado en la cara externa. La base es plana (Hevia y Montes, 2009: Fig.3.2; Hevia, 2009: 356-357).

algunos ejemplares extremadamente próximos en morfología, que no técnicamente, a la pieza que nos ocupa (Serrano, 1995: 238-239, Fig.9. 75-77). El marco cronológico genérico que se apunta para estos talleres meridionales engloba desde época de tiberio hasta mediados del siglo II d.C. (Ibidem, 244). 


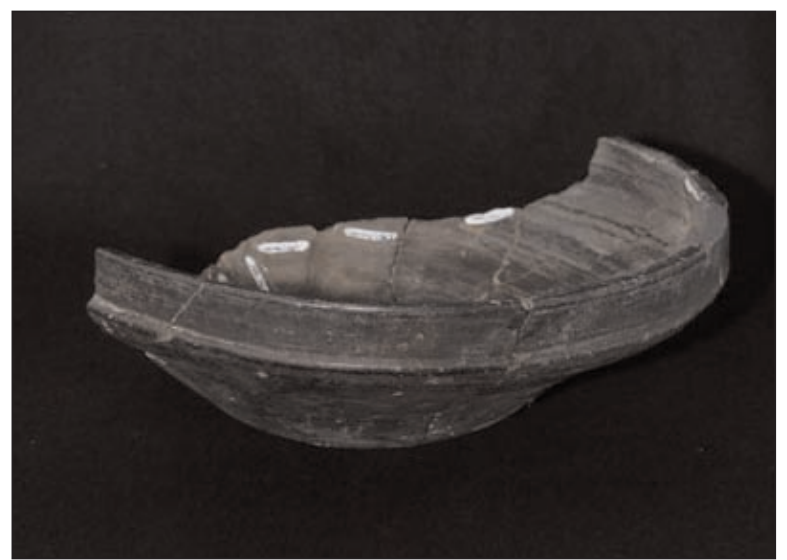

Figura 42. Fuente carenada con baquetón. Foto: J. Arrojo

Tanto perfil como tratamiento técnico difieren claramente de los prototípicos cuencos y fuentes carenados de borde engrosado ${ }^{26}$ que caracterizarán el repertorio habitual en fechas más tardías (Figura 109). El tipo presentado se revela en consecuencia como una fórmula fallida propia de la heterogénea vajilla del siglo I d.C. y cuyo espectro funcional será ocupado en el siglo II d.C. por el referido tipo de carena más suave, que mantiene evidentes vínculos con el repertorio tipológico clásico y en concreto, con la forma Vegas 9 a (1973: 35-37).

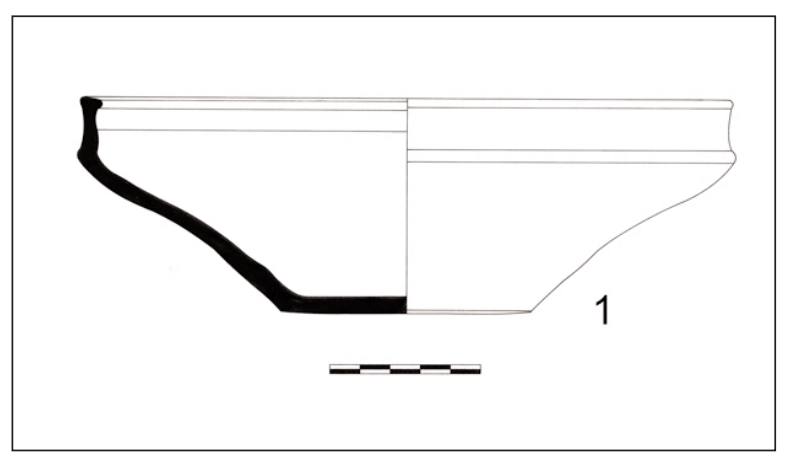

Figura 43. Fuente carenada con baquetón

\section{CATÁlogo}

1. CH.93/1303. Sector R-V. Perfil completo. Pared abierta de perfil curvo con carena alta reforzada por un baquetón de perfil redondeado sobre el que se eleva un borde vertical rematado en un labio reentrante diferenciado al exterior por una incisión. Base plana. Pasta de tonalidad parda en la que se aprecian micas pequeñas, cuarzos y cuarcitas de variado tamaño, intrusiones anaranjadas y esporádicos esquistos. Las superficies, de color negro, recibieron un descuidado bruñido ejecutado con mayor tosquedad sobre la pared interna. Huellas de carbonización en ambas superficies. Dimensiones: diámetro borde: $216 \mathrm{~mm}$; diámetro máximo cuerpo: $219 \mathrm{~mm}$; diámetro base: $83 \mathrm{~mm}$; altura: $71 \mathrm{~mm}$; grosor sección: 4/5 mm. Bibliografía: Hevia, 2009: Ficha 113, 356-357; Hevia y Montes, 2009: Fig.3.2.

\section{Fuentes Biasadas (Figura 44)}

Las fuentes biasadas constituyen una morfología muy característica del repertorio cerámico regional cuyo inicio como producción seriada se inaugura en esta etapa, si bien se prolongará hasta, al menos, fechas avanzadas del siglo II d.C. (Montes, 2009: 436-437). Lo exiguo del repertorio adscribible a estas datas alborales de su fabricación y la escasa entidad de los fragmentos conservados impiden abordar un análisis detallado de sus particularidades formales y técnicas, más allá de la inequívoca asignación genérica al tipo (Hevia y Montes, 2009: Fig.3.11), perfectamente definido más adelante (Benéitez et alii, 1999: 29-30, Fig. 5.8-10). De este modo, no disponemos de datos que permitan confirmar las conclusiones obtenidas en Lugo para piezas semejantes. Allí, en los ejemplares tempranos adscritos al tipo L19 (Alcorta, 2001: 126-127, Fig. 56), se ha observado una tendencia a los perfiles más netamente hemisféricos, a los bordes sencillos, a una mayor profundidad de los recipientes, a un desarrollo más acusado de la nervadura, que adquiere mayor vuelo y que además se ubica en una zona más baja de la pared, y a una presencia más frecuente de ornamentaciones bruñidas (Ibidem: 341 ).

\footnotetext{
26 Para una comparación ajustada, se pueden consultar los ejemplos que se recogen en esta misma publicación.
} 
En nuestro caso contamos con un escaso número de fragmentos que no ofrecen dudas en cuanto a su adscripción formal pero que no han permitido la reconstrucción de perfiles completos. Confirman, en cualquier caso, la presencia del tipo en el yacimiento durante la primera centuria sin que la naturaleza de los contextos de aparición permita hacer estimaciones sobre su frecuencia. En el Chao Samartín será en el siglo II d.C cuando se conviertan en elementos habituales en los ajuares (Figura 113).

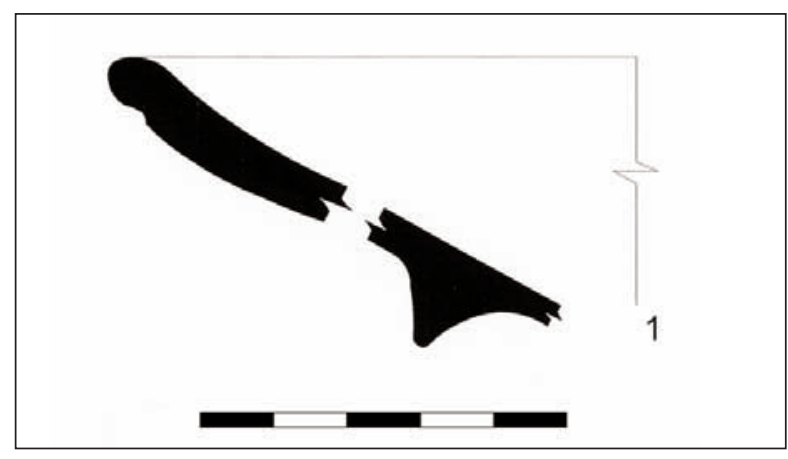

Figura 44. Fuente biasada

\section{CATÁlogo}

1. CH.02/2743. Sector N-1. Fragmento de borde y cuerpo. Borde indiferenciado de perfil redondeado remarcado al exterior por una ancha acanaladura. Cuerpo de perfil curvo recorrido al exterior por una nervadura de sección triangular. Pasta de tonalidad pardo grisácea con desgrasantes micáceos y cuarcíticos pequeños y abundantes esquistos de variadas dimensiones. Superficies someramente bruñidas, la externa de color pardo grisáceo y la interna gris oscura. Dimensiones: diámetro aproximado borde: $120 \mathrm{~mm}$; altura conservada: $21 \mathrm{~mm}$; grosor sección pared: 5.5/7.5 mm. Bibliografía: Hevia, 2006; Hevia y Montes, 2009: Fig. 3.11.

\section{VAJiLla ENGobada DE IMITACión DE TERRA SIGILLATA (Figuras 45-47)}

Los fenómenos imitativos de cerámicas clásicas $\mathrm{y}$, de forma especialmente significativa,

${ }^{27}$ Cabe referir, por ejemplo, el caso de los alfares galos de Aoste (Laroche, 1986) o Galane (Mesplé, 1957). de piezas de terra sigillata, resultan frecuentes en territorios periféricos del Imperio, sobe todo en los momentos iniciales del contacto entre las comunidades indígenas y Roma. Los ejemplos se extienden de manera generalizada a todas las regiones occidentales ${ }^{27}$ y en Hispania podemos referir múltiples casos. No obstante, cabe en este punto reflexionar sobre la variedad de situaciones que explican estos fenómenos y la compleja realidad social que subyace. En determinadas ocasiones, se dan procesos de recreación directa de modelos, tal y como sucede con las producciones de lo que se ha dado en llamar terra sigillata local de tradición itálica (Morillo, 2008: 279). Es el caso, circunscribiéndonos a los ámbitos más próximos, de la vajilla realizada por el figlinarius de la Legio IIII Macedónica L. Terentius (Morillo y García Marcos, 2001: 149) documentada en yacimientos del hinterland del campamento de Herrera de Pisuerga (Carretero, 2000: 447; Sanz Mínguez, 1998: 178 y 355-356; Carretero y Guerrero, 1990: 374-375, Fig.6) o la fabricada en el acantonamiento de la Legio VI victrix de León por diversos artesanos como C. Licinius Maximus, L.M. Gen o el alfarero de la caliga (García Marcos, 2006; Morillo, 2008: 281284; Fig. 4 y 5). En el extremo opuesto se sitúan otros casos en los que el tamiz indígena actúa de una manera mucho más acusada, obteniéndose producciones cerámicas en las que el componente clásico se diluye a causa del peso de los modos y gustos de la tradición alfarera local. El ejemplo lucense que analizaremos en estas líneas resulta muy elocuente en este sentido.

Uno de los ejemplos más representativos identificados de este tipo de fenómenos es el que se produce en el ámbito productivo bracarense (Alarcão, 1966; Alarcão y Martins, 1976), en el que se registran imitaciones de diversas formas de terra sigillata ${ }^{28}$ en yacimientos como, por ejemplo, Aquis Querquennis (González, 2006), Conimbriga (Alarcão, 1976), diversas localizaciones del Alto Alentejo (Nolen, 1986) o la propia Bracara Augusta (Morais, 2008; Delgado y Morais, 2009: 25-29). Otro sector hispano en el

\footnotetext{
${ }^{28}$ Se han reconocido copias de las formas Drag. 24/25, 27, 29, 35, 36 y 37 e Hisp. 4 y 5 (Morais, 2008).
} 
que se detectan producciones afines es el valle del Ebro, en alfares como el identificado en Tarazona (Amaré, 1984: Aguarod, 1984; Aguarod y Amaré, 1985) ${ }^{29}$. En Emerita Augusta, por su parte, también se ha constatado la imitación de formas de terra sigillata (Rodríguez Martín, 1996: 49) en los alfares instalados en la ciudad en el siglo I d.C. ${ }^{30}$, dedicados paralelamente a la manufactura de lucernas, terracotas, cerámica común y paredes finas (Rodríguez Martín, 1996: 162; Mayet, 1975).

Sin embargo, debemos centrarnos en el ámbito productivo lucense a la hora de rastrear vínculos para el elenco aquí presentado, tan expresivo como reducido en lo numérico. En Lucus Augusti se registran, en la primera fase productiva, imitaciones bastante fidedignas en lo morfológico al modelo original de la forma Drag. 2931 (Alcorta, 2001: 131-137, Fig. 58), que parece ser el tipo más frecuente ${ }^{32}$, y que se acompaña de imitaciones de la Ritt. 5 -tipo I5(Ibidem: 139, Fig.59.3) y tal vez, de la Hermet 4 -tipo I4- (Ibidem: 137-138, Fig.59.1-2). En cronologías más avanzadas, que alcanzan la época bajoimperial, se producirán imitaciones de las formas Ritt. 8, Drag.15/17, Drag.27, Drag. 35, Palol 8 y Hayes 59 (Alcorta, 2001: 364-382, Figs.154-161).

La representación de este tipo de producciones en el Chao Samartín se reduce hasta el momento a un fragmento de galbo de una posible Drag. 29 y a una pieza que imita la forma Drag. $24 / 25$.

\section{Imitación Forma Drag. 29}

(Figuras 45 y 47.2 )

Se ha recuperado un pequeño fragmento de la parte inferior del cuerpo de una pieza que,

${ }^{29}$ Entre las formas lisas se imitan los tipos Drag. 27, Hisp. 32 y Drag. 46 (Aguarod, 1984: 102; Aguarod y Amaré, 1985: Fig. 5.4), mientras que por lo que se refiere a las decoradas, se han identificado, al menos, remedos del tipo Hermet 13 (Amaré, 1984: 110).

${ }^{30}$ Se constatan imitaciones de las formas de vasos Hisp.10, Drag. 27 y Drag. 35, de los cuencos Drag. 29 o 37 y Drag. habida cuenta su desarrollo morfológico, el engobe rojo que se ha aplicado sobre ambas superficies y la decoración, resulta verosímilmente asimilable a esta forma. Sobre su superficie externa se plasma un motivo estampillado de arquerías segmentadas simples unidas por sus bases, punto donde se instalan motivos circulares radiales de los que a su vez penden líneas verticales también segmentadas rematadas

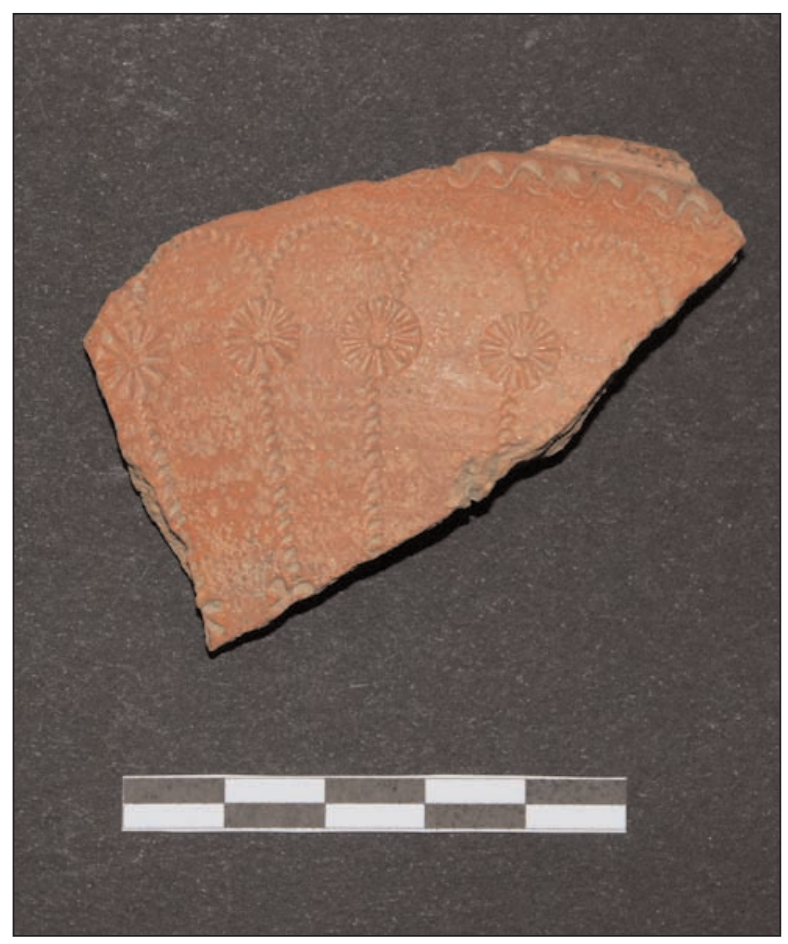

Figura 45. Imitación Drag. 29. Foto: R. Montes

en pequeños tetrapétalos. Sobre las arquerías y bajo sendas acanaladuras se desarrolla un friso de SSS. Se trata de una decoración encuadrable en la calificada por E. Alcorta (2001: 131-132) como local, frente a la clásica (motivos vegetales) y la híbrida, que también se reconocen sobre este tipo de piezas. Sintaxis ornamental, motivos y técnicas decorativas se insertan incuestionablemente en el universo cerámico regional del momento y de confirmarse su apli-

36 y de los platos Drag. $15 / 17$, Drag. 18 y Drag. $18 / 31$ (Rodríguez Martín, 1996: 26-32)

31 Tipo I29

${ }^{32}$ Este importante peso porcentual de la forma Drag. 29 se observa también en el repertorio bracarense (Morais, 2008: 447). 
cación sobre una imitación de terra sigillata ejemplificaría de modo particularmente expresivo el sincretismo entre tradición comarcal e innovación, ya confirmado de todos modos mediante la aparición del engobe rojo.

Entre la serie documentada en Lugo de este tipo de piezas, cabe referir un pequeño fragmento que recibe decoración de arquerías bastante similar a la mostrada en la zona inferior de la pared de nuestra pieza (Alcorta, 2001: 134, Fig.58.6), ubicación infrecuente en los prototipos remedados.

\section{Imitación forma Drag. 24/25}

(Figuras 46 y 47.1)

Se ha identificado un único ejemplar de este tipo, que imita de modo inequívoco las características morfológicas de la forma Drag.24-25 de terra sigillata, presentando borde vertical indiferenciado con acanaladura en el labio y sobre todo, el peculiar baquetón que surca la pared de esta forma. Ambas superficies se encuentran recubiertas de un engobe espeso de tonos rojos oscuros.

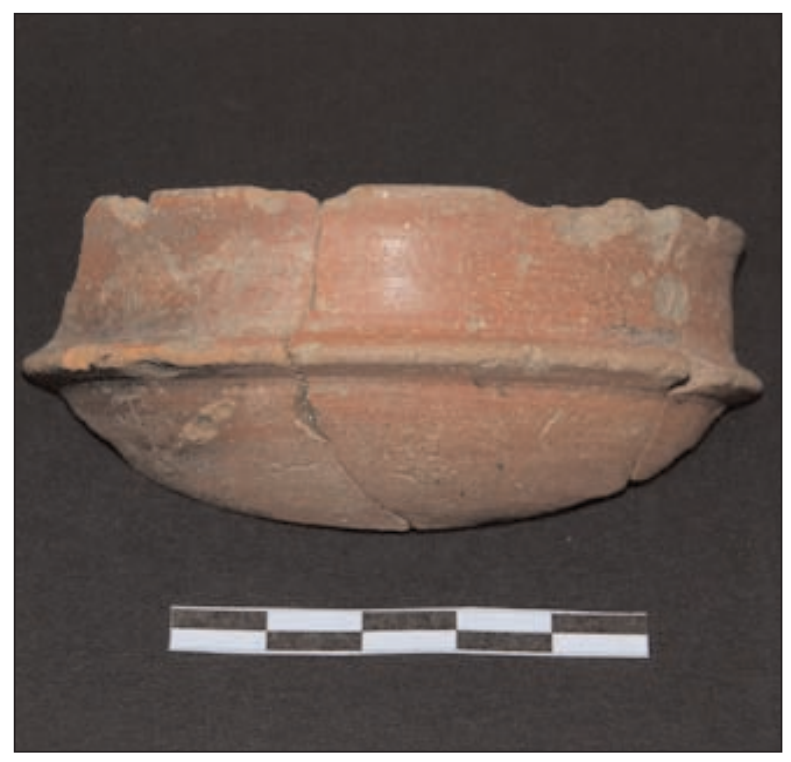

Figura 46. Imitación Drag. 24/25. Foto: R. Montes

Las pastas cuarzo-micáceas vinculan al vaso a la serie cerámica regional, a pesar de la ausencia de referencias lucenses para imitaciones de esta morfología (Alcorta, 2001).

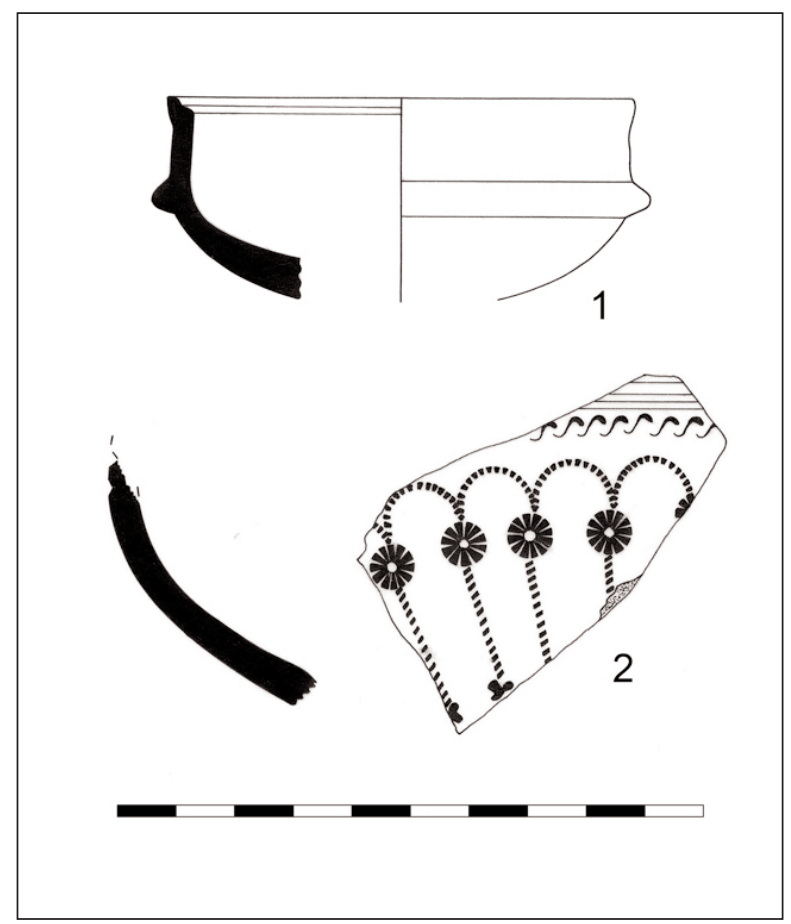

Figura 47. Imitaciones engobadas de terra sigillata.

\section{CATÁlogo}

1. CH.99/1534. Sector C-12 A. Fragmento de borde y cuerpo de vaso de imitación de la forma Drag. 24/25 de terra sigillata. Borde muy corto y levemente oblicuo, recorrido al interior por una acanaladura, con labio de perfil redondeado. Cuerpo surcado en su sector medio por una moldura de sección triangular que lo divide en dos partes: una superior vertical y otra inferior de perfil curvo abierto. Pasta de tonalidad gris anaranjada con abundantes desgrasantes micáceos pequeños y muy pequeños y cuarcíticos pequeños y medios. Superficies cubiertas por un engobe rojo oscuro. Dimensiones: diámetro borde: $80 \mathrm{~mm}$; diámetro máximo cuerpo: $85 \mathrm{~mm}$; altura conservada: $35 \mathrm{~mm}$; grosor medio sección pared: $4 \mathrm{~mm}$. Bibliografía: Menéndez y Sánchez, e.p.

2. CH.99/3589. Sector C-12. Fragmento de sector inferior de pared de posible imitación de la forma Drag. 29 de terra sigillata. Perfil curvo en lo conservado. Decoración impresa consistente en una secuencia de SSS que se desarrolla bajo 
una acanaladura. Debajo de este friso se sitúa una serie de arcos segmentados tangentes de los que penden círculos segmentados de los que cuelgan a su vez que líneas segmentadas rematadas en pequeños tetrapétalos. Pasta de tonalidad anaranjada en la que se observa la presencia de desgrasantes micáceos pequeños y cuarcíticos pequeños y medios. Ambas superficies se hallan cubiertas por un engobe rojo oscuro poco espeso. Dimensiones: $60 \times 65 \mathrm{~mm}$; grosor sección pared: $5.5 \mathrm{~mm}$. Bibliografía: Inédito.

\section{VAJILLA CON DECORACIÓN PINTADA}

(Figura 50)

Bajo esta denominación se aborda el estudio de un conjunto de recipientes cuyo nexo de unión radica en la disposición de secuencias decorativas pintadas aplicadas sobre superficies de tonalidades blanquecinas u ocráceas. Fuera de estas concomitancias, componen un conjunto morfológico heterogéneo para el que resulta problemática tanto su inserción en las series productivas regionales, entendidas éstas como las asociadas al ámbito lucense, como su adscripción cronológica.

Inicialmente, pueden plantearse para este tipo de producciones que, aunque no demasiado asiduamente, se documentan de forma ocasional en el yacimiento (Montes et alii, 2001: 31), sendas hipotéticas filiaciones: la meseteña de tipo cluniense o afín y la galaico-portuguesa (Abascal, 1986). Lo cierto es que la procedencia meseteña fue defendida en su día, no sin ciertas dudas, para un único fragmento de borde y cuello de una jarra (Benéitez et alii, 1999: 24-25, Fig. 4.10) (Figura 50.4). Los nuevos materiales que han ido desde entonces engrosando el aún parco elenco no han hecho sino apuntar en la dirección de un origen galaico-lusitano para estos productos o, al menos, para una parte considerable de los regis-

33 Se trataría de los ejemplos más orientales conocidos de esta producción. trados. No obstante, en algunos yacimientos occidentales se ha constado de manera inequívoca la presencia de piezas de génesis cluniense.

Cierta indefinición de las producciones de este amplio ámbito noroccidental peninsular, la supuesta multiplicidad de talleres con producciones semejantes (González, 1991: 28), la posible confusión con piezas exógenas y las escasas referencias bibliográficas, hacen dificultosa la individualización solvente de grupos de procedencia. De hecho, en un análisis preliminar del elenco que nos ocupa se detecta una relativa heterogeneidad que alcanza a las pastas en que fueron realizadas y sobre todo, a los esquemas y motivos decorativos.

A pesar de las dificultades aludidas, parece ir perfilándose una producción de amplia difusión regional en territorio lucense $y$, sobre todo, bracarense con manifestaciones, además de las aquí recogidas $^{33}$, tanto en yacimientos septentrionales como Lugo (Alcorta, 2001: 140-142, Fig. 60) o A Coruña (Vázquez y Doval, 1996: 102, I339), como en otros más meridionales como Vigo (López Cuevillas, 1958: 321; Hidalgo, 1989: 290, Fig. VII), Aquis Querquennis (González, 1991), Bracara Augusta (Alarcão, 1975: 107; Martins y Morais, 2009: 37-45), Monte Mozinho (Ferreira de Almeida, 1977: Est. VII.7 y XXI.5 y 6; Soeiro, 1984), Briteiros (Abascal, 1986: 133 y 395, Fig.118.634), Padrao (Alarcão, 1975: 107), Paço de Vila Cova (González, 1991: 23), Meixomil (Alarcão, 1975: 103) o incluso Conímbriga (Abascal, 1986: 133 y 395-396, Fig.118.635; Alarcão, 1975: 107, Pl. XV.11 y 12; Alarcão, 1976). Aunque no se pueda de modo fehaciente afirmar una comunidad genética entre todos ellos se observa una evidente confluencia de elementos comunes en el ámbito formal, técnico y, sobre todo, decorativo (Abascal, 1984: 183).

En el estado actual de conocimientos resulta problemática la inclusión de estas producciones en el seno de las fabricaciones regionales. $\mathrm{Ni}$ la composición de sus pastas, ni los acabados y téc- 
nicas decorativas responden al acervo tradicional que manifiestan el resto de tipos que se presentan. Son, más bien, las producciones bracarenses las que parecen constituir el referente general de la serie. Sin embargo, según se desprende de las intervenciones arqueológicas realizadas en Lugo, no resulta extraordinaria la presencia de producciones locales de carácter imitativo, si bien este extremo no queda del todo claro. La calificación de locales que realiza $\mathrm{E}$. Alcorta de las pastas de muchas de estas piezas, diferenciándolas de las meseteñas y de las bracarenses, así parece indicarlo (2001: 160). No obstante, la presencia de formas y motivos ornamentales semejantes entre las producciones meridionales requiere una explicación satisfactoria que tal vez pase por cierta permeabilidad entre talleres de ámbito comarcal cuyo encuadre cronológico y marco de difusión aún están por definir.

Las pautas dominantes en lo técnico reiteran las pastas blanquecinas, amarillento-blanquecinas o rosáceo-blanquecinas depuradas y con acabados pulidos superficiales que en ocasiones conservan ligeras aguadas de similares tonalidades.

Las decoraciones, que se sirven de pigmentos que se mueven en la gama de los ocres, rojizos o anaranjados, repiten de forma sistemática determinados motivos bien característicos que vienen a conformar el elemento esencial en la caracterización de esta familia cerámica:

- Triángulos reticulados a veces aislados y en ocasiones encadenados y unidos por los vértices. Aunque no se han registrado en el Chao Samartín, constituyen uno de los temas más frecuentes, conociéndose en Aquis Querquennis (González, 1991: Fig.1), Lucus Augusti (Ibidem: Fig.2.1; Alcorta, 2001: 140, Fig. 60.1 y 2), A Coruña (Vázquez, 1991: 102， I339; González, 1991: Fig. 3.8), Monte Mozinho (Ferreira de Almeida, 1977: Est.VII.7 y XXI.5 y 6), Briteiros (Cardozo, 1956: 46;
Fig.9, Lám.XV; Abascal, 1984: 184), Guifoes (Abascal, 1984: 183), Meixomil (Alarcão, 1975: 103), Padrao (Ibidem), Conimbriga (Ibidem: Pl. XV.11) y Bracara Augusta (Martins y Morais, 2009: $38-43, \mathrm{~N}^{\circ} 102,103$ y 111$)$.

- Triángulos rayados. Disponemos de referencias relativas a este tipo de motivos en un ejemplar de Briteiros (Abascal, 1986: Fig.118.634) al que cabe sumar otra pieza, procedente del Chao Samartín (Figuras 49 y 50.2).

- Haces de líneas paralelas unidas por un extremo y ocasionalmente rematadas por una línea simple vertical. Se conocen ejemplos, además de un par de ejemplares del Chao Samartín (Figuras 49 y 50.3), en Lugo (Alcorta, 2001: 140, Fig.60.3), Briteiros y Braga (Martins y Morais, 2009: $38-43, \mathrm{~N}^{\circ} 102,103$ y 122 ).

- Motivos vegetales esquemáticos tipo arborescente. Disponemos de ornamentos de esta clase en Lugo (Alcorta, 2001: 140, Fig.60.4), Aquis Querquennis (González, 1991: Fig.1), Bracara Augusta (Delgado y Morais, 2009: 40-45; $\mathrm{N}^{\circ}$ 107, 115, $120 \mathrm{y}$ 123) y en un par de piezas del Chao Samartín $^{34}$ (Figuras 48 y 50.1).

- Guirnaldas. Se conoce un ejemplo de este motivo ornamental en una pequeña jarra o recipiente similar que cuenta con un asa en cuya parte inferior, en el contacto con el cuerpo, se plasma el motivo, configurado por tres líneas unidas en su parte superior, recta la central y con los extremos enrollados hacia fuera las laterales (Figuras 48 y 50.1).

- Arquillos abiertos hacia la parte superior de factura descuidada a modo de ues minúsculas encadenadas en segmentos de varios centímetros de largo. Se cuenta con referencias de este tipo de peculiar ornato en una pieza de las presentadas (Figuras 48 y 50.1 ), a las que podría sumarse otra

34 Una de las piezas se trata de un pequeño fragmento de galbo dispone en una rara posición horizontal. 
de Briteiros (Abascal, 1986: 133 y 395, Fig.118.634), aunque las similitudes entre ambos motivos no resulten estrictas.

- Decoración de líneas simples que actúan de elementos ornamentales complementarios que sirven de delimitadores de metopas y separadores de frisos decorativos (a veces rellenando acanaladuras) u otros motivos. También se identifican pequeñas líneas paralelas ornando asas y bordes (Figura 50.2 y 4 ).

Estas decoraciones se plasman sobre morfologías de lo más diverso que rara vez se repiten en el repertorio disponible, aún manteniendo las pautas técnicas comunes. En el Chao Samartín se han identificado varias formas, que analizaremos a continuación.

\section{Vaso Ovoide Monoasado}

(Figuras 48 y 50.1)

Se trata de una pequeña pieza de perfil ovoide que pudiera corresponderse a una morfología tipo jarra o botella. Cuenta con una base de pie destacado y conserva el arranque de un asa. Los motivos decorativos, realizados con pintura de tonalidad rojiza, se concentran en la mitad superior de la pared, combinando la representación de guirnaldas, temas arborescentes y cadenas de ues (Hevia, 2009: 352-353). Un vaso de morfología similar que porta, igualmente decoración arborescente, se cuenta entre el repertorio de Lugo (Alcorta, 2001: 140-142, Fig.60.4).

\section{Vaso Biasado (Figuras 49 y 50.2)}

El modelo constituye una forma estandarizada a juzgar por su registro, con unas características extremadamente semejantes, en Lugo (Alcorta, 2001: 140, Fig.60.3) ${ }^{35}$, Monte Mozinho (González, 1991: Fig.3.3) y Braga (Delgado y Morais, 2009: $\left.38-39, \mathrm{n}^{\circ} 104\right)$. Consiste en una pequeña jarrita biasada de perfil bitroncocónico sinuoso que remata

35 Otros dos ejemplares, de dimensiones mayores, dibujan perfiles y esquemas ornamentales equiparables (Alcorta,

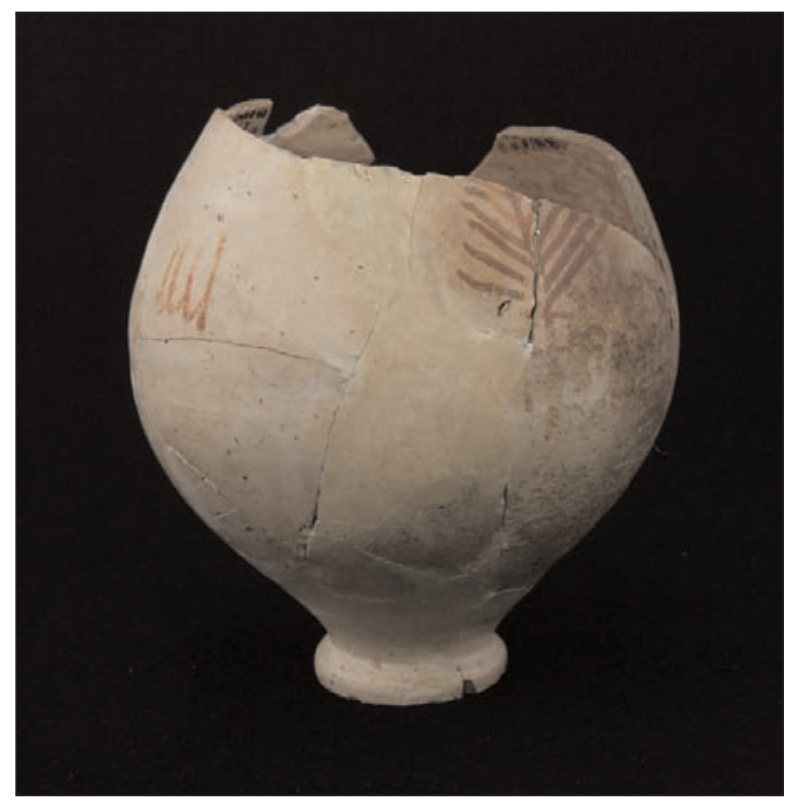

Figura 48. Jarra pintada. Foto: J. Arrojo

en un breve borde exvasado y moldurado y se eleva sobre una base plana con pie de disco, que no se conserva en el ejemplar que se presenta. Dos asas de cinta en $\mathrm{C}$, ornadas con líneas simples, arrancan bajo el borde y alcanzan la acanaladura que sirve de elemento de delimitación inferior a una banda decorada en la que se reconoce una sucesión de triángulos rayados unidos por sus vértices (Hevia, 2009: 368-369).

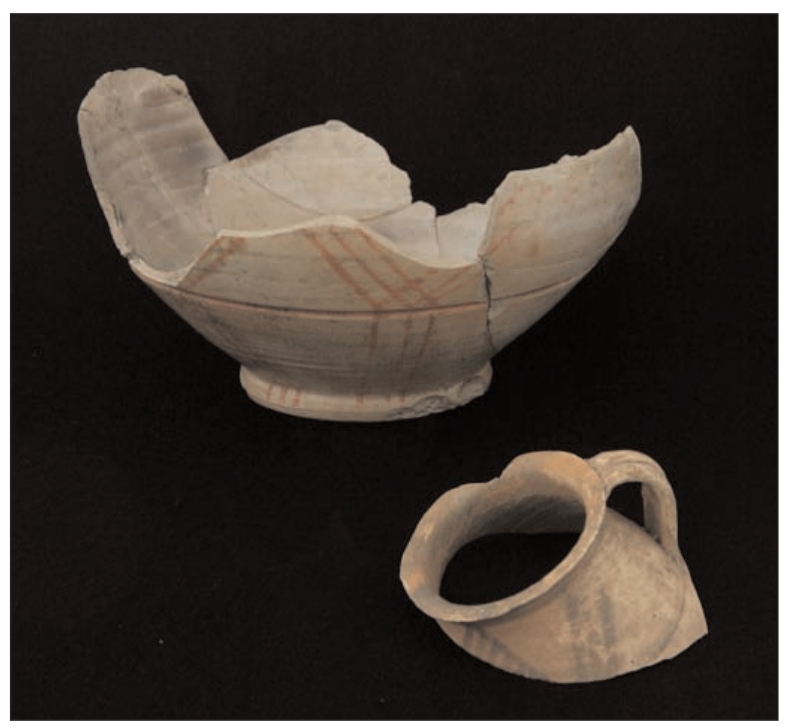

Figura 49. Cerámicas pintadas. Foto: J. Arrojo 


\section{Vaso Globular (Figuras 49 y 50.3)}

El ejemplar recuperado conserva tan sólo la base y la parte inferior del cuerpo, por lo que desconocemos su desarrollo morfológico completo. No obstante, presenta semejanzas evidentes respecto a un tipo referido en Aquis Querquennis (González, 1991: Fig. 1), que se presenta como un recipiente carenado monoasado cuyo perfil recuerda a los tazones monoasados con decoración bruñida o estampillada tan frecuentes en el repertorio regional. También se reconocen ciertas similitudes con algunas piezas del repertorio bracaraugustano (Delgado y Morais, 2009: 38-39; $\mathrm{n}^{\circ}$ 102-103). El ejemplar del Chao Samartín conserva la mitad inferior de una pared de perfil curvo que se asienta sobre una base con pie de disco acanalado cuyo fondo externo ostenta un grafito. Una acanaladura pin- tada divide en dos sectores la ornamentación, consistente hacia la base en líneas verticales mútiples que hacia el borde se bifurcan en diagonal cortándose. (Hevia, 2009: 368-369).

\section{JARRA O BOTELLA DE BORDE BISELADO}

(Figura 50.4)

El fragmento se corresponde con el borde y el cuello de una pieza que, atendiendo a sus características morfológicas, podría adscribirse a la forma 6, 7A o 7B de Abascal (Abascal, 1986, 6869), no pudiendo precisarse más, dado que desconocemos si estaba dotada o no de asas y no conservamos el cuerpo ni la base (Benéitez et alii, 1999: 24-25, Fig. 4.10). Cuenta con una sencilla decoración compuesta por combinación de líneas y círculos rellenos simples.
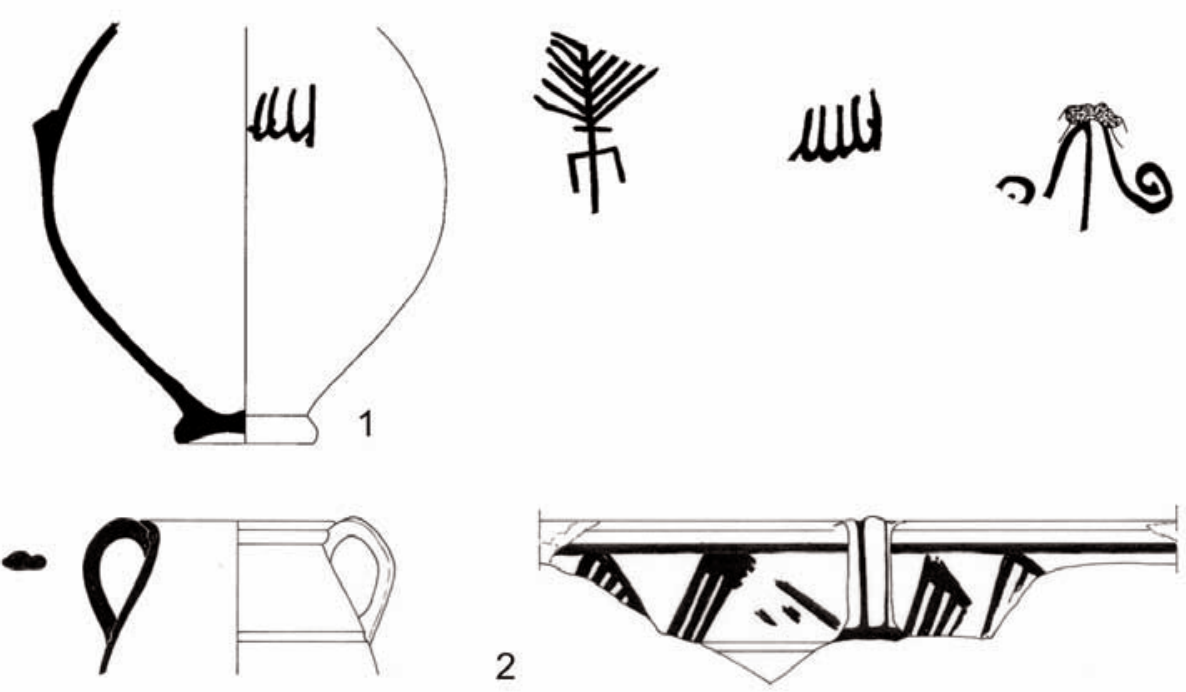

2
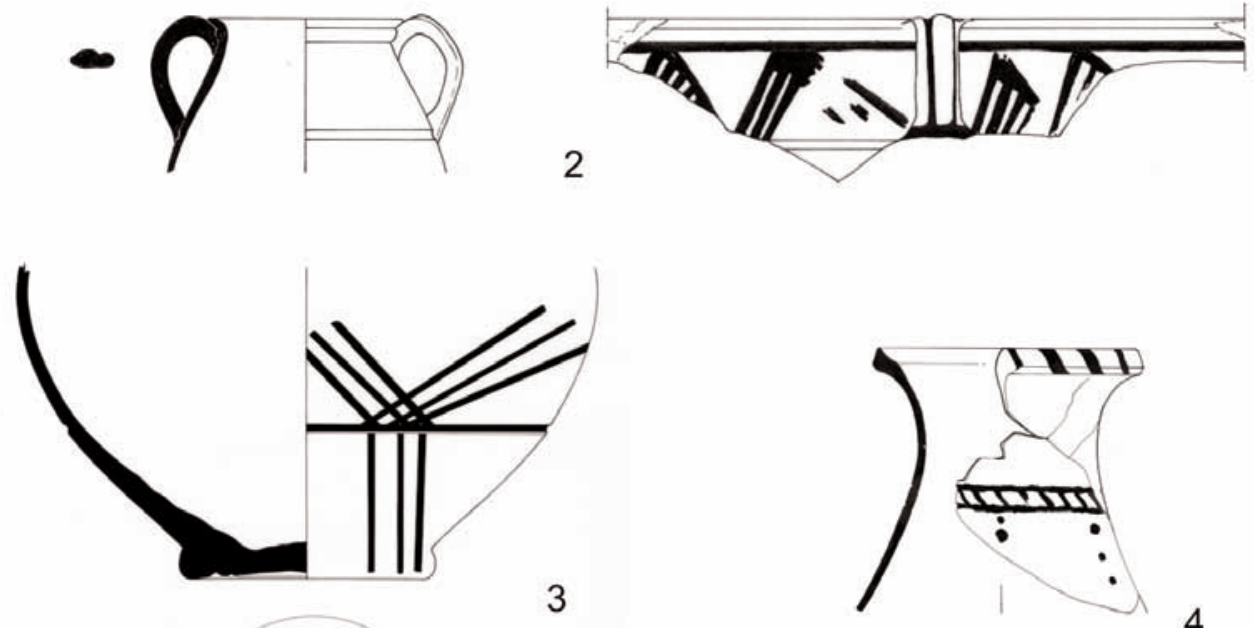

4

RII

Figura 50. Cerámica pintada. 


\section{CATÁl OGO}

1. CH.90/0001. Sector R-VII. Fragmento de cuerpo y base de jarra. Cuerpo de perfil ovoide que conserva el arranque de un asa en la zona central. Base realzada con pie de perfil redondeado y fondo interior umbilicado. Decoración pintada en tonalidad rojiza consistente en cuatro motivos: representación arborescente esquemática, dos cadenas de tres y cuatro estrechos arquillos abiertos hacia arriba (cadenas de ues) y tres trazos simples, dos de ellos rematados en espiral, que penden del asa a modo de guirnalda. Pasta depurada de tonalidad blanquecina. Superficies blanquecinas con ligera aguada externa. Dimensiones: diámetro máximo cuerpo: $121 \mathrm{~mm}$; diámetro base: $40 \mathrm{~mm}$; altura conservada: $128 \mathrm{~mm}$; grosor medio sección pared: $3.5 \mathrm{~mm}$. Bibliografía: Hevia, 2009: Ficha 352, 111-112.

2. CH.95/2964. Sector C-7. Fragmento de borde y cuerpo de jarrita. Borde corto, exvasado, oblicuo y curvo. Cuerpo de perfil curvo en lo conservado surcado por una moldura de sección redondeada en el extremo superior y por una ancha acanaladura más abajo. Conserva un asa de sección elipsoidal recorrida al exterior por sendas acanaladuras que arranca del borde para alcanzar la acanaladura. Decoración pintada en tonos rojizos consistente en una banda de triángulos rayados contenidos entre la moldura y la acanaladura referidas y en líneas simples verticales en la parte exterior del asa. Dimensiones: diámetro borde: $62 \mathrm{~mm}$; altura conservada: $48 \mathrm{~mm}$; grosor medio sección pared: 4 mm. Bibliografía: Hevia, 2009: Ficha 119, 370-371.

3. CH.95 /0978. Sector C-10 A. Fragmento de borde y cuello de jarra. Borde vertical de sección apuntada con bisel exterior y perfil cóncavo al interior. Cuello largo de perfil curvo. La superficie externa presenta decoración pintada realizada con pigmento de color marrón-rojizo distribuida de la siguiente forma: en el perímetro exterior del borde banda de líneas paralelas oblicuas; en el extremo inferior del cuello friso de $4 \mathrm{~mm}$ de ancho, delimitado por dos acanaladuras de trazo bastante irregular e igualmente pintadas, recorrido por líneas oblicuas, en este caso más estrechas; por debajo de este friso se sitúan líneas verticales de puntos. Pasta depurada de tonalidad blanquecina. La superficie externa se encuentra finamente alisada y es posible que la decoración se haya realizado sobre un engobe ocráceo previo. Dimensiones: diámetro borde: $80 \mathrm{~mm}$; altura conservada: $82 \mathrm{~mm}$; grosor medio sección pared: $4 \mathrm{~mm}$. Bibliografía: Benéitez et alii, 1999: 24-25, Fig. 4.10.

4. CH.01/0503. Sector C-12 B. Fragmento de cuerpo y base. Cuerpo de perfil curvo de tendencia globular en lo conservado surcado por una acanaladura en su tercio inferior. Base con pie bajo de sección redondeada recorrido en su fondo externo por sendas acanaladuras perimetrales. Fondo interno ligeramente umbilicado. Decoración pintada en tonos rojizos consistente, en el espacio comprendido entre la referida acanaladura y la base, en haces de tres líneas verticales que por encima del surco se bifurcan entrecruzando sus trayectorias oblicuas. La acanaladura se encuentra igualmente pigmentada. Pasta depurada de tonalidad blanquecina. Superficies blanquecinas, la externa con una ligera aguada. Dimensiones: diámetro máximo cuerpo: $178 \mathrm{~mm}$; diámetro base: $178 \mathrm{~mm}$; altura conservada: $96 \mathrm{~mm}$; grosor medio sección pared: 5 mm. Bibliografía: Hevia, 2009: Ficha 119, 370-371.

\section{Ollas de borde Aconcavado}

(Figuras 51 y 52)

El tipo se erige como uno de los más representativos de los ajuares originarios de contextos del siglo I d.C., no sólo a causa de su frecuente registro, sino también por constituir una de las formas más genuinas de estas fechas, tanto por su relativa homogeneidad como por su exclusividad, ya que resulta completamente desconocido en los repertorios posteriores. De hecho, la concepción formal, su tratamiento y ejecución coadyuvan a su 
inserción en el amplio y diversificado elenco de producciones regionales que durante la primera centuria se mantienen fieles a los modos de fabricación tradicionales.

Aún presentando cierta variabilidad en las soluciones concretas, los recipientes adscritos a esta tipología responden a un mismo diseño que se concreta en un contorno de pared globular habitualmente interrumpido por la proliferación de molduras y/o acanaladuras intercaladas y una característica embocadura que tras una marcada curvatura se resuelve mediante un borde exvasado y oblicuo ligeramente curvado y con suave concavidad interna. Ninguno de los ejemplares documentados conserva la base, que debió de ser plana, según se deduce de algún fragmento recuperado en los mismos contextos y que, aunque no se ha logrado asociar, responde a la misma caracterización técnica que estas piezas (Hevia, 2006; Hevia y Montes, 2009: Fig.3.8).

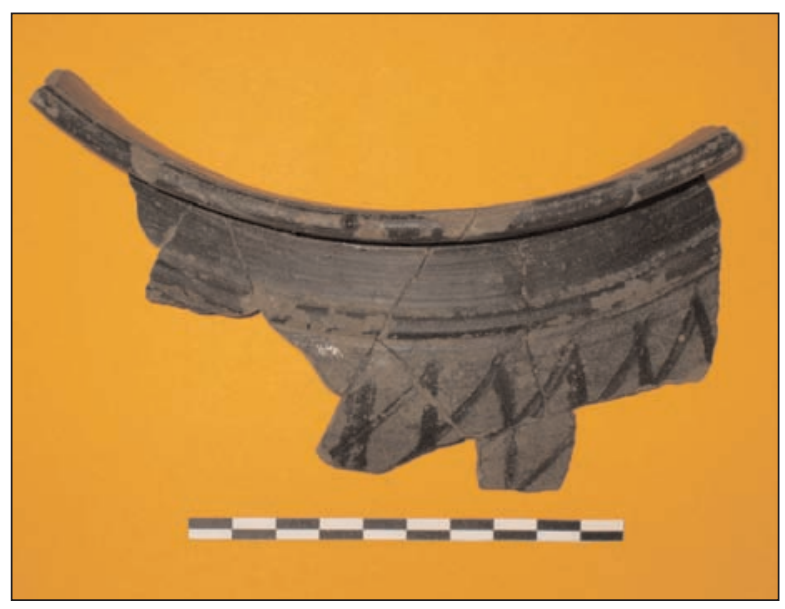

Figura 51. Olla de borde aconcavado. Foto: R. Montes

Dentro de esta concepción formal general se observa una notable diversidad que atañe a la mayor o menor concavidad de los bordes, al perfil de los labios, que pueden hallarse delimitados al interior mediante una acanaladura, y a la disposición, o incluso ausencia, de los referidos elementos articuladores de la pared.

36 Tipo L1, Ollas decoradas de perfil sinuoso y borde exvasado (Alcorta, 2001: 81-88). Las variantes B (Ibidem: fig.37) y C (Ibidem: fig.38)se fabricaron en módulos más semejantes a los de nuestros ejemplares.
La presencia de decoraciones en la mitad superior del galbo, sin ser la norma, no resulta extraordinaria. La articulación ornamental remite a la habitual en otras tipologías en las que las decoraciones se ciñen a las bandas y filetes que delimitan las molduras y acanaladuras que recorren la pieza. Por lo que se refiere a las técnicas y motivos plasmados, se conocen composiciones bruñidas reticuladas y alineaciones de puntos impresas. Ambas modalidades constituyen las fórmulas más características de esta etapa.

Las pastas en que fueron elaboradas, de tonalidad predominantemente grisácea y granulometría media, suelen reiterar las características compositivas propias de los tiempos, con inclusiones cuarzo-micáceas diversas. Un rasgo típico es el esmerado tratamiento exterior consistente en un fino bruñido, aplicado sobre el borde y la pared, que confiere a las piezas una distintiva estampa negra pulida brillante.

La funcionalidad de estos recipientes resulta difícil de fijar, si bien su cuidada elaboración y la ausencia de marcas de hollín descartan un uso en procesos culinarios en caliente. Su tamaño y la posibilidad de recibir una tapadera sugieren un empleo en labores de despensa o tal vez en el servicio de mesa.

En Lucus Augusti, sin que podemos hablar de una concordancia exacta, se cuenta con paralelos asimilables tanto en lo morfológico como en lo técnico en varias de las formas recogidas entre las producciones indígenas de la primera fase (siglo I d.C.). Alguna de ellas presenta contornos de galbo muy semejantes, con intercalación de molduras y frisos con decoración combinada, aunque con soluciones de borde diferentes. Es el caso de alguno de los ejemplares incluidos en los tipos L1 B, L1C ${ }^{36}$ y L2 $2^{37}$. Mayor similitud formal ofrece uno de los recipientes que se incluyen bajo la denominación de Ollas globulares de borde aconcavado -tipo L9- (Alcorta, 2001, 107-108, Fig. 48), datadas genéricamente en los lustros centrales de la primera centuria.

37 Ollas globulares decoradas, con borde exvasado (Ibidem: 89-92, fig. 39-40) 


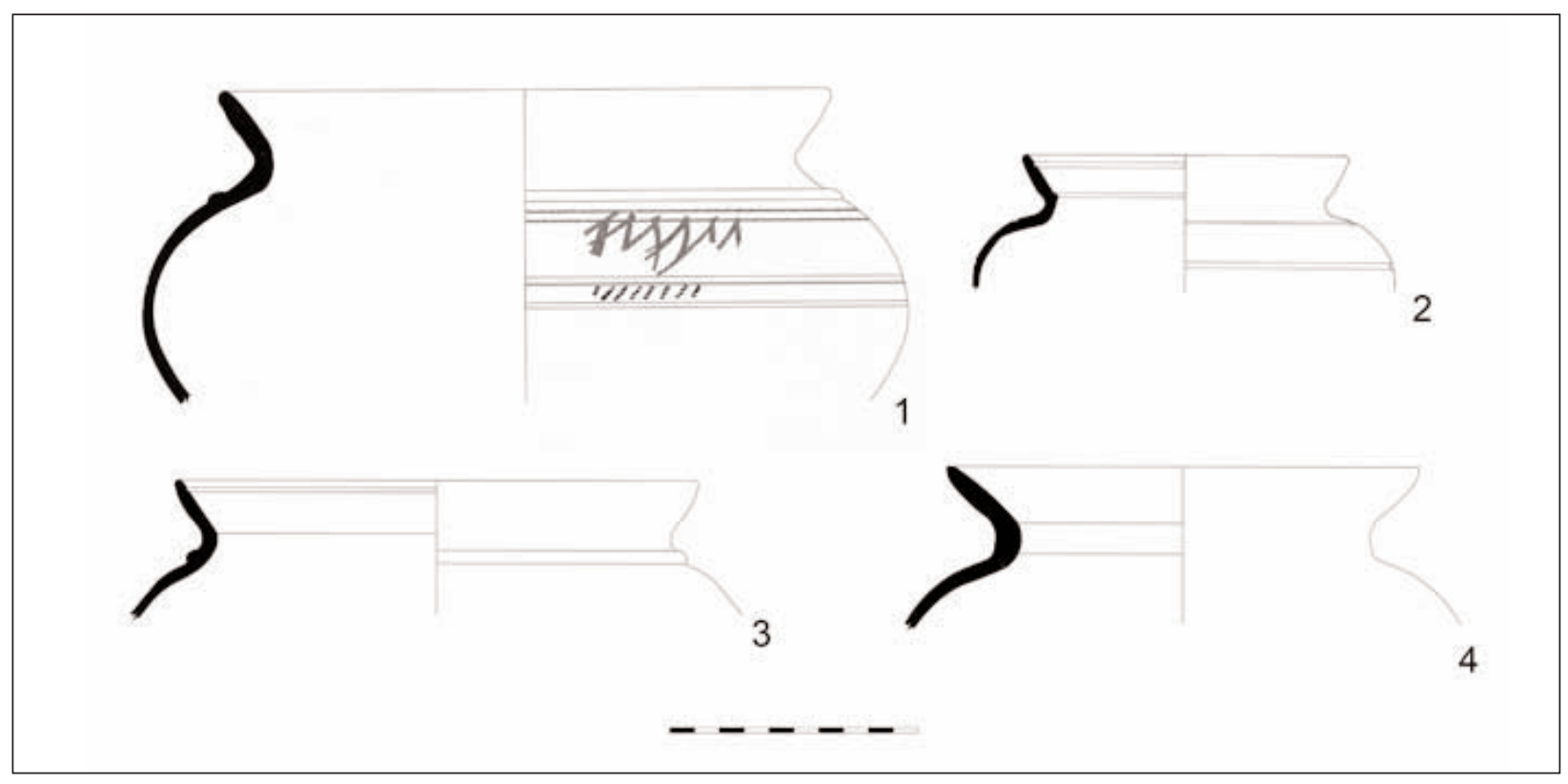

Figura 52. Ollas de borde aconcavado.

\section{CATÁl OGO}

1. CH.02/1777. Sector N-1. Fragmento de borde y cuerpo. Borde exvasado, oblicuo y de perfil curvo ligeramente cóncavo al interior con labio de sección redondeada diferenciado tanto al interior como al exterior por sendas acanaladuras. Cuerpo de perfil curvo cerrado de tendencia globular en lo conservado. Pared recorrida por una moldura de sección redondeada y una acanaladura. Entre ambos elementos se dispone un friso decorado de $38 \mathrm{~mm}$ de ancho en el que se inserta una composición de retícula romboidal bruñida de trama ancha y disposición oblicua. Bajo la acanaladura, banda impresa de alineaciones de puntos oblicuos hacia la derecha. Pasta grisácea con desgrasantes micáceos pequeños y muy pequeños y cuarcíticos pequeños y medios. Superficies de tonalidad negruzca con acabado bruñido fino que afecta al borde y la parte superior del cuerpo. Al interior, bajo la banda bruñida superior, se aprecian las estrías del torneado. Dimensiones: diámetro borde: $250 \mathrm{~mm}$; altura conservada: $83 \mathrm{~mm}$; grosor sección pared: $6 \mathrm{~mm}$. Bibliografía: Hevia, 2006; Hevia y Montes, 2009: Fig.3.8.

2. CH.93/1203. Sector R-V. Fragmento de borde y cuerpo. Borde exvasado, curvo y oblicuo con labio de perfil redondeado remarcado al interior mediante una tenue acanaladura. Cuerpo de tendencia marcadamente globular en lo conservado, surcado por sendas acanaladuras en el hombro. Pasta depurada con desgrasantes micáceos muy pequeños y esporádicas cuarcitas medianas. Superficies negras, la externa, el borde y la parte superior de la interna con un acabado bruñido. Dimensiones: diámetro borde: $130 \mathrm{~mm}$; altura conservada: 52 $\mathrm{mm}$; grosor sección pared: $4 \mathrm{~mm}$. Bibliografía: Inédito.

3. CH.02/2234. Sector N-1. Fragmento de borde y cuerpo. Borde exvasado, oblicuo y de perfil curvo ligeramente cóncavo al interior con labio de sección redondeada diferenciado al interior por una acanaladura. Cuerpo de perfil curvo de tendencia globular en lo conservado recorrido en su extremo superior externo por una moldura de sección redondeada. Pasta de tonalidad grisácea con desgrasantes pequeños y medios micáceos, cuarcíticos y alguno esquistoso. Superficies de color negro sometidas a un acabado bruñido. Dimensiones: diámetro borde: $211 \mathrm{~mm}$; altura conservada: $52 \mathrm{~mm}$; grosor sección pared: 5.5 mm. Bibliografía: Hevia, 2006. 
4. CH.02/1561. Sector N-1. Fragmento de borde y cuerpo. Borde exvasado, oblicuo y de perfil curvo ligeramente cóncavo al interior con labio de sección redondeada diferenciado al interior por una tenue acanaladura. Cuerpo de perfil curvo cerrado de tendencia globular en lo conservado. Pasta grisácea con desgrasantes micáceos pequeños y muy pequeños y cuarcíticos pequeños y medios. Superficies de tonalidad negruzca con acabado bruñido que afecta al borde, la cara externa y la parte superior de la interna. Al interior, bajo la banda bruñida superior, se aprecian las estrías del torneado. Dimensiones: diámetro borde: $190 \mathrm{~mm}$; altura conservada: 61 $\mathrm{mm}$; grosor sección pared: $6 \mathrm{~mm}$. Bibliografía: Hevia, 2006

\section{Ollas de borde Vertical}

(Figuras 53 y 54)

Estas ollas se emparentan con el tipo anterior en cuanto a desarrollo morfológico general, presencia de molduras y acanaladuras en la cara externa, tratamiento específico de las superficies, caracterización de pastas, funcionalidad y cronologías de fabricación. Ambas formas constituyen las fórmulas tipológicas más finas entre las producciones regionales bruñidas negras, de neta raigambre indígena, plenamente vigentes en el siglo I d.C. y que dejarán de documentarse en contextos posteriores.
Se trata de recipientes con cuerpos de perfil globular rematados en un identificativo borde de perfil curvo y labio apuntado o redondeado que mantiene una trayectoria vertical o ligeramente exvasada, desarrollándose casi sin solución de continuidad respecto al galbo (Hevia, 2006).

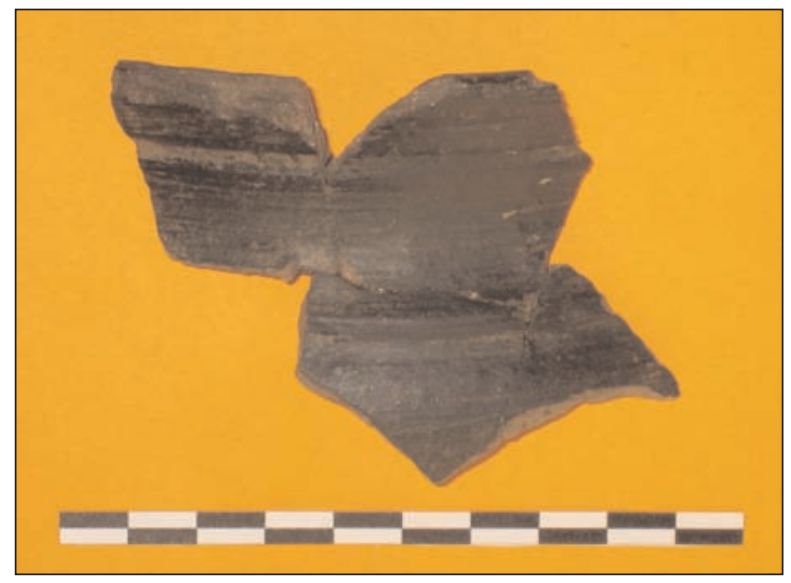

Figura 53. Olla de borde vertical. Foto: R. Montes

Las concordancias más significativas remiten al repertorio de cerámica indígena del siglo I d.C. de Lucus Augusti, hallándose paralelos morfológicos bastante próximos entre las piezas clasificadas como Vasos decorados de perfil sinuoso y borde acampanado -tipo L13- (Alcorta, 2001: 113-115, Fig. 50). Con un perfil de borde similar, estos vasos, siempre con aperturas de borde inferiores a los $120 \mathrm{~mm}$, presentan una banda decorada en el tramo medio de la pared, ornamentación que no puede descartarse en alguna de las vasijas del Chao Samartín, dado el escaso desarrollo que conservan.

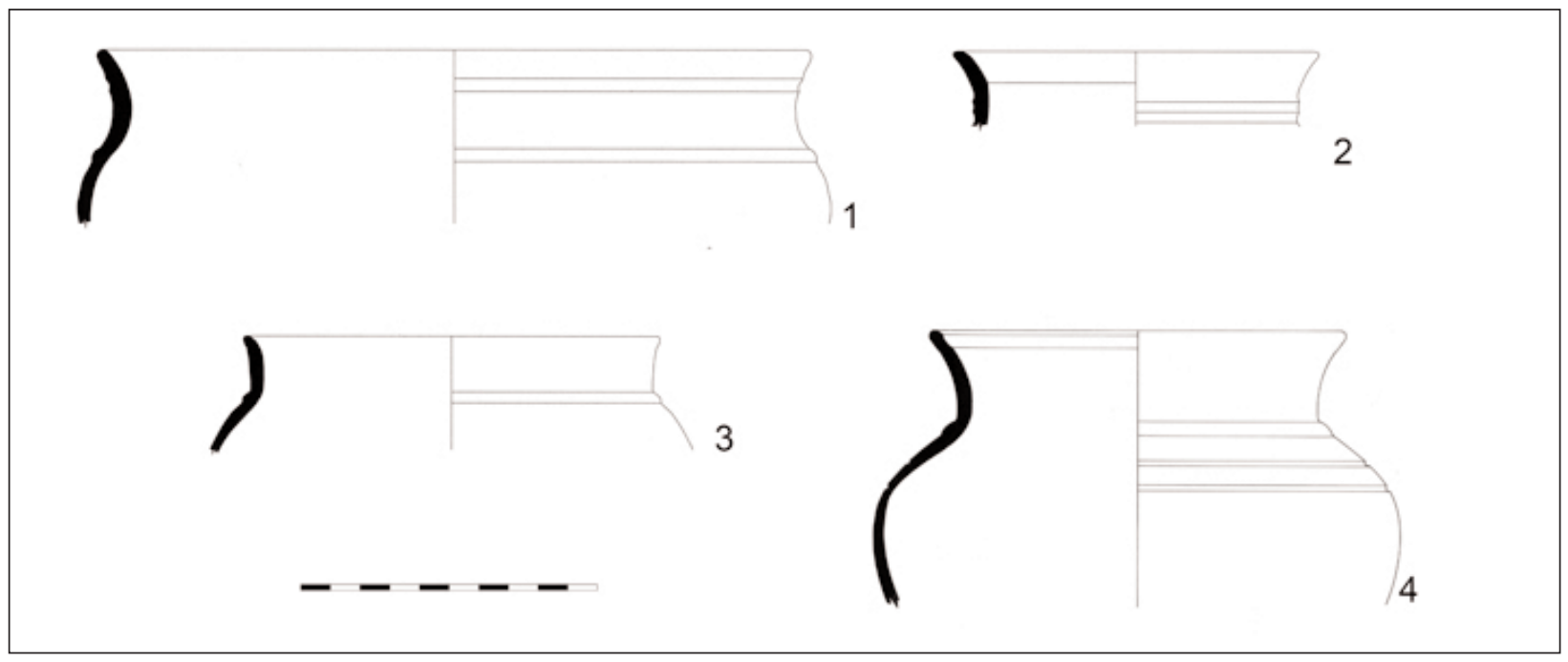

Figura 54. Ollas de borde vertical 


\section{CATÁl OGO}

1. CH.02/2272. Sector N-1. Fragmento de borde y cuerpo. Borde curvo ligeramente exvasado, casi vertical, con labio de perfil redondeado. Al exterior está recorrido por una ancha y poco profunda acanaladura. Cuerpo de tendencia globular en lo conservado surcado por una moldura de sección redondeada en el extremo superior. Pasta de tonalidad grisácea con desgrasantes micáceos pequeños y cuarcíticos de variadas dimensiones, alguno grande. Superficies de color negro con acabado bruñido en borde y superficie externa, mientras que en la interna se aprecian las huellas del torneado. Dimensiones: diámetro borde: $240 \mathrm{~mm}$; altura conservada: $58 \mathrm{~mm}$; diámetro máximo cuerpo: 253 $\mathrm{mm}$; grosor sección pared: $4 \mathrm{~mm}$. Bibliografía: Hevia, 2006.

2. CH.02/2650. Sector N-1. Fragmento de borde y cuerpo. Borde exvasado casi vertical, oblicuo y curvo con labio de perfil redondeado. Cuerpo recorrido por varias acanaladuras al exterior. Pasta grisácea con desgrasantes micáceos pequeños y muy pequeños y cuarcíticos pequeños. Superficies bruñidas de tonalidad negra. Dimensiones: diámetro borde: $123 \mathrm{~mm}$; altura conservada: $25 \mathrm{~mm}$; grosor sección: 3/5.5 mm. Bibliografía: Hevia, 2006.

3. CH.02/2331. Sector N-1. Fragmento de borde y cuerpo. Borde vertical y curvo con labio de perfil redondeado ligeramente engrosado al exterior. Cuerpo de tendencia globular en lo conservado recorrido en su extremo superior por una doble acanaladura y una moldura intermedia baja de sección redondeada. Pasta grisácea con desgrasantes micáceos pequeños y muy pequeños y cuarcíticos finos. Superficies de tonalidad negra con acabado bruñido en borde y cara externa. Al interior resultan visibles las estrías del torno. Dimensiones: diámetro borde: 168 $\mathrm{mm}$; altura conservada: $38 \mathrm{~mm}$; grosor sección: $3.5 \mathrm{~mm}$. Bibliografía: Hevia, 2006.
4. CH.98/0451. Sector R-V. Fragmento de borde y cuerpo. Borde curvo ligeramente exvasado, casi vertical, con labio de perfil redondeado remarcado por una ancha acanaladura al interior. Cuerpo de tendencia globular en lo conservado que cuenta con una moldura en su extremo superior y con, al menos, dos acanaladuras. Pasta micácea fina de tonalidad grisácea en el núcleo y negra en las superficies. Superficies negras. El borde y la superficie externa presentan un acabado bruñido. Huellas de carbonización en la cara externa. Dimensiones: diámetro borde: $140 \mathrm{~mm}$; diámetro máximo cuerpo: $176 \mathrm{~mm}$; altura conservada: $93 \mathrm{~mm}$; grosor sección pared: $4 \mathrm{~mm}$. Bibliografía: Inédita.

\section{Olla Carenada de borde}

\section{HORIZONTAL (Figuras 55 y 56)}

El único ejemplar documentado de este tipo dispone de una compleja articulación morfológica. Presenta un borde exvasado horizontal que remata en un breve labio vertical de perfil redondeado, que se desplaza ligeramente hacia el interior respecto al plano del borde, de modo que, al exterior, el enlace entre elementos ofrece un contorno moldurado. El tramo superior de la pared se desarrolla con una trayectoria de tendencia vertical a la que introduce sinuosidad una ligera concavidad exterior del perfil, delimitada en su extremo superior por una moldura de perfil subtriangular y en el inferior por una doble moldura y una acanaladura. Aunque no se conserva el tramo inferior del cuerpo se observa un notable cambio de plano en la trayectoria a partir de la marcada carena, cuyo inicio coincide con la posición de la referida acanaladura.

La pieza ha sido fabricada con una pasta de tonalidad gris esquistosa en la que se observan inclusiones micáceas pequeñas y presencia, en menor proporción de cuarzos, alguno de tamaño grande. Ambas superficies han recibido un acabado bruñido, aplicado con cierto descuido, que confiere a las superficies un acabado negro brillante (Hevia, 2006). 


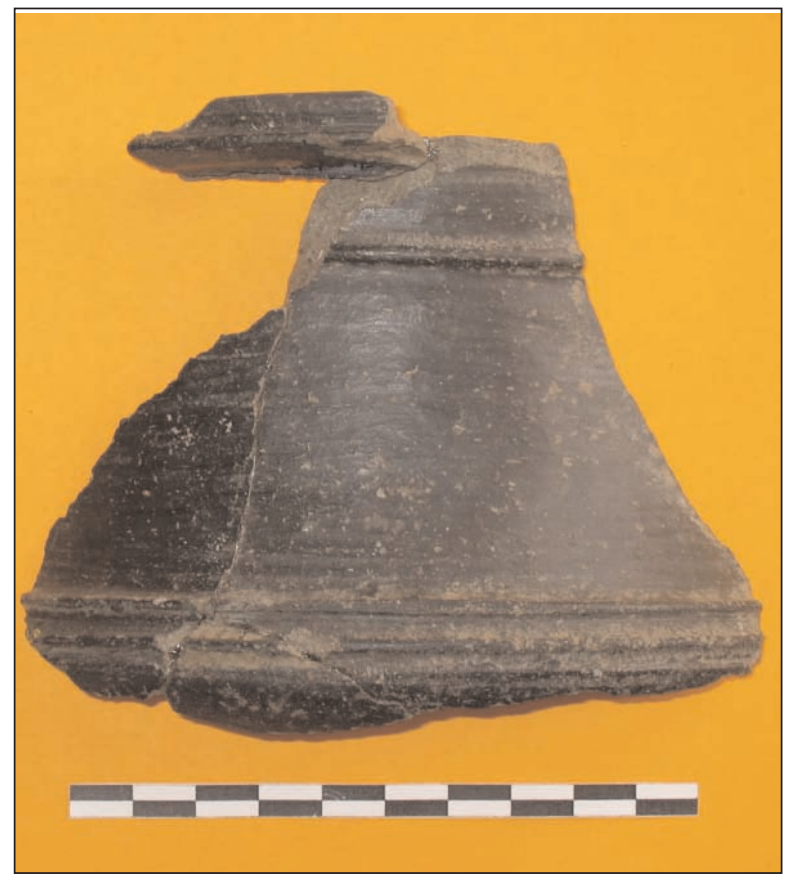

Figura 55. Olla de borde horizontal. Foto: R. Montes

La morfología de la pieza, la calidad de su factura y la ausencia de evidencias de exposición al fuego, apuntan una funcionalidad asociada a labores de despensa, como contenedor de pequeñas cantidades, empleo favorecido por la adaptabilidad del borde a la recepción de una tapadera.

No se han podido localizar similitudes ajustadas para esta pieza. Sin duda el tipo no responde a una seriación productiva consolidada según demuestra su escasa representación y la ausencia de paralelos. La compartimentación de la superfi- cie externa del galbo mediante acanaladuras y molduras se inscribe, al igual que el gusto por los acabados bruñidos negros, en la misma tradición alfarera regional que en estas tempranas fases de romanización continúa fabricando de acuerdo a su herencia tecnológica, aún sin influenciar, plasmada en soluciones formales muy diversificadas y heterogéneas, a la que también se adhieren de un buen número de los tipos regionales documentados en estas fechas tempranas (Hevia, 2006).

\section{CATÁlogo}

1. CH.02/0783. Sector N-1/ M-III. Fragmento de borde y cuerpo. Borde exvasado, recto y horizontal con labio vertical de perfil redondeado surcado al exterior por una ancha acanaladura. Cuerpo de trayectoria vertical con perfil exterior ligeramente cóncavo y carena media-baja reforzada al exterior por dos acanaladuras y dos molduras de perfil subtriangular. En el tercio superior cuenta con otra moldura similar. Pasta de tonalidad gris oscura con desgrasantes micáceos y cuarzos de variadas dimensiones, alguno grande. Superficies negras bruñidas. Dimensiones: diámetro borde: 156 mm; diámetro máximo cuerpo: $173 \mathrm{~mm}$; altura conservada: $93 \mathrm{~mm}$; grosor sección: 4 mm. Bibliografía: Hevia, 2006.

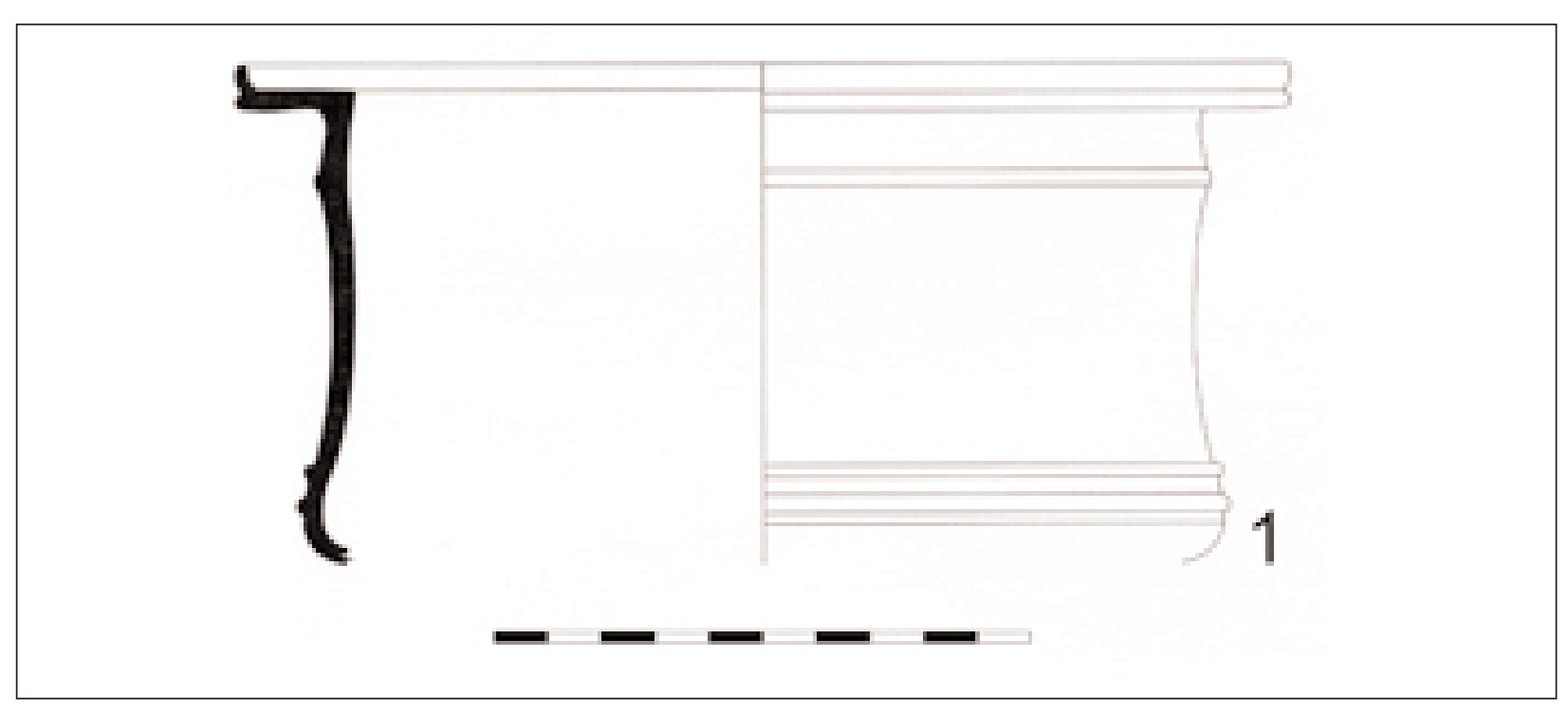

Figura 56. Olla de borde horizontal 


\section{Ollas engobadas CON DECoración ESTAMPILLADA (Figuras 57 y 58)}

Esta familia cerámica, bien documentada, como analizaremos más adelante, en los depósitos del siglo II d.C. (Figura 122), presenta en estas cronologías tempranas sus primeras manifestaciones. La inclusión bajo el epígrafe común de vajilla con decoración estampillada que se ha mantenido en diversas publicaciones relativas a repertorios del Chao Samartín (Benéitez et alii, 1999: 30-33, Fig. 6 y 7; Montes et alii, 2001: 34 y Menéndez y Benéitez, 2002: 292) esconde en realidad una compleja y heteróclita categoría a la que se incorporan morfotipos de lo más diverso con la característica común de encontrarse ornados mediante esta técnica y presentar ocasionales recubrimientos parciales de engobe rojo. En efecto, el avance de las investigaciones y la incorporación de sucesivos hallazgos han permitido verificar que los motivos estampillados, si bien se asocian preferentemente a perfiles sinuosos cerrados, no son exclusivos de éstos (Hevia, 2006).

Sin embargo, en el seno de este heterogéneo grupo se perfila en el siglo I d.C. una serie que, aún sin constituir una tipología en sentido estricto, sí que goza de cierta coherencia interna. Perfiles globulares acusados de tipo tradicional, bordes resueltos en dos planos, proliferación de molduras y acanaladuras que articulan la superficie externa, bases planas con anillo perimetral, pastas finas cuarzo-micáceas de tonalidades ocres o anaranjadas, acabados esmerados y aplicación en toda o parte de la superficie interna de engobe rojo, constituyen rasgos que deben añadirse a la cuestión ornamental a la hora de dotar al grupo de elementos de cohesión (Hevia y Montes, 2009: Fig.3.9; Hevia, 2009: 360-361).

Las decoraciones suelen consistir, como resulta norma habitual en toda la serie, en arquerías segmentadas estampadas de las que penden elementos circulares. Ocasionalmente,

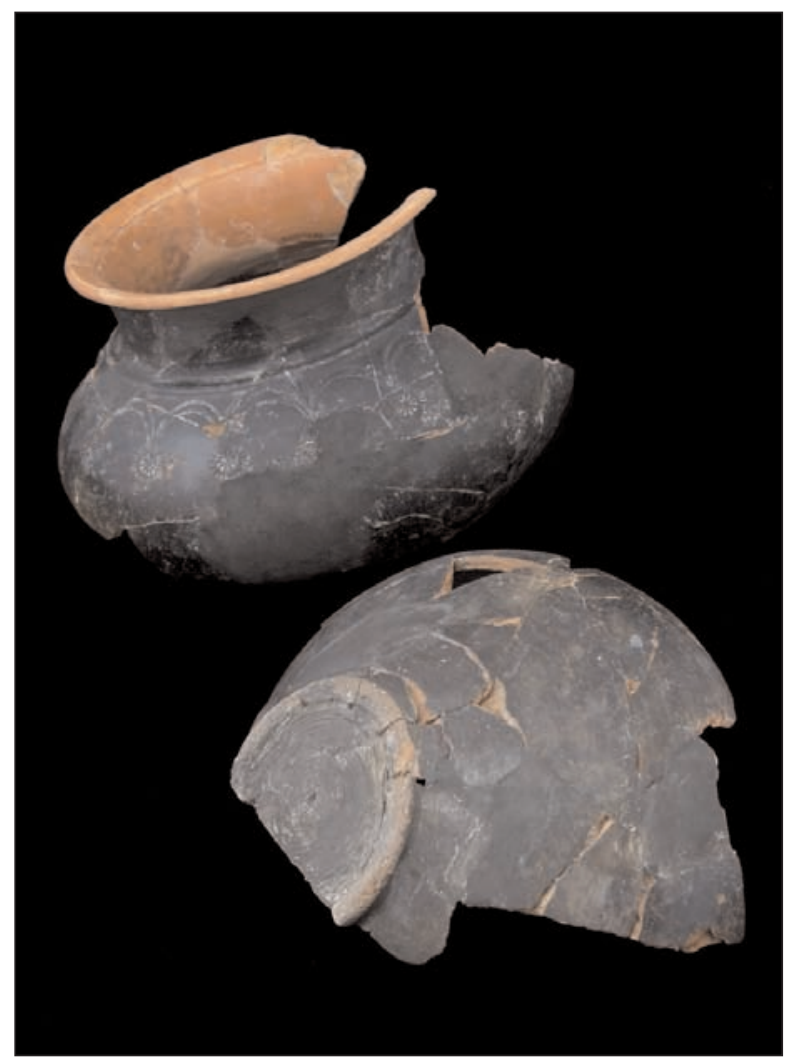

Figura 57. Olla con decoración estampillada. Foto: Á. Villa Valdés

estos temas principales se complementan con otros motivos como frisos de SSS de aire arcaico. En uno de los casos, los frecuentes arcos puntillados se convierten en lineales, mientras que los círculos son sustituidos por motivos angulares. Se trata de una pieza que además de esta singularidad ornamental presenta otras peculiaridades de índole morfológica, como la singular embocadura o la presencia de un pie elevado $^{38}$, que sugieren una posible mayor antigüedad (Figura 58.2).

De alguna forma, este grupo de producciones engobadas con decoración estampada temprana se podría vincular al tipo que en el siglo II d.C. se presenta como la tipología seriada que con mayor nitidez se manifiesta: las denominadas ollas engobadas. Resulta verosímil que nos hallemos ante los dubitativos precedentes que se encuentran en el origen de esta tipología (Benéitez et alii, 1999: 30-33, Fig. 6).

38 Villa y Montes, 2009: 164-165. 

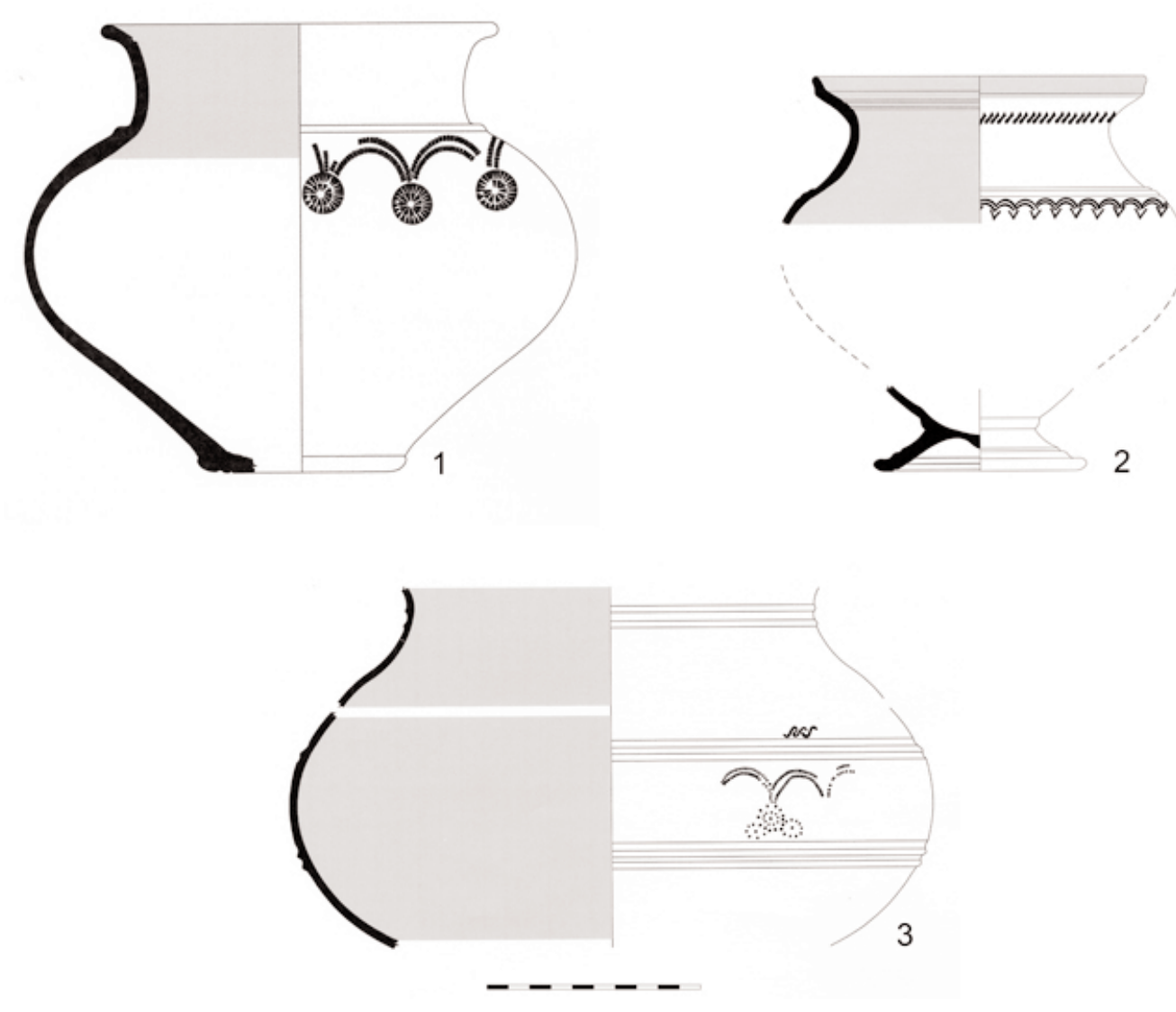

Figura 58. Ollas engobadas con decoración estampillada

\section{CATÁlogo}

1. CH.99/3086. Sector C-12 B. Fragmento de borde, cuerpo y base. Borde exvasado, oblicuo y curvo con acanaladura interior y labio de perfil redondeado. Cuerpo de acentuado perfil sinuoso definido por un breve cuello vertical curvo y una pared globular. En el hombro se sitúa una moldura de sección redondeada. Base anular plana surcada por una doble acanaladura perimetral en el fondo externo. Decoración estampillada que se desarrolla bajo la moldura del hombro consistente en dobles arcos segmentados tangentes de los que penden círculos radiales, también dobles. La superficie externa recibió un esmerado tratamiento, mientras que sobre el labio y el interior de borde y cuello se aplicó un engobe rojizo. Pasta grisácea con desgrasantes micáceos y cuarcíticos pequeños y medianos. Superficies grises, la externa bruñida. Dimensiones: diámetro borde: $130 \mathrm{~mm}$; altura estimada: 145 $\mathrm{mm}$; diámetro máximo cuerpo: $180 \mathrm{~mm}$; diámetro base: $63 \mathrm{~mm}$; grosor medio sección pared: $5 \mathrm{~mm}$. Bibliografía: Hevia, 2006; Hevia, 2009: Ficha 115, 360-361; Hevia y Montes, Fig.3.9.

2. CH.00 /1420. Sector Foso C. Fragmento de borde, cuerpo y base. Borde exvasado, oblicuo y curvo con bisel exterior y perfil levemente cóncavo al interior con labio de perfil redondeado diferenciado al interior por una pequeña moldura. Dos acanaladuras recorren el tránsito entre el borde y el cuerpo al interior. Pared de perfil sinuoso con dos acanaladuras en el extremo superior y una moldura de sección redondeada más abajo. Base con pie alto oblicuo muy desarrollado recorrido al exterior por una acanaladura. Decoración consistente en un friso de impresiones lineales oblicuas 
en el cuello y una banda entre acanaladuras de arcos estampillados triples continuos unidos por sus bases, de las que penden motivos angulares sencillos. Pasta de tonalidad ocre anaranjada con desgrasantes micáceos menudos y abundantes cuarzos de todas las dimensiones. Superficie externa bruñida de tonalidad ocre grisácea e interna anaranjada recubierta, al igual que el borde, de un engobe rojo del que sólo se conserva una parte. Dimensiones: diámetro borde: $164 \mathrm{~mm}$; diámetro base: $100 \mathrm{~mm}$; altura estimada: $210 \mathrm{~mm}$; grosor medio sección pared: $5 \mathrm{~mm}$; Bibliografía: Inédita.

3. CH.02/2609. Sector N-1/Foso E. Fragmento de cuerpo. Cuerpo de perfil globular acusado recorrido al exterior por sendas molduras en su extremo superior y dos pares de acanaladuras más abajo, que configuran un friso decorado de $38 \mathrm{~mm}$ de ancho en el que se disponen arquillos de medio punto dobles estampillados puntillados de los que penden motivos circulares concéntricos dobles también puntillados. La decoración se complementa con una banda de SSS estampillados que se ubica sobre las acanaladuras superiores. Pasta de tonalidad anaranjada con desgrasantes micáceos pequeños y muy pequeños y cuarcíticos pequeños y medianos. Superficie externa con zonas negras y otras pardo anaranjadas e interna anaranjada. Engobe rojo en la parte superior de la cara interna bruñido en el resto. Superficies muy erosionadas con el bruñido exterior y el engobe interno muy perdidos. La decoración apenas resulta perceptible debido al mal estado de conservación. Dimensiones: diámetro máximo cuerpo: $296 \mathrm{~mm}$; altura conservada: $164 \mathrm{~mm}$; grosor medio sección pared: 4 mm. Bibliografía: Hevia, 2006.

\section{Cazuelas bajas de fondo plano}

(Figuras 59 y 60)

Resulta necesario abordar una reflexión preliminar en torno a la terminología aplicada al tipo que nos ocupa que contribuya a no generar confusiones y que equipare las piezas presentadas procedentes del Chao Samartín con las de otros elencos recopiladas bajo diversas denominaciones. El referente formal genérico es sobradamente conocido entre los repertorios de cerámica común romana, habiendo sido recogido por $\mathrm{M}$. Vegas (1973: 43: Fig.15.4) en su tipo 14 A bajo la denominación de platos de borde escalonado. Idéntica terminología u otras similares en las que se mantiene la referencia plato acompañada por una indicación de la especificidad de su borde, característica que le da carta de naturaleza frente a otras formas de platos, se ha consolidado en la bibliografía alusiva. Entre los innumerables ejemplos en este sentido podemos citar el caso de Lucus Augusti donde, para elencos morfológica y genéticamente afines a los del Chao Samartín, se ha optado por mantener el término de platos de borde escalonado o aplicar el de platos de borde ranurado (Alcorta, 1995: 212, Fig.8.2), que parece ser el que finalmente se ha impuesto (Alcorta, 2001: 124-125, Fig. 55.1-3).

En nuestro caso, se ha preferido renunciar, a pesar de su éxito en la bibliografía, a denominaciones que incluyan el término plato, cuya asociación a recipientes del servicio de mesa resulta inevitable. De este modo, se ha optado por su definición como cazuelas $^{39}$, habida cuenta del innegable empleo preferente de estos recipientes en procesos culinarios en caliente, a juzgar por las omnipresentes huellas de exposición al fuego de sus superficies ${ }^{40}$. En anteriores publicaciones (Hevia et alii, 2001; Montes et alii, 2001; Hevia, 2009: 454-455), se optó por la acotación semántica del término mediante la referencia al carácter plano de las bases, tratando de destacar uno de los

39 En la misma línea se postula S. Carretero, quién en su estudio sobre la cerámica de los campamentos de Petavonium, se refiere a una pieza afín como cazuela, aún reconociendo su relación morfológica con los platos de borde escalonado (Carretero, 2000: 671).

40 Aunque su adscripción funcional a la vajilla de cocina resulta obvia, no es descartable un empleo eventual como platos en el servicio de mesa. 
rasgos morfológicos fundamentales del tipo y evitar confusiones con las cazuelas habituales en los estudios de cerámica romana, en los que el término se aplica tradicionalmente a recipientes profundos de base cóncava del tipo caccabus (Aguarod, 1995: 135, Fig. 5.8; Escrivà, 1995: 182, Fig. 18). La posterior identificación en los repertorios del yacimiento de una nueva fórmulación morfológica que comparte con ésta perfil de borde y base plana, ha aconsejado una modificación en las denominaciones, manteniendo la mención al carácter de la base, pero introduciendo una referencia a la altura de las paredes, elemento distintivo entre ambos tipos.

$\mathrm{Al}$ margen de la presencia de esta base plana, la morfología queda definida por el borde exvasado y de perfil curvo que describe al interior una concavidad más o menos acusada ${ }^{41}$ que le confiere la posibilidad de recibir una tapadera ${ }^{42}$. En los cuerpos, por su lado, se identifican variaciones de curvatura, oblicuidad y altura, aunque lo más habitual son las paredes cortas de perfil curvo y ligeramente oblicuas que generan recipientes poco profundos, con un cociente aproximado en torno a 4.25-4.50 entre el diámetro de la boca y la altura total de la pieza. (Hevia, 2009: 454-455).

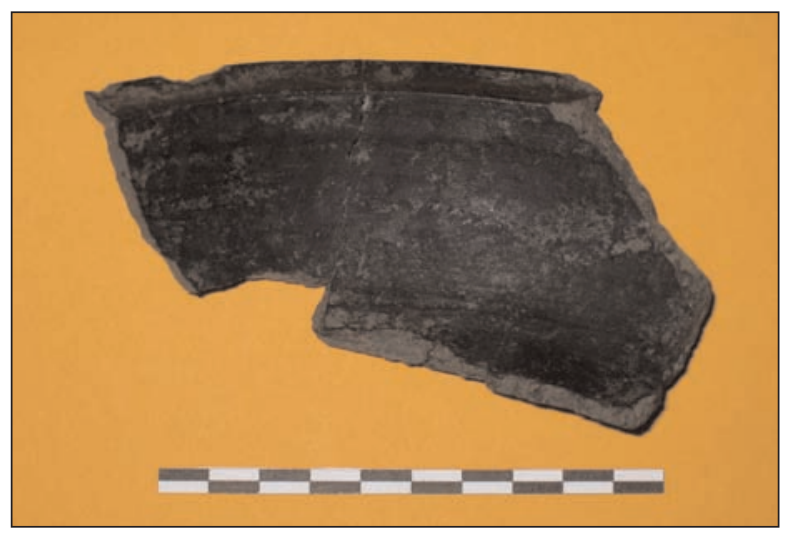

Figura 59. Cazuela baja de fondo plano. Foto: R. Montes

41 En realidad, se observan bordes bastante diferentes que varían desde perfiles netamente curvos a otros angulosos que justificarían la referida denominación de escalonados.

42 De hecho, como detallaremos más adelante, el tipo de tapaderas que prácticamente monopoliza los repertorios de fechas avanzadas parece relacionarse fundamentalmente, a juzgar por sus características técnicas y de tamaño, con estas cazuelas (Hevia, 2009: 454-455).

43 Es el caso de los ejemplos emeritenses (Alvarado y Molano, 1995: 291, Fig.12) o los béticos (Serrano, 1978: 246-247), versiones regionales del referente itálico.
Las aperturas de borde se sitúan entre los 175 y los $215 \mathrm{~mm}$, con bases entre los 120 y los 175 $\mathrm{mm}$ y alturas que fluctúan entre los 40 y los 60 $\mathrm{mm}$. Se trata de dimensiones no demasiado lejanas a las que se han referido en Lucus Augusti para piezas similares del tipo L17, entre 150 y 300 mm de boca (Alcorta, 2001: 124).

Con independencia de sus dimensiones, las características técnicas se mantienen bastante constantes en el repertorio, reiterándose, según los casos, las pastas cuarzo-micáceas groseras y las esquistosas de gusto regional, así como los acabados bruñidos toscos y las cocciones reductoras.

Como ya se ha apuntado, el morfotipo se relaciona con un modelo bien conocido en diversas regiones del Imperio (Vegas, 1973: 43; Fig.15.4). Su introducción en Hispania parece haber tenido lugar en época republicana en forma de importaciones de procedencia itálica, según queda atestiguado en el Valle del Ebro (Aguarod, 1995: 134135; fig. 5.1-3), para ser imitado en diferentes regiones con dispar fortuna técnica y sometido a modificaciones a manera de adaptaciones a los gustos locales ${ }^{43}$. Ciñéndonos a un ámbito geocultural más afín se conocen paralelos en Asturias en El Castro de Mohías (Coaña) ${ }^{44}$, Os Castros de Taramundi (Expósito, 2004) y Monte Castrelo de Pelóu (Grandas de Salime) ${ }^{45}$. Modelos muy semejantes se documentan entre los platos de borde ranurado -tipo L17- identificados en Lucus Augusti (Alcorta, 2001: 124-125, Fig. 55.1-2) ${ }^{46}$ e interpretados como copias de originales romanos, para los que se propone una data de mediados y finales de la primera centuria con alguna perduración, aunque escasa, en la segunda (Alcorta, 1995: 212). Idénticas fechas se postulan para los paralelos, menos ajustados, registrados como pla-

44 Se dispone de la escueta referencia a la presencia de formas 14 A de M. Vegas entre los elementos vinculados a la amortización de uno de los fosos (Carrocera, 1995: 59).

45 Nos referimos a un ejemplar registrado en el transcurso de las campañas de excavación realizadas entre los años 2003 y 2006 (Montes et alii, 2009 e.p.) que permanece aún inédito.

46 Algunos recipientes recibieron un engobe o aguada interior, alejándose de los acabados constatados en el Chao Samartín. 


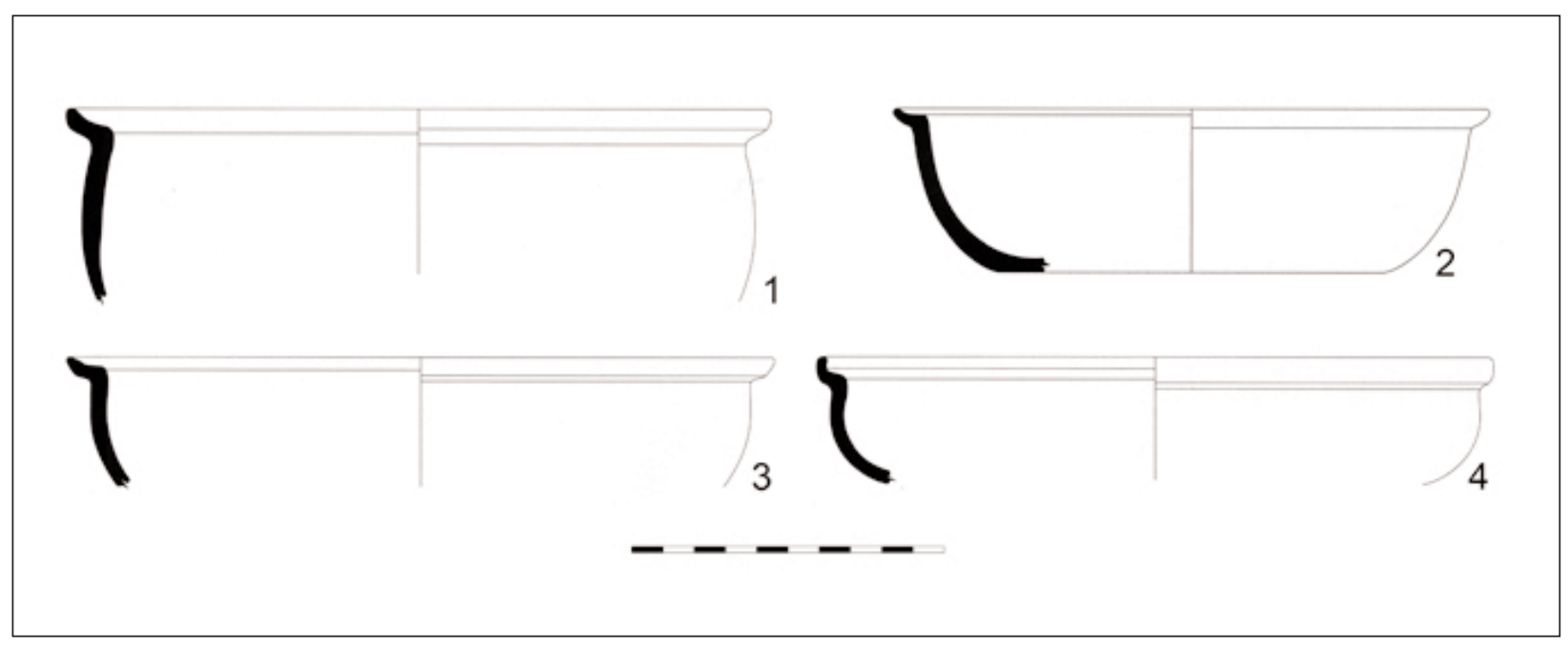

Figura 60. Cazuelas bajas de fondo plano.

tos de cerámica común con superficie alisada en Petavonium (Carretero, 2000: 662, fig. 330.62), que se amplían hasta las primeras décadas del siglo II d.C. para un ejemplar clasificado como cazuela (Ibidem: 671-672, Fig. 337.104) ${ }^{47}$. Estos parámetros cronológicos no pueden ser mantenidos en el caso del Chao Samartín, donde, pese a la constancia de su presencia en el siglo I d.C. (Hevia y Montes, 2009: Fig. 3.7), la representación numérica de este tipo de recipientes en contextos de la segunda mitad del siglo II d.C. (Figura 132), tal y como veremos más adelante, lejos de sugerir una perduración de las producciones tempranas, indica una clara pujanza de la forma en esos momentos avanzados.

\section{CATÁlogo}

1. CH.02/1510. Sector N-1. Fragmento de borde y cuerpo. Borde exvasado de perfil biselado al exterior y cóncavo al interior, con labio de perfil redondeado. Pared ligeramente oblicua de perfil curvo. Pasta de tonalidad anaranjada con abundantes desgrasantes micáceos pequeños y muy pequeños y algún cuarzo. Acabado bruñido tosco en ambas superficies, de color pardo grisáceo la externa y pardo anaranjado la interna. Zonas ennegrecidas en la superficie exterior. Dimensiones: diámetro borde: $225 \mathrm{~mm}$; diámetro máximo cuerpo: 215 $\mathrm{mm}$; altura conservada: $61 \mathrm{~mm}$; grosor medio sección pared: $6 \mathrm{~mm}$. Bibliografía: Hevia, 2006.

2. CH.02/1808. Sector N-1. Fragmento de borde, cuerpo y arranque de base. Borde corto, exvasado, de perfil curvo al exterior y levemente cóncavo al interior, con labio de perfil redondeado. Pared abierta ligeramente oblicua de perfil curvo. Pasta de tonalidad negruzca con abundantes desgrasantes micáceos pequeños y muy pequeños, cuarzos y algún esquisto. Superficies de color negro con tosco acabado bruñido. Dimensiones: diámetro borde: $190 \mathrm{~mm}$; diámetro máximo cuerpo: $178 \mathrm{~mm}$; diámetro base: $123 \mathrm{~mm}$; altura: $52 \mathrm{~mm}$; grosor medio sección pared: $4.5 \mathrm{~mm}$. Bibliografía: Hevia, 2006; Hevia y Montes, 2009: Fig.3.7.

3. CH.02/2736. Sector N-1. Fragmento de borde y cuerpo. Borde bastante corto, exvasado y de perfil biselado al exterior y
47 Uno de los dos ejemplares publicados (Carretero, 2000: 662, Fig. 330.62), menos cercano formalmente a las morfologías más comunes en el Chao Samartín, es encuadrado entre los platos de cerámica común fina. El otro, (Ibidem: 671-672, 337.104) se incluye en el catálogo como cazuela. 
cóncavo al interior, con labio de perfil redondeado. Pared ligeramente oblicua de perfil curvo. Pasta de tonalidad pardo grisácea oscura con desgrasantes micáceos pequeños, abundantes cuarzos medios y pequeños y algún esquisto grande. Superficies negras con acabado bruñido tosco. Dimensiones: diámetro borde: 226 $\mathrm{mm}$; diámetro máximo cuerpo: $211 \mathrm{~mm}$; altura conservada: $41 \mathrm{~mm}$; grosor medio sección pared: 5 mm Bibliografía: Hevia, 2006.

4. CH.02/1785. Sector N-1. Fragmento de borde y cuerpo. Borde corto, exvasado, oblicuo y de perfil anguloso, cóncavo al interior, con labio de perfil redondeado. Pared marcadamente curva oblicua. Pasta de tonalidad grisácea con abundantes desgrasantes micáceos pequeños y muy pequeños y cuarzos medios. Acabado bruñido en ambas superficies, de color pardo grisáceo la externa y anaranjado la interna. Dimensiones: diámetro borde: $216 \mathrm{~mm}$; diámetro máximo cuerpo: $207 \mathrm{~mm}$; altura conservada: $40 \mathrm{~mm}$; grosor medio sección pared: 5 mm. Bibliografía: Hevia, 2006.

\section{Cazuelas hondas de fondo plano}

(Figuras 61 y 62)

Las piezas adscritas a este tipo se caracterizan en lo formal por las paredes altas y de perfil curvo, la base plana y el borde exvasado escalonado preparado para la recepción de una tapadera. Este escalonamiento adopta soluciones diversas que van desde perfiles suaves claramente exvasados a terminaciones de pronunciado bisel y marcada verticalidad, pasando por resultados intermedios. Es nota común la presencia de decoraciones de líneas bruñidas en la superficie externa del cuerpo, ajustándose a la articulación habitual en muchos tipos de bandas decoradas enmarcadas por acanaladuras (Hevia y Montes, 2009: Fig.3.5).

48 La identificación de huellas de carbonización indica una inserción funcional en la vajilla de cocina expuesta a una

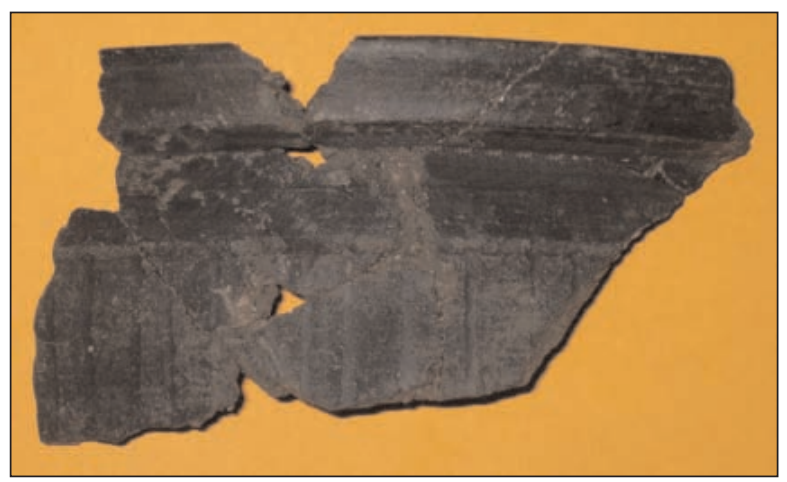

Figura 61. Cazuela honda de fondo plano. Foto: R. Montes

A priori, la forma podría considerarse como una variante de las ya comentadas cazuelas bajas de fondo plano, diferenciada por una notable mayor profundidad de los recipientes y por la aludida presencia de decoración. De hecho, en ausencia de perfiles completos o fragmentos correspondientes a la franja decorada, resulta problemática la adscripción a uno de los dos tipos concretos. A pesar de las incuestionables concomitancias morfológicas, la presencia de decoración y la dispar capacidad, reflejo de una funcionalidad diversificada, coadyuvan, junto a una contextualización estratigráfica de la que se derivan matices cronológicos, en la consideración de estas piezas como un tipo con entidad propia (Hevia, 2006).

Los diámetros de los recipientes se sitúan entre los 215 y lo $260 \mathrm{~mm}$, evidenciando una disparidad dimensional que además de resultar indicativa de una variabilidad de tamaños adaptados a usos específicos ${ }^{48} \mathrm{y}$ cantidades diversas, manifiesta una ausencia de estandarización del tipo, perceptible también en la heterogeneidad de los bordes.

La fabricación regional de estas vasijas resulta incuestionable, respondiendo sus pastas esquistosas y las superficies negras y bruñidas a una tradición técnica bien arraigada, aplicada en este caso sobre una morfología de nueva implantación. No se han podido encontrar paralelos estrictos, más allá de la similitud general que

fuente de calor, sin descartar otros empleos subsidiarios. 


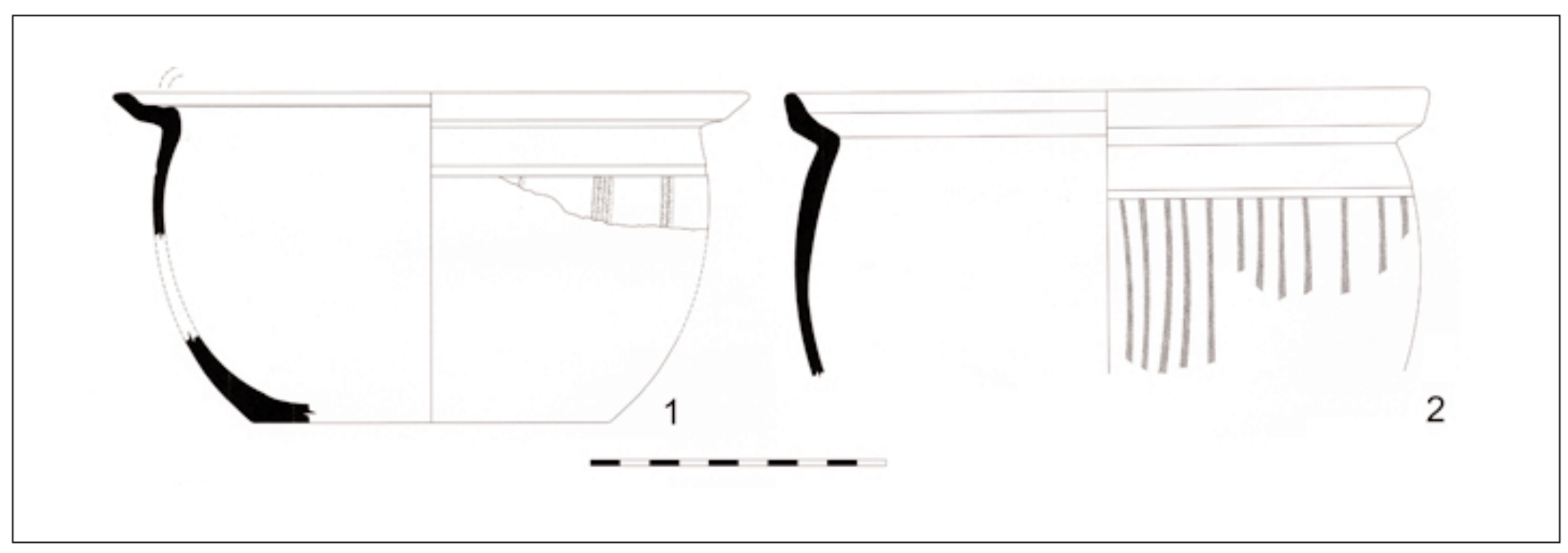

Figura 62. Cazuelas hondas de fondo plano

guardan con el tipo 14 A de Vegas, documentado en múltiples yacimientos bajo diferentes denominaciones e identificable con nuestras cazuelas bajas de fondo plano. Su documentación se restringe, por el momento, al propio Chao Samartín, en donde la presencia de esta forma remite a contextos del sigo I d.C., hallándose ausente en los repertorios que alcanzan el siglo II d.C., o reduciéndose su registro a una presencia testimonial ${ }^{49}$ que debe interpretarse en clave de pervivencia, en un momento en que el protagonismo de recipientes de morfología y funcionalidad equiparable corresponde a otros tipos (Hevia et alii, 1999).

\section{CATÁlogo}

1. CH.02/2828. Sector N-1. Fragmento de borde, cuerpo y base. Borde exvasado, oblicuo, de perfil exterior biselado e interior cóncavo. Labio de perfil redondeado. La transición al cuerpo, de perfil curvo, viene marcada al interior por una acanaladura. En el tercio superior se observa una tenue e irregular acanaladura. Base plana en lo conservado. Decoración en la cara externa bajo la referida acanaladura consistente en haces de líneas bruñidas verticales bastante separados entre sí. Pasta de tonali- dad grisácea cuarzo-micácea con desgrasantes menudos y medios. Superficies negruzcas. Acabado bruñido en borde y parte superior del cuerpo. Al interior, bajo la banda superior bruñida, se observan las líneas del torno. Dimensiones: diámetro borde: $214 \mathrm{~mm}$; diámetro máximo cuerpo: $188 \mathrm{~mm}$; diámetro base: $120 \mathrm{~mm}$; altura estimada: $111 \mathrm{~mm}$; grosor medio sección pared: 6 mm. Bibliografía: Hevia, 2006; Hevia y Montes, 2009: Fig.3.5.

2. CH.02/2337. Sector N-1. Fragmento de borde y cuerpo. Borde exvasado oblicuo de perfil exterior biselado e interior cóncavo. Labio de perfil redondeado. Cuerpo curvo recorrido en su tercio superior externo por una acanaladura bajo la cual se desarrolla una decoración consistente en líneas verticales bruñidas bastante regulares. Pasta de tonalidad pardo grisácea con abundantes desgrasantes micáceos pequeños, cuarzos e intrusiones blanquecinas medias y chamota. Acabado bruñido tosco en ambas superficies, de tonalidad entre pardo grisácea y gris oscura. Dimensiones: diámetro borde: $220 \mathrm{~mm}$; altura conservada: $29 \mathrm{~mm}$; grosor medio sección pared: $6 \mathrm{~mm}$. Bibliografía: Hevia, 2006.
${ }^{49}$ Es el caso del repertorio del sector C-12, construcción en la que los fenómenos de perduración y convivencia de producciones fechadas en el siglo I d.C. con otras de filiación más moderna, tal y como hemos referido, es observable en casi todas las familias cerámicas. 


\section{Cazuelas Troncoconicas}

(Figuras 63 y 64)

Resulta problemática la asignación de una denominación al conjunto de piezas que aquí presentamos que resulte coherente con los criterios expresados en el apartado metodológico. Atendiendo a su morfología no responden a los perfiles de los recipientes tipo olla y su funcionalidad resulta igualmente controvertida dado que, aunque en algún caso presentan concreciones de hollín, la delgadez general de sus paredes y el tratamiento técnico y decorativo no parecen indicar un uso principal en procesos culinarios en caliente. En anteriores publicaciones hemos presentado alguno de estos recipientes bajo la poco comprometida denominación de vasija con decoración de retícula bruñida (Hevia, 2009: 362-363), prefiriendo ahora optar por una denominación que excluya su identificación con el servicio de mesa y concrete su caracterización morfológica.

Se trata de un grupo de piezas de caracteres formales bastante heterogéneos, a pesar de que se mantengan los bordes cortos, exvasados y oblicuos y las bases planas en la totalidad de los casos conocidos. El desarrollo del cuerpo describe, aún con notables diferencias que atañen al grado de globularidad, perfiles curvos troncocónicos que recuerdan a las denominadas cazuelas monoasadas del siglo II d.C. (Figura 133), con las que tal vez pueda establecerse cierto vínculo filogenético (Hevia y Montes, 2009: Fig.3.4). No obstante, esta morfología carece de las asas que constituyen un rasgo definitorio esencial del tipo tardío.

A pesar de la relativa variabilidad formal, el grupo se halla cohesionado gracias a cuestiones de índole técnica y decorativa. La característica fundamental es la presencia de una banda decorada de anchura variable en la zona central (o central-superior del cuerpo) delimitada por acanaladuras y ocupada por ornatos compuestos siempre a base retículas de líneas bruñidas. En algún caso, este friso se completa en la mitad inferior del galbo con toscas y gruesas líneas, igualmente bruñidas, dispuestas en vertical. En lo que se refiere al tratamiento específico de las superficies, hay que destacar el bruñido más o

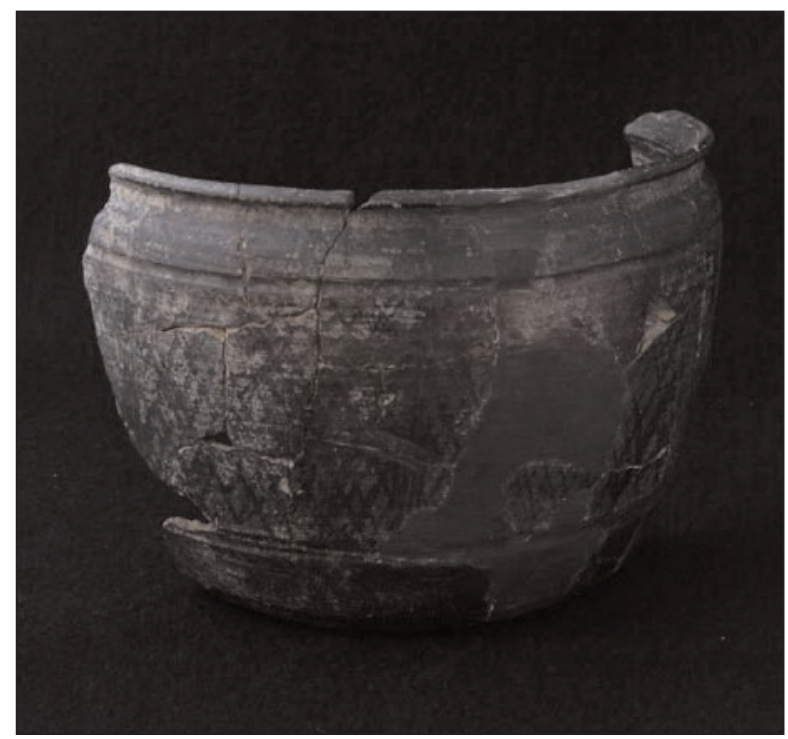

Figura 63. Cazuela troncocónica. Foto: J. Arrojo

menos cuidado del borde y la cara externa de todas las piezas.

A pesar de la innegable adscripción de estas piezas al universo productivo regional, en este caso carecemos de referencias a paralelos ni en el amplio repertorio publicado de Lucus Augusti (Alcorta, 2001) ni en ningún otro yacimiento del entorno.

\section{CATÁlogo}

1. CH.93/1528. Sector R-V. Borde, cuerpo y arranque de base. Borde corto, exvasado y oblicuo con labio de perfil redondeado. Cuerpo curvo de perfil troncocónico recorrido al exterior por una acanaladura en su extremo superior y por otras dos (angosta la superior y muy ancha la inferior) hacia la mitad de la pieza. Base plana en lo conservado. En el tercio superior de la pared, acotado por las acanaladuras, friso decorado mediante una retícula romboidal de trama estrecha y ejecución bastante descuidada. Bajo esta banda, una secuencia de líneas bruñidas se desarrolla hasta las proximidades de la base. El borde y la superficie externa presentan un acabado bruñido, mientras que en la cara interna el somero alisado no oculta las evidencias del torno. Pasta de tonalidad parda en el núcleo y negra en las superficies con micas muy 


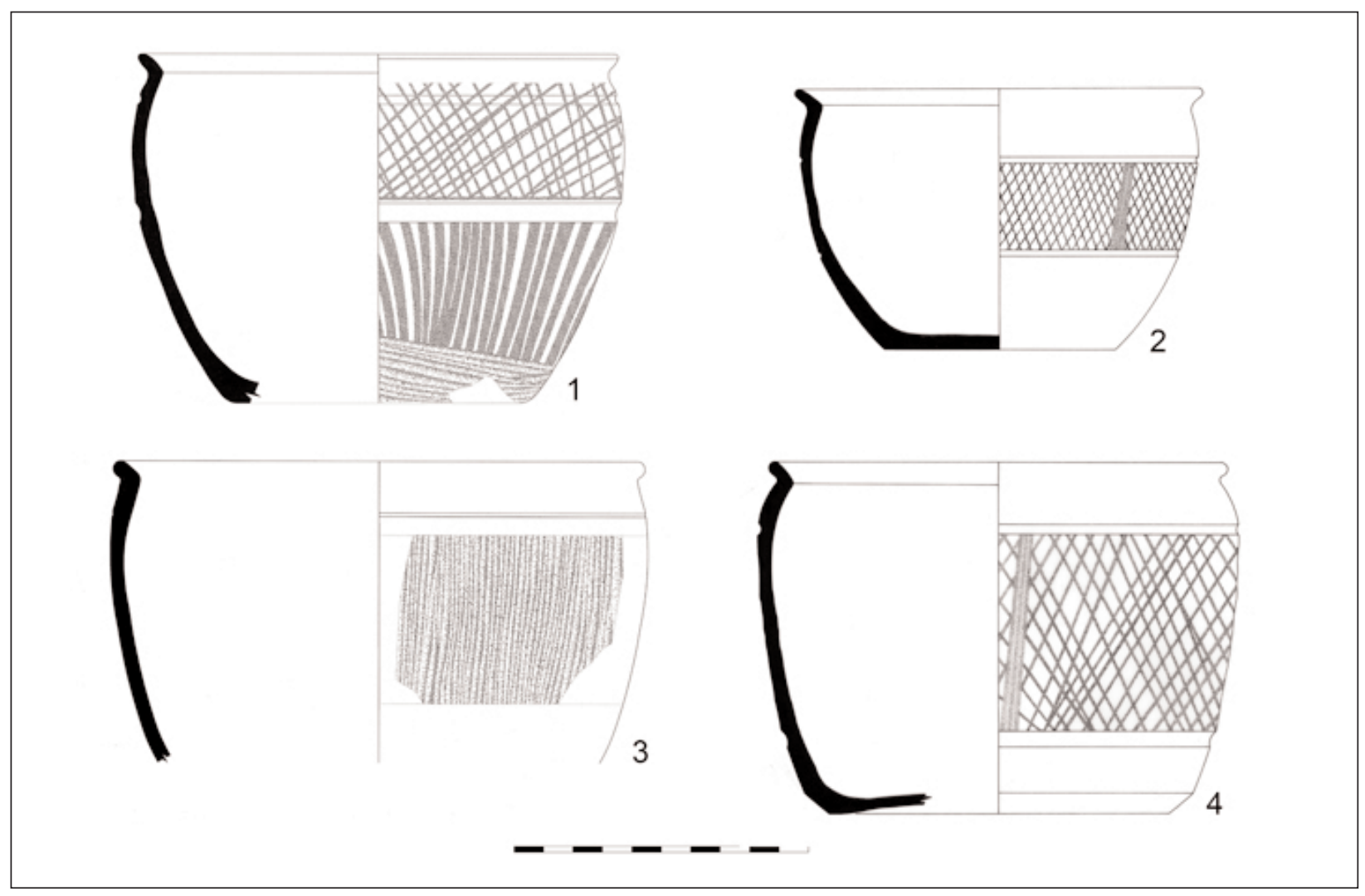

Figura 64. Cazuelas troncocónicas

pequeñas y cuarzos y cuarcitas de diversas dimensiones. Superficies negras. Restos de hollín. Dimensiones: diámetro borde: 166 mm; altura: $121 \mathrm{~mm}$; diámetro máximo cuerpo: $171 \mathrm{~mm}$; diámetro base: $104 \mathrm{~mm}$; grosor medio sección pared: $5 \mathrm{~mm}$. Bibliografía: Inédita.

2. CH.93/0978. Sector R-V. Perfil completo. Borde corto, exvasado, recto y oblicuo con labio de perfil redondeado. Cuerpo curvo de perfil troncocónico surcado al exterior por sendas acanaladuras. Base plana. Decoración circunscrita a una banda de 37 $\mathrm{mm}$ de grosor delimitada por las acanaladuras y en la que se plasma una retícula romboidal bruñida de trama estrecha cruzada por haces de líneas verticales igualmente bruñidas. Pasta con desgrasantes micáceos muy pequeños y cuarcíticos pequeños y medianos de tonalidad gris amarillenta. Superficies negras. La pared externa, el borde y la parte superior de la interna se encuentran finamente bruñidas, siendo visibles en el resto las trazas del torneado.
El fondo externo presenta un emparrillado de líneas toscamente bruñidas entrecruzadas. Hollín en la superficie externa. Dimensiones: diámetro borde: $142 \mathrm{~mm}$; altura: $91 \mathrm{~mm}$; diámetro máximo cuerpo: $138 \mathrm{~mm}$; diámetro base: $82 \mathrm{~mm}$; grosor medio sección pared: $4 \mathrm{~mm}$. Bibliografía: Inédita.

3. CH.99/0772. Foso C. Fragmento de borde y cuerpo. Borde corto, exvasado y oblicuo con labio de perfil redondeado. Cuerpo curvo de perfil troncocónico en lo conservado recorrido en su tercio superior por una acanaladura. Decoración consistente en líneas bruñidas verticales de factura bastante irregular que se desarrolla en una banda de unos $65 \mathrm{~mm}$ bajo la referida acanaladura. Pasta de tonalidad grisácea con abundantes desgrasantes cuarcíticos pequeños y medianos. Superficies negruzcas con acabado bruñido en la externa, el borde y parte superior de la interna. Dimensiones: diámetro borde: $130 \mathrm{~mm}$; diámetro máximo cuerpo: $124 \mathrm{~mm}$; altura conservada: 
$108 \mathrm{~mm}$; grosor medio sección pared: $5 \mathrm{~mm}$. Bibliografía: Inédita.

4. CH.98/4478. Sector R-V. Fragmento de borde, cuerpo y base. Borde corto, exvasado, oblicuo y recto al interior con labio de perfil redondeado. Cuerpo curvo, casi vertical, de perfil troncocónico y con una carena muy baja inmediata a la base. En la cara externa presenta dos anchas acanaladuras, una en el tercio superior y otra en el inferior. Base convexa al interior. Decoración enmarcada en una banda de $68 \mathrm{~mm}$ de grosor, delimitada por las referidas acanaladuras, en la que se plasma una retícula romboidal bruñida de trama estrecha compartimentada ocasionalmente por haces de líneas oblicuas igualmente bruñidas. Pasta de tonalidad grisácea en el núcleo y negra en las superficies con desgrasantes micáceos pequeños y cuarcíticos de variadas dimensiones. La superficie externa y el borde se encuentran toscamente bruñidos, mientras que en la cara interna son visibles las trazas del torneado. Hollín en ambas superficies. Dimensiones: diámetro borde: 158 $\mathrm{mm}$; altura: $122 \mathrm{~mm}$; diámetro máximo cuerpo: $168 \mathrm{~mm}$; diámetro base: $118 \mathrm{~mm}$; grosor medio sección pared: $5 \mathrm{~mm}$. Bibliografía: Hevia, 2009: Ficha 116, $362-$ 363; Hevia y Montes, 2009: Fig.3.4.

\section{Ollas Globulares de Bandas}

\section{Decoradas (Figuras 65 y 66)}

El grupo que vamos a describir a continuación integra piezas que se caracterizan por los clásicos contornos acusadamente globulares, las bases invariablemente planas y los bordes muy desarrollados, con faceta interior, a menudo recorrida por una acanaladura y labios destacados por su engrosamiento. La pauta dominante en los tratamientos superficiales específicos la constituyen los acabados bruñidos más o menos toscos (Hevia, 2006 y 2009: 354-355; Hevia y Montes, 2009: Fig.3.12).

Estos perfiles en $\mathrm{S}$ y las embocaduras estructuradas en planos, si bien resultan inherentes al tipo, no pueden considerarse en exclusiva elementos definitorios del mismo ya que son características compartidas por otras formas de fabricación regional con similar tratamiento técnico ${ }^{50}$. El criterio básico de cohesión grupal que actúa como discriminante para la individualización del tipo es su particular programa ornamental. La mitad superior de las paredes de las vasijas presenta, con distintas combinaciones, una compleja compartimentación espacial en estrechos filetes delimitados por acanaladuras y/o molduras que acogen los motivos decorativos, manteniendo un diseño que entronca con la tradición cerámica castreña. No sólo el esquema ornamental, sino también las técnicas y los motivos decorativos se insertan igualmente en el acervo regional, reiterándose temas ejecutados con diversas técnicas: incisión, bruñido y sobre todo, impresión. Las piezas presentan un alto grado de singularidad, siendo múltiples las combinaciones de técnicas y motivos que se documentan.

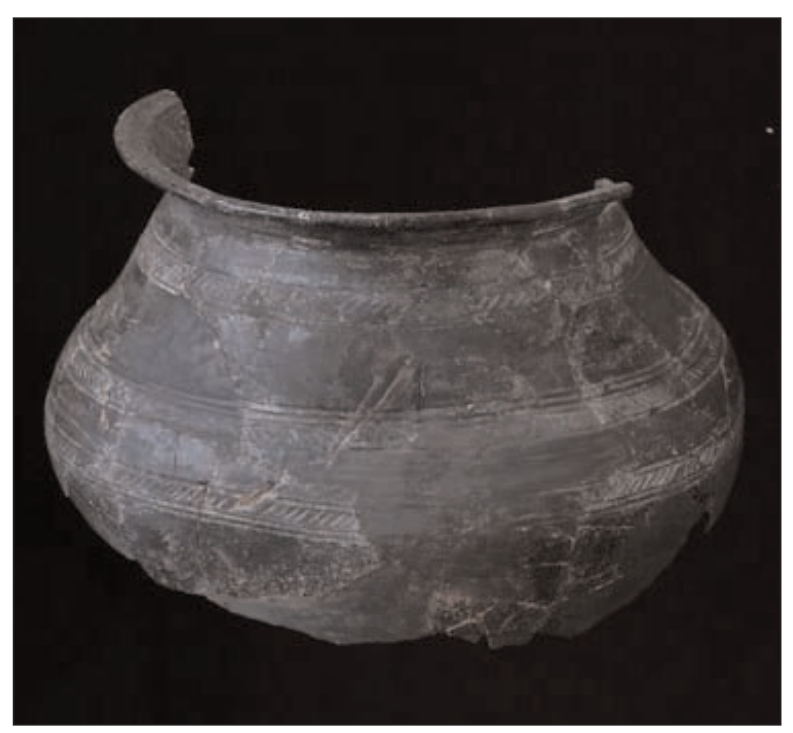

Figura 65. Olla globular de bandas decoradas. Foto: J. Arrojo

50 Por ejemplo las orzas con nervaduras o las ollas globulares engobadas con decoración estampillada. 
Son los temas impresos y, en concreto, las alineaciones de puntos en disposición vertical o, más comúnmente, oblicua la formulación ornamental mayoritaria y más característica. Durante algún tiempo estas decoraciones fueron interpretadas como excisas por ciertos autores (Uría, 1941: 346), empujados por un contexto historiográfico marcado por las tipologías de cerámica excisa propuestas por aquel entonces por $\mathrm{M}$. Almagro (1939). De hecho, con anterioridad a esta publicación, los fragmentos procedentes del Castelón de Coaña, que constituyen las primeras evidencias conocidas en Asturias de este tipo de ornamentación, fueron considerados como decorados con incisiones profundas (García y Bellido y Uría, 1940: 126, Fig.6.D). Tal y como en su día apuntó J.L. Maya (1988: 171) deberían ser interpretadas, en cualquier caso, no como excisas sensu stricto, sino como pseudo-excisas, si bien se ajustaría mejor la denominación de impresas.
En cualquier caso, estos elementos decorativos representan un motivo típico del hierro regional, tal y como queda atestiguado mediante su registro en piezas documentadas en múltiples yacimientos castreños del noroeste peninsular. Es el caso, en territorio galaico, de Forca ${ }^{51}$ (Carballo, 1987: Fig. $18.13,27.190$ y 41.574 y 575; Lám.XXXI), Cameixa (López Cuevillas, 1952: 82-91, lám. XVI, superior izquierda), A Cidade de Caneiro (Hidalgo y Costas, 1979: 152-228, p. 161 y 169; Fig. 6.13 en p.191 y 10.44 y 45 en p.195), Coto do Mosteiro (Orero, 1988: 45, Fig. 49.7 y 10 y 50 y ss, Fig. 60.7, 61.6, 63.7 y 66.4, Lám. XXVII abajo y XXXII medio) o Troña (Pericot y López Cuevillas, 1929: Lám. IV) y en el ámbito astur trasmontano, de la Campa Torres (Maya y Cuesta, 2001: 191-192, Fig.142. 1 y 3).

En estos momentos tempranos del proceso de romanización, estos motivos decorativos se perfilan como elementos que denotan el poder inercial

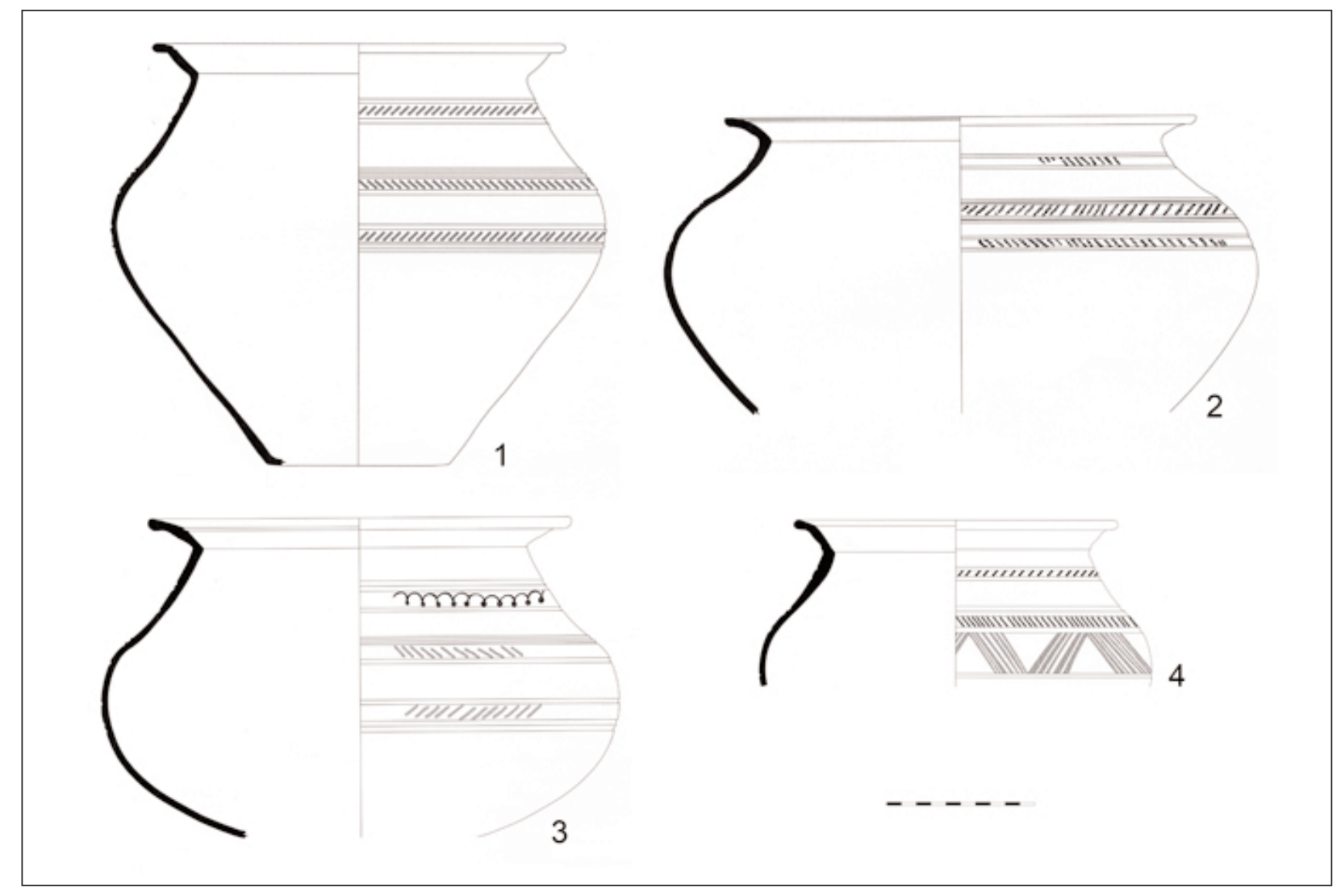

Figura 66. Ollas globulares de bandas decoradas

51 Ejemplares datados en contextos inequívocos de la segunda edad el Hierro, entre los siglos IV y II a.C. (Carballo, 1987). 
de la tradición alfarera castreña indígena, en claro contraste con el carácter de residual que adquieren en fechas posteriores. Así, en el siglo II d.C. manifiestan una clara minoría porcentual respecto a técnicas decorativas como la bruñida, hasta el punto de poder ser consideradas rarezas, cuando no simples perduraciones puntuales de artefactos concretos.

Se conocen ejemplos de este tipo de ornamentos en contextos romanos en el castro de Corporales (Sánchez-Palencia y FernándezPosse, 1985: 247-248, Fig.102, $n^{\circ}$ 659), en la ciudad de Lucus Augusti (Alcorta, 2001: 63, Fig.23), en el castro de Zoñán (Vigo, 2007: 210-211) y probablemente, en los castros asturianos de Coaña (Uría, 1941: 346; Maya, 1988: 154 y 171, Fig. 39 A y B y 50 A, B, C y D), Mohías (Ibidem: 171) y San Chuis (Ibidem: 171, Fig. 50 E).

\section{CATÁlogo}

1. CH.98/1519. Sector R-V. Fragmento de borde, cuerpo y arranque de base. Borde corto exvasado y oblicuo, con labio engrosado de perfil redondeado. Una acanaladura al interior señala la transición al cuello, corto, exvasado, oblicuo y de perfil interior ligeramente cóncavo. El cuello enlaza con la pared mediante un marcado cambio de plano concretado en una arista. Cuerpo de perfil acusadamente globular. Base plana. Decoración articulada en tres estrechos frisos de alineaciones de puntos oblicuos impresos, los del friso central en dirección opuesta a los de los otros dos. Cada secuencia se enmarca en un número diverso de acanaladuras: una a cada lado en el friso superior, dos superiores y una inferior en el intermedio y una superior y dos inferiores en el último. Pasta de color pardo con micas pequeñas y muy pequeñas y cuarzos, cuarcitas y esquistos de todos los tamaños. Superficies de tonalidad negra, la externa toscamente bruñida, siendo visibles las líneas de espatulado. Dimensiones: diámetro borde: $290 \mathrm{~mm}$; altura: $586 \mathrm{~mm}$; diámetro máximo cuerpo: $348 \mathrm{~mm}$; diámetro base: $130 \mathrm{~mm}$; grosor medio sección pared: $4 \mathrm{~mm}$. Bibliografía: Hevia, 2009, Ficha 112, 354355 .
2. CH.02/0794. Sector N-1/Foso E. Fragmento de borde y cuerpo. Borde exvasado, oblicuo y curvo separado al interior del cuello mediante una inflexión reforzada por una acanaladura. Labio de perfil redondeado. Cuello corto, exvasado, oblicuo y de perfil recto al interior y curvo al exterior separado galbo mediante una inflexión a modo de cambio de plano. Cuerpo globular recorrido en su cara externa por varias acanaladuras cuya distribución configura tres frisos decorativos. Decoración impresa consistente en alineaciones de pequeños puntos oblicuos orientados hacia la izquierda en la banda superior, hacia la derecha en la intermedia y hacia la izquierda nuevamente en la inferior. Pasta de tonalidad grisácea con desgrasantes micáceos pequeños, cuarcíticos medianos y grandes y algún esquisto. Superficie externa de color entre pardo y pardo grisáceo e interna gris. Acabado bruñido en borde, cuello y superficie exterior, mientras que en la cara interna se aprecian las huellas del torno. Dimensiones: diámetro borde: $320 \mathrm{~mm}$; altura conservada: $200 \mathrm{~mm}$; diámetro máximo cuerpo: $402 \mathrm{~mm}$; grosor medio sección pared: $5.5 \mathrm{~mm}$. Bibliografía: Hevia, 2006.

3. CH.02/1789. Sector N-1. Fragmento de borde y cuerpo. Borde exvasado, oblicuo y curvo con labio ligeramente engrosado de perfil redondeado. Al interior, queda separado del cuello por una inflexión reforzada mediante una acanaladura. Cuello corto, exvasado, oblicuo y perfil recto al interior y curvo al exterior separado del galbo mediante una inflexión a modo de cambio de plano. Cuerpo globular recorrido al exterior por una serie de acanaladuras cuya distribución configura tres frisos decorativos. Decoración consistente en la banda superior en círculos secantes estampillados sencillos de trazo continuo en cuyas intersecciones penden círculos igualmente sencillos y de trazo continuo. Las dos bandas inferiores se rellenan de alineaciones de puntos impresos, apenas perceptibles, en disposición diagonal hacia la izquierda en 
la superior y hacia la derecha en la inferior. Pasta de tonalidad grisácea con desgrasantes micáceos pequeños, esquistos, abundantes cuarzos de variado tamaño y chamota. Superficies negruzcas. Acabado bruñido en borde, superficie externa y parte superior de la interna. En el resto de la pared interior se aprecian las estrías del torneado. Dimensiones: diámetro borde: 284 mm; altura conservada: $213 \mathrm{~mm}$; diámetro máximo cuerpo: $347 \mathrm{~mm}$; grosor medio sección pared: 4/7 mm. Bibliografía: Hevia, 2006; Hevia y Montes, 2009: Fig. 3.12.

4. CH.98/3412. Sector R-VIII. Fragmento de borde y cuerpo. Borde exvasado, oblicuo y curvo con labio de perfil redondeado separado al interior del cuello mediante una inflexión. Cuello corto, exvasado, oblicuo $\mathrm{y}$ de perfil recto al interior y curvo al exterior separado del cuerpo mediante una inflexión a modo de cambio de plano. Cuerpo globular recorrido en su cara externa por varias acanaladuras cuya distribución configura tres bandas en las que se inserta la decoración. Decoración impresa consistente en alineaciones de pequeños puntos oblicuos orientados hacia la derecha en el filete superior y hacia la izquierda en la intermedia. La banda inferior, de notable mayor anchura, alberga una decoración de haces de líneas bruñidas componiendo un motivo en zig-zag. Pasta de tonalidad grisácea con desgrasantes micáceos pequeños, esquistos y cuarzos de variado tamaño. Superficies de tonalidad pardo grisácea con acabado bruñido en la cara externa, el borde y la parte superior de la interna. Dimensiones: diámetro borde: $156 \mathrm{~mm}$; altura conservada: $93 \mathrm{~mm}$; diámetro máximo cuerpo: $173 \mathrm{~mm}$; grosor sección: $4 \mathrm{~mm}$. Bibliografía: Inédita.

\section{Ollas de borde Cóncavo}

\section{(Figura 67)}

La exigüidad de los fragmentos adscribibles a esta tipología recuperados en contextos tempranos sólo ha permitido la individualización de la forma a partir de la inconfundible morfología de su borde y de la disposición de asa, no habiéndose podido reconstruir ningún perfil completo. A pesar de estas dificultades, su identificación con el tipo denominado ollas de borde cóncavo, documentado profusamente en contextos del siglo II d.C. (Figura 136) (Hevia et alii, 2001: 164, Fig. 2.24-25, 3 y 4.34-47; Hevia, 2009: 460-461), resulta incuestionable. Los rasgos morfológicos y técnicos generales coinciden con los que se describirán más adelante para este grupo de piezas, sin que se observen grandes diferencias a partir del escueto repertorio manejado en estas fechas. No obstante, cabe referir, aún guardando las oportunas reservas que se derivan de tan exiguo elenco, la constatación de perfiles más estilizados que contrastan con los marcadamente globulares y achatados de las producciones seriadas habituales en la segunda centuria.

Esta apreciación morfológica queda corroborada en Lugo, donde ollas de este tipo se registran tanto en la primera fase, en la que las denominadas ollas de cocina monoansadas, con borde de doble inflexión -tipo L5- (Alcorta, 2001: 97-99, Fig.43) se encuentran representadas, aunque parcamente, como en la segunda -tipo O3- (Ibidem: 199-200, Fig. 83), comprendida entre las décadas iniciales de la segunda centuria y las postreras de la cuarta (Ibidem: 49). Será en este periodo cuando se registren ejemplares de globularidad más acentuada y versiones con decoración espatulada (Ibidem: 199).

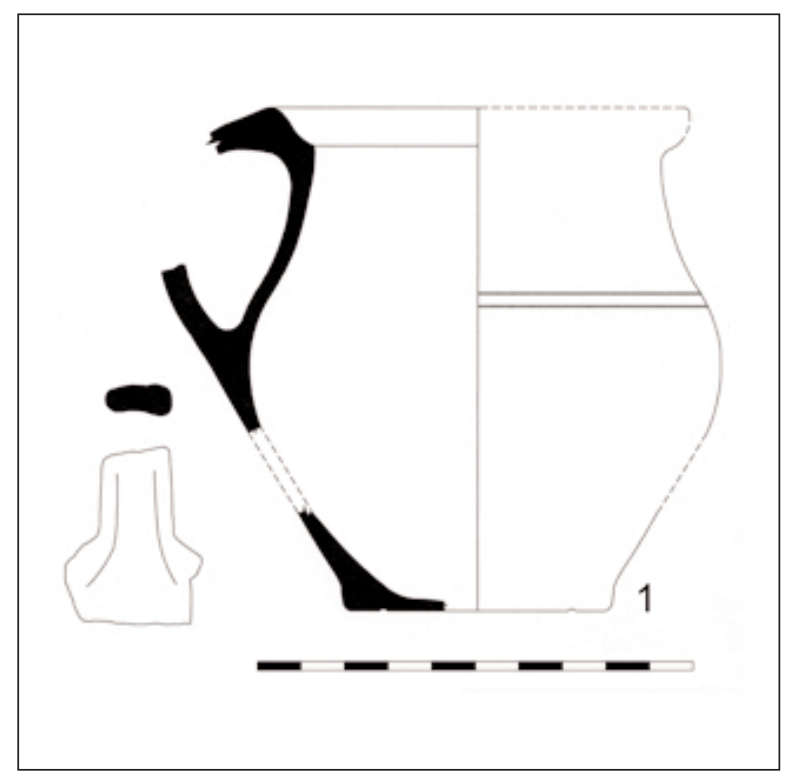

Figura 67. Olla borde cóncavo 


\section{CATÁlogo}

1. CH.02 /2396. Sector N-1. Fragmento de borde, cuerpo, asa y base. Borde exvasado, oblicuo y curvo con perfil cóncavo al interior y labio de sección redondeada. Cuerpo de perfil globular en lo conservado surcado al exterior por una acanaladura en su parte superior. Asa de sección subrectangular ligeramente rehundida al exterior que arranca del labio. Base plana con acanaladura perimetral en el fondo exterior. Pasta de tonalidad grisácea con abundantes desgrasantes micáceos muy pequeños y cuarcíticos y esquistosos pequeños y medios. Superficies entre grises y pardo grisáceas con acabado bruñido al exterior. $\mathrm{Al}$ interior se observan las huellas del torneado. Zonas ennegrecidas en la superficie exterior. Dimensiones: diámetro borde: $117 \mathrm{~mm}$; altura conservada: $80 \mathrm{~mm}$; diámetro máximo cuerpo: $124 \mathrm{~mm}$; diámetro base: 80 mm; grosor medio sección pared: $7 \mathrm{~mm}$. Bibliografía: Hevia, 2006.

\section{Ollas Ovoides Micáceas}

(Figuras 68 y 69)

La individualización del conjunto de ollas recogidas bajo esta denominación aúna criterios técnicos con otros formales que sitúan al tipo como uno de los mejor definidos en este periodo en tanto que producción con carácter específico y marcada homogeneidad interna. Su carácter cronológico exclusivo, circunscrito al siglo I d.C., les confiere una cualidad adicional como indicador temporal compartida tan sólo por unas pocas tipologías.

Desde un punto de vista morfológico los ejemplares registrados describen perfiles ovoides y cuentan con bases planas. Los bordes se muestran simples, exvasados y curvos, con labios de sección redondeada, aún cuando se observa, siempre dentro de este esquema, una cierta variabilidad que afecta a su grosor y grado de inclinación. A pesar del acomodo de todas las piezas a la estructura general descrita, no nos encontramos frente a un modelo de fabricación estandarizada según denotan la diversidad de tamaños y la resolución morfológica concreta de cada recipiente, en la que son perceptibles leves matices que los personalizan y les imprimen un carácter diferenciado (Hevia, 2006).

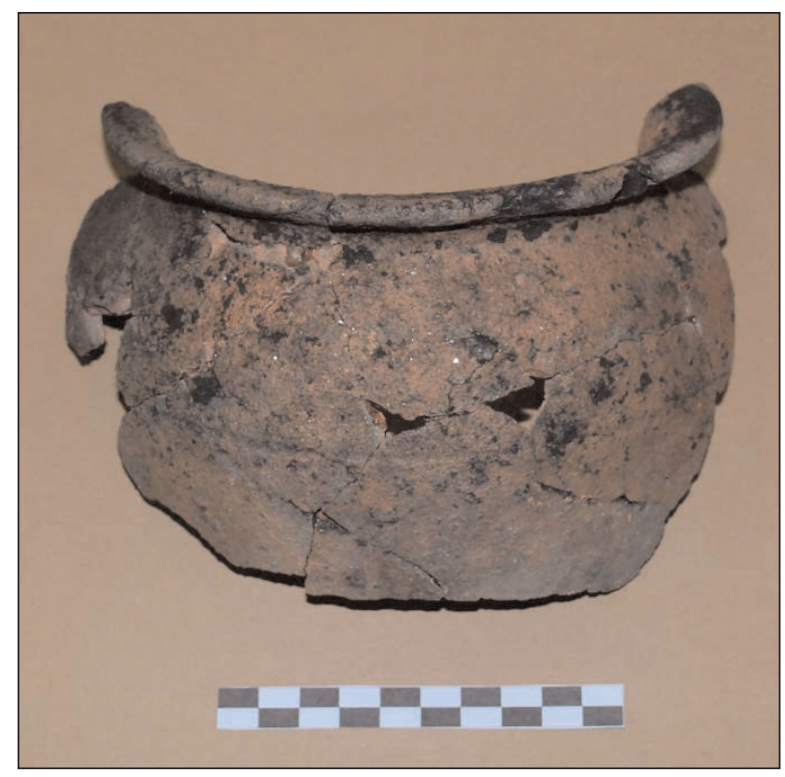

Figura 68. Olla ovoide micácea. Foto: R. Montes

La homogeneidad y especificidad del tipo se revela de modo particular en el tratamiento técnico de las piezas. Aún tratándose de ollas de dimensiones medias, todas ofrecen una estampa robusta con paredes irregulares de grosor considerable que se adelgaza en la mitad superior de las vasijas. A su aspecto rugoso, carente de acabados específicos, coadyuva la fabricación en pastas muy groseras con abundantes inclusiones, con frecuencia de notables dimensiones. Cuarzos, micas y cuarcitas se hallan profusamente representados superando con asiduidad los $5 \mathrm{~mm}$ y confiriendo a las superficies exteriores, en el caso de las micas, un brillo característico. Es habitual así mismo la presencia de vacuolas de diverso tamaño. La escasa pericia técnica se manifiesta tanto en el imperfecto torneado de las piezas como en los deficientes procesos de cocción, cuya irregularidad ha dado lugar a una coloración que va del anaranjado a los grises y pardos, tanto en los núcleos como en las superficies. Su adscripción funcional a la vajilla de cocina para procesos culinarios en caliente se ve reforzada por las frecuentes costras de hollín que presentan todos los ejemplares (Hevia, 2006). 


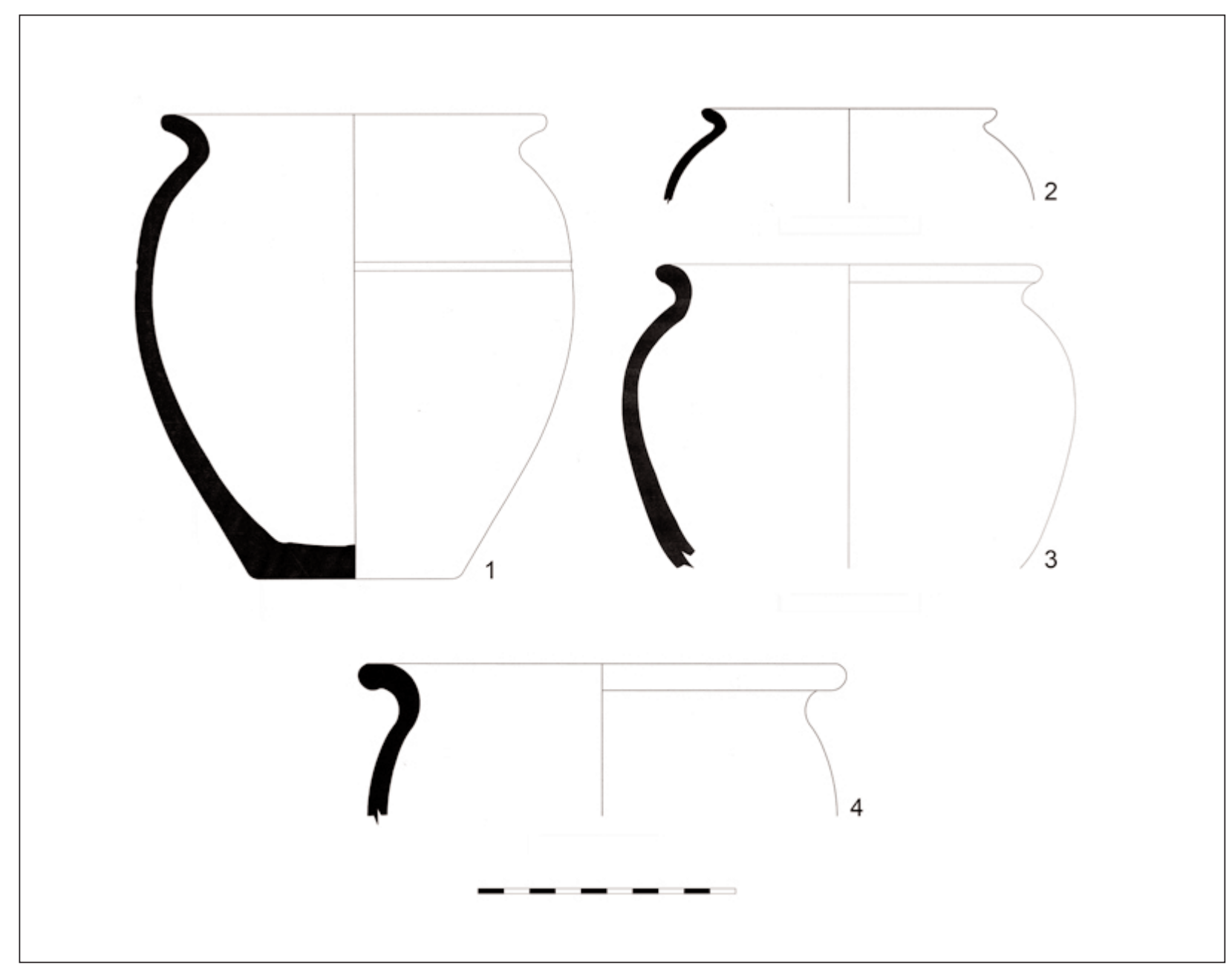

Figura 69. Ollas ovoides micáceas

Aún resultando incuestionable su carácter local o regional, estas producciones resultan, tanto morfológica como técnicamente, insólitas entre los repertorios regionales conocidos, caracterizados por el predominio de las pastas grises-pardas más depuradas y los tratamientos espatulados o bruñidos. Los perfiles ovoideos se documentarán en el Chao Samartín sólo de manera testimonial entre las ollas de los contextos del siglo II d.C. (Benéitez et alii, 1999: 34, Fig.8.5), momento en que el que dominan, casi en exclusiva, los perfiles globulares o sinuosos y en el que están ausentes recipientes equiparables técnicamente con las producciones que aquí se presentan.

En Lucus Augusti, referente habitual para las producciones regionales de nuestro yacimiento, no se han podido identificar paralelos plenamente coincidentes (Alcorta, 2001). Esta circunstancia podría apoyar el carácter más restringido, cronológica y geográficamente, del tipo, situándolo como una manufactura ejecutada por alfareros locales con escaso dominio técnico, que producen para un ámbito de difusión restringido y que cronológicamente circunscribe su presencia, al menos en el Chao Samartín y en el estado actual de conocimientos, a contextos que no superan el siglo I d.C.

\section{CATÁlogo}

1. CH.08 /0350. Sector C-22 K. Perfil completo. Borde exvasado, oblicuo y curvo con labio de perfil redondeado. Cuerpo de perfil ovoide recorrido por una acanaladura al exterior. Base plana. Pasta de tonalidad pardo anaranjada con abundantes desgrasantes micáceos y cuarcíticos medianos, grandes y muy grandes. Superficie exterior pardo grisácea anaranjada rugosa 
e interior anaranjada en la que se observan las huellas del torneado. Dimensiones: diámetro borde: $125 \mathrm{~mm}$; diámetro máximo cuerpo: $136 \mathrm{~mm}$; diámetro base: 67mm; altura: $154 \mathrm{~mm}$; grosor medio sección pared: $6 \mathrm{~mm}$. Bibliografía: Inédita.

2. CH.02/1773. Sector N-1. Fragmento de borde y cuerpo. Borde corto, exvasado, oblicuo y curvo con labio de perfil redondeado. Cuerpo de perfil curvo en lo conservado. Pasta anaranjada con desgrasantes micáceos pequeños y abundantes cuarzos de todos los tamaños. Superficies de tonalidad anaranjada sin acabado específico alguno. Dimensiones: diámetro borde: $115 \mathrm{~mm}$; altura conservada: $36 \mathrm{~mm}$; grosor medio sección pared: $4 \mathrm{~mm}$. Bibliografía: Hevia, 2006.

3. CH.02/1532. Sector N-1. Fragmento de borde y cuerpo. Borde exvasado, oblicuo y curvo. Cuerpo de perfil ovoide. Pasta de tonalidad pardo grisácea con abundantes desgrasantes micáceos y cuarcíticos medianos, grandes y muy grandes. Superficie exterior pardo grisácea anaranjada rugosa e interior pardo anaranjada en la que se observan las huellas del torneado. Hollín en ambas superficies. Dimensiones: diámetro borde: $155 \mathrm{~mm}$; altura conservada: $122 \mathrm{~mm}$; diámetro máximo cuerpo: $182 \mathrm{~mm}$; grosor medio sección pared: $8 \mathrm{~mm}$. Bibliografía: Hevia, 2006.

4. CH.02/2244. Sector N-1. Fragmento de borde y cuerpo. Borde exvasado, oblicuo y curvo con labio de perfil redondeado. Cuerpo de perfil curvo en lo conservado. Pasta de tonalidad grisácea con abundantes desgrasantes micáceos pequeños y medios y cuarcíticos medianos, grandes y muy grandes. Superficie externa gris e interna entre gris y pardo anaranjada. Acabado rugoso. Hollín al exterior. Dimensiones: diámetro borde: $190 \mathrm{~mm}$; altura conservada: $59 \mathrm{~mm}$; grosor medio sección pared: $8 \mathrm{~mm}$. Bibliografía: Hevia, 2006.

\section{Ollas lisas de borde eXVASAdo}

Los recipientes tipo olla representan la morfología de registro más frecuente en los ajuares del Chao Samartín y por norma general, en casi todos los yacimientos del entorno. Sin embargo, abundancia y homogeneidad no se corresponden, escondiéndose bajo unos rasgos genéricos comunes una compleja diversidad difícil de ser sometida a categorización o clasificación tipológica. Las características compartidas remiten a la adscripción funcional a tareas culinarias en caliente, lo que implica determinadas servidumbres morfológicas, a una cierta tosquedad en la ejecución técnica, y a algunos rasgos formales como los bordes exvasados oblicuos, los cuerpos con desarrollos tendentes a la globularidad y las bases planas (Hevia et alii, 2001: 170-177, Fig. 5-8).

El perfil de las paredes constituye un elemento formal que introduce cierta heterogeneidad en estos recipientes, toda vez que, aún manteniendo la general tendencia a los perfiles globulares que dan carta de naturaleza al modelo, se detectan gradaciones derivadas de las dispares relaciones entre los diámetros de los cuerpos y las alturas de las piezas. Así, en algunos casos, el diámetro máximo del galbo adquiere proporciones equiparables o algo menores a las de su altura, como corresponde a recipientes de marcado contorno globular. Sin embargo, en otras ocasiones, ambas dimensiones se igualan o incluso la relación llega a invertirse, resultando las piezas más estilizadas, con perfiles de tendencia ovoide. Las dimensiones de las bases, que se muestran planas en todos los casos conocidos, también contribuyen a aumentar la gracilidad de algunos ejemplares frente a los más globulares.

En cualquier caso, nos encontramos con recipientes de dimensiones que oscilan entre los 180 mm de apertura de boca que presentan los ejemplares más pequeños y los más de $300 \mathrm{~mm}$ de los mayores. Las bases, por su parte, se encuentran en valores entre los 80 y los $120 \mathrm{~mm}$.

En función de la solución escogida para el remate de las embocaduras se pueden distinguir varias series de ollas en el seno de este cuantioso y heteróclito conjunto. 


\section{Ollas LiSAS De Borde exvasado CURVO (Figuras 70 y 71)}

El prototipo de ollas con bordes simples exvasados curvos será una de las soluciones habituales de las ollas de cocina entre los repertorios del Chao Samartín en sus distintas variantes volumétricas (Hevia, 2006).

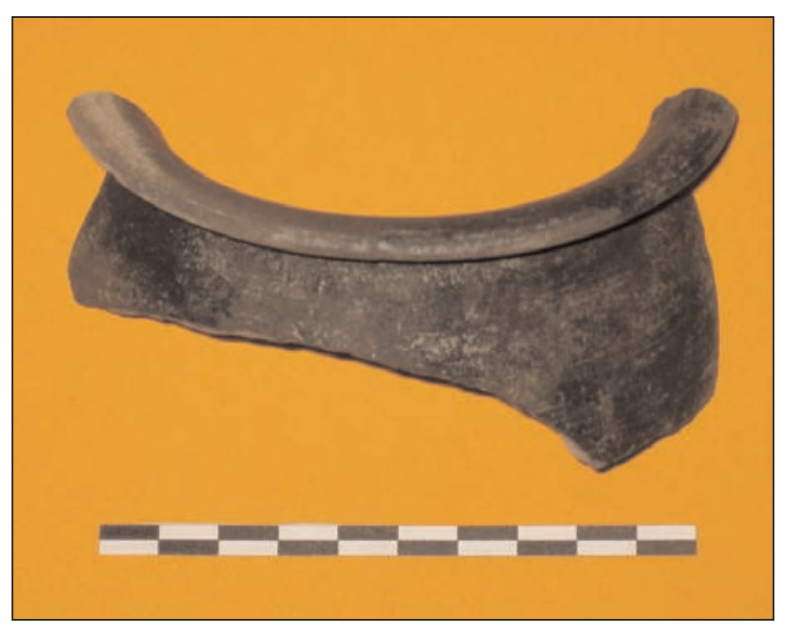

Figura 70. Olla de borde curvo. Foto: R. Montes

Como sucede con la generalidad de las ollas lisas, los paralelos que podrían citarse resultan numerosos si se atiende exclusivamente a la morfología de los tipos, prescindiendo de su caracterización técnica. Circunscribiéndose al ámbito geocultural más afín, en Lugo encontra- mos ejemplares semejantes en el seno del tipo O2 ${ }^{52}$ (Alcorta, 2001: 197-198, Fig. 82), aunque siempre por encima de los $150 \mathrm{~mm}$ de diámetro. Mayores similitudes en lo que refiere a la naturaleza de las pastas y las medidas en que se fabrican se encuentran entre las piezas agrupadas en el tipo O24 (Ibidem: 250-252, fig. 106) alguna de las cuales, aunque en franca minoría, se presentan sin decorar y con una apertura media de borde entre 150 y $180 \mathrm{~mm}$. Para ambos tipos se propone una cronología entre la segunda y la cuarta centuria d.C. (Ibidem).

\section{CATÁlogo}

1. CH.02/2815. Sector N-1. Fragmento de borde y cuerpo. Borde exvasado, oblicuo y curvo con labio de perfil redondeado. Cuerpo de perfil curvo cerrado en lo conservado. Pasta gris con desgrasantes micáceos pequeños y muy pequeños y cuarcíticos pequeños. Superficies pardo grisáceas en las que resultan visibles las estrías del torneado. Acabado alisado al exterior. Concreciones negruzcas fruto de la exposición al fuego en ambas superficies. Dimensiones: diámetro borde: $115 \mathrm{~mm}$; altura conservada: $43 \mathrm{~mm}$; grosor medio sección pared: 5 mm. Bibliografía: Hevia, 2006.

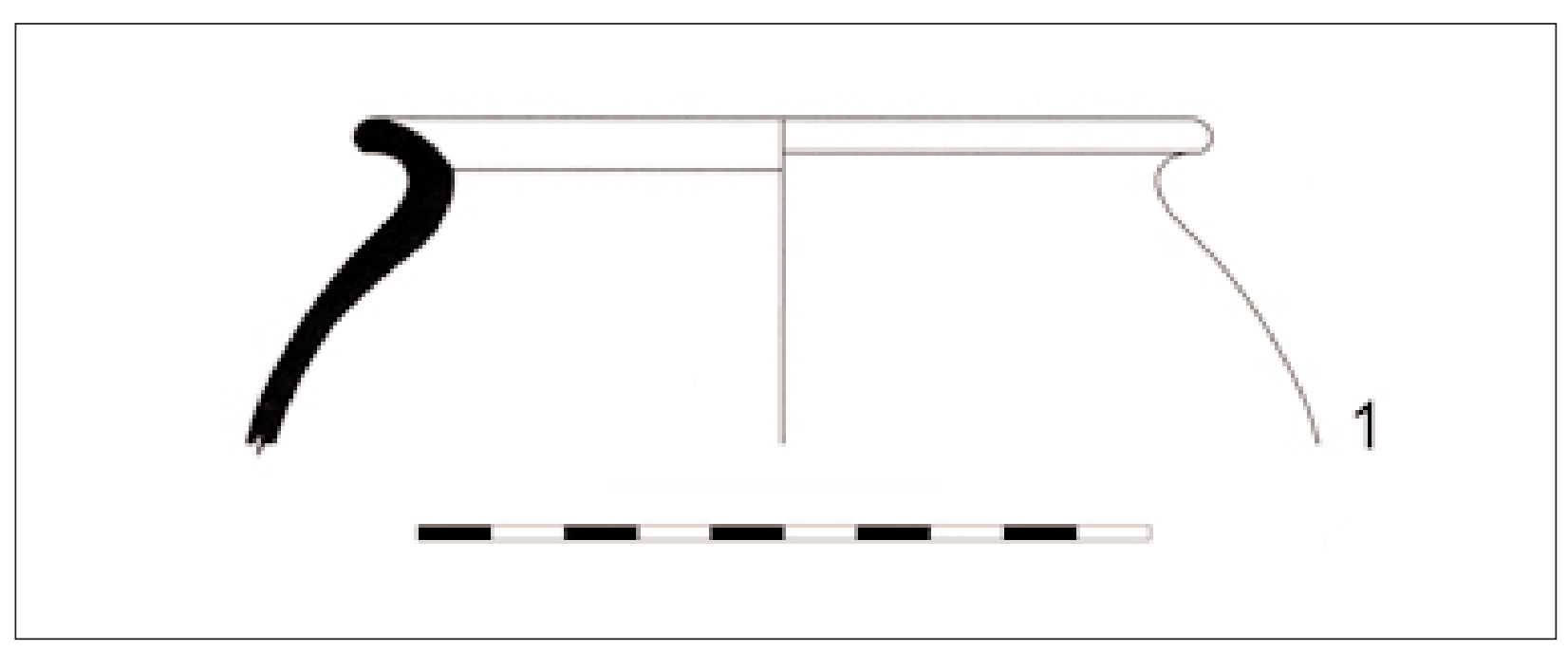

Figura 71. Olla de borde curvo

52 Ollas globulares de borde curvo, sin decoración. 


\section{Ollas lisas De BORDE eXVASAdo FACETADO (Figura 72)}

El tipo responde a una composición morfológica cuya sencillez y versatilidad se encuentran en la base de su éxito y abrumador predomino sobre otras soluciones formales, tanto entre los repertorios de cocina como entre los de almacenamiento y despensa. La embocadura de los recipientes se estructura en dos planos exvasados respecto a la pared, formando el inferior un corto cuello inclinado mientras que el superior, que constituye el borde propiamente dicho, describe una trayectoria tendente a la horizontalidad y se remata en un labio, generalmente engrosado, de sección redondeada. Esta articulación confiere a la boca de las piezas un característico e identificativo perfil facetado y facilita la disposición de una tapadera sobre el plano inclinado inferior. Las paredes, carentes de decoración, dibujan contornos globulares y las bases son planas.

Atendiendo a la configuración del borde y de la presencia o no de una acanaladura coincidente con la inflexión interior entre planos pueden distinguirse dos variantes (Hevia, 2006):

- Ollas de borde facetado con acanaladura. La presencia de ésta debe interpretarse en clave funcional, como elemento de refuerzo para favorecer el encaje de la tapadera, cuya colocación, como ya se ha señalado, se halla posibilitada por el propio diseño facetado.

- Ollas de borde facetado sin acanaladura.

Como es habitual en manufacturas de elevada simplicidad se evidencia, siempre dentro de la estructura definitoria general y al margen de la variante en la que inscriban, una notable heterogeneidad que se concreta en la formulación específica de cada recipiente y que cabe poner en relación con el concurso de alfareros y/o centros de producción diversificados, dada la ausencia de especialización requerida. Desde un punto de vista morfológico las variaciones atañen a las soluciones adoptadas por los bordes, observándose leves matices en el grado de desarrollo de las facetas, su inclinación y la sección de los labios.
La vocación eminentemente utilitaria del tipo se manifiesta en la sencillez de su tratamiento técnico. Las superficies han recibido un simple alisado homogeneizador, reservando para el borde un tratamiento bruñido más cuidado que ocasionalmente se extiende a la pared externa. Predominan las pastas grisáceas y/o pardas con abundantes inclusiones de micas muy pequeñas, escasos cuarzos medios, vacuolas ocasionales y numerosos esquistos y cuarcitas de todos los tamaños que confieren a las piezas un aspecto final y textura característicos.

La forma puede encuadrarse genéricamente en el tipo I de M. Vegas, Ollas con borde vuelto hacia afuera (Vegas, 1973: 11-14), que acoge ollas de perfiles y tamaños muy heterogéneos. Manifiesta, sin apenas modificaciones, una amplia perduración y se documenta con profusión, adaptado a las técnicas y tradiciones alfareras locales, en multitud de yacimientos de todo el Imperio, por lo que serían innumerables los paralelos que podrían citarse. En Lucus Augusti, referente habitual de muchos de los tipos documentados en el Chao Samartín, morfologías similares se recogen bajo la denominación de Ollas globulares de borde exvasado oblicuo, sin decoración ${ }^{53}$, de la fase II, reduciéndose en la fase I (siglo I d.C.) la presencia de perfiles similares a vasijas de almacenamiento ${ }^{54}$.

De modo similar a lo que acontece en Lugo (Alcorta, 2001:193), también en el Chao Samartín constituyen el recipiente de preparación de alimentos y cocción por antonomasia, siendo la olla de cocina mejor representada tanto en el contexto de análisis, como en los repertorios del siglo II d.C. (Figura 140) (Hevia et alii, 2001). Aunque por el momento no puedan establecerse precisiones acerca de una posible evolución cronológica entre las dos variantes indicadas, podría plantearse, a partir de los diversos repertorios del Chao Samartín y a modo de hipótesis que el desarrollo de la investigación deberá confirmar, una mayor modernidad del tipo con acanaladura en el borde, numéricamente inferior en este contexto del siglo I d.C. a la modalidad simplemente facetada y con amplia representación en momentos posteriores (Hevia et alii, 2001: 170-177).

\footnotetext{
53 Tipo O1/O1A (Alcorta, 2001: 193-196, figs. 80-81).

54 Ollas globulares groseras, de almacenaje, Tipo L7 (Alcorta, 2001: 102-104, figs. 45-46)
} 

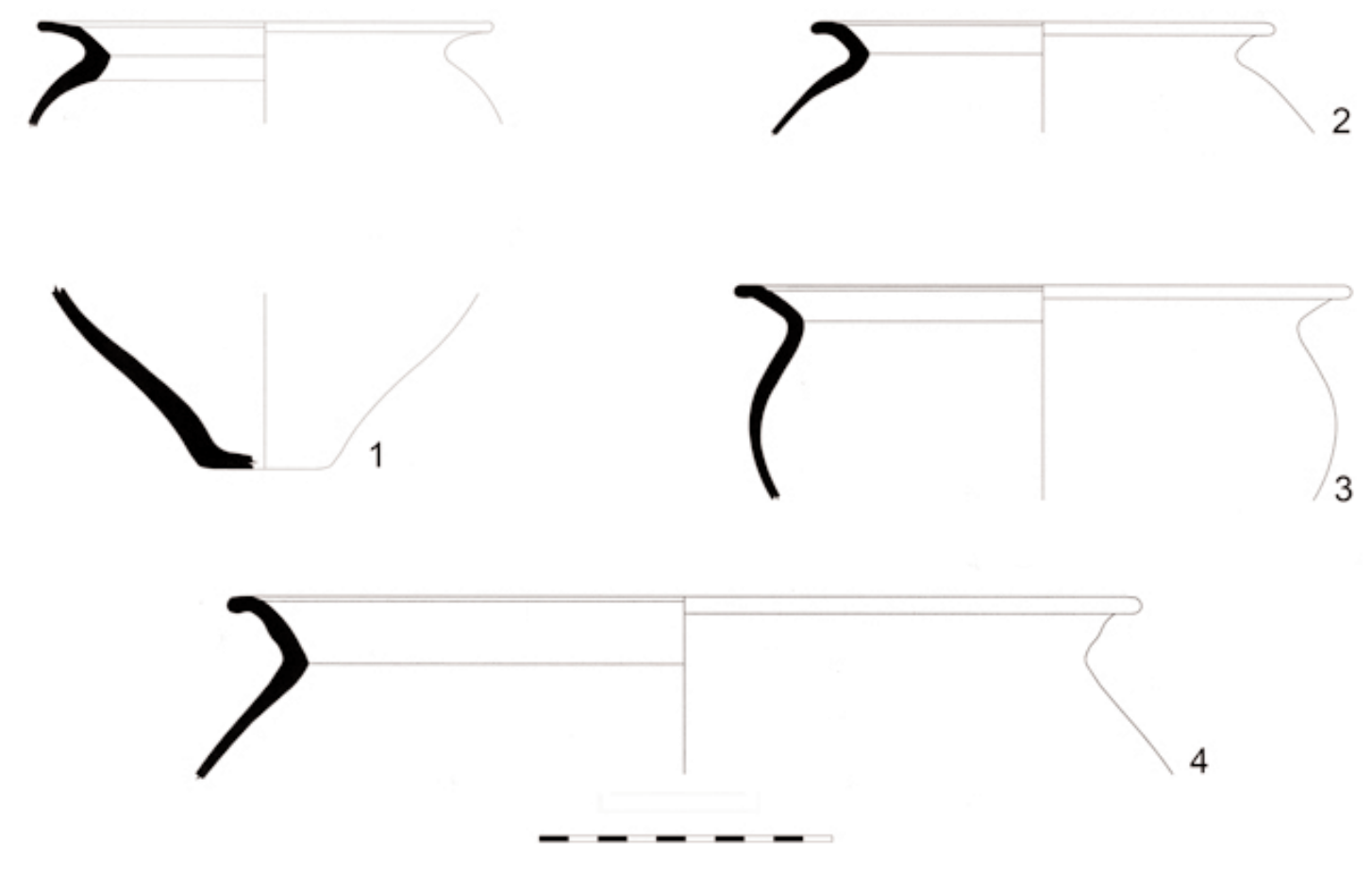

Figura 72. Ollas de borde facetado

\section{CATÁlogo}

1. CH.02/2821. Sector N-1/Foso E. Fragmento de borde, cuerpo y base. Borde exvasado, oblicuo y de perfil de tendencia recta al interior con labio de perfil biselado separado al interior del cuello mediante una suave inflexión. Cuello corto, exvasado, oblicuo y curvo. Cuerpo globular. Base plana en lo conservado. Pasta grisácea con desgrasantes micáceos pequeños, esquistosos y cuarcíticos de todos los tamaños. Superficies grises. Acabado bruñido en borde y alisado en la superficie externa. Al interior, resultan visibles las huellas del torneado. Dimensiones: diámetro borde: $155 \mathrm{~mm}$; altura conservada: $84 \mathrm{~mm}$; diámetro base: $45 \mathrm{~mm}$; grosor medio sección pared: $6 \mathrm{~mm}$. Bibliografía: Hevia, 2006.

2. CH.02/2208. Sector N-1/Foso E. Fragmento de borde y cuerpo. Borde corto, exvasado, oblicuo y recto al interior con labio de perfil redondeado que queda separado del cuello al interior mediante una inflexión suave a modo de cambio de plano. Cuello corto, exvasado, oblicuo y de perfil recto al interior separado del cuerpo mediante una arista. Cuerpo globular. Pasta gris oscura con desgrasantes micáceos pequeños y esquistosos y cuarcíticos pequeños y medios. Superficies grises oscuras con acabado alisado en la externa y bruñido en el borde. Concreciones calcáreas en ambas superficies. Dimensiones: diámetro borde: 158 $\mathrm{mm}$; altura conservada: $38 \mathrm{~mm}$; grosor medio sección pared: $5 \mathrm{~mm}$. Bibliografía: Hevia, 2006.

3. CH.02/1869. Sector N-1. Fragmento de borde y cuerpo. Borde corto, exvasado, de perfil recto al interior y horizontal con labio de perfil redondeado. Queda separado al interior del cuello, corto, oblicuo y recto al interior, por una acanaladura. Cuerpo globular. Pasta de tonalidad grisácea con desgrasantes micáceos muy pequeños y cuarcíticos y esquistosos pequeños y medios. Superficies alisadas, 
excepto en el borde y el cuello al interior, sometidos a un acabado bruñido. Concreciones negruzcas en la cara externa. Dimensiones: diámetro borde: $210 \mathrm{~mm}$; altura conservada: $73 \mathrm{~mm}$; diámetro máximo cuerpo: $200 \mathrm{~mm}$; grosor medio sección pared: 4.5 mm. Bibliografía: Hevia, 2006.

4. CH.02/1772. Sector N-1. Fragmento de borde y cuerpo. Borde exvasado, casi horizontal y de perfil recto al interior con labio ligeramente engrosado de perfil redondeado. Queda separado del cuello, corto, exvasado, oblicuo y de perfil recto al interior y curvo al exterior por una inflexión bien marcada. Cuerpo globular. Pasta grisácea con desgrasantes micáceos pequeños y cuarcíticos y esquistosos variados, alguno muy grande. Superficie externa pardo grisácea e interna gris. Acabado bruñido en borde y cara externa. En la superficie interna se aprecian las estrías del torneado. Dimensiones: diámetro borde: $261 \mathrm{~mm}$; altura conservada: 36 mm; grosor medio sección pared: $5.5 \mathrm{~mm}$. Bibliografía: Hevia, 2006.

\section{Ollas de Líneas verticales}

\section{BRUÑIDAS (Figuras 73 y 74)}

Esta solución tipológica (Hevia et alii, 2001: 177-181, Fig.8 y 9) responde a una formulación morfológica y técnica bastante homogénea en la que las únicas variaciones afectan a la capacidad de los recipientes ${ }^{55}$ y se fija durante el siglo I d.C., para gozar, como veremos, de una larga vigencia (Figura 144) (Hevia, 2006). Formalmente el tipo queda definido por un borde exvasado y oblicuo que se presenta en la modalidad facetada. Por lo que respecta al cuerpo, describe el típico perfil globular de esta categoría funcional. La base es plana. (Hevia, 2009: 364-365 y 456-457).

55 El diámetro mínimo del borde de los ejemplares registrados ronda los $150 \mathrm{~mm}$, sobrepasando las ollas de mayor tamaño los $300 \mathrm{~mm}$. Esta observación, válida para el conjunto de los ejemplares registrados, no lo es tanto para las produc-

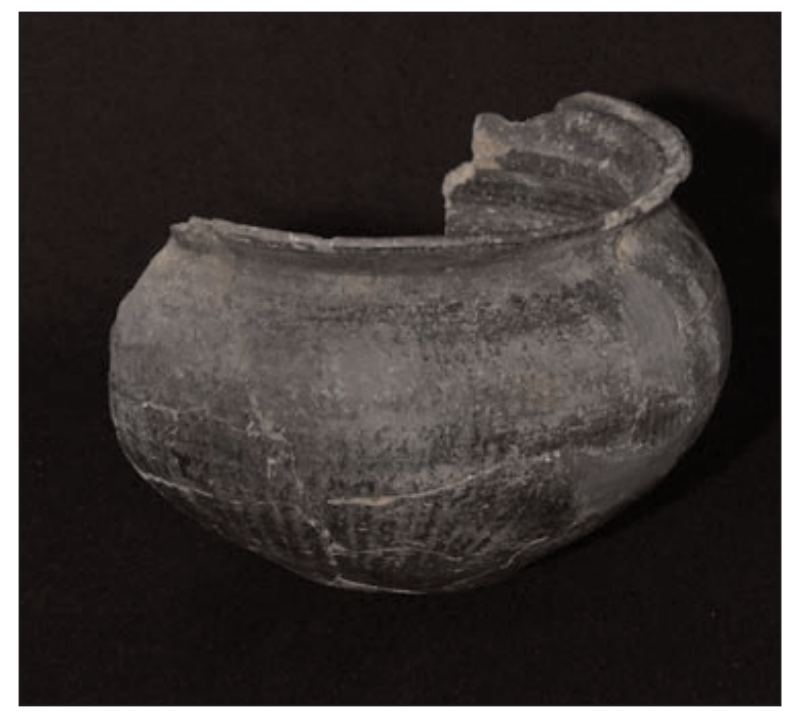

Figura 73. Olla de líneas verticales bruñidas. Foto: J. Arrojo

Sin embargo, el rasgo que con más firmeza confiere al tipo la cualidad de tal es la presencia en la cara externa de una decoración consistente en líneas verticales bruñidas que ocupan toda la pared de la pieza, a excepción de dos pequeñas bandas en los extremos superior e inferior que flanquean el espacio decorativo. No obstante, el aire unitario no reside tan sólo en esta característica ornamental sino también en la homogeneidad morfológica y en determinados rasgos técnicos comunes. En efecto, estas ollas presentan un característico acabado bruñido relativamente cuidado que afecta al borde, al cuello y al espacio externo carente de decoración (parte superior y extremo inferior de la pared). Esta relativa homogeneidad queda refrendada también en función del análisis macroscópico de pastas, que remiten invariablemente a las características regionales toscas esquistosas.

La adscripción funcional del grupo formal a procesos culinarios en caliente parece incuestionable, a juzgar por las evidencias de exposición al fuego de las superficies externas, a pesar de la curiosa vinculación realizada por algunos autores a funciones de almacenamiento, no limitada al

ciones tempranas, en las que se detecta una homogeneidad dimensional mucho mayor, con piezas siempre pequeñas de diámetros en torno a los $150 \mathrm{~mm}$. 
grupo que se trata, sino extendida por igual a la totalidad de producciones con decoración de líneas bruñidas (Ríos y García de Castro, 1998: 46).

Se pueden referir semejanzas para la fórmula tipológica en diferentes yacimientos del occidente asturiano como Arancedo (Maya, 1988: 157, Fig.43.A), Coaña (Ibidem: Fig.42.B, 43.B y 44.A), Pendia (Ibidem: Fig.43.C) ${ }^{56}$ y Mohías (Fernández Ochoa: 1982, 134) ${ }^{57}$. Más precisos son los paralelos registrados en Lucus Augusti, donde se recogen recipientes similares en todas las fases (Alcorta, 2001: 95-97, Fig. 42, 193-196, Fig. 80-81, 250-252, Fig.105). No obstante, porcentualmente no parecen haber alcanzado la rele- vancia constatada en el Chao Samartín, ni tampoco su homogeneidad formal, según evidencia la inclusión de piezas muy semejantes a las nuestras como variantes o subgrupos de categorías mayores, compartiendo tipología con ejemplares lisos como el tipo 01/01A de ollas globulares de borde exvasado oblicuo, sin decoración (Alcorta, 2001: 193-196, Fig. 80-81) ${ }^{58}$ o decorados, caso del tipo L4 de ollas globulares de cocina, decoradas (Alcorta, 2001: 95-97, Fig. 42) y del O24, que incluye las denominadas ollas globulares, espatuladas, de borde vuelto (Ibidem:250-252, Fig.105) $)^{59}$.

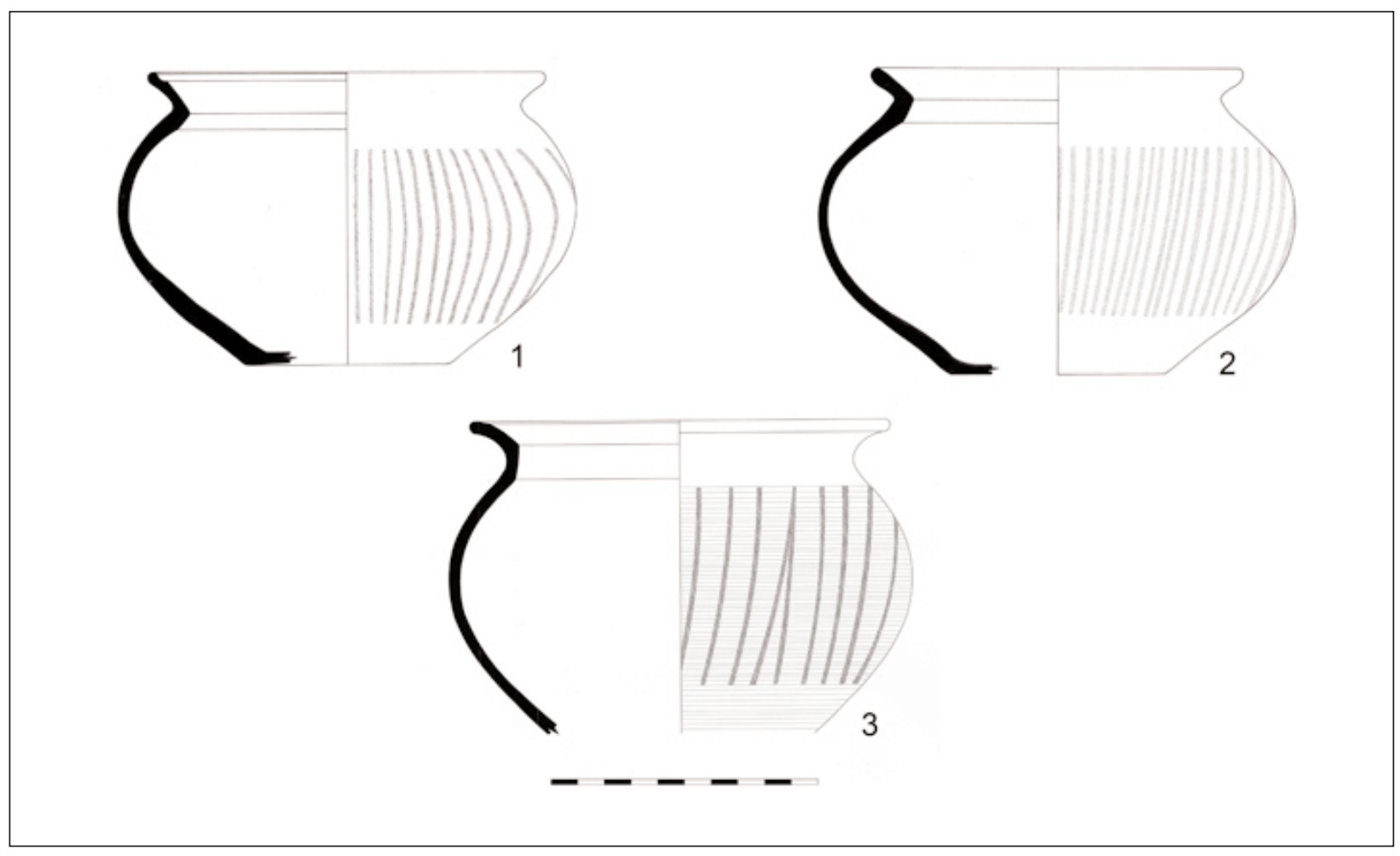

Figura 74. Ollas de líneas verticales bruñidas

56 Todo este conjunto de piezas, recogidas por J.L. Maya en su obra monográfica sobre la cultura material de los castros asturianos y englobadas en la forma I de su propuesta de sistematización tipológica, no presentan una gran uniformidad morfológica y las similitudes con las piezas presentadas del Chao Samartín son bastante vagas y centradas básicamente en la técnica y los motivos decorativos (Maya, 1988: 156158).

57 Lo somero de las descripciones realizadas y la ausencia de representación gráfica impide hacer comparaciones con mayor firmeza. En concreto, las piezas Mh23, 24, 27 y 28 (Fernández Ochoa: 1982: 134-135) pudieran corresponder- se a piezas similares a las descritas, habida cuenta de la presencia en ellas de líneas verticales bruñidas.

58 Incluido en la segunda fase (siglos II-IV d.C.), engloba ollas mayoritariamente lisas de perfiles similares a las nuestras, entre las que se encuentra un ejemplar decorado (Ibidem: 195; Fig.81.6) de gran similitud con el tipo descrito.

59 También de la segunda fase, incluye recipientes con decoración de líneas bruñidas verticales, si bien sus dimensiones y la ausencia de máculas de hollín, parecen apuntar una naturaleza funcional diferente, relacionable con los vasos ovoides grises decorados del Chao Samartín. 


\section{CATÁlogo}

1. CH.93/1495. Sector R-V. Fragmento de borde, cuerpo y arranque de base. Borde exvasado oblicuo y recto al interior con labio de perfil redondeado cóncavo al interior. Cuerpo globular achatado. Base plana en lo conservado. Decoración de líneas verticales bruñidas desiguales en su superficie externa. Pasta grisácea con desgrasantes micáceos pequeños y cuarcíticos y esquistosos medianos y grandes. Superficies negras con acabado bruñido en la externa y el borde. Hollín en la superficie externa. Dimensiones: diámetro borde: $150 \mathrm{~mm}$; altura: $110 \mathrm{~mm}$; diámetro máximo cuerpo: $172 \mathrm{~mm}$; diámetro base: $77 \mathrm{~mm}$; grosor medio sección pared: 4 mm. Bibliografía: Hevia, 2009, Ficha 117, 364-365.

2. CH.93/1590. Sector R-V. Fragmento de borde, cuerpo y arranque de base. Borde exvasado oblicuo y recto al interior con labio de perfil redondeado. Cuello corto recto. Cuerpo globular achatado. Base plana en lo conservado. Decoración en la cara externa consistente en líneas verticales bruñidas que ocupan toda su superficie. Pasta de tonalidad parda clara con desgrasantes micáceos muy pequeños y abundantes esquistos rojizos de todos los tamaños. Superficie externa negra e interior pardo rojiza. El borde y la superficie externa se encuentran bruñidas. Huellas de carbonización en la superficie externa. Dimensiones: diámetro borde: $168 \mathrm{~mm}$; altura: $115 \mathrm{~mm}$; diámetro máximo cuerpo: $180 \mathrm{~mm}$; diámetro base: $40 \mathrm{~mm}$; grosor medio sección pared: $4 \mathrm{~mm}$. Bibliografía: Inédita.

3. CH.98/0447. Sector R-V. Fragmento de borde y cuerpo. Borde exvasado oblicuo y recto con labio de perfil redondeado separado al interior del borde por una acanaladura. Cuello corto vertical y recto. Cuerpo globular. Decoración de líneas bruñidas verticales. Pasta grisácea con desgrasantes micáceos pequeños, cuarcíticos pequeños y medianos y alguno esquistoso. El borde presenta un acabado bruñido, mientras que en el resto de las superficies, de tonos grises oscuros, se aprecian las líneas de torno. Hollín en la superficie externa. Dimensiones: diámetro borde: $158 \mathrm{~mm}$; altura conservada: $118 \mathrm{~mm}$; diámetro máximo cuerpo: $176 \mathrm{~mm}$; grosor medio sección pared: 5 mm. Bibliografía: Inédita

\section{TAPADERAS (Figura 75)}

Las cubiertas cerámicas que aquí se presentan se caracterizan formalmente por sus paredes oblicuas rematadas en bordes simples frecuentemente engrosados y la disposición de un pomo que hace las veces de asidero, pudiendo encuadrarse genéricamente en el tipo 17 de $\mathrm{M}$. Vegas (1973: 53). Aunque no muy numerosos, los ejemplares documentados en contextos tempranos atestiguan su incorporación a los ajuares domésticos del Chao Samartín durante la primera centuria, aún sin alcanzar ni el grado de estan-

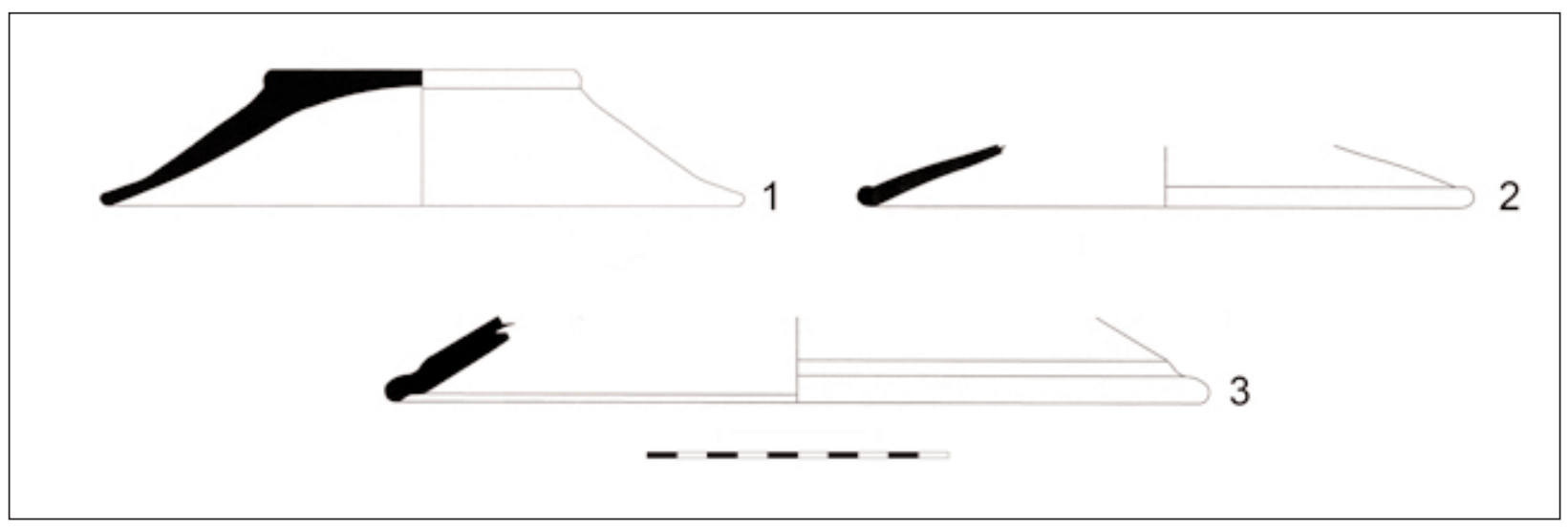

Figura 75. Tapaderas 
darización ni la relevancia cuantitativa que, como veremos, manifiestan en los repertorios del siglo II d.C. (Figura 146) (Hevia, 2009: 458-459). Aún así, se observa en estos tiempos una menor estandarización del tipo, así como una presencia de otras morfologías no regionales de funcionalidad afín que parecen corresponder a producciones alóctonas (Hevia, 2006).

\section{CATÁlogo}

1. CH.02/2478. Sector N-1. Perfil completo. Borde indiferenciado con labio de perfil biselado. Cuerpo abierto y levemente curvo con la zona superior más abierta. Pomo plano con pie de disco y pequeño umbo en el fondo interno. Pasta de tonalidad pardo anaranjada con desgrasantes micáceos pequeños y muy pequeños, cuarzos pequeños y medios y chamota. Superficie externa entre pardo grisácea y pardo anaranjada e interna pardo grisácea. Acabado bruñido tosco en fondo exterior y parte inferior de la superficie externa. En las zonas restantes se observan las huellas del torno. Concreciones calcáreas. Dimensiones: diámetro borde: $219 \mathrm{~mm}$; altura: $40 \mathrm{~mm}$; diámetro base: 108 $\mathrm{mm}$; grosor sección: $6 \mathrm{~mm}$. Bibliografía: Hevia, 2006.

2. CH.02/2254. Sector N-1. Fragmento de borde y cuerpo. Borde indiferenciado con labio engrosado de perfil redondeado. Cuerpo oblicuo de perfil ligeramente cóncavo al exterior. Pasta cuarzo-micácea de tonalidad grisácea. Superficies grises con acabado bruñido. Dimensiones: diámetro borde: $210 \mathrm{~mm}$; altura conservada: $20 \mathrm{~mm}$; diámetro grosor sección: $8 \mathrm{~mm}$. Bibliografía: Hevia, 2006.

3. CH.02/1838. Sector N-1. Fragmento de borde y cuerpo. Borde ligeramente exvasa-

60 No debe obviarse la relevancia que recipientes elaborados en materiales perecederos pudieron tener en el desempeño de tares de almacenamiento.

61 Parece ser que es en estas datas cuando se popularizan en la capital conventual tipos como las grandes ollas globulares grises de borde exvasado y decoración espatulada -tipo O12-, las grandes ollas globulares de borde exvasado, pin- do y horizontal separado del cuerpo al exterior por una tenue acanaladura. Labio de perfil redondeado. Cuerpo oblicuo. Pasta de tonalidad grisácea clara con desgrasantes micáceos pequeños y cuarcíticos pequeños y medios. Superficies rugosas de color anaranjado al exterior y rosáceo al interior en las que resultan visibles las huellas del torneado. Dimensiones: diámetro borde: $280 \mathrm{~mm}$; altura conservada: $29 \mathrm{~mm}$; grosor medio sección pared: $8 \mathrm{~mm}$. Bibliografía: Hevia, 2006.

\section{OrZaS CON NERVADURAS (Figura 76)}

Los recipientes que denominamos orzas con nervaduras componen un morfotipo común y muy característico de los repertorios regionales y representan la fórmula tipológica cerámica ${ }^{60}$ que domina, cuando no monopoliza, las funciones de almacenamiento en estos contextos. Se trata además de recipientes de larga perduración que están presentes en el Chao Samartín, sujetos tan sólo a variaciones de orden menor, al menos desde la segunda mitad del siglo I d.C. hasta momentos avanzados del siglo II d.C. (Figura 150). En Lugo, donde mantienen su vigencia en horizontes de fechas aún posteriores, se constata su perduración hasta mediados del siglo III d.C., momento en el que empiezan a ser sustituidos por otras tipologías (Alcorta, 2001: 217) ${ }^{61}$.

Como es imperativo para el desempeño de las funciones para los que se suponen fueron concebidos, nos encontramos ante recipientes de gran capacidad, con diámetros variables que a veces se sitúan en torno a los $300 \mathrm{~mm}$ para los bordes y los $350 \mathrm{~mm}$ para los galbos, pero que en otras ocasiones alcanzan valores bastante más notables de unos $450 \mathrm{~mm}$ y $500 \mathrm{~mm}$ respectivamente ${ }^{62}$. Formalmente se caracterizan por un borde exvasado facetado del tipo descrito para una de las

tadas y espatuladas -tipo 013- y los recipientes groseros engobados con decoración espatulada -tipo O14- (Alcorta, 2001: 223-233; Fig.95-97). Se trata de morfologías completamente desconocidas en el Chao Samartín.

62 Las piezas de este tipo conocidas en Lugo cuentan con dimensiones similares (Alcorta, 201: 214-217; Figs.90-91). 
variantes de ollas lisas de borde exvasado, con un cuello corto y curvo que precede a un borde también corto y oblicuo. Los cuerpos trazan perfiles globulares y las bases son planas. Sin embargo, el rasgo que dota de una identidad diferenciada de forma más nítida al tipo lo constituye la aplicación en el tercio superior del cuerpo de un número variable de bandas paralelas y continuas de nervaduras o cordones de secciones redondeadas o subtriangulares y dimensiones diversas. Esta presencia, más que como elemento decorativo, debe interpretarse como un refuerzo de las paredes destinado a favorecer los usos para la que ha sido diseñado (Hevia, 2009: 472-473).

Como hemos apuntado, se trata de un tipo de difusión geográfica circunscrita al Noroeste peninsular, no hallándose recogido entre las formas prototípicas de almacenamiento romanas (Vegas, 1973: 115-151; Beltrán, 1990: 260-262). Contamos con paralelos para Asturias en los castros de Arancedo y San Chuis, incluidos por J.L. Maya dentro del grupo de la denominadas cerámicas indígenas o de tradición indígena como tinajas de provisiones (Maya, 1988: 176, Fig. 55B), morfológicamente muy similares a las orzas del Chao Samartín e igualmente dotadas, algunas de ellas, de cordones triangulares en su parte superior.

En la Corona de Quintanilla el morfotipo se documenta tanto en su versión de grandes vasijas para guardar provisiones, con diámetros en torno a los 450 mm (Domergue y Sillières, 1977: 148, fig.54), como en la de pequeñas ollas de cocina de diámetros mucho más reducidos (Ibidem: 142, fig. 46). En Huerña se registran tanto en la capa IV (Domergue y Martín, 1977: 56, fig. 13), como en la capa II (Domergue y Martín, 1977: 124, fig. 33), garantizando la pervivencia de la forma al menos hasta mediados del siglo II d.C.

En Galicia este tipo de recipientes se documentan en el Castro de Santa Águeda (Rodríguez González y Orero Grandal, 1990-91: 173 y 186; fig. 14) y, de manera especialmente significativa, en Lugo, donde las inicialmente denominadas grandes orzas de bandas aplicadas (Alcorta, 1995: 222; Fig. 17.2) y con posterioridad incluidas en el tipo O10 de tinajas globulares de borde vuelto curvo y cordones aplicados (Alcorta, 2001: 214-217; Fig. 90) constituyen la forma de almacenamiento más representativa. Este mismo fenómeno se manifiesta de manera generalizada en otros yacimientos de la región, toda vez que la representación de estas orzas se revela porcentualmente superior a la de otras formas más clásicas de almacenamiento como las dolia, hecho que invita a pensar en un morfotipo de difusión regional tal vez relacionado con la adaptación de modelos previos a la romanización.

Las piezas adscritas a estos contextos tempranos no presentan diferencias significativas respectos a sus herederas de la segunda centuria, momento en el que se mantienen con idéntica pujanza. El único atisbo evolutivo que se puede sugerir, aún teniendo en cuenta lo limitado del repertorio analizado, remite a una mayor frecuencia del registro de ejemplares decorados entre las piezas de cronologías más antiguas.

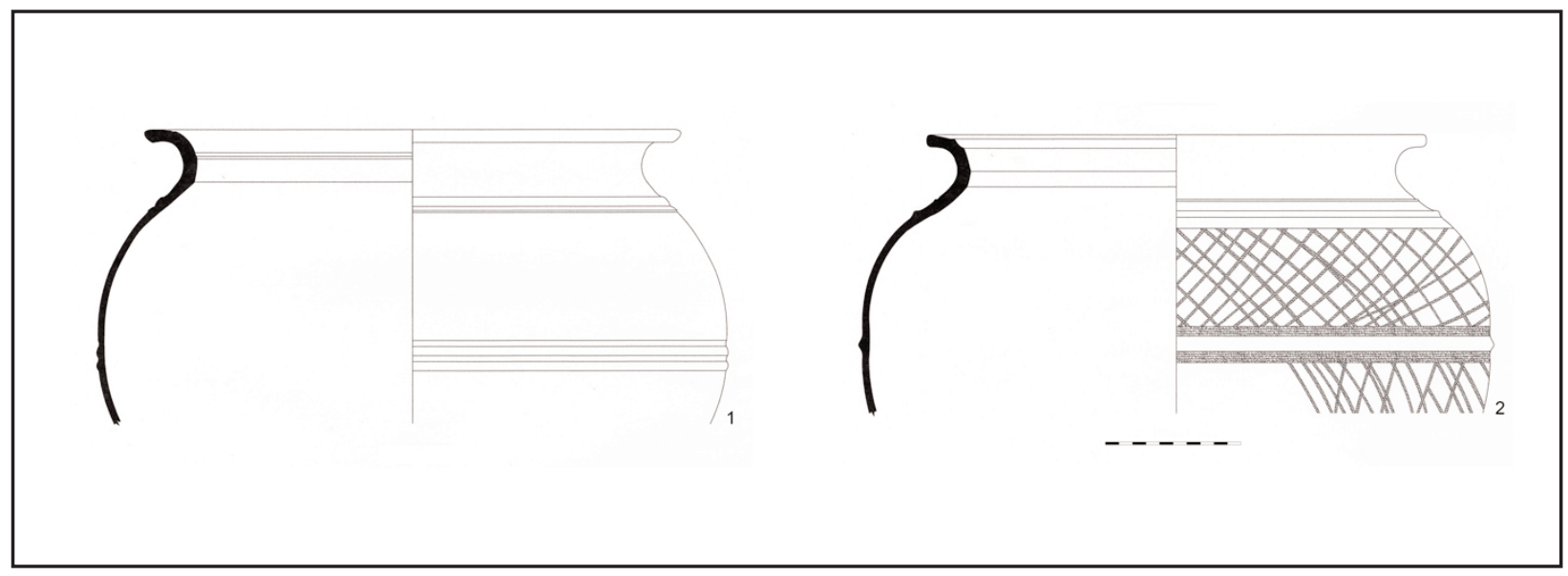




\section{CATÁlogo}

1. CH.02/0768. Sector N-1. Fragmento de borde y cuerpo. Borde exvasado, oblicuo y recto con labio de perfil levemente biselado. Al interior, en la transición al cuello, presenta una tenue acanaladura que refuerza la inflexión. Cuello corto, exvasado y curvo separado al interior del cuerpo mediante una inflexión a modo de cambio de plano. Cuerpo globular recorrido en su mitad superior por dos series de nervaduras pareadas. Decoración de líneas verticales muy gruesas e irregulares bastante separadas entre sí en la parte inferior del cuerpo. Pasta pardo grisácea con desgrasantes micáceos pequeños, cuarcíticos de todos los tamaños y algún esquisto. Superficie exterior de tonalidad pardo grisácea e interna gris. Acabado bruñido en borde y cara externa, mientras que al interior resultan visibles las líneas del torno. Dimensiones: diámetro borde: $410 \mathrm{~mm}$; altura conservada: $223 \mathrm{~mm}$; diámetro máximo cuerpo: $482 \mathrm{~mm}$; grosor medio sección pared: $8 \mathrm{~mm}$. Bibliografía: Hevia, 2006.

2. CH.94/1263. Sector R-V. Fragmento de borde y cuerpo. Borde recto, exvasado y oblicuo con labio ligeramente engrosado de sección redondeada. Cuello exvasado, oblicuo y curvo cuya transición con el borde está marcada por una ancha acanaladura al interior. Cuerpo recorrido en su extremo superior por una acanaladura y, al menos, por dos nervaduras de sección triangular apuntada. Decoración entre las nervaduras consistente en una retícula romboidal de trama ancha y trazo muy irregular que, en las zonas próximas a las nervaduras se halla delimitada por un espatulado horizontal bastante tosco. Bajo el cordón inferior se conserva parcialmente otra secuencia decorada, también con retícula bruñida. Pasta de tonalidad parda con desgrasantes cuarcíticos de todos los tamaños. Superficie interna negra y externa pardo oscuro, gris y anaranjado. Al menos el borde y el extremo superior de la superficie externa han sido bruñidas, siendo visibles en el resto de ambas superficies las líneas del torno. Manchas blanquecinas en la superficie externa. Dimensiones: diámetro borde: $374 \mathrm{~mm}$; altura conservada: $212 \mathrm{~mm}$; diámetro máximo cuerpo: $480 \mathrm{~mm}$; grosor medio sección pared: $5 \mathrm{~mm}$. Bibliografía: Hevia y Montes, 2009: Fig.3.13.

\section{LA VAJILLA DEL SIGLO II D.C.}

\subsection{Contextos Extratigráficos}

El contexto estratigráfico al que se adscriben los materiales que fueron fabricados en el siglo II d.C. se corresponde con niveles vinculados al abandono general del poblado. Para comprender las particularidades del fenómeno hemos de hacer referencia previa a las peculiares circunstancias que concurren en el caso concreto del Chao Samartín y que lo dotan de un extraordinario potencial para el estudio de los materiales en uso en esta época.

El asentamiento de época altoimperial es abandonado de forma repentina tras producirse uno o varios episodios sísmicos (Villa, 1998: 41), según se desprende del análisis combinado de determinados indicios de naturaleza diversa (Villa, 2009). Las consecuencias inmediatas del terremoto consistieron en el brusco colapso de un buen número de estructuras murales, lo que implicó que quedaran sepultados prácticamente incólumes los ajuares de buena parte de los ámbitos

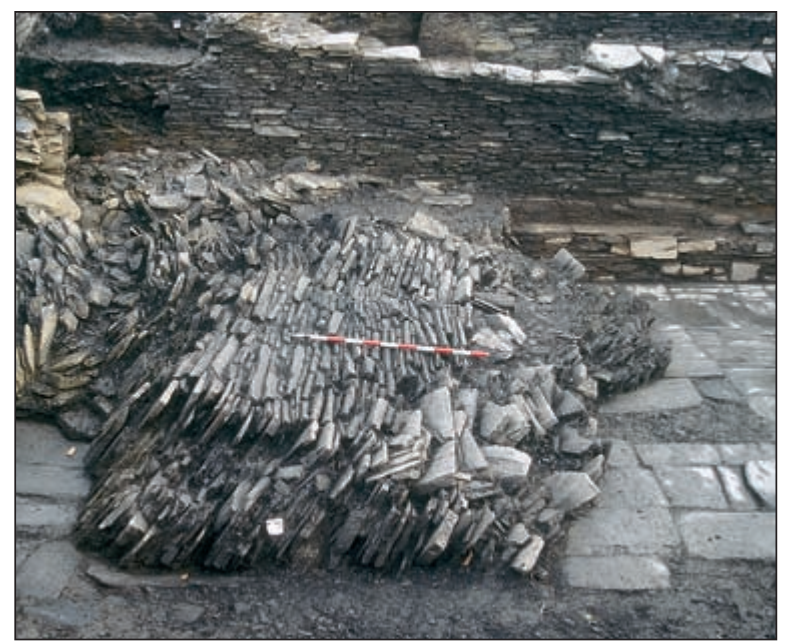

Figura 77. Detalle del colapso del muro occidental de la gran plaza meridional. Foto: Á. Villa. 
domésticos vigentes en estas fechas. Este sellado estratigráfico, que tan sólo ha sufrido puntuales alteraciones en forma de expolios de cronología altomedieval, permite aislar depósitos con contenidos materiales generosos que facilitan la visión de una panorámica, tanto en términos cuantitativos como porcentuales, de la vajilla doméstica en uso en estos momentos.

Este profuso registro material posibilita una aproximación bastante ajustada a la cronología del evento desencadenador del abandono. A este respecto, el artefacto que denota una mayor modernidad reconocido hasta la fecha es un as (Figura 79) acuñado en Roma a nombre de Faustina II entre los años 161 y 176 d.C. (Gil y Villa, 2005: 60).

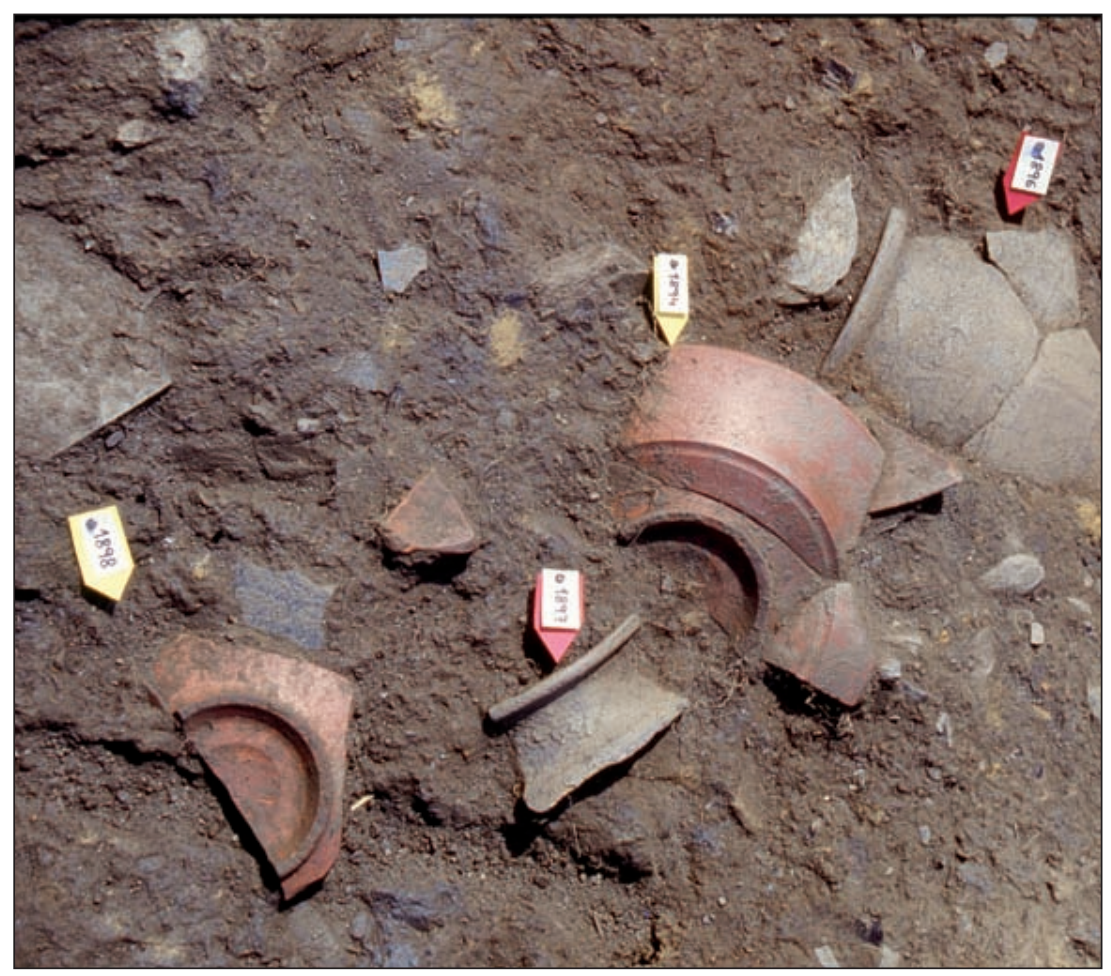

Figura 78. Conjunto cerámico del ajuar de una construcción sellado por el brusco colapso de sus paramentos. Foto: Á. Villa.

El resto de materiales, casi siempre más limitados que el numerario como termini post quem, resultan coherentes con las fechas que proporciona el referido numisma. Cabe de nuevo destacar entre ellos, a causa de lo numeroso y expresivo del repertorio, el conjunto de terra sigillata documentado en estos contextos vinculados al abandono. Un ejemplo paradigmático de ajuar lo constituye el proporcionado por la excavación de la construcción de C-10 $0^{63}$, objeto en su momento de estudio monográfico (Hevia et alii, 1999). El especial interés de esta construcción se basa, en primer lugar, en el ingente volumen de material que albergaba, lo que hace significativo el elenco recuperado desde el punto de vista cuantitativo ${ }^{64}$. Por otra parte, la estratigrafía dota al conjunto de una alta fiabilidad contextual, puesto que los estratos donde se documenta el grueso del material se manifiestan sellados por el derrumbe de las estructuras del edificio, en un proceso de ruina

Figura 79. As de Faustina II. Foto: Á. Villa que se vislumbra brusco, acorde con las circuns-

63 Se puede consultar una descripción del edificio, dividido en dos habitaciones por un tabique medianero, en Villa, 1999 a: 984 .

64 Baste apuntar en este sentido que el conjunto cerámico englobaba un número mínimo de 229 piezas (Beneitez et alii, 1999; Hevia et alii, 1999; Hevia et alii, 2001). 


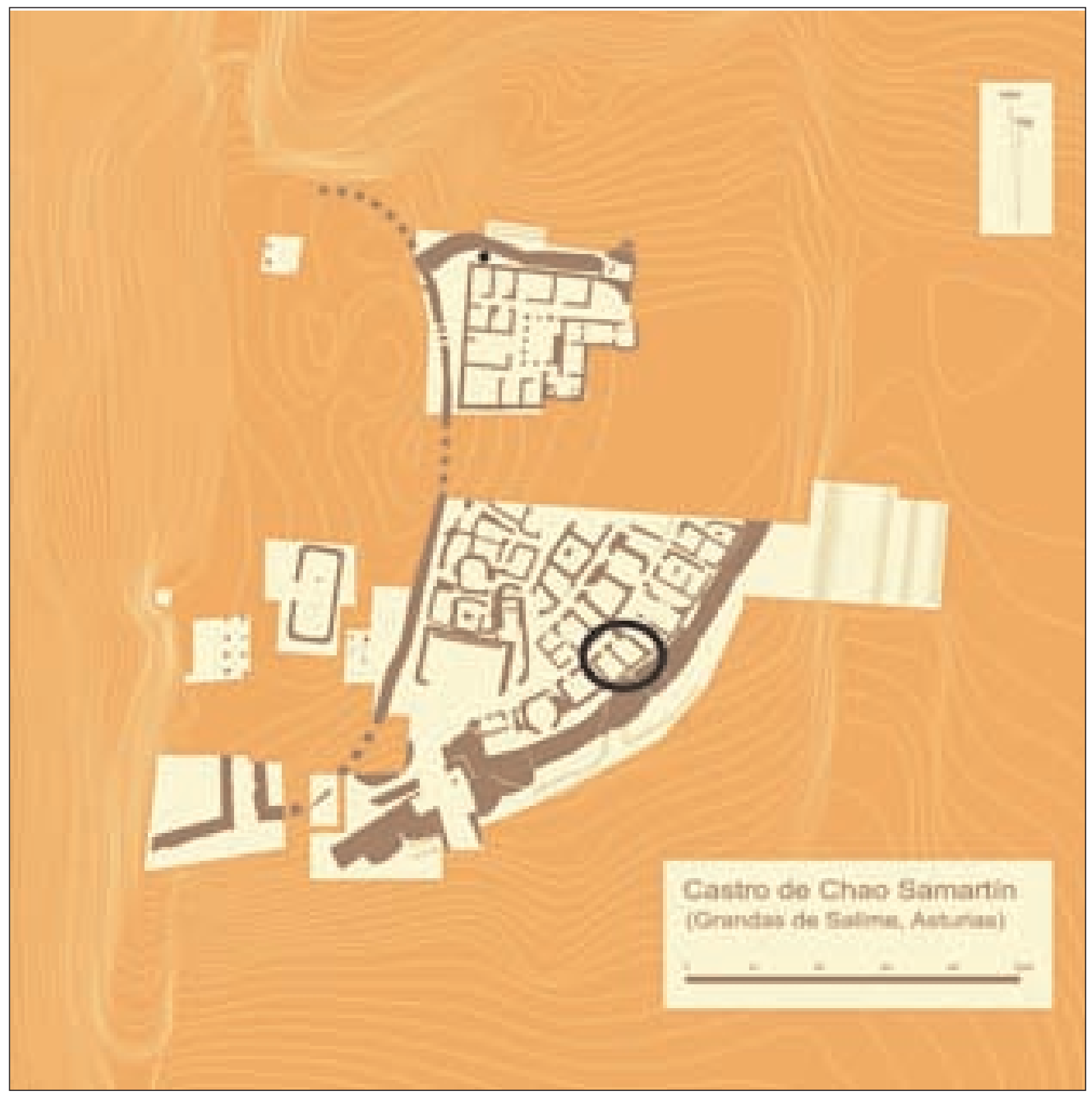

Figura 80. Chao Samartín. Croquis general. Situación del sector C-10. Dibujo: E. Martín y A.Villa

tancias anteriormente comentadas para el abandono general del poblado. Este hecho transfiere al contexto específico de registro un carácter de depósito cerrado y permite un alto grado de reconstrucción de buena parte de las piezas recuperadas y en consecuencia, una aproximación muy verosímil al número de ejemplares totales.

El catálogo de terra sigillata de esta construcción se compone, de una parte, de sendos fragmentos de bases de piezas gálicas interpretables como elementos relictos y correspondientes respectivamente a una Drag. 27 de la moda- lidad marmorata (Hevia et alii: 1999: 162 y 173, Lám. I.1; Menéndez y Sánchez, 2005; Menéndez y Sánchez, 2009: 284-285), fabricada en La Graufesenque hacia mediados del siglo I d.C. (Vernhet, 1991) y a una Drag. 37 con marca del alfarero Nervs (Hevia et alii, 1999: 162 y 173, Lám. I.2; Sánchez, 2003), que trabajó en el mismo centro productor a fines de la primera centuria.

El resto del repertorio remite a producciones hispánicas procedentes de Tritium Magallum que conforman un ajuar que pese a su prodigalidad, resulta bastante monótono en lo que res- 
pecta a la variedad tipológica. Entre las formas lisas el tipo que se encuentra mejor representado es indudablemente el de los platos Drag. 15/17 (Hevia et alii, 1999: 163 y 173-176, Lám. I. 3-4, II y III. 10-22) (Figura 81 y 85.1 y 3 ), sobre cuyos fondos se han identificado además media docena de sellos (Ibidem: 167, Lám.VIII; Sánchez, 2003). Entre ellos destaca la marca del alfarero Agilianvs (Menéndez y Sánchez, 2009: 410-411), con abundantes paralelos en toda Hispania (Mayet, 1984: I.117). Se reconocen también sellos de lectura OFFI.NAS.KAP. (Menéndez y Sánchez, 2009: 448), EX.OF.SAV. (Ibidem: 410-411), OF (...)O y $\mathrm{O}(. .)^{65}$. Se han identificado asimismo vasos de las formas Drag. 35 (Hevia et alii, 1999: 164 y 176-177; Lám. III. 28-32) (Figura 82 y 85.4 ) y 27 (Ibidem: 165 y 177; Lám. IV.33-34) (Figura 85.2).

Rematan el catálogo de formas lisas una pieza del tipo Drag. 46 (Hevia et alii, 1999: Lám. IV.39) y sendos ejemplares adscribibles a la forma Drag. 44 (Ibidem: 165 y 178; Lám. IV.37-38) (Figura 85.6). La presencia de esta última morfología introduce un indicador cronológico de valor, puesto que su fabricación en los talleres hispanos parece iniciarse en el siglo II d.C. (Mayet, 1984: 75-76).

Por lo que se refiere a las formas decoradas, el monopolio de las Drag. 37 resulta completo (Hevia et alii, 1999: 166-167 y 178-180; Lám. V y VI) (Figura 83 y 85.5 y 7 ). Se trata de piezas encuadrables en todos los casos en la variante a y con decoraciones del estilo de círculos, correspondientes al siglo II d.C. (Mezquiriz, 1983: 136).

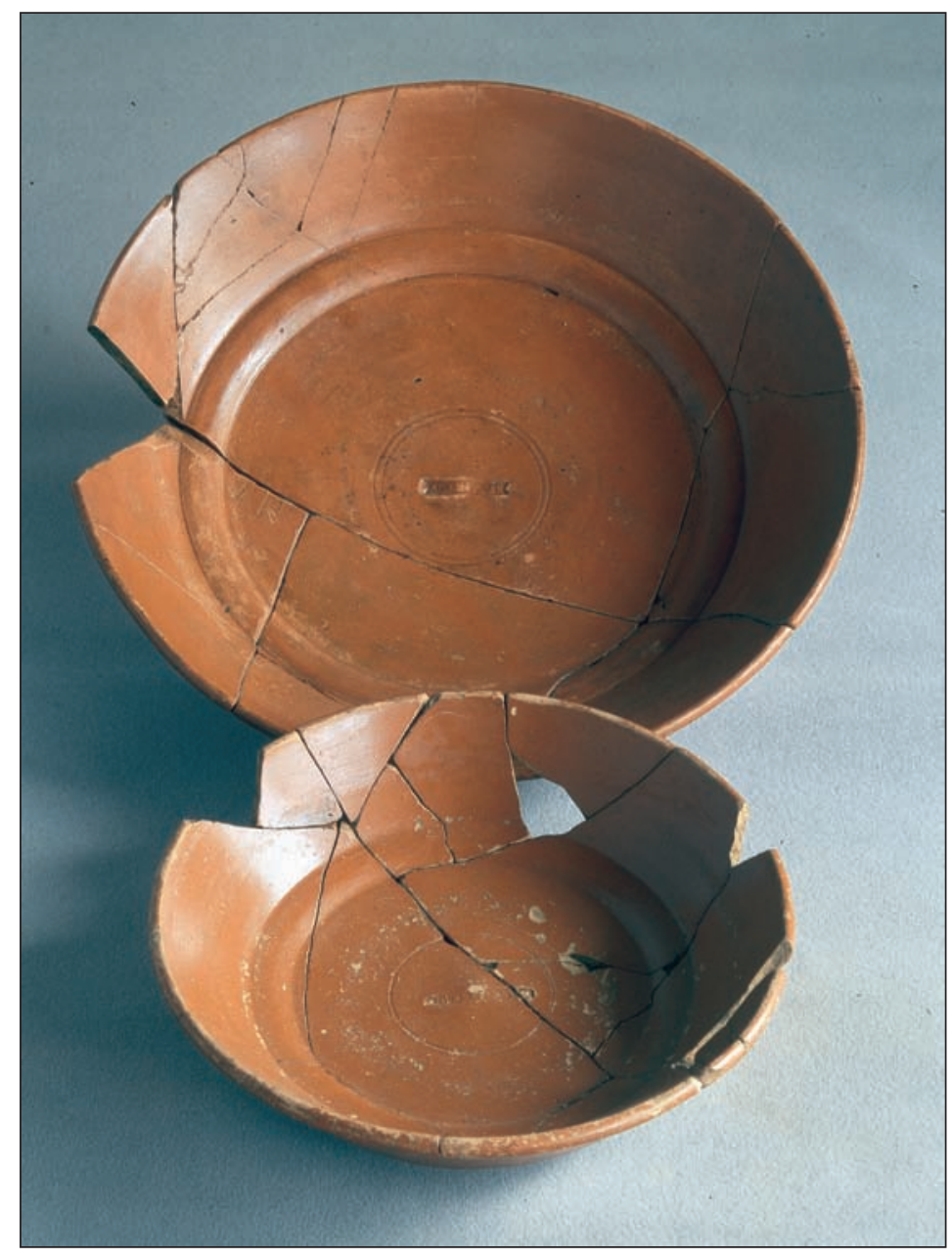

Figura 81. Platos de terra sigillata hispánica de la forma Drag. 15/17. Foto: J. Arrojo

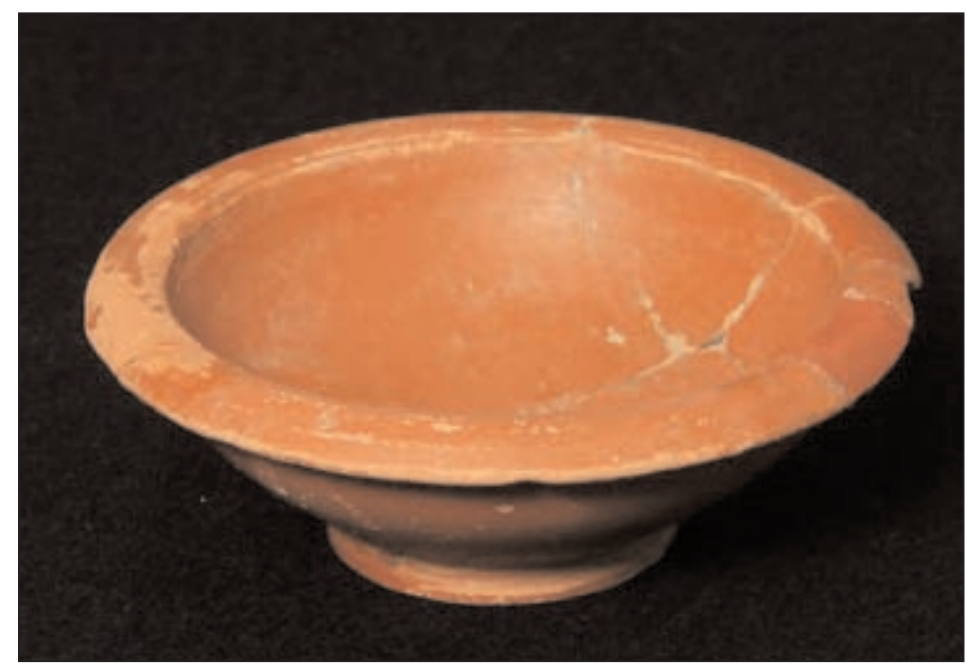

Figura 82. Terra Sigillata Hispánica. Forma Drag. 35. Foto: J. Arrojo

65 Completa la relación de marcas un arranque de cartela bífida (Hevia et alii: 167: Lám.VIII). 
El análisis conjunto del material cerámico de esta construcción ofrece un panorama muy ajustado del ajuar doméstico tipo en momentos avanzados del siglo II d.C., en el que los materiales de fabricación adscribible a la primera centuria resultan porcentualmente irrelevantes y pueden ser interpretados como desechos u ocasionales perduraciones. Tanto su referida escasa presencia, como la precisión del contexto estratigráfico y la rodadura, fragmentación y escaso grado de reintegración de los fragmentos parecen confirmar esta circunstancia.

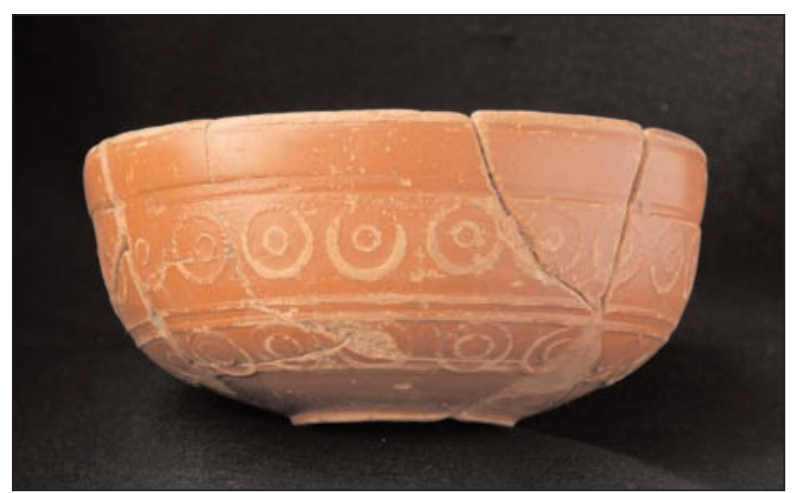

Figura 83. Terra Sigillata Hispánica. Forma Drag. 37. Foto: Á. Villa Valdés

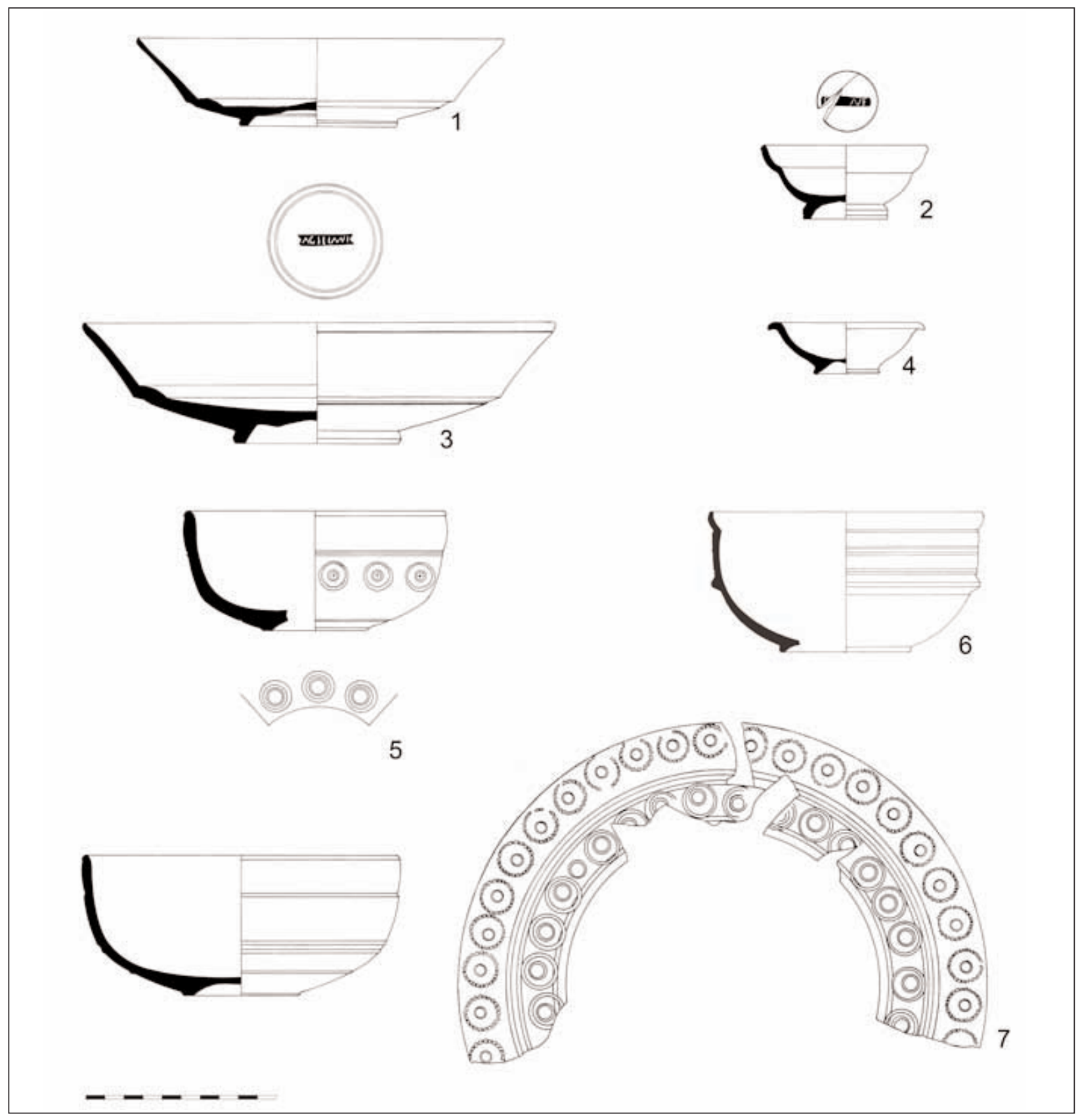

Figura 85. Terra sigillata de la construcción C-10. 1: Drag. 15/17. 2: Drag. 27. 3: Drag. 15/17. 4: Drag. 35. 5: Drag. 37. 6: Drag. 44. 7: Drag. 37. 
Con ciertas matizaciones, este catálogo de la construcción C-10 se repite en buena parte de los contextos de abandono, salvo aquellos en que se producen los fenómenos de acumulación mobiliar analizados al hacer referencia a los contextos del siglo I d.C. Al repertorio de terra sigillata referido se incorporan con cierta asiduidad formas no presentes en éste como las Ritt. 8 (Menéndez y Sánchez, 2009: 414-415) (Figura 84), las Hisp. 4 o las Drag. 36 (Ibidem: 302-303).

En un sentido cronológico semejante al aportado por el registro ergológico apunta la reciente datación arqueomagnética de un horno doméstico cuya fecha de último uso se sitúa, al $95 \%$ de confianza, en un intervalo temporal entre el $181 \mathrm{y}$ el 289 d.C. (Ruiz-Martínez et alii, e.p.).

Así pues, todos los datos disponibles parecen indicar que el cataclismo aconteció en algún momento que debemos situar a partir del año 181 d.C. La ausencia de materiales que proporcionen datas más avanzadas sugiere que el evento ha de fecharse en las dos últimas décadas del siglo II d.C.

Cabe por último referir el hecho de que, frente a lo puntual en lo espacial que resultaban las localizaciones con materiales del siglo I d.C., la representación de contextos relacionados con estas fechas finales resulta mucho más numerosa y sobre todo, se extiende prácticamente a todos los sectores del yacimiento intervenidos.

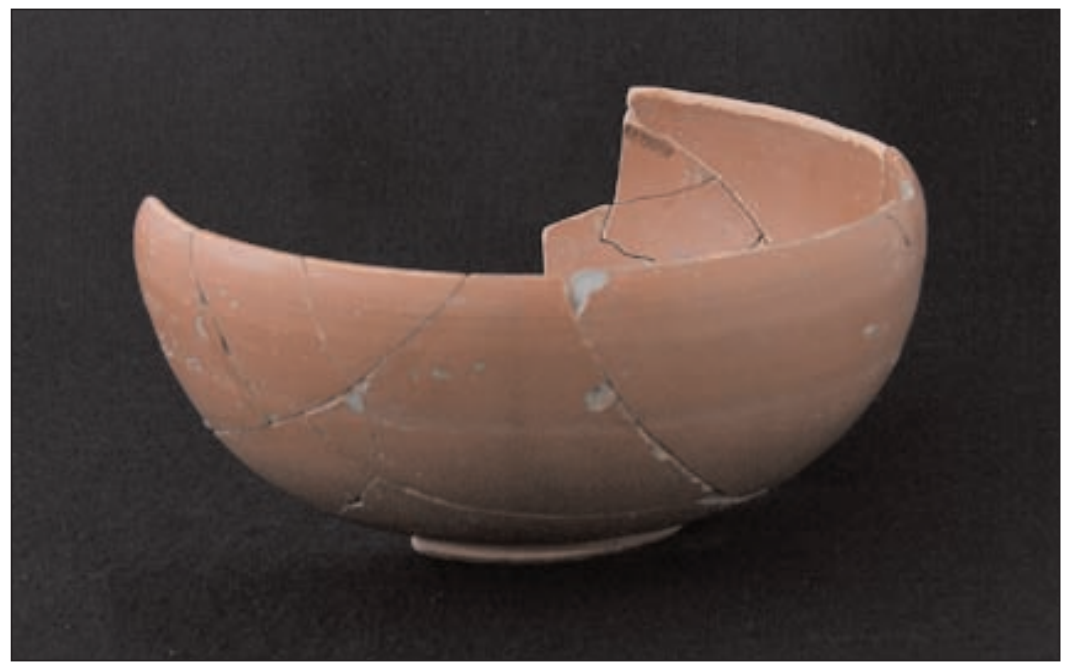

Figura 84. Terra Sigillata Hispánica. Forma Ritt. 8. Foto: J. Arrojo

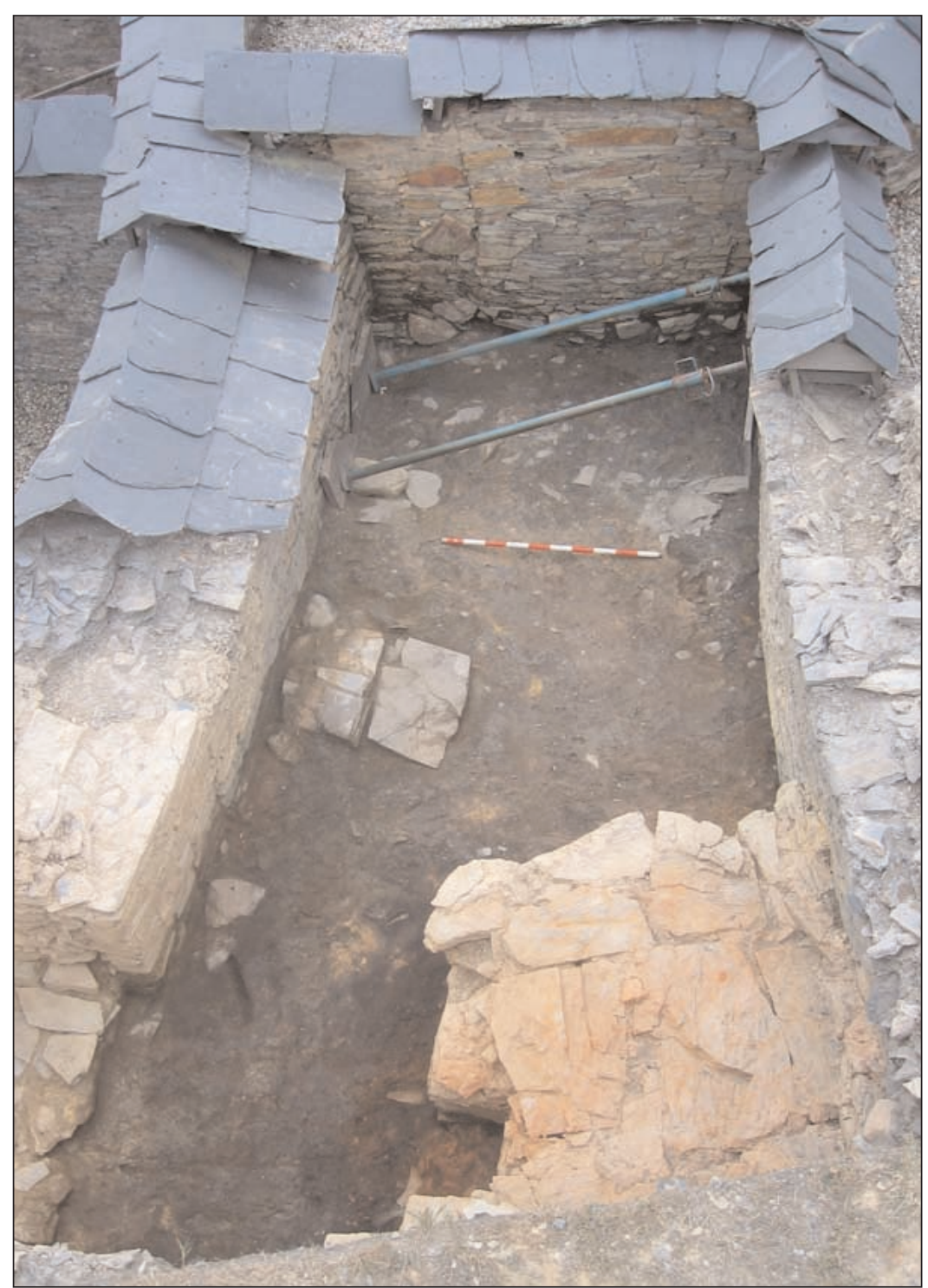

Figura 86. Horno doméstico de la construcción C-18. Foto: Á. Villa 


\subsection{Caracterización general de LAS PRODUCCIONES REGIONALES DEL SIGLO II D.C.}

$\mathrm{Al}$ igual que acontecía con la vajilla de la primera centuria, el estudio de la cerámica de fabricación regional del siglo II d.C. se ve mediatizado por las particulares características contextuales de su localización. Así pues, un rasgo esencial a tener en cuenta es, como hemos referido, el elevado porcentaje de recuperación de las piezas que componían los ajuares originales, muy superior al conseguido para las del siglo I d.C. Esta afortunada circunstancia permite la valoración no sólo cualitativa, sino también cuantitativa de muchos de los repertorios. El grado de reintegración de las diferentes piezas resulta también notable, con las evidentes ventajas que esta circunstancia ofrece al estudio.

Al contrario de lo que ocurría en épocas precedentes, el repertorio alcanza en estos tiempos un alto grado de estandarización tipológica, toda vez que la industria regional se encuentra ya plenamente establecida y ha absorbido las influencias foráneas de todo orden, sintetizándolas con las aportaciones tradicionales (Montes y Hevia, 2008: 770).

De este modo, es ahora cuando podemos proponer un ajuar tipo que constituye el usado en la región avanzado el siglo II d.C. Sus características técnicas generales, aún escondiendo una notable variabilidad, recurren de forma sistemática al empleo de dos tipos fundamentales de pastas, expresadas no obstante en variedades diversas que tienen que ver con la granulometría y la frecuencia de las inclusiones: las cuarzomicáceas y las esquistosas. En cuanto a los tratamientos superficiales a los que se somete a las cerámicas, la norma habitual son los acabados bruñidos en las piezas más finas, reservándose los alisados someros para las producciones menos cuidadas.

66 De acuerdo a un estudio monográfico que aborda de forma sistemática el análisis de la vajilla para beber del yacimiento (Montes, 2005), los vasos ovoides representan un $40.7 \%$ de los recipientes asignados a tal fin, incluyendo formas regionales y piezas importadas.
El repertorio decorativo queda reducido en estos tiempos a dos únicas modalidades que se repiten reiteradamente en aquellos tipos ornamentados. Nos referimos a las decoraciones de líneas bruñidas, netamente dominantes y que se manifiestan mediante diferentes temáticas, entre las que destacan las retículas romboidales y las simples líneas bruñidas, y a los motivos estampillados. Otras fórmulas que habían contado con un notable éxito en el periodo anterior, como las alineaciones de puntos impresos, pierden representatividad hasta desaparecer del repertorio casi por completo.

\subsection{LOS TIPOS CERÁMICOS}

\section{VASOS OVOIDES (Figuras 87-95)}

Los vasos ovoides constituyen una de las formas regionales de vasa potoria más características del repertorio-tipo del Chao Samartín en el siglo II d.C. e indudablemente, la más representada en términos porcentuales (Montes, 2009: $426-427)^{66}$.

Los rasgos morfológicos definitorios del tipo estriban en los bordes cortos, exvasados y oblicuos, los cuerpos con perfil de tendencia ovoi$d^{67}$ y las bases planas con pie de disco.

En cuanto a las dimensiones, se muestran como recipientes de capacidad bastante reducida, con diámetros de borde que generalmente se encuentran en valores comprendidos entre los 70 y los $100 \mathrm{~mm}$, superando rara vez esta cifra. El desarrollo en altura que alcanzan no suele rebasar los $125 \mathrm{~mm}$, mientras que las bases presentan diámetros en torno a los $50 \mathrm{~mm}$.

En lo referente a los aspectos técnicos, suelen estar elaborados en las típicas pastas finas de naturaleza cuarzo-micácea propias de las producciones regionales. Los acabados, por norma general, consisten en bruñidos externos más o menos esmerados en su ejecución, aunque los tratamien-

67 Aunque los ejemplares más característicos describen un perfil netamente ovoide, no faltan las piezas de tendencia globular más o menos acusada. 
tos engobados no son completamente ajenos al tipo. Ambas características combinadas quedan plasmadas en el aspecto pulido con diminutas partículas brillantes en la superficie que dan carta de naturaleza a los ejemplares prototípicos.

A pesar de ajustarse por lo común a estos rasgos generales, esta relativa unidad esconde un grado de heterogeneidad elevado que se detecta tanto en los aspectos morfológicos como en los técnicos. De hecho, podemos establecer una diferenciación de sendas variantes principales (Benéitez et alii, 1999: 16-17; Fig.1) basada sobre todo en el cromatismo de sus superficies.

\section{VASOS ANARANJADOS}

(Figuras 87 y 90-92)

En general, los ejemplares adscribibles a esta variante mantienen unas características bastante homogéneas. Se trata de recipientes cocidos en atmósferas oxidantes que, a pesar de mantener la referida tónica de caracterización técnica ${ }^{68}$, morfológica y dimensional común, observan ciertas diferencias reseñables que conviene concretar en sus rasgos más llamativos, perfilándose tres modalidades básicas (Montes, 2005):

- Vasos finos (Figuras 87 y 90). Constituye el grupo mayoritario y presenta un ajuste bastante estricto a las características morfotécnicas comentadas: oxidación completa, acabados bruñidos bien conseguidos, paredes delgadas, tamaños reducidos y perfiles claramente ovoides (Montes, 2009: 426-427).

- Vasos groseros (Figura 91). En las piezas adscritas a esta modalidad se aprecian diferencias relevantes en el cuidado de los tratamientos superficiales, las pastas y los grosores de las secciones de las paredes. $\mathrm{Su}$ existencia puede obedecer a cierta variabilidad en el proceso productivo, a la existencia de diferentes talleres o, tal vez, a fenómenos de imitación de ámbito local o comarcal de los productos lucenses genuinos. A la genérica tosquedad de los ejemplares pertenecientes a esta variante, tan sólo se pueden añadir como rasgos morfológicos diferenciales cierta preferencia por los perfiles más globulares y por los bordes más desarrollados, que ocasionalmente adquieren una tendencia vertical.

- Vasos engobados (Figura 92). Se trata piezas que presentan aplicación de engobe en sus superficies exteriores, con tonalidades que fluctúan entre el anaranjado y el rojizo. Salvo este detalle particular, un cierto gusto por un tratamiento especialmente cuidado y una tendencia a contar con tamaños reducidos (siempre dentro de las pautas dimensionales que caracterizan al tipo), no se observan diferencias significativas respecto al resto de ejemplares de superficies externas no pigmentadas, sino bruñidas.

El ámbito territorial para el que tenemos constancia del registro de vasos de esta serie anaranjada resulta bastante restringido y se limita a Lucus Augusti (Alcorta, 1995: 217, Fig.13.7) y lo que se

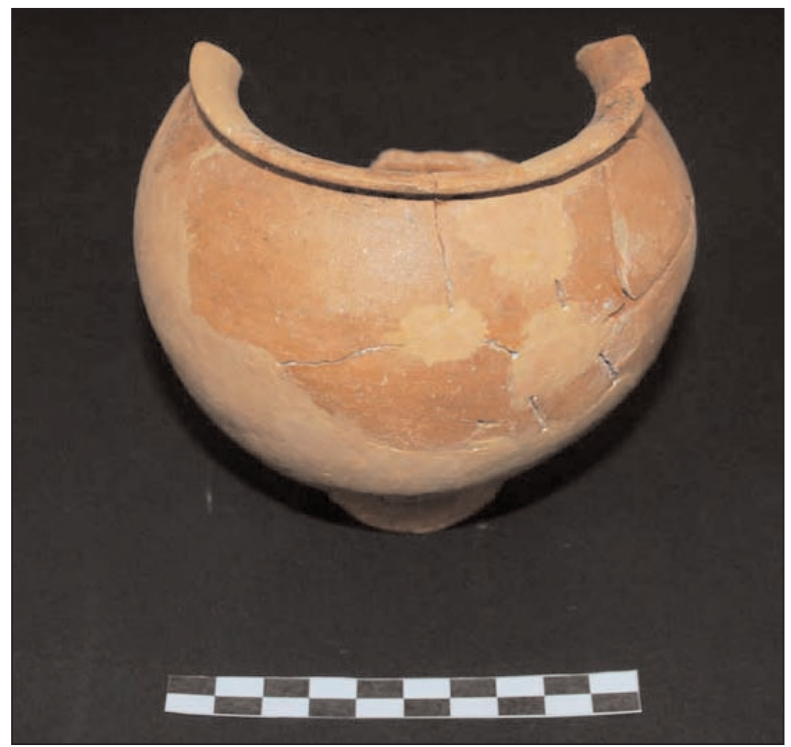

Figura 87. Vaso ovoide anaranjado fino. Foto: R. Montes
68 El predominio de las pastas cuarzo-micáceas finas es absoluto en esta variante. Por el contrario, entre los recipientes de la modalidad gris la presencia de pastas más toscas se torna más destacada. 
puede considerar su estricta área de influencia. Nos referimos a yacimientos castreños como San Chuis (Manzano, 1990: 405, D16 n $\left.{ }^{0} 39-42\right)^{69}$ u Os Castros en Taramundi (Expósito, 2004).

\section{VASOS GRISES}

(Figuras 88-89 y 93-95)

Los ejemplares cocidos en ambientes reductores conforman la variante mayoritaria ${ }^{70}$ y muestran, al igual que ocurría con sus congéneres cocidos en atmósferas oxidantes, cierta variabilidad, mayor aún en este caso, en sus características. Teniendo en cuenta esta heterogeneidad, cabe proponer una triple diferenciación en modalidades (Montes, 2005):

- Vasos finos (Figuras 88 y 93). Piezas con tratamientos superficiales cuidados a modo de esmerados bruñidos equiparables con los de la variante anaranjada y que confiere a los recipientes mejor conservados exteriores lustrosos. Se trata de la modalidad mejor representada ${ }^{71}$, si bien es cierto que las pautas técnicas que muestran no son uniformes y junto a vasos de acabados singularmente esmerados se incluyen otros bastante más groseros, aunque sin alcanzar el grado de tosquedad que caracteriza a la siguiente variante.

- Vasos groseros (Figura 94). Los rasgos definitorios esenciales son la mayor tosquedad de los acabados, las pastas de granulometría más grosera y un mayor grosor de las secciones de sus paredes. Del mismo modo que acontecía con algunos recipientes de la versión anaranjada, se detecta en algunas piezas perfiles más globulares y bordes con cierta tendencia a la verticalidad.

69 Se conoce un pequeño fragmento de base y parte inferior del cuerpo que, a partir de la representación gráfica y de la descripción recogida en la bibliografía, cabe asimilar al modelo. El ejemplar se debe vincular a la modalidad engobada ya que, de acuerdo a la descripción recogida en el catálogo del artículo citado, cuenta con un engobe rojizo.

70 Se estima sus representación en un 54\% del total (Montes, 2005).

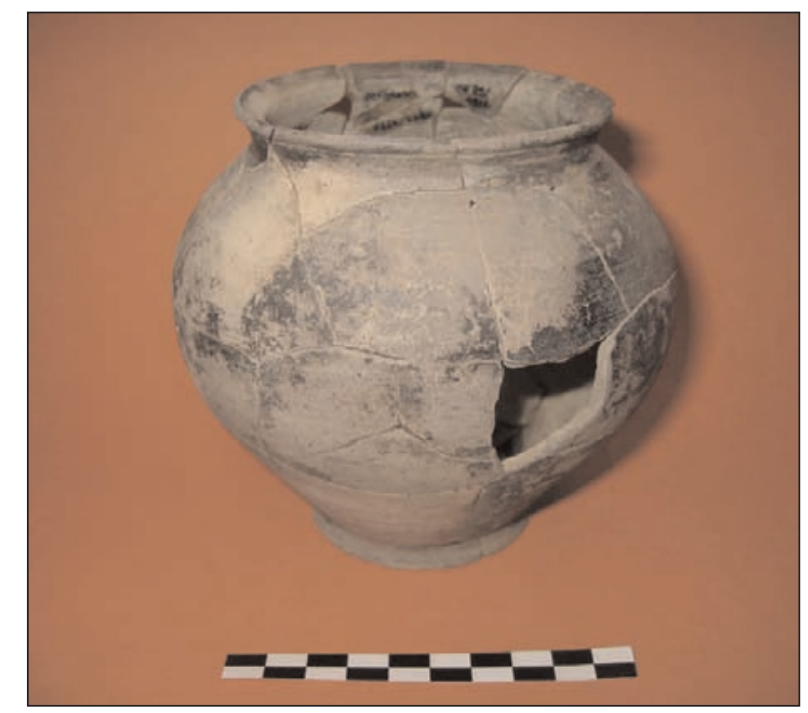

Figura 88. Vaso ovoide gris fino. Foto: R. Montes

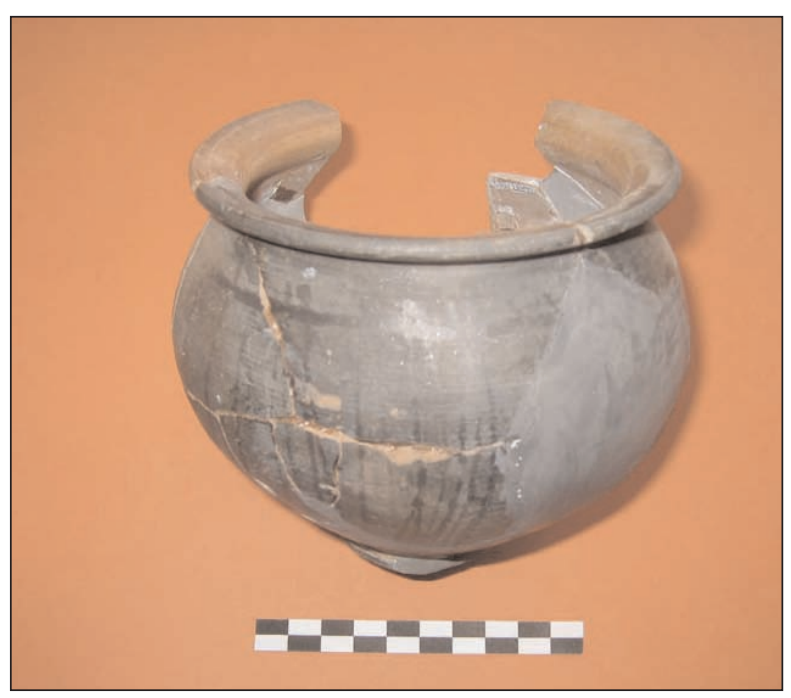

Figura 89. Vaso ovoide gris decorado. Foto: R. Montes

- Vasos decorados (Figura 89 y 95). Los ornatos registrados vienen configurados por líneas bruñidas que, salvo contadas excepciones, se trazan en disposición vertical $^{72}$. En términos generales, los ejemplares que integran esta modalidad, sin llegar a poder ser considerados toscos, no se encuentran entre los más finos de la serie.

71 Representan en torno al $69 \%$ de los vasos grises (Montes, 2005).

72 Se escapan de esta norma general tan sólo alguna rareza (Benéitez et alii, 1999: 16-17, Fig. 1.3), que presenta una peculiar retícula cuadrangular. 
Para estos vasos grises los paralelos que conocemos se circunscriben de nuevo a un territorio que incluye la capital conventual (Alcorta, 1995: Fig. 13.7 y 2001: 271-273, Fig. $114.1-4)^{73}$ y su entorno. En concreto, disponemos de referencias sobre el registro de piezas asimilables a esta variante en yacimientos castreños asturianos como San Chuis (Manzano, 1990: 405, E 12 n $^{\circ}$ 1), El Castelón de Coaña (Maya, 1988: 158, Fig. 47.B), Pendia (García Bellido, 1942: Fig. 10) y Os Castros de Taramundi (Expósito, 2004: 24).

No obstante, al margen de los ejemplares referidos con semejanzas estrictas (formales y tecnológicas) que salpican el territorio histórico lucense y con independencia de la variante concreta, se conocen otros paralelos con similitudes más vagas en un amplio ámbito regional que incluye yacimientos castellano-leoneses como Huerña (Domergue y Martin, 1977) ${ }^{74}$, Rosinos de Vidriales (Carretero, 2000: 489491, Figs. 283. 78-85 y 89, 284. 92-100 y 286. $111)^{75}$, Padilla de Duero (Romero y Sanz: 1990: 167, Fig.2.1), Cacabelos (Gómez Moreno, 1925-26: 62, Lám.16), Montealegre de Campos (Balil y Martín Valls, 1988: 57, 62, 64-67 y 97, Fig. 10 y 13$)^{76}$ o Sasamón (Abásolo y García, 1993: 121, 131-132, 146-147 y 152-153, Fig. 62. 1-2, 67. 2-13 y 75.9-13) ${ }^{77}$. Sin embargo, lo extenso de su ámbito de distribución y lo variado de sus caracteres técnicos sugiere una realidad compleja y una pluralidad de centros productores de influjo local o comarcal, tal y como apunta Carretero (2000: 491), siempre dentro de unos criterios estéticos y sobre todo, morfofuncionales, comunes, seguramente inspirados en las paredes finas genuinas. En este sentido, algunos autores (Alcorta, 1995: 217) los consideran imitaciones locales de paredes finas. A

73 Tipo V3 de vasos ovoides de borde flexionado, sin decoración.

74 Se les recoge bajo la denominación de vasitos ovoides de barro gris (Domergue y Martin, 1977: 110-111).

$75 \mathrm{El}$ autor los engloba en la categoría de vasos ovoides de perfil en $S$, entre los que distingue lo que da en llamar pequeñas ollas de cerámica común que adoptan ciertas caracte- nuestro entender, sin embargo, no se deben interpretar como imitaciones en sentido estricto, sino más bien como formulaciones locales de morfologías de moda que sustituyen funcionalmente a aquellas (Montes y Hevia, 2009: 770).

Las referencias cronológicas que se manejan para este tipo de recipientes tienden a situarlos entre finales de la primera centuria y el siglo II d.C. Entre las producciones con las que se supone una identidad genética, cabe destacar que para la ciudad de Lugo se apuntan cronologías a caballo entre ambos siglos (Alcorta, 2001: 271). Fuera ya de este ámbito, en Rosinos de Vidriales se registran de forma continuada en los niveles relacionados con la presencia del Ala II Flavia, sin que se encuentren presentes en los de la Legio X Gemina (Carretero, 2000: 490), mientras que tanto en Montealegre de Campos (Balil y Martin Valls, 1988: 62) como en Sasamón se documentan en contextos del siglo II d.C., avanzado en el primer caso. En el Chao Samartín no se ha detectado aún su presencia en contextos de la primera centuria, en claro contraste con la popularidad que adquirieron estos vasos en la segunda, a juzgar por su recurrente registro en cuantos horizontes correspondientes a estas fechas han sido excavados.

A partir de la información disponible, hemos de postular para el morfotipo una producción regional, probablemente centrada en Lucus Augusti, en donde se desarrolló una importante industria alfarera a partir de finales del siglo I d.C. (Alcorta, 2001) y en cuyo hinterland se concentran los mencionados paralelos con que se cuenta para este elenco del Chao Samartín. rísticas de las paredes finas y vasos ovoides lisos. Estos últimos podrían encontrarse relacionados con las producciones de Melgar de Tera (Carretero, 2000: 491).

76 Estos autores se refieren a estos recipientes como vasos ovoides de borde vuelto y paredes muy finas.

77 En este caso se propone la denominación de vasos ovoides de imitación de paredes finas (Abásolo y García, 1993). 


\section{CATÁlogo}

\section{VASOS OVOIDES}

\section{(variante anaranjada fina)}

1. CH.95 /0941. Sector C-10 A. Fragmento de borde y cuerpo. Borde corto, exvasado, oblicuo y curvo con labio de perfil redondeado. Cuerpo de perfil curvo en lo conservado. Pasta de tonalidad anaranjada con abundantes desgrasantes micáceos y cuarcíticos de pequeñas y medianas dimensiones. Superficies anaranjadas, la externa sometida a un acabado bruñido, al igual que el borde. Dimensiones: diámetro borde: $80 \mathrm{~mm}$; diámetro máximo cuerpo: $98 \mathrm{~mm}$; altura conservada: $57 \mathrm{~mm}$; grosor medio sección: $3 \mathrm{~mm}$. Bibliografía: Benéitez et alii, 1999: 15-17, Fig.1.18; Montes, 2005.

2. CH.98/3431. Sector C-12. Fragmento de borde y cuerpo. Borde corto, exvasado, oblicuo y curvo con labio de perfil redondeado. Cuerpo de perfil curvo en lo conservado. Pasta anaranjada con abundantes micas muy pequeñas y algún cuarzo pequeño y medio. Superficies de tonalidad anaranjada, la externa con zonas grisáceas. El borde y la cara externa podrían haberse encontrado bruñidos, aunque el estado de conservación impide apreciar este extremo con nitidez. Dimensiones: diámetro borde: $72 \mathrm{~mm}$; diámetro máximo cuerpo: 102 $\mathrm{mm}$; altura conservada: $43 \mathrm{~mm}$; grosor medio sección: $2.5 \mathrm{~mm}$. Bibliografía: Montes, 2005.

3. CH.95/4662. Sector C-10 B. Perfil completo. Borde exvasado, oblicuo y curvo con labio de perfil redondeado. Cuerpo de perfil ovoide. Base con pie de disco y fondo externo cóncavo recorrido por una serie de acanaladuras concéntricas e interno umbilicado. Pasta de tonalidad anaranjada con abundantes desgrasantes micáceos y cuarcíticos pequeños y medianos. Superficies anaranjadas, con acabado bruñido en la externa y el borde. Dimensiones: diámetro borde: $92 \mathrm{~mm}$; diámetro máximo cuerpo: $120 \mathrm{~mm}$; diámetro base: $47 \mathrm{~mm}$; altura: 111 mm; grosor medio sección: $3 / 8 \mathrm{~mm}$. Bibliografía: Benéitez et alii, 1999: 15-17, Fig.1.11; Montes, 2005; Montes, 2009: Ficha 148, 426-427.

4. CH.99/2355. Sector C-19. Fragmento de borde y cuerpo. Borde corto, exvasado, oblicuo y curvo con labio de perfil redondeado. Cuerpo de perfil ovoide. Pasta de tonalidad anaranjada con abundantes desgrasantes micáceos pequeños y muy pequeños y cuarzos de diversas dimensiones (alguno grande). Superficies anaranjadas, la externa, al igual que el borde, bruñida. Dimensiones: diámetro borde: $84 \mathrm{~mm}$; diámetro máximo cuerpo: $112 \mathrm{~mm}$; altura conservada: $99 \mathrm{~mm}$; grosor medio sección: 3 mm. Bibliografía: Montes, 2005.

5. CH.95/4327. Sector C-10 A. Fragmento de borde y cuerpo. Borde corto, exvasado, oblicuo y curvo con labio de perfil apuntado recorrido al exterior por una estrecha acanaladura. Cuerpo de perfil curvo en lo conservado. Pasta de tonalidad anaranjada con abundantes desgrasantes micáceos y cuarcíticos de pequeñas y medianas dimensiones. Superficies anaranjadas, la externa sometida a un acabado bruñido, al igual que el borde. Dimensiones: diámetro borde: $80 \mathrm{~mm}$; diámetro máximo cuerpo: $106 \mathrm{~mm}$; altura conservada: $53 \mathrm{~mm}$; grosor medio sección: $2.5 \mathrm{~mm}$. Bibliografía: Benéitez et alii, 1999: 15-17, Fig.1.9; Montes, 2005.

6. CH.99 /0606. Sector C-12. Fragmento de borde y cuerpo. Borde corto, exvasado, oblicuo y curvo con labio de perfil redondeado. Cuerpo de perfil ovoide. Pasta de tonalidad anaranjada con abundantes micas pequeñas y muy pequeñas y cuarzos pequeños. Superficies anaranjadas, la externa bruñida. Dimensiones: diámetro borde: $80 \mathrm{~mm}$; diámetro máximo cuerpo: $106 \mathrm{~mm}$; altura conservada: $58 \mathrm{~mm}$; grosor medio sección: $2.5 \mathrm{~mm}$. Bibliografía: Montes, 2005. 
7. CH.77 /0193. Sector C-1. Fragmento de borde y cuerpo. Borde exvasado, oblicuo y curvo con labio de perfil redondeado individualizado al interior por una tenue acanaladura. Cuerpo de perfil ovoide. Pasta anaranjada con abundantes micas pequeñas y muy pequeñas, cuarzos pequeños y algún punto negro y rojizo (cerámica ?) de tamaño reducido. La superficie externa y el borde se encuentran bruñidos. Dimensiones: diámetro borde: $85 \mathrm{~mm}$; diámetro máximo cuerpo: $130 \mathrm{~mm}$; altura conservada: $85 \mathrm{~mm}$; grosor medio sección: 3.5 mm. Bibliografía: Montes, 2005.

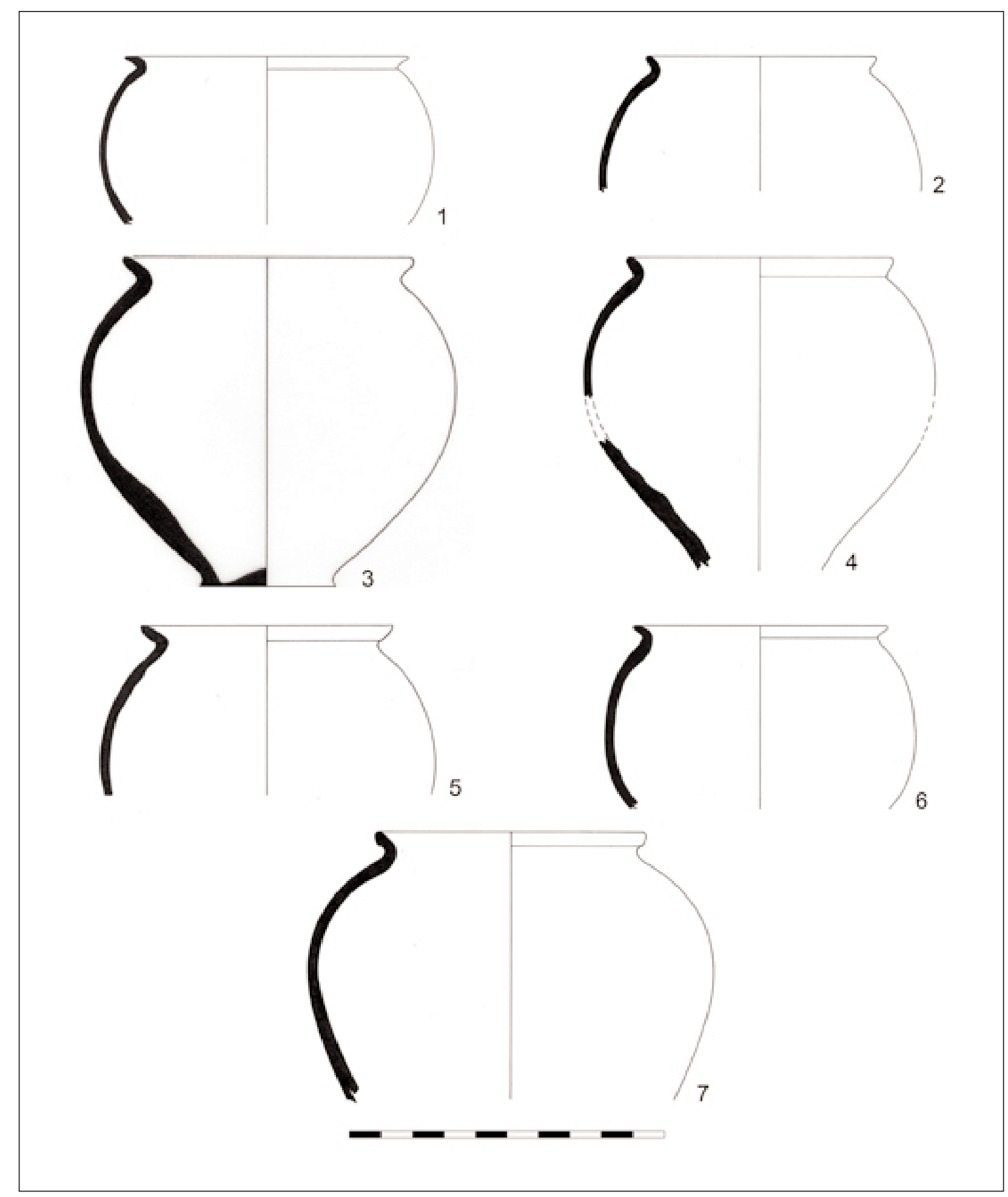

Figura 90. Vasos ovoides anaranjados finos 


\section{VASOS OVOIDES} (variante anaranjada tosca)

1. CH.77 /0004. Sector C-1. Fragmento de borde y cuerpo. Borde exvasado, oblicuo y curvo con labio de perfil redondeado. Cuerpo de tendencia ovoide en lo conservado. Pasta ocre anaranjada con abundantes micas pequeñas y muy pequeñas y cuarzos de todos los tamaños. Superficie externa alisada ocre grisácea e interna ocre anaranjada. Dimensiones: diámetro borde: $98 \mathrm{~mm}$; diámetro máximo cuerpo: $110 \mathrm{~mm}$; altura conservada: $63 \mathrm{~mm}$; grosor medio sección: 4 mm. Bibliografía: Montes, 2005.

2. CH.96 /1518. Sector C-13. Fragmento de borde y cuerpo. Borde corto, exvasado, oblicuo y curvo con labio de perfil redondeado. Cuerpo globular. Pasta anaranjada con desgrasantes micáceos pequeños, algún esquisto y abundantes cuarzos medianos y grandes. Superficie interna anaranjada y externa ennegrecida. No se aprecia acabado específico alguno. Dimensiones: diámetro borde: $76 \mathrm{~mm}$; diámetro máximo cuerpo: $92 \mathrm{~mm}$; altura conservada: $71 \mathrm{~mm}$; grosor medio sección: 5 mm. Bibliografía: Montes, 2005.
3. CH.93 /0819. Sector N-93 / N-93 IV, C-4 C. Fragmento de borde y cuerpo. Borde corto, exvasado, oblicuo, casi vertical y curvo con labio de perfil redondeado. Presenta una fina acanaladura en el exterior. Cuerpo de perfil curvo en lo conservado. Pasta de tonalidad ocre anaranjada con desgrasantes cuarzo-micáceos y cerámicos pequeños y medios. Superficies entre ocres y anaranjadas, la externa bruñida y zonalmente ennegrecida. Dimensiones: diámetro borde: $104 \mathrm{~mm}$; diámetro máximo cuerpo: $118 \mathrm{~mm}$; altura conservada: $44 \mathrm{~mm}$; grosor medio sección: $3.5 \mathrm{~mm}$. Bibliografía: Montes, 2005.

4. CH.96 /1801. Sector R-VIII. Fragmento de borde y cuerpo. Borde corto, exvasado, oblicuo y curvo con labio de perfil redondeado. Cuerpo de perfil curvo en lo conservado. Pasta cuarzo-micácea de tonalidad anaranjada con desgrasantes de diferente tamaño. Dimensiones: diámetro borde: 78 mm; diámetro máximo cuerpo: $104 \mathrm{~mm}$; altura conservada: $43 \mathrm{~mm}$; grosor medio sección: $4 \mathrm{~mm}$. Bibliografía: Montes, 2005.

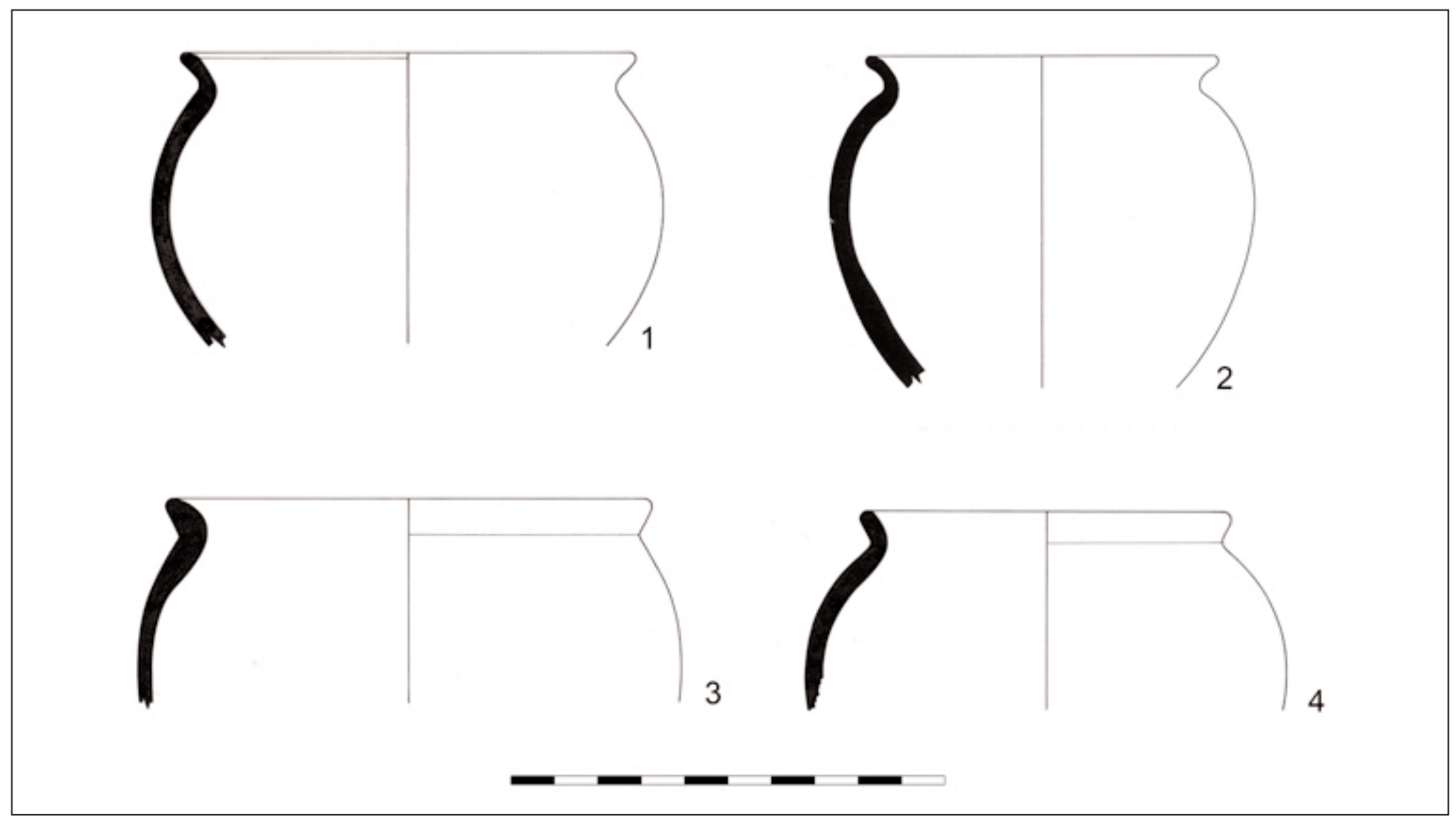

Figura 91. Vasos ovoides anaranjados toscos 


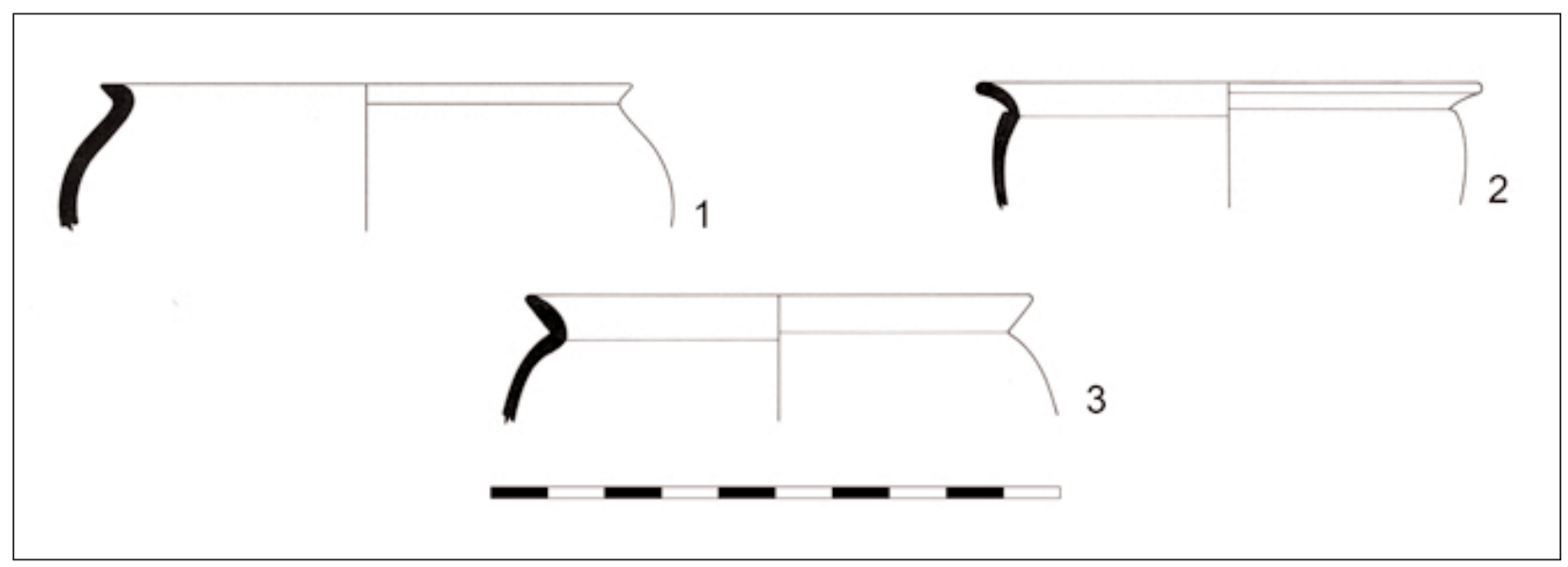

Figura 92. Vasos ovoides anaranjados engobados

\section{VASOS OVOIDES}

(variante anaranjada engobada)

1. CH.96/2744. Sector C-10 B. Fragmento de borde y cuerpo. Borde corto, exvasado, oblicuo y curvo con labio de perfil apuntado recorrido al exterior por una fina acanaladura. Cuerpo de perfil curvo en lo conservado. Pasta de tonalidad anaranjada con abundantes desgrasantes micáceos y cuarcíticos de pequeñas y medianas dimensiones. Superficies anaranjadas, la externa recubierta de un engobe anaranjado. Dimensiones: diámetro borde: $93 \mathrm{~mm}$; diámetro máximo cuerpo: $108 \mathrm{~mm}$; altura conservada: $26 \mathrm{~mm}$; grosor medio sección: 3 mm. Bibliografía: Montes, 2005.

2. CH.01 /5062. Sector C-19. Fragmento de borde y cuerpo. Borde corto, exvasado, oblicuo y curvo con labio de perfil redondeado. La transición al cuerpo, de perfil curvo en lo conservado, viene marcada al exterior por una pequeña acanaladura. Pasta cuarzomicácea de tonalidad anaranjada con desgrasantes pequeños. Superficies anaranjadas, la externa con un posible engobe de tonalidad rojiza. Dimensiones: diámetro borde: $88 \mathrm{~mm}$; altura conservada: $22 \mathrm{~mm}$; grosor medio sección: $2 \mathrm{~mm}$. Bibliografía: Montes, 2005.

3. CH.01/3458. Sector C-17 C. Fragmento de borde y cuerpo. Borde exvasado, oblicuo y curvo con labio de perfil apuntado separado al exterior del cuerpo por una estrecha acanaladura. Cuerpo de perfil curvo en lo conservado. Pasta depurada micácea de color anaranjado. Superficies anaranjadas, la exterior cubierta de engobe. Dimensiones: diámetro borde: $88 \mathrm{~mm}$; altura conservada: $22 \mathrm{~mm}$; grosor medio sección: $2 \mathrm{~mm}$. Bibliografía: Montes, 2005.

\section{VASOS OVOIDES (variante gris fina)}

1. CH.77 /0024. Sector C-1. Perfil completo. Borde exvasado, oblicuo y curvo con labio de perfil redondeado. Cuerpo ovoide. Base plana con pie de disco surcada en su fondo externo por sendas acanaladuras, una perimetral y otra en la zona central. Pasta de tonalidad pardo grisácea rojiza con abundantes desgrasantes micáceos muy pequeños, cuarzos pequeños y medios y algún punto rojo (cerámica?). La superficie externa, la parte superior de la interna y el borde presentan un acabado bruñido bastante fino. Dimensiones: diámetro borde: $85 \mathrm{~mm}$; diámetro máximo cuerpo: $112 \mathrm{~mm}$; diámetro base: $55 \mathrm{~mm}$; altura: $122 \mathrm{~mm}$; grosor medio sección: 3.5 mm. Bibliografía: Montes, 2005.

2. CH.02 /0532. Sector C-17 C. Fragmento de borde, cuerpo y base. Borde exvasado, oblicuo y recto con labio de perfil redondeado. Cuerpo ovoide. Base plana con pie de disco y pequeño umbo en el fondo interno. Pasta grisácea cuarzo-micácea con desgrasantes 
pequeños y medios. Superficies de tonalidades negruzcas. El borde y la cara exterior presentan tosco acabado bruñido. Dimensiones: diámetro borde: $117 \mathrm{~mm}$; diámetro máximo cuerpo: $124 \mathrm{~mm}$; altura conservada: $36 \mathrm{~mm}$; grosor medio sección: 2.5 mm. Bibliografía: Montes, 2005.

3. CH.95/4094. Sector C-10 A. Perfil completo. Borde corto, exvasado, oblicuo y curvo con labio de perfil apuntado. Cuerpo globular. Base plana con pie de disco con el fondo exterior plano y el interior umbilicado. Pasta de tonalidad grisácea con desgrasantes micáceos y cuarcíticos pequeños y medianos. La superficie externa y el borde presen$\tan$ restos de lo que pudo haber sido un acabado bruñido. Dimensiones: diámetro borde: $95 \mathrm{~mm}$; diámetro máximo cuerpo: $138 \mathrm{~mm}$; diámetro base: $68 \mathrm{~mm}$; altura: 127 mm; grosor medio sección pared: $4 \mathrm{~mm}$. Bibliografía: Benéitez et alii, 1999: 15-17, Fig.1.1; Montes, 2005; Montes, 2009: Ficha 148, 426-427.
4. CH.98 /3380. Sector R-VIII. Fragmento de borde y cuerpo. Borde corto, exvasado, oblicuo y curvo con labio de perfil apuntado. Cuerpo ovoide. Pasta cuarzo-micácea de color gris oscuro con desgrasantes menudos y medios. Superficie externa negra bruñida e interna de tonalidad gris oscura. Dimensiones: diámetro borde: $116 \mathrm{~mm}$; diámetro máximo cuerpo: $132 \mathrm{~mm}$; altura conservada: $74 \mathrm{~mm}$; grosor medio sección: 3 mm. Bibliografía: Montes, 2005.

5. CH.77/0005. Sector C-1. Fragmento de borde y cuerpo. Borde corto, exvasado y oblicuo con labio de perfil redondeado. Cuerpo de tendencia globular en lo conservado. Pasta grisácea con abundantes micas pequeñas y medias y cuarzos. La superficie externa y el borde presentan un fino acabado bruñido. Dimensiones: diámetro borde: $98 \mathrm{~mm}$; diámetro máximo cuerpo: $125 \mathrm{~mm}$; altura conservada: $103 \mathrm{~mm}$; grosor medio sección: $3.5 \mathrm{~mm}$. Bibliografía: Montes, 2005.
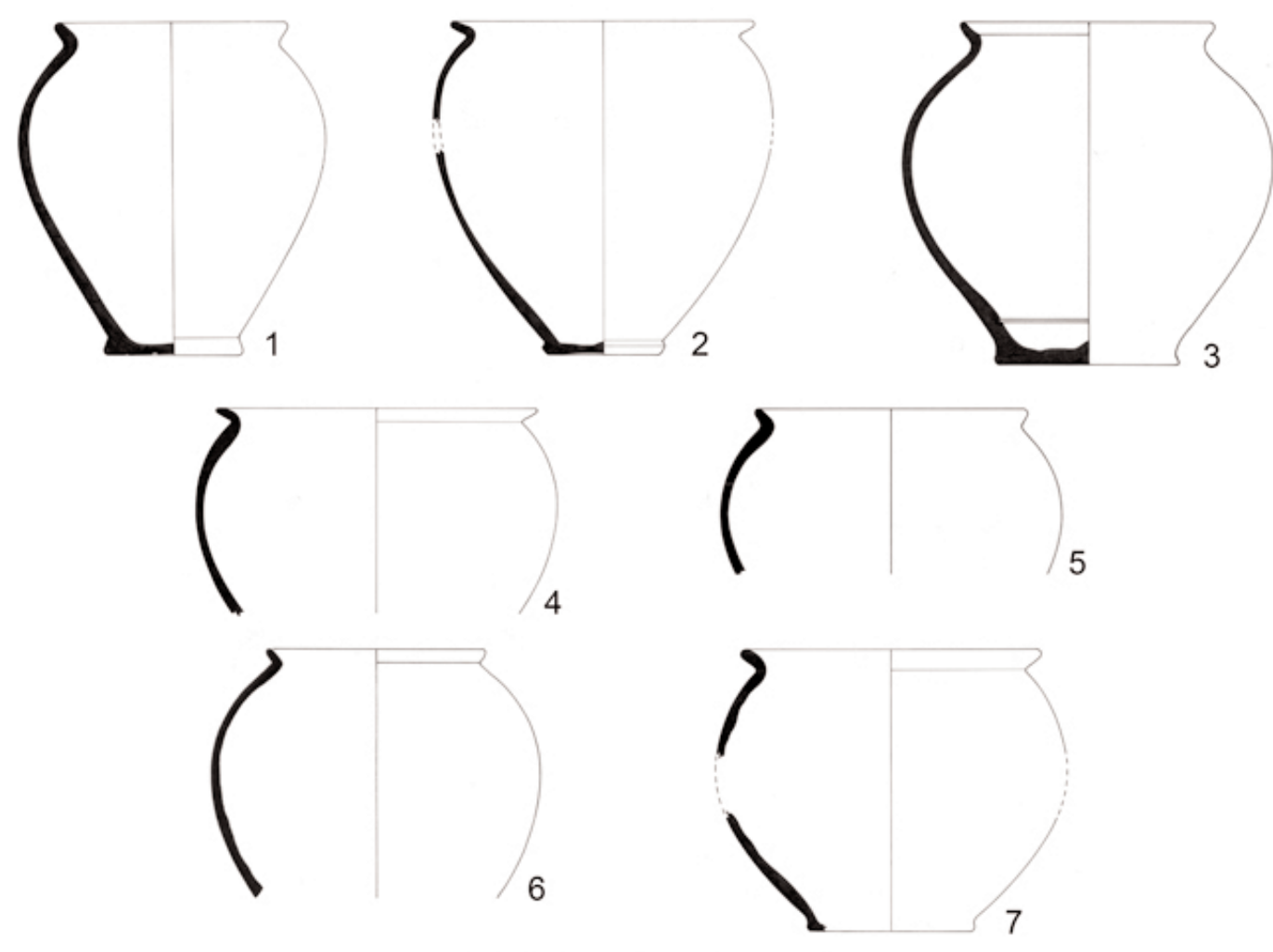

Figura 93. Vasos ovoides grises finos 
6. CH.95 /1274. Sector C-10 B. Fragmento de borde y cuerpo. Borde corto, exvasado, oblicuo y curvo con labio de perfil redondeado. Cuerpo de perfil ovoide. Pasta cuarzo-micácea de tonalidad anaranjada con desgrasantes micáceos y cuarcíticos pequeños y medios. Superficie externa con zonas negras $\mathrm{y}$ otras anaranjadas e interna gris. El borde y la cara externa presentan un fino acabado bruñido. Dimensiones: diámetro borde: 82 mm; diámetro máximo cuerpo: $129 \mathrm{~mm}$; altura conservada: $93 \mathrm{~mm}$; grosor medio sección: $3 \mathrm{~mm}$. Bibliografía: Benéitez et alii, 1999: 15-17, Fig.1.12; Montes, 2005.

7. CH.99 /7238. Sector C-12 B. Fragmento de borde, cuerpo y base. Borde exvasado, oblicuo y curvo con labio de perfil redondeado. Cuerpo globular. Base plana en lo conservado con pie de disco. Pasta de color grisáceo con abundantes desgrasantes micáceos pequeños y muy pequeños y cuarcíticos pequeños y medios. Superficie externa y borde negros bruñidos e interna gris oscura. Dimensiones: diámetro borde: $110 \mathrm{~mm}$; diámetro máximo cuerpo: $130 \mathrm{~mm}$; diámetro base: $60 \mathrm{~mm}$; altura: $104 \mathrm{~mm}$; grosor medio sección: 3.5 mm. Bibliografía: Montes, 2005.

\section{VASOS OVOIDES}

(variante gris tosca)

1. CH.77 /0209. Sector C-1. Fragmento de borde y cuerpo. Borde exvasado, oblicuo y de recto al interior con labio de perfil redondeado. Cuerpo curvo en lo conservado. Pasta grisácea con desgrasantes micáceos pequeños y cuarcíticos pequeños $\mathrm{y}$ medios. La superficie externa y el borde presentan un tosco acabado bruñido. Dimensiones: diámetro borde: $78 \mathrm{~mm}$; altura conservada: $29 \mathrm{~mm}$; grosor medio sección: 4.5 mm. Bibliografía: Montes, 2005.

2. CH.93 /0688. Sector N-93, N-93 /IV. Fragmento de borde y cuerpo. Borde exvasado, oblicuo y curvo con labio de perfil redondeado recorrido por una tenue y muy fina acanaladura. Cuerpo de perfil curvo en lo conservado. Pasta grisácea con abundantes micas pequeñas y cuarzos. Superficie externa de tonalidad negra con tosco acabado bruñido e interna gris oscura. Dimensiones: diámetro borde: $98 \mathrm{~mm}$; altura conservada: $31 \mathrm{~mm}$; grosor medio sección: 5 mm. Bibliografía: Montes, 2005.

3. CH.98 /5159. Sector C-12. Fragmento de borde y cuerpo. Fragmento de borde y cuerpo de vaso ovoide gris. Borde exvasado, ligeramente oblicuo (casi vertical) y curvo con labio de perfil redondeado. Cuerpo de perfil curvo en lo conservado. Pasta grisácea con abundantes micas pequeñas y cuarzos. Superficies negras con tosco acabado bruñido en borde y al exterior. Dimensiones: diámetro borde: $90 \mathrm{~mm}$; diámetro máximo cuerpo: $122 \mathrm{~mm}$; altura conservada: $39 \mathrm{~mm}$; grosor medio sección: 4.5 mm. Bibliografía: Montes, 2005.

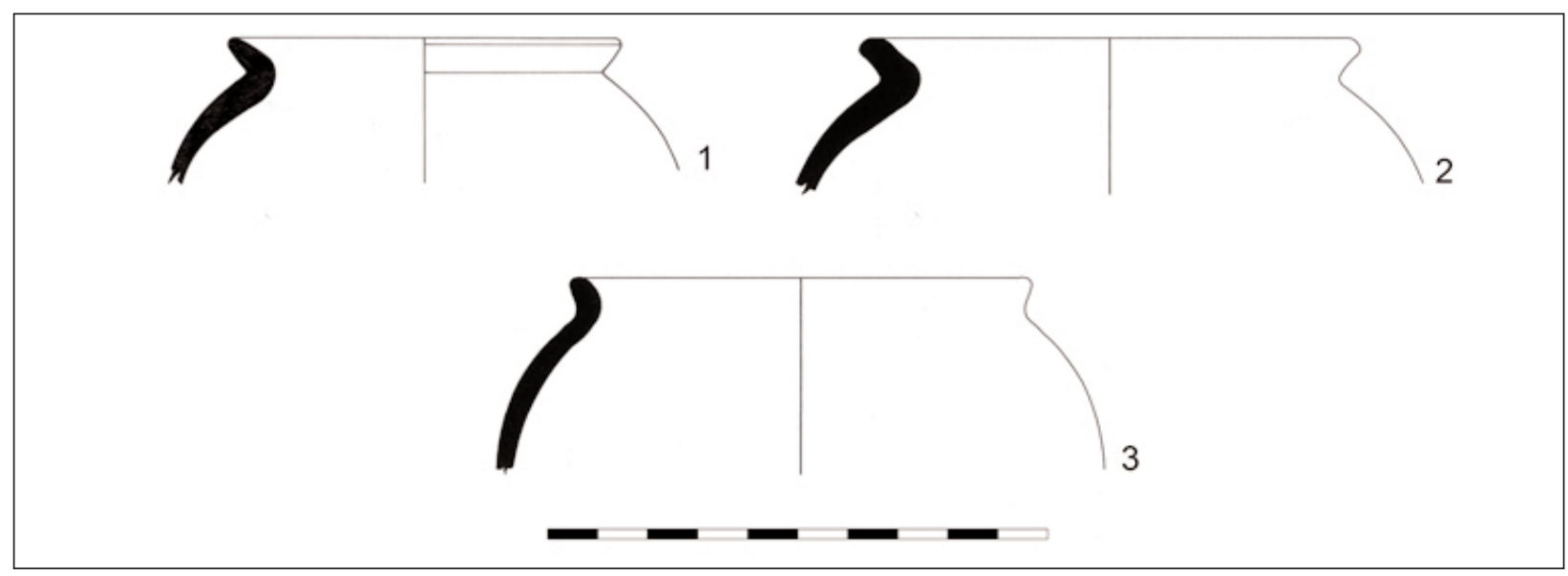

Figura 94. Vasos ovoides grises toscos 


\section{VASOS OVOIDES}

(variante gris decorada)

1. CH.93 /1114. Sector R-V / P-III. Perfil completo. Borde exvasado, oblicuo y curvo al exterior y facetado al interior con labio de perfil redondeado. Cuerpo de perfil globular. Base plana con pie de disco. Decoración de líneas verticales bruñidas bastante irregulares. Pasta de tonalidad grisácea con abundantes desgrasantes micáceos muy pequeños y cuarcíticos pequeños y medios. Dimensiones: diámetro borde: 124 mm; diámetro máximo cuerpo: $139 \mathrm{~mm}$; diámetro base: $50 \mathrm{~mm}$; altura: $114 \mathrm{~mm}$; grosor medio sección: $5 \mathrm{~mm}$. Bibliografía: Montes, 2005; Montes, 2009: Ficha 148, 426-427.

2. CH.96 /3794. Sector C-10 B. Perfil completo. Borde exvasado, oblicuo y curvo con labio de perfil redondeado. Cuerpo de perfil ovoide. Base plana con pie de disco y fondo interno ligeramente umbilicado. Decoración de líneas bruñidas consistentes en una irregular retícula cuadrangular. Pasta cuarzo-micácea de tonalidad gris con desgrasantes micáceos y cuarcíticos peque-

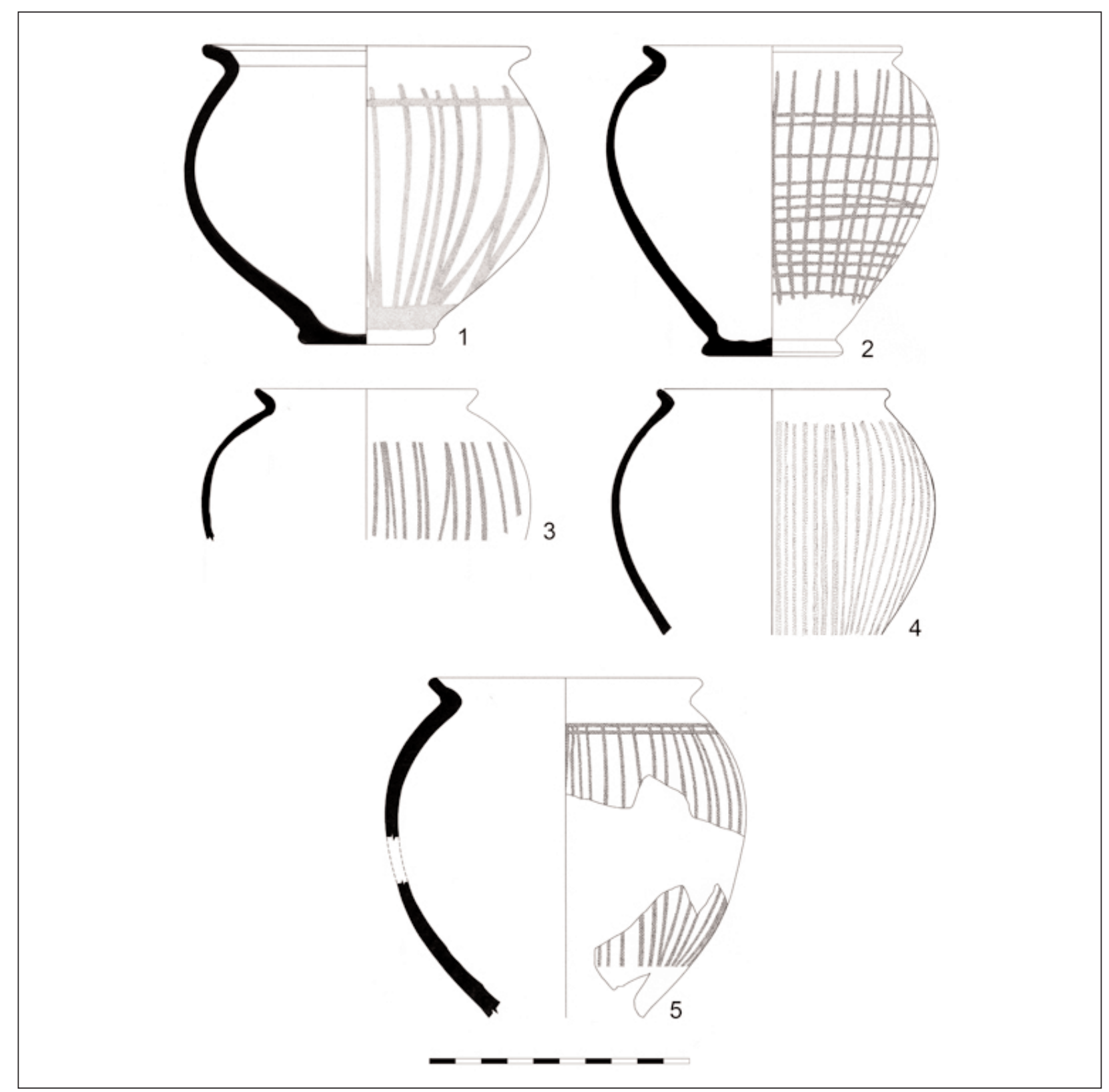

Figura 95. Vasos ovoides grises decorados 
ños y medios. Superficies grises con acabado bruñido en el borde y la cara externa. Dimensiones: diámetro borde: $100 \mathrm{~mm}$; diámetro máximo cuerpo: $126 \mathrm{~mm}$; diámetro base: $55 \mathrm{~mm}$; altura: $118 \mathrm{~mm}$; grosor medio sección: $4 \mathrm{~mm}$. Bibliografía: Benéitez et alii, 1999: 15-17, Fig.1.3; Montes, 2005.

3. CH.98 /3817. Sector C-12. Fragmento de borde y cuerpo. Borde exvasado, oblicuo y curvo con labio de perfil redondeado. Cuerpo de perfil curvo en lo conservado. Decoración de líneas verticales bruñidas finas y de traza bastante irregular que arrancan del tercio superior del cuerpo. Pasta grisácea con desgrasantes pequeños micáceos y cuarcíticos. Superficie externa negra e interna gris. El borde y la parte superior del cuerpo presentan un acabado bruñido bastante fino. Dimensiones: diámetro borde: $86 \mathrm{~mm}$; diámetro máximo cuerpo: $126 \mathrm{~mm}$; altura conservada: 58 $\mathrm{mm}$; grosor medio sección: $3.5 \mathrm{~mm}$. Bibliografía: Montes, 2005.

4. CH.96/2975. Sector C-10 B. Fragmento de borde y cuerpo. Borde muy corto, exvasado, oblicuo y curvo con labio de perfil redondeado. Cuerpo de perfil ovoide. Decoración de líneas verticales bruñidas bastante juntas entre sí que ocupan la totalidad de lo conservado del cuerpo. Pasta cuarzo-micácea de tonalidad grisácea con abundantes desgrasantes micáceos muy pequeños y cuarcíticos pequeños y medios. Superficies entre el gris y el negro en las que el mal estado de conservación no permite apreciar la existencia de un acabado específico. Dimensiones: diámetro borde: $90 \mathrm{~mm}$; altura conservada: $95 \mathrm{~mm}$; grosor medio sección: $4 \mathrm{~mm}$. Bibliografía: Benéitez et alii, 1999: 15-17, Fig.1.5; Montes, 2005.

5. CH.95 /0889. Sector C-10 A / B. Fragmento de borde y cuerpo. Borde exvasado, oblicuo y curvo con labio de perfil redondeado. Cuerpo de perfil ovoide. Decoración de líneas verticales bruñidas.
Pasta cuarzo-micácea de tonalidad beige grisáceo con desgrasantes micáceos y cuarcíticos pequeños y medios. Superficies grises con acabado bruñido en el borde y la cara externa. Dimensiones: diámetro borde: $90 \mathrm{~mm}$; diámetro máximo cuerpo: $130 \mathrm{~mm}$; altura conservada: $123 \mathrm{~mm}$; grosor medio sección: $4.5 \mathrm{~mm}$. Bibliografía: Benéitez et alii, 1999: 15-17, Fig.1.4; Montes, 2005.

\section{TAZONES MONOASADOS}

(Figuras 96-100)

La denominación de tazones monoasados aplicada a este característico morfotipo ha sido la utilizada en publicaciones relativas a repertorios del Chao Samartín en anteriores ocasiones (Benéitez et alii, 1999: 18-19, Fig.2; Montes et alii, 2001: 30-31, Fig. 1.3; Menéndez y Benéitez, 2002: 292, Fig.2.5; Montes y Hevia, 2008: 771) y se encuentra inspirada en la propuesta hecha en su día por E. Alcorta (1995: 206 y 217, Fig. 5. 2-5 y 13.1 y 2), quién denominó inicialmente tazones asados a las piezas que responden a este modelo procedentes de las excavaciones de Lucus Augusti, incluyéndolas entre los vasa potoria. Con posterioridad, este mismo autor pasa a utilizar la terminología de vasos carenados monoansados (Alcorta, 2001), a nuestro entender menos precisa, en cuanto consideramos más ajustado al particular desarrollo morfológico de estas piezas el apelativo de tazones. En este mismo sentido, el perfil carenado no siempre se expresa con idéntica claridad.

Lo cierto es que, con independencia del término utilizado y de las connotaciones funcionales que la asunción de una u otra denominación pudiera conllevar, los rasgos fundamentales del tipo se manifiestan como una formulación morfotécnica que alcanza en el siglo II d.C. un alto grado de estandarización. Se trata de recipientes con el borde exvasado bastante desarrollado, más o menos oblicuo y de tendencia recta, rematado en un labio de perfil casi siempre redondeado y rara vez apuntado.

La base, plana y con pie de disco, suele presentar unas dimensiones reducidas que se sitúan en valores entre dos y tres veces inferiores en diá- 
metro a la boca. Otra característica formal definitoria es la presencia de una única asa de reducido tamaño con perfil en $C$ y secciones variables, normalmente elipsoidales, que arranca de la parte alta del cuerpo para finalizar su recorrido a la altura aproximada del diámetro máximo.

El cuerpo describe perfiles diversos que permiten diferenciar dos modalidades genéricas principales que, sin embargo, en la práctica, esconden una realidad compleja en la que son frecuentes los ejemplares híbridos que presentan caracteres intermedios (Montes, 2005):

- Tazones carenados (Montes, 2009: 406407 y 434-435). Los recipientes carenados, netamente mayoritarios ${ }^{78}$, cuentan con una nítida inflexión media-baja que se ve reforzada por la acanaladura inferior que delimita el espacio decorado. El cuerpo queda dividido de esta forma en dos partes bien diferenciadas: una superior de tendencia más o menos recta y trayectoria vertical o ligeramente cerrada y otra inferior abierta.

- Tazones globulares. En las piezas pertenecientes a esta variante, la inflexión del tercio inferior del galbo resulta notoriamente más suave, curvándose la parte superior del cuerpo, a diferencia del perfil más recto de su congéneres carenados.

Con independencia del desarrollo carenado o globular del cuerpo, su superficie externa se encuentra casi siempre recorrida por sendas acanaladuras, ocasionalmente duplicadas: una en la parte alta y otra superada la mitad de la pieza, sobre la zona de la inflexión. Entre ambas se desarrolla un amplio friso en el que se despliega el programa decorativo. Algunas veces, una moldura recorre la zona del tránsito entre borde y cuerpo.

El tamaño de las diferentes piezas refleja variaciones significativas, hasta el punto que se pueden señalar tres modalidades dimensionales,

\footnotetext{
78 Constituyen el $63 \%$ de las piezas reconocidas (Montes, 2005).

79 Tanto es así que, de acuerdo a un estudio monográfico sobre
}

cuya explicación pudiera guardar relación con criterios de funcionalidad específica (Montes, 2005):

- Vasos con diámetros de boca inferiores a $160 \mathrm{~mm}$ (Montes, 2009: 434-435) (Figura 99). Constituyen la variante abrumadoramente mayoritaria ${ }^{79}$. Este predominio se constata no sólo en el Chao Samartín, sino también en Lucus Augusti, único yacimiento donde el volumen de material adscribible al tipo convierte este dato en significativo. Piezas de estas dimensiones se encuentran de igual modo presentes en los castros de Viladonga (Arias, 1985: Fig. en p. 281, D-7), Zoñán (Vigo, 2007: 172-174, Fig. 93), Coaña (Maya, 1988: 158, Fig. 47.C) y Taramundi (Expósito, 2004), si bien en estos casos la parquedad de los elencos impide que podamos abordar una valoración cuantitativa semejante.

- Grupo de piezas de tamaño medio que cuentan con diámetros con valores comprendidos entre 160 y 200 mm (Figura 100.1-2). Los raros ejemplos con los que contamos cuentan con su correlato en otros vasos semejantes procedentes de Lugo (Alcorta, 2001: 260, Fig. 109.1, 3, 5 y 6).

- Variante grande, con aperturas de boca superiores a $200 \mathrm{~mm}$. (Figura 100.3) Tan sólo conocemos un ejemplar en el Chao Samartín (Montes, 2009: 406-407), que cabría sumar al magro elenco que constituyen otro registrado en Viladonga (Arias, 1985: Fig. en p. 21, I-23) y dos más procedentes de Lucus Augusti (Alcorta, 2001: 260, 109. 2 y 4). En realidad, estas piezas alcanzan dimensiones que superan con amplitud la aludida cifra, situándose por encima de los $220 \mathrm{~mm}$. Se manifiestan de esta manera como un grupo bien diferenciado en cuanto a tamaño, aunque no presentan, al margen de este rasgo, particularidad alguna formal o técnica que permita segregarlo tajantemente del tipo.

el tema (Montes, 2005), representan el $86.7 \%$ del total de las piezas registradas 
Estas variantes propuestas tienen cierta correspondencia aproximada con las planteadas a partir del repertorio de Lucus Augusti. Alcorta propone (2001: 260, Fig. 110 y 111) un primer grupo que denomina tipo $\mathrm{V} 1$ con diámetros de boca entre 150 y $200 \mathrm{~mm}$, bastante próximos a los de la variante mediana del Chao Samartín, y otra modalidad (tipo V1 A), con aperturas entre $100 \mathrm{y}$ $120 \mathrm{~mm}^{80}$.

Como resulta lógico, esta variabilidad dimensional ha de contar con un refrendo en el campo de las prestaciones funcionales. Para la fórmula de menor tamaño nada nos impide su consideración como vasa potoria, tal y como resulta aceptado por lo común en la bibliografía alusiva (Alcorta, 2001: 263-264; Benéitez et alii, 1999: 18-19), pudiendo considerarlos vasos o tazas empleadas como vajilla de mesa en usos vinculados al consumo individual de líquidos o a empleos afines. El problema se suscita con las modalidades de dimensiones más destacadas, especialmente con la de mayor tamaño. A pesar de la estricta equivalencia formal, técnica y ornamental, la función no puede ser la misma. Se han planteado diversas posibilidades como la de su uso colectivo en el servicio de mesa (Alcorta, 2001: 264), la de su empleo en labores de almacenamiento de determinados productos ${ }^{81}$ (Ibidem) o la de su utilización en procesos culinarios en frío (Alcorta, 1995: 217). La vinculación, no sólo de estos recipientes de dimensiones mayores, sino también de los de la variante menor, a funciones de cocina en caliente, rechazada para Lugo a causa de la ausencia de vestigios de carbonización, no resulta tampoco descartable, aunque sea a modo de uso subsidiario o eventual, habida cuenta del registro sobre las superficies externas de algunas piezas del Chao Samartín, de concreciones negras que deben interpretarse como resultado de su exposición al fuego. Cabe apuntar la posibilidad de su empleo en el calentamiento de líquidos.

80 Lo cierto es que en el Chao Samartín la mayoría de las piezas se encuadran precisamente en los valores que quedan entre ambas modalidades.

81 En el sentido de recipientes que hemos denominado como vajilla de despensa, destinada a contener pequeñas cantida-
Las decoraciones ${ }^{82}$, siempre ceñidas, como hemos referido, a la parte superior del galbo, entre las prototípicas acanaladuras que recorren este espacio, presentan dos modalidades principales diferenciadas en función de la técnica ornamental empleada (Montes, 2005): las bruñidas y las estampilladas. Los recipientes que reciben este último tipo de decoraciones serán tratados más adelante al abordar el tema de la vajilla con decoración estampillada. Por lo que se refiere a las bruñidas, las combinaciones conocidas resultan múltiples. Podemos sintetizar esta extensa variedad agrupándolas en las siguientes variantes, que podríamos considerar básicas:

- Composiciones de líneas verticales simples de dispar grosor y regularidad que ocupan la totalidad del espacio decorado (Figura 96). La variante, relativamente frecuente en el Chao Samartín, se registra también en otros yacimientos como Lugo (Alcorta, 2001: Fig.110. 1-4), Coaña (Maya, 1988: 158, Fig.47.C) o Taramundi (Expósito, 2004)

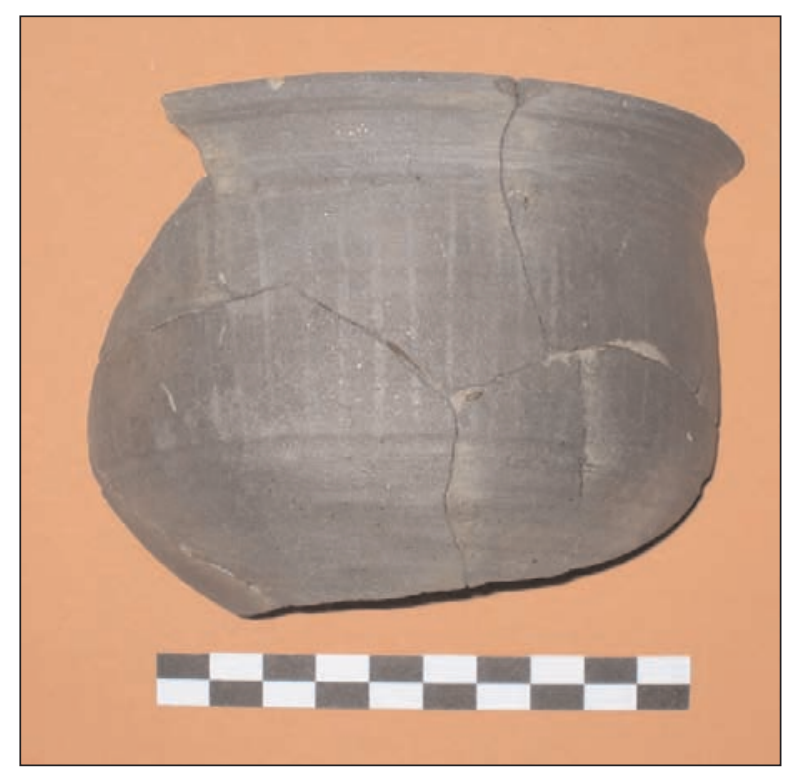

Figura 96. Tazón monoasado con decoración de líneas verticales bruñidas. Foto: R. Montes

des y diferenciada de la vajilla de almacenamiento, enfocada al acopio a largo plazo (Benéitez et alii, 1999, 30).

82 Son bastante raros los ejemplos que carecen de decoración (por ejemplo, en Arias, 1985: fig. en p. 21, I-23; Benéitez et alii, 1999: Fig. 2.3; Alcorta, 2001: Fig.109.1-2). 
- Composiciones dibujadas a partir de líneas de trazo sencillo. Se identifican dos modalidades:

- Retículas romboidales simples de trama estrecha (Figura 96). Este tema ornamental mantiene un neto predominio sobre cualquier otro ${ }^{83}$. Un fenómeno similar ocurre en el amplio repertorio registrado en Lugo (Alcorta, 2001: Fig.109.3, 4 y 6 y 110.5 y 6 ).

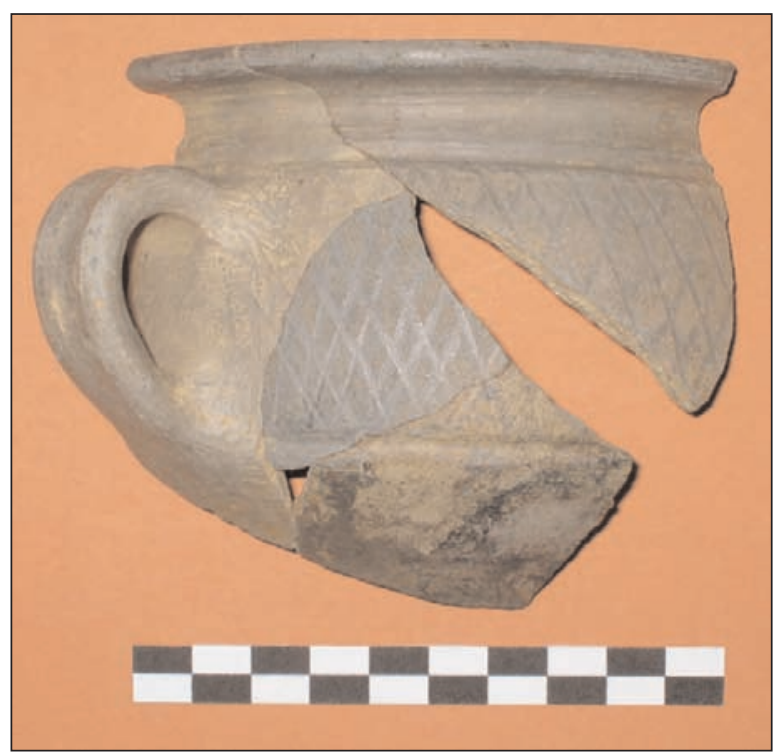

Figura 97. Tazón monoasado con decoración de retícula bruñida. Foto: R. Montes

- Combinaciones de líneas verticales que delimitan metopas cuadrangulares ocupadas por aspas conseguidas por dobles líneas diagonales cruzadas.

- Composiciones elaboradas a partir de haces de líneas que configuran motivos diversos. Se distinguen dos posibilidades:

- Retículas romboidales (Figura 98) anchas en las que la altura de los rombos coincide con la anchura del campo decorativo (Benéitez et alii, 1999: Fig. 2.1 y 11; Montes, 2009: 406-407 y 434-435).

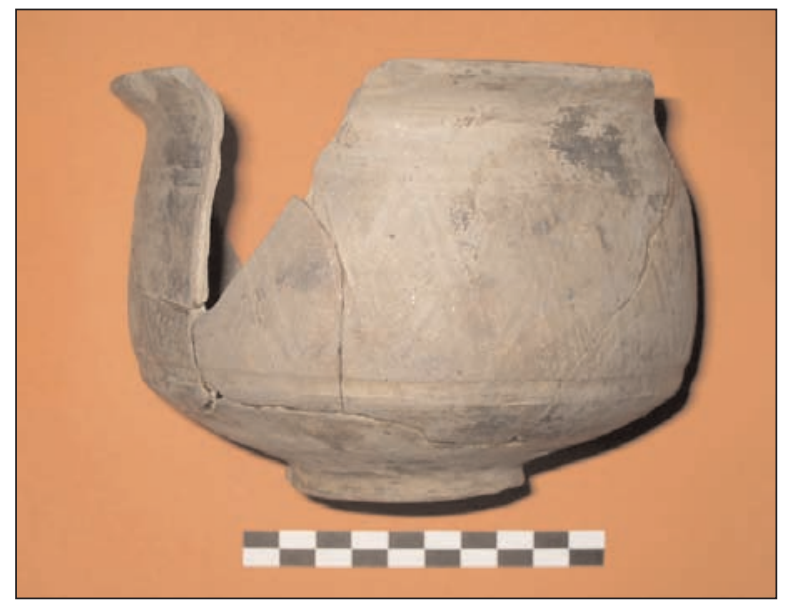

Figura 98. Tazón monoasado con decoración de haces de líneas bruñidas. Foto: R. Montes

- Composiciones metopadas dibujadas por haces de líneas verticales en cuyo interior se insertan motivos aspados configurados igualmente mediante haces de líneas (Benéitez et alii, 1999: Fig.2.2) o de simples haces diagonales.

- Motivos configurados a partir de líneas y haces de líneas en combinaciones irregulares diversas. Además de en el Chao Samartín (Benéitez et alii, 1999: Fig.2.8) se conocen ejemplos en Lucus Augusti (Alcorta, 2001: Fig.110.8).

En el apartado técnico la homogeneidad es la norma habitual, con pastas cuarzo-micáceas, tonalidades superficiales generalmente grises o negruzcas y acabados bruñidos en la superficie externa (Benéitez et alii, 1999: 18). Estas particularidades las relacionan indefectiblemente con toda una serie cerámica de caracteres afines que incluye una amplia diversidad de tipos y que se vincula al ámbito de producción regional lucense (Alcorta, 2001). Así pues, se evidencia una diferenciación entre estas piezas con tonalidades grises o negras cocidas en atmósfera reductora y con decoraciones de líneas bruñidas, que constituyen el grupo mayoritario, y una variante minoritaria, que se analizará más adelante, también regional, de vasos con superficies

83 Se haya presente en más de la mitad de los tazones documentados (Montes, 2005). 
y pastas ocráceas, típicas decoraciones estampadas y engobe rojo interno, que se presenta como manifestación marginal de toda una familia cerámica que cuenta con sus mejores ejemplos en otros ámbitos morfofuncionales (Montes, 2005).

Los únicos paralelos estrictos que hemos podido rastrear para el tipo remiten a un espacio geográfico restringido al ámbito de influencia lucense. Los referentes más nítidos son los numerosos ejemplos procedentes de la propia ciudad de Lugo, pertenecientes a los tipos V1 y V1 A de la segunda fase (Alcorta, 2001: 260265, Fig. 109-110 $)^{84}$, las piezas procedentes de Os Castros de Taramundi (Expósito, 2004), las registradas en A Coruña (Vázquez y Doval, 1996: 101, Fig. 27 y 28) y elementos puntuales procedentes de yacimientos próximos como Viladonga (Arias, 1985: Fig. en p. 21, I-23 y 28 , D-7) ${ }^{85}$, Zoñán (Vigo, 2007: 172-174, Fig. 93), El Castelón de Coaña (Maya, 1988: Fig. 47.C) y Pendia ${ }^{86}$.

Similitudes más vagas y alejadas desde el punto de vista morfotécnico se registran, dentro de un amplio marco regional, por ejemplo, en Conimbriga (Alarcão, 1975: 85, Pl. XXIV.498, XXVI.552 B y XXVII.555 y 556) ${ }^{87}$ o en diversos yacimientos del Alto Alentejo (Nolen, 1986: 75 y 109, Est. XXI, no 210 y Est. XL, no 418- 419).

El tipo, en definitiva, parece responder pues a una formulación morfológica marcadamente regional. No obstante, algunos indicios apuntan

${ }^{84}$ La variante bajoimperial V1 B, vinculada por Alcorta a esta morfología (Alcorta, 2001: Fig. 111), presenta unas marcadas particularidades formales que la alejan de modo sustancial del tipo de referencia.

85 Ver también en Arias y Durán, 1996, fig. en p. 86. Aunque la pieza presenta una morfología perfectamente asimilable al tipo, cuenta con la singularidad que representa su decoración, que combina una más estrecha de lo habitual banda ocupada por retícula bruñida con otra con motivos impresos lineales puntillados en zig-zag enmarcados por acanaladuras y bandas igualmente puntilladas. Carecemos de información alguna relativa a las características técnicas del ejemplar.

86 Piezas inéditas documentadas en el transcurso de las recientes excavaciones realizadas en el yacimiento bajo la direc- en la línea de su interpretación como un modelo que, en distintas versiones regionales y dentro de una amplia flexibilidad formal y técnica, se difunde en época altoimperial por la Península Ibérica, tal y como atestigua su registro en diversos puntos de la misma ${ }^{88}$ y que en el territorio lucense se manifiesta como un prototipo perfectamente asimilado y sintetizado con la tradición local que asomará en el tratamiento técnico y ornamental. De este modo, la dualidad morfotécnica (grises bruñidas y ocres estampilladas) concreta opera tan sólo en un marco territorial reducido, como se ha apuntado, al noreste de Galicia y el occidente de Asturias.

La, al parecer, constante presencia de fragmentos atribuibles a este tipo de piezas en los vertederos relacionados con los hornos de fabricación cerámica documentados en Lugo viene a confirmar su vinculación a la actividad productiva de la industria alfarera lucense (Alcorta, 2001: 264) ${ }^{89}$. Las bases cronológicas de referencia remiten en este foco productor a amplias datas que abarcan desde momentos vagamente preflavios para determinados tipos de regusto indígena ${ }^{90}$, relacionados más bien con los modelos arcaicos homónimos también reconocidos en el Chao Samartín en el siglo I d.C., hasta fechas a partir del siglo II d.C. para las modalidades estándar (tipos V1 / V1 A) del tipo de las aquí presentadas.

ción de F. Rodríguez del Cueto y Á. Villa Valdés.

87 Se trata de recipientes que manifiestan cierta semejanza formal, nunca estricta, y en la mayor parte de los casos, consisten en producciones anaranjadas finas (excepto la primera de las piezas referidas) bien diferenciadas de las grises prototípicas del ámbito lucense.

88 Por citar algún ejemplo, además de los lusos ya referidos en el texto, mencionaremos los denominados urceus / copulum definidos en Liria (Escrivá, 1995: 173-174, Fig.7.6) con un perfil del galbo bastante semejante, pero carentes de asa.

89 Alcorta (2001, nota 525) refiere también la presencia en la periurbana villa de Barbaín de varios fragmentos de este tipo de recipientes asociados a hornos cerámicos.

90 Tipos L15, L15A y L16 


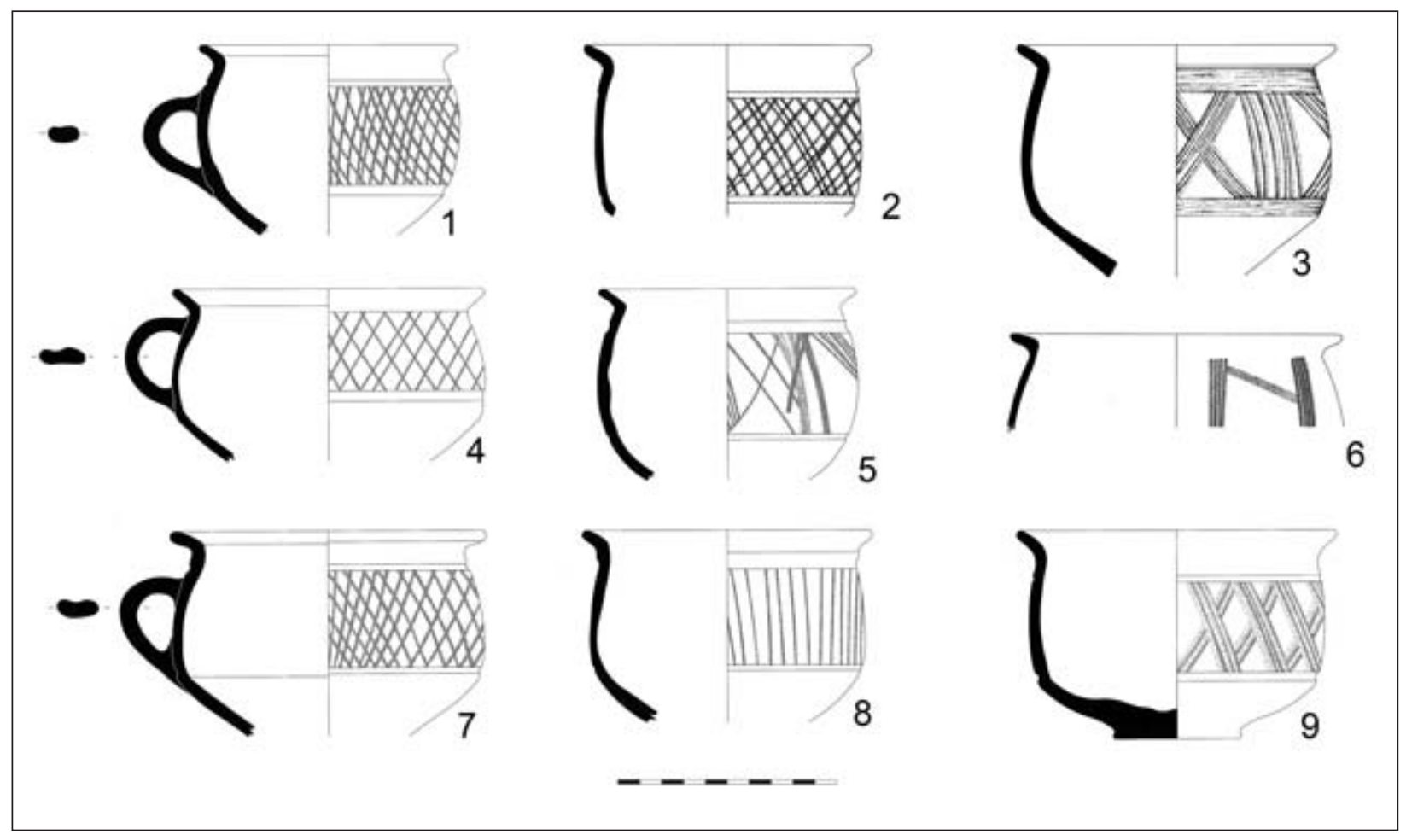

Figura 99. Tazones pequeños

\section{CATÁlogo}

\section{TAZONES MONOASADOS (variante pequeña)}

1. CH.95/1284. Sector C-10 B. Fragmento de borde y cuerpo. Borde exvasado, oblicuo y recto al interior con labio de perfil redondeado. Cuerpo de perfil globular recorrido por una acanaladura en su extremo superior y otra en la parte media-baja. Asa en $\mathrm{C}$ de sección elipsoidal que parte del tercio superior del cuerpo y llega a la zona de la acanaladura inferior. Entre las acanaladuras se desarrolla un friso decorativo ocupado por una composición de retícula bruñida romboidal simple de trama estrecha y factura bastante irregular. Pasta de tonalidad que varía entre los tonos grisáceos y los anaranjados en el núcleo con abundantes desgrasantes micáceos pequeños y muy pequeños y algún cuarzo de diverso tamaño. Superficie externa mayoritariamente gris con zonas anaranjadas que presenta, al igual que el borde, un acabado bruñido. Superficie interna de color gris. Dimensiones: diámetro borde: $120 \mathrm{~mm}$; diámetro máximo cuerpo: $122 \mathrm{~mm}$; altura conservada: $88 \mathrm{~mm}$; grosor medio sección: $4.5 \mathrm{~mm}$. Bibliografía: Benéitez et alii, 1999: 18-19, Fig.2.7; Montes, 2005.

2. CH.96/2696. Sector C-10 B. Fragmento de borde y cuerpo. Borde exvasado, oblicuo y de tendencia recta al interior con labio de perfil redondeado. Cuerpo con carena media-baja con una parte superior levemente curva de tendencia vertical surcada por sendas acanaladuras: una en el tercio superior y otra en la zona de la carena. Decoración de retícula bruñida romboidal simple de trama estrecha que se ubica entre las acanaladuras. Pasta grisácea con abundantes desgrasantes micáceos pequeños y muy pequeños y cuarzos pequeños, medios y alguno grande. Superficies de tonalidad grisácea con zonas ennegrecidas. Acabado bruñido en borde y cara externa. Dimensiones: diámetro borde: $130 \mathrm{~mm}$; diámetro máximo cuerpo: $121 \mathrm{~mm}$; altura conservada: 77 $\mathrm{mm}$; grosor medio sección: $4 \mathrm{~mm}$. Bibliografía: Benéitez et alii, 1999: 1819, Fig.2.4; Montes, 2005. 
3. CH.95/2814. Sector C-10 A / B. Fragmento de borde y cuerpo. Borde exvasado, oblicuo y recto con labio de perfil redondeado. Cuerpo de perfil carenado con carena suave media-baja. Decoración de metopas cuadrangulares configuradas por haces de líneas bruñidas verticales en cuyo interior se ubican aspas dibujadas a partir del cruce de otros haces de líneas igualmente bruñidas. El friso decorativo, al contrario de lo que es habitual en este tipo de piezas, no se encuentra enmarcado por acanaladuras, siendo sustituidas en esta ocasión por pequeñas bandas de bruñido horizontal. Pasta de tonalidad gris en las superficies y anaranjada en el núcleo con abundantes desgrasantes micáceos pequeños y muy pequeños y algún cuarzo de diverso tamaño. Superficies grises, la externa y el borde bruñidos. Dimensiones: diámetro borde: $143 \mathrm{~mm}$; diámetro máximo cuerpo: $140 \mathrm{~mm}$; altura conservada: $105 \mathrm{~mm}$; grosor medio sección: 5 mm. Bibliografía: Benéitez et alii, 1999: 1819, Fig.2.2; Montes, 2005.

4. CH.98 /2961. Sector C-7 / C-12. Fragmento de borde, cuerpo y asa. Borde exvasado, oblicuo y de tendencia recta al interior con labio de perfil redondeado. Cuerpo con carena media-baja que lo divide en una parte superior de perfil curvo ligeramente reentrante y otra inferior abierta. Cuenta con sendas acanaladuras, una muy tenue en la transición al borde, y otra, más ancha y profunda, en la zona de la carena. Asa en $\mathrm{C}$ que arranca del extremo superior del galbo para alcanzar la carena. Decoración de líneas bruñidas que configuran una retícula romboidal simple de trama estrecha que se desarrolla entre las acanaladuras, en un friso de unos $30 \mathrm{~mm}$ de ancho. Pasta de tonalidad grisácea con abundantes desgrasantes micáceos pequeños y muy pequeños y cuarzos de diverso tamaño. Superficie externa gris bruñida e interna gris más oscura. Dimensiones: diámetro borde: $138 \mathrm{~mm}$; diámetro máximo cuerpo: $140 \mathrm{~mm}$; altura conservada: 77 $\mathrm{mm}$; grosor medio sección: $4 \mathrm{~mm}$. Bibliografía: Montes, 2005.
5. CH.95 /0757. Sector C-10 A. Fragmento de borde y cuerpo. Borde exvasado, oblicuo y recto con labio de perfil redondeado. Cuerpo de perfil globular recorrido al exterior por sendas acanaladuras: una en el extremo superior y otra en el tercio inferior. Decoración entre las acanaladuras, en una banda de unos $50 \mathrm{~mm}$ de ancho, consistente en líneas bruñidas oblicuas de distintos tamaños que no parecen responder a un esquema compositivo planificado. Así, en ocasiones, se unen formando haces y en otras se cruzan configurando retículas muy abiertas. Pasta de tonalidad grisácea con abundantes desgrasantes micáceos pequeños y muy pequeños y cuarzos de tamaño pequeño y medio. Superficies grisáceas, con acabado bruñido en la externa y el borde. Dimensiones: diámetro borde: 114 $\mathrm{mm}$; diámetro máximo cuerpo: $120 \mathrm{~mm}$; altura conservada: $85 \mathrm{~mm}$; grosor medio sección: $4 \mathrm{~mm}$. Bibliografía: Benéitez et alii, 1999: 18-19, Fig.2.8; Montes, 2005.

6. CH.93 /1221. Sector R-V. Fragmento de borde y parte superior del cuerpo. Borde exvasado, oblicuo y recto al interior con labio de perfil redondeado. Cuerpo de perfil curvo en lo conservado. Decoración metopada configurada por haces de líneas bruñidas verticales entre las cuales se desarrollan haces diagonales. Pasta de tonalidad beige grisácea con abundantes micas pequeñas y muy pequeñas y cuarzos medios. Superficies grises oscuras. La cara externa y el borde presentan acabado bruñido. Dimensiones: diámetro borde: 150 $\mathrm{mm}$; altura conservada: $42 \mathrm{~mm}$; grosor medio sección: $4 \mathrm{~mm}$. Bibliografía: Montes, 2005.

7. CH.98 /3630. Sector C-12 / C-7. Fragmento de borde, cuerpo y asa. Borde exvasado y oblicuo, de perfil curvo al exterior y tendencia recta al interior con labio de perfil redondeado. Cuerpo carenado con inflexión en la zona media-baja, con una parte superior de perfil curvo y ligeramente entrante y otra inferior abierta. Presenta sendas acanaladuras, una en la parte supe- 
rior del cuerpo y otra en la zona de la carena. Asa en $\mathrm{C}$ de sección elipsoidal que arranca de la zona superior del cuerpo y que llega a la carena. Decoración de líneas bruñidas que configuran una retícula romboidal simple de trama estrecha que se desarrolla entre las acanaladuras, en una banda de unos $42 \mathrm{~mm}$ de ancho. Pasta de tonalidad grisácea con abundantes desgrasantes micáceos pequeños y muy pequeños y cuarzos de diverso tamaño. Superficie externa gris clara bruñida e interna de color beige grisáceo. Borde igualmente bruñido. Dimensiones: diámetro borde: $138 \mathrm{~mm}$; diámetro máximo cuerpo: $138 \mathrm{~mm}$; altura conservada: $92 \mathrm{~mm}$; grosor medio sección: $4.5 \mathrm{~mm}$. Bibliografía: Montes, 2005.

8. CH.01 /4489. Sector C-19. Fragmento de borde y cuerpo. Borde exvasado, oblicuo y levemente curvo con labio de perfil redondeado. La transición al cuerpo está marcada al exterior por una pequeña moldura de sección redondeada. Cuerpo de tendencia globular con una suave inflexión mediabaja marcada al exterior por una ancha acanaladura que lo divide en dos partes: una superior de tendencia vertical y otra inferior abierta. Decoración de finas líneas verticales bruñidas enmarcadas en un friso delimitado por la moldura superior y la acanaladura inferior. Pasta de tonalidad grisácea con abundantes desgrasantes micáceos pequeños y muy pequeños y cuarzos medios y pequeños. Superficies grises con acabado bruñido en borde y al exterior. Dimensiones: diámetro borde: $128 \mathrm{~mm}$; diámetro máximo cuerpo: 124 $\mathrm{mm}$; altura conservada: $86 \mathrm{~mm}$; grosor medio sección: $4 \mathrm{~mm}$. Bibliografía: Montes, 2005.

9. CH.95 /3037. Sector C-10 A. Perfil completo. Borde exvasado y oblicuo, recto al interior y curvo al exterior, con labio de perfil redondeado. Cuerpo de perfil carenado con inflexión acusada baja que lo divide en una parte superior de tendencia vertical y otra inferior abierta. Base plana con pie de disco y fondo interno ligeramente umbi- licado. Decoración de retícula romboidal ancha configurada por haces de tres líneas en sentidos opuestos, en un friso de unos $50 \mathrm{~mm}$ delimitado por las acanaladuras. Pasta de tonalidad grisácea con abundantes desgrasantes micáceos pequeños y muy pequeños y cuarzos de diverso tamaño, alguno grande. Superficies grises, bruñidas en el exterior y el borde. Dimensiones: diámetro borde: $150 \mathrm{~mm}$; diámetro máximo cuerpo: $136 \mathrm{~mm}$; diámetro base: $58 \mathrm{~mm}$; altura: $96 \mathrm{~mm}$; grosor medio sección: 6 mm. Bibliografía: Benéitez et alii, 1999: 18-19, Fig.2.1; Montes, 2005; Montes, 2009: Ficha 152, 434-435.

\section{TAZONES MONOASADOS (variante mediana)}

1. CH.01/2363. Sector C-19. Fragmento de borde, cuerpo y asa. Borde exvasado, oblicuo y de perfil de tendencia recta al interior y curva al exterior con labio de perfil biselado. Cuerpo carenado con inflexión media-baja que presenta en el extremo superior una moldura baja de perfil redondeado y más abajo, una ancha y poco profunda acanaladura. Asa en $C$ que arranca de la parte media del cuerpo y llega a la zona de la carena. Decoración bruñida compuesta por una retícula romboidal simple de trama estrecha que se desarrolla bajo la referida acanaladura. Pasta de tonalidad grisácea con abundantes desgrasantes micáceos pequeños y muy pequeños $\mathrm{y}$ cuarzos de diverso tamaño. Superficies grises claras, la externa con acabado bruñido. Dimensiones: diámetro borde: $198 \mathrm{~mm}$; diámetro máximo cuerpo: $194 \mathrm{~mm}$; altura conservada: $128 \mathrm{~mm}$; grosor medio sección: 5 mm. Bibliografía: Montes, 2005.

2. CH.95 /0466. Sector C-10 A / B. Perfil completo. Borde exvasado, oblicuo y recto con labio ligeramente engrosado de perfil redondeado. Cuerpo de perfil globular algo achatado recorrido por una acanaladura en su parte superior y otra en la parte mediabaja. Base plana con pie de disco. Fondo interior ligeramente umbilicado y exterior 


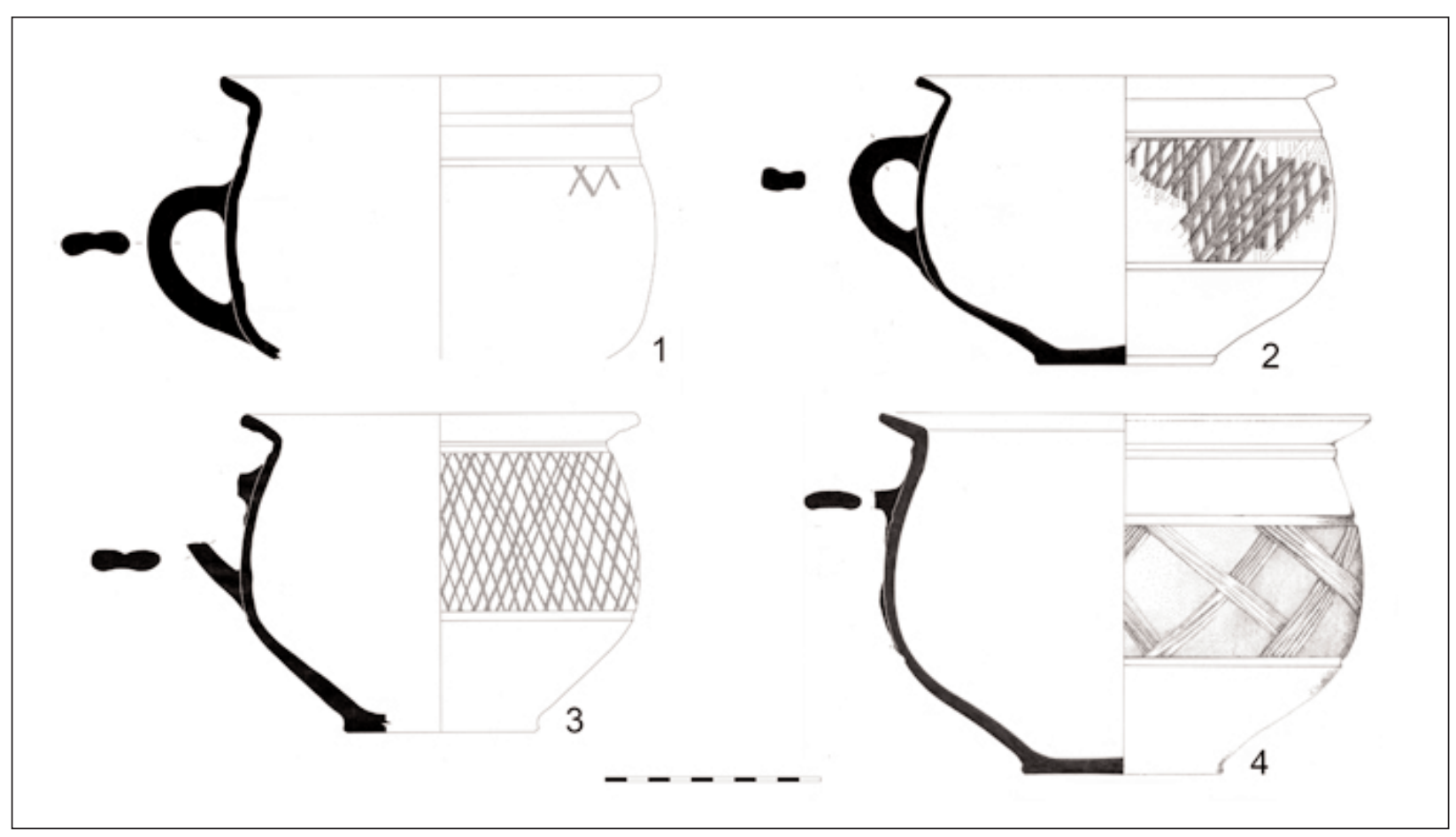

Figura 100. Tazones medianos y grandes.

recorrido por dos acanaladuras concéntricas, una perimetral. Asa en C de sección subcuadrangular ligeramente rehundida al exterior que arranca de la parte superior del cuerpo para alcanzar la acanaladura inferior. Entre las acanaladuras se desarrolla un friso decorativo de unos 60 $\mathrm{mm}$ de ancho ocupado por una composición de retícula bruñida romboidal simple de trama estrecha y factura bastante irregular. Pasta de tonalidad gris anaranjada con abundantes desgrasantes micáceos pequeños y muy pequeños y cuarzos de diverso tamaño, alguno muy grande. Superficies de color gris anaranjado, la externa, al igual que el borde, con un acabado bruñido. Dimensiones: diámetro borde: $194 \mathrm{~mm}$; diámetro máximo cuerpo: $194 \mathrm{~mm}$; diámetro base: $80 \mathrm{~mm}$; altura: $134 \mathrm{~mm}$; grosor medio sección: $5 \mathrm{~mm}$. Bibliografía: Benéitez et alii, 1999: 1819, Fig.2.10; Montes, 2005.

3. CH.95 /0907. Sector C-10 A / B. Fragmento de borde, cuerpo, base y asa. Borde exvasado, oblicuo y recto al interior con labio engrosado de perfil redondeado. Cuerpo de perfil levemente care- nado con sendas anchas acanaladuras, una en la transición al borde y otra en la carena. Asa en $\mathrm{C}$ de sección arriñonada aplanada que arranca del tercio superior del cuerpo y alcanza la carena. Decoración de retícula bruñida romboidal simple de trama estrecha circunscrita a la banda de unos $70 \mathrm{~mm}$ de anchura que cierran las acanaladuras. Pasta de color grisáceo con abundantes desgrasantes micáceos pequeños y muy pequeños y cuarcíticos y partículas rojizas de diversas dimensiones. Superficie externa y borde bruñidos de tonalidad ocre grisácea. Superficie interna gris. Dimensiones: diámetro borde: $180 \mathrm{~mm}$; diámetro máximo cuerpo: $184 \mathrm{~mm}$; diámetro base: $90 \mathrm{~m}$; altura: $145 \mathrm{~mm}$; grosor medio sección: 5 mm. Bibliografía: Benéitez et alii, 1999: 18-19, Fig.2.9; Montes, 2005.

\section{TAZONES MONOASADOS (variante grande)}

1. CH.95 /0550. Sector C-10 A. Perfil completo. Borde exvasado, oblicuo y recto al interior con labio de perfil redondeado. 
Cuerpo globular con ligera inflexión, a modo de carena suave media-baja. La transición al borde viene marcada al exterior por una moldura de sección triangular. Más abajo, aún en la parte superior de la pieza, presenta una ancha y poco profunda acanaladura y otra más en la zona de la inflexión. Base plana con pie de disco. Conserva los arranques de un asa en C de sección elipsoidal que parte de la zona alta para alcanzar la acanaladura inferior. Decoración enmarcada en un friso entre acanaladuras de unos $60 \mathrm{~mm}$ de ancho que encierra una retícula romboidal de trama ancha configurada por haces de líneas bruñidas dispuestas en sentidos opuestos, cortándose. Pasta de tonalidad grisácea con abundantes desgrasantes micáceos pequeños y muy pequeños y cuarzos de diversas dimensiones. Superficies grises con acabado bruñido al exterior y en borde. Dimensiones: diámetro borde: $225 \mathrm{~mm}$; diámetro máximo cuerpo: $220 \mathrm{~mm}$; diámetro base: 90 $\mathrm{mm}$; altura: $165 \mathrm{~mm}$; grosor medio sección: $5.5 \mathrm{~mm}$. Bibliografía: Benéitez et alii, 1999: 18-19, Fig.2.11; Montes, 2005; Montes, 2009: Ficha 138, 406-407.

\section{VASOS GLOBULARES}

(Figuras 101-103)

Al margen de los tipos de vasos comentados hasta el momento, que alcanzan un alto grado de estandarización y que se encuentran representados con generosidad en los ajuares de este periodo, también se identifican ejemplares aislados o pequeños grupos de piezas que, teniendo en cuenta sus características morfotécnicas, podrían incluirse sin género de dudas en el ámbito productivo regional.

Uno de estos tipos no ajustados a las morfologías más habituales lo constituyen los vasos globulares que se presentan en estas líneas. Se trata de pequeños recipientes que tienen en común la marcada globularidad de su galbos, que muestran perfiles casi esféricos, los bordes muy desarrollados y de tendencia vertical, las bases planas y las superficies bruñidas de tonos ocráceos (Montes, 2009: 446-447) (Figura 101 y 103.2).

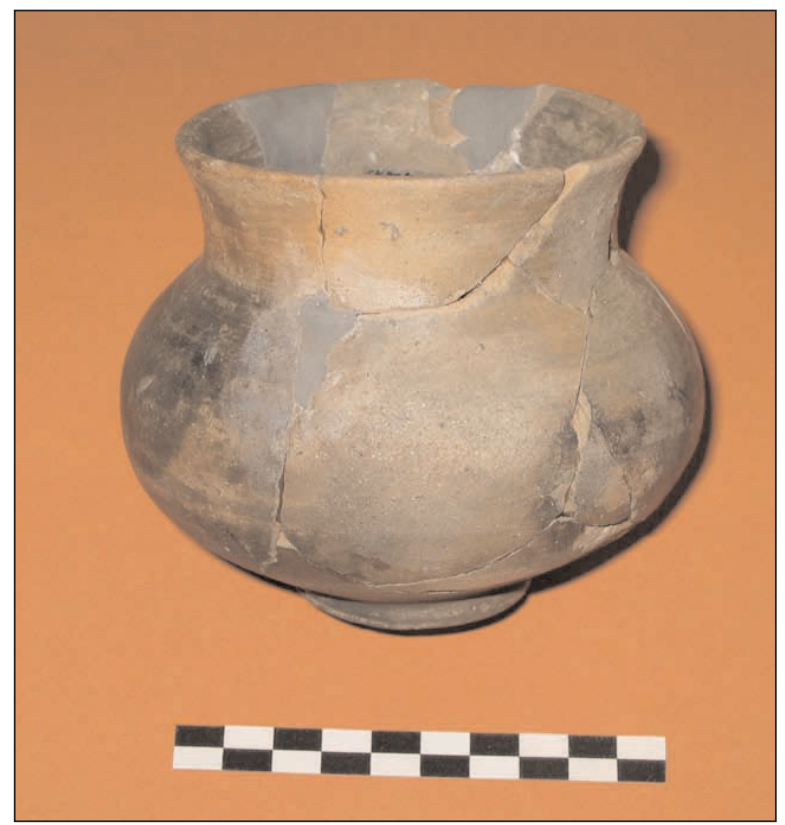

Figura 101. Vaso globular. Foto: R. Montes

En uno de los ejemplares presentados, la definición morfológica se completa con un asa en $\mathrm{C}$ instalada en la zona de la panza (Figura 102 y 103.1).

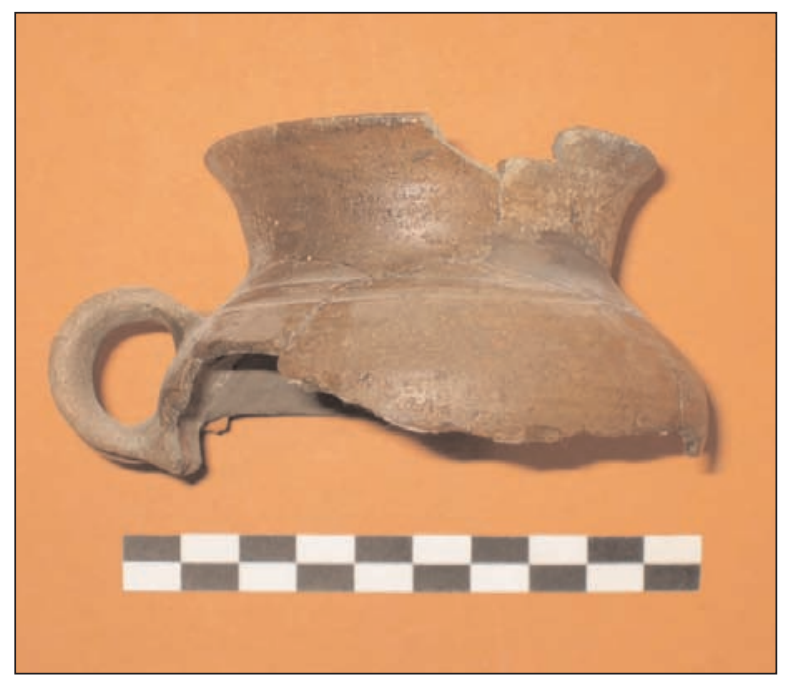

Figura 102. Vaso globular monoasado. Foto: R. Montes

Lo atípico de la presencia de estas piezas en el repertorio formal al uso queda reafirmado por su completo desconocimiento en el elenco publicado procedente de Lucus Augusti (Alcorta, 2001), referente recurrente de la cerámica regional documentada en el yacimiento. 


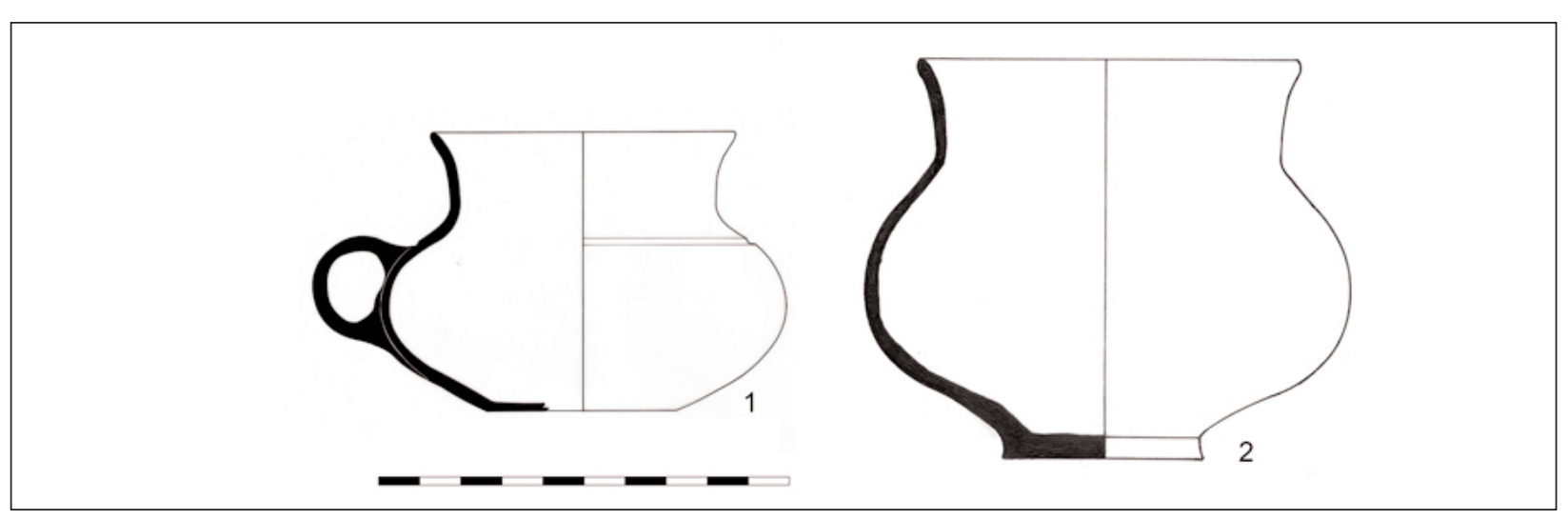

Figura 103. Vasos globulares

\section{CATÁlogo}

1. CH.00 /1742. Sector C-11 B. Perfil completo. Borde indiferenciado, exvasado, curvo y ligeramente oblicuo con labio de perfil redondeado. Cuello de tendencia vertical separado del cuerpo al exterior mediante una acanaladura. Cuerpo globular achatado. Base plana. Asa en C instalada en la zona del diámetro máximo de la panza. Pasta de tonalidad ocre grisácea con desgrasantes micáceos y cuarcíticos pequeños y medios. Superficies ocráceas, la externa y el borde con acabado bruñido. Dimensiones: diámetro borde: $74 \mathrm{~mm}$; diámetro máximo cuerpo: $100 \mathrm{~mm}$; diámetro base: $46 \mathrm{~mm}$; altura conservada: 69 $\mathrm{mm}$; grosor medio sección pared: $4 \mathrm{~mm}$. Bibliografía: Montes, 2005.

2. CH.95/2657. Sector C-10 A. Perfil completo. Borde indiferenciado, ligeramente exvasado y curvo. Cuello de tendencia vertical y perfil curvo. Cuerpo globular. Base plana con pie de disco. Pasta de tonalidad pardo grisácea con abundantes desgrasantes micáceos pequeños y muy pequeños y cuarzos pequeños y medios. Superficies de color gris ocráceo con acabado bruñido en el borde y la cara exterior. Dimensiones: diámetro borde: 92 $\mathrm{mm}$; diámetro máximo cuerpo: $117 \mathrm{~mm}$; diámetro base: $50 \mathrm{~mm}$; altura: $96 \mathrm{~mm}$; grosor medio sección pared: $3.5 \mathrm{~mm}$.; Bibliografía: Benéitez et alii, 1999: 1718, Fig.3.4; Montes, 2005; Montes, 2009: Ficha 158, 446-447.

\section{VASOS CON DECORACIÓN DE DEPRESIONES}

(Figuras 104 y 105)

Se han identificado varios vasos con decoraciones de depresiones en su cara externa que responden a las características técnicas habituales de la serie regional, con acabados bruñidos y pastas cuarzo-micáceas relativamente groseras (Montes, 2005). Se trata de pequeños recipientes de borde corto y exvasado, base plana y desarrollo del cuerpo indeterminado, habida cuenta de la carencia de perfiles con un grado de reintegración suficiente (Figuras 104 y 105).

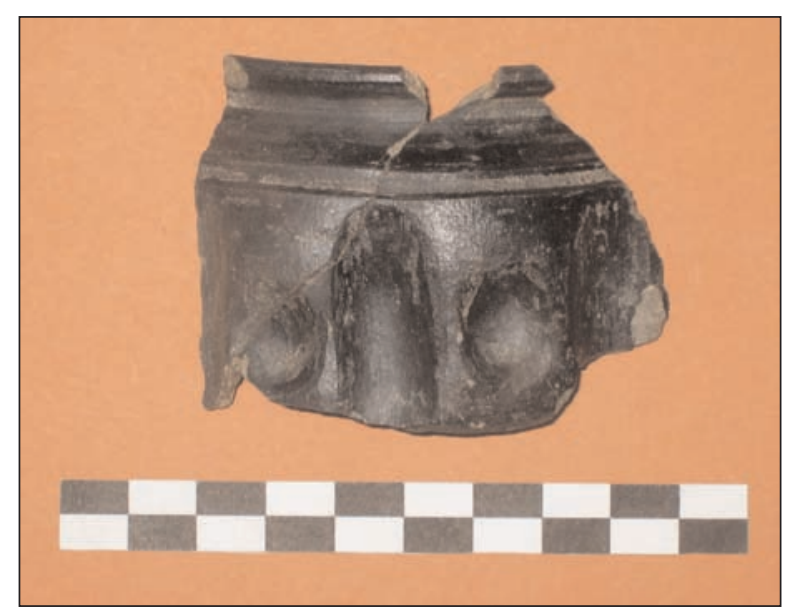

Figura 104. Vaso con decoración de depresiones. Foto: R. Montes

Se ha planteado para este tipo de ornamentación de hoyitos o depresiones, tan característico de determinadas formas de paredes finas como la Mayet VI (1975: Pl. XI), tipo al que parecen remedar estos vasos, una época de apogeo entre la segunda mitad del siglo I d.C. y el siglo II d.C. (Carretero, 2000: 514). 


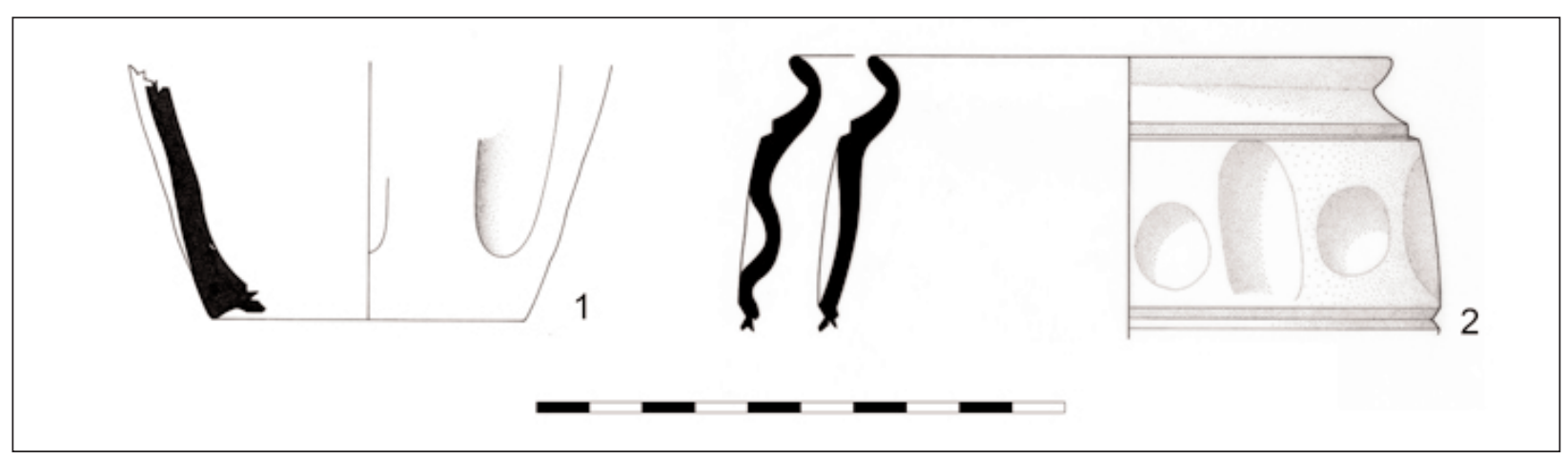

Figura 105. Vasos con decoración de depresiones

\section{CATÁlogo}

1. CH.99/3711. Sector C-11 A. Fragmento de cuerpo y arranque de base. Cuerpo de perfil ligeramente abierto, casi vertical. Base plana en lo conservado con el fondo externo surcado por una acanaladura perimetral. Presenta en la superficie externa decoración de depresiones verticales de forma ovalada alargada que arrancan del extremo inferior del cuerpo. Pasta cuarzo-micácea de tonalidad grisácea con desgrasantes pequeños, medios y grandes. Superficie externa negra bruñida e interna gris. Dimensiones: diámetro base: $60 \mathrm{~mm}$; altura conservada: $59 \mathrm{~mm}$; grosor medio sección pared: $5 \mathrm{~mm}$. Bibliografía: Montes, 2005.

2. CH.01 /0804. Sector C-12 B. Fragmento de borde y cuerpo. Borde corto, exvasado, oblicuo y curvo con labio de perfil redondeado. Hombro destacado reforzado al exterior por una acanaladura. Cuerpo de tendencia vertical en lo conservado. Una segunda acanaladura constituye el límite inferior de un friso decorado de $31 \mathrm{~mm}$ de ancho en el que se alternan depresiones ovaladas y circulares. Pasta grisácea con desgrasantes micáceos muy pequeños y abundantes partículas cuarcíticas y puntos blanquecinos de pequeño y mediano tamaño. Superficies de tonalidad negra, con acabado bruñido en la externa y el borde que le confiere un aspecto zonalmente brillante. Dimensiones: diámetro borde: 98 $\mathrm{mm}$; altura conservada: $53 \mathrm{~mm}$, grosor medio sección pared: $3.5 \mathrm{~mm}$. Bibliografía: inédito.

\section{JARRAS DE BOCA TRILOBULADA}

(Figuras 106-107)

Las jarras de boca trilobulada se muestran como la morfología de recipientes destinados al servicio y trasiego de líquidos con una mayor representación en los repertorios del yacimiento del siglo II d.C. (Benéitez et alii, 1999: 22-23, Fig. 3.12-14 y 4.1-6; Montes, 2009: 438-439) y sin duda, como el modelo que alcanza un mayor grado de estandarización.

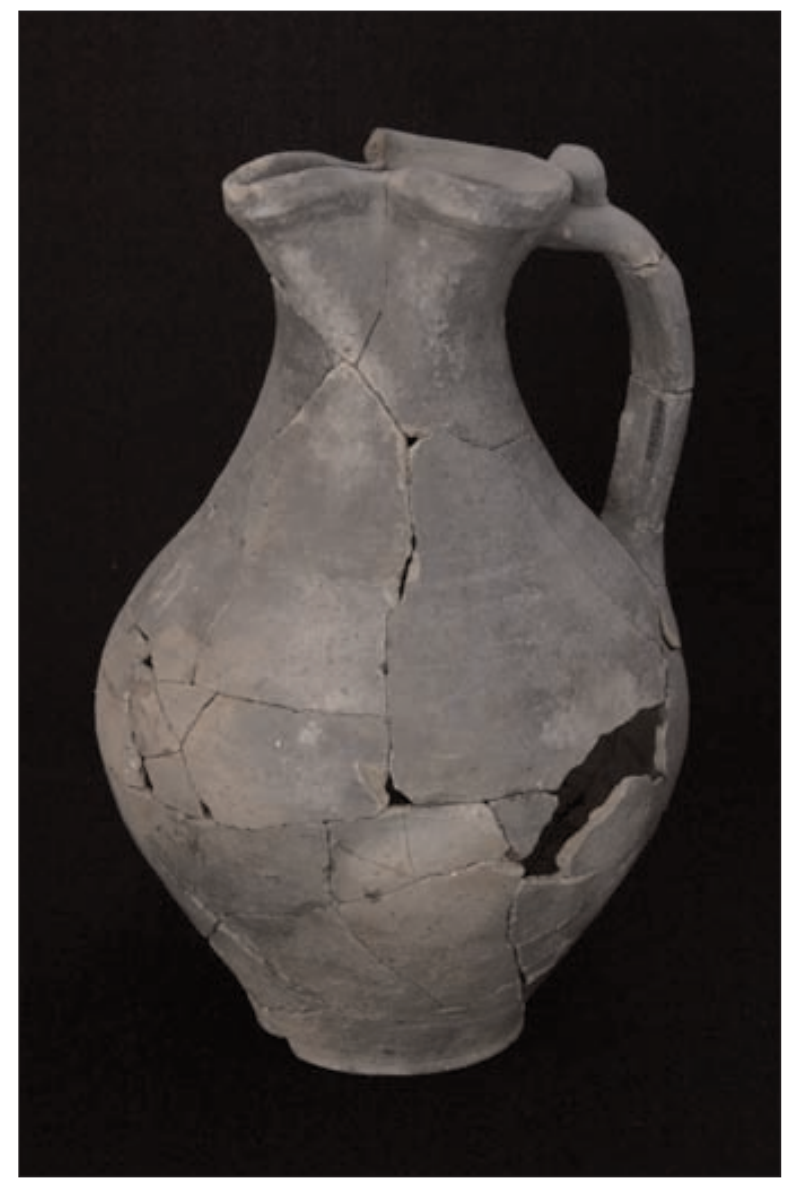

Figura 106. Jarra de boca trilobulada. Foto: J. Arrojo 
El referente morfológico genérico, inspirado en el oinochoe helenístico (Beltrán, 1990: 195) remite a las lagonae de la forma Vegas 46, muy difundidas por todo el ámbito circunmediterráneo ya desde época augustea y que perdurarán sin grandes modificaciones hasta el siglo IV d.C. (Vegas, 1976: 109).

La tipología se expresa en el caso de las piezas aquí presentadas como una fórmula específica con unas características bastante homogéneas que la inscriben plenamente en el ámbito productivo regional. Los bordes, con la típica forma trilobulada que da nombre al tipo, se manifiestan en todos los casos conocidos hasta el momento en su versión de pico cerrado, con labio de perfil biselado al exterior y cóncavo al interior. La transición al galbo, que presenta desarrollos más o menos globulares o estilizados según los casos, se resuelve mediante un cuello corto de estrechez variable. En ocasiones, entre ambos sectores una acanaladura o una pequeña arista recorre la cara externa de la pieza, sirviendo de elemento de definición del tránsito. Las bases son planas con fondos interiores también planos o umbilicados.

Otro elemento formal característico es la presencia de una única asa en L invertida de sección elipsoidal con acanaladura central y anchura variable que arranca bajo el borde para alcanzar la parte inferior del cuello, en el tránsito al cuerpo. La presencia de un apéndice de botón en su parte superior, en el contacto con el borde, resulta relativamente frecuente entre los ejemplares conocidos (Montes y Hevia, 2008: 770).

En cuanto a las dimensiones, las bocas suelen presentar ejes mayores (entre el asa y la piquera) entre 75 y $95 \mathrm{~mm}$, mientras que los menores se muestran algo más pequeños, entre 65 y $85 \mathrm{~mm}$. La combinación entre los valo- res de los diámetros máximos de las panzas (170-185 mm) y las alturas (en torno a los 250 $\mathrm{mm}$ ) introducen la aludida heterogeneidad morfológica, que atañe a la mayor o menor estilización de los recipientes, a la que también contribuye la variabilidad en la anchura y altura del cuello.

Las pastas en que suelen estar realizadas estas jarras, siempre relacionadas con las habituales en las producciones regionales, son de naturaleza cuarzo-micácea relativamente grosera, aunque en ocasiones algunos ejemplares cuentan con pastas esquistosas más groseras. Los tratamientos superficiales suelen consistir en someros alisamientos que regularizan toscamente la cara externa y que dotan a las jarras de superficies externas rugosas.

Los paralelos más ajustados a los particulares rasgos formales y técnicos de este grupo de piezas nos traslada a Lucus Augusti, donde la frecuente presencia de ejemplares equiparables (Alcorta, 2001: 287-289, Fig. 120) avala la identidad genética entre ambos repertorios, debida indudablemente a su elaboración en los hornos cerámicos de la capital conventual (Alcorta, 2001). En el ámbito territorial del noroeste peninsular, aunque fuera ya del marco estricto de distribución de estos productos, la morfología es conocida en yacimientos como Conimbriga (Alarcão, 1975: P1. XXIII.455, XXV.505, XLIV.847 y XLV.853), Petavonium (Carretero, 2000: 673675, Fig. 338), Legio ${ }^{91}$, el castro de Llagú (Berrocal et alii, 2002: 260, Fig.56.2 y 3) y El Castelón de Coaña (Maya, 1988: 234), si bien en estos casos las descripciones disponibles de las características formales y técnicas de las piezas difieren sustancialmente de las referidas para el grupo lucense.

denominada Forma 2 de jarras de cuello estrecho y boca lobulada con pico vertedor (Fernández, 2003: 138-139: Fig. 103 a 105).

91 En el repertorio recuperado en el vertedero localizado en el solar situado en la calle Maestro Copín c/v San Salvador del Nido de León se integran varias jarras de este tipo incluidas por la autora del estudio de los materiales en la 

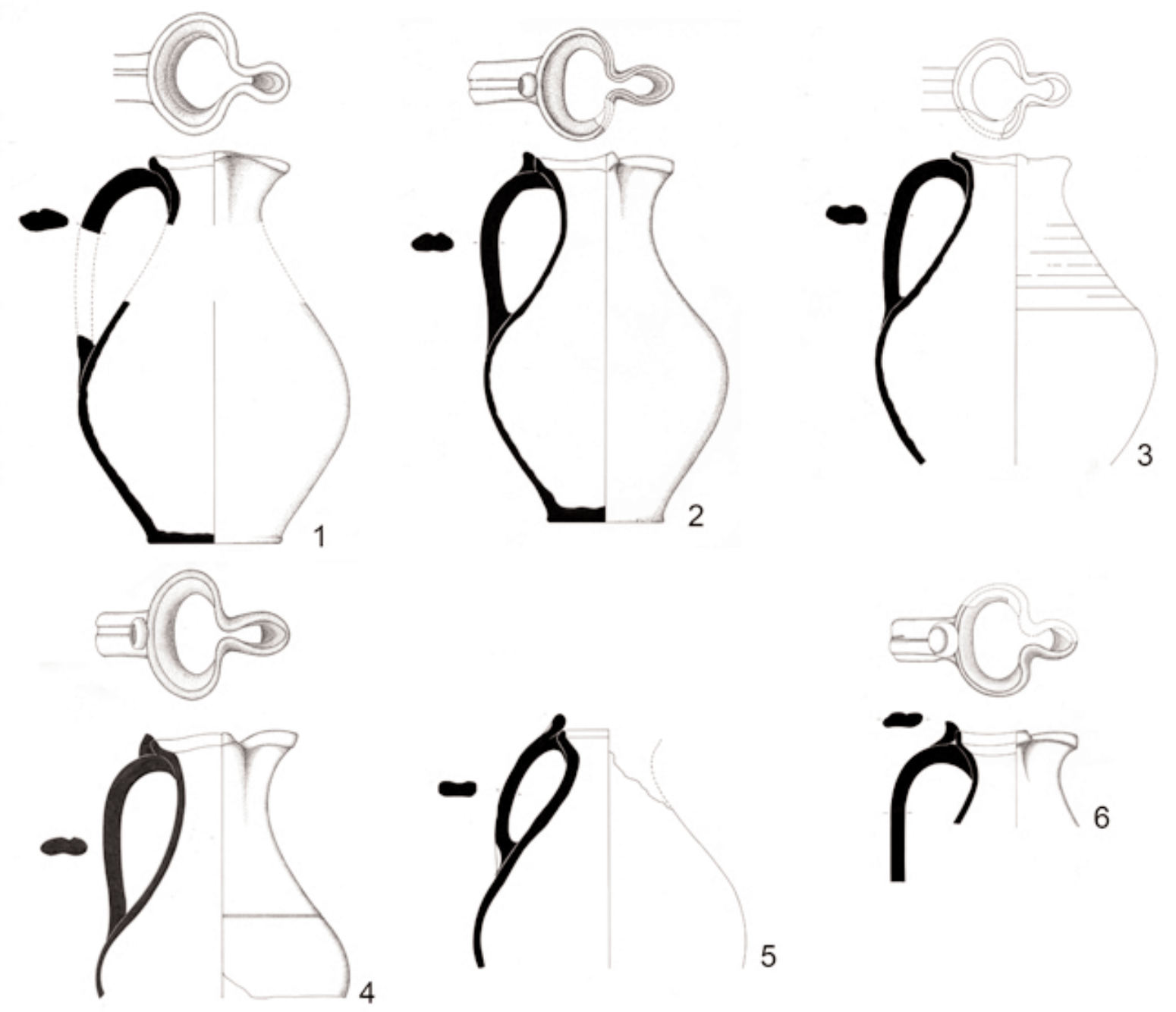

5

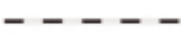

Figura 107. Jarras de boca trilobulada

\section{CATÁlogo}

1. CH.95 /1133. Sector C-10. Perfil completo. Borde exvasado con labio de perfil cóncavo al interior y bisel exterior. Cuello ancho de perfil curvo, cuerpo globular y base plana. Asa con perfil en L invertida de sección elipsoidal con acanaladura central que arranca bajo el borde y finaliza hacia la mitad del cuerpo, donde se conserva únicamente el arranque. Pasta grosera de tonalidad beige con abundantes desgrasantes, micáceos, cuarcíticos y esquistosos de diverso tamaño. Superficie externa grisácea e interna beige. Acabado alisado somero al exterior. Dimensiones: longitud eje mayor boca: $95 \mathrm{~mm}$; longitud eje menor boca: $80 \mathrm{~mm}$; diámetro máximo cuerpo: $178 \mathrm{~mm}$; diámetro base: $89 \mathrm{~mm}$; altura aproximada: $260 \mathrm{~mm}$; grosor medio sección pared: $6 \mathrm{~mm}$. Bibliografía: Hevia et alii, 2001: 22-23, Fig.4.1.

2. CH.95 /1646. Sector C-10 A. Perfil completo. Borde exvasado con labio de perfil cóncavo al interior y bisel exterior. Cuello largo y estrecho de perfil curvo. Cuerpo globular. Base plana con fondo interior umbilicado. Asa con perfil en L invertida de sección elipsoidal con acanaladura central que arranca bajo el borde y finaliza al inicio del cuerpo. Presenta apéndice de 
botón en su extremo superior y digitación circular en el inferior. Pasta de tonalidad grisácea anaranjada con desgrasantes micáceos, cuarcíticos y esquistosos pequeños y medianos. Superficies rugosas de tonalidad gris al exterior y pardo anaranjada al interior, siendo visibles las líneas del torno en ambas caras. Dimensiones: longitud eje mayor boca: $90 \mathrm{~mm}$; longitud eje menor boca: $74 \mathrm{~mm}$; diámetro máximo cuerpo: $161 \mathrm{~mm}$; diámetro base: $75 \mathrm{~mm}$; altura: $245 \mathrm{~mm}$; grosor medio sección pared: $5 \mathrm{~mm}$. Bibliografía: Benéitez et alii, 1999: 22-23, Fig.3.12; Montes, 2009: Ficha 154, 438-439.

3. CH.96/2439. Sector C-10. Fragmento de borde, cuerpo y asa. Borde exvasado con labio con bisel exterior y perfil cóncavo al interior. Cuello largo, ancho y curvo, de tendencia muy abierta, recorrido en su extremo inferior por una pequeña arista que marca el inicio del desarrollo del cuerpo. Cuerpo de perfil claramente globular. Asa con perfil en L invertida de sección elipsoidal con acanaladura central y digitación circular en su extremo inferior que arranca de debajo del borde y finaliza a la altura de la arista. Pasta de tonalidad pardo anaranjada con desgrasantes micáceos menudos y cuarcíticos, cerámicos y esquistosos medios y grandes. Superficie externa gris e interna parda. Somero alisado al exterior, siendo visibles las líneas del torno también en la superficie externa, en la que llega incluso a configurar pequeñas acanaladuras en la zona del cuello. Dimensiones: longitud eje mayor boca: 78 $\mathrm{mm}$; longitud eje menor boca: $67 \mathrm{~mm}$; diámetro máximo cuerpo: $186 \mathrm{~mm}$; altura conservada: $205 \mathrm{~mm}$; grosor medio sección pared: $5 \mathrm{~mm}$. Bibliografía: Benéitez et alii, 1999: 22-23, Fig.4.2.

4. CH.95/2785. Sector C-10 A. Fragmento de borde, cuerpo y asa. Borde exvasado con labio de perfil cóncavo al interior y bisel exterior. Cuello largo y curvo recorrido en su extremo inferior por una pequeña acanaladura de sección circular.
Cuerpo de tendencia globular en lo conservado. Asa con perfil en L invertida de sección elipsoidal con acanaladura central, apéndice de botón en su extremo superior y digitación circular en el inferior. Arranca bajo el borde y finaliza inmediatamente después de la acanaladura. Pasta de tonalidad pardo anaranjada con desgrasantes micáceos muy pequeños y cuarcíticos pequeños, medios y alguno grande. Las superficies, de color gris, no evidencian ningún acabado específico, siendo visibles las líneas del torno también en la superficie externa. Dimensiones: longitud eje mayor boca: 95 $\mathrm{mm}$; longitud eje menor boca: $85 \mathrm{~mm}$; diámetro máximo cuerpo: $168 \mathrm{~mm}$; altura conservada: $170 \mathrm{~mm}$; grosor medio sección pared: $5 \mathrm{~mm}$. Bibliografía: Benéitez et alii, 1999: 22-23, Fig.3.14.

5. CH.96 /2706. Sector C-10. Fragmento de borde, cuerpo y asa. Borde exvasado de perfil cóncavo al interior con labio de perfil cóncavo al interior y bisel exterior. Cuello corto, ancho y curvo, de tendencia muy abierta. Cuerpo de perfil globular. Asa en L invertida de sección elipsoidal, ligeramente rehundida en el centro, con apéndice de botón de sección circular en el extremo superior y digitación circular en el inferior. Arranca directamente del borde y finaliza antes del inicio del desarrollo del cuerpo. Pasta grosera de color pardo con abundantes desgrasantes micáceos pequeños y cuarcíticos y esquistosos de diversas dimensiones. Las superficies, de tonalidad grisácea la externa y pardo grisácea la interna, no evidencian ningún acabado específico, exceptuando la superficie externa del asa que ha sido toscamente bruñida, siendo visibles las líneas del espatulado. Dimensiones: diámetro máximo cuerpo: $180 \mathrm{~mm}$; altura conservada: $161 \mathrm{~mm}$; grosor medio sección pared: $6 \mathrm{~mm}$. Bibliografía: Benéitez et alii, 1999: 22-23, Fig.3.13.

6. CH.99 /1234. Sector C-7. Fragmento de borde, cuello y asa. Borde exvasado face- 
tado con labio de sección redondeada y perfil cóncavo al interior. Cuello de perfil curvo en lo conservado. Asa de sección elipsoidal con acanaladura central y apéndice de botón en su extremo superior que arranca del borde. Pasta grosera de tonalidad grisácea clara con desgrasantes micáceos pequeños y medianos y abundantes cuarzos de diversas dimensiones. Superficies rugosas de tonalidad ocrácea sometidas a un somero alisado. Dimensiones: longitud eje mayor boca: 80 $\mathrm{mm}$; longitud eje menor boca: $74 \mathrm{~mm}$; altura conservada: $61 \mathrm{~mm}$; grosor medio sección pared: $4.5 \mathrm{~mm}$. Bibliografía: Inédita.

\section{CUENCOS / FUENTES CARENA- DOS DE BORDE ENGROSADO}

(Figuras 108-109)

El morfotipo, identificable con la forma Vegas 9 a del repertorio romano típico (Vegas, 1973: 35-37), se caracteriza por tratarse de un recipiente bajo rematado en un borde engrosado con el labio de perfil redondeado. Los perfiles de los galbos, que trazan en su parte superior una característica carena más o menos acusada, aunque nunca abrupta, muestran cierta variabilidad que los hace fluctuar entre formas de clara tendencia hemisférica hasta morfologías más angulosas del tipo que S. Carretero (2001: 666) denomina aquilladas. Resulta frecuente la presencia en el extremo superior externo del cuerpo de una acanaladura que lo separa del borde, así como de otra más abajo, en la zona de la carena. La base, plana y realzada, desarrolla diámetros en torno a la mitad de las dimensiones del borde.

En función de la heterogeneidad de tamaños cabe distinguir dos grandes variantes o módulos dimensionales (Montes, 2009: 432-433):

- Cuencos (Figura 109. 2 y 4). Se trata de recipientes tipo escudilla, con diámetros de boca por debajo de los $200 \mathrm{~mm}$ (Benéitez et alii, 1999: 26-27, Fig.5. 1$3)$. Cabe suponer para estas piezas un uso destinado al servicio individual de ali-

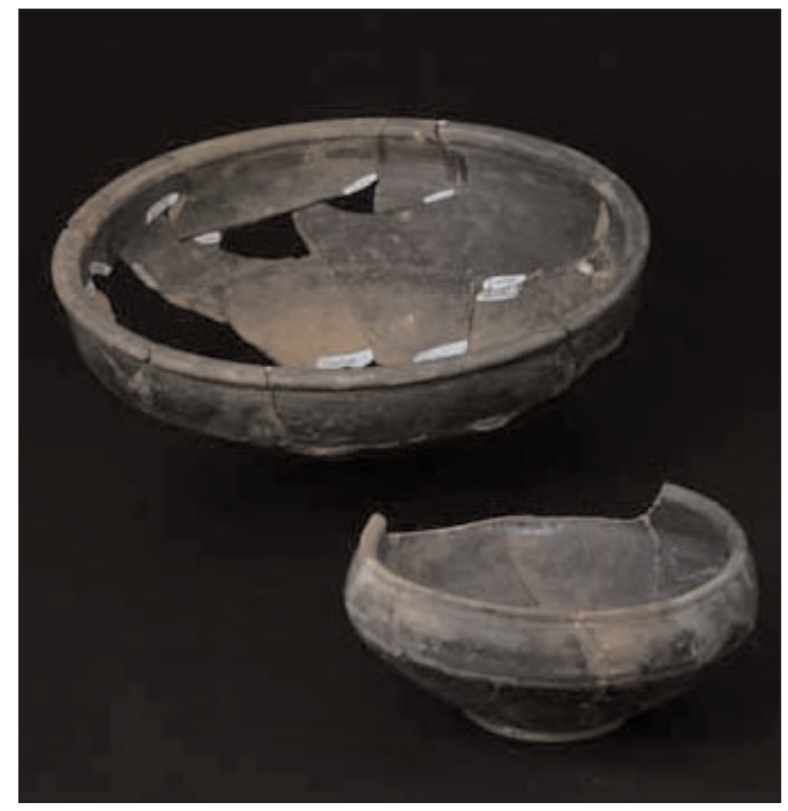

Figura 108. Cuenco y fuente carenados de borde engrosado. Foto: J. Arrojo

mentos en la mesa, aunque no deben descartarse de forma tajante otro tipo de empleos como el de salseras o saleros (Alcorta, 2001: 331).

- Fuentes (Montes y Hevia, 2008: 770) (Figura 109. 1 y 3). Los valores diametrales de los bordes son en este caso superiores a los $200 \mathrm{~mm}$, rebasando en ocasiones, incluso ampliamente, los 300 $\mathrm{mm}$. La función que se puede hipotetizar para estos recipientes se vincula al servicio colectivo de mesa (Montes et alii, 2001: 32; Alcorta, 2001: 330), sin obviar la posibilidad complementaria de usos ajenos a estos servicios, en procesos culinarios en frío o en labores higiénicas (Alcorta, 2001: 331).

Al margen de las características morfológicas y dimensionales referidas, los acabados bruñidos, las tonalidades grises o negras de las superficies y las pastas cuarzo-micáceas depuradas se hacen omnipresentes en este tipo cerámico. Todos estos rasgos, habida cuenta el gran parecido que guardan con otros tipos de mesa como, por ejemplo, los vasos ovoides grises o los platos no engobados, vinculan a estas piezas a una familia de cerámica fina gris que se integra en el seno de las producciones regionales lucenses y que remeda morfologías clásicas. 
La terminología empleada para referirse al morfotipo que se ha descrito, tanto en una como en otra versión, resulta variada y conviene referirse a ella para evitar confusiones. El referente terminológico clásico remite a la denominación adoptada por Vegas (1973) de cuencos carenados de borde engrosado, término que adoptamos en ésta y en anteriores publicaciones (Benéitez et alii, 1999: 26-27, Fig. 5.1-3; Montes et alii, 2001: 32, Fig.1.6; Montes y Hevia, 2008: 770), al igual que sucede con otros autores como E. Alcorta, que describe inicialmente las versiones de mayor tamaño registradas en Lucus Augusti como grandes cuencos de borde engrosado (Alcorta 1995: 215, fig. 11.2), diferenciándolas de los cuencos carenados de borde engrosado (Ibidem: 216, fig. 12.2 y 6) de dimensiones más modestas. Con posterioridad, este mismo autor incluye ambas fórmulas entre los cuencos de cuerpo carenado y borde engrosado de bastoncillo -tipo C2- (Alcorta, 2001: 329-331, Fig.138), relegando el empleo del término fuentes carenadas de labio engrosado -tipo F2- para formas distantes a las morfologías de referencia (Ibidem: 342, Fig.143) $)^{92}$.

Además de estas citas referidas a la ciudad de Lugo los paralelos más próximos se extienden a yacimientos como Os Castros de Taramundi (Expósito, 2004; Montes, 2009: 432433), Huerña ${ }^{93}$ (Domergue y Martin, 1977: 54 y 122, Figs. $13.183-184$ y $32.618-623)^{94}$ y tal vez, la Corona del Castro de Arancedo (Maya, 1988: 175-176, Fig. 55 A). Algo más lejanos, tanto desde el punto de vista geográfico como técnico, se encuentran los ejemplares procedentes de Rosinos de Vidriales (Carretero, 2000: 665-668, Figs. 333.81-85, 334.86-91 y 335.92-95), para los que se plantea una distinción entre una variante hemisférica y otra de perfil aquillado. Estas piezas presentan unas pastas ocres o anaranjadas (Ibidem: 665) que difieren de los restantes ejemplos citados, elaborados en pastas grises o negruzcas, a pesar de la comunidad formal y la semejanza en el tratamiento de las superficies.

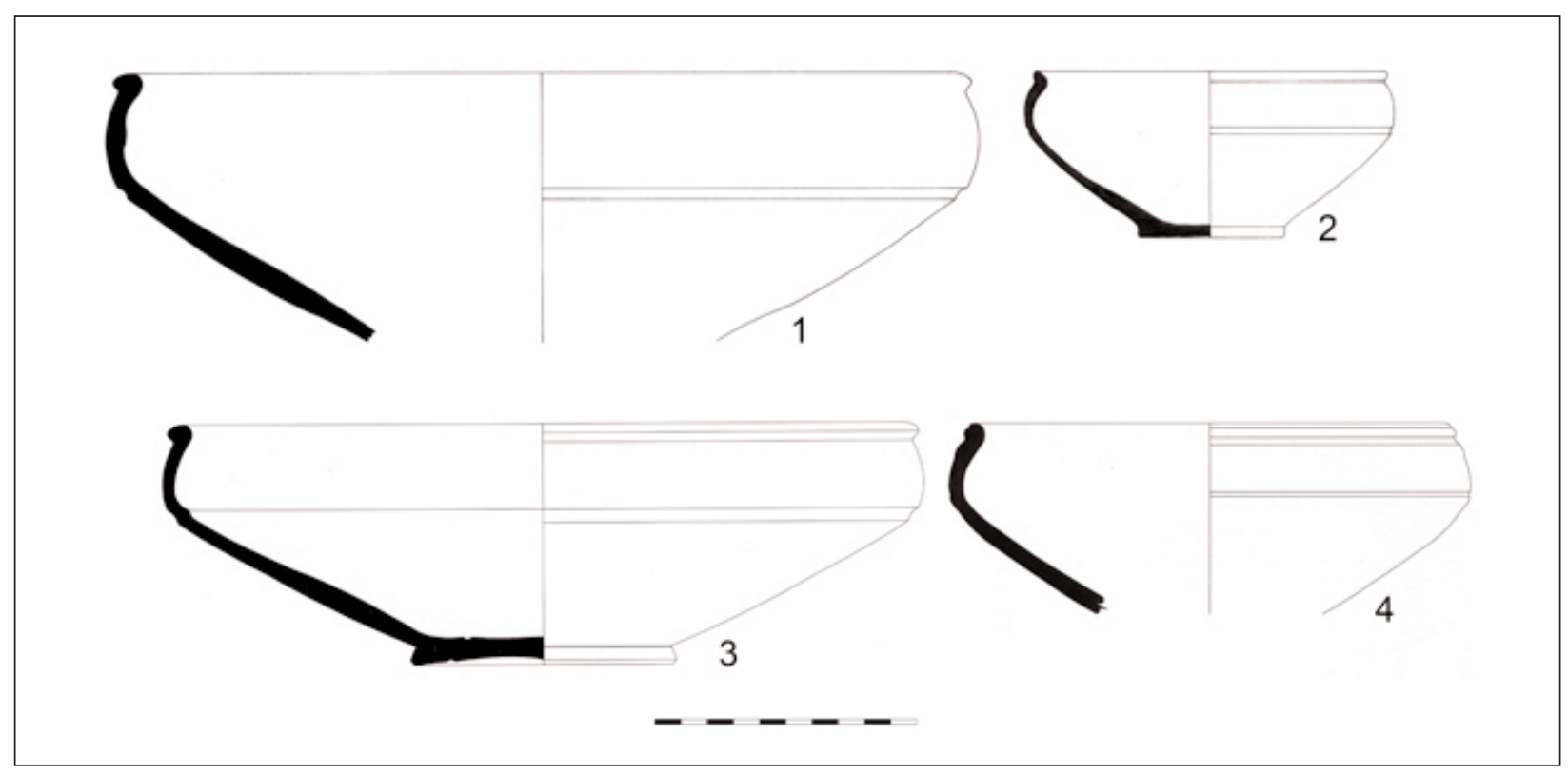

Figura 109. Cuencos-fuentes carenadas

92 Resulta curioso, no obstante, que en esta clasificación se obvia la cuestión de las dimensiones, pues en el apartado de fuentes se incluyen ejemplos de talla similar o incluso menor que la de algunos de los cuencos.

93 Encuadrables en ambas categorías dimensionales, pues presentan diámetros variables que oscilan entre los 18 y $\operatorname{los} 24 \mathrm{~cm}$.
94 En estos casos, las concomitancias no se limitan a los aspectos morfológicos, sino que se extienden a las características de pasta, tratamientos y cromatismo, hasta el punto de hacer evidente el aire de congeneidad entre los diferentes repertorios. 


\section{CATÁlogo}

1. CH.93 /1573. Sector R-V. Fragmento de borde y cuerpo. Borde corto exvasado engrosado con el labio de sección redondeada. Cuerpo con carena alta recorrido al exterior por una acanaladura ancha y poco profunda. Pasta fina de tonalidad pardo anaranjada con desgrasantes micáceos muy pequeños y cuarcíticos y cerámicos pequeños y medianos. Superficies bruñidas de tonalidad gris oscura. Dimensiones: diámetro borde: $289 \mathrm{~mm}$; diámetro máximo cuerpo: $294 \mathrm{~mm}$; altura conservada: $90 \mathrm{~mm}$; grosor medio sección: $6 \mathrm{~mm}$. Bibliografía: Inédita.

2. CH.95 /0461. Sector C-10 A. Perfil completo. Borde engrosado ligeramente exvasado con labio de perfil redondeado. La transición a la pared está marcada por una acanaladura estrecha y poco profunda. Cuerpo con carena alta recorrido por otra acanaladura que coincide con la inflexión. Base plana con pie de disco. Pasta fina de tonalidad pardo anaranjada con abundantes desgrasantes micáceos y cuarcíticos pequeños y muy pequeños. Superficies grisáceas, con acabado bruñido en la externa y el borde y alisado en la interior. Dimensiones: diámetro borde: $158 \mathrm{~mm}$; diámetro máximo cuerpo: $166 \mathrm{~mm}$; diámetro base: 66 $\mathrm{mm}$; altura: $75 \mathrm{~mm}$; grosor medio de la sección: $4 \mathrm{~mm}$. Bibliografía: Benéitez et alii, 1999: 26-27, Fig. 5.2; Montes, 2009: Ficha 151, 432-433.

3. CH.93 /1129. Sector R-V. Perfil completo. Borde corto exvasado engrosado con el labio de sección redondeada. Cuerpo con carena alta recorrido al exterior por una acanaladura ancha y poco profunda. Base plana con pie de disco surcado en el fondo exterior por una acanaladura. Pasta fina de tonalidad pardo anaranjada con desgrasantes micáceos muy pequeños y cuarcíticos y cerámicos pequeños y medianos. Superficies bruñidas de tonalidad gris oscura. Dimensiones: diámetro borde: 254 mm; diámetro máximo cuerpo: $257 \mathrm{~mm}$; diámetro base: $88 \mathrm{~mm}$; altura: $82 \mathrm{~mm}$; grosor medio sección: $4.5 \mathrm{~mm}$. Bibliografía: Inédita.

4. CH.95/1085. Sector C-10 A. Fragmento de borde y cuerpo. Borde engrosado con labio de sección redondeada recorrido por una estría bastante profunda en su superficie externa. La transición a la pared está señalada por una acanaladura. Cuerpo con carena alta recorrido por otra acanaladura que coincide con la inflexión. Pasta fina de tonalidad gris clara con abundantes desgrasantes micáceos muy pequeños y cuarcíticos pequeños y medios. Superficies bruñidas de tonalidad gris negruzca. Dimensiones: diámetro borde: $158 \mathrm{~mm}$; diámetro máximo cuerpo: $174 \mathrm{~mm}$; altura conservada: $64 \mathrm{~mm}$; grosor medio sección: 5 mm. Bibliografía: Benéitez et alii, 1999: 26-27, Fig. 5.3.

\section{PLATOS GRISES}

(Figura 110-111)

Nos encontramos ante un tipo que, aún sin contar con una amplia representación dentro del elenco del yacimiento ${ }^{95}$, no resulta extraordinario y exhibe un alto grado de homogeneidad técnica y morfológica que lo inserta indefectiblemente entre las producciones regionales. También en Lugo, la forma, definida por E. Alcorta bajo la denominación de platos grises lisos de borde biselado -tipo P1- (2001: 359-360, Fig. 151) se documenta en porcentajes sensiblemente inferiores a otros tipos.

Se trata de platos bajos de pared oblicua curva y borde indiferenciado ligeramente incurvado y casi siempre biselado al exterior. Las bases son planas y se encuentran recorridas al exterior por un número variable de acanaladuras. Los acaba-

95 Se nota cierta concentración en determinados sectores, de los depósitos. 
dos bruñidos más o menos esmerados combinados con las atmósferas reductoras de cocción dotan a los recipientes de unas superficies grises o negras finas en las que resaltan las partículas micáceas tan características de las pastas de determinadas manufacturas lucenses finas (Montes, 2009: 450-451).

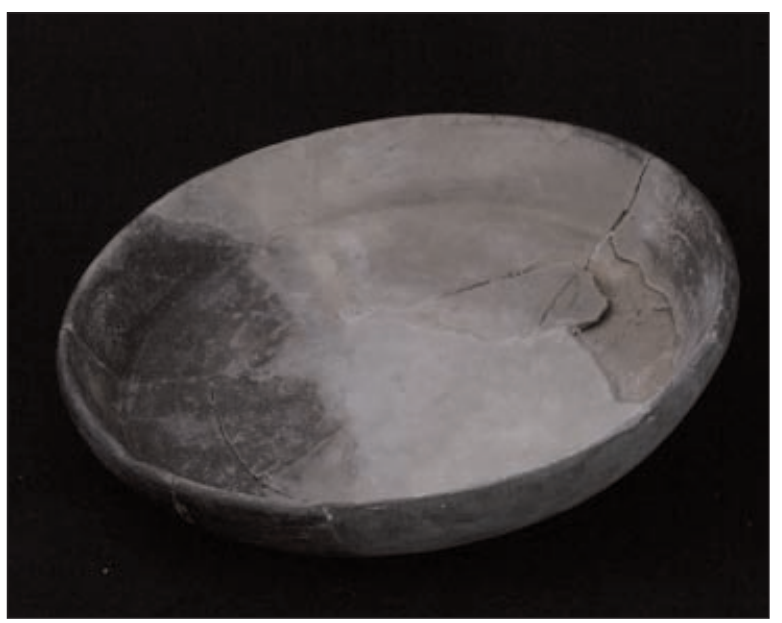

Figura 110. Plato gris. Foto: J. Arrojo

Los diámetros de la embocadura de estos platos fluctúan entre algo menos de $200 \mathrm{~mm}$ y los $250 \mathrm{~mm}$, manteniendo en todo caso una relación diámetro-altura constante, en torno a 1: 6/6.5. En el repertorio procedente de Lucus Augusti, de manifiesta afinidad, los tamaños presentan, salvo algún ejemplar de dimensiones más modestas, valores semejantes, aunque las relaciones entre las aperturas del borde y la altura muestran mayores diferencias (Alcorta, 2001: 359-360, Fig. 151). Algo similar acontece en entre los ejemplares registrados en Huerña, donde además se registran oscilaciones mayores en los diámetros (Domergue y Martin, 1977: 119-120, Fig. 31).

Tanto formal como estéticamente recuerdan a las producciones abiertas de engobe rojo interior que, en proporción mucho mayor, conviven en los ajuares con estos platos. Este hecho, de por sí poco significativo, unido a la similitud de tratamientos, a las semejanzas apreciables en las pastas y a la presencia bastante reiterada de evidencias de exposición al fuego, nos sitúa ante la perspectiva de plantear, a modo de hipótesis, la comunidad funcional de ambos tipos, su fabricación en los mismos alfares e incluso, la naturaleza imitativa de un tipo respecto a otro ${ }^{96}$.

El referente formal genérico, de clara filiación clásica, se manifiesta bastante difundido por toda la península en momentos altoimperiales. Así, encontramos platos semejantes, dentro de una evidente variedad morfotécnica, y con cronologías que oscilan desde época julio-claudia hasta finales del siglo II d.C., en lugares tan distantes como la Bética (Serrano, 1995: 235, fig. 6.48), Mérida (Alvarado y Molano, 1995: 290-291, fig. 11) o Conímbriga (Alarcão, 1975). Para el ámbito del Noroeste, se han documentado, como hemos referido, ejemplos muy cercanos en Lugo (Alcorta, 2001: 359, Fig. 151) y Huerña (Domergue y Martin, 1977: 119; Fig. 31), a los que habría que sumar otros como los de Rosinos de Vidriales (Carretero, 2000: Figs. 331-333; $\mathrm{n}^{\circ}$ 64-80), si bien en este caso las pastas grises dominantes en los anteriores ejemplares, son minoritarias, alejándose de la comunidad de origen que parecen apuntar las restantes referencias.

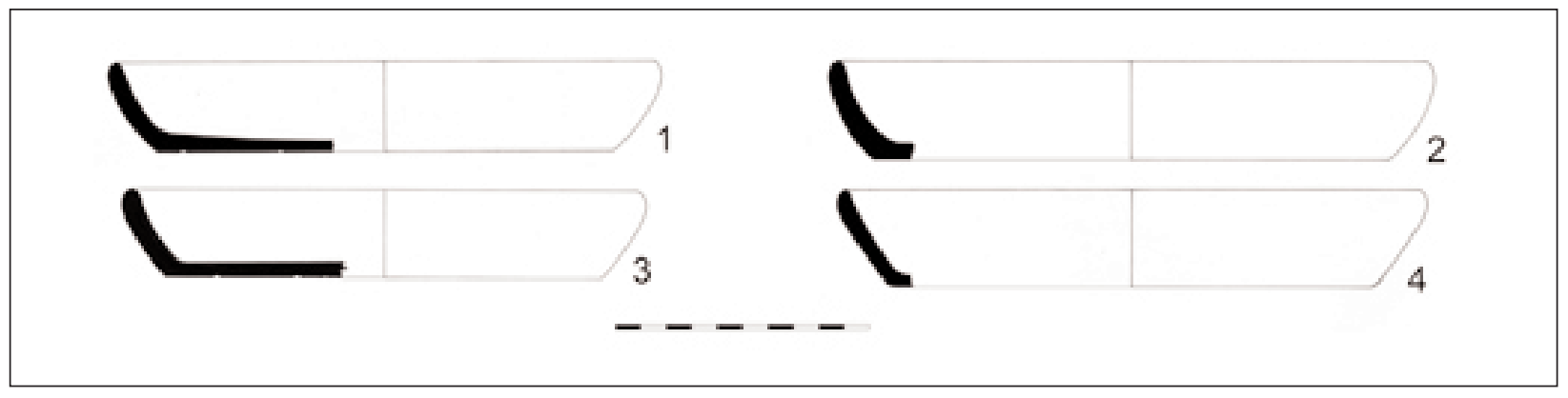

Figura 111. Platos grises

96 Para los alfares locales emeritenses se apunta una inspiración de los platos, en su mayoría engobados, en las fuentes con engobe rojo pompeyano y sus imitaciones (Alvarado y Molano, 1995). 


\section{CATÁlogo}

1. CH.93 /1566. Sector R-V. Fragmento de borde, cuerpo y base. Borde indiferenciado ligeramente incurvado con labio de perfil biselado. Pared corta, oblicua y curva. Base plana con dos acanaladuras concéntricas en el fondo externo. Pasta de tonalidad grisácea fina con abundantes desgrasantes micáceos pequeños y muy pequeños y cuarcíticos pequeños y medianos. Superficies bruñidas de tonalidades grisáceas, con zonas oscuras y otras más claras. Dimensiones: diámetro borde: $216 \mathrm{~mm}$; diámetro base: $178 \mathrm{~mm}$; altura: $35 \mathrm{~mm}$; grosor medio sección: $7 \mathrm{~mm}$. Bibliografía: Montes, 2009: Ficha 160,450-451.

2. CH.93 /1549. Sector R-V. Fragmento de borde, cuerpo y arranque de base. Borde indiferenciado ligeramente incurvado con labio de perfil biselado. Pared corta, oblicua y curva. Base plana en lo conservado. Pastas finas con el núcleo de tonalidad grisácea clara y las superficies pardo grisáceas. Se observan desgrasantes micáceos muy pequeños y abundantes y cuarcíticos pequeños. Las superficies presentan un acabado bruñido y tonos grises oscuros al interior y negros al exterior. Dimensiones: diámetro borde: $232 \mathrm{~mm}$; diámetro base: $200 \mathrm{~mm}$; altura: $38 \mathrm{~mm}$; grosor medio sección: $8 \mathrm{~mm}$. Bibliografía: Inédita.

3. CH.93 /1393. Sector C-5. Fragmento de borde, cuerpo y base. Borde indiferenciado ligeramente incurvado con labio de perfil redondeado. Pared corta, oblicua y curva. Base plana recorrida en su fondo externo por dos acanaladuras. Pasta de tonalidad pardo grisácea con abundantes desgrasantes micáceos muy pequeños y cuarcíticos pequeños y medianos. Superficies bruñidas de tonos

97 La forma incluiría dos tipos diferenciados sobre todo por cuestiones cronológicas: cuencos o fuentes semiesféricas con reborde perimetra -L19-, documentado en la primera centuria d.C. y fuentes semiesféricas biansadas con reborde perimetral -F1-, su sucesor, que se prolongará en uso hasta época bajoimperial (Ibidem: 341 ).

98 Se trata de una pieza expuesta en una de las vitrinas del Aula Didáctica del yacimiento. grises oscuros. Dimensiones: diámetro borde: $204 \mathrm{~mm}$; diámetro base: $170 \mathrm{~mm}$; altura conservada: $34 \mathrm{~mm}$; grosor medio sección: 7.5 $\mathrm{mm}$. Bibliografía: Inédita.

4. CH.93 /1001. Sector R-V. Fragmento de borde, cuerpo y arranque de base. Borde indiferenciado ligeramente incurvado con labio de perfil biselado. Pared corta, oblicua y curva. Base plana en lo conservado. Pasta de tonalidad pardo grisácea con abundantes desgrasantes micáceos muy pequeños y cuarcíticos pequeños y medianos. Superficies bruñidas de tonos grises oscuros. Dimensiones: diámetro borde: $226 \mathrm{~mm}$; diámetro base: $188 \mathrm{~mm}$; altura conservada: $37 \mathrm{~mm}$; grosor medio sección: $6 \mathrm{~mm}$. Bibliografía: Inédita.

\section{FUENTES BIASADAS}

(Figuras 112 y 113)

Esta morfología representa uno de los elementos más singulares del repertorio regional de cerámica común del Chao Samartín (Zarzalejos, 1995: 267; Benéitez et alii, 1999, 29-30, Fig. 5.8-10; Montes, 2009: 436-437) y se muestra en el siglo II d.C. como una forma perfectamente consolidada y estandarizada cuyos orígenes se rastrean, como hemos descrito, en los repertorios de la primera centuria.

Lo cierto es que tal y como acontece con otros muchos tipos, y en este caso con particular radicalidad, los paralelos conocidos para esta forma se limitan al estricto ámbito comarcal, reduciendo los ejemplos tan sólo a yacimientos como Lucus Augusti (Alcorta, 2001: 126-127 y 339-341, Fig. 56 y 142 $)^{97}$, Viladonga ${ }^{98}$, Os Castros de Taramundi (Expósito, 2004), Monte Castrelo de Pelóu ${ }^{99}$, y probablemente, San Chuis (Manzano,

99 En el marco de las recientes campañas de excavación que se han realizado en el muy próximo castro de Pelóu (Grandas de Salime, Asturias) (Montes et alii, 2009), nos consta el registro de algún ejemplo, aún inédito, de este tipo de recipientes. 
1990: 402, Fig. en p.403) ${ }^{100}$ y El Castelón de Coaña (Maya, 1988: 158, Fig.48.A) ${ }^{101}$. Fuera de este reducido marco territorial se registran fórmulas morfológicas tal vez equiparables funcionalmente con estas piezas, como es el caso de un barreño biasado documentado en Rosinos de Vidriales (Carretero, 2000: 708-709, Fig. 369. 251) o ciertas cazuelas nervadas que cuentan también con dos asas, conocidas en el norte de Portugal (Martins, 1990: Fig.24).

En lo formal, el modelo se define como una fuente bastante profunda de grandes dimensiones, en las que las aperturas de la boca se sitúan entre los 300 y $420 \mathrm{~mm}$ y mantienen una relación en torno a 1:3/3.5 respecto a la altura total ${ }^{102}$. El borde se muestra indiferenciado y normalmente engrosado, la pared es abierta de tendencia hemisférica y la base plana. Su individualización como tipo deriva sobre todo de la presencia de dos características que lo personalizan y dan carta de naturaleza: una nervadura aplicada que recorre la parte superior del galbo y un par de asas en C enfrentadas. Se da la curiosa circunstancia de que mientras en la mayoría de los ejemplares registrados en el Chao Samartín las asas parten del borde y alcanzan la nervadura, en Lugo arrancan de este punto para llegar hasta una zona más baja del galbo.

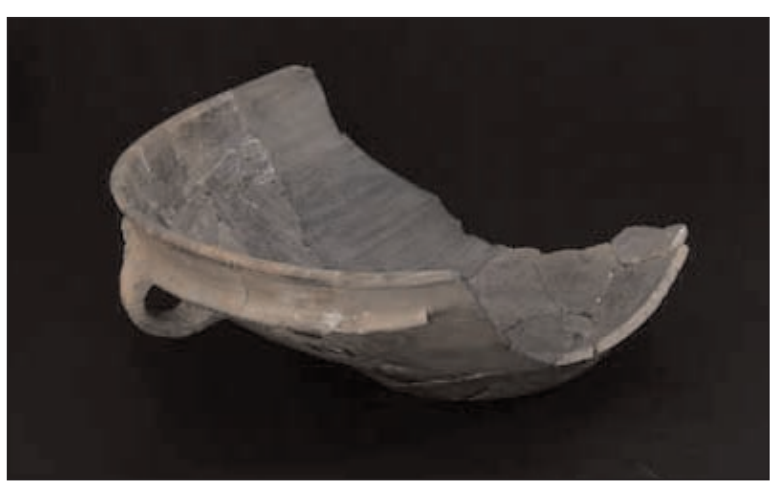

Figura 112. Fuente biasada. Foto: J. Arrojo

100 Es probable que algunos fragmentos clasificados como grandes cuencos en el castro allandés de San Chuis pertenezcan a piezas de este tipo (Manzano, 1990: 402, Fig. en p.403).

101 Se trata de un ejemplar del que se conserva un pequeño fragmento de borde con decoración de retícula bruñida en la cara externa que no presenta ninguna de las características discriminantes del tipo, lo que unido al extraño perfil del labio, ponen en suspenso la adscripción a esta morfología.

102 Se trata de dimensiones aproximadamente equiparables a
Por norma general, se fabricaron en pastas groseras de tonalidades pardas y grisáceas, con abundantes inclusiones de cuarzos, cuarcitas y esquistos de todos los tamaños y acabados rugosos, con numerosas irregularidades.

Aunque la mayor parte de los ejemplos conocidos en el yacimiento carecen de decoración, disponemos de alguna pieza que rompe esta norma, vinculándose a lo que acontece por ejemplo, en Lugo, donde se conocen con cierta frecuencia composiciones diversas de líneas bruñidas (Alcorta, 2001: 126 y 339-341, Fig. 56.1 y 2 y 142.5) y más raramente, ondulaciones incisas (Ibidem: Fig.142.4). Debe hacerse notar que, mientras que en todos estos casos lucenses las ornamentaciones se ubican en la superficie exterior, ya sea sobre o por debajo de la nervadura, en el Chao Samartín conocemos un ejemplar con decoración de líneas bruñidas dispuestas en la cara interna (Figura 113.1) (Benéitez, et alii, 1999: Fig.5.8; Montes, 2009: 436-437) $)^{103}$.

Tal y como hemos referido, en Lucus Augusti el tipo se documenta tanto en la primera fase (siglo I d.C. $)^{104}$, con una datación preflavia comprobada (Alcorta, 2001: 127), como en la segunda (siglos II-IV d.C.) ${ }^{105}$, momento en el que se percibe con nitidez su generalización en el Chao Samartín.

La funcionalidad de estos recipientes es difícil de precisar, pudiendo descartarse, a tenor de la ausencia de huellas de exposición al fuego, un empleo en procesos culinarios en caliente. Resulta factible un uso como fuente en el servicio de mesa, aunque no puede desestimarse una vinculación a procesos culinarios en frío o a tareas extraculinarias. E. Alcorta, a partir de las piezas de Lugo, propuso en su momento su empleo como soperas (Alcorta, 1991: 41), aunque posteriormente ha postulado usos hipotéticos vinculados a la manipulación de alimentos, las labores alfareras o la higiene personal (Alcorta, 2001: 341).

las de las piezas semejantes procedentes de otros yacimientos como Lugo (Alcorta, 2001: 126-127, Fig. 56 y 339-341; Fig.142) u Os Castros de Taramundi (Expósito, 2004).

103 Se trata, por lo demás, de un ejemplar con ciertas singularidades en lo tocante al perfil del galbo y la composición de las pastas.

104 Tipo L19: Cuenco o fuente hemisférica con reborde perimetral (Alcorta, 2001:126-127, Fig.56).

105 Tipo F1: Fuente semiesférica, biansada, con reborde perimetral (Alcorta, 2001: 339-341, Fig.142). 

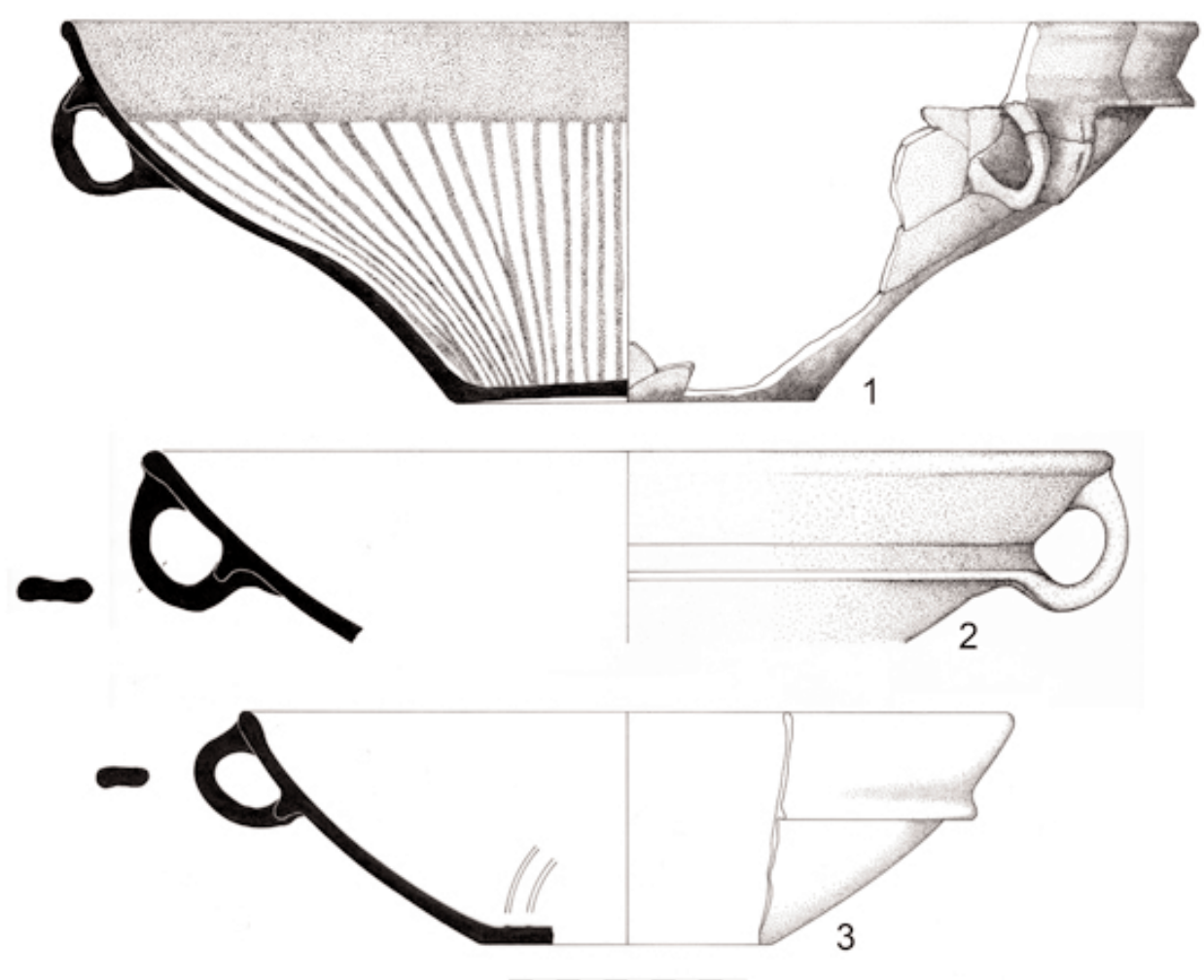

Figura 113. Fuentes biasadas

\section{CATÁlogo}

1. CH.95 /1041. Sector C-10. Perfil completo. Borde simple engrosado con labio de perfil redondeado. Pared oblicua con perfil en $\mathrm{S}$ muy abierta que presenta en su tercio superior una pronunciada nervadura o visera de sección apuntada y trayectoria oblicua descendente. La pieza está dotada de dos pequeñas asas con perfil en $\mathrm{C}$ y sección elipsoidal, rehundida al exterior, cuyo arranque superior parte de la nervadura. Base de fondo ligeramente ascendente. Decoración de líneas bruñidas radiales en la cara interna que confluyen hacia el fondo. Pasta de tonalidad grisácea con desgrasantes micáceos y cuarcíticos pequeños y medianos y alguno esquistosos. Superficies ocráceas, la externa con un somero acabado bruñido en el extremo inferior y el fondo. El bruñido aparece más cuidado en el borde y tercio superior interior. Dimensiones: diámetro borde: 420 $\mathrm{mm}$; diámetro base: $140 \mathrm{~mm}$; altura: 145 $\mathrm{mm}$; grosor medio sección pared: $6 \mathrm{~mm}$.
Bibliografía: Benéitez et alii, 1999: 29-30, Fig. 5.8; Montes, 2009: Ficha 153, 436437.

2. CH.95/4372. Sector C-10. Fragmento de borde cuerpo y asa. Borde simple engrosado con labio de perfil redondeado. Pared oblicua, muy abierta, de perfil curvo con tendencia hemisférica que presenta en su tercio superior una pronunciada nervadura o visera de sección triangular, extremo redondeado y trayectoria oblicua descendente. Se conserva un asa con perfil en $\mathrm{C}$ y sección elipsoidal, rehundida al exterior, que arranca inmediatamente debajo del borde y llega hasta la nervadura. Pasta grosera de tonalidad parda grisácea con abundantes inclusiones esquistosas y cuarcíticas de todos los tamaños (alguna muy grande) y micáceas menudas. Superficies rugosas de tonalidad ocre grisáceo y carentes de acabado específico. Dimensiones: diámetro borde: 398 $\mathrm{mm}$; altura conservada: $78 \mathrm{~mm}$; grosor medio sección pared: $6 \mathrm{~mm}$. Bibliografía: Benéitez et alii, 1999: 29-30, Fig. 5.9. 
3. CH.95/4642. Sector C-2. Fragmento de borde, cuerpo, asa y base. Borde simple ligeramente engrosado con labio de perfil redondeado. Pared oblicua curva de perfil hemisférico que presenta en su mitad superior una nervadura o visera de sección triangular, extremo redondeado y trayectoria oblicua descendente. Base plana en lo conservado recorrida por sendas acanaladuras en el fondo interno. Pasta grosera de tonalidad parda grisácea con abundantes desgrasantes esquistosos y cuarcíticos de todos los tamaños (alguno muy grande) y micáceos menudos. Superficies de color ocráceo, la externa someramente alisada. En la cara interna y en algún punto de la externa resultan visibles las líneas del torneado. Dimensiones: diámetro borde: 322 $\mathrm{mm}$; diámetro base: $120 \mathrm{~mm}$; altura: 96 $\mathrm{mm}$; grosor medio sección pared: $6 \mathrm{~mm}$. Bibliografía: Inédita.

\section{Vajilla Engobada}

(Figuras 114-120)

En el seno de la cerámica galaico-romana del momento se identifican varios grupos de materiales cuya coherencia interna los convierte en familias perfectamente definidas que incluyen tipologías específicas diversas.

Entre éstos destaca una vajilla engobada en la que se integran platos, cuencos y jarras con rasgos comunes muy homogéneos, que componen la serie cerámica más cohesionada de las identificadas. Además, el registro de muestras de piezas de estas tipologías en contextos geográficos ajenos al ámbito habitual de distribución de estas producciones, circunscrito al territorio regional de manera estricta, las avalan como manufacturas de éxito con vocación exportadora. Tomando como argumentos, por un lado, esta extensa área de difusión y por otro, sus concomitancias técnicas, patentes en una simple observación macroscópica, y corroborada mediante analíticas petrográficas (Lapuente et alii, 1995), se puede postular una fabricación localizada en la zona noroccidental peninsular y más concretamente, es posible certificar una relación genética con la pujante actividad artesanal documentada en Lucus Augusti desde fines del siglo I d.C. (Alcorta, 2001).

Se trata en todos los casos de productos finos en los que ocasionalmente se estampan sellos de alfarero, extremo que viene a confirmar el especial prestigio de que gozaban estas piezas respecto a otras de similar génesis. El catálogo de estas marcas en el yacimiento, limitado a su plasmación sobre platos ${ }^{106} \mathrm{y}$ sobre un fondo perteneciente a una pieza de forma indeterminada, comprende un total de cinco sellos:

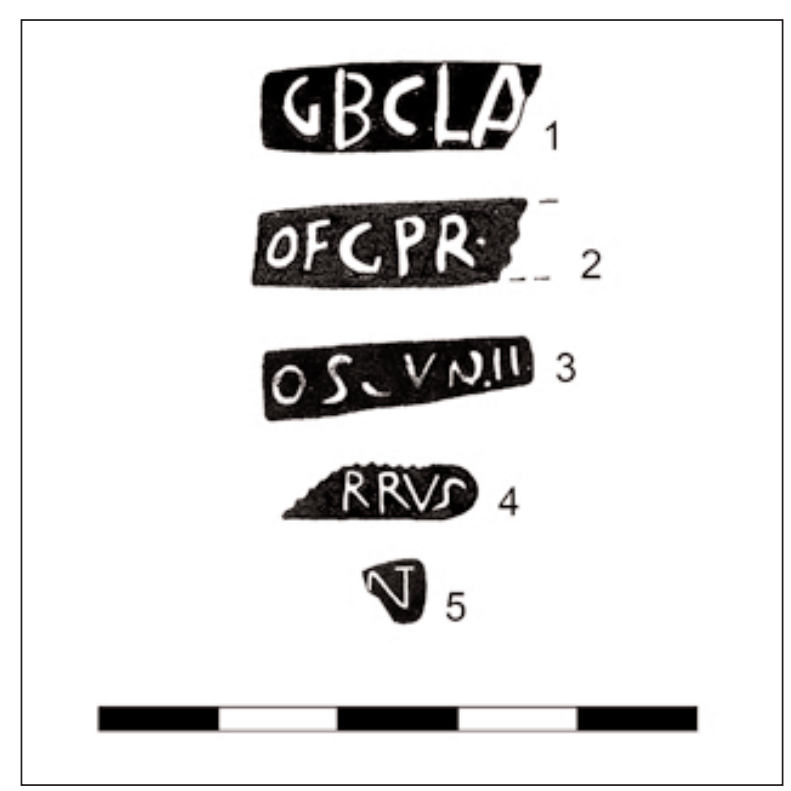

Figura 114. Sellos impresos sobre piezas de la serie engobada.

- OF GPR.(...) (Villa, 1999: 117, Lám. IV.20; Hevia et alii, 1999: 157, Fig. 1.1; Montes, 2009: 444-445). Aparece sobre el fondo externo de una fuente con las superficies exfoliadas, lo que ha impedido la conservación íntegra del sello. Carecemos de referencias relativas a paralelos para la marca.

- G.B.CLA (Sánchez, 2003). Se trata de una marca en cartela rectangular impresa en el fondo externo de un fragmento de base correspondiente a un plato o fuente de diámetro indeterminado. Se conoce un sello de 
idéntica lectura en Valdeorras (Ourense) (Alcorta, 2001: 320), al que cabe añadir otro de lectura G.B. procedente de Porta de Arcos de Rodeiro (Pontevedra) (Álvarez, 2000: 48, Foto 2$)^{107}$, aplicados en estas ocasiones sobre cuencos.

- OS(...)VINTI (Sánchez, 2003; Montes, 2009: 444-445). Se trata de un sigillum estampado sobre el fondo externo de un plato de pequeñas dimensiones. Podría asimilarse al taller de Quintus, para el que se conocen referencias relativas a cuatro cuencos lucenses (Alcorta, 1991: 6.1; 1995: Fig. 20. 2, 3 у 2001: 313-316, Fig.135) y hasta media docena de platos de Asturica Augusta (Alcorta, 2001: 320). De este modo, se erige como la marca más profusamente documentada.

- (...)NI. Pequeño fragmento de sello impreso en el fondo exterior de una fuente y tal vez correspondiente a la oficina de Saturninus o a la de Rufianus. Para la primera se conoce una marca de lectura (...)RNINI (Alcorta, 2001: Fig. 135.9) sobre un cuenco lucense. En el caso de la segunda, el rol de paralelos resulta mayor y se extiende a sendos platos procedentes de Lucus Augusti (Alcorta, 2001: 316-317, Fig. 135.8) y Castromao (Caamaño, 1979: 9192; Figs. I.31 y V.31) respectivamente y a un cuenco proveniente del campamento de Petavonium (Carretero, 2000: 646-647, Fig.320 y 322.13).

- (...)RRVS. Estampación, obra seguramente de un alfarero de nombre Reburrus (Sánchez, 2003), sobre fondo externo de morfología indeterminada. Este sello no cuenta con paralelos seguros, pero cabe establecer un hipotético vínculo con el EX. O. VAL. REB, interpretado como ex $o$ (fficina) Val(erius) Reb(urrus), documentado en un plato de engobe rojo interno procedente de Calahorra (Luezas, 1997: 263, Fig.1) y emparentable, dadas sus características técnicas y morfológicas, con estas producciones.
A esta relación de sellos se deben añadir otros no presentes en el Chao Samartín como el O.RVFI de un cuenco de Lugo (Alcorta, 2001: 316-317, Fig.135.8), el OF.CAPITO de otro ejemplar similar también procedente de la capital conventual (Ibidem: 318, Fig.134.1 y 135.10) y los sellos presentes en platos astorganos de lectura respectiva OF.RU.SA, OF.PERE, EX.OF.PRIM y L.UM (Ibidem, 2001: 320).

\section{CUENCOS ENGOBADOS}

(Figuras 115-116)

Los cuencos engobados representan, no sólo uno de los tipos más representativos de la serie, sino también una de las formas de cerámica de mesa más genuinas, sin duda, de la industria regional (Montes, 2009: 444-445).

Sus características técnicas y morfológicas lo dotan de una fuerte personalidad, siempre dentro de cierta variabilidad, relativa sobre todo al perfil del galbo, que fluctúa, aún manteniendo una general tendencia vagamente troncocónica, entre piezas de desarrollo nítidamente carenado y otras de perfil más curvilíneo. Estos cuencos se presentan como recipientes altos de borde exvasado oblicuo con perfil suavemente cóncavo al interior y base plana. El perfil prototípico del cuerpo, dentro del referido margen de heterogeneidad, dibuja una tenue carena media-baja que separa una parte superior levemente abierta de otra inferior mucho más oblicua.

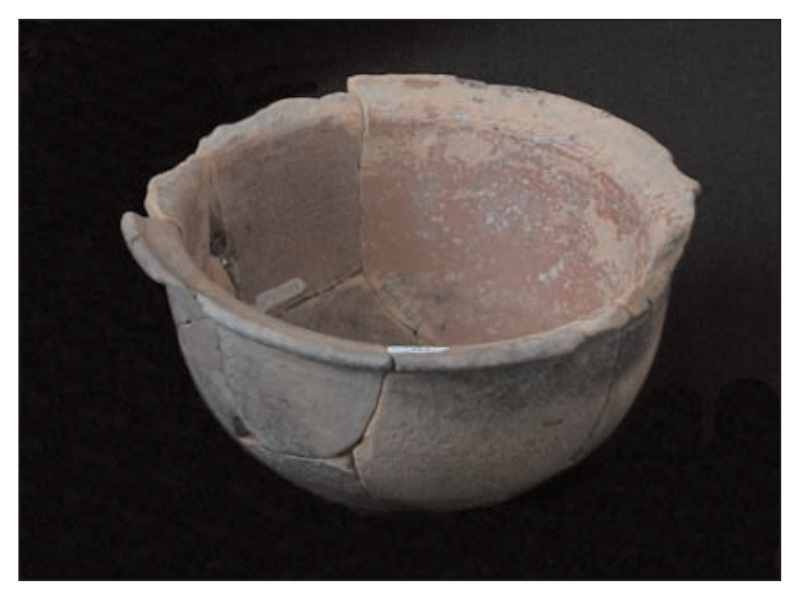

Figura 115. Cuenco engobado. Foto: J. Arrojo

107 La adscripción del sello a un cuenco no resulta irrefutable. 
La presencia del engobe rojo constituye otro de los rasgos fundamentales del tipo, tal vez el de mayor singularidad. El pigmento recubre la totalidad del interior de la pieza y el borde, para rebasar el labio y cubrir una característica franja al exterior de aproximadamente uno o dos centímetros de anchura. El resto de la superficie externa recibe un fino acabado bruñido que le confiere un brillo y pulimento que recuerda, entre otros, al descrito para los vasos ovoides de la variante anaranjada.

En cuanto a la cuestión de las dimensiones de estos cuencos se observa entre los diferentes recipientes un margen bastante amplio cuyo extremo inferior lo encontraríamos en las piezas con diámetros de borde situados en torno a los $150 \mathrm{~mm}$. Estas dimensiones resultan equiparables a los de la variante modular ES1A que E. Alcorta (2001: 312) propone para el repertorio de Lugo y a las del grupo con diámetros por debajo de los $150 \mathrm{~mm}$. identificado en Rosinos de Vidriales (Carretero, 2000: 646-649, Fig.321.11-12 y 322. 13-17). En el extremo opuesto se encuentran los ejemplares de dimensiones más destacadas, alguno de los cuales supera los $200 \mathrm{~mm}$ de apertura de boca, como los de la variante ES1 de Lugo (Alcorta, 2001: 312) y alguna de las piezas registradas en Huerña (Domergue y Martin, 1977: 54, 122, fig. 13 y 32, $\mathrm{n}^{\mathrm{o}} 188$ y 624), un cuenco procedente de Sasamón (Abásolo y García, 1993: 157 -159, fig. 78.9) y otro documentado en las excavaciones de la Plaza del Marqués, en Gijón, que alcanza los $280 \mathrm{~mm}$ (Fernández Ochoa, 1994, 66, fig. 10, n 51). Las piezas que integran el repertorio del Chao Samartín se encuentran en todos los casos reconocidos hasta el momento en valores intermedios.

La significación de esta diversidad de dimensiones puede que haya que buscarla en cuestiones funcionales o quizás, en una evolución temporal, toda vez que se comprueba el carácter tardío de los ejemplos mayores entre los referidos. A este respecto conviene no obstante recordar que en el Chao Samartín es entre los repertorios del siglo I d.C.

108 Pieza inédita documentada en el transcurso de las excavaciones realizadas recientemente en el yacimiento (Montes et alii, 2009).

109 Tipo ES 1 / 1 A de Alcorta.

110 Presentes tanto en la primera como, con mayor asiduidad, en la segunda fase de ocupación.
(Figuras 40 y 41 ) en los que se documentan las piezas de dimensiones más destacadas.

A pesar de su inequívoca validez funcional como elementos del ajuar de mesa, no se deben soslayar las reiteradas evidencias de exposición al fuego constatadas tanto en el yacimiento como en otros lugares (Alcorta, 2001: 324), que insta a contemplar la posibilidad de usos complementarios o eventuales. En este sentido, E. Alcorta defiende una polivalencia que incluiría, entre otros, su empleo en el horneado de determinadas preparaciones culinarias (Ibidem).

El tipo cuenta con una amplia difusión, conociéndose ejemplos en el convento lucense, en castros asturianos de las cuencas del Navia y el Eo como El Castelón de Coaña (Maya, 1988: 224, Fig.76.A, B y E), La Corona de Arancedo (Ibidem: Fig.76.C), San Chuis (Ibidem: Fig. 76.D y 77.D; Marín), Os Castros de Taramundi (Expósito, 2004) y el Monte Castrelo de Pélou ${ }^{108} \mathrm{y}$ en yacimientos gallegos como Agro de Ouzande (Ayán et alii, 2002-2003: 106, Fig.10. CA 58) y, sobre todo, en la capital conventual Lucus Augusti (Alcorta, 2001, 312-324, Fig. 134 у 135) $)^{109}$.

Al territorio astur cismontano llegan con frecuencia estas producciones, tal y como atestiguan los hallazgos de Huerña (Domergue y Martin, 1977: 54, 122, Fig. 13 y 32, $n^{\circ} 188,624$ y $625^{110}$, Asturica Augusta (Carretero, 2000: 647) y Rosinos de Vidriales (Ibidem: 646-649, Fig.321.11-12 y 322. 13-17). Para el flanco trasmontano de la cordillera se conocen referencias para la ciudad de Gijón (Fernández Ochoa, 1994: 66, Fig. 10, nº 51; Fernández Ochoa, 1997: 103) ${ }^{111}$, Lugo de Llanera (Fernández Ochoa et alii, 2001. 90, fig. 3. 24) y el castro de Campa Torres (Maya, 1988: 225, Fig. 77.E). En el ámbito cluniense contamos con la noticia del hallazgo en Sasamón ${ }^{112}$ (Abásolo y García, 1993: 157 -159, Fig. 78.9) de piezas equiparables, del mismo modo que acontece para el territorio bracarense en Bracara Augusta (Alcorta, 2001: 323, nota 691).

111 Para estas piezas gijonesas se proponen fechas tardías, del siglo III d.C: (Fernández Ochoa, 1997,:103).

112 Igualmente de cronología avanzada (Abásolo y García, 1993). 


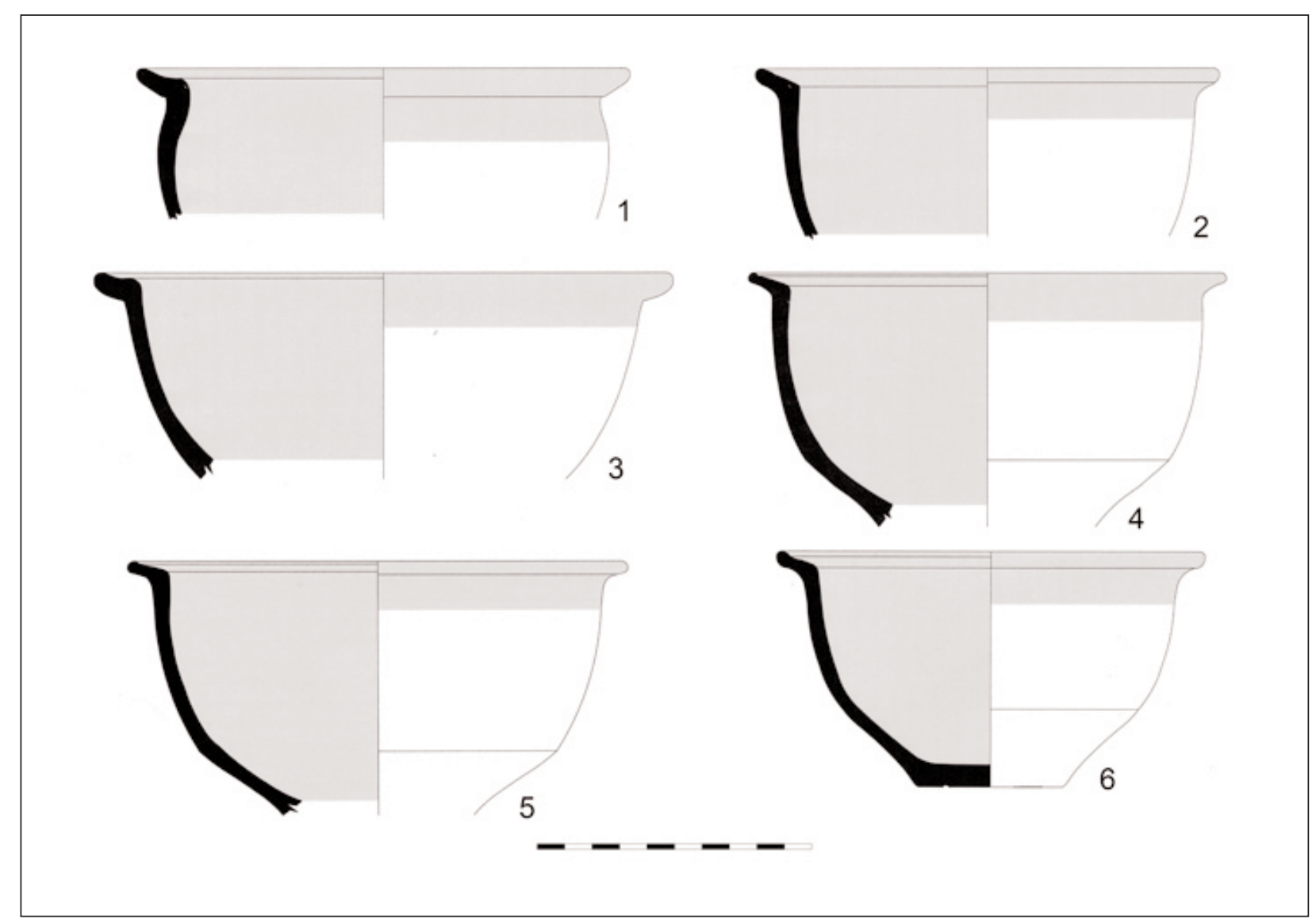

Figura 116. Cuencos engobados

\section{CATÁlogo}

1. CH.95 /1652. Sector C-9. Fragmento de borde y cuerpo. Borde exvasado oblicuo de perfil ligeramente cóncavo al interior con labio de perfil redondeado. Una fina incisión separa al exterior el borde del cuerpo, que presenta perfil curvo en lo conservado. Pasta de tonalidad anaranjada con abundantes desgrasantes micáceos y cuarcíticos pequeños y medianos. Superficie externa bruñida de color anaranjado. La superficie interna, el borde y una franja inmediata a éste al exterior de unos $2 \mathrm{~cm}$ de anchura se encuentran recubiertos de engobe rojo. Dimensiones: diámetro borde: $177 \mathrm{~mm}$; altura conservada: $52 \mathrm{~mm}$; grosor medio sección: $6 \mathrm{~mm}$. Bibliografía: Inédita.

2. CH.98/3690. Sector C-12. Fragmento de borde y cuerpo. Borde exvasado oblicuo de perfil recto en el que apenas se nota la característica concavidad interior. Labio de sección redondeada. Cuerpo hemisférico en lo conservado. Pasta fina de tonalidad anaranjada con abundantes desgrasantes micáceos y cuarcíticos pequeños y medios. La superficie externa, de tonos anaranjados, presenta un fino alisado, mientras que la interna, el borde y una banda de unos 2 $\mathrm{cm}$ de la externa se encuentran recubiertos de engobe rojo. Dimensiones: diámetro borde: $170 \mathrm{~mm}$; altura conservada: $85 \mathrm{~mm}$; grosor medio sección: $5 \mathrm{~mm}$. Bibliografía: Inédita.

3. CH.93 /1084. Sector R-V. Fragmento de borde y cuerpo. Borde exvasado oblicuo de perfil ligeramente cóncavo al interior con labio levemente engrosado de perfil redondeado. Cuerpo de tendencia hemisférica en lo conservado. Pasta fina cuarzo-micácea con desgrasantes pequeños y medianos. La superficie interna, el borde y una franja inmediata a éste al exterior de unos $2 \mathrm{~cm}$ de anchura se encuentran recubiertos de engobe rojo, mientras que el resto de la superficie externa, de tonalidad anaranjada, se encuentra bruñida. Dimensiones: diámetro 
borde: $208 \mathrm{~mm}$; altura conservada: 74 mm.; grosor medio sección: $5 \mathrm{~mm}$. Bibliografía: Inédita.

4. CH.96 /2636. Sector C-10. Fragmento de borde y cuerpo. Borde exvasado oblicuo con labio engrosado de perfil redondeado y levemente cóncavo al interior. Cuerpo de perfil de tendencia hemisférica con un leve cambio de plano en la mitad inferior. Pasta fina de tonalidad anaranjada cuarzo-micácea con desgrasantes pequeños y muy pequeños. Superficie externa de tonalidad anaranjada finamente bruñida. Recubrimiento de engobe rojo intenso en la superficie interna, el borde y el extremo superior de la pared externa. Dimensiones: diámetro borde: $180 \mathrm{~mm}$; altura conservada: 95 mm: grosor medio sección pared: 5 mm. Bibliografía: Benéitez et alii, 1999: 27-28, Fig. 5.4.

5. CH.98 /3703. Sector C-17. Fragmento de borde y cuerpo. Borde exvasado oblicuo de perfil ligeramente cóncavo al interior con labio engrosado de perfil redondeado. Cuerpo de tendencia hemisférica con un leve cambio de plano en la mitad inferior. Pasta fina de tonalidad anaranjada con abundantes desgrasantes micáceos y cuarcíticos pequeños y medios. Superficie externa anaranjada con acabado bruñido. La superficie interna, el borde y una franja de unos $2 \mathrm{~cm}$ de la cara exterior se encuentran recubiertas de engobe rojo. Dimensiones: diámetro borde: $170 \mathrm{~mm}$; altura conservada: $90 \mathrm{~mm}$; grosor medio sección: 5 mm. Bibliografía: Inédita.

6. CH.96 /2464. Sector C-10 B / C-14 A. Perfil completo. Borde exvasado oblicuo de perfil ligeramente cóncavo al interior con labio de perfil redondeado. Cuerpo de tendencia hemisférica con un leve cambio de plano en la mitad inferior. Base plana recorrida en su fondo externo por una acanaladura. Pasta fina de tonalidad anaranjada con abundantes desgrasantes micáceos y cuarcíticos pequeños y medios. La superficie externa, de tonos anaranjados, presenta un fino alisado, mientras que la interna, el borde y una banda de unos $2 \mathrm{~cm}$ de la externa se encuentran recubiertos de engobe rojo. Dimensiones: diámetro borde: 152 $\mathrm{mm}$; diámetro base: $50 \mathrm{~mm}$; altura: $85 \mathrm{~mm}$; grosor medio sección: 5 mm. Bibliografía: Benéitez et alii, 1999: 29-30, Fig. 5.5; Montes, 2009: Ficha 157, 444-448.

\section{PLATOS-FUENTES}

(Figuras 117-118)

El tipo remite a los recipientes abiertos ampliamente conocidos en la bibliografía como platos / fuentes de imitación de engobe rojo pompeyano. Los genuinos platos engobados, precedentes genéricos del modelo, fueron elaborados en la Península Itálica desde mediados del siglo III a.C. y alcanzaron Hispania desde, al menos, el siglo II a.C. (Aguarod, 1991: 52). Habrá, no obstante, que aguardar, aproximadamente, hasta mediados del siglo I d.C. para que cristalicen fenómenos imitativos y comiencen a documentarse producciones hispánicas (Beltrán, 1990: 206; Aguarod, 1991: 40-41), recogidas por M. Vegas en su forma 15A (Vegas, 1973: 48-49, fig. 16.9). Sin embargo, bajo esta denominación general se esconde una compleja realidad que engloba diferentes variantes morfológicas y una pluralidad de focos productivos aún sólo intuida y de la que se han reconocido algunos talleres en la tarraconense (Aguarod, 1991: 82) y en la Bética, entre las producciones tipo Peñaflor (Sánchez, 1992: 262; Bustamante y Huguet, 2008: 300).

Es en este ambiente de recreación de un modelo de indudable éxito en el que se debe entender la producción en Lucus Augusti desde finales del siglo I o comienzos del II d.C. de diversas modalidades de estos recipientes (Alcorta, 2005 b: 2730). Nos referimos fundamentalmente a los tipos denominados respectivamente platos engobados de borde biselado (tipo EP1), platos de borde biselado y pared rehundida (tipo EP 2), platos de paredes exvasadas y borde redondeado -tipo EP 3- y fuentes de borde horizontal (tipo EP 4), cuya producción arranca en época altoimperial. A estos modelos tempranos habría que añadir los tipos bajoimperiales conocidos como fuentes de borde deprimido (tipo EP 5), fuentes de borde moldura- 
do (tipo EP 6) y fuentes de borde moldurado y decoración de depresiones (tipo EP 7), además de otras piezas no estandarizadas (Alcorta, 2001: 344-358, Fig. 144-150). La variante mejor representada en el Chao Samartín, al igual que ocurre en el propio Lugo (Alcorta, 2001: 344-358) es la de los platos de borde biselado (Hevia et alii, 2001) inspirados en la forma Luni 5, aunque no son completamente extrañas en el repertorio otras modalidades, como los de borde redondeado.

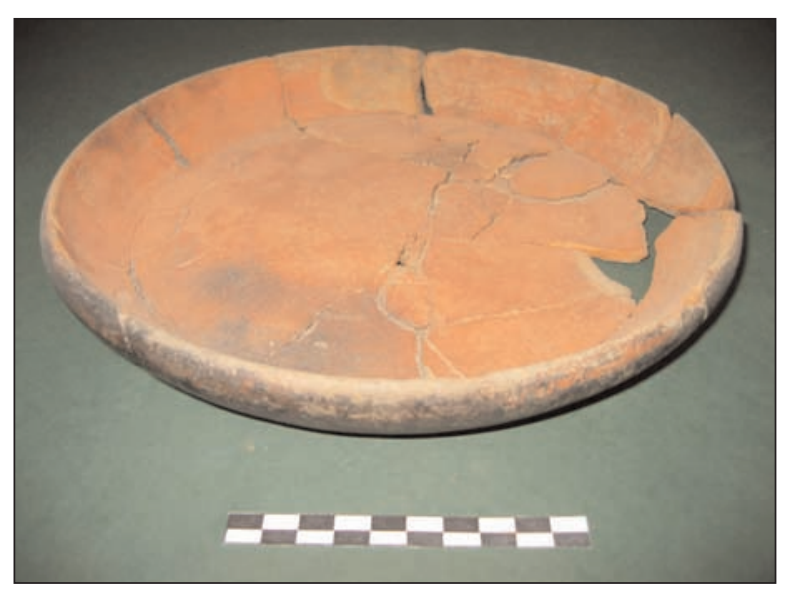

Figura 117. Fuente engobada. Foto: R. Montes

Se trata de recipientes bajos, con relaciones entre los diámetros del borde y la altura total que suelen mantenerse en valores de 6/7.5:1 ${ }^{113}$, que adoptan formas simples de bordes indiferenciados rematados en suave bisel, paredes curvas abiertas y amplias bases planas frecuentemente recorridas en su fondo externo por varias acanaladuras concéntricas. El engobe rojo cubre la totalidad de la superficie interna, alcanzando normalmente una pequeña franja de la pared externa correspondiente al labio.

Sus dimensiones varían considerablemente, hasta el punto de poder establecer sendos módulos (Montes, 2009: 444-445):

- Platos con diámetros de borde reducidos, en torno a los 200-230 mm, emparentables con los de la variante modular EP1 de Lugo, con aperturas entre los 200 y los $250 \mathrm{~mm}$ (Alcorta, 2001: 344, Fig.

113 De esta norma se escapan tan sólo aquellos ejemplares que responden a variantes tipológicas distintas. En estas
144. 2-4 y 2005 b: 28-29, Fig.12 y 13). Algún ejemplar, como el sellado por la oficcina de Quintus (Montes, 2009: 444445), presenta dimensiones bastante menores, de unos $150 \mathrm{~mm}$ de boca, entroncando con los platillos de la variante EP1A de Lucus Augusti, que cuentan con valores entre los 150 y los 180 mm (Ibidem: Fig.144.1).

- Grandes fuentes con aperturas de borde de más de $230 \mathrm{~mm}$ y que llegan a alcanzar los $275 \mathrm{~mm}$. En Lugo se conocen ejemplares del tipo, conocido como variante modular EP1B, de hasta más de $1 \mathrm{~m}$ de diámetro (Ibidem; Fig. 144.6).

Estas piezas cuentan en todos los casos con las características técnicas que definen la totalidad de la serie. Sus rasgos fundamentales estriban en las pastas finas micáceas, la fractura por exfoliación y el engobe de tonalidad roja oscura y espesor y adherencia variables.

Su utilización en procesos culinarios en caliente ha alterado notablemente la tonalidad y el acabado de sus superficies que, en los casos en que no se documentan máculas de hollín, ofrecen una tonalidad anaranjada y un aspecto pulido brillante similar a los cuencos de la serie, tornándose grisáceas o negruzcas cuando la exposición al fuego ha sido reiterada.

En el contexto genérico del noroeste peninsular es frecuente la presencia de recipientes de este tipo desde algún momento indeterminado del siglo I d.C. en múltiples yacimientos como El Castelón de Coaña (Maya, 1988: 224, Fig. 75A y C), San Chuis (Maya, 1988: 225, Fig. 75 B,D y F; Manzano, 1990: 402-405), La Corona de Arancedo (Maya, 1988: 225, Fig. 75 E), El Castro de Pendia (Fernández Ochoa, 1982: 121, Pen 5 y Pen 6), La Campa Torres (Maya y Cuesta: 1993, 38), Lugo de Llanera (Fernández Ochoa et alii, 2001: 89, Fig.2. 11 y 12 y Fig. 17.169), la villa de Vega del Ciego (Fernández Ochoa, 1982: 149, Fig. 37), Gijón (Fernández 


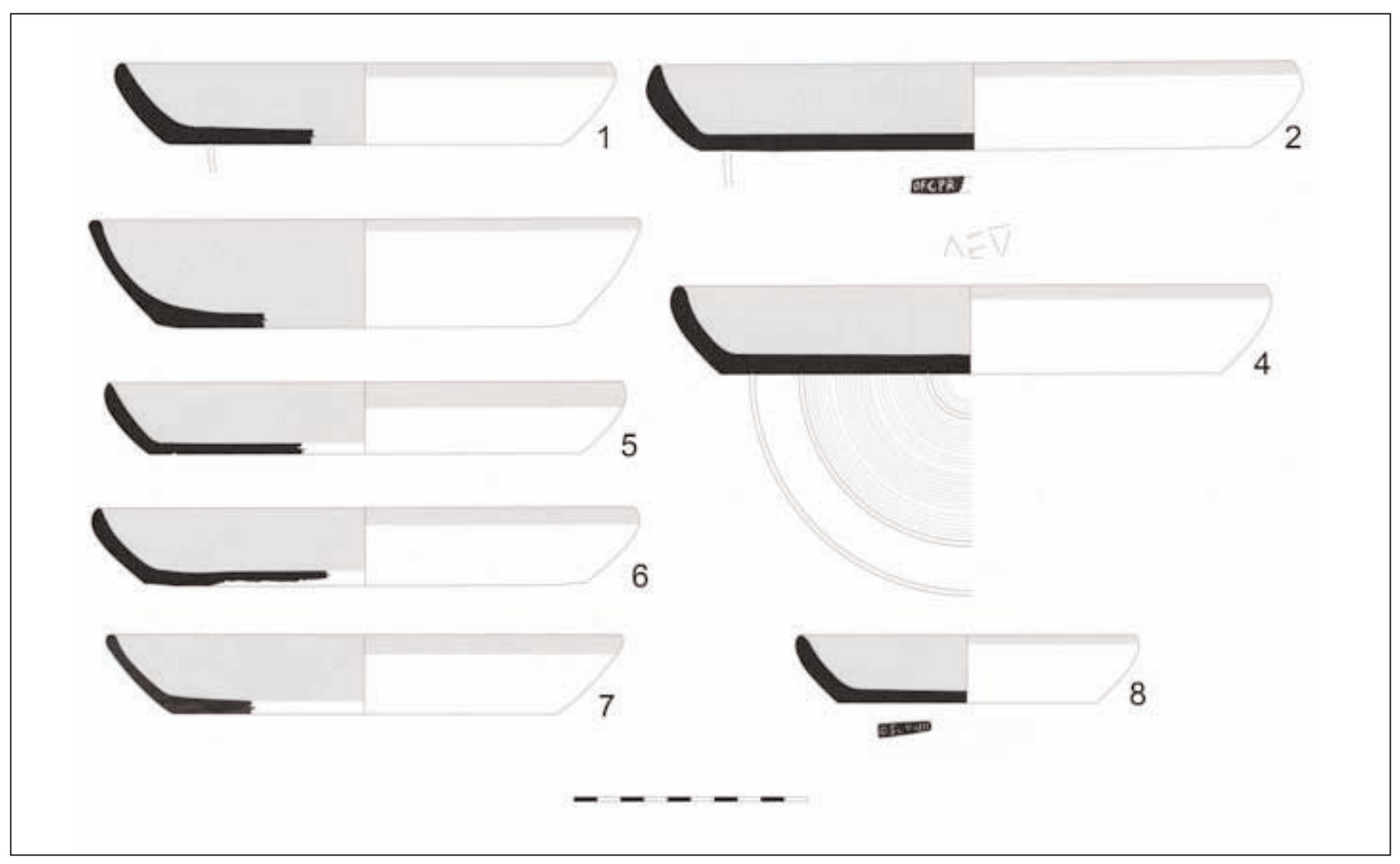

Figura 118. Platos-fuentes engobados

Ochoa, 1997: 101-102) ${ }^{114}$, Lugo (Caamaño, 1979: 90-91, Fig. I, 30 y Lám. I, 30; Alcorta, 1995: 223224, Fig. 19, 1.3; Alcorta, 2001), Castromao (Caamaño, 1979: 91-92, Fig. I, 31 y Lám. I, 31), Rosinos de Vidriales (Carretero, 1998: 10381039), Astorga (Alcorta, 2001: 320), León (Lapuente et alii, 1996; Fernández, 2003: 129) y Huerña (Domergue y Martin, 1977: 55 y 22; Fig.13.188y 189 y Fig.32.626-629).

Este extenso aunque no exhaustivo elenco de referencias debe ser sometido a análisis particularizado, puesto que es probable que convivan en la relación piezas que respondan a realidades bien diferentes. El dilatado espectro cronológico, el vasto marco territorial y la pertenencia a ámbitos culturales diferentes, aún a sabiendas de la proyección extrarregional de estas producciones, avalada por los sellos, así lo sugieren, pudiendo mezclarse con los productos lucenses ocasionales piezas itálicas y manufacturas de otras procedencias.

114 Se trata, en el caso de Gijón y Vega del Ciego, de piezas de cronología tardía, aunque equiparables en sus caracte-

\section{CATÁlogo}

1. CH.95/0964. Sector C-10 A. Fragmento de borde, cuerpo y base. Borde indiferenciado ligeramente envasado con labio de sección biselada. Pared corta oblicua de perfil curvo. Base plana con acanaladura en el fondo exterior. Pasta de tonalidad grisácea con desgrasantes micáceos y cuarcíticos pequeños, muy pequeños y medianos. Superficie externa bruñida de tonalidad grisácea con restos de hollín adheridos. Engobe rojo en el interior y borde. Dimensiones: diámetro borde: $204 \mathrm{~mm}$; diámetro base: $160 \mathrm{~mm}$; altura: $33 \mathrm{~mm}$; grosor medio sección pared: $8 \mathrm{~mm}$. Bibliografía: Hevia et alii, 2001: 155-158, Fig. 1.2.

2. CH.95 /0546. Sector C-10 A. Perfil completo. Borde indiferenciado ligeramente envasado con labio de perfil biselado. Cuerpo corto, oblicuo y curvo. Base plana

rísticas morfológicas y físicas macroscópicas, con las restantes. 
con acanaladura externa perimetral. Pasta de tonalidad anaranjada con abundantes inclusiones micáceas menudas y cuarzos pequeños y medianos. Superficie externa de tonalidad gris oscura con tratamiento bruñido y evidentes huellas de su exposición al fuego. Engobe rojo en el interior y borde. Marca de alfarero en el fondo externo, inscrita en cartela rectangular de extremos redondeados incompleta por la derecha (16 x $5 \mathrm{~mm}$, en lo conservado). Letras finas muy claras y bien definidas. Buena impresión, de tamaño regular salvo la primera letra, un poco más pequeña y con un punto en su zona central. El primer grupo de letras aparece separado del siguiente, que no se conserva, por un punto. Lectura: OF GPR.(...). Dimensiones: diámetro borde: $275 \mathrm{~mm}$; diámetro base: $237 \mathrm{~mm}$; altura: $37 \mathrm{~mm}$; grosor medio sección pared: 9 mm. Bibliografía: Sánchez, 2003; Hevia et alii, 2001: 155-158, Fig. 1.1; Menéndez y Benéitez, 2002: Fig.4.2; Montes, 2009: Ficha 157, 444-445.

3. CH.95/2716. Sector C-10 A. Fragmento de borde, cuerpo y base. Borde indiferenciado con labio ligeramente engrosado de perfil redondeado. Pared oblicua de perfil curvo engrosada en su extremo inferior. Base plana. Pasta grosera de tonalidad grisácea con abundantes desgrasantes cuarcíticos de diversas dimensiones (alguno grande) y alguno micáceo. Superficie externa ocre anaranjada con un acabado bruñido. Engobe fino rojo en el interior y en el tercio superior de la cara externa. Dimensiones: diámetro borde: $240 \mathrm{~mm}$; diámetro base: $180 \mathrm{~mm}$; altura: $45 \mathrm{~mm}$; grosor medio sección pared: $5.5 \mathrm{~mm}$. Bibliografía: Hevia et alii, 2001: 155-158, Fig. 1.3.

4. CH.99 /6348. Sector C-17 C. Perfil completo. Borde indiferenciado ligeramente envasado con labio de perfil biselado. Pared corta, oblicua y curva. Base plana recorrida en su fondo externo por tres acanaladuras concéntricas que destacan entre las líneas del torneado, visibles en todo el fondo. Grafito en el fondo interno de lectu- ra AEV. Pasta de tonalidad anaranjada con abundantes desgrasantes micáceos muy pequeños y cuarcíticos pequeños y medianos. Superficie externa anaranjada bruñida. Superficie interna y borde cubiertos de engobe rojo. Dimensiones: diámetro borde: $270 \mathrm{~mm}$; diámetro base: $226 \mathrm{~mm}$; altura: $40 \mathrm{~mm}$; grosor medio sección pared: $8 \mathrm{~mm}$. Bibliografía: Inédita.

5. CH.02 /1487. Sector C-17 C. Fragmento de borde, cuerpo y base. Borde indiferenciado ligeramente envasado con labio de perfil biselado apuntado. Pared corta, oblicua y curva. Base plana recorrida en su fondo externo por una acanaladura perimetral. Pasta anaranjada fina con desgrasantes micáceos muy pequeños y cuarcíticos pequeños y medianos. Superficie externa bruñida de tonos grisáceos. Superficie interna y borde cubiertos de engobe rojo. Dimensiones: diámetro borde: $220 \mathrm{~mm}$; diámetro base: $185 \mathrm{~mm}$; altura: $30 \mathrm{~mm}$; grosor medio sección pared: $6.5 \mathrm{~mm}$. Bibliografía: Inédita.

6. CH.98 /1691. Sector C-4 C. Fragmento de borde, cuerpo y base. Borde indiferenciado ligeramente envasado con labio de perfil biselado. Pared corta, oblicua y curva. Base plana. Pasta de tonalidad anaranjada con desgrasantes micáceos y cuarcíticos pequeños y medios. Superficie externa bruñida de color gris oscuro con evidentes huellas de exposición al fuego (zonas ennegrecidas y concreciones de hollín). Superficie interna y borde cubiertos de engobe rojo. Dimensiones: diámetro borde: $250 \mathrm{~mm}$; diámetro base: $189 \mathrm{~mm}$; altura: $33 \mathrm{~mm}$; grosor medio sección pared: $6 \mathrm{~mm}$. Inédita.

7. CH.99 /6894. Sector R-XIV. Fragmento de borde, cuerpo y base. Borde indiferenciado con labio de perfil redondeado. Pared corta, oblicua y curva. Base plana en lo conservado. Pasta fina de tonalidad anaranjada con desgrasantes micáceos muy pequeños y cuarcíticos pequeños. Superficie externa anaranjada bruñida. Superficie interna y borde engobados. 
Dimensiones: diámetro borde: $230 \mathrm{~mm}$; diámetro base: $170 \mathrm{~mm}$; altura: $35 \mathrm{~mm}$; grosor medio sección pared: $4.5 \mathrm{~mm}$. Inédita.

8. CH.99 /1274. Sector C-7. Perfil completo. Borde indiferenciado ligeramente envasado con labio de perfil biselado. Pared corta, oblicua y curva. Base plana. Ostenta sello de alfarero de lectura OS(...)VINTI en cartela rectangular impreso sobre el fondo externo. Pasta anaranjada con desgrasantes micáceos y cuarcíticos. Superficie externa bruñida de tonalidad gris. La cara interna, el borde y una pequeña franja al exterior se encuentran cubiertos de engobe rojo. Dimensiones: diámetro borde: $152 \mathrm{~mm}$; diámetro base: $114 \mathrm{~mm}$; altura: $30 \mathrm{~mm}$; grosor medio sección pared: $7 \mathrm{~mm}$. Bibliografía: Sánchez, 2003; Menéndez y Benéitez, 2002: Fig. 4.1; Montes, 2009: Ficha 157, 444-445.

\section{VASOS OVOIDES DE HOMBRO RESALTADO}

(Figuras 119 y 120)

La vajilla lucense engobada fina altoimperial incluye, además de los cuencos y platos/fuentes descritos, otros tipos de representación marginal en el repertorio ${ }^{115}$. Es el caso, de un conjunto de recipientes cerrados que se individualizan formalmente por su corto borde exvasado, el perfil ovoide con hombro destacado mediante engrosamiento o ejecución de acanaladuras y aristas y la base plana con pie de disco. El engobe rojo que caracteriza toda la serie se limita en estos ejemplares al borde y el extremo superior de la pared hasta alcanzar el hombro, tanto en la pared externa como en la interna.

En la capital conventual, donde la producción de esta vajilla resulta indudable, se documentan,

115 Además de los tipos con engobe rojo interior que aquí se presentan se encuentran actualmente en estudio un conjunto de jarras/botellas recientemente documentados e insertos técnicamente en esta misma serie cerámica. Formas, a prio$r i$, emparentables con éstas se registran también entre los repertorios lucenses (Alcorta, 2001). entre los denominados vasos globulares de borde exvasado y hombro acentuado -tipo V4(Alcorta, 2001: 274-275, Fig. 115) ejemplares con vagas similitudes morfológicas, alguno además con recubrimiento engobado.

El carácter singularmente fino del tipo se atisba igualmente en el esmerado tratamiento que reciben el resto de las superficies, caracterizado por un acabado bruñido bien cuidado que junto al carácter depurado y micáceo de las pastas en que fueron realizadas les confiere un aspecto pulido y brillante. Un elemento más a valorar en este

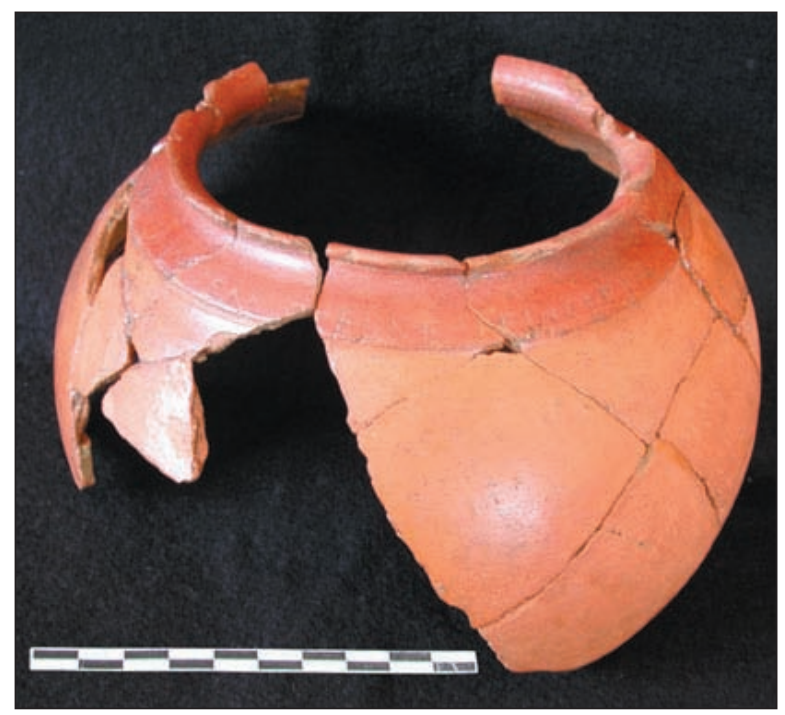

Figura 119. Vaso ovoide de hombro resaltado con inscripción.

Foto: Á. Villa Valdés

mismo sentido es el registro sobre el hombro de uno de los ejemplares que componen el tipo (Villa y Montes, 2009: 386-387) (Figura 119) de una inscripción ${ }^{116}$ que ha sido interpretada como la expresión escrita de un presente (tal vez el contenido del vaso) de los habitantes de Buroflavia (posiblemente, la actual Puebla de Burón, en consagrada, Lugo) a la civitas Ocela, cuya capital se considera establecida en el Chao Samartín (Francisco y Villa, 2005).

116Lectura: COPIAM [.]VROFLAVIENSES SALVTEM OCELAE FELICITER Las letras presentan un tamaño medio 4 $\mathrm{mm}$, salvo en COPIAM donde alcanza los $10 \mathrm{~mm}$ (Villa y Montes, 2009: 386). 


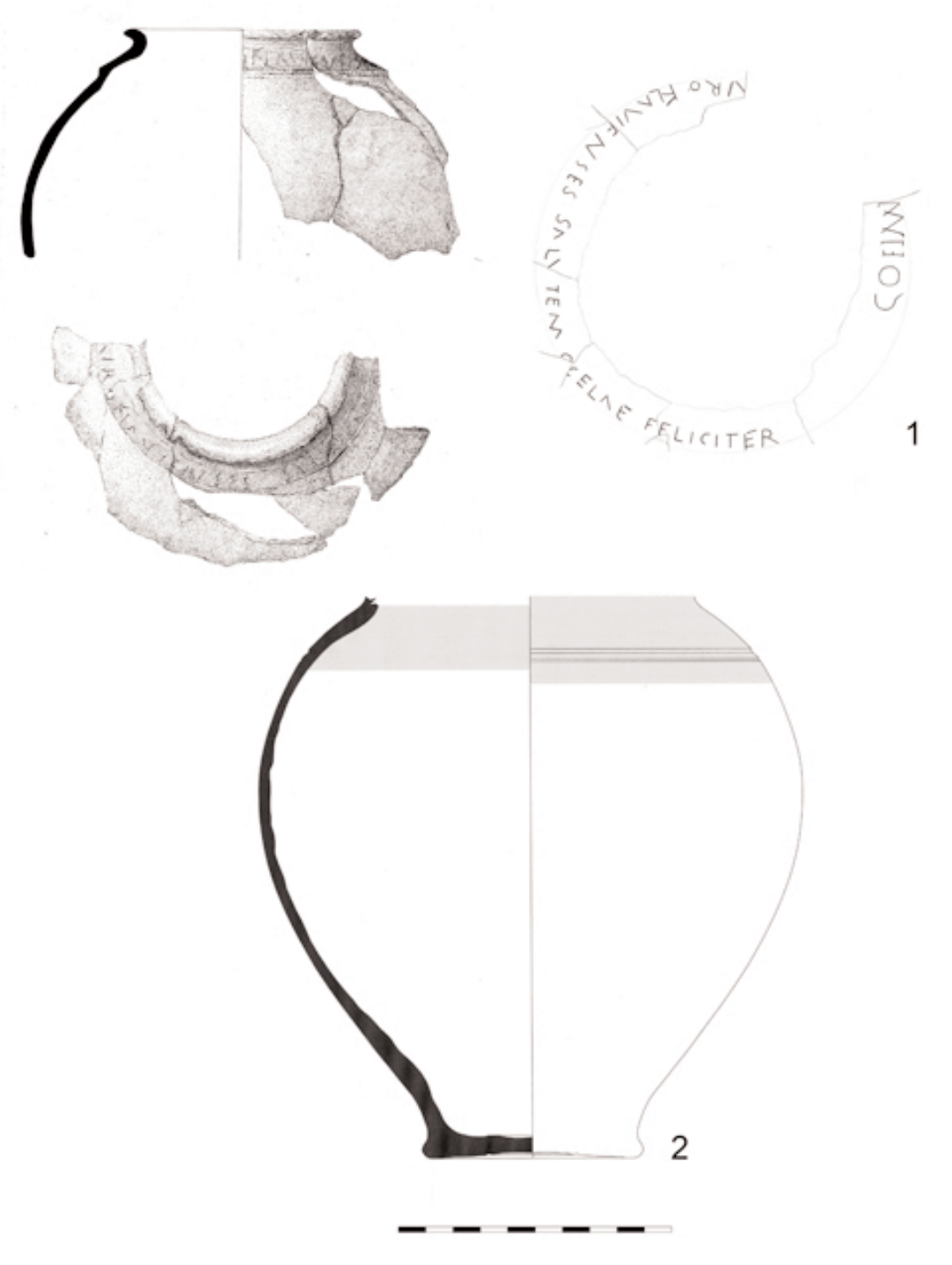

Figura 120. Vasos ovoides de hombro resaltado

\section{CATÁlogo}

1. CH.99 /5881. Sector C-17. Fragmento de borde y cuerpo. Borde corto, exvasado, oblicuo y curvo con labio de perfil redondeado. Cuerpo de perfil curvo en lo conservado que presenta en el hombro un resalte configurado por una arista de sección triangular. Pasta fina de tonalidad anaranjada con abundantes desgrasantes micáceos pequeños y muy pequeños y cuarcíticos pequeños y medianos. Superficies de color anaranjado con acabado bruñido al exterior. El borde y una pequeña banda en ambas superficies que llega hasta el resalte del hombro han recibido un engobe rojo. En la cara externa, sobre el sector engoba- do del hombro, se ha inscrito un grafito de lectura COPIAM [.]VROFLAVIENSES SALVTEM OCELAE FELICITER. Dimensiones: diámetro borde: $115 \mathrm{~mm}$; diámetro máximo cuerpo: $179 \mathrm{~mm}$; altura conservada: $110 \mathrm{~mm}$; grosor medio sección: $5 \mathrm{~mm}$. Bibliografía: Francisco y Villa, 2005; Villa, 2007: 132, Fig. 2; Villa y Montes, 2009: Ficha 128, 386-387.

2. CH.99/0454. Sector C-14 C. Fragmento de cuerpo y base. Cuerpo de perfil ovoide recorrido en la zona del hombro por una acanaladura y una fina incisión. Base plana con pie de disco. Pasta fina de tonalidad anaranjada con desgrasantes micáceos pequeños y muy pequeños y cuarcíticos 
pequeños, medios y alguno grande. Superficies anaranjadas, la externa bruñida. El extremo superior de ambas caras ha recibido un recubrimiento de engobe rojo que al exterior supera mínimamente la acanaladura, quedando al interior un poco más reducida. Dimensiones: diámetro máximo cuerpo: $200 \mathrm{~mm}$; diámetro base: $82 \mathrm{~mm}$; altura conservada: $203 \mathrm{~mm}$; grosor medio sección: 5 mm. Bibliografía: Inédita.

\section{Vajilla con Decoración Estampillada} (Figuras 122-128)

Bajo esta denominación unitaria de vajilla con decoración estampillada hemos agrupado en anteriores ocasiones (Benéitez et alii, 1999: 30-33, Fig.6 y 7; Montes et alii, 2001: 34; Menéndez y Benéitez, 2002: 292; Fig. 3.3 y 4; Montes y Hevia, 2008: 768), focalizando la atención de forma prioritaria en la técnica y los motivos decorativos como criterios discriminantes y soslayando en buena medida los aspectos morfológicos y cronológicos, un nutrido repertorio de piezas de naturaleza morfológica y técnica bastante heterogénea.

El principal rasgo común que presenta este conjunto cerámico consiste en la plasmación sobre las superficies de las piezas de ornamentaciones estampilladas que reiteran de modo sistemático determinados motivos muy característicos. El esquema que se repite de modo constante es el de arquerías de medio punto de las que penden otros temas ornamentales. Las arquerías se desarrollan de acuerdo con alguna de las siguientes modalidades:

- Arcos simples continuos. Se trata de una fórmula poco frecuente, que se da en algunas piezas de fisonomía antigua, con evidentes vinculaciones con la cerámica indígena. Son también conocidos en Lugo (Alcorta, 2005 a: Fig.1.8 y 9 y Fig.2.6).

- Arcos simples puntillados (Figuras 122.3 y 124.2 y 3 ). Este modelo, minoritario,

${ }^{117}$ Este tipo de composiciones dobles son conocidas también en el repertorio de Lucus Augusti, donde se les aplica la aunque no raro, en el repertorio del Chao Samartín, se documenta de igual modo en Lucus Augusti con bastante profusión (Ibidem: 40; Lám.1 y 2.1-7).

- Arcos dobles puntillados (Figuras 122.1y $2,124.1,126$ y 128). Constituye la modalidad mejor representada, habiendo sido también reconocida en otros yacimientos como Lugo (Ibidem: Lám.3), O Castro de Zoñán (Vigo, 2007: 215-216), La Escrita (Carrocera y Requejo; 1989: 24 y 28, Fig. 2.6) o San Chuis (Ibidem, Fig.2.5).

La norma habitual es la sucesión corrida de arcos unidos por sus diámetros mayores, donde se instalan los motivos pendientes. Sin embargo, en algún caso los arcos se muestran secantes, componiendo temas de arquerías entrecruzadas en los que se duplican los motivos colgantes ${ }^{117}$.

Por lo que respecta a estos motivos complementarios se identifican las siguientes variedades:

- Motivos circulares. Son el tema más habitual, pudiendo presentarse de diversas formas:

- Dobles concéntricos continuos (Figura 124.2). Resultan relativamente habituales también en el catálogo de piezas de este tipo documentado en Lugo (Alcorta, 2005 a: Fig.1. 3-4; Fig. 2.1 y 3 y Fig.3.6 y 14).

- Simples puntillados (Figuras 122.3, 124.1 y 3 y 128). No son desconocidos tampoco en el nutrido elenco de Lucus Augusti, hasta el punto de constituir el tema con una mayor representación (Ibidem: Fig. 1.1, 2 y 9; Fig. 2.7, 9 y 10 y Fig. $3.1,8$ y 11).

- Dobles concéntricos puntillados. Porcentualmente, resulta el motivo más repetido en el Chao Samartín, habiendo sido también reconocido en Lugo (Ibidem: Fig. 1.9; Fig. 3.7), aunque con menor abundancia. 
- Puntillados formando combinaciones complejas de varios círculos unidos por sus circunferencias conformando una especie de racimo (Figura 126.1).

- Radiales simples (Figura 126.2). En estos casos, la estampación del círculo se realiza, no a partir de pequeños puntos como en las modalidades anteriores, sino de líneas o triangulitos estilizados. Disponemos de algún ejemplo similar en Lucus Augusti (Alcorta, 2005 a: Fig.3.13).

- Radiales concéntricos dobles. En alguna ocasión, el círculo interno se presenta como simple continuo, mientras que el externo se muestra radial (Carrocera y Requejo, 1989: 24 y 28; Fig.2.4).

- Motivos fitomorfos a modo de sencillas palmetas u hojas (Figura 122.2 y 126.3). Tal y como acontece en Lugo (Alcorta, 2005 a: 40 y 2005 b: 22; Fig. 5), este tipo de ornatos tiende a asociarse a piezas engobadas del tipo de los tazones monoasados o las imitaciones de terra sigillata, tal vez como trasunto de las decoraciones plasmadas en éstas últimas. Se dispone de algún ejemplo más de este tipo de motivos en los castros asturianos de La Escrita (Carrocera y Requejo, 1989: 24 y 28; Fig.2.6) y San Isidro (Ibidem: Fig.2.8).

Resulta relativamente frecuente, sobre todo entre las piezas más finas de la familia, la presencia de elementos lineales que cuelgan de estos motivos para rematar en otros nuevos, círculos por lo general. De este modo, se prolonga el campo decorativo hacia la parte inferior del recipiente y se dota a la ornamentación de un marcado carácter barroco ${ }^{118}$.

Por otra parte, cabe referir que en determinadas ocasiones, los círculos que suelen asociarse a las uniones de los arcos migran hacia otras partes de la composición, instalándose, por ejemplo, en el hueco exterior que queda entre sus semicircunferencias (Alcorta, 2001: Fig. 2.1 y Fig.3.6).
Tampoco resulta desconocida su presencia aislada como decoración única o incluso su asociación a decoraciones bruñidas, impresas o incisas.

A pesar de estas características comunes, las notables diferencias morfológicas que hemos apuntado, invitan a un análisis más detallado del elenco que contribuya a ser más precisos en la individualización de tipologías concretas.

En primer lugar, conviene separar ciertas rarezas que tienden a escorarse cronológicamente hacia momentos tempranos del siglo I d.C., tal y como se ha referido al tratar esta fase (Figuras 57 y 58). Constituyen la expresión en este tipo de vajilla del habitual fenómeno de transformación que conduce de una etapa de mayor indefinición y amplia variedad de tipos a la reiteración sistemática en momentos más tardíos de modelos formales, en un proceso de paulatina estandarización. Es el caso de piezas que combinan la decoración estampillada con otras técnicas ornamentales típicas y casi exclusivas de fechas tempranas como las impresiones de alineaciones de puntos.

A unas circunstancias similares responden las imitaciones engobadas con decoraciones estampilladas de formas de terra sigillata y las primeras manifestaciones de ollas globulares engobadas, también abordadas en el análisis de la vajilla del siglo I d.C.

Desdeñados estos ensayos tempranos nos queda un amplio conjunto de piezas que responden a formulaciones tipológicas variadas cuya cristalización como fabricaciones seriadas se alcanzará en el siglo II d.C. En este punto conviene una reflexión al respecto de la cronología general de estas producciones. Desestimada definitivamente la vieja adscripción cronológica de estas piezas a momentos tardíos (siglos IV-VI d.C.), basada en su errónea vinculación al grupo avanzado de la terra sigillata hispánica tardía de imitación paleocristiana (Carrocera y Requejo, 1989: 27), se apuntan cronologías de fabricación julio-claudias para Lugo (Alcorta, 2005 a), centro neurálgico de su producción. Si bien resulta inne-

118 Ver también Alcorta, 2005 a: Fig.3.5. 
gable el comienzo de la fabricación de alguno de los ejemplares integrado en esta familia cerámica en datas tempranas, coincidiendo con el arranque de la actividad alfarera regional, tal y como denuncian las imitaciones de terra sigillata y determinadas piezas que mantienen estrechos vínculos con el acervo indígena, no es tan claro su cese en datas flavias. Bien al contrario, en el Chao Samartín se puede asegurar la vigencia de determinadas morfologías con decoraciones estampilladas en contextos situados en momentos avanzados del siglo II d.C. La recurrencia de su registro como parte integrante de los ajuares característicos de los niveles de abandono en el yacimiento avala esta propuesta de datación.

\section{OLLAS GLOBULARES ENGOBADAS}

(Figuras 121 y 122)

Constituyen el grupo de piezas con decoración estampillada más homogéneo y con el grado de estandarización más destacado de cuantos integran esta serie cerámica. Se trata de recipientes con superficies bien bruñidas de color acastañado o grisáceo claro al exterior y recubiertas de engobe rojo en la parte superior de la superficie interna, el borde y en ocasiones, el cuello al exterior. Su morfología remite en todos los casos conocidos a recipientes cerrados dotados de pequeñas bases planas con anillo perimetral y a perfiles del galbo acusadamente globulares y achatados que rematan en típicos bordes exvasados facetados, a menudo recorridos por una acanaladura coincidente con la acusada inflexión (Montes, 2009: 440-441). Las paredes reiteran de modo sistemático secuencias ornamentales de arquillos puntillados de los que penden motivos circulares también puntillados o estilizaciones vegetales. Estos temas se inscriben en frisos más o menos amplios delimitados por acanaladuras y molduras, cuya multiplicación, unida a los desarrollos globulares, conecta estas piezas con la tradición anterior, representada por tipos como las ollas globulares de bandas decoradas, tan representativas de las primeras fases de la cerámica común de época romana en el yacimiento, o los precedentes engobados con decoración estampillada del siglo I d.C.

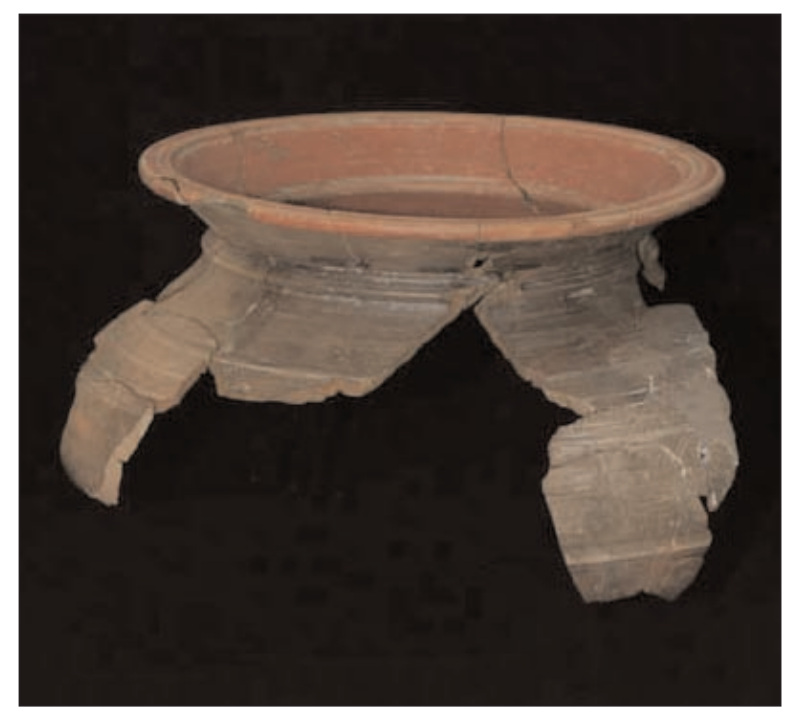

Figura 121. Olla globular engobada con decoración estampillada.

Foto: J. Arrojo

El modelo ha sido registrado en el yacimiento en dos modalidades dimensionales:

- Piezas de tamaño reducido con diámetros de boca en torno a los $150 \mathrm{~mm}$ y alturas algo inferiores.

- Grupo de ejemplares mucho mayores y de registro más frecuente cuyo diámetro alcanza casi el doble de apertura de borde, situándose en torno a los $300 \mathrm{~mm}$ (Montes, 2009: 440-441).

La difusión de este tipo, tal y como corresponde a un modelo de rasgos de gusto tan marcadamente regional, se restringe al ámbito de distribución habitual de las producciones lucenses. En el propio Lucus Augusti encontramos ejemplos formalmente semejantes entre las ollas decoradas de perfil sinuoso y borde exvasado del tipo L1 (Alcorta, 2001: 81-89, Figs. 34-38), si bien las decoraciones dominantes entre éstas son los reticulados bruñidos. Piezas de perfil similar pero también con decoración bruñida se conocen en el castro de San Chuis (Allande) (Jordá et alii, 1989: Fig. p. 42) y el de Viladonga (Lugo) (Arias, 1985: 22). Así mismo, entre las ollas globulares decoradas del tipo L2 de Lugo (Alcorta, 2001: 89-90, Figs. 39 y 40), aún con un desarrollo morfológico más lejano, se encuentran ejemplos de esquemas ornamentales similares y presencia habitual de engobe rojo al interior. Más próximas se encuentran un peque- 


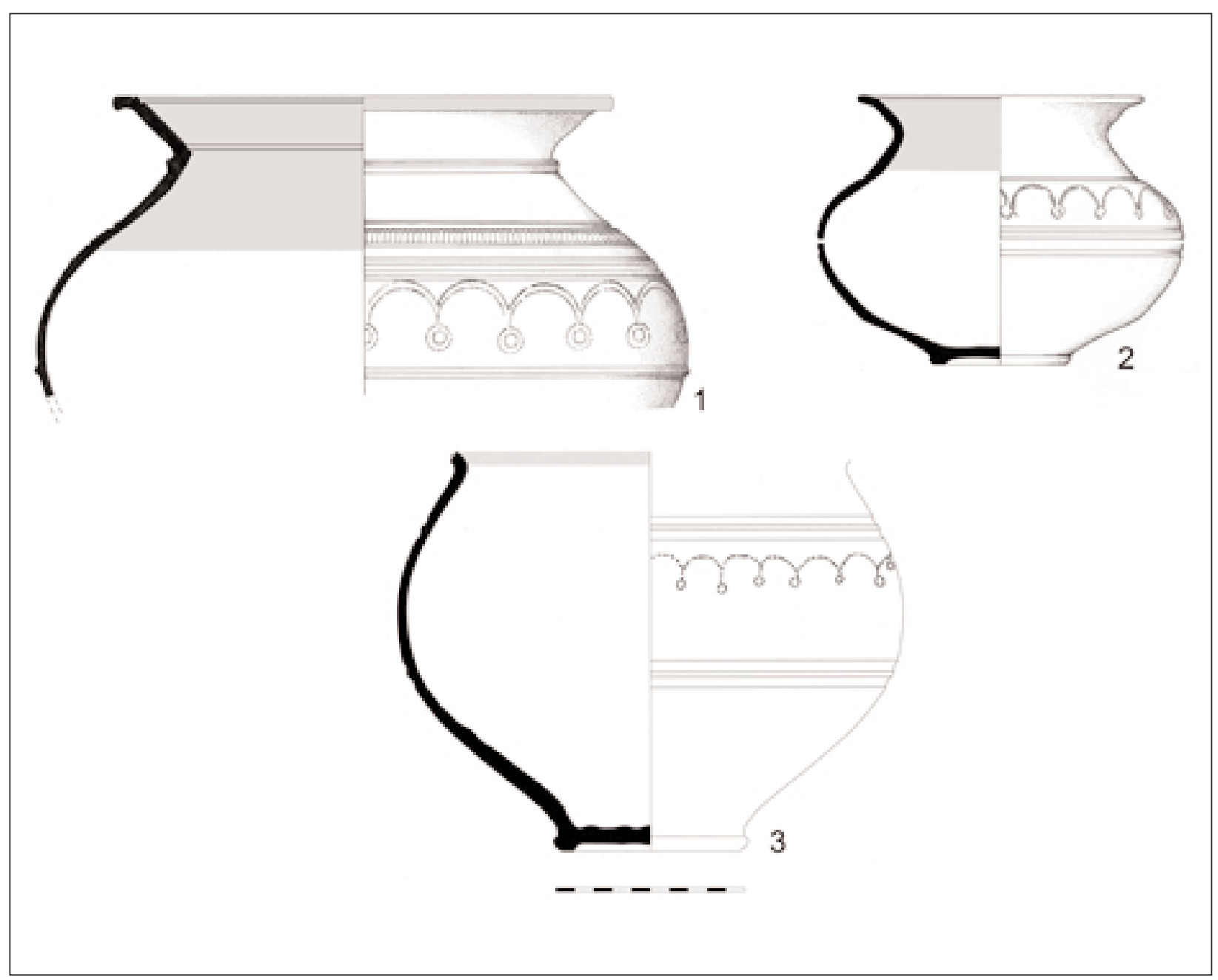

Figura 122. Ollas globulares engobadas con decoración estampillada

ño grupo de piezas con vestigios de engobe documentadas en castros del occidente asturiano que pudieran relacionarse con el tipo. Es el caso de una pieza ${ }^{119}$ del propio Chao Samartín (Carrocera y Requejo, 1989: 24 y 28, Fig. 2.4 y Carrocera, 1990: fot. en p. 128) $)^{120}$, un fragmento de La Escrita (Ibidem: Fig.2.6) ${ }^{121}$ y otros dos procedentes de San Isidro (Ibidem: Fig.2.8) ${ }^{122}$.

${ }^{119}$ Expuesta en la actualidad en el Aula Didáctica del castro de Coaña.

${ }^{120} \mathrm{El}$ remate del borde en doble toro representado en el dibujo no es correcto. El desgaste del cuello de la pieza ha llevado a los citados autores a una interpretación gráfica errónea de la misma, considerando la boca de la pieza lo que constituye una doble moldura situada en la zona del cuello. En realidad, se trata de un ejemplar que responde de modo fidedigno al tipo descrito en estas líneas.

${ }^{121}$ La representación gráfica del fragmento ha de ser errónea, así como su interpretación morfológica. En vez de tratarse de un fragmento correspondiente a la zona del cuello de una

\section{CATÁlogo}

1. CH.95 /0479. Sector C-10 A. Fragmento de borde y cuerpo. Borde exvasado horizontal recorrido al interior por una acanaladura con labio engrosado de perfil redondeado. Cuello recto oblicuo recorrido al interior por sendas acanaladuras que marcan sus botella, tal y como apuntan E. Carrocera y O. Requejo (1989: 28, Fig.2.6), se trata de un segmento de la parte inferior del galbo que presenta las características arquerías (invertidas en el referido dibujo) de cuyas uniones penden palmetas. La presencia del par de acanaladuras inferiores recuerda de igual modo a otros ejemplares de la serie.

122 A pesar de lo escueto de los fragmentos conservados, resulta verosímil que de nuevo la representación gráfica de los mismos se encuentre errada. La disposición de las palmetas así lo sugiere. 
extremos, mientras que al exterior un grueso baquetón de sección triangular señala el tránsito al galbo. Cuerpo globular surcado por numerosas molduras y acanaladuras que delimitan dos zonas decorativas situadas en la mitad superior: un pequeño friso continuo de arquillos angulosos burilados instalados en un filete de la parte superior y una banda en la que se plasman arcos estampillados dobles segmentados de los que penden motivos circulares, formados por círculos concéntricos, también segmentados. Otro grueso baquetón de sección triangular, situado en la zona media del cuerpo, marca el final de la franja decorada. Pasta de tonalidad ocre grisácea con desgrasantes micáceos y cuarcíticos pequeños y medianos. Superficie externa bruñida de tonos ocráceos. El borde, el cuello y el tercio superior del cuerpo presentan al interior un engobe de color rojo. Dimensiones: diámetro borde: $265 \mathrm{~mm}$; diámetro máximo cuerpo: $345 \mathrm{~mm}$; altura conservada: $148 \mathrm{~mm}$; grosor medio sección pared: 4.5 mm. Bibliografía: Benéitez et alii, 1999: 31-32, Fig. 6.1; Montes, 2009: Ficha 155, 440-441.

2. CH.95 /1691. Sector C-10. Perfil completo. Borde exvasado horizontal con labio de perfil redondeado. Cuello corto, oblicuo y recto al interior y levemente engrosado al exterior. Cuerpo de perfil marcadamente globular surcado por una profunda y ancha acanaladura en el hombro y por otras dos más finas coincidentes con el diámetro máximo de la pared. Base plana de pie realzado con anillo perimetral de perfil curvo. Decoración estampillada ocupando una banda de $32 \mathrm{~mm}$ entre las acanaladuras, consistente en arcos de medio punto simples puntillados unidos por sus bases y palmetas colgantes. Pasta de tonalidad grisácea con desgrasantes micáceos y cuarcíticos pequeños y medios y algún esquisto. Superficie externa bruñida de color ocre grisáceo. El borde, el cuello y el tercio superior del cuerpo presentan al interior recubrimiento de engobe rojo.
Dimensiones: diámetro borde: $152 \mathrm{~mm}$; diámetro máximo cuerpo: $194 \mathrm{~mm}$; diámetro base: $76 \mathrm{~mm}$; altura: $142 \mathrm{~mm}$; grosor medio sección pared: $4 \mathrm{~mm}$. Bibliografía: Benéitez et alii, 1999:

3. CH.95 /0249. Sector C-10 A / B. Fragmento de cuerpo y base. Cuello curvo en lo conservado. Cuerpo globular recorrido en su cara externa por sendos pares de anchas acanaladuras. Base plana con pie realzado con anillo perimetral de perfil curvo. En la zona media del cuerpo, ocupando el tercio superior de la amplia franja delimitada por las acanaladuras pareadas, se dispone una decoración estampillada compuesta de una tosca arquería de arcos segmentados simples, de cuyas intersecciones penden motivos circulares también simples. Pasta de tonalidad pardo anaranjada con abundantes desgrasantes micáceos pequeños y muy pequeños y cuarzos menudos y medios. La superficie externa, de tonos ocre grisáceos oscuros presenta acabado bruñido, mientras que la interna cuenta con un somero alisado en el cuello y arranque del borde, resultando visibles en el resto de la superficie las estrías y acanaladuras producidas por el torneado. El extremo superior del cuello presenta restos de un engobe rojo oscuro en su cara interna. Dimensiones: diámetro máximo cuerpo: $260 \mathrm{~mm}$; diámetro base: $94 \mathrm{~mm}$; altura conservada: $209 \mathrm{~mm}$; grosor medio sección pared: $5.5 \mathrm{~mm}$. Bibliografía: Benéitez et alii, 1999: 31-32, Fig. 6.2.

\section{OLLAS BRUÑIDAS GRISES}

(Figuras 123 y 124)

Junto a la serie engobada referida convive otro grupo de vasijas que morfológicamente responde en lo esencial a los mismos rasgos, si bien en este caso la heterogeneidad resulta bastante mayor, conviviendo piezas de perfiles netamente globulares achatados del estilo de los descritos para las engobadas, junto a desarrollos más estilizados, de tendencia ovoide.

El tipo de pasta en que fueron fabricadas resulta también similar, así como el tratamiento 
bruñido de las superficies y obviamente, los motivos decorativos y en buena medida, la sintaxis ornamental. La mayor diferencia estriba pues en el cromatismo oscuro, gris o negro, de las superficies, frente a los tonos ocráceos que adquieren sus congéneres y sobre todo, a la ausencia del recubrimiento pigmentado interno (Montes, 2009: 442-443).

La difusión de este tipo de piezas resulta de nuevo estrictamente regional y se limita a algún ejemplar procedente de Lugo (Alcorta, 1995, 205, Fig. 4.1) y a un pequeño fragmento de San Chuis (Carrocera y Requejo, 1989: 24 y 28; Fig. 2.5; Manzano, 1990: 409, Fig. p. 407).

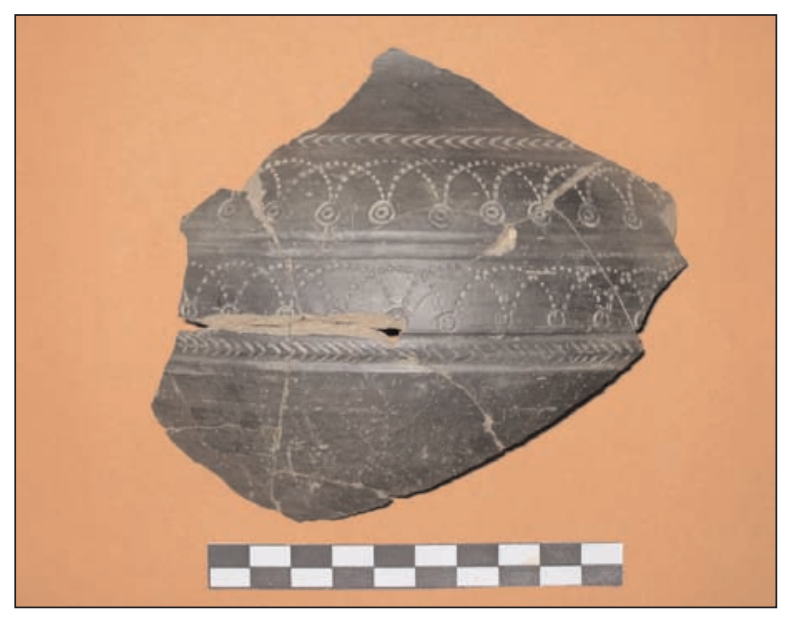

Figura 123. Olla bruñida con decoración estampillada. Foto: R. Montes

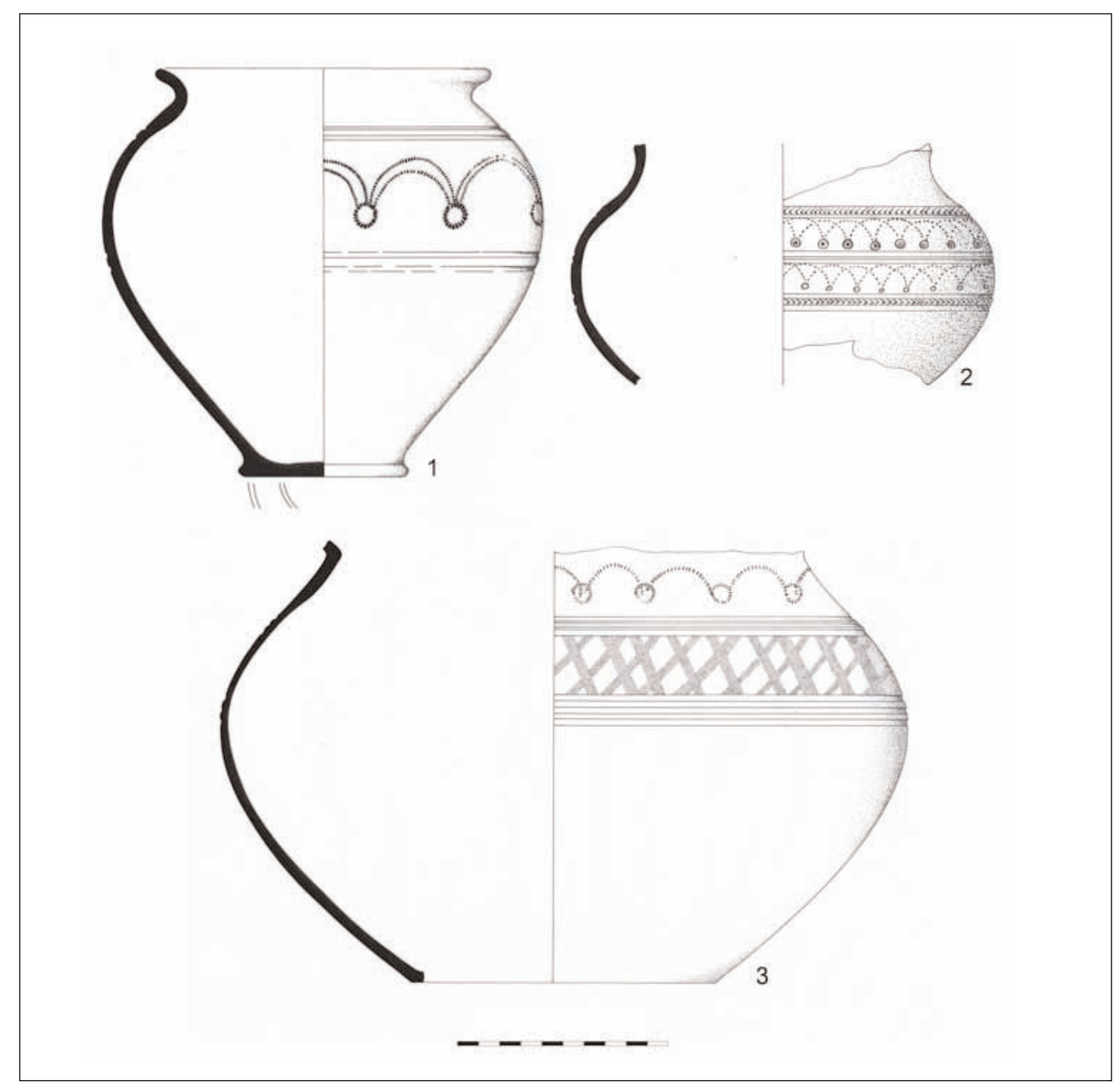

Figura 124. Ollas bruñidas con decoración estampillada 


\section{CATÁlogo}

1. CH.95/1075. Sector C-10. Perfil completo. Borde exvasado, oblicuo y curvo con labio de perfil redondeado. Cuerpo de perfil ovoide recorrido por sendos pares de acanaladuras, uno en el tercio superior y otro en la zona media. Base plana con pie de disco y fondo exterior surcado por dos acanaladuras concéntricas. En la mitad superior del cuerpo, enmarcado por los referidos pares de acanaladuras, se dispone un friso decorativo estampillado formado por una sucesión de arcos segmentados dobles de los que penden círculos simples también segmentados. Pasta de tonalidad grisácea con abundantes desgrasantes micáceos y cuarcíticos pequeños y medianos. Superficie externa, borde, fondo exterior y extremo superior bruñidos, ofreciendo un acabado negro mate donde el bruñido se conserva. Dimensiones: diámetro borde: $160 \mathrm{~mm}$; diámetro máximo cuerpo: $210 \mathrm{~mm}$; diámetro base: $82 \mathrm{~mm}$; altura: $194 \mathrm{~mm}$; grosor medio sección pared: $4.5 \mathrm{~mm}$. Bibliografía: Benéitez et alii, 1999: 32-33, Fig. 7.6.

2. CH.95 /0646. Sector C-10 A. Fragmento de cuerpo. Perfil marcadamente globular recorrido por cinco acanaladuras, una en el extremo superior y agrupadas por pares las restantes. Decoración estampillada consistente en una doble banda de arquerías superpuestas separadas por el par de acanaladuras centrales y delimitadas arriba y abajo por las otras acanaladuras. Las arquerías se componen de arcos segmentados simples que forman intersecciones con otra serie de arcos idénticos. En las uniones de los extremos de ambas penden motivos circulares continuos, concéntricos en el friso superior y simples en el inferior. Sobre la acanaladura superior y en el filete que queda entre las dos inferiores se plasman secuencias de ángulos impresos con los vértices hacia la izquierda y hacia la derecha respectivamente. Pasta grisácea con desgrasantes micáceos y cuarcíticos pequeños y medianos. Superficie externa e interior del cuello cuidadosamente bruñidas, siendo el bruñido más irregular en el resto de la pared interior. Dimensiones: diámetro máximo cuerpo: $200 \mathrm{~mm}$; altura conservada: $114 \mathrm{~mm}$; grosor medio sección pared: $4.5 \mathrm{~mm}$. Bibliografía: Benéitez et alii, 1999: 3233, Fig. 7.4; Montes, 2009: Ficha 156, 442-443.

3. CH.95 /1207. Sector C-10 A. Fragmento de cuerpo y arranque de base. Cuerpo globular recorrido por dos acanaladuras en el tercio superior y otras tres en la zona del diámetro máximo. Base plana en lo conservado. La mitad superior del cuerpo presenta dos frisos decorativos: en el hombro una arquería estampillada formada por arcos segmentados simples de los que cuelgan motivos circulares también simples y segmentados. Bajo esta secuencia se dispone una banda bruñida a base de haces de líneas que se cruzan formando rombos que ocupan todo el ancho de la franja, delimitada entre lo pares de acanaladuras. Pasta de tonalidad grisácea con desgrasante micáceos y cuarcíticos pequeños y medios. Superficie externa e interior del hombro bruñidos. Dimensiones: diámetro máximo cuerpo: $336 \mathrm{~mm}$; diámetro base: 145 $\mathrm{mm}$; altura conservada: $205 \mathrm{~mm}$; grosor medio sección pared: $5 \mathrm{~mm}$. Bibliografía: Benéitez et alii, 1999: 3233, Fig. 7.5.

\section{TAZONES MONOASADOS ENGOBADOS}

(Figuras 125 y 126)

Integran este grupo una serie de vasos que morfológicamente remiten de forma estricta a la estandarizada morfología de los tazones monoasados (Figuras 96-100). De este modo, el tipo presenta una dualidad de producciones. De una parte, se encuentra el grupo mayoritario de tazones grises o negros con decoraciones de líneas 
bruñidas que se insertan en la serie cerámica gris fina, ya analizada, y por otra, esta variante minoritaria ${ }^{123}$ de vasos con superficies y pastas ocráceas, típicas decoraciones estampadas y engobe rojo interno, que se presenta como modalidad marginal y que remite a la familia de las producciones estampilladas aquí presentada (Montes, 2005).

Al igual que explicamos pormenorizadamente al hacer referencia a sus congéneres bruñidos, estas piezas presentan bordes exvasados oblicuos, cuerpos carenados o globulares, asas en $\mathrm{C}$ y probablemente, bases planas con pie de disco $^{124}$. La articulación del campo decorativo se corresponde igualmente a la de aquellos, que queda delimitada generalmente por molduras y acanaladuras.

Los temas ornamentales no difieren sustancialmente de los plasmados en otros tipos afines, si bien se observa cierta tendencia a motivos recargados y de buena factura.

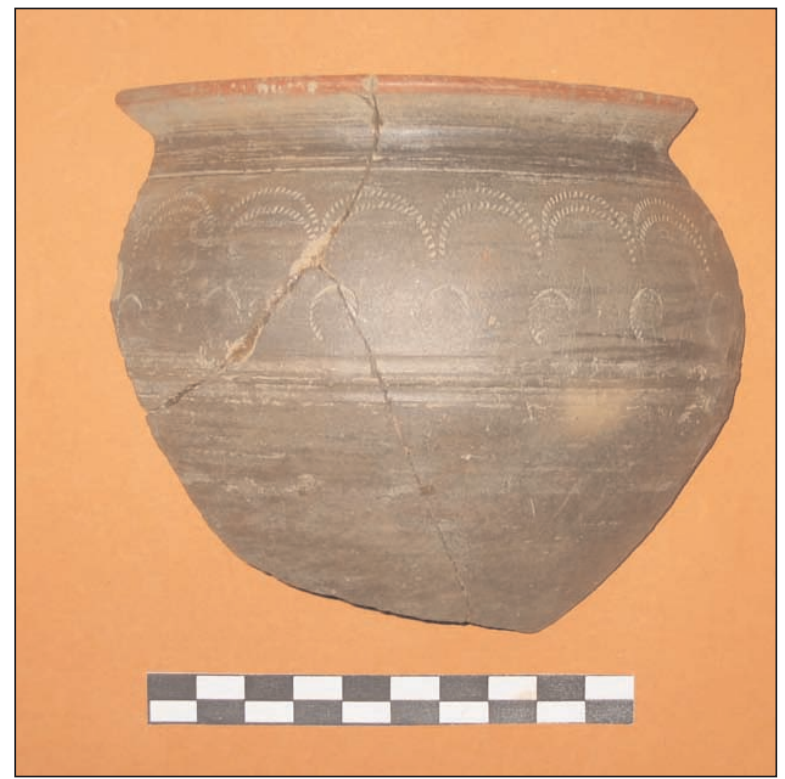

Figura 125. Tazón monoasado engobado con decoración estampillada. Foto: R. Montes

En el repertorio cerámico de Lugo son conocidos tazones asimilables al tipo (Alcorta, 2005 a: Fig. 3.4 y 5).

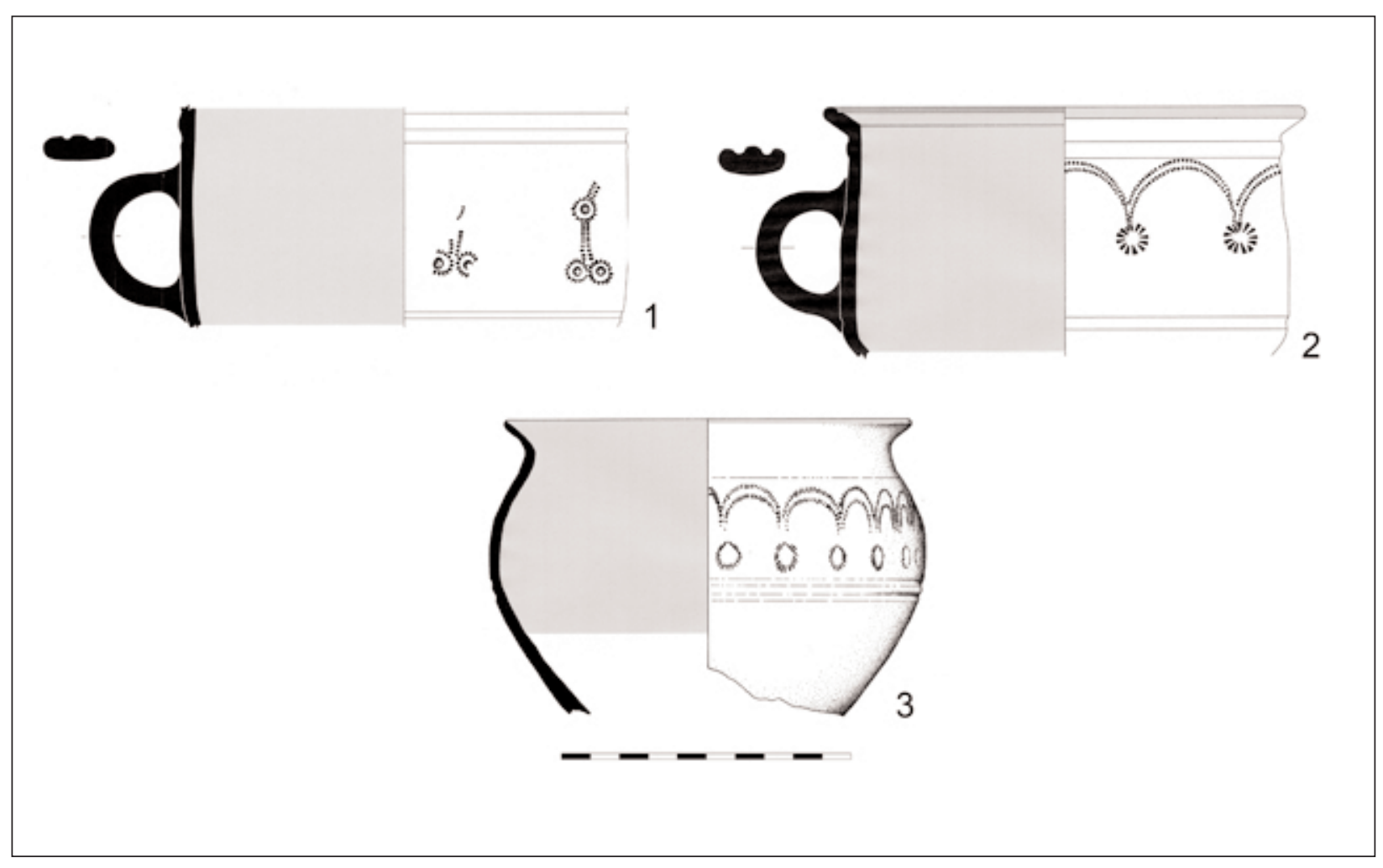

Figura 126. Tazones engobados con decoración estampillada

${ }^{123}$ En torno al $8 \%$ del total de los tazones decorados (Montes, 2005).
${ }^{124} \mathrm{La}$ ausencia de perfiles completos impide corroborar este extremo. 


\section{CATÁlogo}

1. CH.99 /0677. Sector C-12. Fragmento de cuerpo y asa. Cuerpo de perfil vertical en lo conservado con posible arranque de carena media-baja en el extremo inferior. Se encuentra recorrido por una moldura de sección redondeada en el extremo superior y por una acanaladura en la zona de la posible carena. Asa en $\mathrm{C}$ de sección elipsoidal con dos acanaladuras al exterior que arranca debajo de la moldura y alcanza la zona de la carena. Decoración estampillada consistente en arcos dobles puntillados en cuyas intersecciones se sitúan motivos circulares radiales también puntillados que encierran en su interior otros círculos continuos más pequeños. De los círculos penden dobles líneas verticales que rematan en otros dobles círculos similares a los superiores. Pasta grisácea con abundantes micas pequeñas y muy pequeñas y cuarzos medios. Superficie externa gris oscura bruñida. Superficie interna con engobe rojo. Dimensiones: diámetro máximo cuerpo: $147 \mathrm{~mm}$; altura conservada: $73 \mathrm{~mm}$; grosor medio sección pared: $4.5 \mathrm{~mm}$. Bibliografía: Montes, 2005.

2. CH.98 /4031. Sector Foso C / R-VIII / C12 B. Fragmento de borde y cuerpo. Borde exvasado, oblicuo y recto recorrido al interior por una acanaladura. Labio de perfil redondeado. Cuerpo con carena media-baja bien marcada que lo divide en una parte superior de perfil recto vertical y otra inferior curva abierta. Se encuentra recorrido por una moldura de sección redondeada en el extremo superior y por una acanaladura en la zona de la carena. Asa en C de sección elipsoidal con dos acanaladuras al exterior que arranca debajo de la moldura y alcanza la zona de la carena. Decoración estampillada consistente en una arquería doble puntillada de la que penden en las intersecciones motivos circulares radiales también puntillados. Pasta gris anaranjada con abundantes micas pequeñas y muy pequeñas y cuarzos medios. Superficie externa ocre grisácea bruñida. El labio, la parte interna del borde y la zona superior del cuerpo cuentan con engobe rojo, mientras que la parte inferior presenta una tonalidad anaranjada. Dimensiones: diámetro borde: $168 \mathrm{~mm}$; diámetro máximo cuerpo: $158 \mathrm{~mm}$; altura conservada: $87 \mathrm{~mm}$; grosor medio sección pared: $4.5 \mathrm{~mm}$. Bibliografía: Montes, 2005.

3. CH.98 /3450. Sector R-VIII / C-12. Fragmento de borde y cuerpo. Borde exvasado, oblicuo y recto con labio de perfil redondeado. Cuerpo globular recorrido por dos finas incisiones en su extremo superior y por un par de acanaladuras hacia la mitad de su desarrollo. Decoración estampillada consistente en una arquería doble puntillada de la que penden en las intersecciones motivos vegetales estilizados tipo palmetas, también puntillados. Pasta grisácea con desgrasantes micáceos y cuarcíticos menudos. Superficie externa ocre grisácea bruñida. El labio, la parte interna del borde y los dos tercios superiores del cuerpo al interior cuentan con engobe rojo, mientras que la parte inferior presenta una tonalidad anaranjada. Dimensiones: diámetro borde: 140 $\mathrm{mm}$; diámetro máximo cuerpo: $150 \mathrm{~mm}$; altura conservada: $102 \mathrm{~mm}$; grosor medio sección pared: 4 mm. Bibliografía: Inédita.

\section{VASOS OVOIDES MONOASADOS ENGOBADOS}

(Figuras 127 y 128)

Otra de las tipologías marginales de la serie estampillada se vincula en lo morfológico al tipo de los vasos ovoides, tan característico del momento y que como hemos comentado, se muestra en diferentes versiones.

La pieza que se presenta (Benéitez et alii, 1999, 33; Fig. 7.3; Montes, 2009: 424-425), exponente de un grupo al que se adscriben otros fragmentos con escaso grado de reintegración, responde, si exceptuamos la presencia extraordinaria del asa y cierta tosquedad en la factura, a esta tipología, caracterizada por los bordes cortos exvasados, los cuerpo ovoides y las bases planas con pie de disco. 


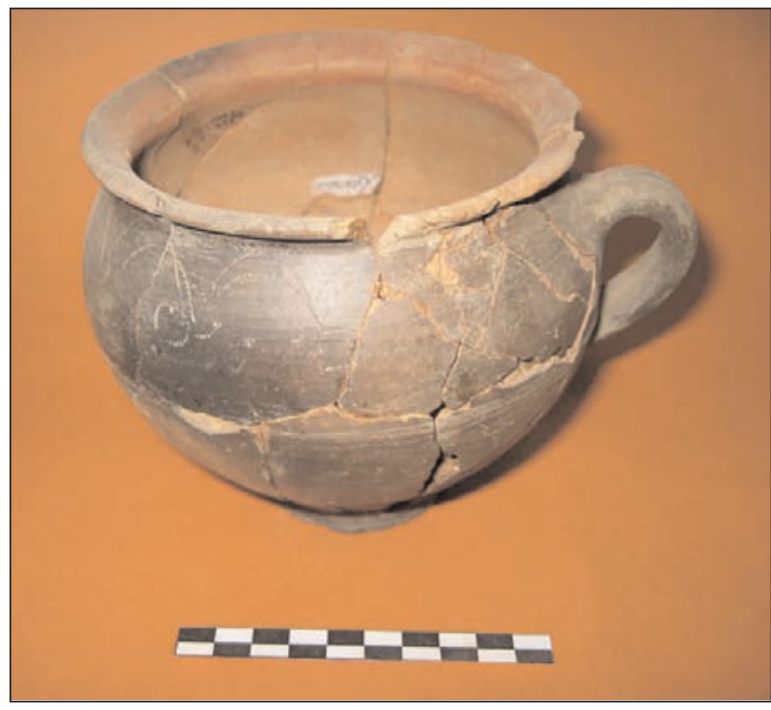

Figura 127. Vaso monoasado con decoración estampillada. Foto: R. Montes

\section{CATÁlOGO}

1. CH.95 /4389: Perfil completo. Borde corto, exvasado, oblicuo y curvo con labio de perfil redondeado. Cuerpo ovoide recorrido por dos acanaladuras poco marcadas en su tramo central. Base plana con pie de disco y fondo interior umbilicado. Asa en $\mathrm{C}$ de sección elipsoidal ligeramente rehundida, que arranca del tercio superior del cuerpo y finaliza en su zona media. Decoración estampillada instalada en el hombro consistente en una banda de arquillos dobles puntillados de los que cuelgan motivos circulares simples también puntillados. Pasta de tonalidad anaranjada con desgrasantes micáceos y cuarcíticos pequeños y medios. Superficie externa bruñida de tonalidad ocre grisácea oscura. El borde y extremo superior de la pared interior presentan engobe rojo. Dimensiones: diámetro borde: $125 \mathrm{~mm}$; diámetro máximo cuerpo: 142 $\mathrm{mm}$; diámetro base: $61 \mathrm{~mm}$; altura: 127 $\mathrm{mm}$; grosor medio sección pared: $6 \mathrm{~mm}$. Bibliografía: Benéitez et alii, 1999: 33, Fig. 7.3; Montes, 2009: Ficha 147, 424-425.

\section{OLLAS BIASADAS}

(Figuras 129 y 130)

Se trata de un tipo de recipiente que, aunque no se muestra excesivamente pródigo en lo tocante a su representación en el yacimiento (Beneitez

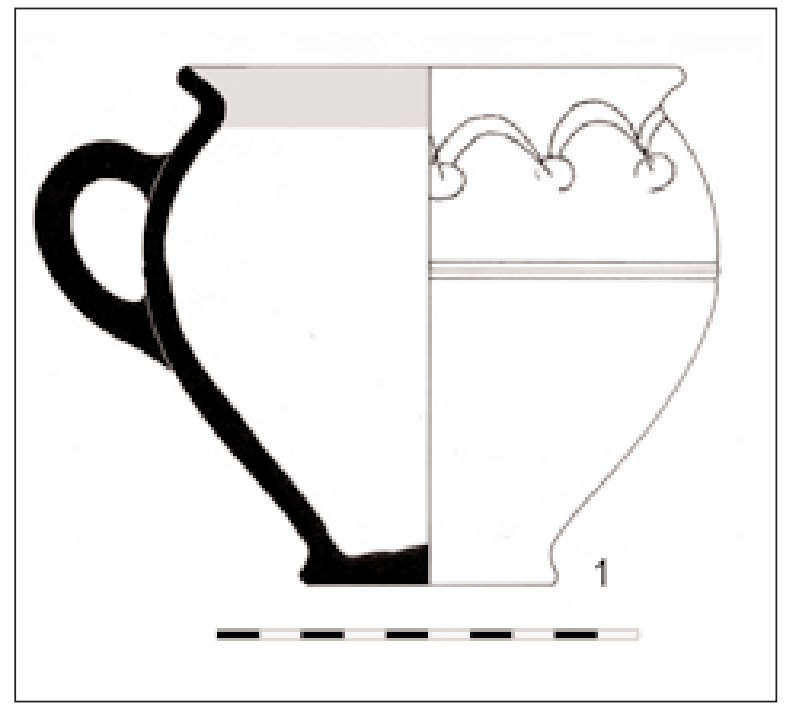

Figura 128. Vaso monoasado con decoración estampillada

et alii, 1999: 33-34; Fig. 8. 1 y 2), sí que se manifiesta como una forma de carácter bien definido que compendia de manera singularmente expresiva las peculiaridades técnicas y decorativas que suelen caracterizar a buena parte de las producciones regionales (Hevia, 2009: 470-471).

En cuanto a sus rasgos morfológicos, se definen por el borde exvasado curvo de perfil cóncavo al interior, el cuello corto curvado, el cuerpo marcadamente globular y la base plana. Uno de los elementos formales definitorios del modelo radica en la presencia de sendas asas en $\mathrm{C}$ de sección arriñonada que arrancan del borde para alcanzar el hombro.

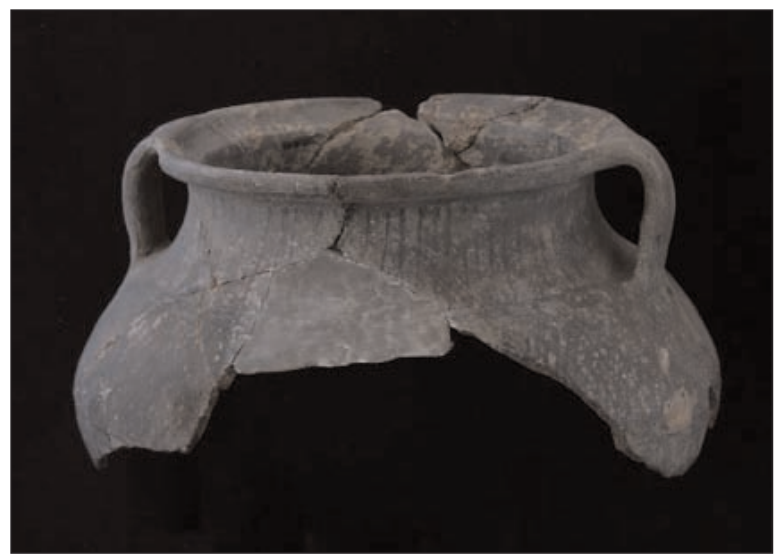

Figura 129. Olla biasada. Foto: J. Arrojo

Estas ollas manifiestan escasa variación dimensional, presentándose como recipientes de capacidad relativamente abundante, con aperturas 
de boca en torno a los $200 \mathrm{~mm}$, diámetros máximos de la panza de unos $260 \mathrm{~mm}$ y alturas que alcanzan aproximadamente $\operatorname{los} 220 \mathrm{~mm}^{125}$.

La decoración se hace omnipresente en estas piezas, siguiendo unas pautas de distribución bastante rígidas. Sendos pares de acanaladuras situados en la zona media de la pared articulan la ornamentación, siempre consistente en líneas bruñidas, en tres espacios:

- Cuello. En este sector se trazan líneas verticales simples que quedan enmarcadas entre el arranque del borde y las acanaladuras superiores.

- Zona media del cuerpo. Retícula romboidal bruñida de trama estrecha y factura bastante cuidada que constituye el cuerpo principal de la decoración, quedando enmarcada entre acanaladuras.

- Parte inferior del galbo. Se repiten nuevamente las líneas verticales que convergen hacia la zona de la base, sin llegar a alcanzarla $^{126}$.

Las pastas en que fueron elaboradas se enmarcan en las típicas regionales de naturaleza cuarzomicácea. De igual modo, las superficies grisáceas y los cuidados acabados avalan su adhesión a la comunidad productiva de las cerámicas regionales y en concreto a una serie de cerámicas grises con decoraciones bruñidas que se extiende a tipos de lo más diverso (Hevia, 2009: 470-471).

La atribución funcional que suponemos, teniendo en consideración la ausencia sistemática de huellas de exposición al fuego, sus dimensiones, su morfología y los cuidados de orden estético que manifiestan, vincula estas piezas con labores de despensa o almacenamiento. En una línea similar se postulan autores como E. Alcorta (Alcorta, 1995: 211) o C. Domergue y Th. Martin (1977: 79), si bien el primero apunta también la remota posibilidad de su empleo en el servicio de mesa (Alcorta, 2001: 250).

${ }^{125}$ En términos generales, estas dimensiones de las piezas del Chao Samartín tienden a resultar algo menores que las de las ollas similares identificadas en Lugo (Alcorta, 2001: 250).
Paralelos para este tipo de ollas han sido documentados en Lugo, entre las piezas del tipo O23, denominadas ollas biasadas de cuerpo sinuoso y decoración espatulada (Alcorta, 2001: 248-250; Fig. 104.2-4). También resultan conocidas en Huerña, donde se les ha aplicado la terminología de ollas con ranura en el borde (Domergue y Martin, 1977: 79; Fig. 20 n 324) y más vagamente, en Conímbriga (Alarcão, 1975: Pl. VI.99 y VII.100).

Las cronologías propuestas para el repertorio lucense, encuadrado entre la segunda y la cuarta centuria (Alcorta, 2001: 250) se ajustan perfectamente a las fechas de los contextos de aparición en el Chao Samartín. En el caso de Huerña, la referencia estratigráfica del ejemplar señalado remite a la denominada capa III, interpuesta entre los dos niveles de hábitat reconocidos y datada entre el 70-75 y el 150-160 d.C, resultando por tanto acorde con las cronologías apuntadas.

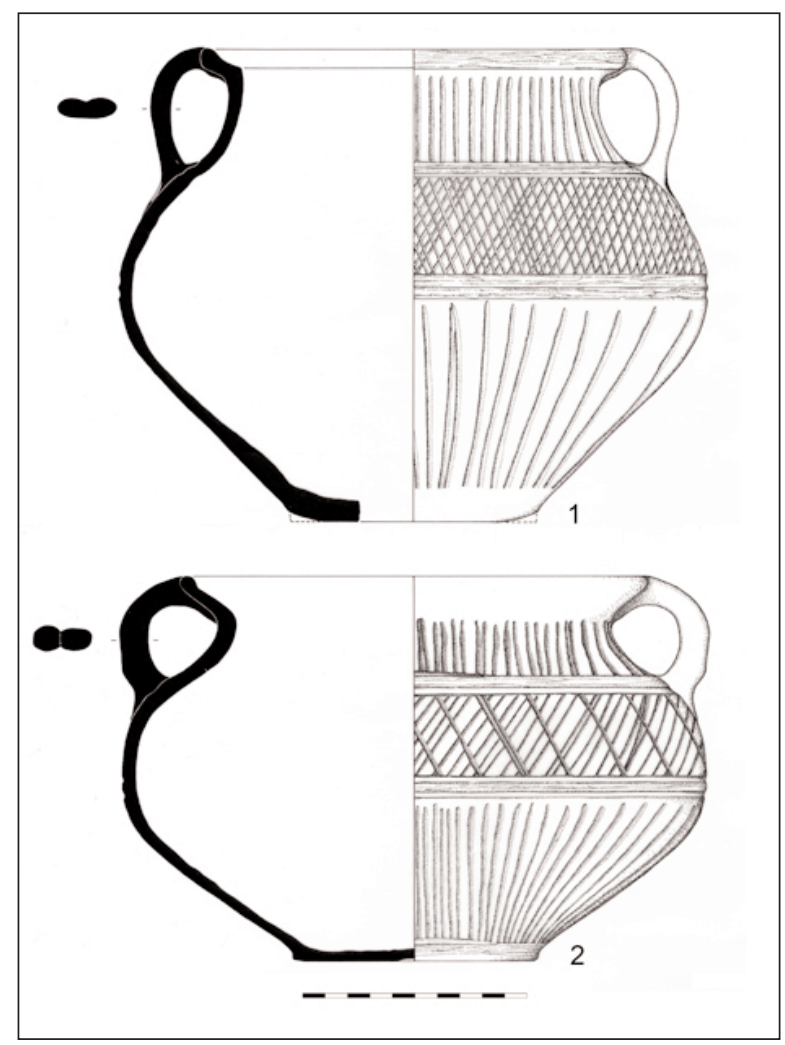

Figura 130. Ollas biasadas

${ }^{126}$ Esta sintaxis decorativa se repite en los paralelos conocidos en Lucus Augusti, a excepción de una pieza (Alcorta, 2001: 249; Fig.104.2), en que la retícula romboidal de la zona central se ve sustituida por líneas simples oblicuas. 


\section{CATÁlogo}

1. CH.95 /1343. Sector C-10. Fragmento de borde, cuerpo, base y asa. Borde exvasado y oblicuo de perfil exterior curvo e interior cóncavo, con labio de sección redondeada. Cuerpo globular recorrido por acanaladuras pareadas en el diámetro máximo de la pared. Base plana en lo conservado. Asa en $\mathrm{C}$ de sección elipsoidal que arranca del borde y alcanza el hombro. Decoración de líneas bruñidas en toda la superficie externa consistente en líneas paralelas verticales en el cuello, reticulado romboidal entre los dos pares de acanaladuras de la mitad superior del cuerpo y líneas verticales convergiendo hacia la base en la mitad inferior. Pasta de tonalidad grisácea zonalmente anaranjada con desgrasantes micáceos pequeños y muy pequeños y cuarcíticos de diversas dimensiones. Superficies de tonalidad gris, con acabado bruñido en la externa y el borde. Dimensiones: diámetro borde: $190 \mathrm{~mm}$; diámetro máximo cuerpo: 264 $\mathrm{mm}$; diámetro base: $110 \mathrm{~mm}$; altura: 212 $\mathrm{mm}$; grosor medio sección pared: $6 \mathrm{~mm}$. Bibliografía: Benéitez et alii, 1999: 3334, Fig. 8.2; Montes, 2009: Ficha 170, 470-471.

2. CH.96 /2670. Sector C-10. Perfil completo. Borde exvasado, oblicuo y de perfil curvo con labio de perfil redondeado. Cuerpo globular recorrido por acanaladuras pareadas en y diámetro máximo de la pared. Base plana. Asa en $\mathrm{C}$ de sección arriñonada que arranca del borde y alcanza el hombro. Decoración de líneas bruñidas en toda la superficie externa consistente en líneas paralelas verticales en el cuello, un reticulado configurado por líneas oblicuas cruzadas por otras más gruesas y espaciadas entre los dos pares de acanaladuras de la mitad superior del cuerpo y líneas verticales convergiendo hacia la base en la mitad inferior. Pasta de tonalidades grisáceas y anaranjadas con desgrasantes micáceos pequeños y muy pequeños y cuarcíticos de diversas dimensiones. Superficie externa de tonalidad gris, con acabado bruñido que se extiende al borde. Superficie interna gris en la parte superior y anaranjada en el resto. Dimensiones: diámetro borde: $210 \mathrm{~mm}$; diámetro máximo cuerpo: $262 \mathrm{~mm}$; diámetro base: 110 $\mathrm{mm}$; altura: $215 \mathrm{~mm}$; grosor medio sección pared: $6 \mathrm{~mm}$. Bibliografía: Benéitez et alii, 1999: 33-34, Fig. 8.1.

\section{CAZUELAS BAJAS DE FONDO PLANO (Figuras 131 y 132)}

El tipo, cuyas particularidades ya han sido explicadas de manera pormenorizada al presentar las piezas documentadas en contextos del siglo I d.C. (figuras 59 y 60), alcanza en estas fechas avanzadas una representación porcentual en los ajuares muy destacada, hasta el punto de convertirse en una de las tipologías más frecuentes y representativas.

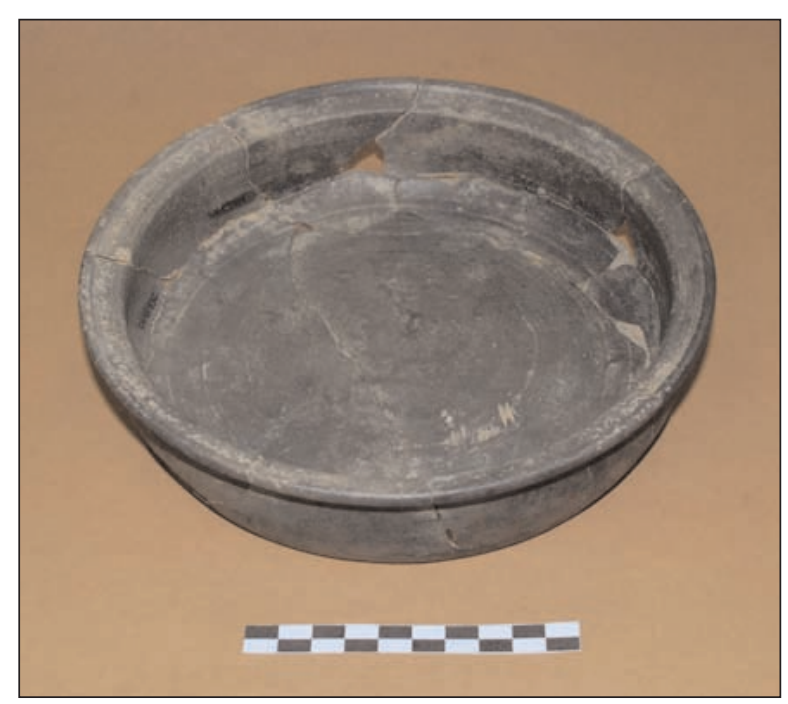

Figura 131. Cazuela de fondo plano. Foto: R. Montes

En el estado actual de conocimientos no es posible establecer en el Chao Samartín una evolución morfológica entre los ejemplares de la primera centuria y los del siglo II d.C., si bien entre estos últimos se observa una estandarización mucho mayor y una menor variabilidad en la altura de las paredes. A diferencia de lo que acontece en Lugo, en donde los recipientes del tipo parecen alcanzan su mayor éxito en momentos tempranos (Alcorta, 2001: 124-125, Fig.55), los conjuntos cerámicos de yacimiento en su fase de abandono registran sin excepción ejemplos de esta forma. 

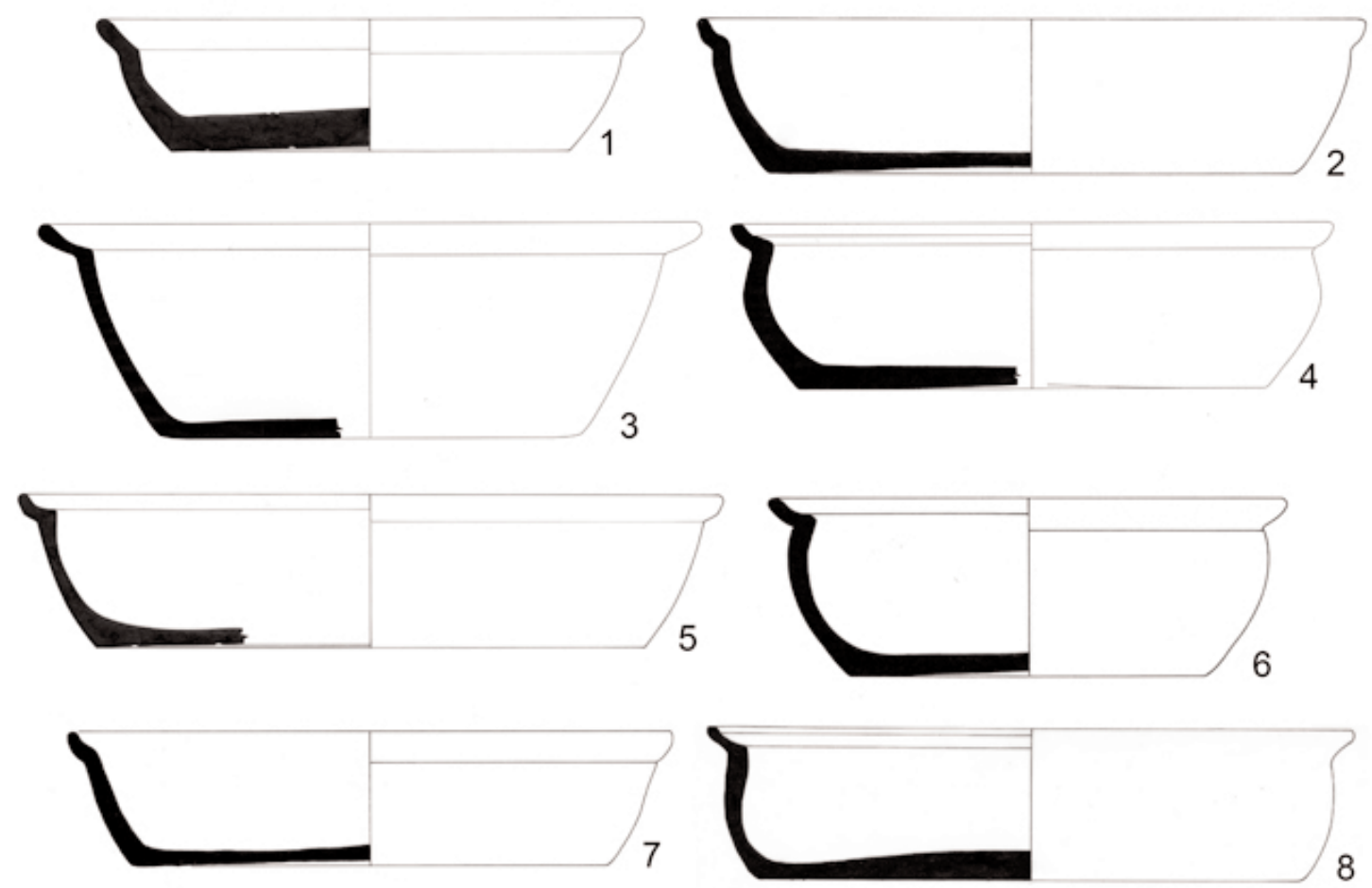

Figura 132. Cazuelas de fondo plano

\section{CATÁlogo}

1. CH.99 /6328. Sector C-17 C. Perfil completo. Borde exvasado oblicuo de perfil curvo al exterior y ligeramente cóncavo al interior con labio de perfil redondeado. Pared corta, oblicua y curva. Base plana surcada en el fondo interno por dos acanaladuras en la zona intermedia y en el externo por otras dos, una perimetral. Pasta de tonalidad pardo grisácea con desgrasantes micáceos pequeños y muy pequeños y cuarcíticos pequeños y medianos. Superficies grises oscuras, excepto el fondo externo, que presenta tonalidades pardo anaranjadas. Acabado bruñido. Dimensiones: diámetro borde: $174 \mathrm{~mm}$; diámetro base: $126 \mathrm{~mm}$; altura: $42 \mathrm{~mm}$; grosor medio sección pared: $7 \mathrm{~mm}$. Bibliografía: Inédita.

2. CH.96 /2663. Sector C-10 B. Perfil completo. Borde exvasado oblicuo de perfil curvo al exterior y cóncavo al interior con labio de perfil redondeado. Pared corta, oblicua y curva. Base plana. Pasta grisácea con abundantes micas muy pequeñas y alguna mediana y cuarzos y cuarcitas pequeños y medianos. Superficies grises con tosco acabado bruñido. Dimensiones: diámetro borde: $194 \mathrm{~mm}$; diámetro base: $152 \mathrm{~mm}$; altura: $43 \mathrm{~mm}$; grosor medio sección pared: $6 \mathrm{~mm}$. Bibliografía: Hevia et alii, 2001: 158-161, Fig. 1.7; Hevia, 2009: Ficha 162, 454-455.

3. CH.96 /0070. Sector R-V. Fragmento de borde, cuerpo y base. Borde exvasado, oblicuo y de perfil curvo con labio de perfil redondeado. Pared más alta de lo habitual en el tipo, oblicua y curva. Base plana. Pasta de tonalidad pardo grisácea con desgrasantes cuarcíticos de todos los tamaños y micáceos pequeños. Superficies grises oscuras bruñidas. Dimensiones: diámetro borde: $224 \mathrm{~mm}$; diámetro base: $142 \mathrm{~mm}$; altura: $71 \mathrm{~mm}$; grosor medio sección pared: 5 mm. Bibliografía: Inédita.

4. CH.95 /1308. Sector C-10 B. Perfil completo. Borde exvasado oblicuo de perfil curvo al exterior y cóncavo al interior con 
labio de perfil redondeado. Pared corta, oblicua y curva. Base plana. Pasta de tonalidad grisácea con abundantes desgrasantes cuarcíticos y esquistosos pequeños y medianos y micas pequeñas. Superficies grises toscamente bruñidas. Dimensiones: diámetro borde: $203 \mathrm{~mm}$; diámetro base: $160 \mathrm{~mm}$; altura: $56 \mathrm{~mm}$; grosor medio sección pared: $8 \mathrm{~mm}$. Bibliografía: Hevia et alii, 2001: 158-161, Fig. 1.4.

5. CH.01/3024. Sector C-17 C. Fragmento de borde, cuerpo y base. Borde exvasado oblicuo de perfil curvo al exterior y cóncavo al interior con labio de perfil redondeado. Pared corta, oblicua y curva. Base plana recorrida en su fondo externo por sendas acanaladuras. Pasta de tonalidad pardo grisácea con abundantes desgrasantes cuarcíticos y esquistosos de diversas dimensiones y micáceos menudos. Superficie externa de color entre pardo grisáceo y anaranjado e interna gris oscura. Acabado bruñido, más tosco al interior. Dimensiones: diámetro borde: $224 \mathrm{~mm}$; diámetro base: $174 \mathrm{~mm}$; altura: $49 \mathrm{~mm}$., grosor medio sección pared: $4.5 \mathrm{~mm}$. Bibliografía: Inédita.

6. CH.95 /0472. Sector C-10 A. Perfil completo. Borde exvasado oblicuo de perfil curvo al exterior y cóncavo al interior con labio de perfil redondeado. Pared corta, ligeramente oblicua y curva. Base plana. Pasta de tonalidad grisácea o anaranjada según zonas con abundantes desgrasantes cuarcíticos y esquistosos pequeños y medianos y micáceos pequeños. Superficies bruñidas de tonalidad gris zonalmente ennegrecidas por la exposición al fuego. Una parte de la pieza presenta tonalidades rojizas. El fondo externo presenta una parrilla de líneas espatuladas. Dimensiones: diámetro borde: $175 \mathrm{~mm}$; diámetro base: $120 \mathrm{~mm}$; altura: $60 \mathrm{~mm}$., grosor medio sección pared: $6 \mathrm{~mm}$. Bibliografía: Hevia et alii, 2001: 158-161, Fig. 1.5; Hevia, 2009: Ficha 162, 454-455.

7. CH.95 /1980. Sector C-10. Perfil completo. Borde exvasado oblicuo de perfil biselado al exterior y cóncavo al interior con labio de perfil redondeado. Pared corta, oblicua y ligeramente curva. Base plana. Pasta de tonalidad grisácea con abundantes desgrasantes cuarcíticos pequeños y medianos y micas y esquistos en menor proporción. Superficies grises bruñidas con una parrilla de líneas espatuladas en el fondo exterior. Dimensiones: diámetro borde: $212 \mathrm{~mm}$; diámetro base: $168 \mathrm{~mm}$; altura: $49 \mathrm{~mm}$; grosor medio sección pared: $6 \mathrm{~mm}$. Bibliografía: Hevia et alii, 2001: 158-161, Fig. 1.8; Hevia, 2009: Ficha 162, 454-455.

8. CH.95 /0685. Sector C-10 A. Perfil completo. Borde exvasado oblicuo de perfil curvo al exterior y cóncavo al interior con labio de perfil redondeado. Pared corta, vertical y ligeramente curva. Base plana de fondo interno convexo y externo recorrido por una acanaladura central y otras dos perimetrales. Pasta pardo grisácea con desgrasantes micáceos y cuarcíticos pequeños y medianos. Superficies bruñidas de tonalidad gris oscura. Dimensiones: diámetro borde: $206 \mathrm{~mm}$; diámetro base: $174 \mathrm{~mm}$; altura: $49 \mathrm{~mm}$; grosor medio sección pared: $5.5 \mathrm{~mm}$. Bibliografía: Hevia et alii, 2001: 158-161, Fig. 1.6; Hevia, 2009: Ficha 162, 454-455.

\section{CAZUELAS MONOASADAS}

(Figuras 133-134)

En primer lugar, resulta necesario abordar el tema de la designación elegida para hacer referencia al morfotipo, toda vez que varía respecto a la utilizada en anteriores publicaciones. En efecto, piezas adscritas a esta morfología fueron denominadas en su día ollas globulares monoasadas (Hevia et alii, 2001: 161-164, Fig. 2.18-23; Montes et alii, 2001) y, más recientemente, ollas monoasadas (Hevia, 2009: 466-467). Sin embargo, la aplicación del término olla no parece resultar adecuada para el caso de estas vasijas en las que la relación dimensional entre embocadura, diámetro máximo y altura no se ajusta a la convención habitual para la definición de las ollas. De igual modo, el perfil troncocónico se ajusta más a la realidad de las piezas que la calificación de globulares. 
El tipo engloba un grupo de piezas cuyo diseño formal común remite a recipientes de borde exvasado oblicuo rematados en labios redondeados y con perfil interior recto. La posesión de una única asa en $\mathrm{C}$ que se ubica hacia la zona media de la pieza le confiere igualmente una de sus características definitorias. Las bases se presentan siempre planas, resultando este rasgo morfológico de crucial importancia, no sólo para la asignación del morfotipo a la vajilla de cocina, sino también para la propia diferenciación de piezas, ya que la semejanza formal con tipos de mesa como los tazones monoasados en su variante globular imposibilita, en ausencia de las bases, una discriminación cierta. En los fondos externos es frecuente toparse con una serie de líneas espatuladas verticales y horizontales dispuestas a modo de parrilla, que parece responder más a intenciones funcionales que estéticas. Por lo que respecta al perfil del galbo, constituye el rasgo que experimenta mayores variaciones, aunque el dibujo arquetípico es el de recipientes de perfiles curvos más o menos troncocónicos con bases bastante amplias en relación con el diámetro de sus bordes (Hevia, 2009: 466-467). Éstos alcanzan dimensiones que se mantienen entre los 140 y $175 \mathrm{~mm}$, mientras que las bases se sitúan entre los 80 y los 95 mm. El diámetro máximo del galbo ronda los mismos valores que los de la boca y las alturas oscilan entre los 110 y los $130 \mathrm{~mm}$, conformando conjuntamente unos recipientes bastante profundos y de capacidad media.

A pesar de esta relativa variabilidad formal el tipo reafirma su condición de tal a partir de argumentos de índole técnica y ornamental. Una característica fundamental es el desarrollo de una banda decorada de anchura variable, aunque generalmente no demasiado amplia, en la zona central del cuerpo (extraordinariamente en la central-superior o ampliada hacia la parte inferior), delimitada por acanaladuras y ocupada por cuidados ornatos compuestos de retículas

${ }^{127}$ Ejemplos de decoraciones semejantes las encontramos, sobre tipologías bien diferentes, entre algunas piezas de

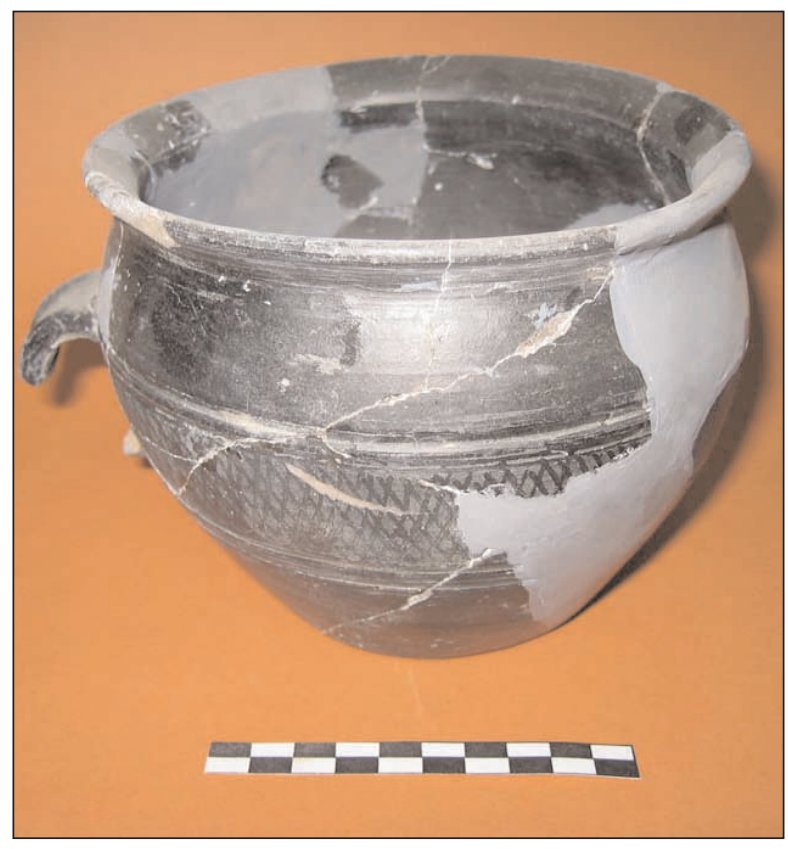

Figura 133. Cazuela monoasada. Foto: R. Montes

romboidales de líneas bruñidas. El modelo más frecuente lo constituyen los típicos reticulados de trama estrecha, aunque ocasionalmente se registran composiciones de líneas diagonales cruzadas por otras más gruesas y distantes componiendo una peculiar retícula ${ }^{127}$.

En lo que se refiere al tratamiento específico de las superficies, hay que destacar el bruñido más o menos cuidado del borde y la cara externa de todas las piezas. Es precisamente este último aspecto el que invita a poner en cuestión la inserción del tipo en la vajilla de cocina asociada a procesos culinarios en caliente, si bien la habitual documentación de vestigios de carbonización en las superficies externas y la naturaleza de las bases así parecen indicarlo.

El hipotético vínculo genético propuesto entre estas piezas del siglo II d.C. y las homónimas referidas al analizar la vajilla del siglo I d.C., con las que mantienen ciertas semejanzas, palia en cierta medida la completa ausencia de paralelos formales entre los repertorios regionales conocidos. 


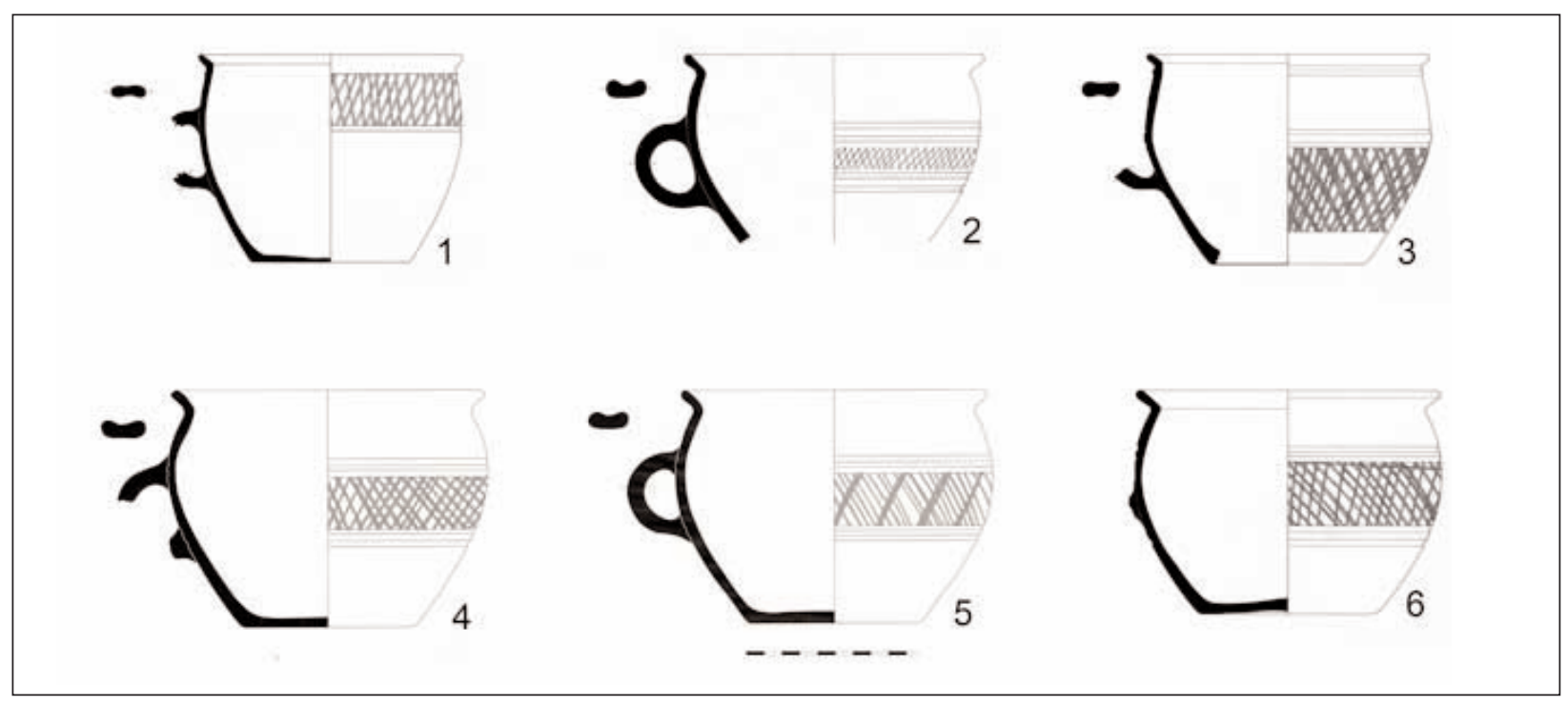

Figura 134. Cazuelas monoasadas

\section{CATÁlogo}

1. CH.99/3385. Sector C-12. Perfil completo. Borde corto, exvasado, oblicuo y recto al interior con labio de perfil redondeado. Cuerpo curvo de perfil troncocónico recorrido en la parte superior de su carta externa por una pequeña arista de sección triangular y más abajo, por una acanaladura. Base plana. Asa en $\mathrm{C}$ de sección elipsoidal. Decoración en una banda de $26 \mathrm{~mm}$ de ancho delimitada por la arista y la acanaladura referidas situada en el extremo superior del cuerpo y consistente en una retícula bruñida romboidal de trama estrecha. Pasta de tonalidad grisácea con desgrasantes micáceos y cuarcíticos y esquistosos pequeños y medianos. Superficies negras con acabado bruñido en la externa, el borde y la parte superior de la interna. Dimensiones: diámetro borde: $140 \mathrm{~mm}$; diámetro máximo cuerpo: $138 \mathrm{~mm}$; diámetro base: $83 \mathrm{~mm}$; altura: $110 \mathrm{~mm}$; grosor medio sección pared: $3.5 \mathrm{~mm}$. Bibliografía: Inédita.

2. CH.99 /0672. Sector C-7. Fragmento de borde, cuerpo y asa. Borde exvasado, oblicuo y recto al interior con labio de perfil redondeado. Cuerpo curvo de perfil troncocónico recorrido en su cara externa por sendos pares de acanaladuras. Asa en $\mathrm{C}$ de sección elipsoidal rehundida al exterior situada en la zona central de la pared. Decoración en una banda de $16 \mathrm{~mm}$ de ancho delimitada por las referidas acanaladuras situada hacia la mitad del cuerpo y consistente en una retícula bruñida romboidal de trama estrecha. Pasta de tonalidad grisácea con desgrasantes micáceos y cuarcíticos pequeños y medianos (alguno grande). Superficies negras con acabado bruñido en la externa, el borde y la parte superior de la interna. En el resto de la cara interna resultan visibles las estrías del torneado. Restos de hollín en la cara externa. Dimensiones: diámetro borde: $158 \mathrm{~mm}$; diámetro máximo cuerpo: $156 \mathrm{~mm}$; altura conservada: $100 \mathrm{~mm}$; grosor medio sección pared: $5 \mathrm{~mm}$. Bibliografía: Inédita.

3. CH.99/0295. Sector C-12 B. Fragmento de borde y cuerpo. Borde corto, exvasado, oblicuo y recto al interior con labio de perfil redondeado. Cuerpo curvo de perfil troncocónico recorrido en su cara externa por un par de acanaladuras. Conserva el arranque de un asa en $\mathrm{C}$ de sección elipsoidal. Decoración situada en la mitad inferior del cuerpo, en una banda de $47 \mathrm{~mm}$ de ancho delimitada en su parte superior por las referidas acanaladuras y por una banda bruñida en la inferior y consistente en una retícula bruñida romboidal de trama estrecha. Pasta de tonalidad grisácea con desgrasantes micáceos y cuarcíticos pequeños 
y medianos. Superficies negras con acabado bruñido en la externa, el borde y la parte superior de la interna. En el resto de la cara interna resultan visibles las estrías del torneado. Dimensiones: diámetro borde: 150 $\mathrm{mm}$; diámetro máximo cuerpo: $152 \mathrm{~mm}$; diámetro base: $80 \mathrm{~mm}$; altura: $110 \mathrm{~mm}$; grosor medio sección pared: $4 \mathrm{~mm}$. Bibliografía: Inédita.

4. CH.95 /1108. Sector C-10. Perfil completo. Borde exvasado, oblicuo y recto al interior, con labio de perfil redondeado. Cuerpo curvo de perfil troncocónico recorrido al exterior por sendos pares de acanaladuras. Base plana con parrilla espatulada en fondo exterior. Asa, de la que se conservan los arranques, con perfil en $\mathrm{C}$ y sección elipsoidal ligeramente rehundida. Decoración en una banda de $28 \mathrm{~mm}$ de ancho delimitada por las referidas acanaladuras situada en la mitad superior del cuerpo y consistente en una retícula bruñida romboidal de trama estrecha. Pasta de tonalidad grisácea con desgrasantes micáceos pequeños y muy pequeños y cuarcíticos pequeños y medios. Superficies de tonalidad negra con fino acabado bruñido exterior, en el borde e inicio de la pared interior. Dimensiones: diámetro borde: $164 \mathrm{~mm}$; diámetro máximo cuerpo: $168 \mathrm{~mm}$; diámetro base: $90 \mathrm{~mm}$; altura: $124 \mathrm{~mm}$; grosor medio sección pared: $4 \mathrm{~mm}$. Bibliografía: Hevia et alii, 2001: 161-164, Fig. 2.19; Hevia, 2009: Ficha 168 , 466-467.

5. CH.95 /0948. Sector C-10 A. Perfil completo. Borde exvasado, oblicuo, de perfil recto, con labio de perfil redondeado. Cuerpo curvo de perfil troncocónico recorrido por sendos pares de acanaladuras. Base plana con parrilla espatulada en fondo exterior. Asa con perfil en C y sección elipsoidal ligeramente rehundida. Decoración en una banda de $30 \mathrm{~mm}$ de ancho situada en la mitad superior del cuerpo delimitada por las referidas acanaladuras consistente en líneas bruñidas oblicuas cruzadas, en sentido contrario, por otras más anchas y espaciadas. Pasta de tonalidad grisácea con desgrasantes micáceos pequeños y muy pequeños y cuarcíticos pequeños y medios. Superficies de tonalidad negra con fino acabado bruñido exterior, en el borde e inicio de la pared interior. Dimensiones: diámetro borde: $172 \mathrm{~mm}$; diámetro máximo cuerpo: $180 \mathrm{~mm}$; diámetro base: $96 \mathrm{~mm}$; altura: $131 \mathrm{~mm}$; grosor medio sección pared: $5 \mathrm{~mm}$. Bibliografía: Hevia et alii, 2001: 161-164, Fig. 2.18; Hevia, 2009: Ficha 168, 466-467.

6. CH.02 /0578. Sector C-17 C. Perfil completo. Borde exvasado, oblicuo y recto al interior con labio de perfil redondeado. Cuerpo curvo de perfil troncocónico recorrido en su carta externa por sendos pares de acanaladuras. Base ligeramente convexa al exterior con parrilla espatulada en fondo exterior. Conserva el arranque de un asa en C. Decoración en una banda de $34 \mathrm{~mm}$ de ancho delimitada por las referidas acanaladuras situada hacia la mitad del cuerpo y consistente en una retícula bruñida romboidal de trama estrecha. Pasta de tonalidad grisácea con desgrasantes micáceos y cuarcíticos pequeños y medianos. Superficies negras con acabado bruñido en la externa, el borde y la parte superior de la interna. En el resto de la cara interna resultan visibles las estrías del torneado. Dimensiones: diámetro borde: $160 \mathrm{~mm}$; diámetro máximo cuerpo: $162 \mathrm{~mm}$; diámetro base: $94 \mathrm{~mm}$; altura: $118 \mathrm{~mm}$; grosor medio sección pared: $4.5 \mathrm{~mm}$. Bibliografía: Inédita.

\section{OLLAS DE BORdE CÓNCAVO} (Figuras 135 y 136)

Las ollas de borde cóncavo constituyen un tipo formal que, aunque remite genéricamente a una morfología habitual en los repertorios clási$\cos$ de época altoimperial, recogida por $\mathrm{M}$. Vegas en el grupo $1 \mathrm{~A}$, incluido entre las ollas con ranura en el borde (Vegas, 1973: 14, Fig. 3.12 a 15), en su formulación regional más particular circunscribe su presencia a un entorno reducido al territorio más próximo. A pesar de la indudable raigambre latina del tipo, manifestada en su documentación, entre otros, en yacimientos de la Campania (Di Giovanni, 1996: 93, fig. 
20) y en Herculano (Scatozza, 1996: 136, Fig. 2, 7-8) y en su difusión en la Península Ibérica desde época augustea (Beltrán, 1990: 201; Vegas, 1973: 14, Fig. 3, 12-15), los paralelos concretos resultan bastante limitados. De hecho, tan sólo se pueden rastrear semejanzas estrictas en Lugo (Alcorta, 2001: 97-99 y 199-200, Fig. 43 y 83.1-5), entre las ollas del tipo O3 y de forma más inconcreta, entre las del tipo L5 de la primera centuria, y en los castros de Viladonga (Arias, 1985: lám. 28), Zoñán (Vigo, 2007: 191194) ${ }^{128}$ y Taramundi (Expósito, 2004).

La cohesión grupal se concreta en lo formal en un peculiar perfil acusadamente globular que remata en un borde exvasado y oblicuo con perfil cóncavo al interior adaptado para la recepción de una tapadera y cuenta con base plana. Se detectan ciertas diferencias en los desarrollos del galbo, de tal modo que junto a los ejemplares más típicos, de perfil netamente globular y achatado, se identifican otros más estilizados. Son frecuentes las acanaladuras en el tercio superior de la superficie externa del cuerpo, sirviendo en ocasiones de delimitación de un campo decorativo. La presencia de una única asa en $\mathrm{C}$, que suele arrancar del borde para alcanzar la zona de diámetro máximo, donde ocasionalmente presenta una digitación, constituye otro de los rasgos morfológicos típicos.

Estas ollas presentan unas dimensiones relativamente modestas con diámetros que en el borde oscilan entre 110 y $140 \mathrm{~mm}$ para alcanzar los 145-180 mm en el punto de desarrollo máximo del cuerpo y reducirse a valores que fluctúan entre los 60 y los $80 \mathrm{~mm}$ en las bases ${ }^{129}$. Ciertas pequeñas diferencias en la relación entre los diámetros de la base y el borde, que se mantiene por norma general en torno a una relación $1: 2$, pero que en algunos casos se aproximan a $1: 1.5$, introducen parte de la variabilidad de perfiles apuntada con anterioridad.

\footnotetext{
128 Tipo cerrados-07.

${ }^{129}$ De esta norma se escapa algún ejemplar aislado que cuenta con un tamaño sensiblemente mayor.

${ }^{130}$ Ver comentarios alusivos a los ejemplares registrados en
}

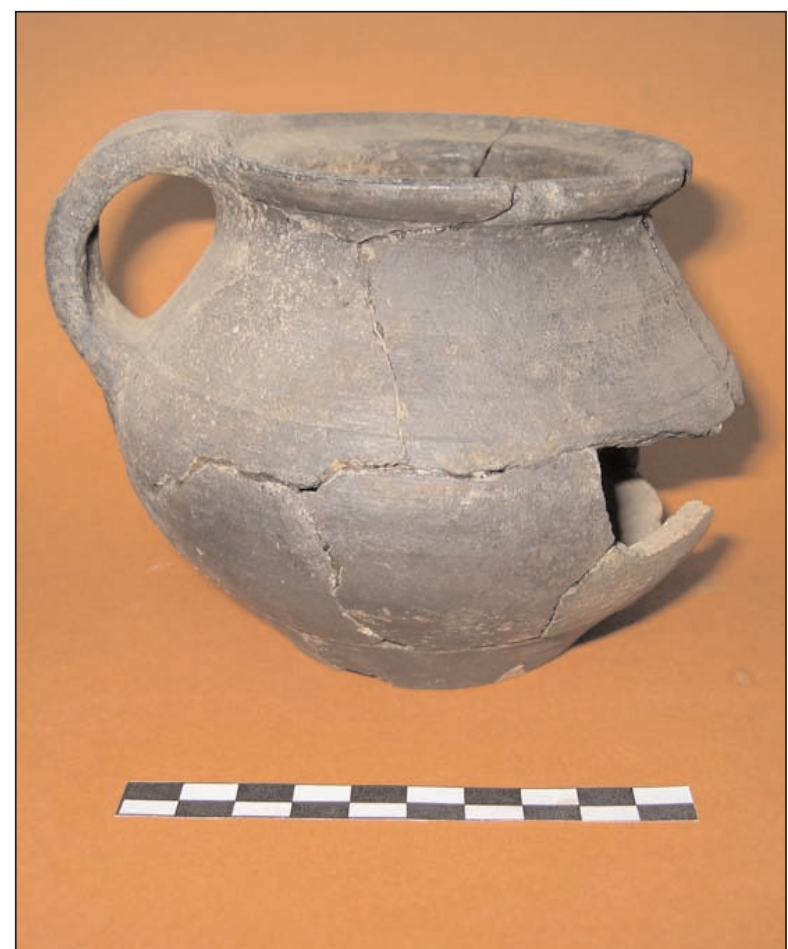

Figura 135. Olla de borde cóncavo. Foto: R. Montes

Por lo que respecta a los aspectos técnicos, la norma habitual son los acabados alisados o bruñidos más o menos toscos (Hevia, 2009: 460461 y 464-465). Las pastas suelen ser groseras, de naturaleza cuarzo-micácea o esquistosa según los casos (Hevia et alii, 2001: 164-170; Fig. 2-4).

Cierto porcentaje de ejemplares, seguramente menor que el original debido al destacado desgaste de las superficies por la acción del fuego inherente a su función culinaria, conservan decoraciones de líneas verticales bruñidas que se plasman en la parte central e inferior de la cara externa del cuerpo, siempre por debajo de las acanaladuras en aquellos casos en que dispone de ellas.

La cronología de fabricación del tipo arranca en la primera centuria, tal y como queda atestiguado no sólo en el Chao Samartín ${ }^{130}$, sino también en $\operatorname{Lugo}{ }^{131}$.

contextos del siglo I d.C. en el apartado correspondiente.

${ }^{131}$ El tipo L5, emparentable con nuestras piezas, remonta sus orígenes a estas datas (Alcorta, 2001: 97-99, Fig. 43). 


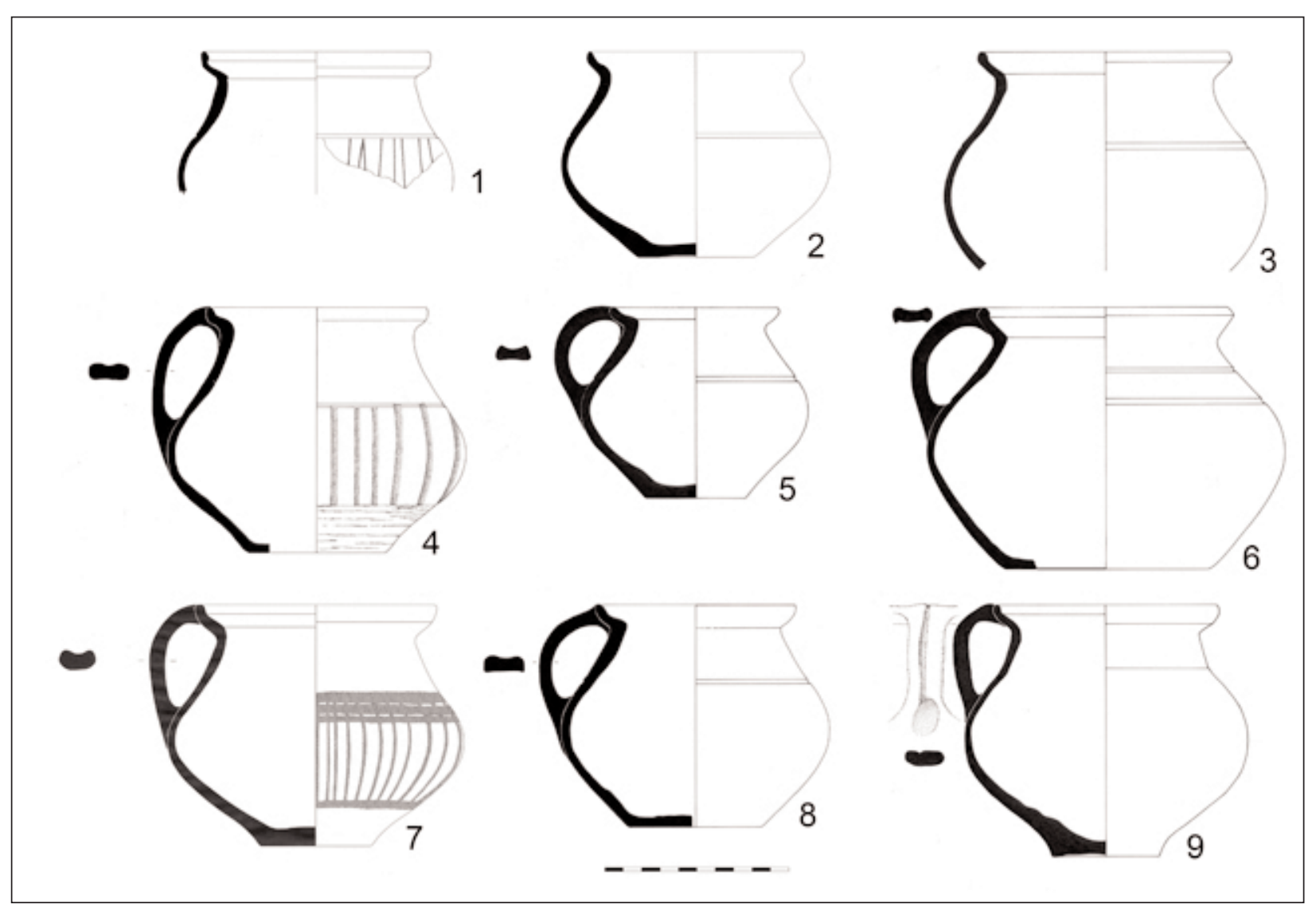

Figura 136. Ollas de borde cóncavo

\section{CATÁlogo}

1. CH.96 /0058. Sector R-V. Fragmento de borde y cuerpo. Borde exvasado oblicuo de perfil biselado al exterior y cóncavo al interior con labio engrosado de perfil redondeado. Cuerpo globular en lo conservado recorrido por una acanaladura en su tercio superior. Decoración de finas líneas verticales bruñidas de factura y disposición irregulares bajo la referida acanaladura. Pasta grisácea con desgrasantes micáceos, esquistosos y cuarcíticos de diversas dimensiones. Superficies grises, la externa alisada. Dimensiones: diámetro borde: $126 \mathrm{~mm}$; diámetro máximo cuerpo: $152 \mathrm{~mm}$; altura conservada: $78 \mathrm{~mm}$; grosor medio sección pared: $4.5 \mathrm{~mm}$. Bibliografía: Inédita

2. CH.95/2510. Sector C-10 A. Perfil completo. Borde exvasado oblicuo, de perfil biselado al exterior y cóncavo al interior con labio de perfil apuntado. Cuerpo globular achatado con acanaladura en la mitad superior. Base plana. Pasta grisácea con desgrasantes esquistosos y cuarcíticos pequeños y media- nos. Somero alisado exterior. Dimensiones: diámetro borde: $117 \mathrm{~mm}$; diámetro máximo cuerpo: $148 \mathrm{~mm}$; diámetro base: $64 \mathrm{~mm}$; altura: $114 \mathrm{~mm}$; grosor medio sección pared: $4 \mathrm{~mm}$. Bibliografía: Hevia et alii, 2001: 164-170, Fig. 3.29.

3. CH.95 /1814. Sector C-10 A. Fragmento de borde y cuerpo. Borde exvasado oblicuo, de perfil biselado al exterior y cóncavo al interior con labio de perfil redondeado. Cuerpo globular recorrido por una acanaladura en su parte superior. Pasta grisácea con desgrasantes esquistosos y cuarcíticos. Superficies grises con somero alisado exterior. Dimensiones: diámetro borde: $140 \mathrm{~mm}$; diámetro máximo cuerpo: $180 \mathrm{~mm}$; altura conservada: $120 \mathrm{~mm}$; grosor medio sección pared: $5 \mathrm{~mm}$. Bibliografía: Hevia et alii, 2001: 164-170, Fig. 4.38.

4. CH.95 /1791. Sector C-10. Perfil completo. Borde exvasado oblicuo, de perfil biselado al exterior y cóncavo al interior con labio de perfil redondeado. Cuerpo globular achatado recorrido al exterior por una acanaladura. 
Asa en C de sección rectangular con acanaladura, que arranca del borde y llega a la zona media del cuerpo. Base plana. Banda decorada de $55 \mathrm{~mm}$ de ancho de líneas bruñidas verticales delimitada por la referida acanaladura en su parte superior. Pasta grisácea con desgrasantes cuarcíticos y esquistosos de variadas dimensiones. Superficies negruzcas con tosco acabado bruñido externo $\mathrm{y}$ en la parte superior interna. Dimensiones: diámetro borde: $122 \mathrm{~mm}$; diámetro máximo cuerpo: $165 \mathrm{~mm}$; diámetro base: $76 \mathrm{~mm}$; altura: $135 \mathrm{~mm}$; grosor medio sección pared: $4.5 \mathrm{~mm}$. Bibliografía: Hevia et alii, 2001: 164-170, Fig. 4.46. Hevia, 2009: Ficha 165, 460-461.

5. CH.95/4380. Sector C-10. Perfil completo. Borde exvasado oblicuo, de perfil curvo al exterior y ligeramente cóncavo al interior con labio de perfil redondeado. Cuerpo globular achatado surcado por una acanaladura. Asa en $\mathrm{C}$ de sección plana, rehundida al exterior, que arranca del labio y reposa en la zona media del cuerpo. Base plana. Pasta grisácea con abundantes desgrasantes esquistosos, cuarcíticos y micáceos de tamaño diverso. Bruñido externo. Dimensiones: diámetro borde: $93 \mathrm{~mm}$; diámetro máximo cuerpo: $125 \mathrm{~mm}$; diámetro base: $55 \mathrm{~mm}$; altura: $105 \mathrm{~mm}$; grosor medio sección pared: $5 \mathrm{~mm}$. Bibliografía: Hevia et alii, 2001: 164-170, Fig. 3.31; Hevia, 2009: Ficha 165, 460-461.

6. CH.96 /3818. Sector C-10. Perfil completo. Borde exvasado oblicuo de perfil cóncavo al interior con labio de perfil redondeado. Cuerpo globular achatado con acanaladura en la mitad superior. Asa en $C$ de sección subrectangular rehundida al exterior que arranca directamente sobre el labio y se apoya sobre la zona central del cuerpo. Base plana. Pasta de tonalidad grisácea con abundantes desgrasantes esquistosos medianos y grandes y alguno cuarcítico. Superficies negruzcas con acabado alisado al exterior. Dimensiones: diámetro borde: $110 \mathrm{~mm}$; diámetro máximo cuerpo: $149 \mathrm{~mm}$; diámetro base: $73 \mathrm{~mm}$; altura: $123 \mathrm{~mm}$; grosor medio sección pared: $4.5 \mathrm{~mm}$. Bibliografía: Hevia et alii, 2001: 164-170, Fig. 3.30.
7. CH.95 /1104. Sector C-10. Perfil completo. Borde exvasado oblicuo, de perfil curvo al exterior y ligeramente cóncavo al interior con labio de perfil redondeado resaltado al interior. Cuerpo globular achatado. Asa en C de sección elipsoidal rehundida al exterior. Base plana. Decoración configurada por una serie de líneas verticales, enmarcadas entre líneas horizontales (tres arriba y una abajo). Pasta grisácea con desgrasantes cuarcíticos y esquistosos pequeños y micáceos muy pequeños. Acabado bruñido exterior y en borde y parte superior interna. Dimensiones: diámetro borde: $132 \mathrm{~mm}$; diámetro máximo cuerpo. $161 \mathrm{~mm}$; diámetro base: $60 \mathrm{~mm}$; altura; $130 \mathrm{~mm}$; grosor medio sección pared: $4 \mathrm{~mm}$. Bibliografía: Hevia et alii, 2001: 164-170, Fig. 2.24.

8. CH.95/1585. Sector C-10 A. Fragmento de borde, cuerpo y base. Borde exvasado oblicuo, de perfil biselado al exterior y cóncavo al interior con labio de perfil redondeado. Cuerpo globular achatado recorrido por dos acanaladuras en su tercio superior. Asa en $\mathrm{C}$ de sección subrectangular, ligeramente rehundida, que arranca del borde y llega a la zona media del cuerpo. Base plana en lo conservado. Pasta de tonalidad grisácea con abundantes esquistos pequeños y medios y algunos desgrasantes cuarcíticos pequeños. Acabado bruñido en fondo exterior y parte inferior del cuerpo. Dimensiones: diámetro borde: $144 \mathrm{~mm}$; diámetro máximo cuerpo: $211 \mathrm{~mm}$; diámetro base: $122 \mathrm{~mm}$; altura: $154 \mathrm{~mm}$; grosor medio sección pared: 5 mm. Bibliografía: Hevia et alii, 2001: 164170, Fig. 3.33.

9. CH.95 /1546. Sector C-10 A. Perfil completo. Borde exvasado oblicuo de perfil cóncavo al interior con labio de perfil redondeado. Cuerpo globular achatado con arista señalando la transición con el cuello. Asa en C de sección elipsoidal, con acanaladura longitudinal y digitación inferior, que parte del borde y llega a la zona media del cuerpo. Base plana. Pasta de tonalidad grisácea con abundantes micas, cuarzos y cuarcitas de diverso tamaño. Superficies negras, la externa alisada. Dimensiones: diámetro borde: $125 \mathrm{~mm}$; diámetro máximo cuerpo: 156 
$\mathrm{mm}$; diámetro base: $60 \mathrm{~mm}$; altura: 140 $\mathrm{mm}$; grosor medio sección pared: $4.5 \mathrm{~mm}$. Bibliografía: Hevia et alii, 2001: 164-170, Fig. 3.27.

\section{OLLAS LISAS DE BORDE EXVA- SADO CURVO}

(Figuras 137 y 138)

Las diversas variedades de ollas lisas de borde exvasado que se han apuntado para el siglo I d.C. mantienen su vigencia en estos momentos avanzados, conservando sin grandes modificaciones sus rasgos fundamentales (Hevia et alii, 2001: Fig. 5-7). Es el caso de estas ollas de borde curvo simple, que constituyen el segundo grupo en importancia cuantitativa en los repertorios del siglo II d.C., tras el de los recipientes que muestran los bordes facetados.

La heterogeneidad morfológica constituye, al igual que acontecía con sus congéneres antiguos, una constante y se concreta sobre todo en diferen-

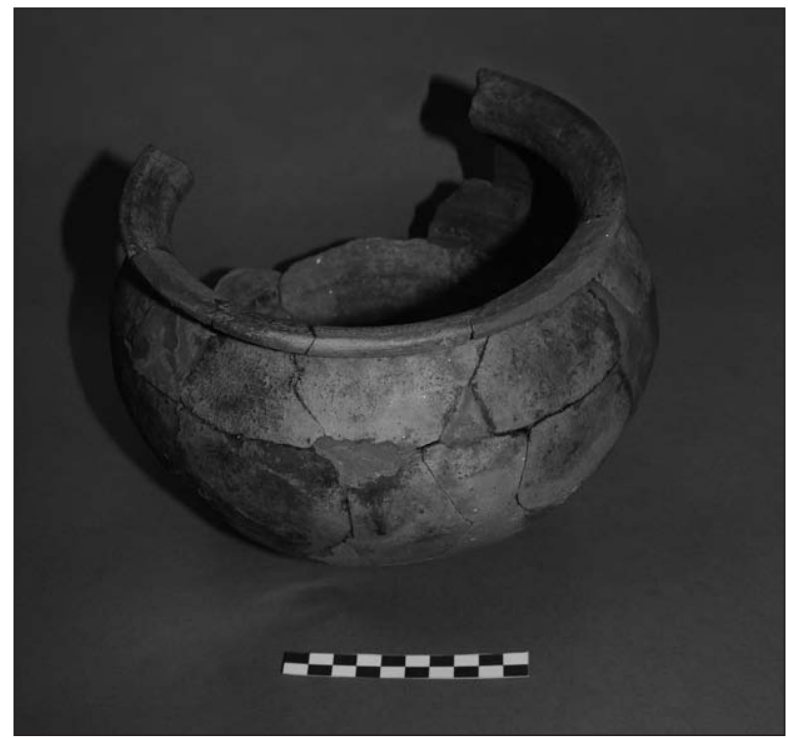

Figura 137. Olla de borde exvasado curvo. Foto: R. Montes

cias relativas a la globularidad de los recipientes, la capacidad de éstos y determinados detalles como la presencia de acanaladuras en el borde o de molduras en la superficie externa.
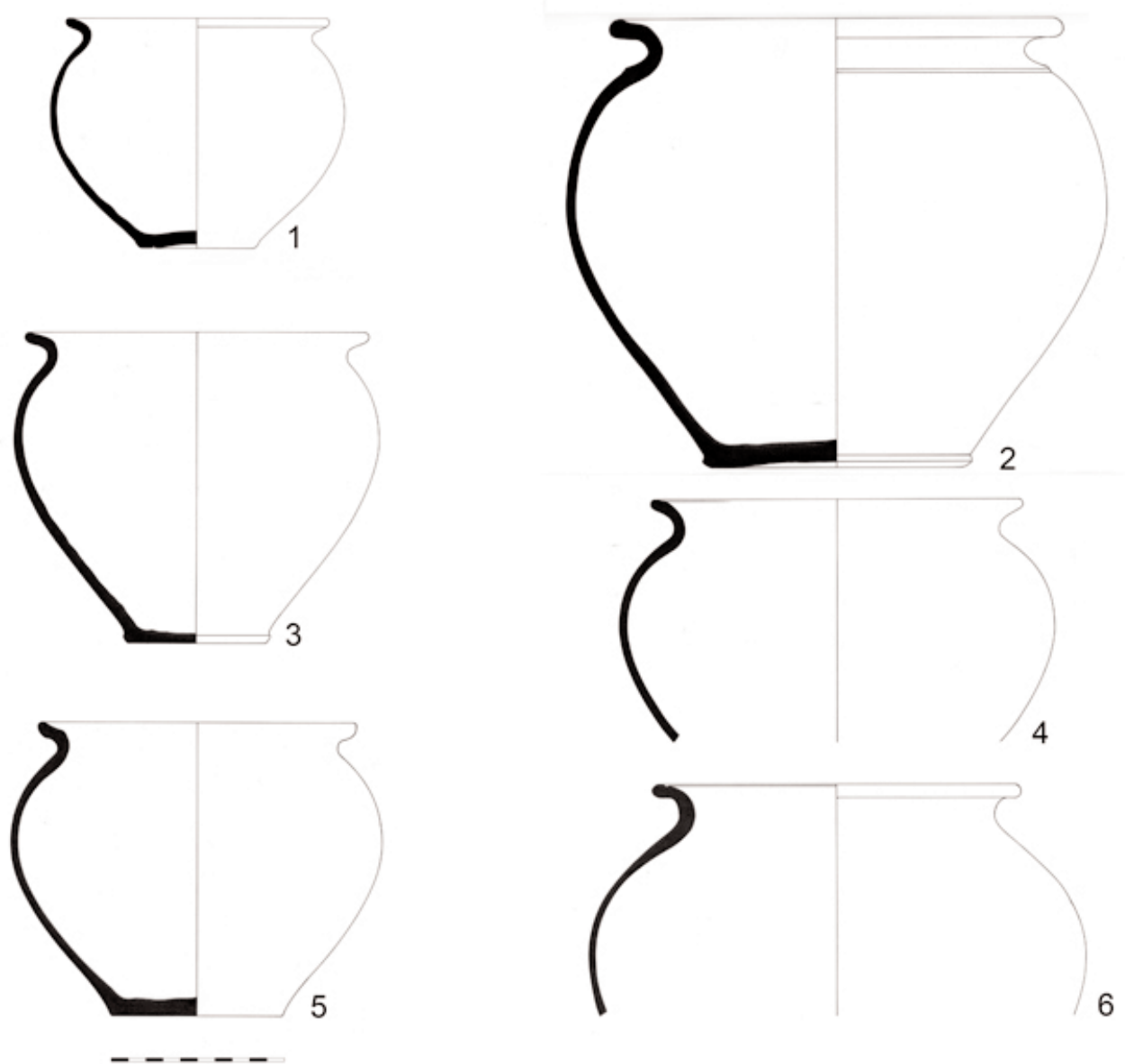

Figura 138. Ollas de borde exvasado curvo. 


\section{CATÁlogo}

1. CH.02 /0338. Sector C-17 C. Perfil completo. Borde exvasado, oblicuo y curvo con labio de perfil redondeado. Cuerpo globular. Base cóncava. Pasta de tonalidad pardo grisácea con desgrasante micáceos y cuarcíticos de pequeños y medianos. Superficies grises, la externa someramente alisada. Dimensiones: diámetro borde: $153 \mathrm{~mm}$; diámetro máximo cuerpo: $172 \mathrm{~mm}$; diámetro base: $68 \mathrm{~mm}$; altura.: $135 \mathrm{~mm}$; grosor medio sección pared: $4.5 \mathrm{~mm}$. Bibliografía: Inédita.

2. CH.96 /2716. Sector C-10. Perfil completo. Borde exvasado, oblicuo y curvo con labio engrosado de sección redondeada. Cuerpo globular recorrido en su extremo superior por una moldura de sección biselada. Base realzada ligeramente cóncava al exterior. Pasta de tonalidad pardo grisácea con desgrasantes micáceos y cuarcíticos de diversas dimensiones. Somero alisado exterior e interior borde y cuello. Dimensiones: diámetro borde: 256 $\mathrm{mm}$; diámetro máximo cuerpo: $316 \mathrm{~mm}$; diámetro base: $148 \mathrm{~mm}$; altura: $263 \mathrm{~mm}$; grosor medio sección pared: $6 \mathrm{~mm}$. Bibliografía: Hevia et alii, 2001: 170-177, Fig. 5.49.

3. CH.95/0490. Sector C-10. Perfil completo. Borde exvasado, oblicuo y curvo con labio de perfil redondeado. Cuerpo globular. Base plana. Pasta grisácea con abundantes micas pequeñas y cuarzos medios. Somero alisado en superficie externa y borde. Dimensiones: diámetro borde: 198 mm; diámetro máximo cuerpo: $213 \mathrm{~mm}$; diámetro base: $81 \mathrm{~mm}$; altura: $182 \mathrm{~mm}$; grosor medio sección pared: $5 \mathrm{~mm}$. Bibliografía: Hevia et alii, 2001: 170-177, Fig. 5.54.

4. CH.96 /2394. Sector C-10. Fragmento de borde y cuerpo. Borde exvasado, oblicuo y curvo con labio de perfil redondeado. Cuerpo globular. Pasta con desgrasantes micáceos pequeños y cuarcíticos y punto rojizos medianos y grandes. Somero ali- sado exterior que no impide observar las huellas del torno. Dimensiones: diámetro borde: $215 \mathrm{~mm}$; diámetro máximo cuerpo: $254 \mathrm{~mm}$; altura conservada: $142 \mathrm{~mm}$; grosor medio sección pared: $5 \mathrm{~mm}$. Bibliografía: Hevia et alii, 2001: 170-177, Fig. 7.67.

5. CH.95/0449. Sector C-10 A. Perfil completo. Borde exvasado, oblicuo y curvo con labio de perfil biselado. Cuerpo globular. Base plana. Pasta con desgrasantes micáceos y cuarcíticos de diversas dimensiones. Somero alisado exterior. Dimensiones: diámetro borde: $186 \mathrm{~mm}$; diámetro máximo cuerpo: $219 \mathrm{~mm}$; diámetro base: $100 \mathrm{~mm}$; altura.: $172 \mathrm{~mm}$; grosor medio sección pared: $5 \mathrm{~mm}$. Bibliografía: Hevia et alii, 2001: 170-177, Fig. 5.52.

6. CH.95/0553. Sector C-10 A. Fragmento de borde y cuerpo. Borde exvasado oblicuo y curvo con labio engrosado de perfil redondeado, señalado al interior por una acanaladura. Cuerpo globular. Pasta grisácea con desgrasantes micáceos menudos y abundantes esquistos y cuarzos de todos los tamaños. Borde bruñido, no pudiendo determinarse si la superficie externa se encontraba igualmente bruñida debido a su estado de conservación. Dimensiones: diámetro borde: $210 \mathrm{~mm}$; diámetro máximo cuerpo: $292 \mathrm{~mm}$; altura conservada: $136 \mathrm{~mm}$., grosor medio sección pared: $5 \mathrm{~mm}$. Bibliografía: Hevia et alii, 2001: 170-177, Fig. 7.62.

\section{OLLAS LISAS DE BORDE EXVASADO FACETADO}

(Figuras 139 y 140)

Esta variante de ollas lisas, caracterizada por el peculiar remate de la embocadura, que se desarrolla en dos planos exvasados que conforman un cuello corto oblicuo y un borde horizontal con labio de perfil redondeado generalmente engrosado, conserva el predominio que ya mostraba en el siglo I d.C. en este espectro morfo- 


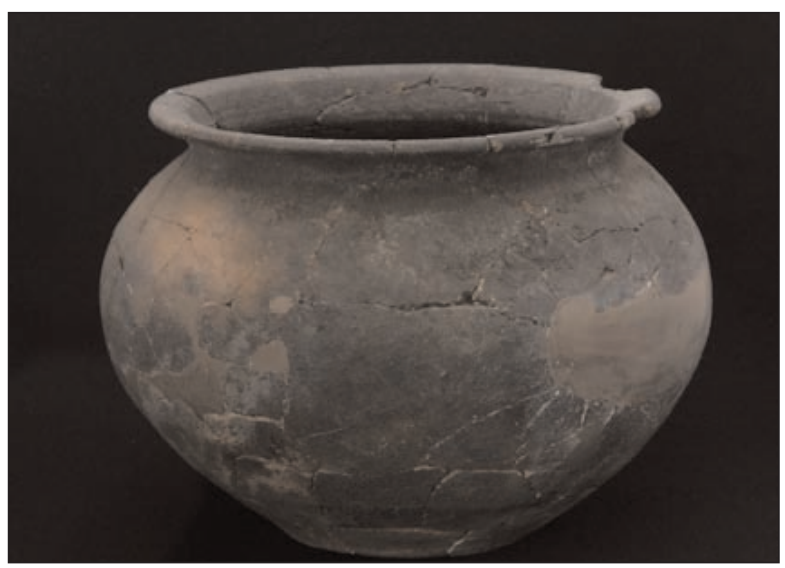

Figura 139. Olla de borde exvasado facetado. Foto: J. Arrojo funcional (Hevia et alii, 2001: Fig.5-7; Hevia, 2009: 478-479).

Se pueden hacer notar variaciones internas del modelo de rango equiparable a las observadas en las anteriores ollas de borde curvo, que atañen a las dimensiones, al perfil más o menos globular de los galbos y a la presencia o no de acanaladuras en el borde, que permiten constatar las dos variantes ya reseñadas para este tipo entre las piezas de contextos más tempranos.

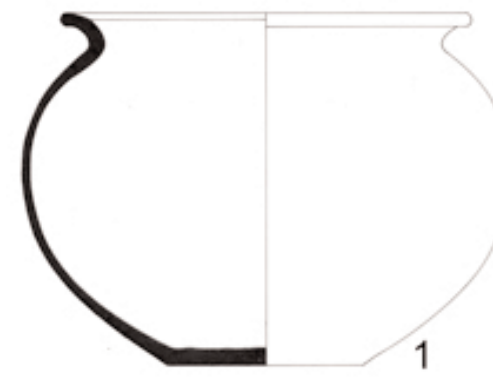

1

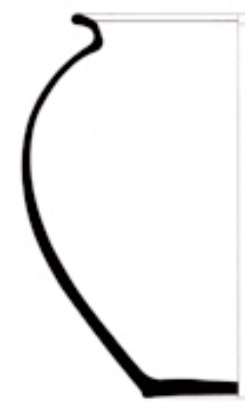

2

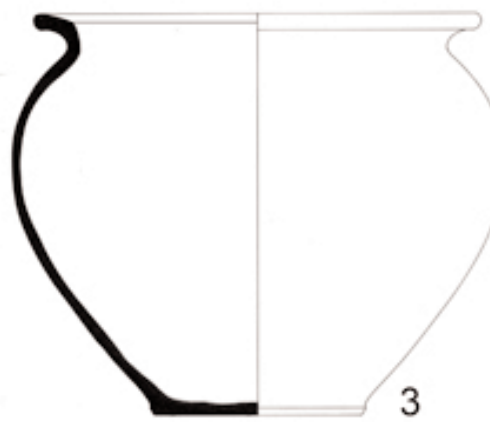

3
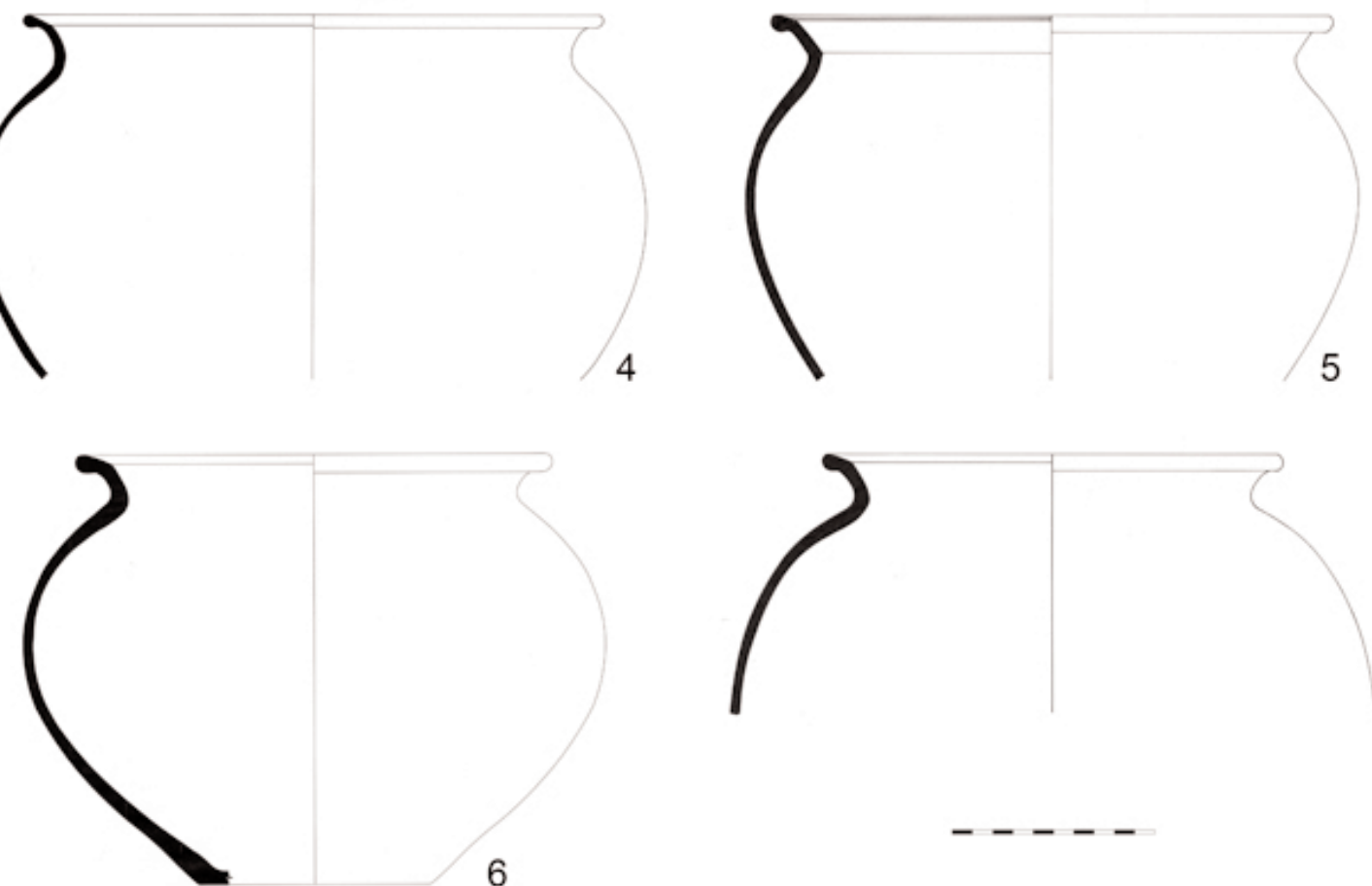

6

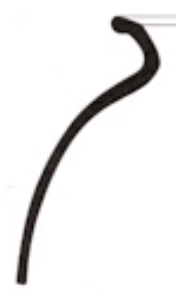

Figura 140. Ollas de borde exvasado facetado 


\section{CATÁlogo}

1. CH.95/1581. Sector C-10 A. Perfil completo. Borde exvasado, oblicuo y curvo, con labio de perfil redondeado. Cuello corto, oblicuo, de perfil curvo, diferenciado al interior mediante una inflexión. Cuerpo globular. Base plana. Pasta con micas pequeñas y muy pequeñas (alguna mediana), cuarzos de todos los tamaños y abundantes esquistos medianos y grandes. Somero alisado exterior. Dimensiones: diámetro borde: $210 \mathrm{~mm}$; diámetro máximo cuerpo: $251 \mathrm{~mm}$; diámetro base: $100 \mathrm{~mm}$; altura: $181 \mathrm{~mm}$; grosor medio sección pared: 5 mm. Bibliografía: Hevia et alii, 2001: 170-177, Fig. 5.53.

2. CH. 93 /1134. Sector R-V. Perfil completo. Borde exvasado, oblicuo y recto al interior con labio de perfil redondeado. Cuello corto, exvasado, oblicuo, de perfil recto, señalado al interior mediante una inflexión. Cuerpo globular. Base ligeramente cóncava al exterior. Pasta cuarzo-micácea. Superficies alisadas. Dimensiones: diámetro borde: $172 \mathrm{~mm}$; diámetro máximo cuerpo: $222 \mathrm{~mm}$; diámetro base: $96 \mathrm{~mm}$; altura: $197 \mathrm{~mm}$; grosor medio sección pared: $5 \mathrm{~mm}$. Bibliografía: Inédita.

3. CH.95 /0601. Sector C-10. Perfil completo. Borde exvasado, oblicuo y recto al interior con labio de perfil redondeado. Cuello corto, exvasado, de perfil curvo, diferenciado al interior mediante una inflexión. Cuerpo globular. Base plana con pie de disco. Pasta grisácea con desgrasantes micáceos pequeños y medianos y cuarcíticos medianos y grandes. Somero alisado exterior. Dimensiones: diámetro borde: $224 \mathrm{~mm}$; diámetro máximo cuerpo: $250 \mathrm{~mm}$; diámetro base: $105 \mathrm{~mm}$; altura: $208 \mathrm{~mm}$; grosor medio sección pared: $4.5 \mathrm{~mm}$. Bibliografía: Hevia et alii, 2001: 170-177, Fig. 5.54.

4. CH.95 /2623. Sector C-10 A. Fragmento de borde y cuerpo. Borde exvasado, oblicuo y recto al interior con labio engrosado de perfil redondeado. Cuello corto, exvasado y oblicuo de perfil ligeramente curvo, diferenciado al interior mediante una inflexión. Cuerpo globular. Pasta grisácea con desgrasantes micáceos pequeños y muy pequeños y abundantes esquistos rojizos y negros, cuarzos y cuarcitas de todos los tamaños, algunos muy grandes. Somero alisado en superficie externa, cuello y borde. Dimensiones: diámetro borde: $302 \mathrm{~mm}$; diámetro máximo cuerpo: $352 \mathrm{~mm}$; altura conservada: $192 \mathrm{~mm}$; grosor medio sección pared: $4 \mathrm{~mm}$. Bibliografía: Hevia et alii, 2001: 170-177, Fig. 6.57.

5. CH.95/2960. Sector C-10 A. Fragmento de borde y cuerpo. Borde exvasado, oblicuo y recto al interior con labio engrosado de perfil redondeado. Cuello corto, exvasado, oblicuo, de perfil recto, señalado al interior por dos acanaladuras. Cuerpo globular. Pasta cuarzo-micácea grosera. Acabado bruñido en la superficie interna de borde y cuello. Dimensiones: diámetro borde: $298 \mathrm{~mm}$; diámetro máximo cuerpo: $324 \mathrm{~mm}$; altura conservada: $193 \mathrm{~mm}$; grosor medio sección pared: $6 \mathrm{~mm}$. Bibliografía: Hevia et alii, 2001: 170-177, Fig. 6.59.

6. CH.95/0724. Sector C-10 B. Fragmento de borde, cuerpo y arranque de base. Borde exvasado, oblicuo y ligeramente curvo con labio engrosado de perfil redondeado. Cuello corto, exvasado, oblicuo, de perfil curvo, diferenciado al interior mediante una inflexión. Cuerpo globular. Base plana en lo conservado. Pasta con abundantes cuarzos, cuarcitas y esquistos rojos y negros de todos los tamaños, algunos de más de $5 \mathrm{~mm}$. Somero alisado en superficie externa, cuello y borde. Dimensiones: diámetro borde: 248 mm; diámetro máximo cuerpo: $300 \mathrm{~mm}$; diámetro base: $120 \mathrm{~mm}$; altura: $221 \mathrm{~mm}$; grosor medio sección pared: $5 \mathrm{~mm}$. Bibliografía: Hevia et alii, 2001: 170-177, Fig. 6.55; Hevia, 2009: Ficha 174, 478-479.

7. CH.95/0264. Sector C-10 A. Fragmento de borde y cuerpo. Borde exvasado, oblicuo y recto con labio engrosado de perfil redondeado. Cuello corto, exvasado, oblicuo y de perfil ligeramente curvo, diferenciado al interior. Cuerpo globular. Pasta pardo grisácea con abundantes desgrasantes esquistosos de todos los tamaños y algunos cuarzos y micas. Somero alisado en superficie externa, borde y cuello. Dimensiones: diámetro borde: $305 \mathrm{~mm}$; altura conservada: $172 \mathrm{~mm}$; grosor medio sección: 7 mm. Bibliografía: Hevia et alii, 2001: 170-177, Fig. 7.61. 


\section{OLLAS LISAS DE BORDE EXVASADO RECTO}

(Figuras 141 y 142)

En la segunda centuria, el amplio conjunto que componen las ollas lisas de borde exvasado, aunque dominado por los tipos de borde curvo y facetado, incorpora nuevas variedades, que podríamos considerar marginales. Es este el caso de las ollas de borde recto, caracterizadas por la embocadura exvasada, casi horizontal y de perfil recto bastante desarrollado, sin que ni sus restantes rasgos morfológicos ni su caracterización técnica presenten diferencias significativas respecto a sus congéneres (Hevia, 2009: 462-463).

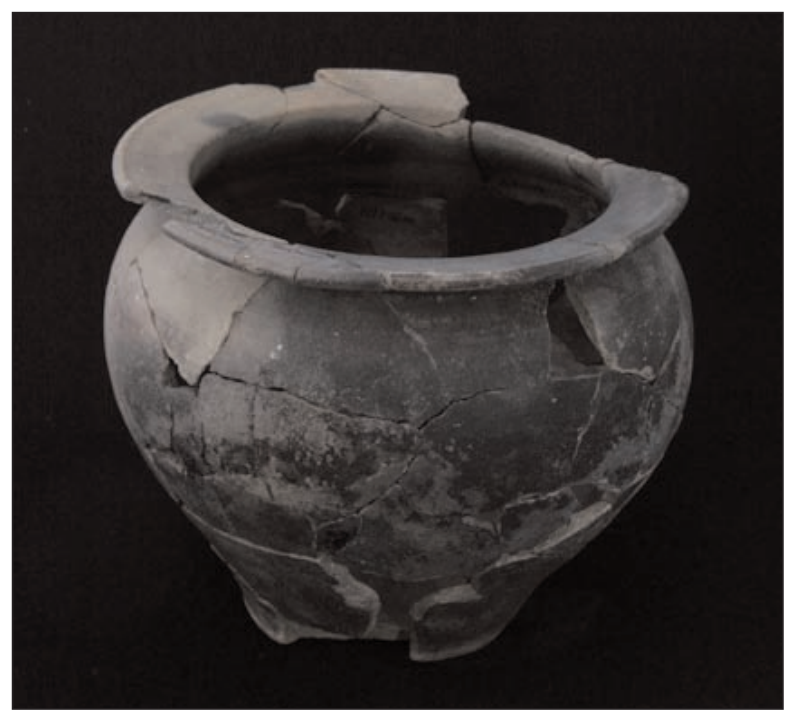

Figura 141. Olla de borde exvasado recto. Foto: J. Arrojo

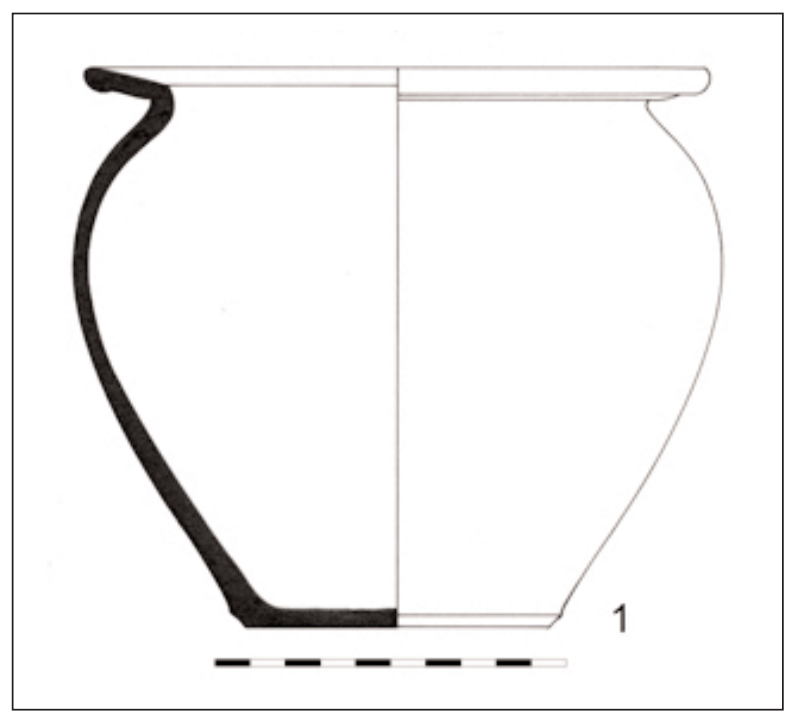

Figura 142. Olla de borde exvasado recto

\section{CATÁlogo}

1. CH.95/1948. Sector C-10. Perfil completo. Borde exvasado oblicuo y recto, casi horizontal, con labio engrosado de perfil redondeado. Cuerpo globular. Base plana. Pasta grisácea con abundantes desgrasantes micáceos pequeños y medianos y cuarcíticos medios. Acabado alisado al exterior, ofreciendo, no obstante, un acabado rugoso que permite apreciar las líneas del torno. Dimensiones: diámetro borde: $178 \mathrm{~mm}$; diámetro máximo cuerpo: $184 \mathrm{~mm}$; diámetro base: $86 \mathrm{~mm}$; altura: $160 \mathrm{~mm}$; grosor medios sección pared: $5 \mathrm{~mm}$. Bibliografía: Hevia et alii, 2001: 181, Fig. 9.84; Hevia 2009: Ficha 166, 462-463.

\section{OLLAS CON DECORACIÓN DE LÍNEAS VERTICALES BRUÑ̃IDAS}

(Figura 143 y 144)

Las ollas con decoración de líneas bruñidas verticales siguen desempeñando en la segunda centuria el papel de cierta relevancia en los ajuares que había sido constatado en la primera, tal y como se desprende de su registro constante, aunque minoritario respecto a otros tipos de ollas de cocina (Hevia et alii, 2001: 177-181, Fig. 8 y 9). Aunque las diferencias entre las piezas tempranas y estas de cronologías avanzadas no resultan demasiado importantes y a pesar de que los elen$\cos$ no son lo suficientemente expresivos, se observa una mayor heterogeneidad formal entre los últimos. En primer lugar, los bordes de la variante facetada, ya sea con acanaladura o sin

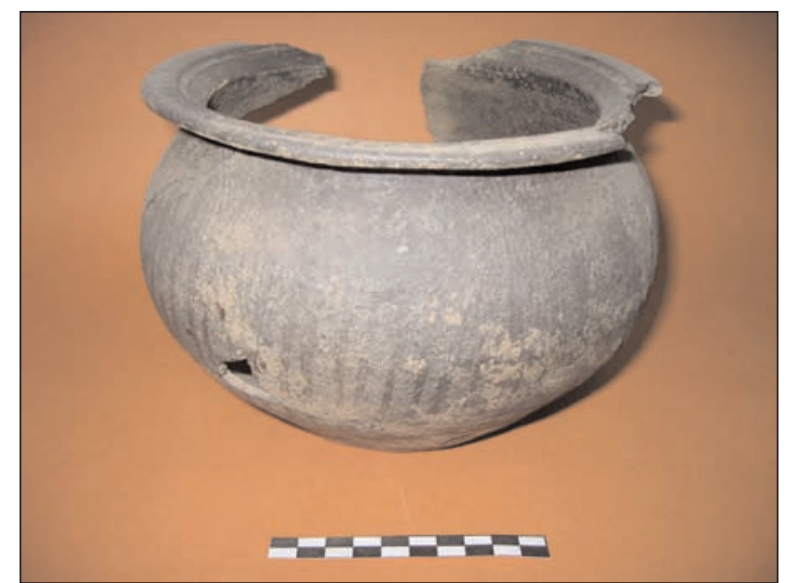

Figura 143. Olla de líneas verticales bruñidas. Foto: R. Montes 


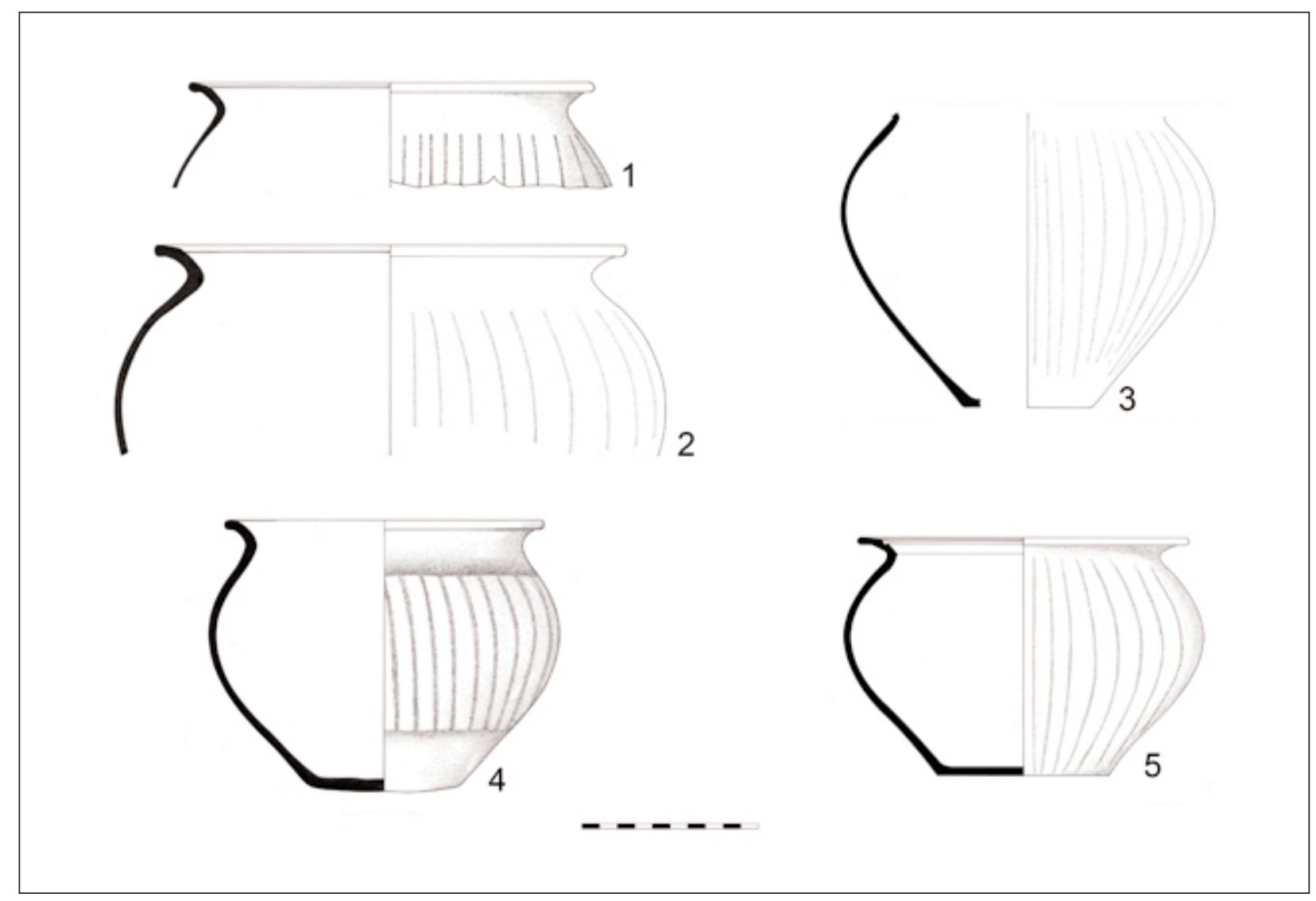

Figura 144. Ollas de líneas verticales bruñidas

ella, pierden el monopolio que mantenían anteriormente, para combinarse con soluciones curvas simples. Se detectan también variaciones más notables en la globularidad de los galbos, que abandonan en algunos casos el característico achatamiento antes dominante para optar por desarrollos más estilizados. Por otra parte, la homogeneidad dimensional que presentaba el repertorio antiguo se ve sustituida por una variedad bastante mayor, con piezas de capacidad diversa (Hevia, 2009: 456-457).

\section{CATÁlogo}

1. CH.95 /1977. Sector C-10 A / B. Fragmento de borde y cuerpo. Borde exvasado, oblicuo, y recto al interior con labio de perfil redondeado. Cuello corto, exvasado, oblicuo y de perfil curvo, diferenciado al interior por una acanaladura. Cuerpo globular decorado con líneas verticales bruñidas que arrancan debajo del cuello. Pasta de tonalidad grisácea con desgrasantes micáceos pequeños y media- nos, abundantes esquistos medianos y grandes y esporádicos cuarzos grandes y muy grandes. Tosco alisado externo y borde bruñido. Dimensiones: diámetro borde: $243 \mathrm{~mm}$; altura conservada: $65 \mathrm{~mm}$ grosor medio sección pared: $3.5 \mathrm{~mm}$. Bibliografía: Bibliografía: Hevia et alii, 2001: 177-181, Fig. 8.77.

2. CH.95 /1843. Sector C-10 A. Fragmento de borde y cuerpo. Borde exvasado, oblicuo y curvo con labio de perfil biselado. Cuello corto, exvasado, oblicuo, de perfil curvo diferenciado al interior por una acanaladura. Cuerpo globular. Decoración de líneas bruñidas verticales que arrancan debajo del cuello. Pasta grisácea con desgrasantes micáceos y cuarcíticos pequeños. Bruñido en superficie externa y borde. Dimensiones: diámetro borde: 282 mm; diámetro máximo cuerpo: 331 mm; altura conservada: $130 \mathrm{~mm}$; grosor medio sección pared: 5 mm. Bibliografía: Hevia et alii, 2001: 177-181, Fig. 8.79. 
3. CH.95/2989. Sector C-10 A. Fragmento de cuerpo y base. Cuerpo globular. Base plana en lo conservado. Decoración de líneas bruñidas verticales en toda la superficie externa. Bruñido exterior. Pasta con desgrasantes micáceos pequeños y cuarcíticos medianos y grandes. Dimensiones: diámetro máximo cuerpo: $303 \mathrm{~mm}$; diámetro base: $104 \mathrm{~mm}$; altura conservada: $244 \mathrm{~mm}$; grosor medio sección pared: 5 mm. Bibliografía: Hevia et alii, 2001: 177-181, Fig. 9.83.

4. CH.95/2652. Sector C-10. Perfil completo. Borde exvasado, oblicuo y curvo con labio de perfil redondeado diferenciado al interior por una acanaladura. Cuello corto, exvasado, oblicuo y curvo, diferenciado al interior mediante una inflexión. Cuerpo globular. Base ligeramente convexa al exterior. Decoración de líneas bruñidas verticales que arrancan debajo del cuello y llegan hasta el tercio inferior de pared. Pasta de tonalidad grisácea con desgrasantes micáceos, cuarcíticos y esquistosos de diversas dimensiones. Bruñido en superficie externa, borde y cuello. Dimensiones: diámetro borde: $188 \mathrm{~mm}$; diámetro máximo cuerpo: $229 \mathrm{~mm}$; diámetro base: 90 $\mathrm{mm}$; altura: $170 \mathrm{~mm}$; grosor medio sección pared: $4 \mathrm{~mm}$. Bibliografía: Hevia et alii, 2001: 177-181, Fig. 8.76.

5. CH.98/3394. Sector R-VIII. Perfil completo. Borde exvasado, oblicuo y curvo con labio de perfil redondeado diferenciado al interior por una acanaladura. Cuello corto, exvasado, oblicuo y recto al interior, diferenciado mediante una inflexión. Cuerpo globular. Base plana. Decoración de líneas bruñidas verticales que arrancan debajo del borde y llegan hasta la base. Pasta de tonalidad grisácea con desgrasantes micáceos, cuarcíticos y esquistosos de diversas dimensiones. Bruñido en superficie externa, borde y cuello. Dimensiones: diámetro borde: $200 \mathrm{~mm}$; diámetro máximo cuerpo: $218 \mathrm{~mm}$; diámetro base: 104 $\mathrm{mm}$; altura: $148 \mathrm{~mm}$; grosor medio sección pared: $4.5 \mathrm{~mm}$. Bibliografía: Hevia, 2009: Ficha 163, 456-457.

\section{TAPADERAS}

(Figuras 145 y 146)

El morfotipo, asimilable de manera genérica a la forma Vegas 17 (1973: 53, Fig. 18, 1-7), manifiesta una gran constancia en su presencia en los repertorios del siglo II d.C. del yacimiento (Hevia et alii, 1999: 181-184, Fig. 10), si bien se gesta en tiempos más antiguos, toda vez que su incorporación a los ajuares del siglo I d.C. se encuentra plenamente constatada (Figura 75).

Se trata de piezas que mantienen una elevada homogeneidad morfológica y técnica con bordes indiferenciados de perfiles redondeados o apuntados comúnmente engrosados y paredes curvas y oblicuas que se rematan en pomos destacados normalmente rehundidos que hacen las veces de asideros (Hevia, 2009: 454-455 y 458459). En ocasiones, una acanaladura recorre el tránsito interior entre borde y cuerpo. La apertura de pequeñas perforaciones circulares, ya sea en el pomo o más frecuentemente, en la pared, no resulta tampoco extraordinaria.

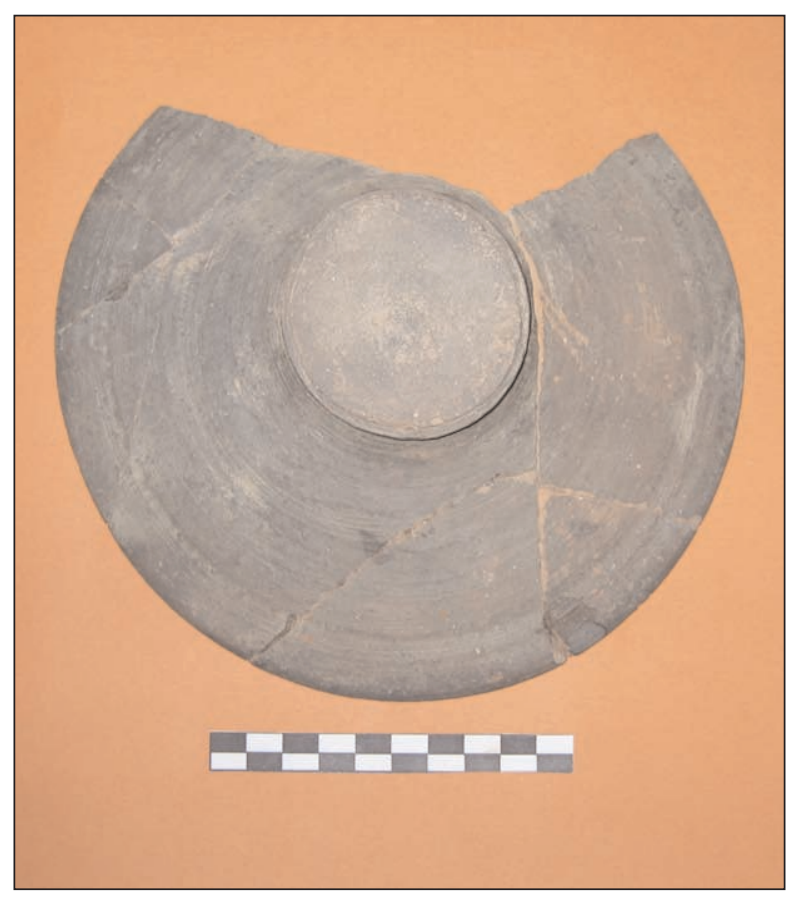

Figura 145. Tapadera. Foto: R. Montes

Las pastas en que fueron fabricadas estas piezas son grises u ocráceas y groseras, encajando a la perfección con las habituales esquistosas regionales en sus versiones toscas. Los acabados 
consisten en someros alisados o descuidados bruñidos, según los casos. De forma excepcional se documenta la aplicación de ornatos bruñidos en forma de líneas que recorren radialmente la superficie externa de la pared (Figura 146.1).

En cuanto a la relación de complementariedad inherente a su función que han de tener las tapaderas respecto a otras piezas (Alvarado y Molano, 1995: 289), los datos disponibles parecen indicar que, aunque el catálogo de morfotipos susceptible de recibir tapadera es amplio, en este caso se limita a unas pocas morfologías. A pesar de que sólo algunos tipos presentan bordes específicamente diseñados para la recepción de una tapadera, esta circunstancia no invalida su asociación a recipientes que, por su uso, debieron disponer de ellas, caso de las ollas de cocina y de recipientes de almacenamiento y despensa. Los ejemplares documentados en el yacimiento presentan, salvo contadas excepciones, máculas de fuego en sus superficies, indicativo de una asociación preferente a piezas empleadas en procesos culinarios en caliente. Otros recipientes para los que no conocemos tapaderas cerámicas adecuadas a su diámetro y características técnicas, pudieron contar con cubiertas perecederas o incluso bases reaprovechadas como parecen indicar algunos ejemplos recortados post-ruptura documentados. El análisis comparado de las dimensiones y las características técnicas parecen circunscribir su relación, al menos prioritaria, a las cazuelas de fondo plano y en menor medida, a las ollas de borde cóncavo (Hevia et alii, 2001). Los diámetros del borde de las tapaderas resultan harto expresivos en este sentido, toda vez que fluctúan, según los ejemplares, entre los 170 y los $210 \mathrm{~mm}$, equiparables a los de los bordes las referidas cazuelas.

Con cierta frecuencia se ha propuesto una polivalencia funcional de estos artefactos como tapas en sentido estricto y como platos, empleo este último que únicamente resulta verosímil para ejemplares llanos o con suficiente superficie de apoyo, caso, por ejemplo, de las coberte-

${ }^{132}$ Se documentan modelos similares sin aparentes diferencias significativas tanto en la primera como en la segunda fase ras habituales en los platos de engobe rojo pompeyano clásicos (Sánchez, 1995: 263; Aguarod, 1995: 133). Dadas sus características formales, no parece que esta dualidad funcional pueda sostenerse para piezas como las del Chao Samartín. En cualquier caso, no puede ser mantenida para aquellos ejemplares que cuentan con orificios para dar salida al vapor, ya sea en la asidera o en la pared.

Tal y como hemos comentado al hacer referencia a las tapaderas registradas en contextos del siglo I d.C., no parece que esta morfología, desde su inauguración en fechas tempranas, experimente modificaciones morfológicas notables de las que pueda derivarse una evolución cronológica, manteniendo un diseño muy estable a lo largo del tiempo (Vegas, 1978: 53). No obstante la validez genérica de esta argumentación, lo cierto es que las tapaderas adolecen tradicionalmente de análisis tipológicos evolutivos similares a los que habitualmente se aplican, permitiendo la obtención de conclusiones cronológicas válidas, sobre otros tipos de cerámica común. Cuando estos análisis se han abordado, circunscritos a producciones concretas, caso de los productos de engobe rojo o las importaciones africanas, y/o a ámbitos geoculturales específicos (Aguarod, 1995; Sánchez, 1995: 263-265), los efectos sobre la definición y caracterización de los tipos resultan notables. En el ámbito del noroeste resulta patente, como apunta E. Alcorta (1995: 213), la necesidad de afrontar un estudio más profundo de estos materiales conducente, tanto a su asociación a recipientes concretos, como a la fijación de producciones y de la evolución formal de las mismas.

Ejemplos cercanos en virtud del desarrollo formal que manifiestan se encuentran en Huerña (Domergue y Martin, 1977, 53, fig.12, 178; 117, fig. 29, 587-592) ${ }^{132}$ y sobre todo, en Lugo, donde el tipo T1 de tapaderas de paredes oblicuas (Alcorta, 2001: 256-258; Fig. 108. 1-6) se halla bien representado. de ocupación, lo que viene a reafirmar la escasa validez del grupo como argumento cronológico. 


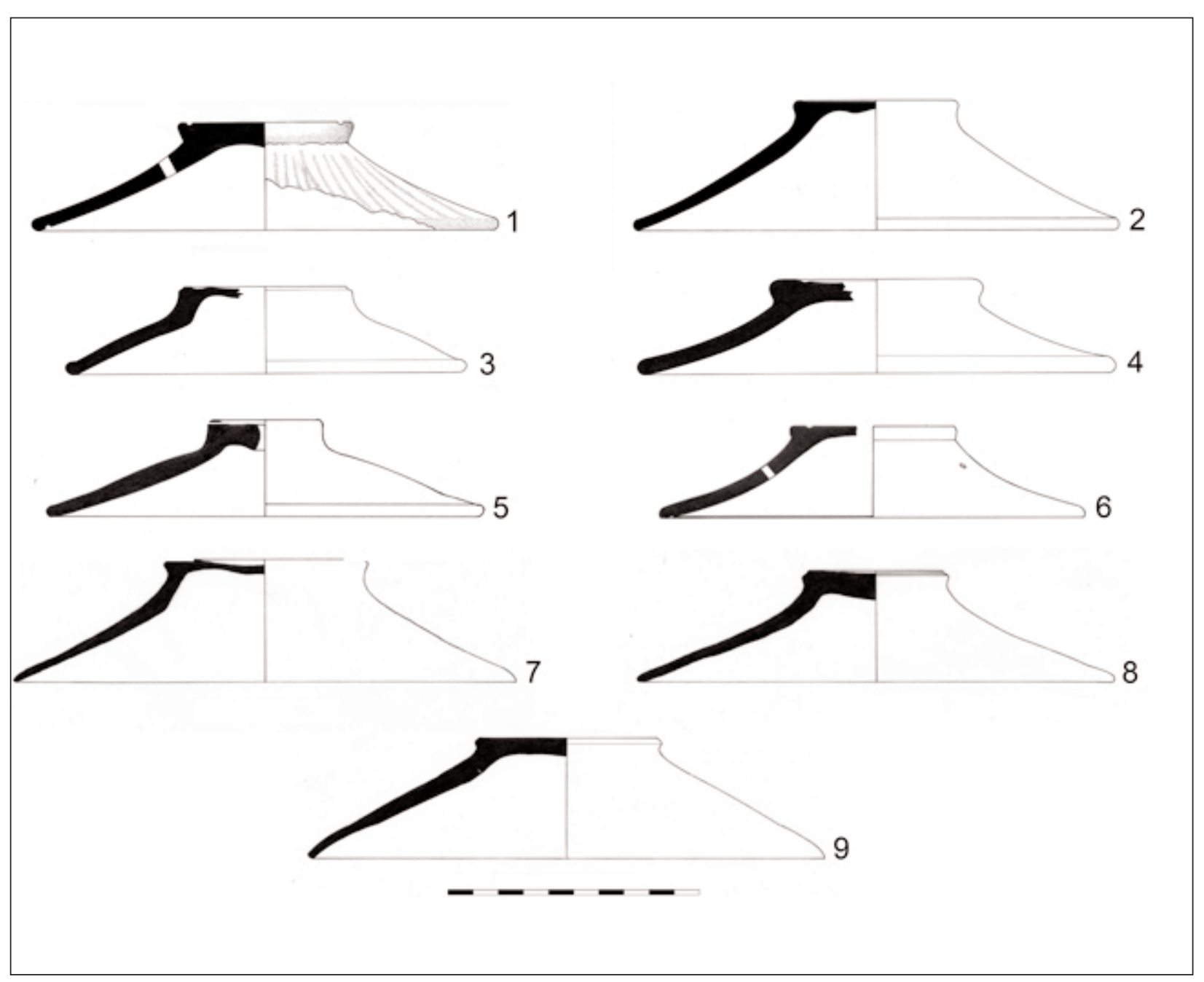

Figura 146. Tapaderas

\section{CATÁlOGo}

1. CH.98/2924. Sector C-7. Perfil completo. Borde indiferenciado con labio de perfil redondeado señalado al interior por una acanaladura. Cuerpo oblicuo ligeramente curvo que presenta un orificio circular en su mitad superior de $4 \mathrm{~mm}$ de diámetro. Pomo cilíndrico rehundido al interior y plano al exterior con acanaladura perimetral. Decoración en la carta externa consistente en líneas paralelas bruñidas que van desde el pomo hasta el borde. Pasta de tonalidad pardo grisácea con micas, esquistos y cuarzos pequeños y medianos. Acabado someramente alisado. Dimensiones: diámetro borde: 184 $\mathrm{mm}$; diámetro pomo: $70 \mathrm{~mm}$; altura: 43 $\mathrm{mm}$; grosor medio sección pared: $6 \mathrm{~mm}$. Bibliografía: Inédita.
2. CH.98/2951. Sector C-7. Perfil completo. Borde indiferenciado con labio de perfil redondeado. Cuerpo oblicuo ligeramente curvo. Pomo cilíndrico rehundido al interior y plano al exterior. Pasta de tonalidad pardo grisácea con micas, esquistos y cuarzos pequeños y medianos. Acabado someramente alisado. Dimensiones: diámetro borde: $192 \mathrm{~mm}$; diámetro pomo: $65 \mathrm{~mm}$; altura: $51 \mathrm{~mm}$; grosor medio sección pared: $6 \mathrm{~mm}$. Bibliografía: Inédita.

3. CH.00 /0180. Sector C-17 B. Fragmento de borde, cuerpo y pomo. Borde indiferenciado con labio de perfil redondeado. Cuerpo oblicuo recto. Pomo cilíndrico rehundido al interior y plano al exterior. Pasta de tonalidad pardo grisácea con 
micas, esquistos y cuarzos pequeños y medianos. Acabado someramente alisado. Dimensiones: diámetro borde: $160 \mathrm{~mm}$; diámetro pomo: $66 \mathrm{~mm}$; altura: $35 \mathrm{~mm}$; grosor medio sección pared: $6 \mathrm{~mm}$. Bibliografía: Inédita.

4. CH.00 /3780. Sector C-17 C. Fragmento de borde, cuerpo y pomo. Borde indiferenciado con labio de perfil redondeado. Cuerpo oblicuo ligeramente curvo. Pomo cilíndrico plano. Pasta de tonalidad pardo grisácea con micas, esquistos y cuarzos pequeños y medianos. Acabado someramente alisado. Dimensiones: diámetro borde: $190 \mathrm{~mm}$; diámetro pomo: $84 \mathrm{~mm}$; altura: $37 \mathrm{~mm}$; grosor medio sección pared: $6 \mathrm{~mm}$. Bibliografía: Inédita.

5. CH.95 /1917. Sector C-10 A. Perfil completo. Borde indiferenciado engrosado recorrido al exterior por una acanaladura con labio de perfil redondeado. Cuerpo recto oblicuo, engrosado en su mitad superior. Pomo cilíndrico rehundido al interior y cóncavo al exterior que presenta orificio central de $5.5 \mathrm{~mm}$. Pasta pardo grisácea con abundantes micas pequeñas y cuarzos y esquistos de diverso tamaño. Somero alisado interior. Dimensiones: diámetro borde: $174 \mathrm{~mm}$; diámetro pomo: $46 \mathrm{~mm}$; altura: $39 \mathrm{~mm}$; grosor medio sección pared: $7 \mathrm{~mm}$. Bibliografía: Hevia et alii, 2001: 181-184, Fig.10.88; Menéndez y Benéitez, 2002: Fig. 4.4; Hevia, 2009: Ficha 164, 458-459.

6. CH.95/3027. Sector C-10 A. Perfil completo. Borde indiferenciado con labio de perfil redondeado señalado al interior por una acanaladura. Cuerpo oblicuo ligeramente cóncavo que presenta un orificio circular en su mitad superior de $3 \mathrm{~mm}$ de ancho. Pomo cilíndrico plano con acanaladura exterior perimetral. Pasta de tonalidad grisácea con micas, esquistos y cuarzos pequeños, medianos y alguno grande. No recibió acabado específico alguno. Dimensiones: diámetro borde: $170 \mathrm{~mm}$; diámetro pomo: $62 \mathrm{~mm}$; altura: $37 \mathrm{~mm}$; grosor medio sección pared: 5.5 mm. Bibliografía: Hevia et alii, 2001: 181-184, Fig.10.89.

7. CH.95 /1686. Sector C-10 A. Perfil completo. Borde indiferenciado con labio de perfil redondeado. Cuerpo recto oblicuo. Pomo cilíndrico rehundido al interior y ligeramente cóncavo al exterior. Pasta cuarzo-micácea con desgrasantes pequeños y medios. No recibió acabado específico. Dimensiones: diámetro borde: 202 $\mathrm{mm}$; diámetro pomo: $80 \mathrm{~mm}$; altura: 50 $\mathrm{mm}$; grosor medio sección pared: $5 \mathrm{~mm}$. Bibliografía: Hevia et alii, 2001: 181184, Fig.10.87; Hevia, 2009: Ficha 164, 458-459.

8. CH.95 /1060. Sector C-10 A. Perfil completo. Borde indiferenciado con labio de perfil redondeado. Cuerpo recto oblicuo. Pomo cilíndrico de sección biselada rehundido al interior y ligeramente cóncavo al exterior. Pasta cuarzo-micácea con desgrasantes pequeños y medios. No recibió acabado específico. Dimensiones: diámetro borde: $190 \mathrm{~mm}$; diámetro pomo: $53 \mathrm{~mm}$; altura: $45 \mathrm{~mm}$; grosor medio sección pared: $6 \mathrm{~mm}$. Bibliografía: Hevia et alii, 2001: 181-184, Fig.10.86; Hevia, 2009: Ficha 162, 454-455.

9. CH.95 /1181. Sector C-10 A. Perfil completo. Borde indiferenciado, levemente envasado, con labio de perfil redondeado. Cuerpo recto oblicuo. Pomo cilíndrico rehundido al interior y recto al exterior. Pasta cuarzo-micácea grosera. Espatulado exterior en pomo y extremo superior del cuerpo. Dimensiones: diámetro borde: $206 \mathrm{~mm}$; diámetro pomo: $74 \mathrm{~mm}$; altura: $49 \mathrm{~mm}$; grosor medio sección pared: 6 mm. Bibliografía: Hevia et alii, 2001: 181-184, Fig.10.85. 


\section{MORTEROS}

(Figuras 147 y 148)

Los morteros cerámicos se incorporan a los ajuares regionales en forma de radical novedad tipológica durante el siglo I d.C. Los primeros ejemplos documentados consisten en importaciones de los tipos en boga por aquellas fechas como los Cap Dramont $1^{133}$ y Cap Dramont 2 (Joncheray, 1973) ${ }^{134}$ de procedencia tanto itálica (Hevia y Montes, 2009: 644; Fig.2.6) como de imitaciones hispánicas (Ibidem: Fig.2.7).

En el Chao Samartín, en el siglo II d.C., el papel desempeñado anteriormente por estas manufacturas foráneas se ve sustituido por

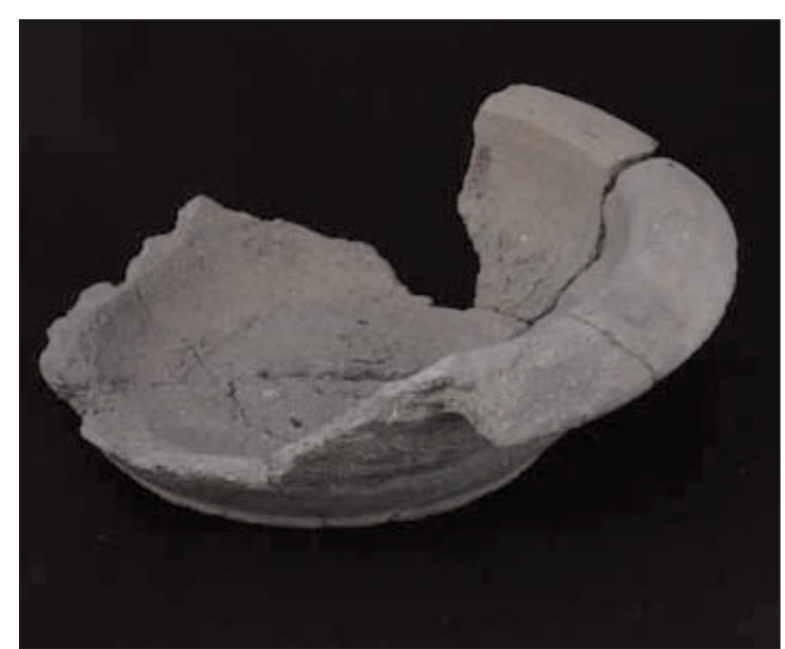

Figura 147. Mortero. Foto: J. Arrojo modelos que responden a unas características técnicas bien diferentes (Zarzalejos, 1995: 267), verosímilmente asimilables a la actividad alfarera regional. Ésta se encuentra plenamente constatada en Lucus Augusti, ya sea imitando los citados modelos importados desde época temprana (Alcorta, 2001: 147-152, Fig. 54 y 65) o mediante formulaciones morfológicas propias más adelante (Ibidem: 306-312).

La diferencia más significativa que presentan estas producciones regionales respecto a los prototipos de referencia radica en la pasta en que fueron fabricados y en la sustitución de las partículas abrasivas de la cazoleta que presentan los mortaria foráneos por el mero afloramiento de las gruesas inclusiones de la pasta en que

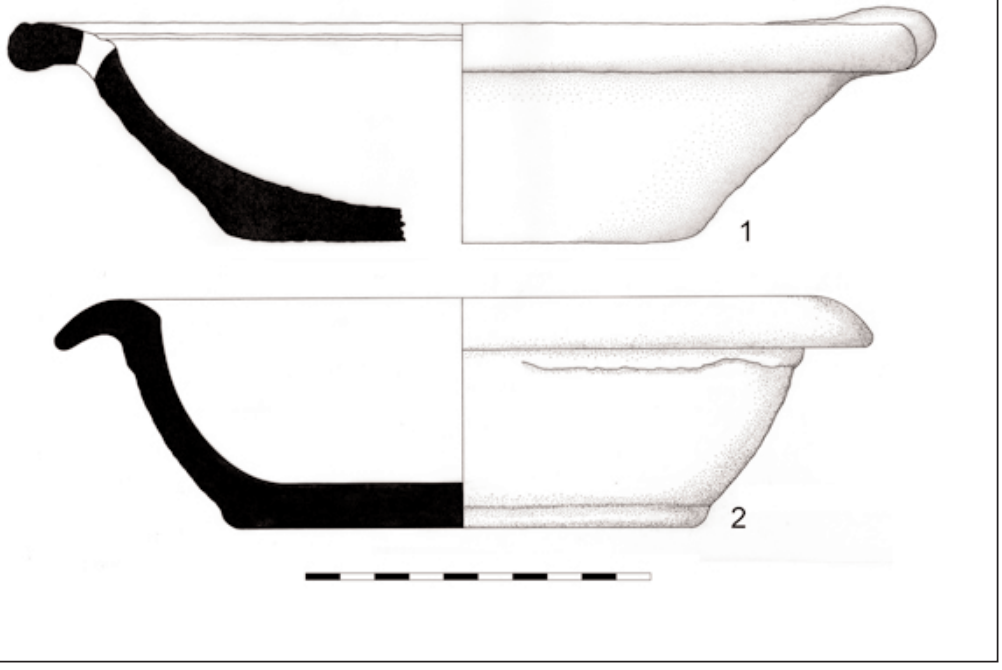

Figura 148. Morteros recipientes de amplio borde exvasado curvo, cazoleta poco profunda de perfil curvo abierto y base plana resaltada. (Hevia, 2009: 468-469).
${ }^{133}$ Aunque en el Chao Samartín resultan por el momento desconocidos, se han registrado en otros yacimientos del entorno como Lugo, donde se recopilan una veintena de ejemplares del tipo (Alcorta, 1994 y 2001: 147-150, Fig.64).
${ }^{134}$ Conocidos también en Lugo (Alcorta, 2001: 150-152, Fig.65). 


\section{CATÁlOgo}

1. CH.94 /0971. Sector N-94. Fragmento de borde, cuerpo y base. Borde exvasado curvo con labio engrosado de perfil redondeado recorrido al interior por una acanaladura, bajo la cual se abre un orificio circular de unos $5 \mathrm{~mm}$ de diámetro. Conserva el arranque de la piquera. Pared poco profunda, oblicua y levemente curva. Base plana. Pasta de tonalidad pardo anaranjada con desgrasantes cuarcíticos gruesos. Superficies rugosas de tonos pardo anaranjados. Dimensiones: diámetro borde: $261 \mathrm{~mm}$; diámetro base: $134 \mathrm{~mm}$; altura: $64 \mathrm{~mm}$; grosor medio sección pared: $9 \mathrm{~mm}$. Bibliografía: Inédita.

2. CH.98/3675. Sector C-12. Perfil completo. Borde exvasado, curvo y descendente con labio de perfil redondeado. Pared poco profunda, oblicua y curva. Base plana. Pasta de tonalidad pardo anaranjada con desgrasantes cuarcíticos gruesos. Superficies rugosas de tonalidad pardo anaranjada. Dimensiones: diámetro borde: $253 \mathrm{~mm}$; diámetro base: $142 \mathrm{~mm}$; altura: $71 \mathrm{~mm}$; grosor medio sección pared: $9 \mathrm{~mm}$. Bibliografía: Menéndez y Benéitez, 2002: Fig.4.11.

\section{ORZAS CON NERVADURAS}

(Figuras 149 y 150)

El tipo, tan genuino del repertorio regional y vinculado a tareas de almacenamiento, inicia su presencia en el yacimiento durante la primera centuria (Figura 76) y continúa plenamente vigente en el siglo II d.C. Poco cabe añadir como particularidad específica de los ejemplares de ésta época más allá de la menor frecuencia con la que se documentan piezas con decoraciones bruñidas. Por lo demás, el morfotipo mantiene sin cambios sus rasgos formales definitorios con los típicos bordes facetados, los cuerpos globulares recorridos en su cara externa por un número variable de nervaduras y las bases planas (Hevia, 2009: 472-473).

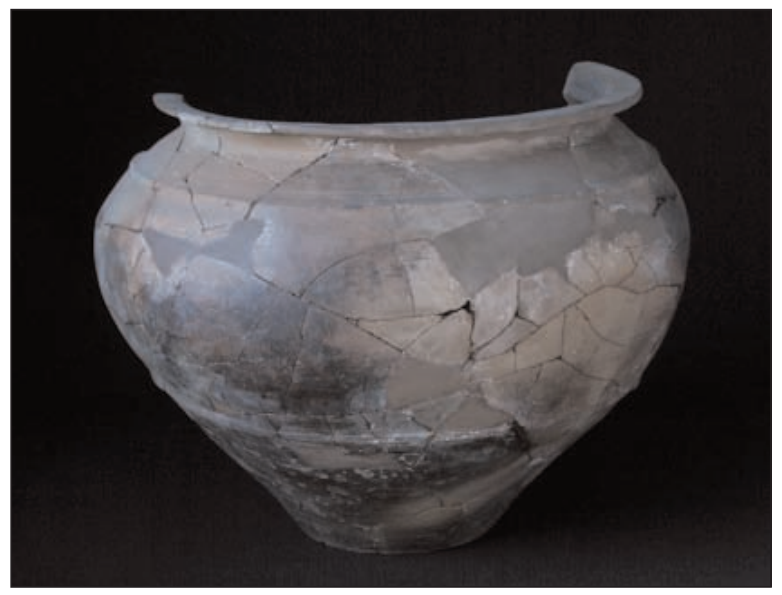

Figura 149. Orza con nervaduras. Foto: J. Arrojo

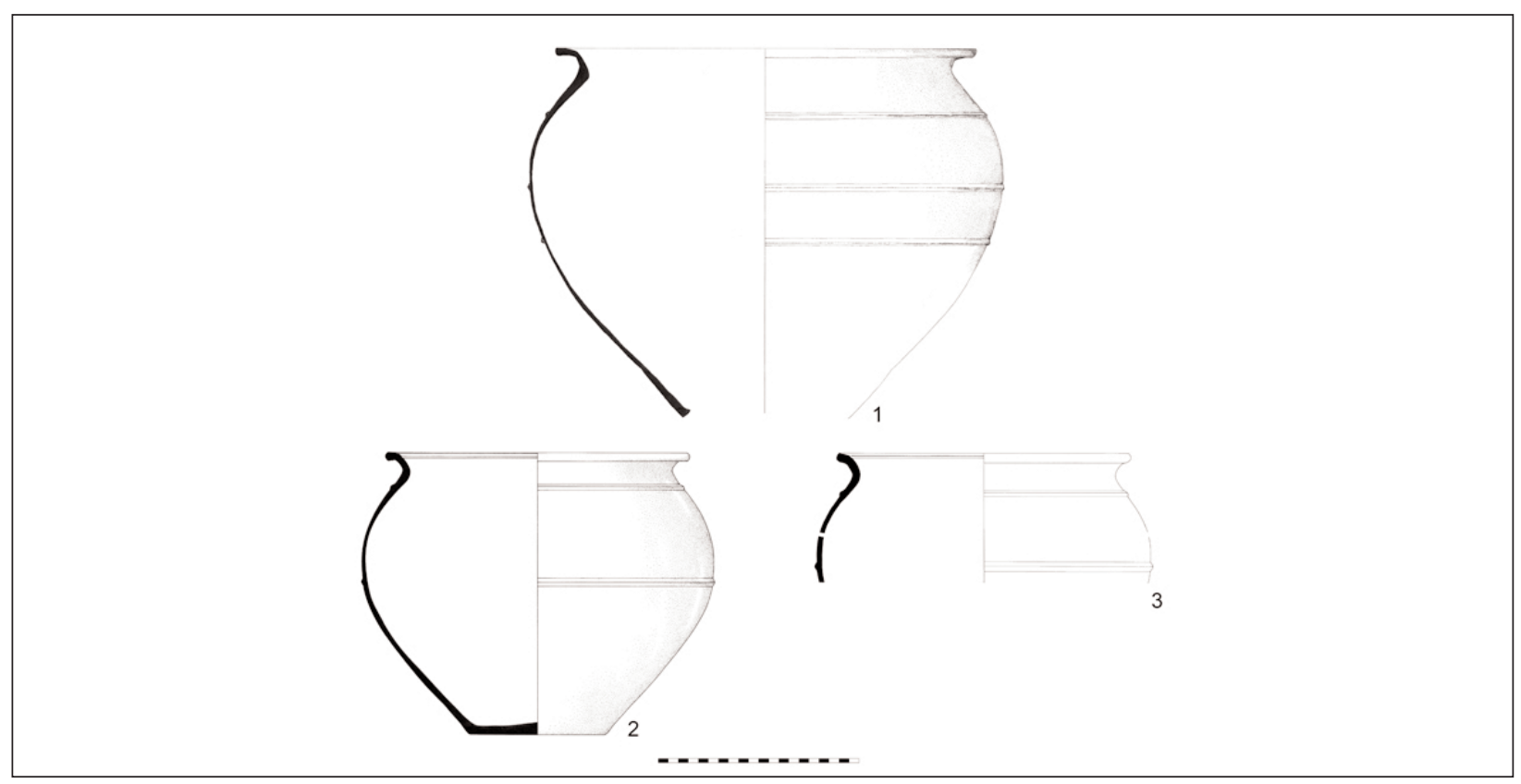

Figura 150. Orzas con nervaduras 


\section{CATÁlogo}

1. CH.95 /0473. Sector C-10 A. Fragmento de borde y cuerpo. Borde exvasado, oblicuo y curvo con labio de perfil redondeado. Cuello corto, exvasado, de perfil ligeramente curvo y diferenciado al interior mediante una inflexión. Cuerpo globular recorrido, en su tercio superior, por tres nervaduras de sección triangular. Pasta cuarzo-esquistosa con desgrasantes pequeños, medianos y grandes. Somero alisado exterior. Dimensiones: diámetro borde: $450 \mathrm{~mm}$; diámetro máximo cuerpo: $504 \mathrm{~mm}$; altura conservada: $396 \mathrm{~mm}$; grosor medio sección pared: $7 \mathrm{~mm}$. Bibliografía: Hevia et alii, 2001: 186-190, Fig.11.100.

2. CH.95/0920. Sector C-10. Perfil completo. Borde exvasado, oblicuo y curvo con labio de perfil redondeado. Cuello corto, exvasado y oblicuo de perfil curvo diferenciado al interior por una acanaladura. Cuerpo globular recorrido en su tercio superior por dos nervaduras de sección triangular, la primera de ellas situada inmediatamente por debajo del cuello. Base plana con el fondo interior umbilicado y parrilla espatulada en el fondo exterior. Pasta cuarzo-micácea grosera. Somero alisado exterior y tosco bruñido en borde e interior del cuello. Dimensiones: diámetro borde: $320 \mathrm{~mm}$; diámetro máximo cuerpo: $375 \mathrm{~mm}$; diámetro base: $143 \mathrm{~mm}$; altura: $320 \mathrm{~mm}$; grosor medio sección pared: $6 \mathrm{~mm}$. Bibliografía: Hevia et alii, 2001: 186-190, Fig.10.99; Menéndez y Benéitez, 2002: Fig.5.2.

3. CH.96 /3239. Sector C-10. Fragmento de borde y cuerpo. Borde corto, exvasado, oblicuo y ligeramente curvo con labio de perfil redondeado. Cuello corto, exvasado y oblicuo de perfil curvo, diferenciado al interior por una acanaladura. Cuerpo de tendencia globular en lo conservado, recorrido en su superficie externa por dos nervaduras de sección triangular. Pasta cuarzo-micácea grosera. Somero alisado exterior y tosco bruñido en borde e interior del cuello. Dimensiones: diámetro borde: 296 mm; diámetro máximo cuerpo: $339 \mathrm{~mm}$; altura conservada: $130 \mathrm{~mm}$; grosor medio sección: $5 \mathrm{~mm}$. Bibliografía: Hevia et alii, 2001: 186-190, Fig.12.102.

\section{CONCLUSIONES}

El estudio de la cerámica romana altoimperial de fabricación regional del Chao Samartín permite la comprobación de una evolución en las formas, los usos y los modos técnicos cuya significación última trasciende lo artefactual y tiene su refrendo en los profundos cambios de índole política, económica y social que acontecen en este convulso periodo de su historia. La validez de las conclusiones obtenidas habrá de ser sometida a las lógicas revisiones que se deriven de las sucesivas aportaciones de una investigación arqueológica aún en curso y deberán, en todo caso, considerar las matizaciones que introducen las señaladas singularidades de los contextos de procedencia de los materiales.

La diferenciación, que constituye el eje vertebrador del discurso desplegado, entre una vajilla propia del siglo I d.C. y otra característica de la siguiente centuria, aún pecando de generalizadora en tanto que esquematiza una dinámica evolutiva compleja con indudables matices diacrónicos apenas percibidos aún, se revela válida en cuanto a lo expresivo de la confrontación de los respectivos elencos e incipientemente fructífera como instrumento de aproximación cronológica, no sólo para el marco estricto del yacimiento, sino también para la generalidad del ámbito geocultural en que éste se inscribe.

La cerámica regional del siglo I d.C. se caracteriza sobre todo por dos rasgos esenciales: su apego a la tradición y el escaso grado de estandarización tipológica (Hevia, 2006). Los repertorios de estas fechas muestran un radical contraste entre las manufacturas importadas, que se presentan variadas en cuanto a su procedencia (Montes y Hevia, 2008: 764-768), y las producciones regionales. En estos momentos tempranos la alfarería regional carece de capacidad técnica y operativa para satisfacer los requerimientos de unos nuevos consumidores que solicitan productos avenidos a sus propios gustos y tradiciones 
culturales. El desajuste consecuente entre oferta y demanda ha de ser solventado recurriendo al abastecimiento en mercados externos.

La relación de tipos documentados en los contextos de la primera centuria del Chao Samartín, evidencia hasta que punto la industria regional, aún en fase de incipiente consolidación como tal, continúa fabricando modelos anclados en el sustrato cultural anterior a la romanización, tanto en su concepción morfológica como en su solución técnica. Muchos de ellos dejarán de registrarse tras el cambio de siglo, pudiendo su escasa representación y la originalidad de la resolución concreta de cada recipiente señalar la existencia de producciones a escala territorial más restringida, de carácter subconventual, acaso comarcal o local, enfocadas a la fabricación de piezas de uso frecuente y de escasa exigencia técnica como algunos tipos de ollas de cocina. Esta hipótesis, a falta de analíticas apropiadas que la confirmen o descarten, podría explicar la presencia en el elenco estudiado de algunos grupos peculiares como las ollas ovoides micáceas, para las que no conocemos paralelos.

No obstante, el carácter tradicional de estas producciones pronto se verá resquebrajado por el influjo romano, concretado en la embrionaria asimilación de recursos formales y sobre todo, ornamentales y técnicos, que derivan de la asunción de prácticas culinarias y criterios estéticos novedosos (Montes y Hevia, 2008: 769). Se inaugura así un proceso de síntesis que irá forjando una vajilla definida por la particular simbiosis de elementos romanos y locales (Montes et alii, 2001) y que se erige en testimonio material de la aculturación en curso. Ya en el siglo I d.C. se constatan los primeros ensayos de modelos que pasarán a ser producidos de manera sistemática por la industria regional en la segunda centuria, caso entre otros de las fuentes biasadas o los tazones monoasados. La expresión más paradigmática de este fenómeno de hibridación la representan algunas de las piezas que integran la serie engobada (Hevia y Montes, 2009: 648, Fig. 3.9), en las que se identifica la convivencia de morfologías y técnicas decorativas imbricadas en el acervo tradicional con elementos genuinamente latinos. Este sincretismo se extiende de igual modo a tipologías de raigambre clásica reelaboradas con un marcado carácter regional que se expresa en decoraciones y acabados.

Este proceso culminará en el siglo II d.C., cuando se puede hablar en propiedad de una auténtica vajilla regional de características propias que ha completado su particular gestación, consolidándose la síntesis iniciada tiempo atrás. La consecuencia lógica que se deriva es el registro de un elenco coherente, con un grado de estandarización tipológica mucho mayor que el precedente y completo en cuanto que da satisfacción a las demandas instrumentales generadas (Montes y Hevia, 2008: 770). Las importaciones cesan de manera drástica, quedando reducidas, salvo muy puntuales excepciones, al aporte constante de la terra sigillata tritiense (Menéndez y Sánchez, e.p.).

El centro de referencia, prácticamente exclusivo, para los tipos documentados en el Chao Samartín en la segunda centuria remite a la capital conventual Lucus Augusti, en donde se confirma la instalación de una pujante industria alfarera a partir de fines del siglo I d.C. (Alcorta, 2005 c: 448). A los talleres lucenses se adscriben las series grises finas de acabados pulidos brillantes que copan las morfologías de mesa y también las series engobadas, tanto las producciones lisas selladas con engobe rojo interior como la vajilla engobada con decoración estampillada. Mayor diversidad técnica y formal muestran las producciones de pastas esquistosas más groseras habitualmente asociadas a recipientes de cocina y almacenamiento con tratamientos más toscos y decoración menos frecuente y elaborada. A este respecto, igual que acontece con piezas que presentan rasgos peculiares respecto a los modelos de referencia, no debe obviarse la multiplicidad de talleres en la propia ciudad de Lugo, algunos con producciones más groseras e incluso, en su entorno próximo, en asentamientos de carácter rural (Alcorta, 2001: 445).

El fenómeno de mengua en la importancia relativa de las importaciones y de regionalización de la producción cerámica observado en el caso del Chao Samartín, viene a coincidir con lo 
registrado en otros yacimientos del noroeste peninsular. El más cercano tanto geográfica como culturalmente lo constituye Lucus Augusti, auténtico punto de referencia constante en el estudio de cerámica de la comarca. En esta ciudad se aprecia en la primera centuria la convivencia de una corriente inercial de cerámicas de tradición indígena y otra de productos de carácter romano inequívoco, entre las que se irán infiltrando de forma paulatina modalidades híbridas (Alcorta, 2001: 448). A partir de finales del siglo I d.C. se comienza a consolidar la actividad de la industria alfarera local (Alcorta, 2001: 193-197), auspiciada por el estado y nacida con la vocación de abastecer no sólo la demanda de la ciudad, sino la de una relativamente extensa área de influencia en la que se incluye el Chao Samartín. En el muestrario regional se plasman de forma singular los frutos de la referida síntesis de la doble tradición indígena y romana (Alcorta, 2001: 448), reduciéndose la presencia de productos foráneos a tipos muy concretos.

Aunque el estrecho paralelismo que mantienen las circunstancias lucenses y las del Chao Samartín, derivadas de un alto grado de dependencia en el abastecimiento cerámico, no tiene parangón, en otros asentamientos del Noroeste se confirma el modelo general consistente en unas primeras fases de coexistencia de tradiciones cerámicas seguido de un proceso de asimilación y una regionalización de la actividad productiva que cristalizará plenamente a lo largo del siglo I d.C. o adentrados ya en el siglo II d.C, según los casos particulares. El ejemplo de Asturica Augusta resulta bastante significativo. En la capital astur se detecta en el siglo II d.C. un predominio de manufacturas locales y regionales que restringen las importaciones masivas a poco más que la terra sigillata tritiense. Sin embargo, en fechas anteriores, éstas resultan numerosas y variadas en cuanto a procedencias, como corresponde a un núcleo de gran capacidad en la generación de demanda (Morillo et alii, 2005).
Otro yacimiento en el que se constatan fenómenos de similar índole es Rosinos de Vidriales (Zamora). En este caso, resulta especialmente paradigmático lo que acontece con la llegada de paredes finas, de procedencia itálica y gala en un primer momento ${ }^{135}$, de talleres hispánicos como Rubielos de Mora (Atrián, 1967), Mérida (Rodríguez, 1996) o los de la Bética (Mayet, 1975) con posterioridad y por último, a partir de la instalación del complejo de Melgar de Tera en sus cercanías, exclusivamente regionales. Es también en estas fechas cuando la denominada cerámica de tradición astur, trasunto de la producción lucense referida para Lucus Augusti y el Chao Samartín, logra constituirse en una serie coherente y porcentualmente relevante en el repertorio del campamento (Carretero, 2000: 597).

En Bracara Augusta se detecta un proceso equiparable en lo concerniente al paulatino asentamiento en la urbs de una actividad industrial de difusión comarcal que genera una producción que incluye diversos tipos clásicos como paredes finas, imitaciones de terra sigillata o lucernas y series características de la zona como las denominadas cerámicas bracarenses (Morais, 2005: 130; Delgado y Morais, 2009). A juzgar por la cronología de estos productos, la actividad alfarera bracarense debía encontrarse ya consolidada en un momento inconcreto del siglo I d.C.

Así pues, podemos concluir la existencia en todo el Noroeste de un proceso de paulatina regionalización de la producción cerámica encaminada a la reducción de los gastos derivados de los largos transportes y a la racionalización del abastecimiento que, en diferentes ritmos en función de las distintas áreas y sus particulares circunstancias de integración en la romanidad, se concreta en fechas que se centran entre época flavia y comienzos del siglo II d.C.

Las conclusiones obtenidas en el Chao Samartín conviene matizarlas si pretendemos su generalización al entorno próximo. En este sentido, se deben resaltar las manifiestas divergen-

${ }^{135}$ Exclusivas hasta época de Claudio (Carretero, 2000: 808-811). 
cias que se detectan entre los ajuares de yacimientos coetáneos del mismo territorio a causa de lo que se ha definido como colosal contraste social derivado de fenómenos de jerarquización funcional de las comunidades castreñas (Villa, 2005 b: 128-129). La relevancia administrativa que adquiere el yacimiento tras la conquista, continuación de su ancestral centralidad y sustanciada en lo arquitectónico mediante la instalación de la domus sobre el antiguo caserío castreño, ha de contar con un refrendo necesario en los ajuares cerámicos. En la implementación de tan profundos cambios fue determinante el papel desempeñado por el ejército, cuyo establecimiento en el sitio queda demostrado mediante argumentos basados en el registro arqueológi$\mathrm{co}^{136}$ (Villa et alii, 2006: 596). Esta preeminencia socio-económica se traduce en una mayor fluidez en el contacto con los circuitos habituales de distribución de materiales y por tanto, en una mayor accesibilidad a las importaciones, indudablemente sobrerepresentadas respecto a otros poblados coetáneos.

También en la ciudad de Lugo, indudablemente el caso mejor conocido en el ámbito geográfico que nos puede servir de comparación (Alcorta, 1995; Alcorta, 2001), actúan, dado su carácter urbano y preponderante en la región, estos factores de distorsión. El estudio de repertorios procedentes de yacimientos castreños no centrales ha de contribuir a corregir esta desviación y proporcionar una visión más ajustada y general de la cerámica en uso en época altoimperial. En este sentido, algunas aportaciones relativas a conjuntos como los de San Chuis (Manzano, 1985; Marín, 2007), Arancedo (Marín, 2008), Zoñán (Vigo, 2007) u Os Castros de Taramundi (Expósito, 2004; Rodríguez, 2004), a las que habrán de sumarse los estudios en curso sobre yacimientos como Pendia, Cabo Blanco o Monte Castrelo de Pelóu, deben contribuir a paliar estas lagunas.

136 Elementos como el numerario (Gil y Villa, 2004) o determinadas producciones cerámicas como ciertas lucernas o las paredes finas de Melgar de Tera (Carretero, 2000: 540) encon-

\section{BIBLIOGRAFÍA}

ABASCAL PALAZÓN, J.M. (1984): “La cerámica pintada de época romana en Portugal y sus conexiones periféricas", Revista de Guimaraes, XCIV. Guimaraes, 179-208.

ABASCAL PALAZÓN, J.M. (1986): La cerámica pintada romana de tradición indígena en la península Ibérica. Centros de producción, comercio y tipología. Madrid.

ABÁSOLO, J.A. y GARCÍA, R. (1993): Excavaciones en Sasamón (Burgos), E.A.E., 164. Madrid.

AGUAROD OTAL, M.C. (1984 a): “Avance al estudio de un posible alfar romano en Tarazona: II. Las cerámicas engobadas no decoradas", Turiaso, V, 29-106.

AGUAROD OTAL, M.C. y AMARÉ TAFALLA, M.T. (1985): "Un alfar romano de cerámica engobada, común y lucernas en Tarazona, (Zaragoza)", Actas del XVIII C.N.A. Zaragoza, 84-861.

AGUAROD OTAL, M.C. (1991): Cerámica romana importada de cocina en la Tarraconense, Instituto Fernando El Católico, Zaragoza.

AGUAROD OTAL, M.C. (1991): “La cerámica común de producción local/regional e importada. Estado de la cuestión en el valle del Ebro", Cerámica comuna romana d'època altoimperial a la Península Ibérica. Estat de la quiestió. Monografies Emporitanes VIII. Empuries, 129-154.

ALARCÃO, A.M. (1966): “Bref aperçu sur la céramique romainetrouvée à Bracara Augusta », Rei Cretariae Romanae Fautorum, Acta 8, 45-50.

ALARCÃO, A.M. y MARTINS, A. (1976): “Uma cerâmica aparentada com as 'paredes finas' de Mérida”, Conimbriga. Coimbra, 91-110.

ALARCÃO, J. de (1975): Fouilles de Conimbriga, V. La céramique commune locale et régionale. París.

ALARCÃO, J. de (1976): Fouilles de Conimbriga, VI. Ceramiques diverses et verres. París.

trarían la explicación de su presencia por este motivo (Villa et alii, 2006: 596). 
ALCORTA IRASTORZA, E. J. (1991): “Cerámica de cociña e mesa na Galicia romana a través dos achádegos de Lucus Augusti”, Larouco, 1. SadaA Coruña, 35-52.

ALCORTA IRASTORZA, E. J. (1994): "Sobre un mortarium sellado procedente de Lucus Augusti”, Actas XXIII C.N.A. Vigo, 289-295.

ALCORTA IRASTORZA, E. J. (1995): “Avance al estudio de la cerámica común romana de cocina y mesa de Lucus Augusti", Cerámica comuna romana d'època altoimperial a la Península Ibérica. Estat de la qüestió. Monografies Emporitanes VIII. Empuries, 201-226.

ALCORTA IRASTORZA, E. J. (2001): Lucus Augusti II. La cerámica común romana de cocina y mesa hallada en las excavaciones de la ciudad, Fundación Pedro Barrié de la Maza.

ALCORTA IRASTORZA, E. J. (2005 a): “Algunas notas en torno a la decoración de arquerías de la cerámica de tradición indígena hallada en Lucus Augusti”, Croa, 15.37-44.

ALCORTA IRASTORZA, E. J. (2005 b): "Anotaciones a las primeras vasijas engobadas tempranas sobre cerámicas indígenas, de Lucus Augusti”, Boletín do Museo Provincial de Lugo. Lugo, 15-40.

ALCORTA IRASTORZA, E. J. (2005 c): "Lucus Augusti como centro de producción y consumo cerámico", en C. Fernández Ochoa y P. García Díaz (ed.): Unidad y diversidad en el Arco Atlántico en época romana, III Coloquio Internacional de Arqueología en Gijón, BAR Internacional Series 1371. Oxford, 191-202

ALMAGRO, M. (1939): "La cerámica excisa de la Primera Edad del Hierro”, Ampurias, 1.

ALVARADO GONZALO, M. de y MOLANO BRÍAS, J. (1995): “Aportaciones al conocimiento de las cerámicas comunes alto-imperiales en Augusta Emérita: el vertedero de la calle Constantino", Cerámica comuna romana d'època altoimperial a la península Ibérica. Estat de la qüestió. Monografies Emporitanes VIII, Empuries, 281-295.

ÁLVAREZ TORRÓN, M.L. (2000): “Cerámica procedente del yacimiento de Porta de Arcos (RodeiroPontevedra)", Cuaderno de Estudios Gallegos, XLVII, 112, 42-62.
AMARÉ TAFALLA, Ma . T. (1984): Avance al estudio de un posible alfar romano en Tarazona: III. La cerámica engobada decorada, Turiaso, V, 109139.

AMARÉ TAFALLA, Ma. T. (1988/89): "Notas sobre un posible taller de lucernas romanas en Córdoba", Ifigea $V$-VI, 103-115.

ARIAS VILAS, F. (1985): Castro de Viladonga. Castro de Rei (Lugo). Campaña de 1983, Arqueoloxía/Memorias 2, Consellería de Educación e Cultura, Xunta de Galicia.

ARIAS VILAS, F. y DURÁN FUENTES, M.C. (1996): Museo do Castro de Viladonga. Santiago.

ATRIÁN JORDÁN, P. (1967): "Restos de una alfarería de cerámica romana en Rubielos de Mora (Teruel)". Teruel, 38. Teruel, 195-208.

AYÁN VILA, X., ABOAL FERNÁNDEZ, R. y PRIETO MARTÍNEZ, P. (2003-2004): "Excavación en el yacimiento galaicorromano de Agro de Ouzande (Silleda, Pontevedra): Resultados preliminares", Lancia, 5. León, 99-120.

BALIL ILLANA, A. y MARTÍN VALLAS, R. (1988): Tessera Hospitales de Montealegre de Campos (Valladolid). Estudio y contexto arqueológico, Monografías del Museo Arqueologico de Valladolid, 6, Valladolid.

BELTRÁN LLORIS, M. (1990): Guía de la cerámica romana. Zaragoza.

BELTRÁN LLORIS, M., AGUAROD OTAL, M.C., HERNÁNDEZ PRIETO, M.A., MÍNGUEZ MORALES, J.A., PAZ PERALTA, J.A., GONZÁLEZ PENA, M.L. y CABRERA MILlET, M. (1998): Colonia Victrix Iulia Lepida-Celsa (Velilla del Ebro, Zaragoza. III,1 y III,2. El intrumentum domesticum de la "Casa de los Delfines”. Zaragoza.

BENÉITEZ GONZÁLEZ, C., HEVIA GONZÁLEZ, S. y MONTES LÓPEZ, R. (1999): “Cerámica común romana del Chao Samartín (Grandas de Salime, Asturias). I. Vajilla de mesa y despensa", Lancia, 3. León, 11-48.

BERNAL CASASOLA, D. (1993): "Una pieza excepcional del Museo Nazionale de Roma y el problema de las lucernas tipo Andújar", Espacio, Tiempo y Forma (Hist.Ant), serie II6. Madrid, 207-220. 
BERNAL CASASOLA, D. y RIBERA I LACOMBA, A. (2008): Cerámicas hispanorromanas. Un estado de la cuestión. XXIII Congreso Internacional de la Asociación Rei Cretariae Romanae Fautores.

BUSTAMANTE ÁLVAREZ, M. y HUGUET ENGUITA, E. (2008): “Las cerámicas tipo Peñaflor”en Bernal Casasola, D. y Ribera i Lacomba, A. (eds. cient.): Cerámicas hispanorromanas. Un estado de la cuestión. XXIII Congreso Internacional de la Asociación Rei Cretariae Romanae Fautores, 297-306.

CAAMAÑO GESTO, J.M. (1980): "Marcas de alfarero en cerámica romana, encontradas en Galicia", Gallaecia, 5. Santiago, 63-100.

CARBALLO ARCEO, L.X. (1987): Castro da Forca. Campaña de 1984, Arqueoloxía / Memorias, 8.

CARDOZO, M. (1956): Citania de Briteiros y castro de Sabroso, Revista de Guimaraes, 65.

CARRERAS MONFORT, C. (2000): "Producción de Haltern 70 y Dressel 7-11 en las inmediaciones del Lacus Ligustinus (Las Marismas, Bajo Guadalquivir)", Congreso Internacional Ex Baetica Amphorae. Conservas, aceite y vino de la Bética en el Imperio Romano. Écija.

CARRERAS MONFORT, C. y BERNI, P. (2003): "Las ánforas de Astorga", en Amaré Tafalla, $\mathrm{M}^{\mathrm{a}} \mathrm{T}$. (dir): Astorga IV. Lucernas y ánforas. León, 633673.

CARRETERO VAQUERO, S. (2000): El campamento romano del ala II Flavia en Rosinos de Vidriales (Zamora). La cerámica, Zamora.

CARRETERO VAQUERO, S. y GUERRERO, J. (1990): "La cerámica romana de Eras del Bosque (Palencia). Nuevos materiales cerámicos”, Actas del II Congreso de Historia de Palencia, I. Arte, Arqueología y Edad Antigua. Palencia, 367-381.

CARRETERO VAQUERO, S. y ROMERO CARNICERO, M.V. (1996): Los campamentos romanos de Petavonium (Rosinos de Vidriales, Zamora), Fundación Rei Afonso Henriques. Serie Monografías y Estudios, Zamora, 1996.

CARROCERA FERNÁNDEZ, E. (1990): “La cultura castreña en Asturias", Historia de Asturias. I. Prehistoria-Historia Antigua. Oviedo, 121-136.

CARROCERA FERNÁNDEZ, E. (1995): "El territorio de los Astures: los castros", Astures, Gijón, 53-65.
CARROCERA FERNÁNDEZ, E. Y REQUEJO PAGÉS, O. (1989): "Producciones cerámicas tardías en castros y villas asturianas", Boletín de Arqueología Medieval, 3. Madrid, 21-30.

COELHO DA SILVA, A. (1986): A Cultura Castreja do Noroeste de Portugal. Paços de Ferreira.

COSTA QUARESMA, J.C. da (2003): “Terra Sigillata Sudgálica num centro de consumo: Chaos Salgados, Santiago do Cacém (Mirobriga?)". Trabalhos de Arqueologia 30. Lisboa.

DOMERGUE, C. y MARTIN, T. (1977): Minas de oro romanas de la provincia de León.II. , Excavaciones arqueológicas en España, 94, Madrid.

ESCRIVÁ TORRES, V. (1995): “Cerámica común romana del Municipium Liria Edetanorum. Nuevas aportaciones al estudio de la cerámica de época altoimperial en la Hispania Tarroconensis" en Cerámica comuna romana d'època altoimperial a la Península Ibérica. Estat de la qüestió. Monografies Emporitanes VIII, Empuries, $167-$ 186

EXPÓSITO MANGAS, D. (2004): Clasificación tipológica de la cerámica común romana del yacimiento de Os Castros (Taramundi), Trabajo de Investigación Curso de Doctorado, Inédito.

FERNÁNDEZ FREILE, B.E. (2003): León I. La época romana en León: Aspectos arqueológicos. Estudio arqueológico de un vertedero romanao situado en la calle Maestro Copín c/v San Salvador del Nido en la ciudad de León, Arqueología Leonesa, II. León.

FERNÁNDEZ IZQUIERDO, A. (1980): “Estudio de los restos arqueológicos submarinos en las costas de Castellón", Cuadernos de Prehistoria y Arqueología Castellonenses, 7, 135-196.

FERNÁNDEZ MIRANDA, M. y FERNÁNDEZ OCHOA, C. (1995): Astures. Pueblos y culturas en la frontera del Imperio romano. Gijón.

FERNÁNDEZ OCHOA, C. (1982): Asturias en la época romana, Monografías Arqueológicas 1, Universidad Autónoma de Madrid, Madrid.

FERNÁNDEZ OCHOA, C. (1994): Una industria de salazones de época romana en la Plaza del Marqués, Gijón.

FERNÁNDEZ OCHOA, C. (1997): La muralla romana de Gijón (Asturias), Madrid. 
FERNÁNDEZ OCHOA, C., GARCÍA DÍAZ, P. y ZARZALEJOS PRIETO, M. (2001): Excavaciones arqueológicas en Santa María de Lugo de Llanera (Asturias). Memoria de las campañas de 1991 a 1995, R.I.D.E.A., Oviedo.

FERNÁNDEZ OCHOA, C. y GARCÍA DÍAZ, P. (2005): Unidad y diversidad en el Arco Atlántico en época romana, III Coloquio Internacional de Arqueología en Gijón, BAR Internacional Series 1371, Oxford.

FERREIRA DE ALMEIDA, C.A. (1977): Excavaçoes no Monte Mozinho II (1975-76), Peñafiel.

FOY, D. NENNA, M.D. (2001): Tout feu, tout sable. Mille ans de verre antique dans le Midi de la France. Aix-en-Provence.

FRANCISCO MARTÍN, J. de y VILLA VALDÉS (2005): "Toponimia antigua de algunos asentamientos castreños en el occidente de Asturias", Revista de Filoloxía Asturiana 3/4. Años 2003/2004. Oviedo, 11-29.

GAGO MUÑIZ, O. (2008): La pintura mural romana en el Chao Samartín, en J. Rodríguez Muñoz (Coord.): La Prehistoria en Asturias. Oviedo, 809-816.

GAGO MUÑIZ, O. (2009 a): La pintura mural en A. Villa (ed.): Museo Castro Chao Samartín. Grandas de Salime. Asturias. Catálogo. Oviedo, 214-217.

GAGO MUÑIZ, O. (2009 b): Pintura mural en A. Villa (ed.): Museo Castro Chao Samartín. Grandas de Salime. Asturias. Catálogo. Oviedo, 344-345.

GARCÍA MARCOS, V. (2006): “ Las producciones de terra sigillata de tradición itálica en el campamento de la legio VI victrix en León", en A. Morillo (ed): Arqueología Militar Romana en Hispania. Producción y abastecimiento en el ámbito militar. León, 91-110

GARCÍA Y BELLIDO, A. (1942): "El Castro de Pendia", Archivo Español de Arqueología, XV, 49, 288-305.

GARCÍA Y BELLIDO, A, FERNÁNDEZ DE AVILÉS, A. y GARCÍA GUINEA, M. (1970): Excavaciones y exploraciones arqueológicas en Cantabria, Anejos de A.E.A., V. Madrid.

GARCÍA Y BELLIDO, A. URÍA, J. (1940): “Avance a las excavaciones del Castelón de Coaña", Revista de la Universidad de Oviedo, 2.
GIMENO GARCÍA-LOMAS, R. (1990): "El alfar romano de Melgar de Tera", Actas del primer Congreso de Historia de Zamora, tomo II. Zamora, 587-610.

GIL SENDINO, F. y VILLA VALDÉS, A. (2005): “El Castro de Chao Samartín (Grandas de Salime, Asturias). Los hallazgos monetarios", en C. Fernández Ochoa y P. García Díaz (ed.): Unidad y diversidad en el Arco Atlántico en época romana, III Coloquio Internacional de Arqueología en Gijón, BAR Internacional Series 1371. Oxford, 55-64.

GÓMEZ MORENO, M. (1925-1926): Catálogo Monumental de España. Provincia de León (1906-1908). Madrid.

GONZÁLEZ FERNÁNDEZ, E. (1991): “Aquis Querquennis: Aportación ó estudio dos vasos globulares pintados con decoración triangular", Larouco, 1. A Coruña, 23-34.

HARTLEY, K.F. (1973): « La difusión des mortiers, tuiles et autres produits en provenance des fabriques italiennes », Cahiers d'Archéologie Subaquatiques, II, 49-57.

HEVIA GONZÁleZ, S. (2006): Castro de Chao Samartín (Grandas de Salime, Asturias). El ajuar cerámico del siglo I d.c., Trabajo de Investigación Curso de Doctorado, Inédito.

HEVIA GONZÁLEZ, S. (2009): en A. Villa (ed.): Museo Castro Chao Samartín. Grandas de Salime. Asturias. Catálogo. Oviedo, Fichas 92, 97-98, 111-119, 162-172 у 174-175.

HEVIA GONZÁLEZ, S., MENÉNDEZ GRANDA, A. y SÁNCHEZ HIDALGO, E. (1999): “Terra sigillata del Chao Samartín”, Lancia, 3. León, 159190

HEVIA GONZÁLEZ, S. y MONTES LÓPEZ, R. (2009): “Cerámica común del siglo I d.C. en el castro del Chao Samartín (Grandas de Salime, Asturias). Notas sobre el repertorio en un ambiente militarizado", en A. Morillo, N. Hanel y E. Martín (eds.): Limes XX. Estudios sobre la frontera romana. Madrid, 639-654.

HEVIA GONZÁLEZ, S., MONTES LÓPEZ, R. BENÉITEZ GONZÁLEZ, C. (2001): “Cerámica común romana del Chao Samartín (Grandas de Salime- Asturias): Vajilla de cocina y almacenamiento", B.S.A.A., LXV (1999), 153-196, Valladolid. 
HIDALGO CUÑARRO, J.M. (1988): La romanización del castro de Vigo: el comercio de importación de cerámicas finas romanas, Habis, 20, 279-292.

HIDALGO CUÑARRO, J.M. y COSTAS GOBERNA, F.J. (1979), "El castro de A cidade de Caneiro, Fozara (Ponteareas)", El Museo de Pontevedra, XXIII, 152-228.

HIDALGO CUÑARRO, J.M. y RODRÍGUEZ PUENTE, E. (1987): Castro de Fozara. Campaña de 1984, Arqueología/ Memorias, 9. Santiago.

ISINGS, C. (1957): Roman glass from dated finds. Groningen/Djarkarta.

JONCHERAY, J.P. (1973): "Contribution à l'étude del'épave Dramont D (campagnes 1970-71)", Cahiers d'Archéologie Subaquatiques, II, 9-48.

JORDÁ CERDÁ, J.F., MANZANO HERNÁNDEZ, M.P., JORDÁ PARDO, J.F., GONZÁLEZTABLAS SASTRE, F.J., CARROCERA FERNÁNDEZ, E. y BÉCARES PÉREZ, J. (1989): "El castro asturiano de San Chuis", Revista de Arqueología, 95, 38-48.

LAPUENTE MERCADAL, M.P., PÉREZ-ARANTEGUI, J., AGUAROD OTAL, C., ALCORTA IRASTORZA, E., (1996) "Caracterización de imitaciones provinciales micáceas de engobe interno rojo-pompeyano en el norte de la Península Ibérica", Revue d'Archéométrie, 19.

LAROCHE, C. (1986): « La production de céramiques fines d'Aoste (Isère), deuxieme moitié du Ier s. Après J.C. », Congrès Toulouse. Marseille, 19-24.

LÓPEZ CUEVILLAS, F. (1952): Carballino (Orense), Castro de Cameixa, Campaña de 1945, N.A.H., I, $1-3,82-91$

LÓPEZ MULLOR, A. (1981): Notas para una clasificación de los tipos más frecuentes de la cerámica romana en Cataluña, Ampurias, 43. Barcelona, 201-215.

LÓPEZ RODRÍGUEZ, J.R. (1982): Cuatro lucernas hispanorromanas, Homenaje a Conchita Fernández Chicarro. Madrid, 381-390.

LUEZAS PASCUAL, R.A. (1997): Marca de ceramista sobre un plato engobado procedente de Calagurris Ivlia (Calohorra-La Rioja), Kalakorikos, 2, 263-274.

MACCABRUNI, C. (1987): Cerámica romana con invetriatura al piombo, Céramiques hellenistiques et romaines, Lévêque, P. y Morel, J (eds). París, 167-189.
MADARIAGA GARCÍA, B. (2004): "Vidrio romano en los castros del Occidente de Asturias", Jornadas sobre el vidrio en la España Romana. La Granja, 213-223.

MADARIAGA GARCÍA, B. (2005): "Vajilla de vidrio romano en el castro del Chao Samartín (Grandas de Salime, Asturias)", en C. Fernández Ochoa y P. García Díaz (eds.): Unidad y diversidad en el Arco Atlántico en época romana II. Producción, circulación y consumo. BAR International Series 1371. Oxford, 239-244.

MADARIAGA GARCÍA, B. (2009): en A. Villa (ed.): Museo Castro Chao Samartín. Grandas de Salime. Asturias. Catálogo. Oviedo. Fichas 94 y 96.

MANZANO HERNÁNDEZ, M.P. (1990): “Avance sobre la cerámica común del castro de San Chuís -Pola de Allande-“, Zephyrus XXXIX-XL. Salamanca 1986-1987, 397-410.

MARÍN SUÁREZ, C. (2007): "Los materiales del castro de San L.Luis (Allande, Asturias)", Complutum, 18, 131-160.

MARÍN SUÁREZ, C. (2008): "Revisión y estudio de los materiales del Castro de Arancedo (El Franco, Asturias)", Férvedes, 5. $1^{\text {er }}$ Congreso de Arqueoloxia de Villalba.

MARTÍN HERNÁNDEZ, E. (2006): “Cerámica romana de paredes finas de época julioclaudia en el campamento de la Legio VI victrix. Estudio preliminar de los materiales procedentes del polígono de La Palomera", en A. Morillo (ed.): Arqueología romana en Hispania. Producción y abastecimiento en el ámbito militar. León, 399-417.

MARTÍN HERNÁNDEZ, E. (2008): León II. Cerámica romana de paredes finas de época julioclaudia en el campamento de la Legio VI Victrix en León. Los materiales del Polígono de La Palomera, Arqueología Leonesa, II. León

MARTINS, M. (1990): O povoamento proto-histórico e a romanizaçâo da bacia do curso médio de Cávado, Cadernos de Arqueologia. Monografías, 5. Braga.

DELGADO, M. y MORAIS, R. (2009): Guia das ceramicas da produçao local de Bracara Augusta,

MAYA GONZÁLEZ, J.L. (1988): La cultura material de los castros asturianos, Estudios de Antigüedad, 4/5, Universitat Autònoma de Barcelona, Bellaterra. 
MAYA GONZÁLEZ, J.L. y CUESTA TORIBIO, F. (1993): "Indigenismo y romanización”, en M.C. Morales Saro y F.J. Fernández Conde (Cord.): Orígenes. Arte y cultura en Asturias. Siglos VII$X V$. Oviedo, 11-23.

MAYA GONZÁLEZ, J.L. y CUESTA TORIBIO, F. (2001): El castro de la Campa Torres. Periodo prerromano, Serie Patrimonio, 6, Gijón.

MAYET, F. (1975): Les cerámiques a parois fines dans la Péninsule Ibérique, París.

MAYET, F. (1984): Les céramiques sigilées hispaniques. Contribution à l'histoire economique dela Péninsule Ibérique sous l'Empire Romain. París.

MENÉNDEZ GRANDA, A. (2003): Terra Sigillata del castro de Chao Samartín (Castro, Grandas de Salime). Los materiales del sector N-1 y propuestas metodológicas para su estudio. Trabajo de Investigación. Universidad de Oviedo. Inédito.

MENÉNDEZ GRANDA, A. y BENÉITEZ GONZÁLEZ, C. (2002): "La ocupación romana de los castros asturianos a través del ajuar cerámico: análisis historiográfico", Los poblados fortificados del Noroeste de la península ibérica: Formación y desarrollo de la cultura castreña. Coloquios de arqueología en la cuenca del Navia. Homenaje al prof. Dr. José Manuel González y Fernández-Vallés, 279-299. Navia.

MENÉNDEZ GRANDA, A. y SÁNCHEZ HIDALGO, E. (2001): “Terra sigillata marmorata documentada en el castro de Chao Samartín (Grandas de Salime, Asturias)", Memorias de Historia Antigua. Oviedo, 217-226.

MENÉNDEZ GRANDA, A. y SÁNCHEZ HIDALGO, E. (2009): en A. Villa (ed.): Museo Castro Chao Samartín. Grandas de Salime. Asturias. Catálogo. Oviedo, Fichas 76-79, 81, 83, 86-88, 99-101, 123, 140-144, 146 у 159.

MENÉNDEZ GRANDA, A. y SÁNCHEZ HIDALGO, E. (e.p.): La Terra Sigillata del castro de Chao Samartín (Asturias): aproximación a su estudio, Consejería de Cultura, Comunicación Social y Turismo del Principado de Asturias.

MESPLE, P. (1957): «L'atelier de potier galloramain de Galene à Lombez (Gers) », Gallia, $X V, 11-71$.

MEZQUIRIZ DE CATALÁN, M.A. (1961): Terra Sigillata Hispánica. Valencia.
MONTES LÓPEZ, R. (2004): Aproximación a los hallazgos de paredes finas de Melgar de Tera en Asturias. Nuevas piezas procedentes del Chao Samartín (Castro, Grandas de Salime), Sautuola, $X$, Santander, 281-294.

MONTES LÓPEZ, R. (2005): Vajilla para beber de época altoimperial romana procedente del castro del Chao Samartín (Grandas de Salime, Asturias), Trabajo de Investigación Curso de Doctorado, Inédito.

Montes López, R. (2006): Jarritas facetadas en el castro del Chao Samartín (Grandas de Salime, Asturias), Sautuola, XI, Santander, 205-210.

MONTES LÓPEZ, R. (2009): en A. Villa (ed.): Museo Castro Chao Samartín. Grandas de Salime. Asturias. Catálogo. Oviedo, Fichas 89-90, 138, 147-158 y 160 .

MONTES LÓPEZ, R., BENÉITEZ GONZÁLEZ, C. y HEVIA GONZÁLEZ, S. (2001): “La cerámica común romana del Chao Samartín. Base para una tipología en el territorio lucense (finales del s.I $-1^{\mathrm{a}} \operatorname{mitad}$ s.II d.C.)", Rev. Arqueología, 247. Madrid, 28-37.

MONTES LÓPEZ, R. y HEVIA GONZÁLEZ, S. (2008): "La cerámica de los castros en época romana", en J. Rodríguez Muñoz (Coord.): La Prehistoria en Asturias. Oviedo, 761-772.

MONTES LÓPEZ, R. y HEVIA GONZÁLEZ, S. (2009): "La cerámica común" en A. Villa (ed.): Museo Castro Chao Samartín. Grandas de Salime. Asturias. Catálogo. Oviedo, 207-211.

MONTES LÓPEZ, R., HEVIA GONZÁLEZ, S., VILLA VALDÉS, Á y MENÉNDEZ GRANDA, A. (2009): "Monte Castrelo de Pelóu (Grandas de Salime). Avance sobre su secuencia estratigráfica e interpretación histórica", en Excavaciones arqueológicas en Asturias 6 (2003-2006). Oviedo, $301-310$.

MORAIS, R. (2008): “Las cerámicas bracarenses”, en Bernal Casasola, D. y Ribera i Lacomba, A. (eds. cient.): Cerámicas hispanorromanas. Un estado de la cuestión. XXIII Congreso Internacional de la Asciación Rei Cretariae Romanae Fautores, 445-470.

MORILLO CERDÁN, A. (1999): Lucernas romanas en la región septentrional de la península ibérica. Contribución al conocimiento de la implantación romana en Hispania, Monographies Instrumentum, 8. Montagnac. 
MORILLO CERDÁN, A. (2006): Arqueología romana en Hispania. Producción y abastecimiento en el ámbito militar. León.

MORILLO CERDÁN, A. (2008): "Producciones cerámicas militardes en Hispania" en Bernal Casasola, D. y Ribera i Lacomba, A. (eds. cient.): Cerámicas hispanorromanas. Un estado de la cuestión. XXIII Congreso Internacional de la Asociación Rei Cretariae Romanae Fautores, 275-293.

MORILLO CERDÁN, A. Y GARCÍA MARCOS, V. (2001): "Producciones cerámicas militares de época augusteo-tiberiana en Hispania”, Rei Cretariae Romanae Fautorum. Acta 37. Abingdon, 147-155.

MORILLO CERDÁN, A., AMARÉ TAFALLA, Mª .T. y GARCÍA MARCOS, V. (2005): “Asturica Augusta como centro de producción y consumo cerámico", en C. Fernández Ochoa y P. García Díaz (ed.): Unidad y diversidad en el Arco Atlántico en época romana, III Coloquio Internacional de Arqueología en Gijón, BAR Internacional Series 1371, Oxford, 139-161.

MORILLO CERDÁN, Á. y RODRÍGUEZ MARTÍN, G. (2008): "Lucernas hispanorromanas", en Bernal Casasola, D. y Ribera i Lacomba, A. (eds. cient.): Cerámicas hispanorromanas. Un estado de la cuestión. XXIII Congreso Internacional de la Asociación Rei Cretariae Romanae Fautores, 407-427.

MOUTINHO, A. y MARTINS, A. (1976): “Cerámica aparentada con as paredes finas de Mérida", Conimbriga, XV. Coimbra, 91-110.

NOLEN, J.U.S. (1986): Cerâmica comun de necrópolis do Alto Alentejo. Lisboa.

ORERO GRANDAL, L. (1988): Castro Coto do Mosteiro. Campañas de 1984-1985, Arqueología/ Memorias, 10. Santiago.

ORTON, C., TYERS, P. y VINCE, P. (1997): La cerámica en arqueología. Barcelona.

OSWALD, F. Y PRYCE, T. (1966): An introduction of study of terra Sigillata. Londres.

PASSELAC, M. y VERNHET, A. (1993) : "Céramique sigillée sud-gaulloise ", Latara, 6. Lattes, 569-580.

PÉREZ ALMOGUERA, A. (1993): "Imitaciones de terra sigillata en Lérida”, Estudios Universitaris Cataláns. Homenatge a M.Tarradell. Barcelona, 768-780
PERICOT, L. y LÓPEZ CUEVILLAS, F. (1929): Excavaciones en la citania de Troña, Memorias de la Junta Superior de Excavaciones y Antigüedades, 115.

POLAK, M. (2000): Soud Gaulish terra sigillata from Vechten. Nijmegen, Rei Cretariae Romanae Fautores. Acta suplementum, 9. Oxford.

RÍOS GONZÁLEZ, S. y GARCÍA DE CASTRO, C. (1998), Asturias castreña, Historia de Asturias y Gijón.

ROCA ROUMENS, M. (1976): Sigillata hispánica producida en Andujar (Jaen). Jaen.

RODRÍGUEZ DEL CUETO, F. (2004): Caracterización técnica de la Cerámica Común Romana del castro de Os Castros (Taramundi). Trabajo de Investigación Curso de Doctorado, Inédito

RODRÍGUEZ MARTÍN, F.G. (1996): Materiales de un alfar emeritense: Paredes finas, lucernas, sigillatas y terracotas, Cuadernos Emeritenses-11. Mérida.

RODRÍGUEZ MARTÍN, F.G. (2006): “La comercialización de productos emeritenses hacia los campamentos astures durante el Alto Imperio", en A. Morillo (ed.): Arqueología romana en Hispania. Producción y abastecimiento en el ámbito militar. León, 185-203.

ROMERO CARNICERO, Ma.V. (1985): Numancia I. La terra sigillata. Excavaciones arqueológicas en España 146. Madrid.

ROMERO CARNICERO, M ${ }^{\mathrm{a}}$.V. y SANZ MINUÉS, C. (1990): "Sepulturas romanas de incineración en la provincia de Valladolid: los depósitos de Padilla de Duero y Simancas", Numantia, III, 165-174.

RUIZ-MARTÍNEZ, V.C., PAVÓN-CARRASCO, F.J. y CATANZARITI, G. (2008): First archaeomagnetic data from northern Iberia, J. Phys. Chem. Herat (2008), doi:10.1016/j.pce.2008.02.023.

SABRIE, M. Y R. (1981): «Les mortiers », en V.Solier, Les épaves de Gruissan, 88-93, Archaeonautica, 3.

SÁNCHEZ SÁNCHEZ, J.C. (1992): Cerámica común romana de Mérida (estudio preliminar). Series de Arqueología Extremeña, 3.

SÁNCHEZ HIDALGO, E. (2003): Cerámica sellada de época romana en Asturias. Las marcas de alfarero del Chao Samartín, Trabajo de Investigación Curso de Doctorado, Inédito. 
SÁNCHEZ HIDALGO, E. y MENÉNDEZ GRANDA, A. (2005): Avance al estudio de la terra sigillata sudgálica del castro de Chao Samartín (Grandas de Salime, Asturias), en Fernández Ochoa, C. y García Díaz, P. (Eds.): Unidad y diversidad en el arco atlántico en época romana. III Coloquio Internacional de Arqueología de Gijón. BAR Internacional Series 1371. Oxford, 251-258.

SÁNCHEZ-PALENCIA， F.J. y FERNÁNDEZPOSSE, M.D. (1985): La Corona y el Castro de Corporales I. Truchas (León). Campañas de 1978 a 1981, Excavaciones Arqueológicas en España, 141. Madrid.

SANZ MÍNGUEZ, C. (1998): Los vacceos: cultura y ritos funerarios de un pueblo prerromano del valle medio del Duero. La necrópolis de Las Ruedas, Padilla del Duero (Valladolid), Memorias de Arqueología de Castilla y León, 6.

SERRANO RAMOS, E. (1978): “Cerámica común del alfar de Cartuja (Granada)", Baetica 1. Málaga, 243-272.

SERRANO RAMOS, E. (1995): "Producciones de cerámicas comunes locales de la Bética", Cerámica comuna romana d'época altoimperial a la península Ibérica. Estat de la qüestió. Monografies Empuritanes VIII. Empuries, 225249.

SOEIRO, T. (1984): Monte Mozinho. Apontamento sobre a ocupaçao entre Sousa e Tâmega em época romana, Penafiel, Boletím Municipal de Cultura, $3^{\mathrm{a}}$ serie, 1.

SOTOMAYOR, M., PÉREZ CASAS, A. y ROCA ROUMENS, M. (1976): "Los alfares romanos de Andujar (Jaén)": Dos nuevas campañas, N.A.H., 4, 111-147.

SUÁREZ VEGA, R. (1995): "Fragmento de skyphoi de cerámica vidriada”, Astures. Gijón, 280.

TUFFREAU-LIBRE M.(1987): « La céramique commune en Gaule romaine », Céramiques Hellénistiques et Romaines II, centre de Recherches d’histoire ancienne, 70, París, 203229.

URÍA RIU, J. (1941): "Fragmentos de cerámica excisa del Castelón de Coaña”, A.E.A., 43.

URTEAGA ARTIGAS, M. (2003): “El puerto romano de Ollaso (Irún) y la desembocadura del río Bidasoa”, en C. Fernández Ochoa (Ed.): Gijón, puerto romano. Gijón, 192-212.
VÁZQUEZ GÓMEZ, X.L. y DOVAL GALÁN, J.F. (1996): "Cerámica común romana da Coruña", Larouco, 2, 119-126. A Coruña.

VERNHET, A. (1991): La Graufesenque. Céramiques gallo-romaines. Millau.

VILLA VALDÉS, A. (1998)a. "El castro del Chao Samartín”, Revista de Arqueología, 211. Madrid, 32-41.

VILLA VALDÉS, A. (1998)b: "Excavaciones en el castro del Chao Samartín (Campaña de 1995)" Actas del Congreso Internacional sobre los orígenes de la ciudad en el N.O. hispánico. Lugo, 979-991.

VILLA VALDÉS, A. (1999): "Castro del Chao Samartín (Grandas de Salime): tres años de investigación arqueológica (1995-1998)", E.A.A., 4, 1995-1998. Oviedo, 111-123.

VILLA VALDÉS, A. (2002): “Periodización y registro arqueológico en los castros del occidente de Asturias”, en M.A. de Blas y A. Villa (eds.): Los poblados fortificados del noroeste de la Península Ibérica: formación y desarrollo de la cultura castreña. Coloquios de arqueología en la cuenca del Navia. Navia, 159-188.

VILlA VALDÉS, A. (2005 a): El Castro de Chao Samartín (Grandas de Salime, Asturias). Guía para su interpretación y visita, Grandas de Salime.

VILLA VALDÉS, A. (2005 b): "Castros y recintos fortificados en el occidente de Asturias: Estado de la cuestión”, Boletín Auriense, 33 (2003).

VILLA VALDÉS, A. (2009): “Geoarchaological context of the detructon and abandonment of a fortified village in Asturias in the II $^{\text {nd }}$ century A.D.: Chao Samartín (Grandas de Salime, Asturias, Spain)", en R. Pérez López, C. Grützner, J. Lario, K. Reicherter y P.G. Silva (eds.): Arqueoseismology and paleoseismology in the Alpine-Himalayan collisional zone. $1^{\text {st }}$ INQUACGCP 567 International Workshop on earthquake archaeology and paleoseismology, Baelo Cladia (Cadiz, Spain), 7-13 September 2008, 160-161.

VILLA VALDÉS, A., MENÉNDEZ GRANDA, A. y FANJUL MOSTERIRÍN, J.A. (2007): "Excavaciones arqueológicas en el poblado fortificado de Os Castros, en Taramundi", E.A.A., 5, 1995-1998. Oviedo, 267-275. 
VILLA VALDÉS, A., MENÉNDEZ GRANDA, A. y GIL SENDINO, F. (2006): "Fortificaciones romanas en el castro de Chao Samartín (Grandas de Salime, Asturias)", II Congreso de Arqueología Militar Romana en Hispania. Producción y abastecimiento en el ámbito militar, León-Octubre 2004, 583-600.

VILLA VALDÉS, Á. y MONTES LÓPEZ, R. (2009): en A. Villa (ed.): Museo Castro Chao Samartín. Grandas de Salime. Asturias. Catálogo. Oviedo, Fichas 27 y 128.

VILLA VALDÉS, Á., MONTES LÓPEZ, R., HEVIA GONZÁLEZ, S., PASSALACQUA, N.V., WILSON, A.C. y CABO PÉREZ, L. (2008): “Avance sobre el estudio de la necrópolis medieval del Chao Samartín en Castro (Grandas de Salime, Asturias)", Territorio, Sociedad y Poder, 3. Oviedo, 57-82.
VEGAS, M. (1973): Cerámica común romana del Mediterráneo Occidental. Barcelona.

VIGO GARCÍA, A. (2007): O Castro de Zoñán (Mondoñedo, Lugo). Escavacións 2002-2004. Mondoñedo.

ZARZALEJOS PRIETO, M. (1995): “Cerámica común de cocina: mortero (mortarium) y fuente", Astures. Gijón, 267. 